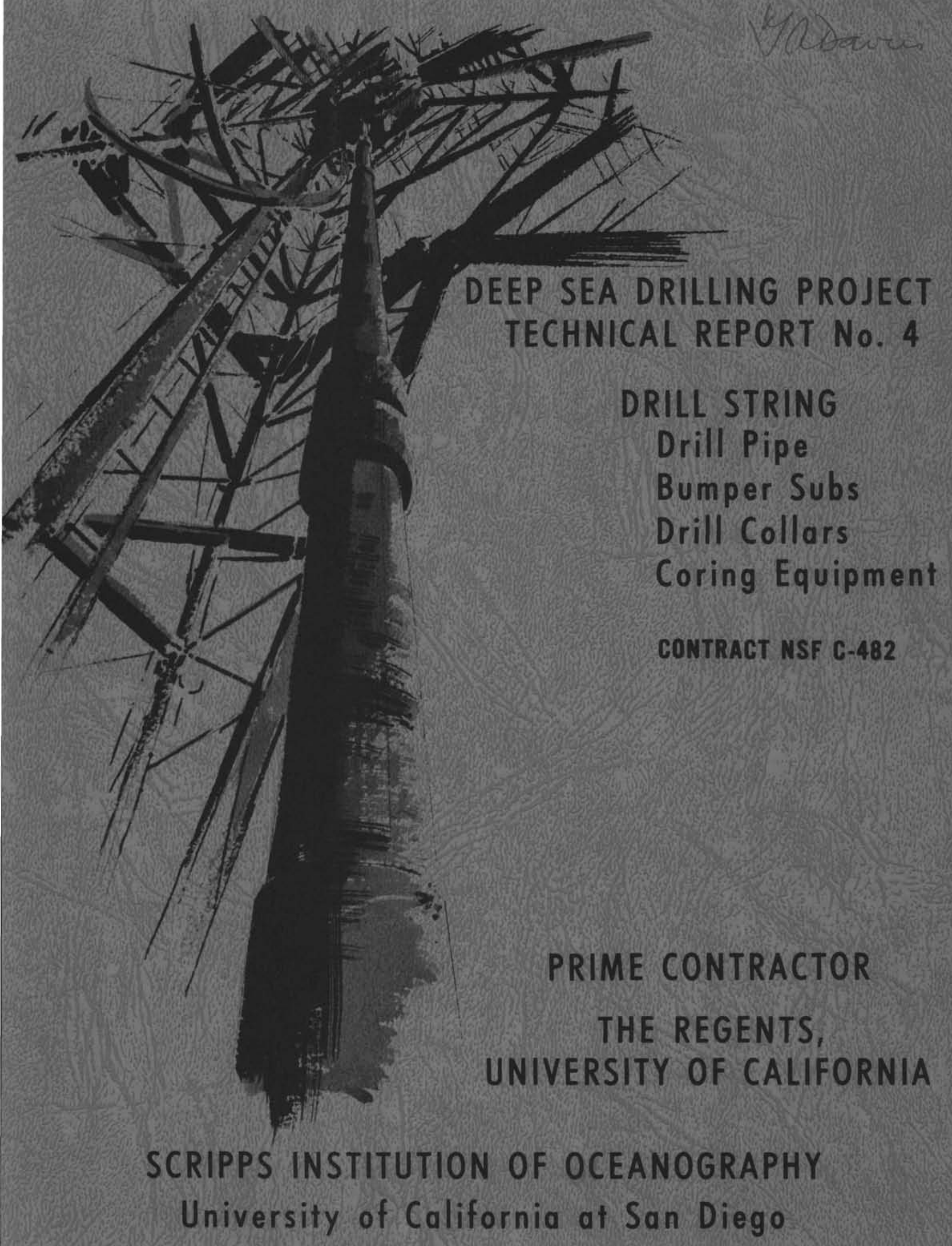




\title{
DRILL STRING
}

Drill Pipe

Bumper Subs

Drill Collars

Coring Equipment

\author{
Prepared For \\ National Science Foundation \\ Under Provisions of Contract NSF C-482
}

\section{By}

Deep Sea Drilling Project

Scripps Institution of Oceanography University of California at San Diego

W.A. Nierenberg, Director

Scripps Institution of Oceanography

Co-Principal Investigator
M.N.A. Peterson

Scripps Institution of Oceanography Co-Principal Investigator 


\section{INTRODUCTION}

Many new and complicated technical systems had to coalesce on D/V Glomar Challenger to enable the Deep Sea Drilling Project to enjoy the continuous success it has recorded todate.

Dynamic positioning worked beyond fondest expectations and the problem of re-entry was overcome with little difficulty, but without a good, tough drill string - some of which is still in service after more than three years of drilling and coring in a hostile environment there would be no Deep Sea Drilling Project.

Included in this Technical Report are extensive discussions on drill pipe, bumper subs, drill collars and coring equipment.

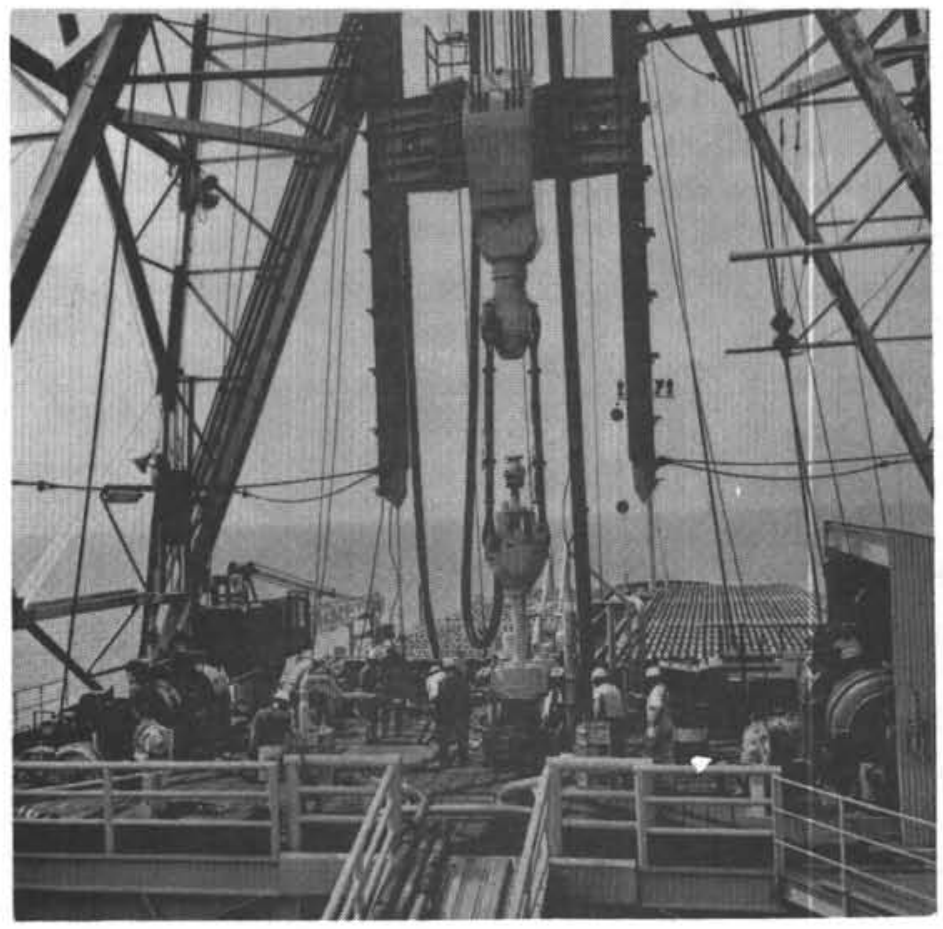

Glomar Challenger drilling crew rigs hydraulically operated power sub, center, preparatory to commencing drilling operations at a deep water drilling site in the Gulf of Mexico during the first leg of the Deep Sea Drilling Project. At right is the drawworks and, on opposite side of derrick floor is the specially designed core line reel used in the retrieving of the core barrel. Beyond derrick floor is Global Marine designed automatic drill pipe racker which holds 24,000 feet of 5-inch drill pipe. View, looking forward, was taken from wheel house of vessel.

While on station, the drill string is suspended from D/V Glomar Challenger with no lateral support between the keel and the ocean floor. Drilling and coring are accomplished by turning the string at the top with a power sub. The heave, roll and pitch of the drilling vessel add additional stresses.

Since drilling and coring are done without using a riser system for drilling mud returns, raw sea water is normally used, further increasing the stress on the pipe. 
Corrosion inhibitors are used, but the automatic pipe racks are above deck, exposing the pipe to a moist marine environment while in storage.

Sites have been cored with surface observed currents of four knots. Subsurface currents are not measured. Even with these hazards, drill string losses todate have been caused primarily by operational problems.

Global Marine Inc. designed the drill string to be part of their answer to the Project's Request for Proposal. This design, with minor modifications, was the one taken to sea. As operational problems arose, the Deep Sea Drilling Project and Global Marine Inc. mutually agreed on modifications.

The initial Program Plan attempted to schedule D/V Glomar Challenger to drilling sites during the most favorable weather conditions and to stay within the 30 degree parallels. As drilling crews gained confidence, sites were successfully worked in the North Atlantic and the North Pacific. A further three-year extension would take the Challenger into the Arctic and Antarctic Oceans.

With this increased confidence in the drill string and an upgraded program for the dynamic positioning system, it would be possible to drill in water depths less than 3,000 feet. This capability would open vast new areas of scientific interest.

Scripps Institution of Oceanography, of the University of California at San Diego, is managing institution for the Deep Sea Drilling Project. The Project is funded by the National Science Foundation, an agency of the United States Federal Government and is a part of the Foundation's National Ocean Sediment Coring Program.

Actual drilling is being done by Global Marine Inc. , of Los Angeles, California, under contract to Scripps Institution of Oceanography.

Advice regarding scientific planning for the Deep Sea Drilling Project is being provided by panels whose members are broadly representative of the nation's scientific community drawn from many Universities, Government Agencies, and industrial organizations.

The Joint Oceanographic Institutions for Deep Earth Sampling (JOIDES), consisting of Lamont-Doherty Geological Observatory of Columbia University, Woods Hole Oceanographic Institution, The Rosenstiel School of Marine and Atmospheric Sciences, of the University of Miami (Florida), The University of Washington (Seattle), and Scripps Institution of Oceanography, assisted in the formulation of plans for the Project. JOIDES panels still give scientific advice and guidance to the Deep Sea Drilling Project.

Many individuals from the petroleum industry have also furnished technical advice and assistance to the Project.

April, 1972 
The Deep Sea Drilling Project gratefully acknowledges the contributions of many companies and individuals to the successful adaptation to drilling in the deep oceans of the various drill string components - drill pipe, bumper subs, drill collars and coring equipment - which have so far been responsible for recovering more than 10 miles of priceless sedimentary core material from beneath the deep ocean floor after 21 expeditions of the Project.

Our thanks go to:

Mr. Jack Reed and Dr. Thad Vreeland, of Global Marine Inc., for design and analysis of the drill string configuration;

Mr. Alex Maradudin (deceased), formerly with Standard Oil Company of California, for review and supervision of manufacture of the drill pipe;

Dr. Arthur Lubinski, of Pan-American Petroleum Corporation's Research Division, for review of the proposed drill string configuration;

The Petroleum Industry Technical Assistance Panel for its valuable advice;

DRILCO for review of proposed drill collar tool joint change;

Hycalog, Inc. for the design and expediting of basic coring equipment and the training of Project personnel;

Christian Diamond Products Company for design of alternate coring methods and counsel for appropriate Project personnel;

Project Engineer Darrell L. Sims for engineering management.

We acknowledge the continuing help of Mr. A. R. McLerran, National Science Foundation Field Project Officer with the Deep Sea Drilling Project and the support of the National Science Foundation.

The support and guidance of the Joint Oceanographic Institutions for Deep Earth Sampling (JOIDES) in fostering the Deep Sea Drilling Project is fully acknowledged.

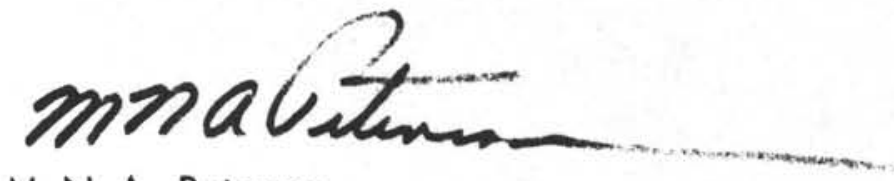

M.N.A. Peterson

Co-Principal Investigator

Deep Sea Drilling Project 
Drill Pipe

$\begin{array}{ll}\text { Bibliography } & 7\end{array}$

Bumper Subs

Appendix Number 1

Bumper Sub Recommended Inspection and Service

Appendix Number 2

Charpy Impact Curves

Bibliography

Drill Collars

39

Bibliography

Coring Equipment

Bibliography

52

Drilling, Coring and Core Recovery Through Leg 18

Drill String Loss Through Leg 18

Drilling Status Through Leg 21

Appendices

Appendix A

Metal Corrosion in Saline Waters

Appendix B

Evaluation of Methods to Alleviate Corrosion Fatigue in Type 135 Drill-Pipe Steel for Offshore-Drilling Applications 
Appendix C

Mechanics of Long Drill Strings

80

Appendix D

Hydrogen Movement in Steel-Entry, Diffusion, and Elimination

Appendix E

Sample Examination, Hillman-Kelley, Global Marine, Inc.

5" O.D. x 19.50\# Special BR-135 Drill Pipe

Appendix F

Study of Hydrogen-Stress Cracking of Deep Sea Drilling Project

S-135 Drill Pipe if Exposed to Black Sea Water

\section{Appendix G}

Stress-Corrosion Cracking and Hydrogen-Stress Cracking of

High-Strength Steel 
DRILL PIPE 
The statement of work in the Request For Proposal for Deep Sea Drilling Project drill pipe was quite short - "Two 23,000-foot drill strings, one working and one spare should be aboard, with all necessary collars, bits, core barrels and accessory items. "Steel, nonferrous or combination strings were considered. A 2 1/2-inch core encased in a plastic liner was requested. The proposal was to give the type, grade, diameter, weight per foot and length of stands, and to include an analysis of this design based on relevant operating conditions.

Global Marine Inc., selected to be the subcontractor, proposed 5-inch outside diameter, $19.6 \mathrm{lb}$. per foot grad S-135 external upset steel pipe fitted with modified $5 \mathrm{1} / 2$-inch full hole flash-weld, 18-degree taper tool joints. A detailed analysis of this string conducted by Dr. Thad Vreeland, of Pasadena, California, for Global Marine Inc. concluded this string would give excellent life up to and including the design depth of 22,500 feet total drill string length.

The Deep Sea Drilling Project enlisted the assistance of major oil companies to review the proposal. The then Technical Assistance Panel, composed of representatives from major oil companies, agreed that the proposal was acceptable. Dr. Arthur Lubinski and his group at Pan-American Petroleum Corporation Research Division in Tulsa, Oklahoma, reviewed Dr. Vreeland's mathematical model and advised they were in agreement.

Global Marine Inc. was so advised and placed their order. The pipe was rolled by Jones and Laughlan Steel Company, of Pittsburgh, Pennsylvania, and the tool joints made and installed by Hughes Tool Company, of Houston, Texas.

The services of Mr. Alex Maradudin (now deceased) were obtained by the Project to review the Purchase Order for mill and test procedures. Mr. Maradudin, a retired metallurgist from Standard Oil Company of California's Research Laboratory, La Habra, California, and an expert in oil field tubular goods, advised that the Purchase Order was technically acceptable.

To insure the minimum of manufacturing defects, Mr. Maradudin was retained by Global Marine Inc. to supervise the manufacture and inspection of the S-135 drill pipe.

The drill pipe was cleaned and sandblasted after the tool joints were attached and given final sonoscope and end area inspection. The outside was coated with a zinc-rich organic coating and the inside coated with corrosion preventative oil.

The drill pipe was not plactic-coated on the inside. The Project and Technical Assistance Panel felt the coating could become brittle at the low temperatures of the deep ocean and that extensive coring would scar and peel the coating. 
The external coating definitely has retarded corrosion. External corrosion was first noticed on Leg 12, or two years after the pipe was placed in service.

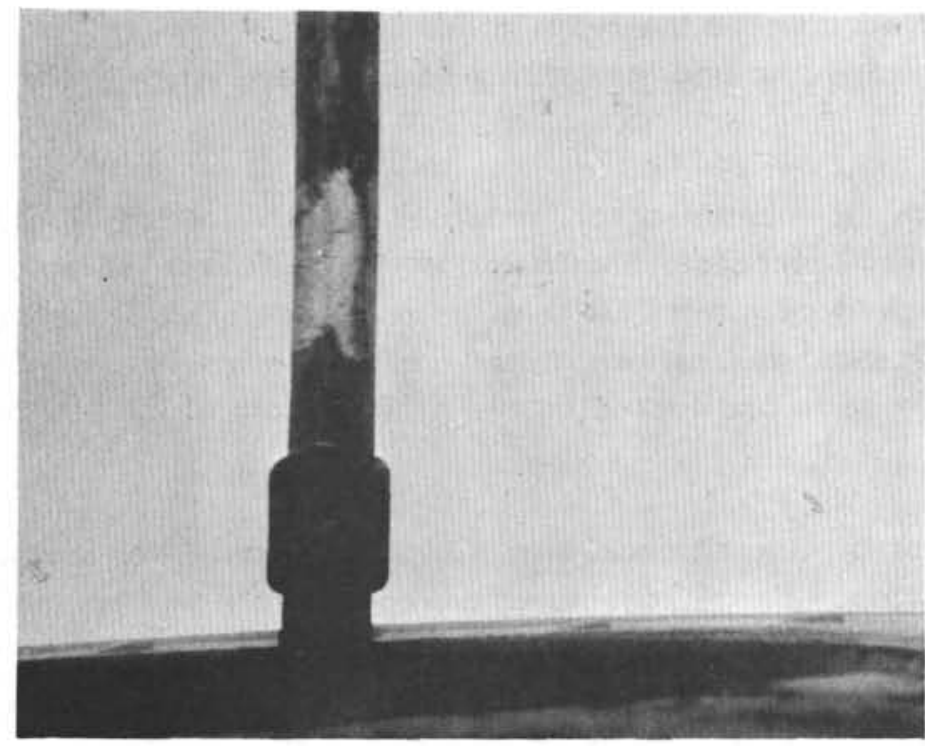

External corrosion of 5-inch drill pipe at least two years after being placed in service.

On the first few runs in deep water, the external coating seemed to form blisters. When the pipe was pulled up in shallower water, these blisters would flake off, making enough acoustical noise to confuse the positioning system.

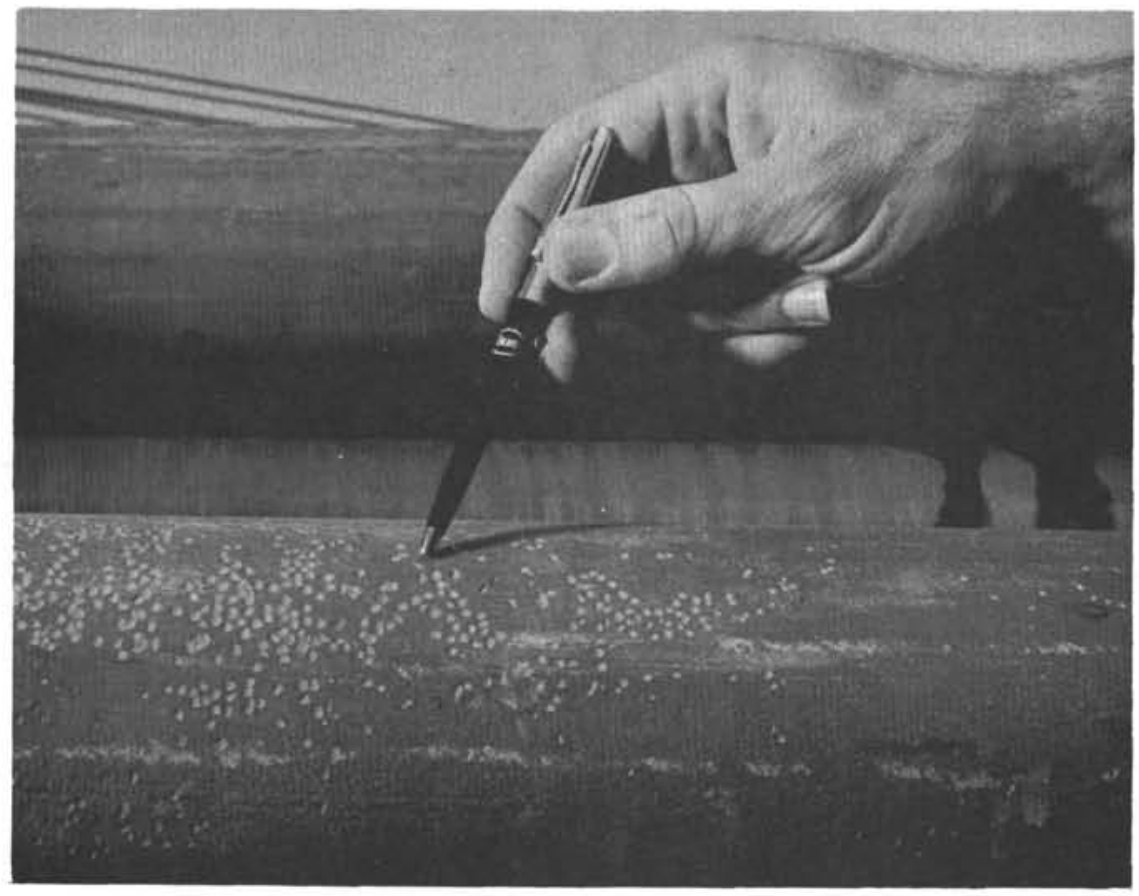

Blisters in external coating apparently caused by water at depth being trapped. 
Hydraulically installed rubber drill pipe protectors were installed at 5-foot intervals along the single 30 -foot stands of pipe. This was done to reduce resonant motion, to protect the drill string during automatic pipe-racking operation, and to provide color coding of the protector rings as a reference system for identification of individual lengths. Although this color code would have made it possible to establish stress exposure of the pipe, it was operationally impossible to establish and follow such a program. As the Deep Sea Drilling Project progressed, stress fatigue did not appear as a problem, so interest in such a program diminished.

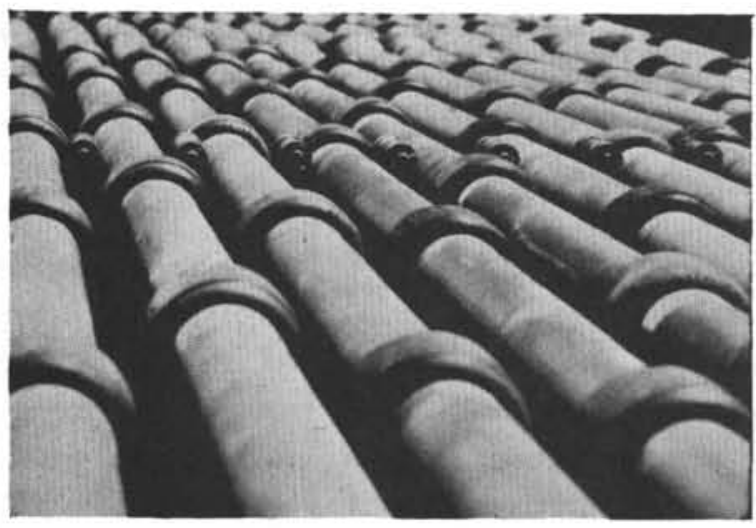

Color coded drill pipe protectors at 5 foot intervals on the drill string.

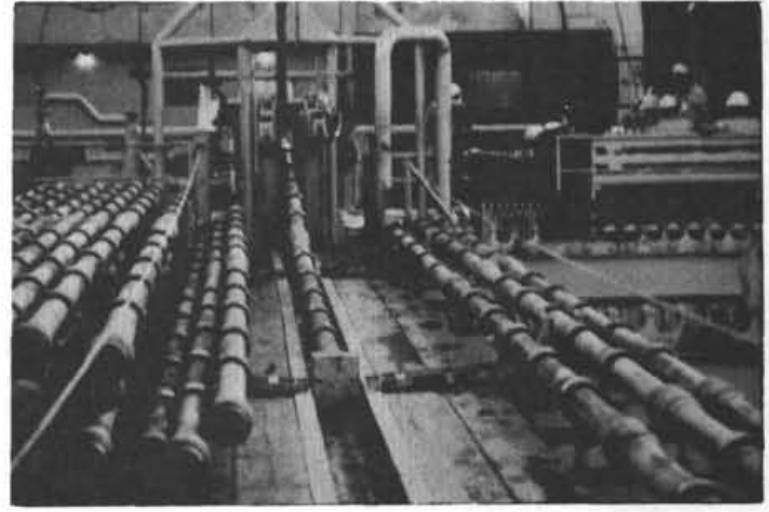

Mechanical pipe racker used to store the drill string.

Thread protectors were installed and the pipe transported to Orange, Texas, where it was loaded aboard D/N Glomar Challenger after builder's trials. When placed in the automatic pipe racker, each joint of the pipe was made up and broken down several times with a high zinc-content thread lube to prevent galling.

The drill pipe is run into and pulled out of the hole with an IDECO Dual Elevator system. One elevator is used to pull the pipe in the conventional manner. The second set replaces the drill pipe slips and supports the pipe on the rotary table. As the drill pipe is laid down in the pipe racker, the No. 1 elevator has been lowered back to the drill floor. This elevator is set to one side and the links that attach the elevators to the traveling block are removed and hooked onto the No. 2 elevator. This elevator now becomes the No. 1 elevator and the string is lifted and set off on the remaining elevator, thus the elevators are leap-frogged while pulling or running the pipe.

This system eliminates marking and necking the pipe with slips. As $\mathrm{S}-135$ is notch sensitive, eliminating slip marks undoubtedly has extended the drill pipe life. 
The introduction of re-entry to the Program Plan also introduced several problems involving the drill pipe. The actual use factor of re-entry was an unknown, but if re-entry was to be used frequently, it would be operationally desirable to run the cones and bases through the moon pool. This would require either removing or modifying the drill pipe supporting expotential horn. As re-entry was specifically eliminated from the original Request For Proposal, and casing was the only other tubular goods to be run through the horn, the opening at the top of the fixed horn was 30 inches. In addition, the Project had received requests to drill sites that required a drill string longer than 22,500 feet.

A subcontract was entered into with the Southwest Research Institute to determine the feasibility of these questions. Their report indicated drill pipe support, such as given by the expotential horn, is necessary. The present horn is structurally over designed and could be a lighter removable structure. The "piccalo" or scabbard-type support could be shortened from 80 to 50 feet and given necessary support to the drill pipe. The report, in addition to supporting Dr. Vreeland's work, extended computed estimates of drill pipe life for a 30,000 foot string. The computer program for this report is available if modification or review of the drill pipe is required.

The Request For Proposal included pipe inspection at frequent intervals as a requirement, but did not specify the type of inspection. Global Marine Inc. officials stated in their reply they would furnish magnetic particle and Magna Glo ultra violet inspection for tool joints and heavy sections. A sonic (assumed to be Sonoscope, trade name of Tuboscope's electromagnetic inspection equipment) pipe inspection unit would be used to inspect the pipe in the pipe racker. The subcontract retained the magnetic particle (Magna Glo or similar) inspection for tool joints, bumper subs, drill collars and heavy sections and specified inspecting the drill pipe with a magnetic flux-type instrument similar to Tuboscope equipment.

Global Marine Inc. had planned to use Tuboscope's well-head isolog which would allow inspection on each trip. This unit is placed on the rotary table and the pipe inspected as the string is pulled out of the hole. This is an external unit with the coils and detector placed around the pipe. The dual elevator system would have required placing the unit under the rotary table, however, Dr. Vreeland's conclusion that support was needed through the expotential horn of the drill pipe with rubber protectors made inspection with an external system very undesirable, as the coils and detector head would have to be opened and moved across each protector. In addition, this well-head unit was in the developmental stage and results still questionable, as the pipe had to be centered as it is pulled through the unit. Inspection in the pipe racker with the external sonoscope would have been so slow as to be prohibitive.

An industry search for an internal sonoscope indicated Tuboscope was the only company interested. Tuboscope had designed and tested for Phase II of Mohole, a prototype internal sonoscope. The sonde was to be run on the 7 -conductor logging line so the string could be inspected while in the hole. Tuboscope advised they could furnish a more sensitive 
and dependable sonde if inspection was limited to one stand at a time (100 feet). This would allow inspecting the pipe in the racker even though the racker supported the pipe at three places with steel fingers. This blip would be put on the tape and easily identified.

Tuboscope built the system and the shipboard equipment was installed at Hoboken, New Jersey, at the end of Leg 1 in 1968. The pipe was inspected then and has been inspected at the end of all succeeding legs. Todate (end of Leg 20) inspection seems to be adequate. There have been no drill pipe failures due to flaws or stress corrosion. On Leg 18, a crack was visually detected in a joint of pipe approximately three feet above the pin. The crack was $7 / 8$-inch long and apparently was caused by fatigue. It is not known if this joint of pipe had been in service from the start of operations in 1968. In fact, the only drill pipe failure was caused by trying to core without bumer subs in the bottom hole assembly.

Suspect joints are removed from the string on the next site as the string is lowered. At first, these were inspected at the next port by optical boroscope. Accumulated scale in the pipe made this a slow process, so an ultrasonic instrument was placed on board and now the drilling crew checks the suspect joints.

The inspection after Leg 11 indicated several joints had internal pitting. Four joints with the deepest indentations were carefully inspected and the points marked. The joints were shipped to Los Angeles, California, where they were inspected, using the external sonoscope. A comparison of inspection records indicated the external sonde was located pits that should be checked with either the boroscope or supersonic probe. Depths of pits were measured with the ultrasonic probe. One joint was then cut into coupons and sent to several major oil company laboratories for examination. The concensus of opinion was the pitting was caused by aerated salt water.

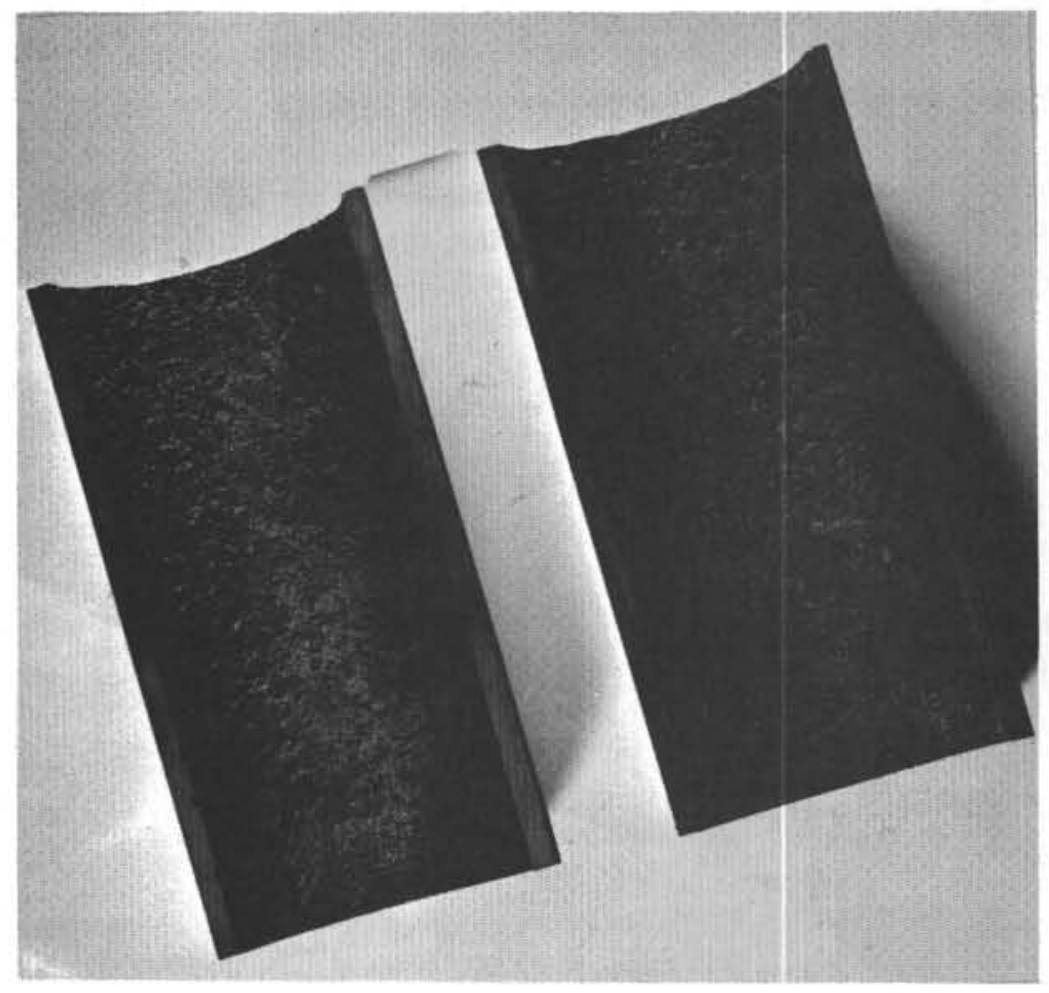

Drill pipe coupon used to check sonoscope inspection accuracy. 
Several procedures are used to control corrosion. The pipe is flushed with fresh water just before pulling and a slug of mud is pumped in and a slug of cationic oil soluble corrosion inhibitor is added on top of the mud. After racking, a pipe rattler is used to loosen the scale so the inhibitors can wet the pipe. Tight thread protectors are used on the pin end of the stand to reduce sweating and keep sea water out during rough weather. The pin end faces forward. Corrosion measuring rings are run at several spots in the string to watch for any change in the rate of metal loss.

When the scientific community became aware that one of the legs on the first extension granted the Deep Sea Drilling Project would be in the Mediterranean Sea, several scientists expressed interest in a site located in the Black Sea. The Project was asked to estimate logistics.

As the Black Sea has an appreciable $\mathrm{H}_{2} \mathrm{~S}$ content, the drill string would be one area that could be affected.

An industry and literature survey indicated S-135 drill pipe could be subjected to hydrogen embrittlement if the site in the Black Sea were drilled. Using Grade "E" drill pipe would eliminate this problem, but the cost would be prohibitive to transport sufficient pipe and change it out twice on D/V Glomar Challenger. Two rules of thumb established by the oil industry to select steel tubular goods for $\mathrm{H}_{2} \mathrm{~S}$ environment are:

(1) Elongation should be $23 \%$ to $25 \%$ after quench and temper since rolled goods usually have local hard spots.

(2) Keep the yield point of steel below 80,000 psi and the hardness below Rc 22.

In addition, the maximum length of drill string required in the Black Sea would be 10,000 feet, or half the designed length of the Deep Sea Drilling Project drill string. The $\mathrm{H}_{2} \mathrm{~S}$ concentration increases with water depth, so it would be affecting the section of drill string with lower stress levels.

A review of these factors indicate the Deep Sea Drilling Project's S-135 drill pipe could be used to drill in the Black Sea. It should be noted that the hydrogren in the steel is released if exposed to the atmosphere, so it is not permanently changed.

Despite these studies that indicated the feasibility of using S-135 drill pipe in hydrogensulfide laden situations, drilling was not attempted in the Black Sea during Phase II because scheduling of $D / V$ Glomar Challenger to undertake such drilling would have permitted an unsatisfactorily small amount of time for the Mediterranean Program.

In summary, the first three years of operations have proved the drill pipe to be more than adequate for the water depths and sea states operated in. Also, using a continuous drill pipe string has simplified handling, racking, inspection and logistics.

Although pitting is evident and will increase with use, it is not possible to project the useful life of the drill pipe.

16 
1. Heave Dynamics of Long Drill Strings Suspended From a Floating Vessel. Dr. T. Vreeland, Jr.

2. Control of Bending Stresses in a Long Drill String Due to Ship Roll and Pitch.

3. An Analytical Study of Drill String Vibration. J.J. Bailey.

(a) Finnie Transactions of ASME, May 1960.

4. Part I Volume II Appendices. Global Marine Inc.

5. Project Mohole Bibliography. Studies and Reports - National Science Foundation Contract NSF-260.

(a) Fatigue Analysis of Mohole Drill Pipe and Associated Problems. CurtissWright Corporation.

(b) Techniques and Equipment Demonstrations of Tubular Goods Inspection. Final Report.

(c) The Effects of High Pressure on Electrolysis and the Absorbtion of Hydrogen by Steel at Ambient and Elevated Temperatures. Battelle Memorial Institute.

(d) Testing of Drill Pipe and Casing Materials. Battelle Memorial Institute.

(e) Drill Pipe Analysis. Battelle Memorial Institute.

(f) Evaluation of Drill Pipe for Mohole Project. Reed Roller Bit Company.

(g) Studies of Alternate Drill Pipe Steels. (Note: other than S-135). Battelle Memorial Institute.

(h) Tentative Specifications for Mohole Drill Pipe. Rev. \#1.

6. Paper - Drilling Operations in Deep Marine Environments. Dan R. Bullard, Jr.

7. Analysis of the Drill String of the JOIDES Drilling Vessel. Nov. 6, 1967. NESCO. 
8. The Influence of Pressure on Buckling and Straightness of Tubular Goods and Rods in Wells. A. Lubinski. Pan American Petroleum Corporation.

9. A study of the Buckling of Rotary Drilling Strings. A. Lubinski. Barnsdall Research Company.

10. Problems in the Load-Carrying Applications of High-Strength Steels. SymposiumDefense Metals Information Center. Battelle Memorial Institute.

11. The Problem of Hydrogen in Steel. Defense Metals Information Center. Battelle Memorial Institute. 
BUMPER SUBS 
In the Request For Proposal, the Deep Sea Drilling Project asked that drill collars (size and bore) be specified and include sufficient shock bumper subs for the drill string. In addition, bumper sub size and make were requested. The shock bumper sub was identified at the Proposers' Conference as a balanced (hydraulically) bumper sub.

The proposal of Global Marine Inc. included hydraulically balanced bumper subs, but stated it was believed that the cost of maintenance would be high since this work aboard a vessel would be very difficult or impossible.

The Project made an industry search and found no balanced bumper subs with a $4 \quad 1 / 8-$ inch bore had been manufactured. Such subs had been designed for Project Mohole, but never had been detailed built. A sub with a 60 -inch stroke would be 30 -feet long and difficult to handle.

The Deep Sea Drilling Project accepted Global Marine Inc. 's alternate proposal and the subcontract included 8 1/4-inch outside diameter by 4 1/8-inch inside diameter by 60 -inch stroke Baash-Ross type OSG-2 oil packed bumper subs with $65 / 8$-inch API Regular tool joints. As the $4 \mathrm{1} / 8$-inch bore is not an industry standard, these subs are made on special order.

It soon became apparent that the oil-filled feature was unnecessary. As all drilling and coring is done without returns, the drilling fluid is always free of cuttings. Also, in general, formations drilled and cored in deep ocean basins are less abrasive than those drilled on land and have less tendency to sand-up and stick bumper subs. In addition, the service break is the weakest joint in the bottom hole assembly and an oil-filled sub requires two service breaks against one of a non-oil-filled bumper sub.

Baash-Ross Division, Joy Oil Tools, Houston, Texas, was the supplier of these non-oilfilled bumper subs. The male and female splines of this type bumper sub are exposed to the annulus. Vent holes are drilled in the body to allow free flow of annulus fluid as the bumper sub opens and closes. These subs were built so the female spline section is at the lower end of the male section when the bumper sub is closed. Thus, if a bumper sub is used in the closed position while drilling below the sea floor, cuttings can fill up the exposed male spline section, locking the equipment in the closed position.

There was some question whether Baash-Ross could fit the necessary number of subs into their production schedule, so the Project accepted the substitution of an equivalent design by Shaffer Oil Tool Company, of Beaumont, Texas. 
When the drill collar tool joint was changed from 6 5/8-inches API Regular to NC-61 at the end of Leg 9 , change over subs were made so the bumper subs could be run inverted. This reduced the tendency for the equipment to freeze.

Concurrently with these changes, bumper sub suppliers, Global Marine Inc. and the Project were conducting studies to reduce bottom hole assembly failures.

One area of suspect was the change in impact properties and yield strength of bottom hole assembly components operating at the low temperatures $\left(33^{\circ} \mathrm{F}\right)$ found in deep water. The International Nickel Company, Inc. , of New York City, was very helpful in furnishing reports on some of their tests on properties of steels at low temperatures. These and drilling experiences in Alaska and Northern Canada indicated the 4142 steel being used should not be affected at this temperature. As $\mathbf{4 3 4 0}$ steel has some properties that are superior to 4142 , the bumper sub suppliers are using this steel.

Shaffer Oil Tool Company proposed a bumper sub that has the packing for the wash pipe accessible from the inside bore. This eliminates the necessity of a service break which increases the strength of the bumper sub.
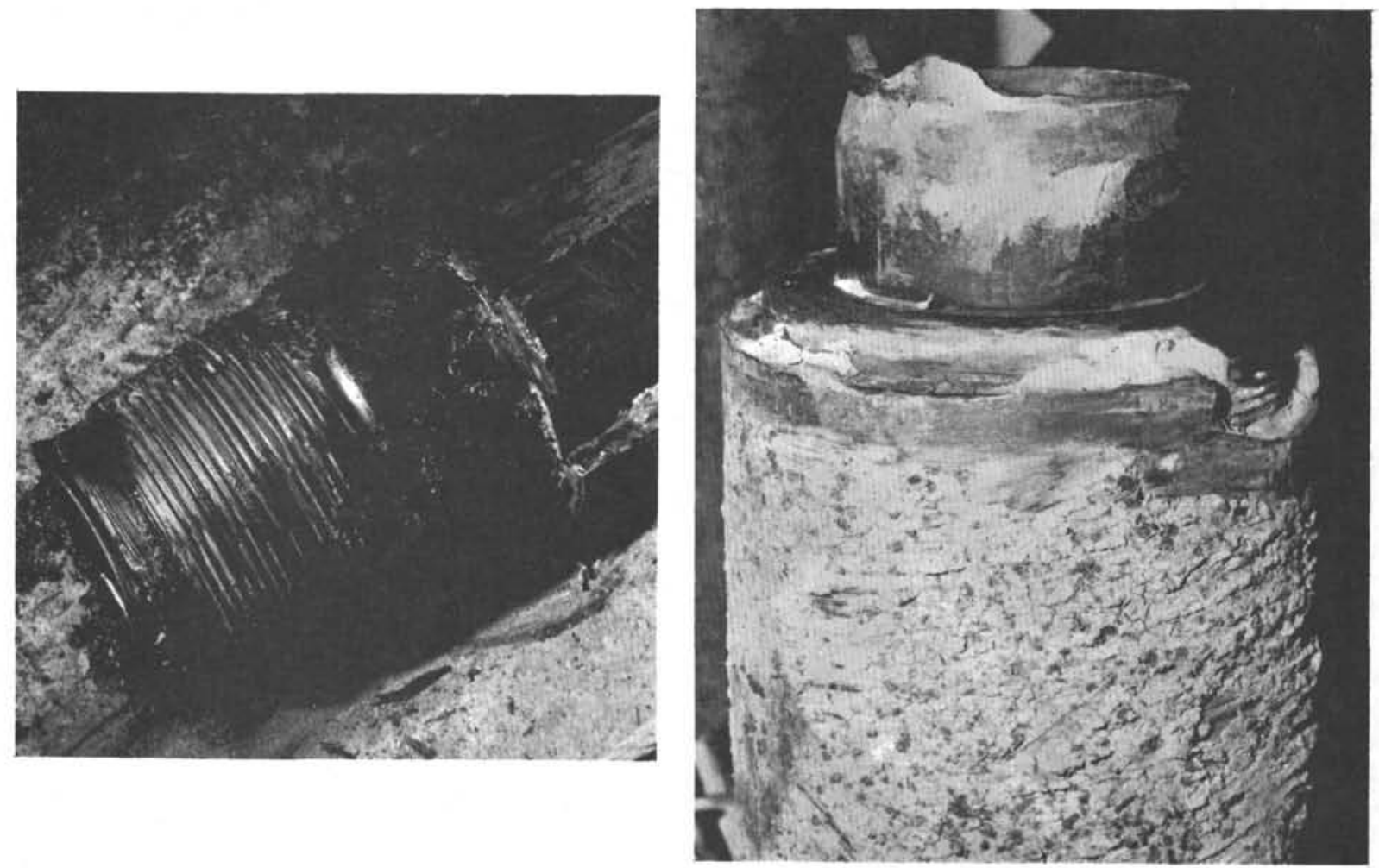

The service break of a bumper sub is the weakest joint in the bottom hole assembly. These are typical failures of this joint. 
Several bumper subs of this design have been placed aboard D/V Glomar Challenger and are being tested.

During these discussions, it was suggested many times that the outside diameter of the bumper sub should be increased so a stronger service joint could be used. Although this would increase bumper sub life and reduce bottom hole assembly losses, the consensus was that the increase in the diameter of a section of the drill string would increase the possibility of sticking the string. This is a very real possibility in the sites which have been drilled through alternating very hard layers and very soft layers. A high volume of drilling fluid is necessary to penetrate hard layers. This erodes pockets in the soft layers and continued drilling then fills up these pockets with cuttings which fall back when circulation is stopped. If the enlargement in the drill string is immediately below this cavity, bridging and sticking of the drill string is then probable.

Since the inception of this program, the state of the art of motion compensators has advanced rapidly.

At present, one system designed and built by VETCO Offshore Industries, Inc. , of Ventura, California, is being field tested. This system uses a pair of hydraulic cylinders to connect the hook to the traveling block. The hook is lowered or raised to compensate for vessel motion. In effect, a constant pressure is maintained below the hydraulic pistons. Oil is added or bled off to compensate for vertical vessel motion. The motion sensor directs oil flow. A gas-oil accumulator evens out oil flow and reduces energy input requirement.

Field trials look very promising. Several units are being installed on floating platforms and on the SEDCO 445 drill ship.

The second system uses one large hydraulic cylinder to move the crown block sheaves up and down to compensate for ship motion. This system is being installed on a Royal Dutch Shell drill ship.

All studies todate indicate a motion compensator would eliminate the need for bumper subs and would increase drilling penetration and core recovery. The Deep Sea Drilling Project is following these units with interest. A three-year extension of operations (Phase II) would make it feasible to investigate installation of a motion compensator aboard $D / V$ Glomar Challenger. 
APPENDIX

(Bumper Subs)

1. Bumper Sub Recommended Inspection and Service.

2. Charpy Impact Curves. 
APPENDIX NUMBER 1

BUMPER SUB RECOMMENDED INSPECTION AND SERVICE 


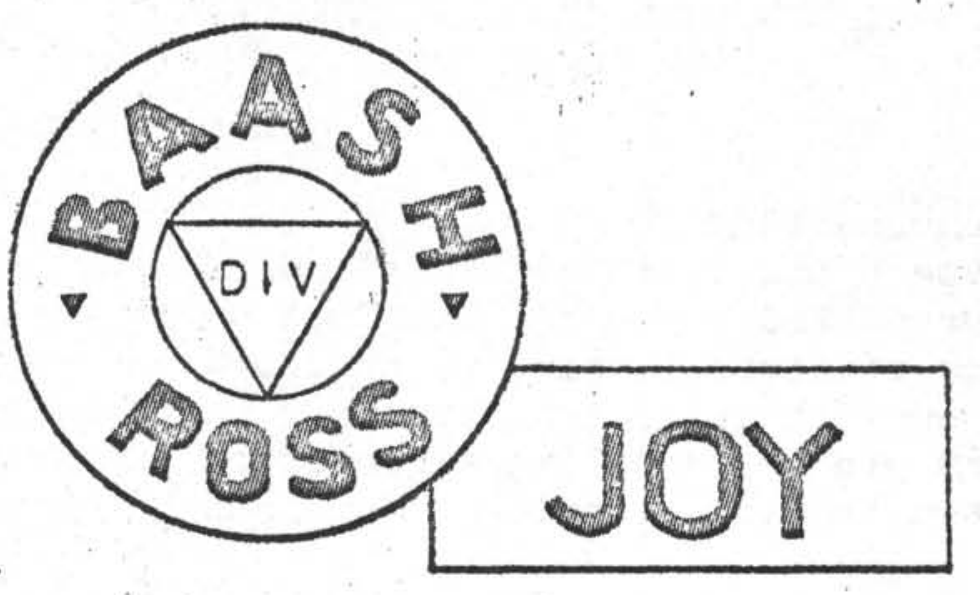

BUMPER SUB

RECOMMENDED

INSPECTION AND SERVICE

TYPE 6ST-PM-1

RENEWABLE SPLINE TYPE

BAASH-ROSS DIVISION

OF JOY MANUFACTURING CO.

BROCHURE NO.

4-1-69 


\section{RECOMMENDED INSPECTION AND SERVICE OF \\ 6SI-PM BUMPER SUBS}

\section{TOOL JOINTS AND ASSEMBLY THREADS}

After each run, inspect the Tool Joint box and pin for erosion marks, gall marks, nicks or pulled threads. The Tool Joint shoulders should be checked for signs of fluid lapping which would indicate that the joint was not made up with sufficient torque. Characteristic of a loose joint is a dry pin and a dull gray color on the area around the joint shoulder caused by fluid lapping in and out between the shoulders.

After 10 or 12 repacks, or approximately 1000-1200 hours of running time, the tool joints should be magnafluxed for minute fatigue cracks that may have resulted from improper joint make-up. Excessive or insufficient make-up torque will eventually cause cracks to appear in the first or second threads near the base of the pin. If the tool joints are damaged to any great extent, they should be recut.

After each repack, inspect connecting or assembly threads for similar type of damage as above. The joint shoulders should also be inspected for extreme flaring or compression of metal indicating a loose connection. The fin, or flare, on the pin joint shoulder can be removed by grinding. If the assembly joints do not have the recommended draw to shoulder for power make-up, (see separate sheet), the box joint face should be faced back as required.

NOTE: Refex to recommended joint make-up torque as shown on separate sheet of this report for the specific joint and size of Bumper Sub.

$\underline{B O D Y}$

After each run, the body O.D. should be checked for wear. The body should be replaced if worn $3 / 16^{\prime \prime}$ under the original diameter. The top box connection should be checked for swelling. The swelling of the box joint would indicate that the body O.D. is worn more than recommended, a loose connection has developed or that excess torque has been transmitted through the tool. If this joint does not have the recommended draw to shouider for power make-up, the joint face should be faced back as required.

\section{SPLINE INSERTS}

For best results, the Spline Inserts should be replaced when they are worn $50 \%$ of their original width. 
MANDREL

After each repack, the spline width should be checked for wear. If the spline is worn more than $50 \%$ of the original width, the Mandrel should be replaced. The amount of wear can be determined by visual inspection of the spline on the lower end of the Mandrel where wear does not occur. The bumping shoulder on the top end of the Mandrel immediately below the stuffing box should be inspected for mushrooming and should be ground flush with 0. . . before reassembling.

After 10 or 12 repacks, the lower connection should be magnafluxed for minute cracks that may have developed from extreme torque or flexing of the joint due to a loose connection. At this time, the pin joint threads should be inspected for erosion marks, gall marks, nicks, or pulled threads. If flaring or mushrooming has developed on the spline end (joint shoulder), spline should be ground as required.

After each repack, the packing cell in the top end of the Mandrel should be checked for signs of erosion or washing out of the sealing surface. The threads in the packing cell should be checked for such damage as pulled or crossed threads and/or worn threads. Such damage can be repaired by building up with weld and remachining to size.

PACKING BUSHING, FOLLOWER RING, PACKING NUT \& PACKING

The Packing Bushing and Follower Ring are bored 1/32" larger than the Washpipe O.D. and for best results should be replaced if worn $1 / 16^{\prime \prime}$ or more on diameter, that is, if the I.D. is larger by $3 / 32$ " or more than the 0.D. of the Washpipe. This wear tolerance would not apply to the Packing Nut as its larger bore does not effect the sealing capabilities of the packing. The Packing Nut, however, should be checked for worn, stripped, or crossed threads and replaced as required. Generally speaking, depending on the particular area and on the type of operation, the packing should last upward from 60 hours, unless the Packing Bushings or Washpipe are damaged or worn beyond the recommended tolerance.

\section{WASHPIPE}

After each repack, the hard chrome surface on the Washpipe should be checked for pits or score marks. If the Washpipe has developed a few pits but looks like it can be salvaged, brazing can be applied to the pitted area and ground flush. Exposed edges on the chrome can cause further damage to the Washpipe or to the packing. If it is required that the Washpipe be replaced due to prolonged use in salt water or other corrosive elements, it is suggested that the new Washpipe be secured in place using teflon tape on the threads and making up the joint to the recommended torque (see attached sheet). 
RECOMMENDED JOINT MAKE-UP TORQUE FOR

ASSEMBLY OF BUMPER SUBS

6-5/8 A.P.I. REG. 8-1/4 0.D. X 4-1/8 I.D. X 60" STROKE TYPE 6SI-PM BUMPER SUB (6 SPLINE INSERTS)

COMPLETE PT. NO. 7521-1212-5

CONNECTION

6-5/8 A.P.I. Reg. Tool Joints (4-1/8 I.D.)

Top Sub to Body Thread

(1/16-1/8 Draw to Shoulder)

Washpipe to Top Sub Thread

Mandre1 to Bottom Sub Thread

(1/16-1/8 Draw to Shoulder)
TORQUE FT./LBS.

$33,000-36,000$

$38,000-42,000$

$2,500-3,000$

$16,000-18,000$

NOTE: To prevent galling of joints at make-up and in service due to high torsional loads, all threads and shoulders should be lubricated with a good quality lubricant recommended for such service. The lubricant recommended for this type of service is one that will provide sufficiently high coefficient of friction to prevent further make-up of joint in transmission of torque. 


\section{BAASH-ROSS DIVISION OF \\ JOY MANUFACTURING COMPANY}

\section{PARTS LIST}

\section{DESCRIPTION}

BUMPER SUB 6SI-PM-1 RENEWABLE SPLINE TYPE 8-1/4 0.D. $X$ 4-1/8 I.D. X 60" STROKE 6-5/8 A.P.I. REGULAR TOOL JOINT. COMPLETE PART NO. 7521-1212-5

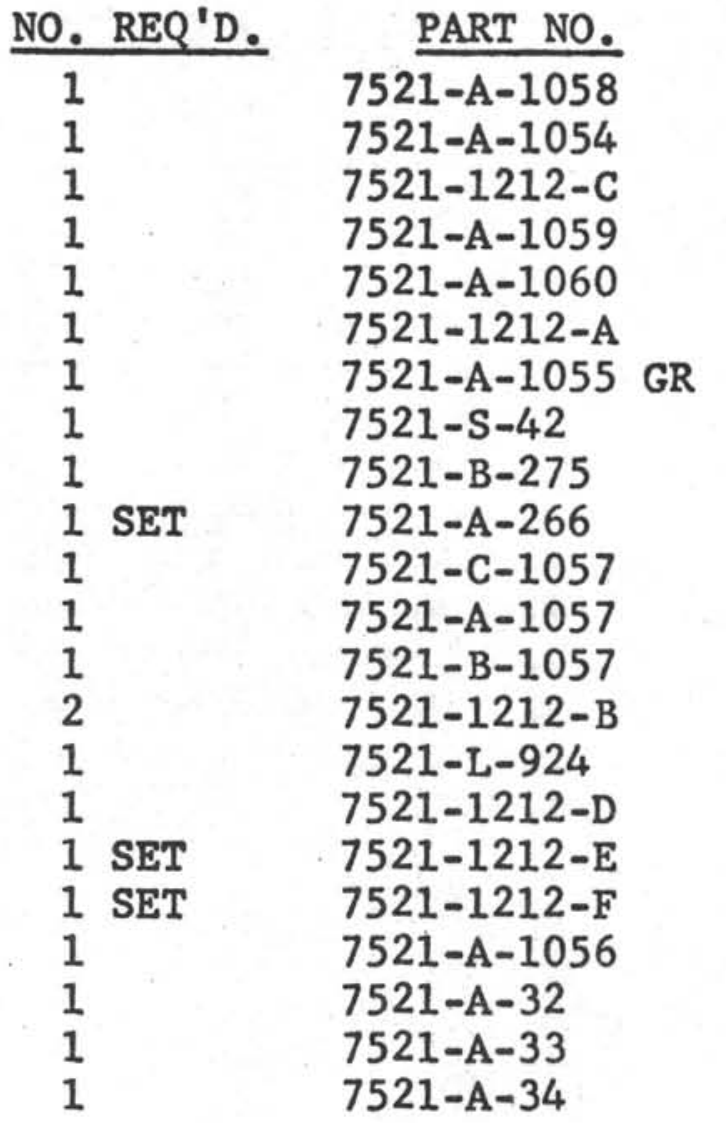

NAME OF PART

BODY

MANDREL

"O" RING (MANDREL)

BOTTOM SUB (PIN)

TOP SUB (BOX)

"O" RING (TOP SUB)

WASHPIPE

LOCK RING

PACKING NUT

SPLINE INSERT (6 INSERTS)

FOLLOWER RING

HIGH PRESSURE PACKING BUSHING

LOW PRESSURE PACKING BUSHING

"O" RING (PACKING BUSHING)

SEAL RING

"O" RING FOR SEAL RING

LOW PRESSURE PACKING

HIGH PRESSURE PACKING

WRENCH

LOCK RING INSERTER

LOCK RING GROOVE CLEANER

LOCK RING REMOVER 
BAABIL-ROSS TYPE 6SI-PM-1

$6-5 / 8$ SIZE - 8-1/4 O.D. X 4-1/8:I.D. X 6O" STROKE

$(4-5 / 8$ DIA. WASHPIPE - AREA 16.800)

COMPLETE PART NO. $7521-1212-5$

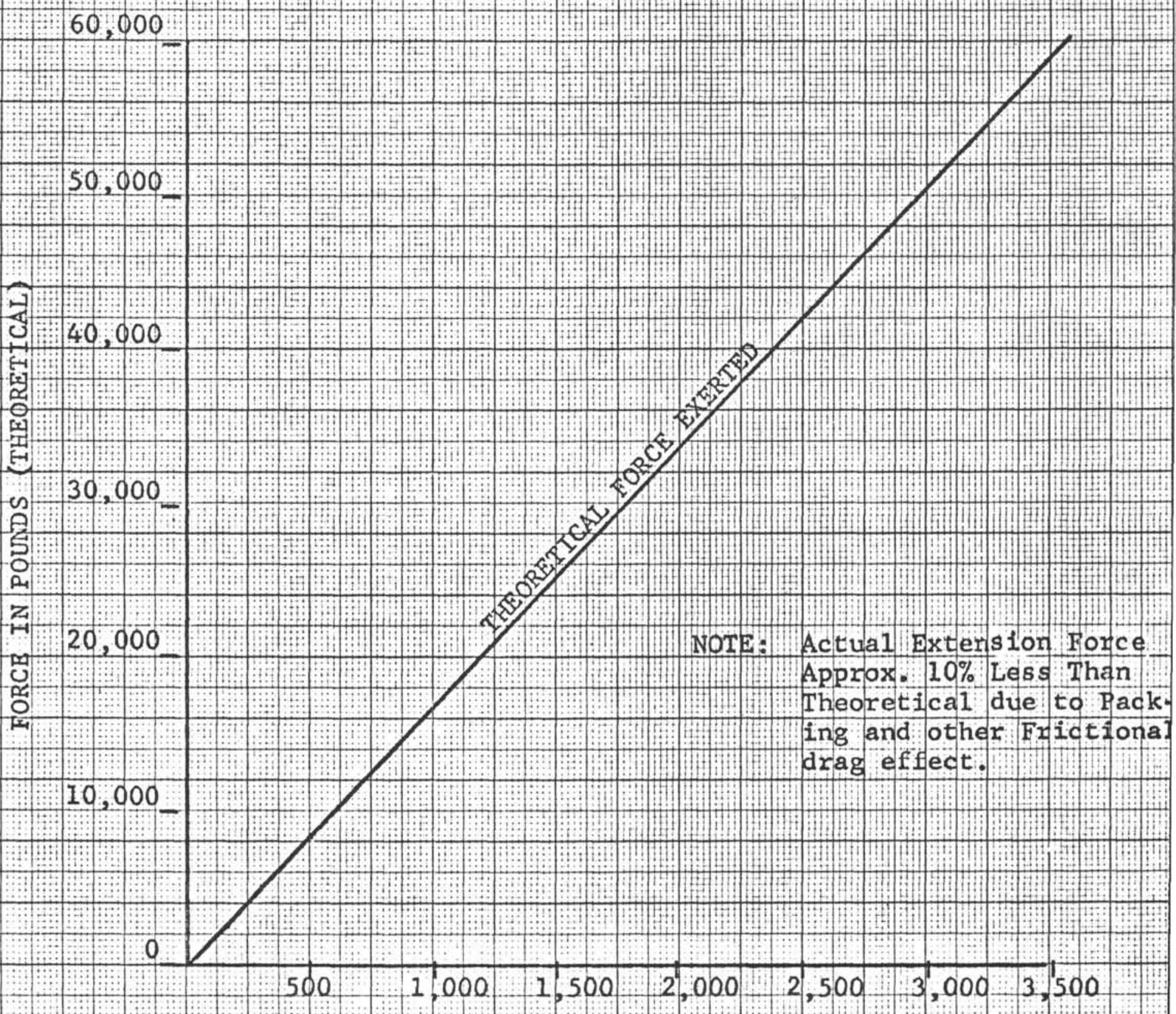

* DIFFERENTIAL PRESSURE (P.S.I.)

$/ 19$

* DIFFERENTIAL PRESSURE EQUALS INTERNAL

RRESSURE MINUS EXIERNAL PRESSURE 


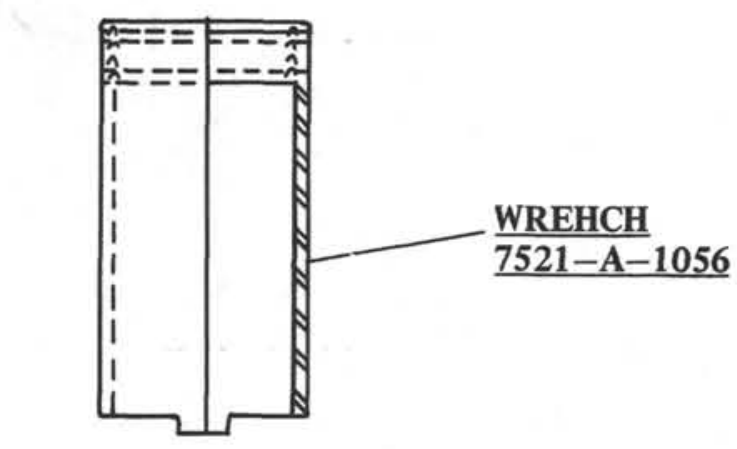

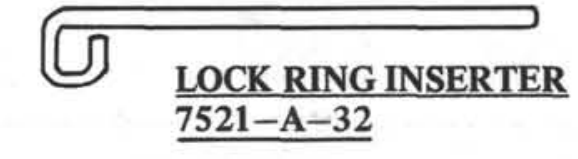

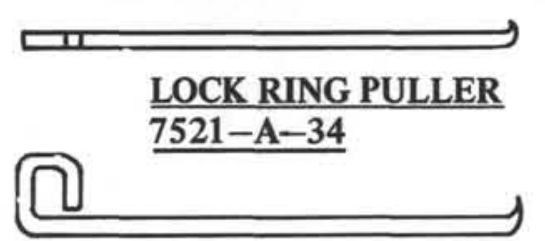

LOCK RING GROOVE CLEANER $\underline{7521-A-33}$

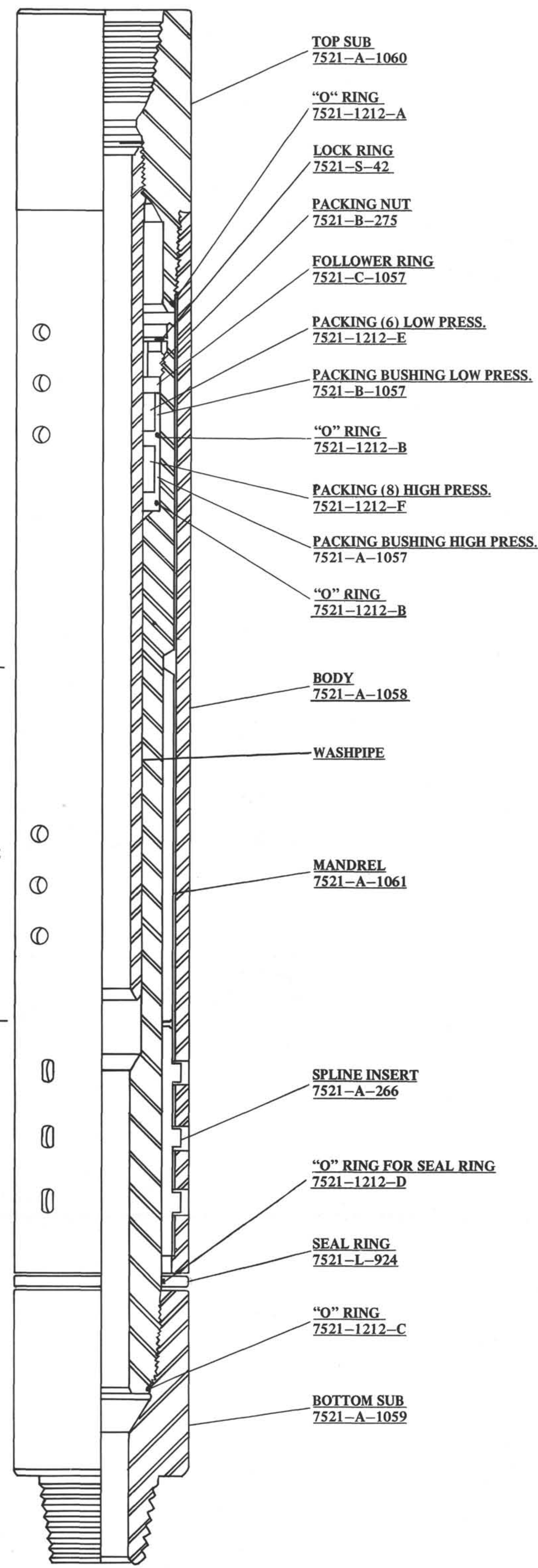




\section{CHARPY IMPACT CURVES}

Excerpt from report: Notch-Impact Transition Temperature of Quenched and Tempered Low Alloy Steels. F. L. LaQue. W.A. Wesley. June 29, 1956. The International Nickel Company. 


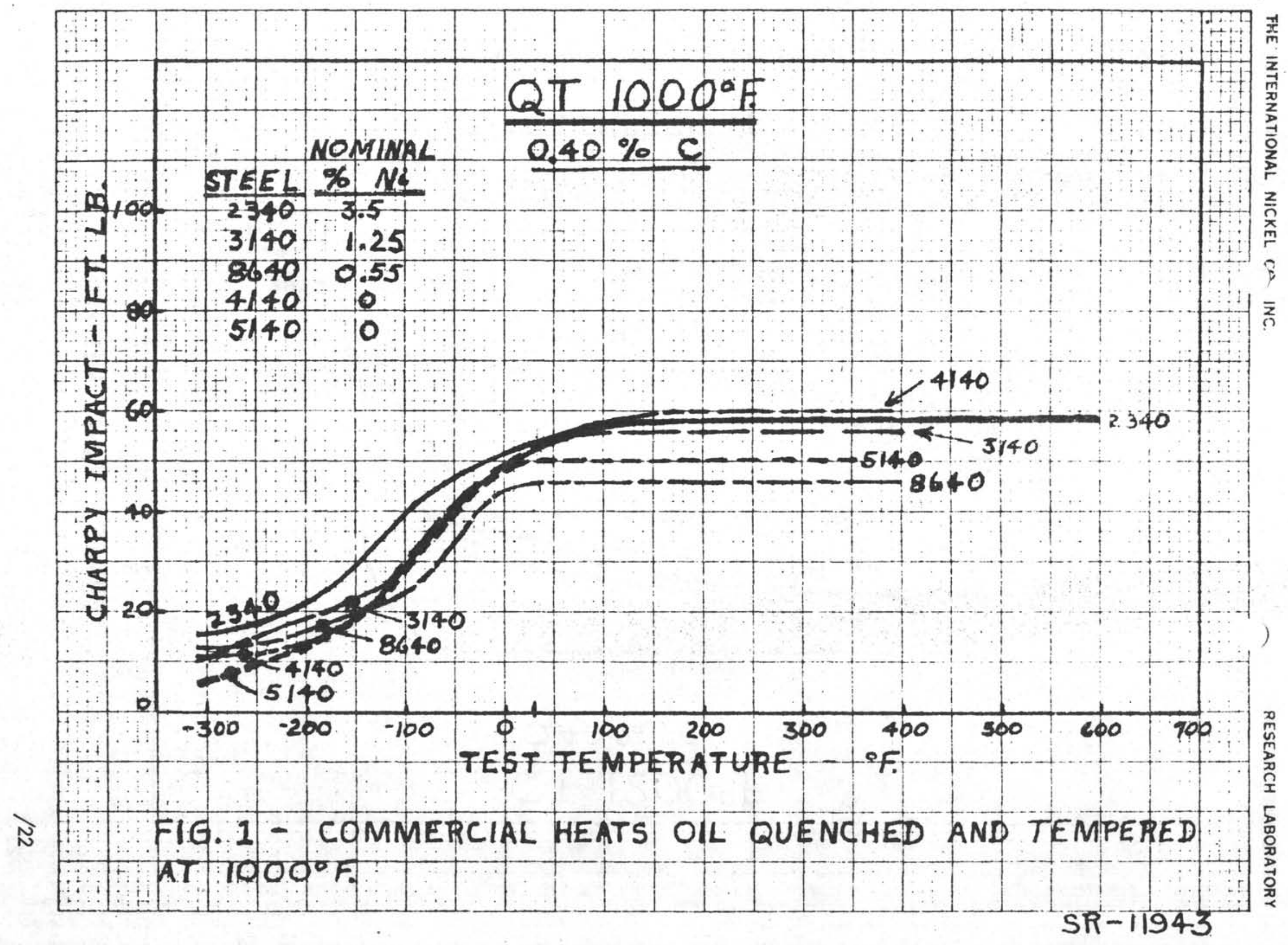




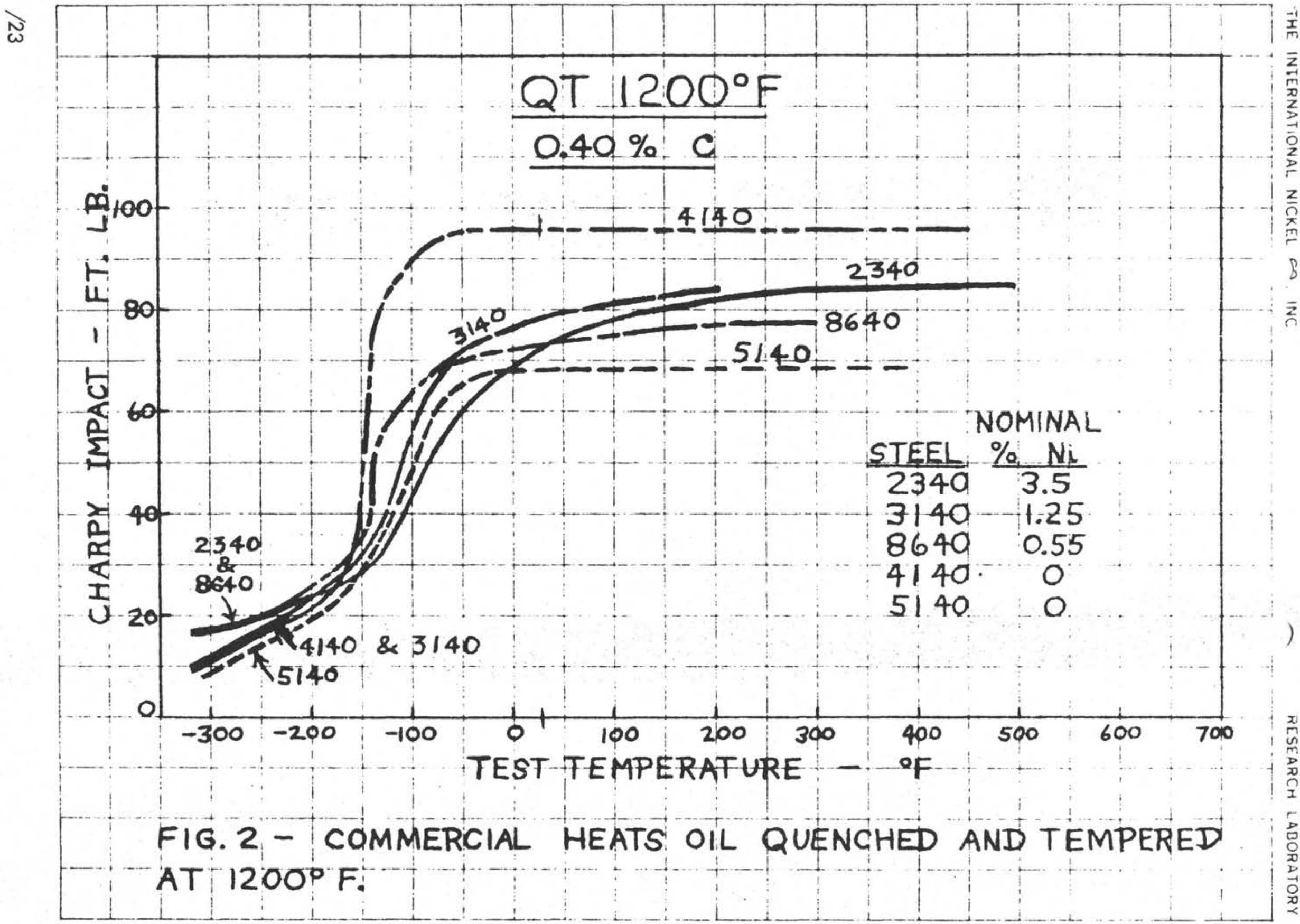




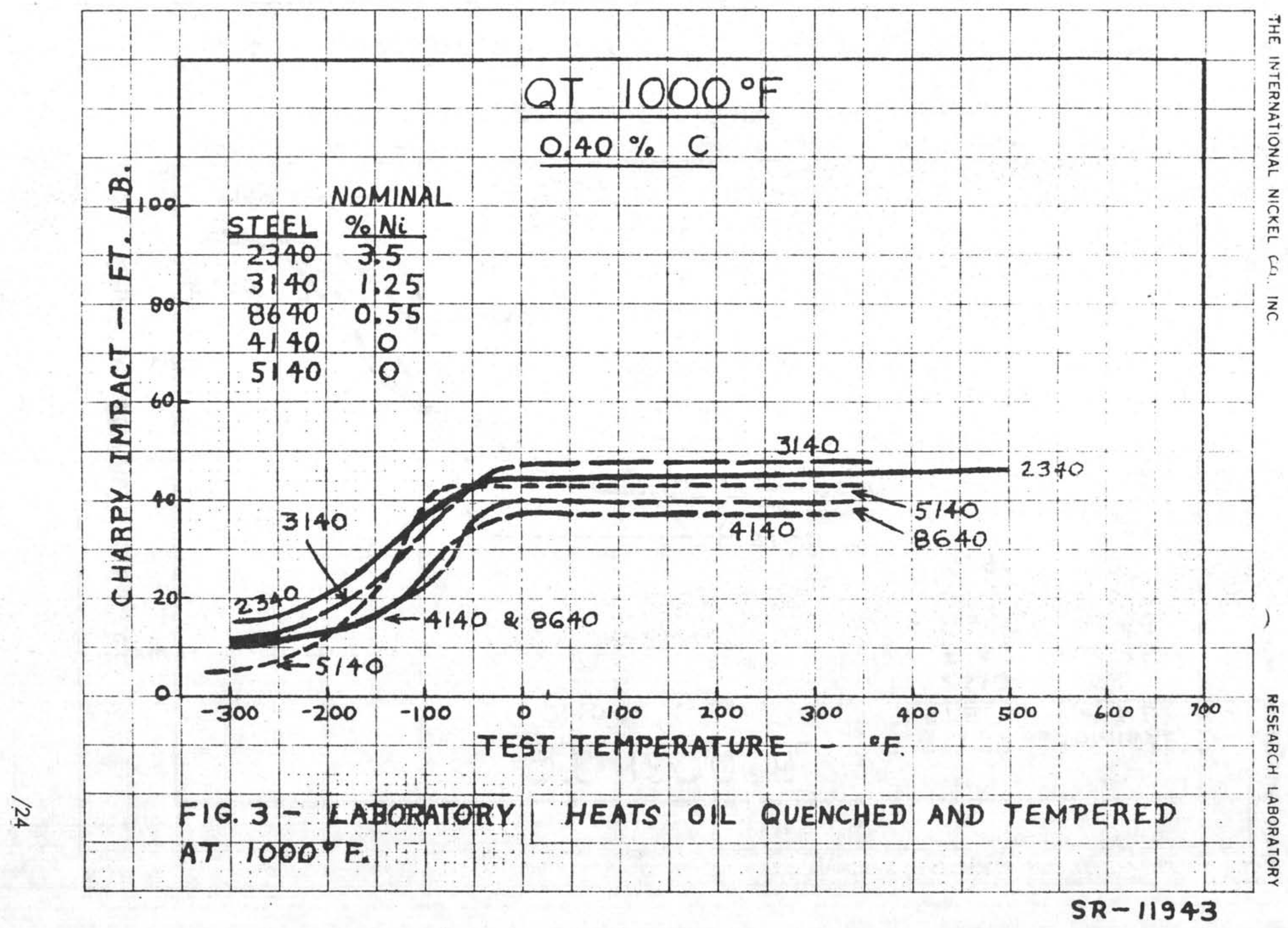


जे

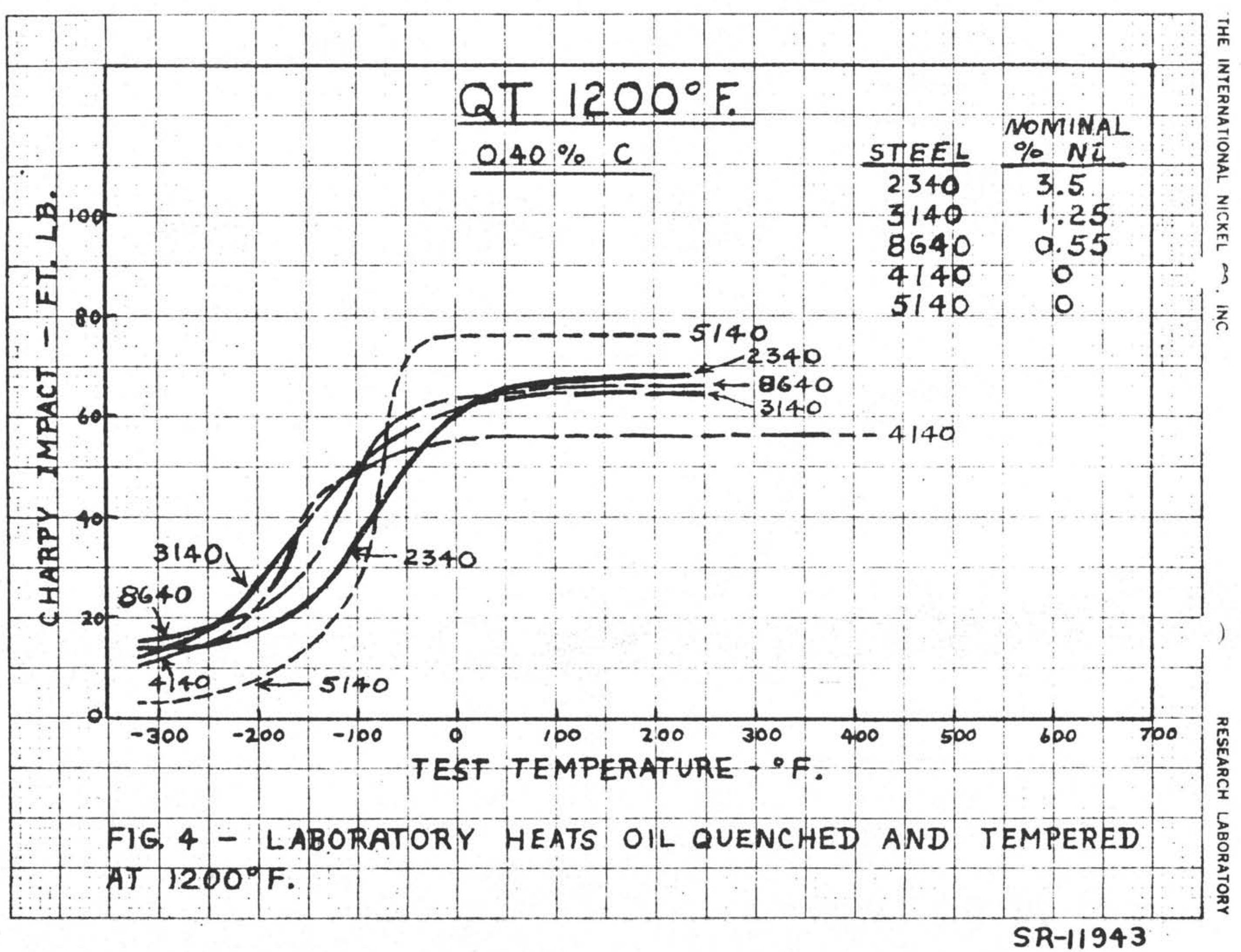




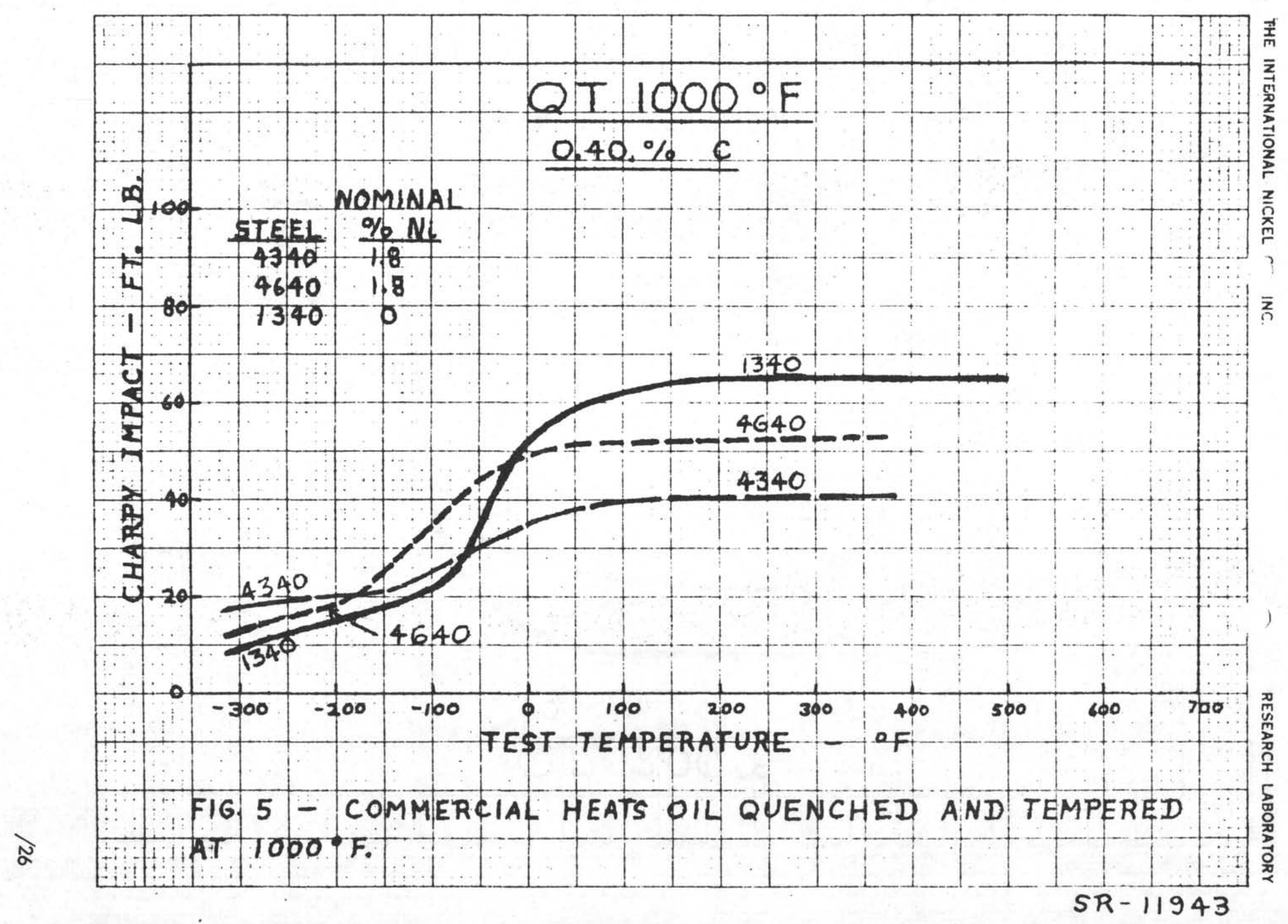




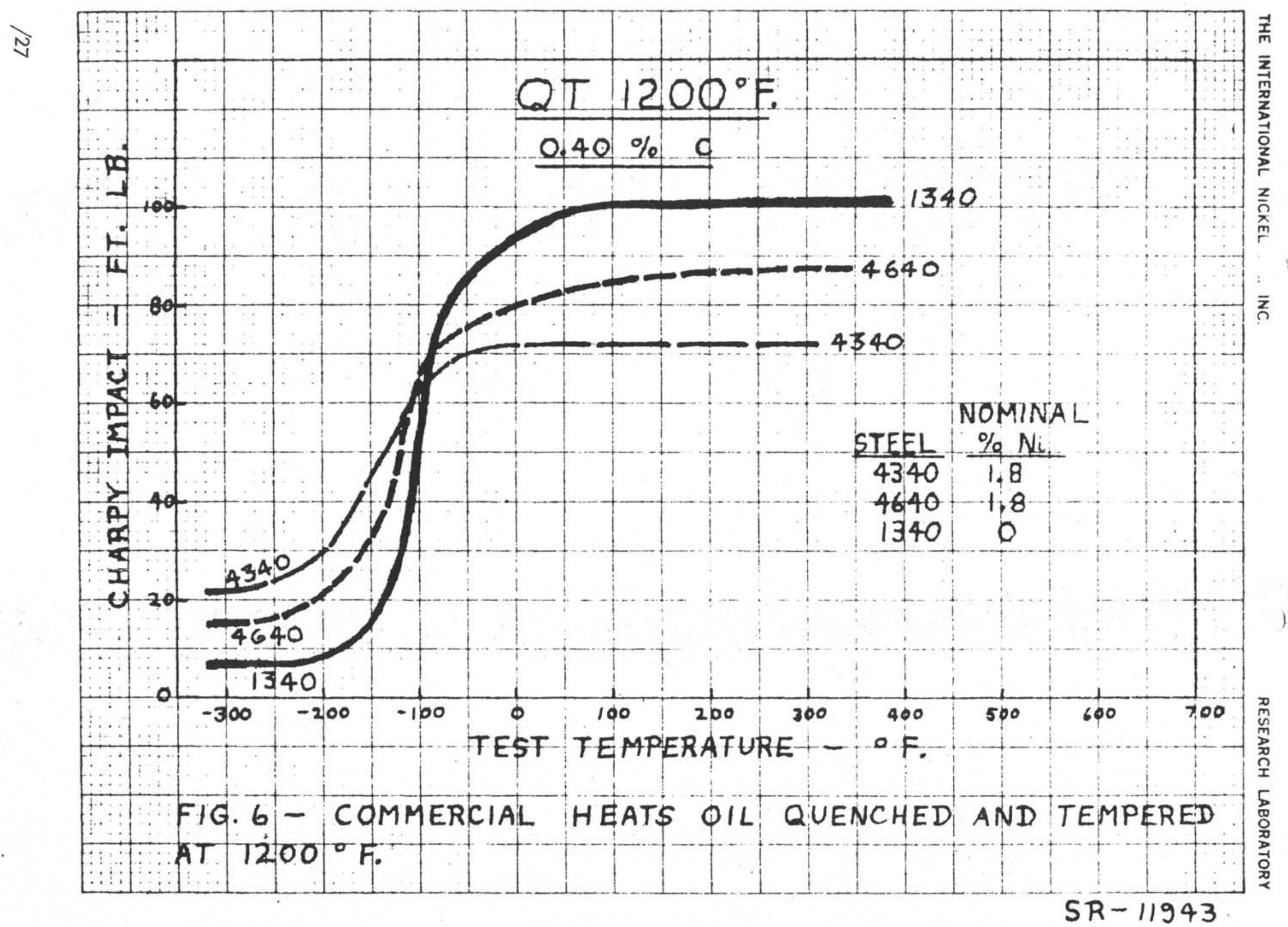




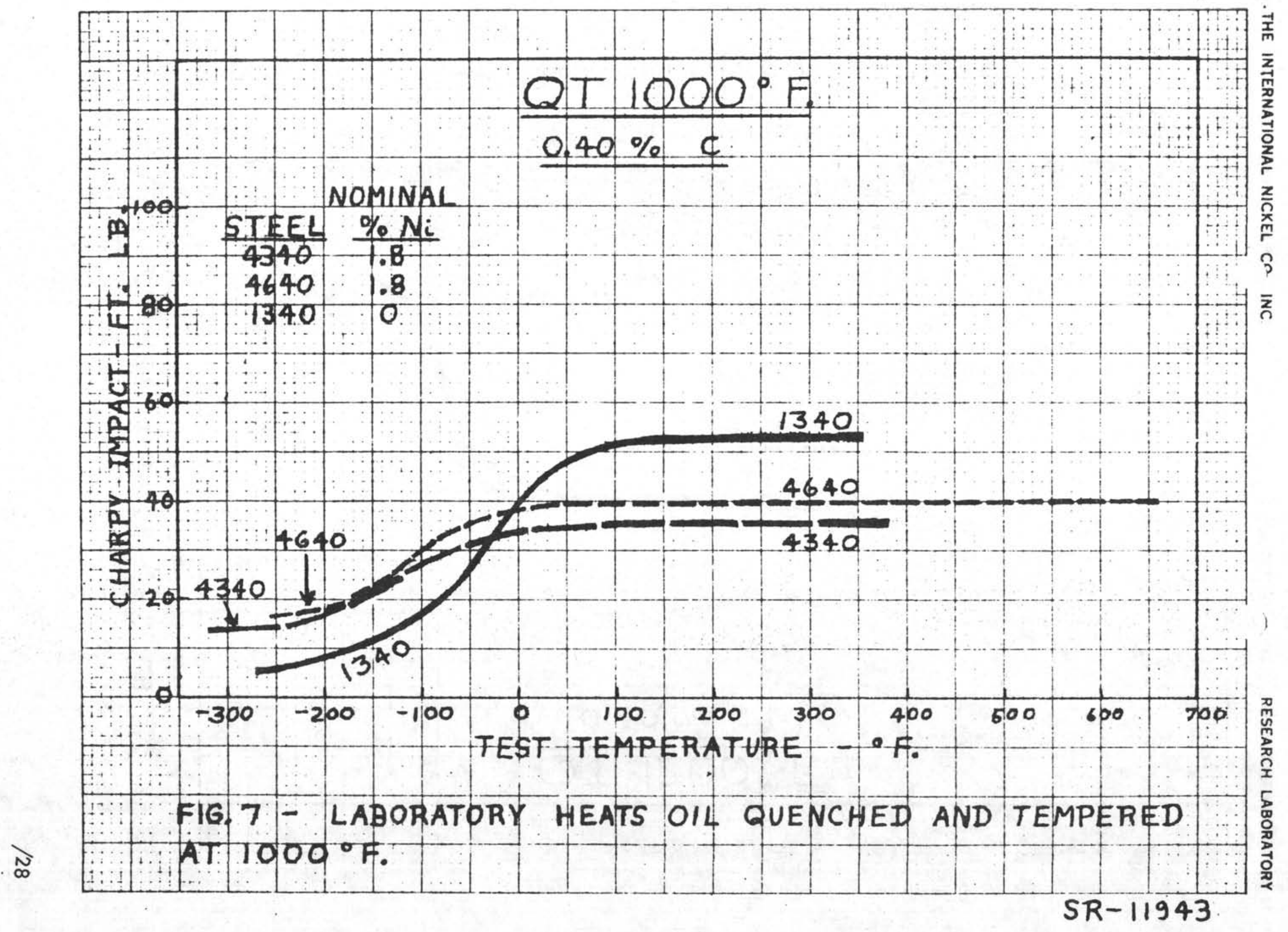


సิ

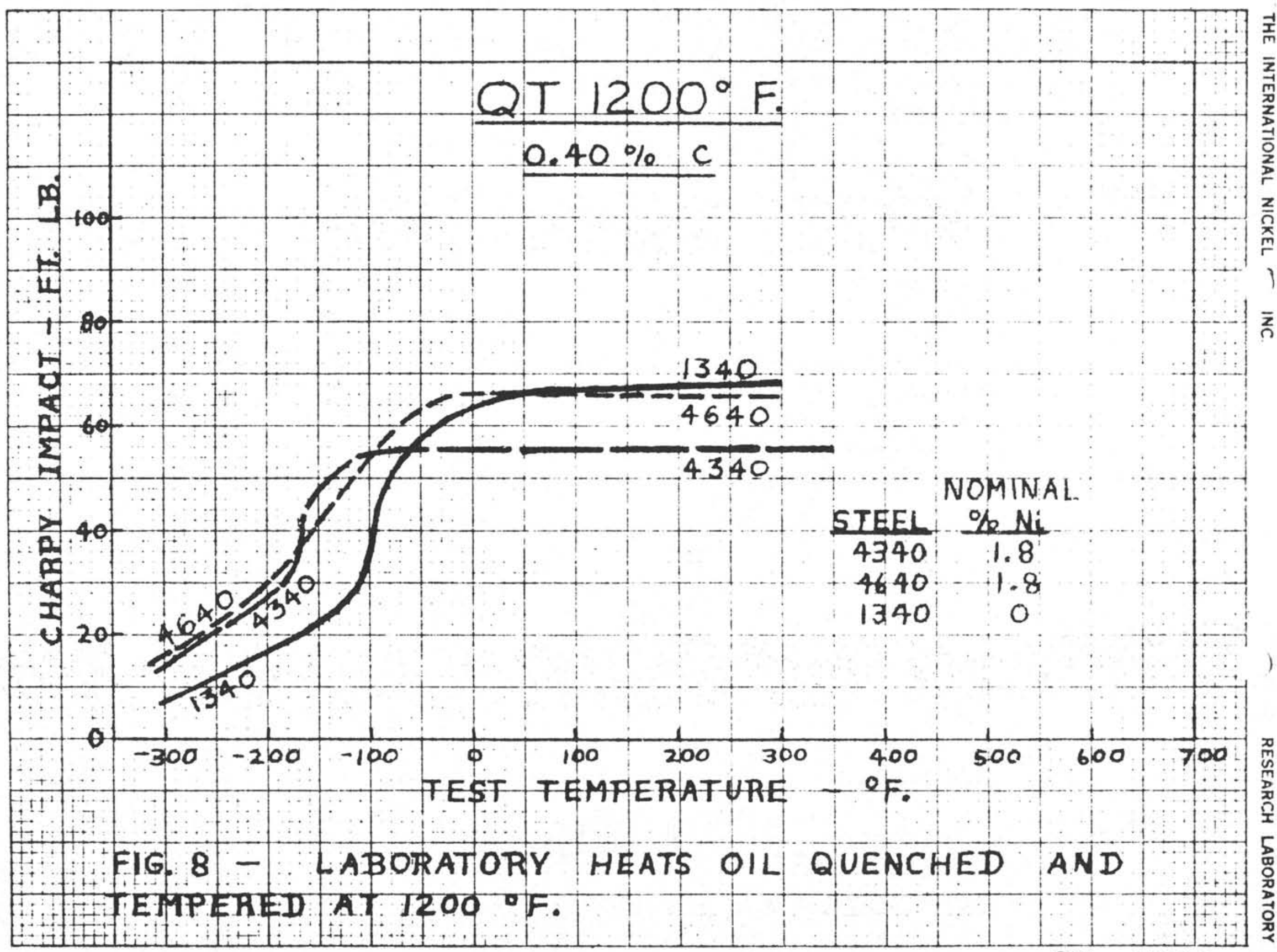




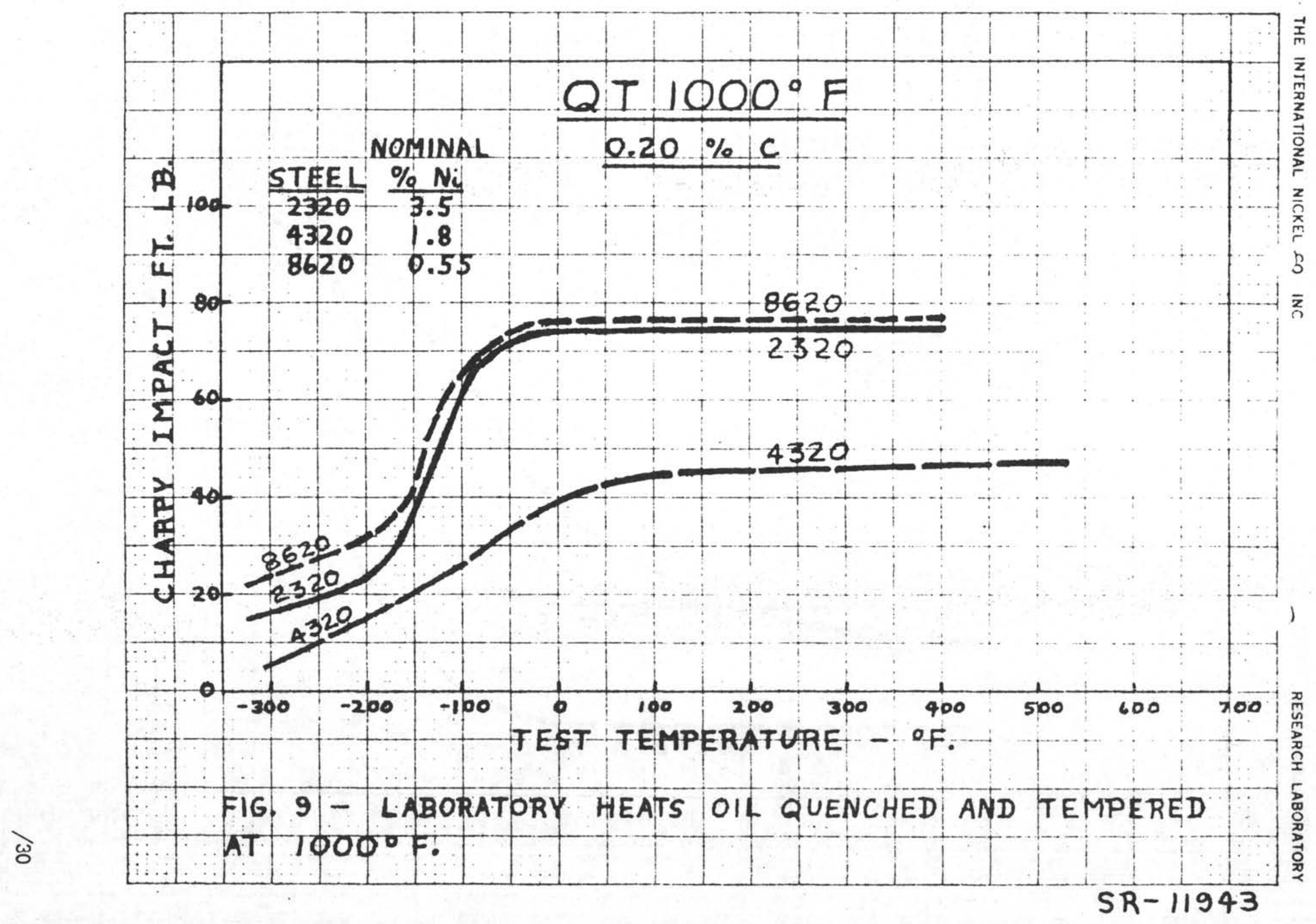


$\underline{\omega}$

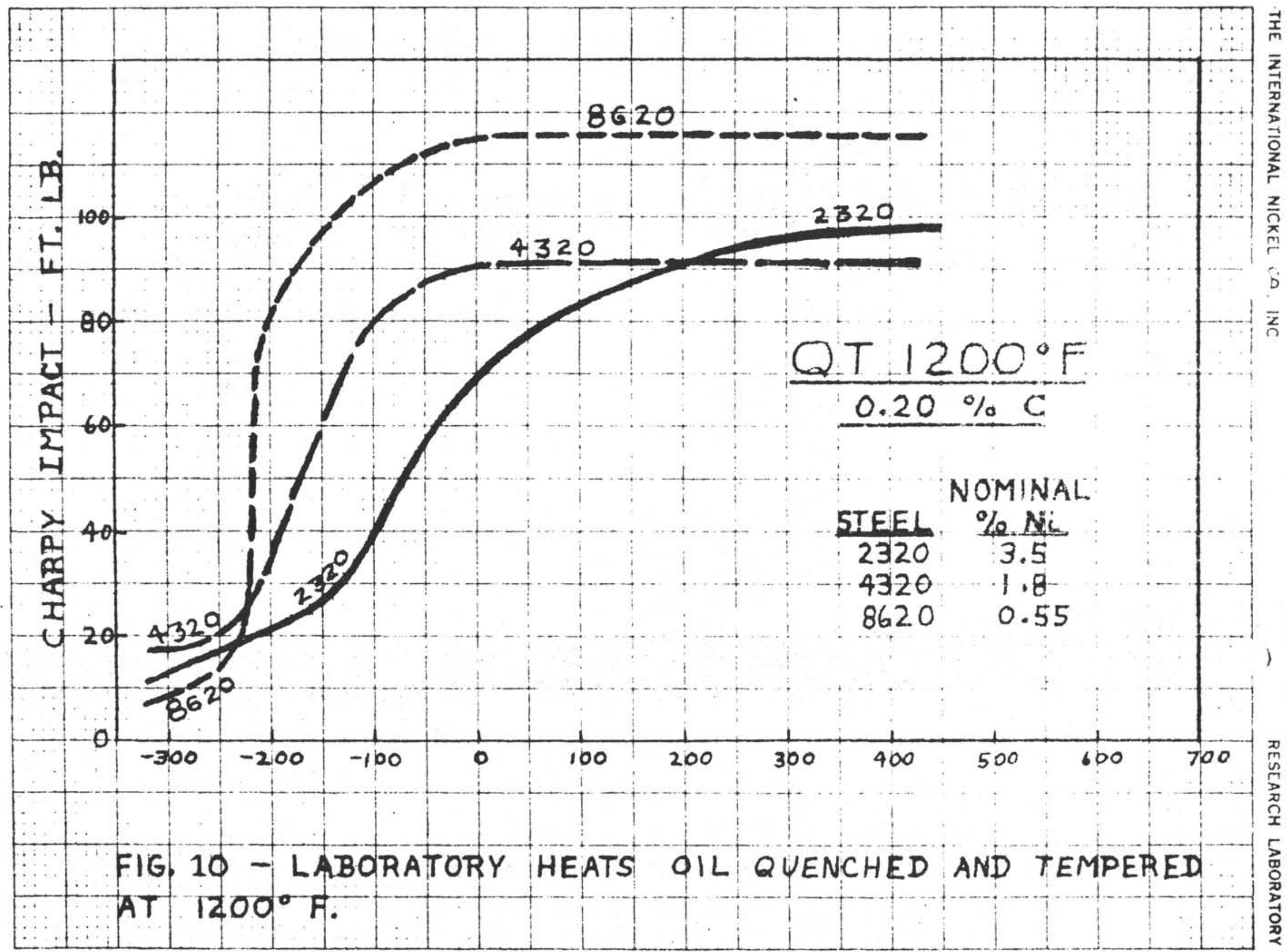




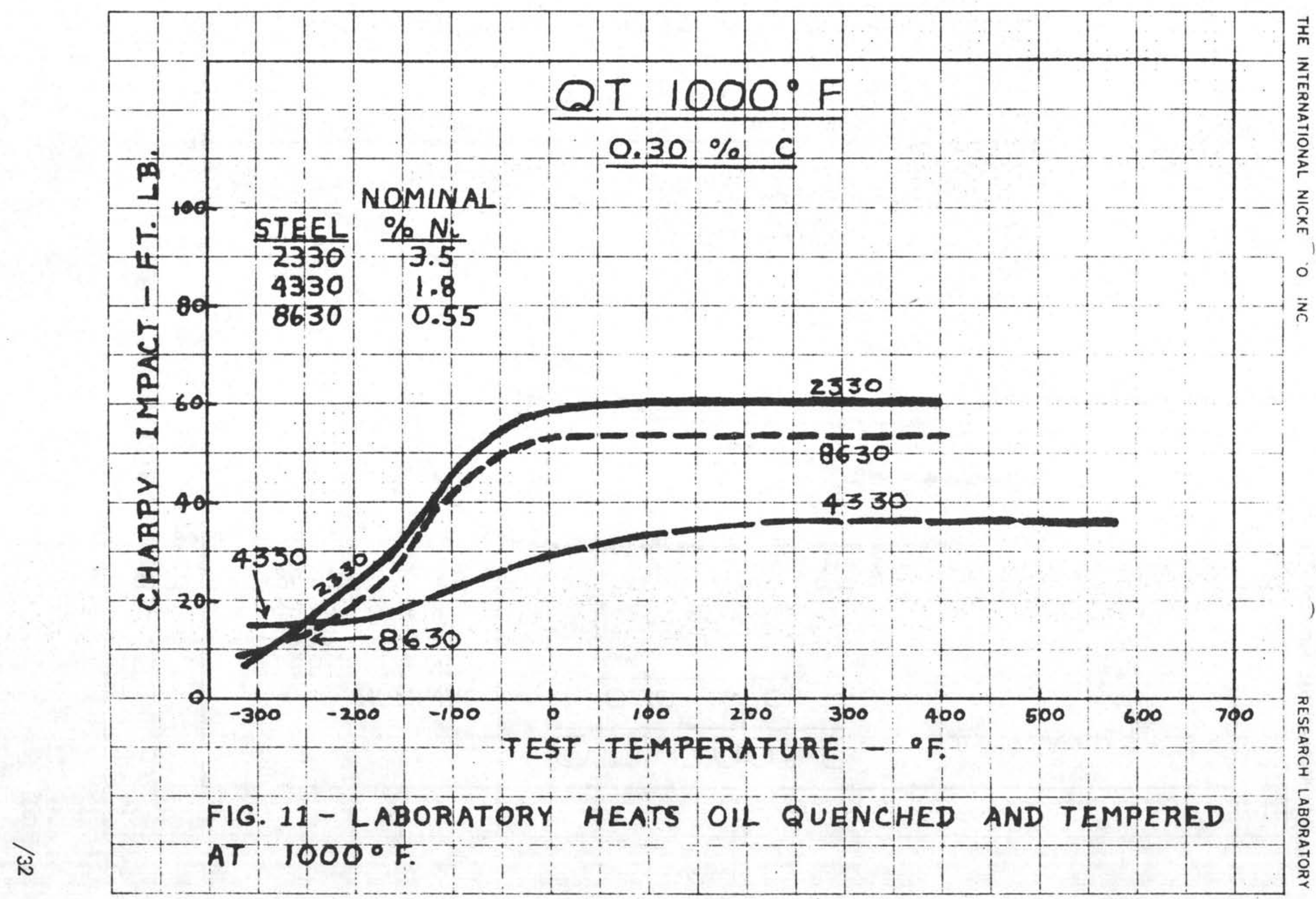


ఏ્ఱ

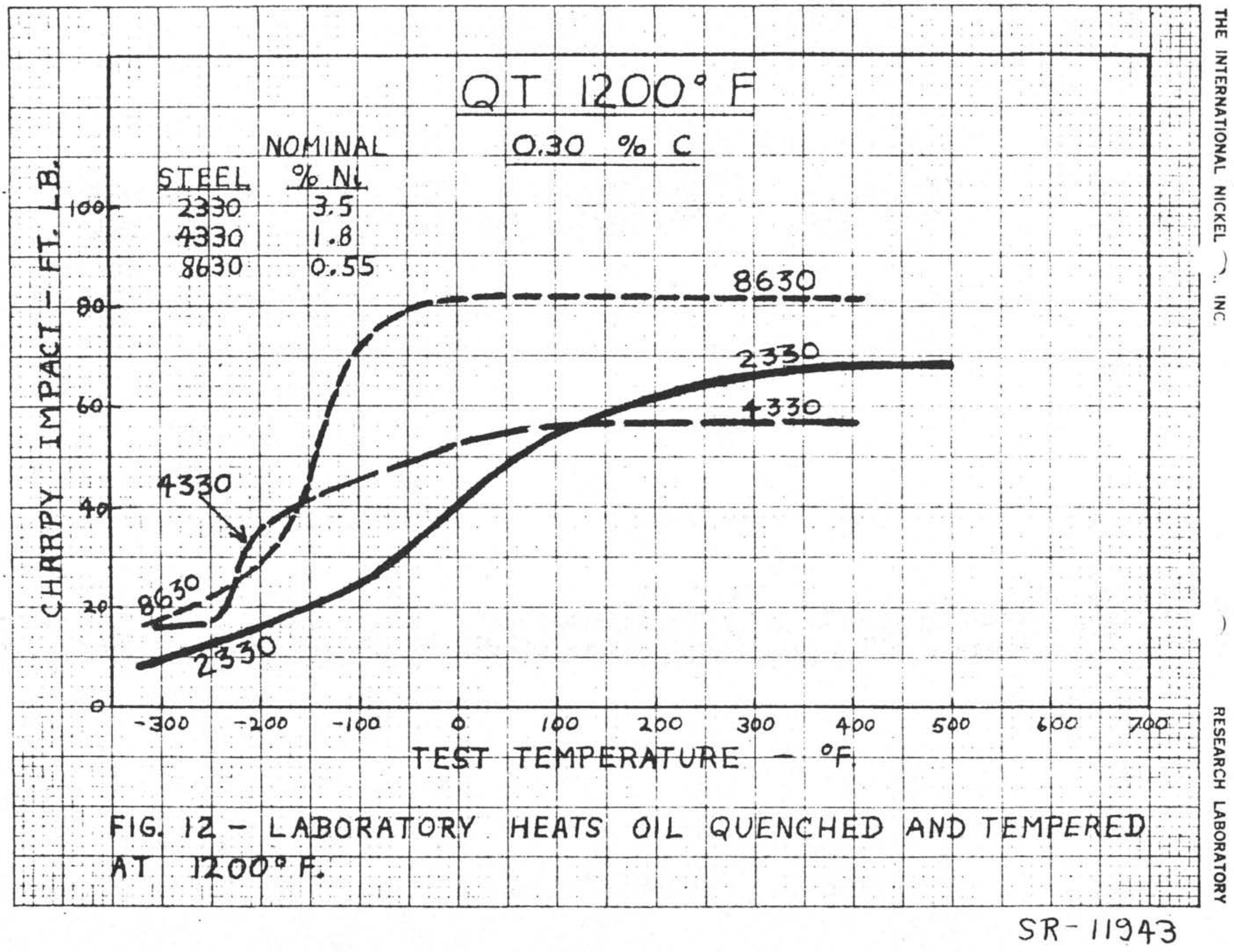




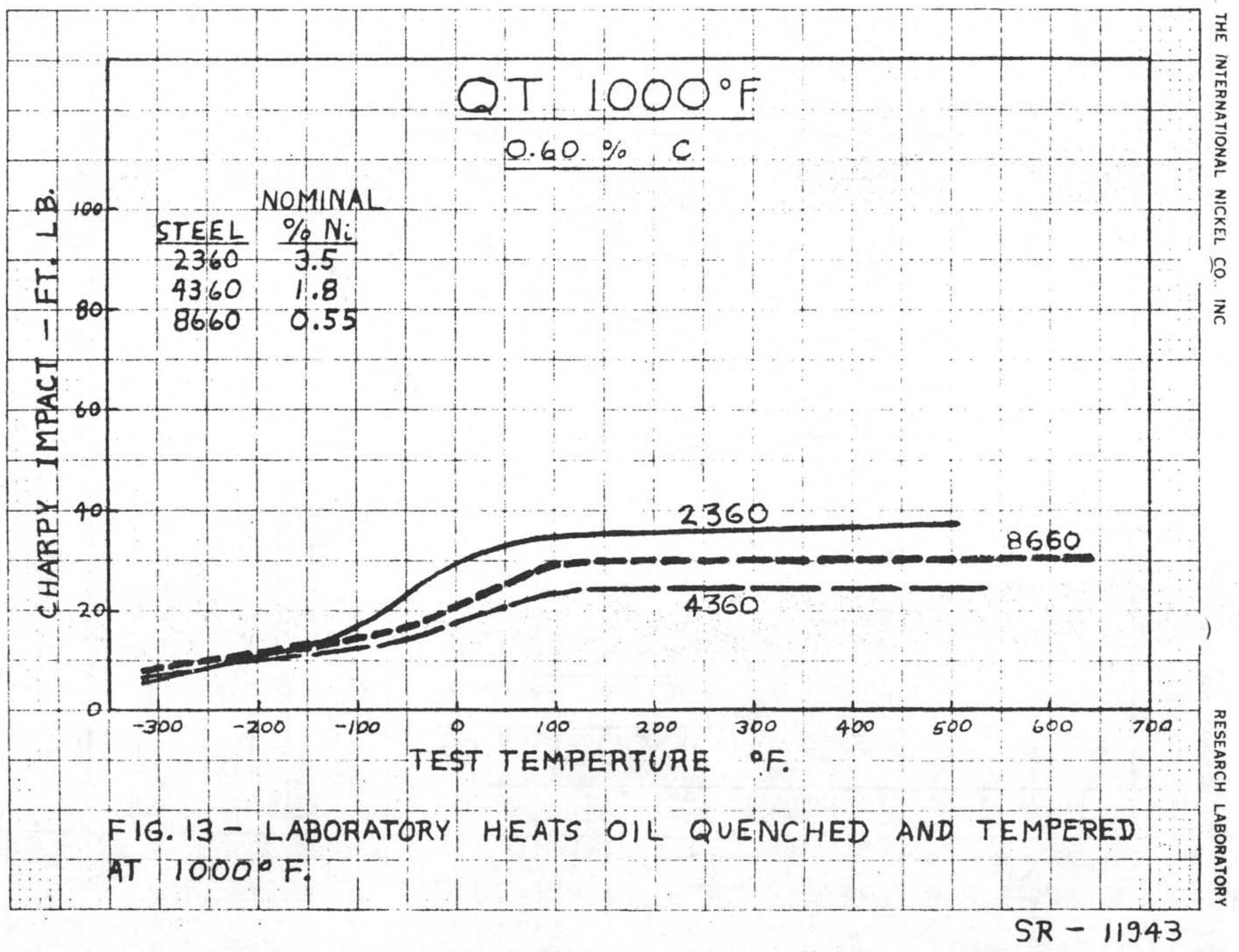


心్

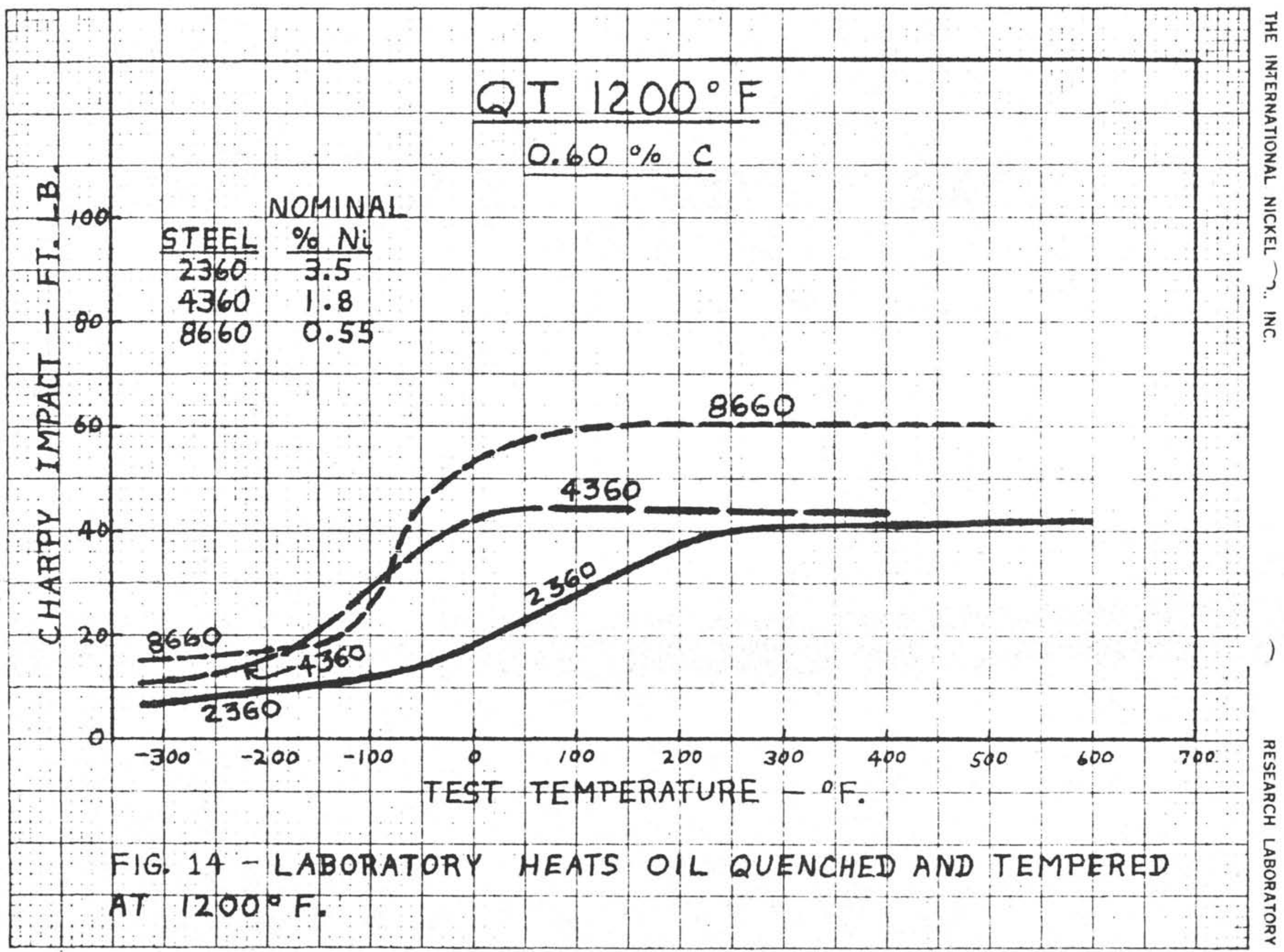




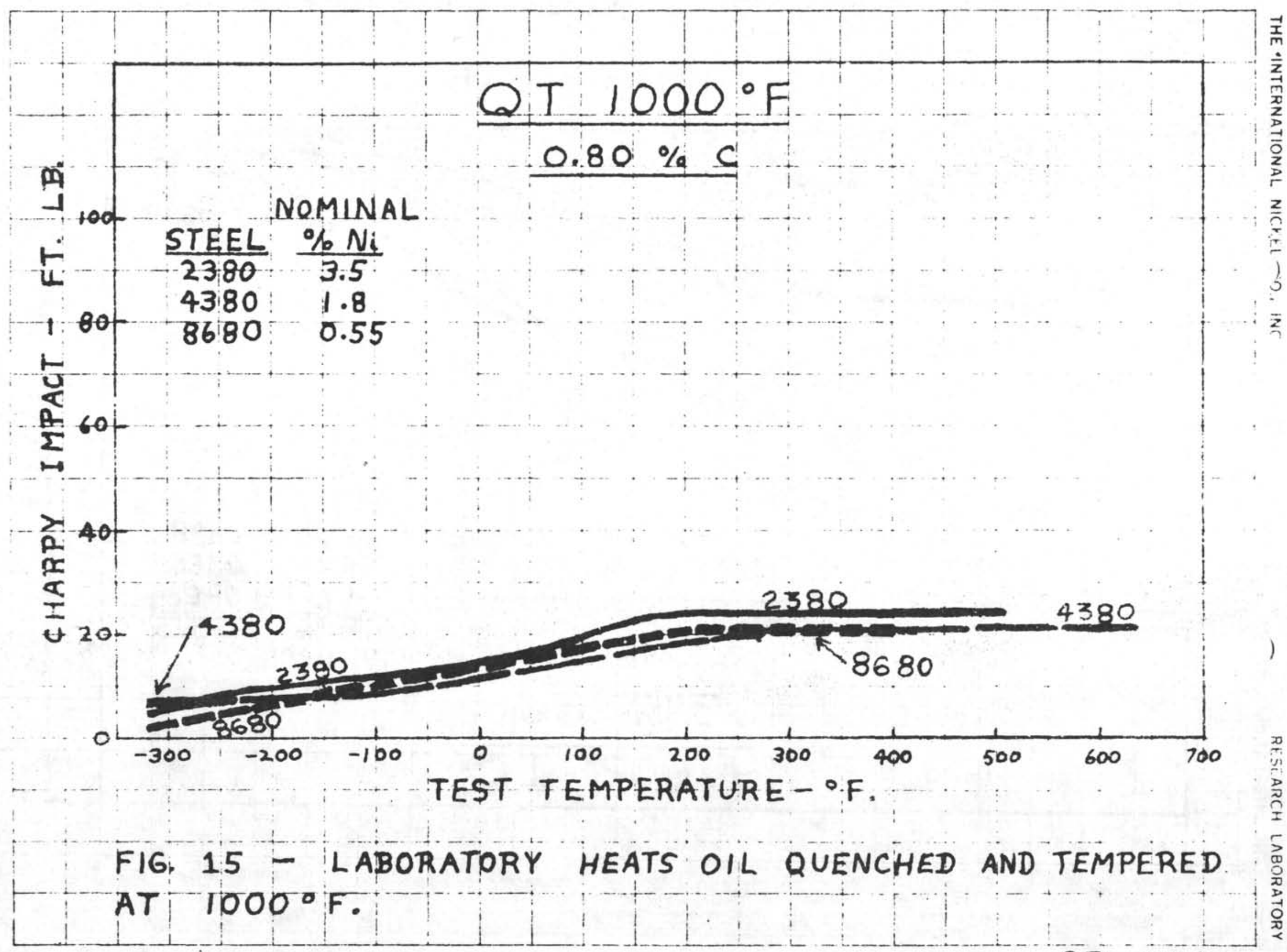




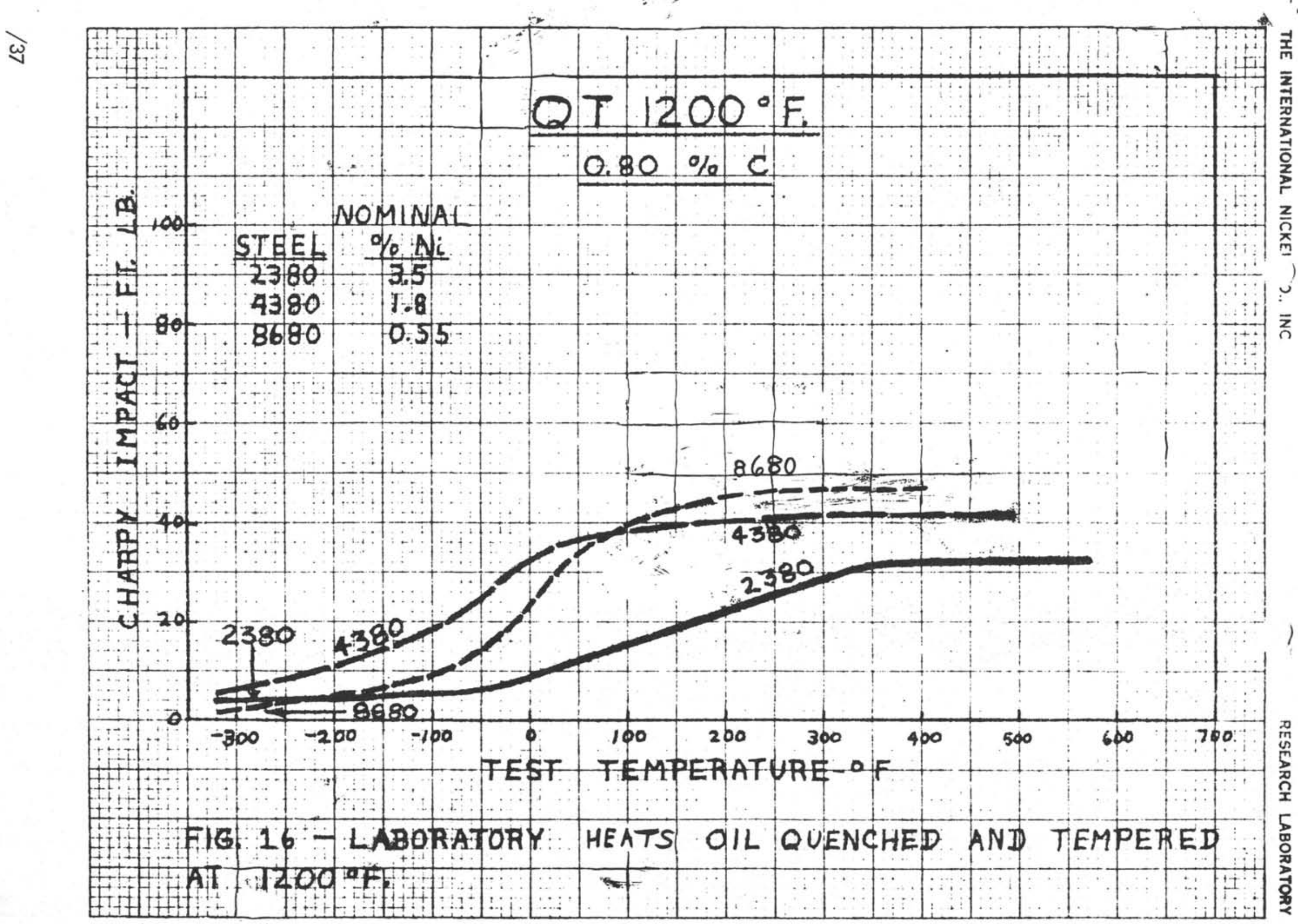




\section{BIBLIOGRAPHY}

(Bumper Subs)

1. Use of Bumper Subs When Drilling From Floating Vessels. W.D. Greenfield. Arthur Lubinski. Pan American Petroleum Corporation. December 1967. Journal of Petroleum Technology.

2. Impact Properties of Some Low Alloy Nickel Steels at Temperatures Down to $-200^{\circ}$ Fahr. T.N. Armstrong and A. P. Gagne Bin. March 1940. Transactions of the A.S.M.

3. Quotation Q-1070-V-890. VETCO Motion Compensator. October 15, 1970. VETCO Offshore Industries, Inc.

4. Mechanics Research Inc. Report on VETCO Motion Compensator $600,000 \mathrm{lb}$. and $400,000 \mathrm{lb}$. units. Loads for 5-inch Drill Pipe. Sept. 4, 1970. Prepared for VETCO.

5. The Neutral Zones in Drill Pipe and Casing and Their Significance in Relation to Buckling and Collapse. A. Klinkenberg. 1951. API Proceedings. Drlg. and Prod. Vol. IV.

6. Composite Catalogue.

7. Trade Journals.

8. See Bibliographies Drill Pipe, Drill Collars and Core Barrels. 
DRILL COLLARS 
In response to the Deep Sea Drilling Project Request For Proposal, Global Marine Inc. proposed 8 1/4-inch outside diameter by 4 1/16-inch inside diameter by 30-foot drill collars with 6 5/8-inch API Regular tool joints. The outside diameter of the collar would match the outside diameter of the proposed bumper subs, and in a $97 / 8$-inch hole, would leave adequate hole clearance to permit free circulation. The $41 / 16-$ inch bore would give clearance for the wireline retrievable core barrel. In addition, 7 1/4-inch outside diameter by 4 1/16-inch inside diameter by 30 -feet drill collars with $51 / 2$-inch API Full Hole tool joints were to be used as transition joints between the 8 1/4-inch collars and the drill string.

These same collar specifications were carried over to the subcontract. The collars were actually bored 4 1/8-inch inside diameter to match the inside diameter of the drill string tool joint. In addition, 5 1/2-inch range three heavy wall drill pipe was to be placed aboard D/N Glomar Challenger to assist in the transition from the 7 1/4inch outside diameter collars to the 5-inch drill pipe.

A 6 5/8-inch API Regular tool joint is normal on 8 1/4-inch outside diameter collars. However, the increase in bore from the normal 2 13/16-inch inside diameter to 4 1/8inch inside diameter gives and unbalanced joint in that the cross section of the pin is reduced and is much weaker than the box. This tool joint was approved by the Deep Sea Drilling Project and Global Marine Inc. as it is a universal joint with gauges and hobbs available in many countries for repair. Also, the initial Program Plan envisioned drilling and coring soft sediments with minimum recovery of basement and hard formations.

It soon became apparent that chert and other hard formations could be and were being encountered well above basement. Drill collar tool joint and bumper sub service joint failure increased when attempts were made to penetrate these layers as the core bits available were mostly diamond or sintered carbide drag bits. Failure because of high downhole torque seemed to predominate. Excursions of the ship because of erratic positioning before the drill collars were drilled below the mud line also increased losses.

In areas such as the Northwest Pacific where resistant horizons were encountered at shallow depths beneath the bottom, insufficient soft overburden existed to properly stabilize the bottom hole assembly. After a number of failures associated with bumper subs or drill collar joints, it was concluded that these failures resulted from excessive working of the unsupported and relatively inflexible components of the bottom hole assembly.

Initially upon this determination, an operational restriction was placed on the drilling activities of $D / V$ Glomar Challenger requiring a minimum of 100 meters of generally unconsolidated overburden above the first resistant horizon. 

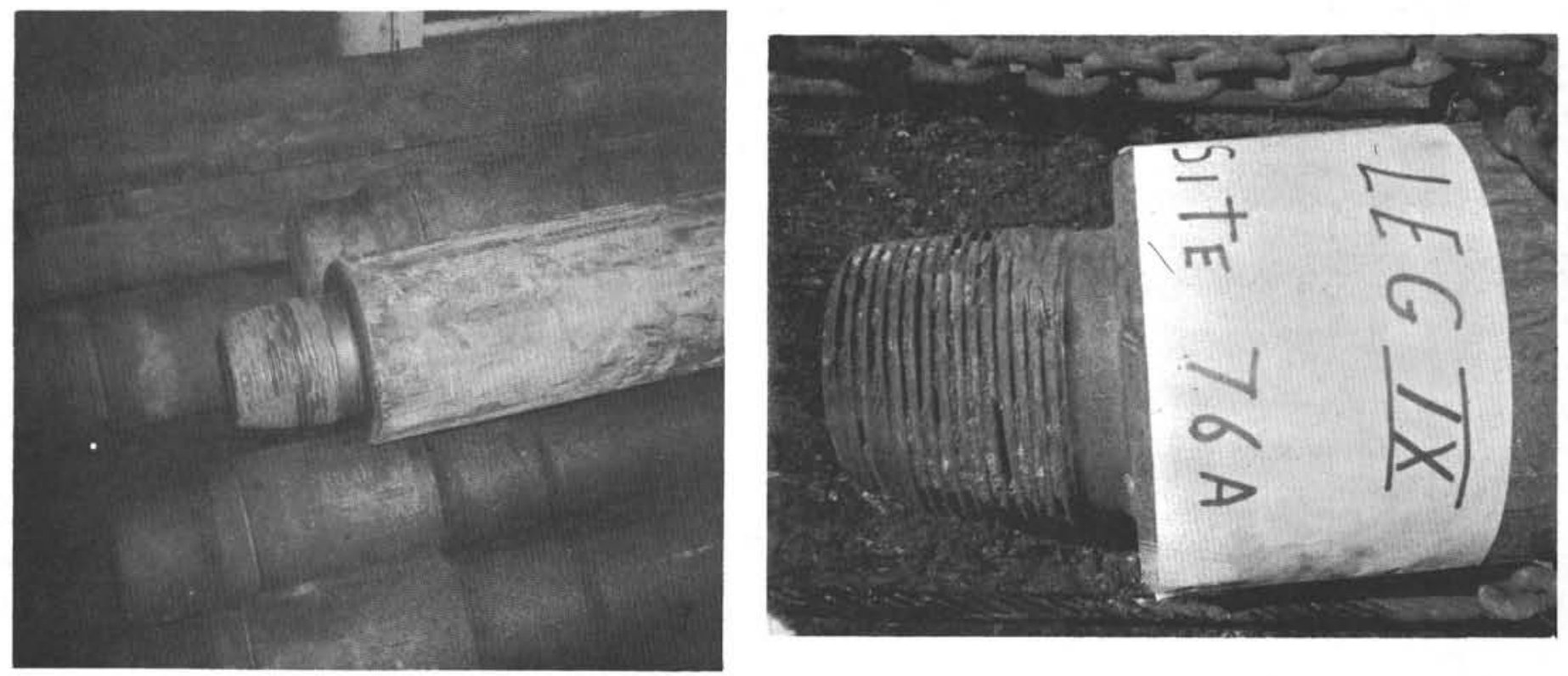

Typical drill collar tool joint failures. These failures have been reduced by changing to a balanced tool joint.

Satisfactory efforts to increase the strength of bottom hole assembly components have led to a relaxation of this operational limitation and during Phase II, 50 meters has been regarded as the minimum permissable thickness of uppermost unconsolidated material.

In at least one site by carefully entering by means of minimum bit weight, penetration of a resistant layer at approximately 20 meters of depth was safely and satisfactorily accomplished.

Before the restriction, bottom hole assembly losses were twice the projected rate and it was necessary to air lift drill collars, core barrels and bumper subs to San Juan, Puerto Rico, where D/V Glomar Challenger made an unscheduled stop between Sites 27 and 28 on Leg 4 to pick them up.

The Deep Sea Drilling Project contacted oil field tubular goods experts among the major oil companys and leading contractors and finally engaged the services of a consultant, Mr. W.S. Crake (Chairman, API Tubular Goods Committee, Gulf Coast Division) to review the drill string design.

A review of bottom hole assembly losses and industry comments in addition to those of the Deep Sea Drilling Project, Global Marine Inc., and suppliers resulted in the following decision: Resupply D/V Glomar Challenger with the same bottom hole assemblies as used on the first four legs. This decision was based on several factors: 
(1) Although bottom hole assembly loss was high, total footage drilled, footage cored and footage of core recovered was far above projected rates, indicating a balanced assembly.

(2) Lead time before entering the Pacific was very short to change drill collar, bumper sub and bit size.

(3) Drilling conditions in the Pacific were unknown.

The track in the Pacific originally was scheduled to go from the Panama Canal to Tahiti, to Honolulu, to Guam, to Honolulu and into Los Angeles. This track was changed to have Leg 4 end in San Diego, and Leg 5 go from San Diego to Honolulu, or in the exact reverse of the original schedule. The port call at San Diego allowed resupplying in a stateside port and for maintenance on drill collars and bumper subs in shops knowledgeable of this type of equipment.

A minimum of chert or hard formations was encountered on Leg 5. However, on Leg 6 and following legs, many chert and hard formation layers were found at shallow formation depths, indicating the condition would be prevalent in the Pacific.

Concurrent with this discovery, the Deep Sea Drilling Project and Global Marine Inc. were conducting an industry search to determine the best tool joint 8 1/4-inch outside diameter and 4 1/8-inch inside diameter. Both the 5 1/4-inch API Internal Flush and the NC-61 were acceptable. Global Marine Inc. felt more comfortable with the NC-61, so it was established as the tool joint for $8 \quad 1 / 4$-inch outside diameter by $4 \quad 1 / 8-$ inch inside diameter tubular goods. Before the end of Phase I of the Project, it was planned to re-cut all drill collars, bumper subs, change over subs and other allied equipment to this thread at the first opportunity.

This opportunity came between Legs 9 and 10 when D/V Glomar Challenger went into drydock at the Tood Shipyards in Galveston, Texas. The numerous drill collar manufacturers in nearby Houston made it possible to re-cut all drill collars and bumper subs to the NC-61 thread.

Since this change over, the Deep Sea Drilling Project has not had a failure in an NC-61 tool joint. This, in part, is probably because of the increased use of carbide insert roller core bits. Roller bits are less likely to subject the bottom hole assembly to the high instantaneous torques caused by drag bits.

As drilling rates, coring rates and core recovery remain high, there are no plans to change drill collar specifications. 
1. Why a Balanced Drill String Published by DRILCO.

2. Don't Ruin Those New Drill Collars.

3. Technical Proposal Part I Volume I. Global Marine Inc.

4. Tool Failures on Leg 3 and 4. James T. Dean.

5. A Review of Downhole Drill String Failures Through Sept. 1, 1969. W.F. Allinder. et al.

6. Report Drill String Problems. W.S. Crake.

7. Deep Sea Drilling Project Drill String. D. L. Sims. Nov. 1969. ASME.

8. Final Report Deep Water Drill String. National Science Foundation Contract C-260.

9. Daily Drilling Reports. Deep Sea Drilling Project.

10. Scientific and Technical Progress Reports - Project Mohole Drill Collars - March 1964.

11. See Bibliographies on Drill Pipe Bumper Subs and Coring Equipment. 
CORING EQUIPMENT 
A request to include core barrels and accessory items was contained in the Deep Sea Drilling Project's Request For Proposal which went to bidders in 1967. It also specified continuous coring with wireline core barrels using commercially available equipment. Bidders were told clear plastic liner tubes could be used in the inner barrel.

In their answer, Global Marine Inc. proposed to furnish a Christensen 6 3/4-inch outside diameter core barrel to take a $21 / 2$-inch core. This barrel would be equipped with center drills, mechanical punch corers and piston cores. It could also be used to take oriented cores and several types of catchers were available.

After evaluating all proposals, the Deep Sea Drilling Project decided it would be to the advantage of the Project if the coring equipment was selected and supplied by the Project.

A statement of work was written and incorporated in a Request For Quotation (RFQ). This RFQ was sent to all suppliers of oil industry coring equipment and two companies, Christensen Diamond Products Company, of Salt Lake City, Utah, and Hycalog Inc., of Lafayette, Louisiana, were responsive. Both companies were very active in coring including wireline coring.

Two different types of coring equipment were proposed. Christensen proposed a version of the Reed Robishaw wireline retrievable barrel. This barrel has the landing collar at the upper end of the inner barrel. A spring-loaded latch is placed immediately above this collar to hold the inner barrel down for retrieval. A bearing hanger allows the inner barrel to remain stationary while the core is being cut. Christensen also proposed extending the inner core barrel below the core bit to prevent washing the core. The barrel would be spring loaded to retract flush with the core bit. The core would be 2 1/2-inches outside diameter, requiring a bit with a $3 \quad 1 / 2$-inch center opening. This barrel also could be made up solid on the center bit assembly to cut punch cores, while a solid center bit would be used when drilling ahead.

The Hycalog design used an inner barrel with the landing collar close to the bit. The landing seat is actually the inner race of a ball bearing. This bearing, in addition to stopping the inner barrel, centered the barrel to the core bit and prevented the inner barrel from drooping if the hole was at an angle. This design also had a spring-loaded latch to hold the inner barrel down and drive the center bit. The Hycalog outer barrel had a large inside diameter of 6 5/8-inches for high rates of circulation when drilling hard formations and required a core barrel thread for connections. This connection is similar to the one used on wash-over pipe and is much weaker than the drill collar connections. The RFQ asked for a 30-foot long core barrel made up in 15-foot units, as it was not known if 30 -foot cores could be consistently recovered. 


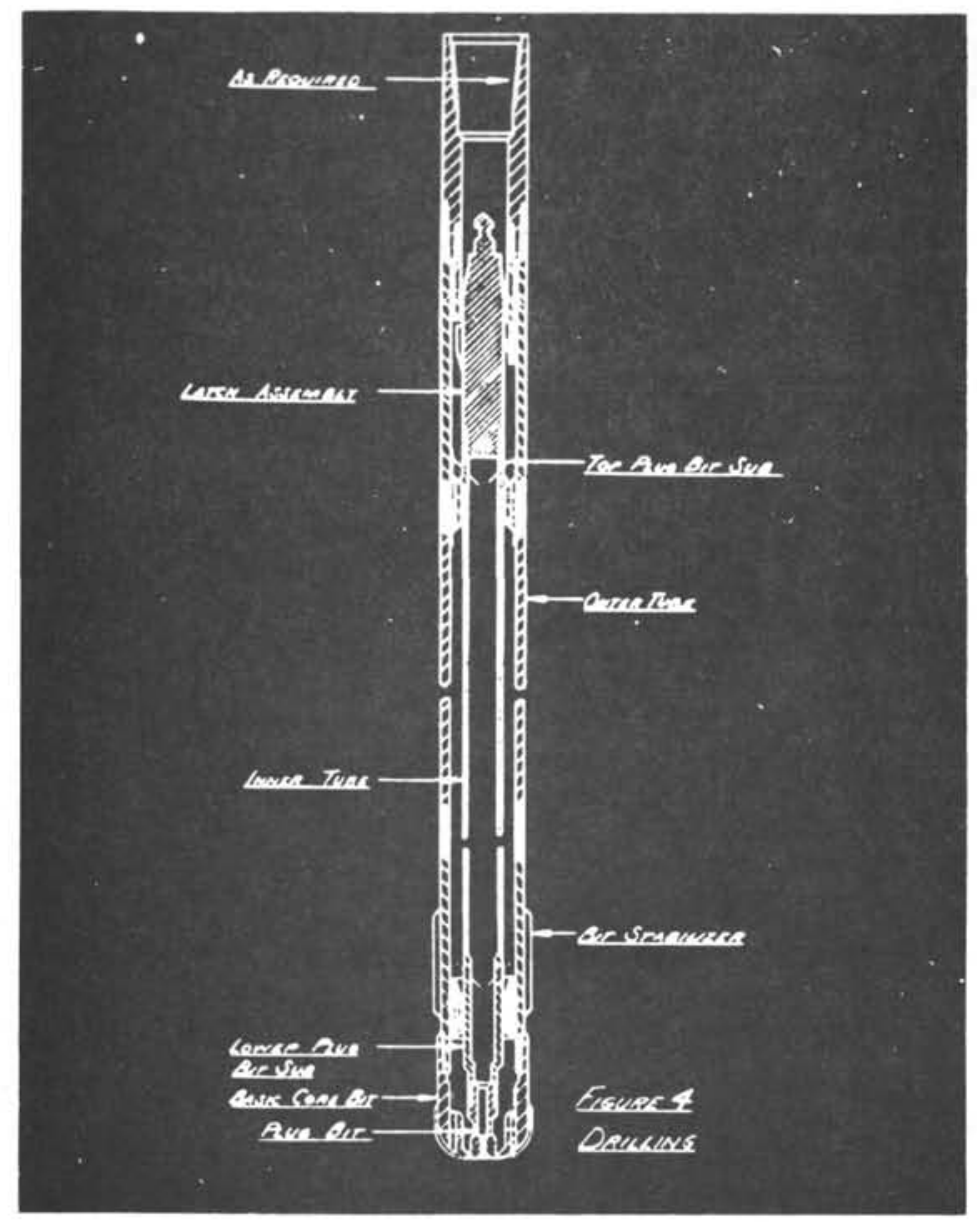

This wireline retrievable core barrel has given excellent service for Deep Sea Drilling Project.

The Christensen-style core barrel offered was the old standby of the oil fields. However, the Hycalog barrel was designed specifically to overcome problems encountered in exploratory coring in the Gulf of Mexico. The Hycalog unit gave excellent recovery and they were used for the Blake Plateau Coring Program during April-May of 1965. This program was sponsored by the Joint Oceanographic Insitutions for Deep Earth Sampling (JOIDES) and funded by the National Science Foundation.

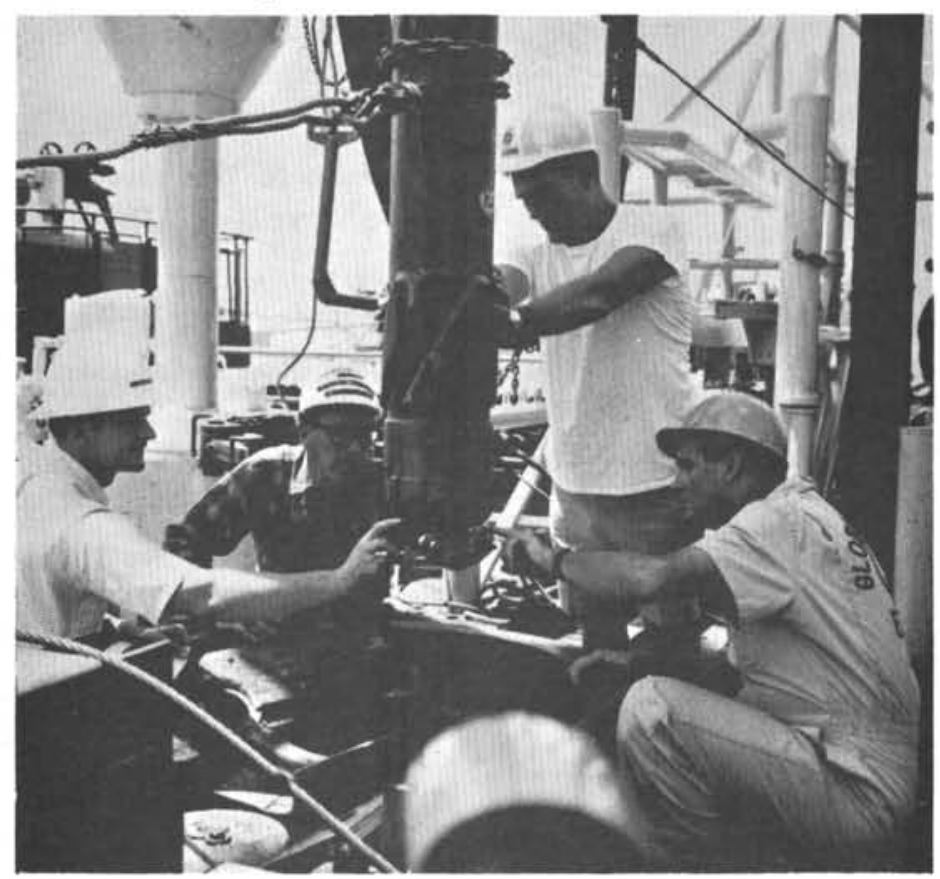

The original core barrel had a 9 1/4-inch outside diameter bit and was run with a stabalizer immediately above the bit. 
Since there was insufficient time to test coring equipment and select a supplier for Leg 1, the Deep Sea Drilling Project had both Christensen and Hycalog core barrels aboard D/N Glomar Challenger when the Project became operational on August 11, 1968.

Since Leg 1 would be in the Gulf of Mexico, the Project decided to use the Hycalog barrel as the primary equipment with two Christensen barrels aboard for evaluation.

It soon became apparent that the Hycalog connection was too weak. Formations encountered were much harder than expected. A review of drilling and coring on Leg 1 indicated much higher circulating rates were not required, so the Hycalog bit, head, and top bumper subs for the outer barrel were changed so that a standard 30-foot drill collar could be used as an outer core barrel.

Several units of core barrel conversion subs to adapt the Hycalog equipment to run with a standard drill collar were placed aboard D/V Glomar Challenger at San Juan, Puerto Rico, during Leg 4. This configuration proved to be an improvement and is now the accepted core barrel design. The tool joints to the drill collar were changed to NC-61 when the collars were re-cut at Galveston. Core recovery with the 30-foot assembly was good, so eliminating the 15-foot barrel did not reduce core recovery.

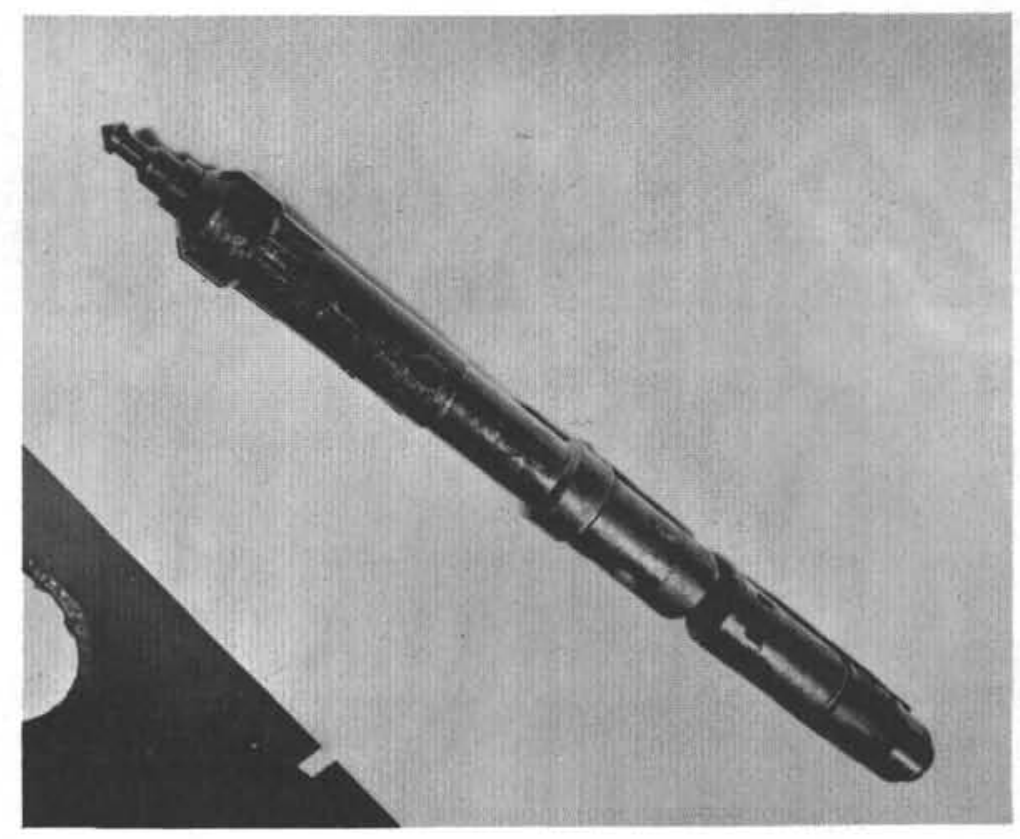

Core barrel latch and Reed PDD spear point.

The first core barrels of both Hycalog and Christensen used the Reed PDD spear point on the latch pull rod and the Reed PDD overshot to retrieve the filled core barrel. The crews experienced excessive mechanical failure due to the large drill collar bore since PDD equipment is normally run in $33 / 16$-inch inside diameter drill collars. 
Conversion units to a 3-inch Otis fish neck spear were made and could be attached to the pull rod and an Otis latch used for retrieving. This proved a more dependable unit so replacement latches were built with Otis spear points.

Other weak points in the coring equipment have been modified or made stronger.

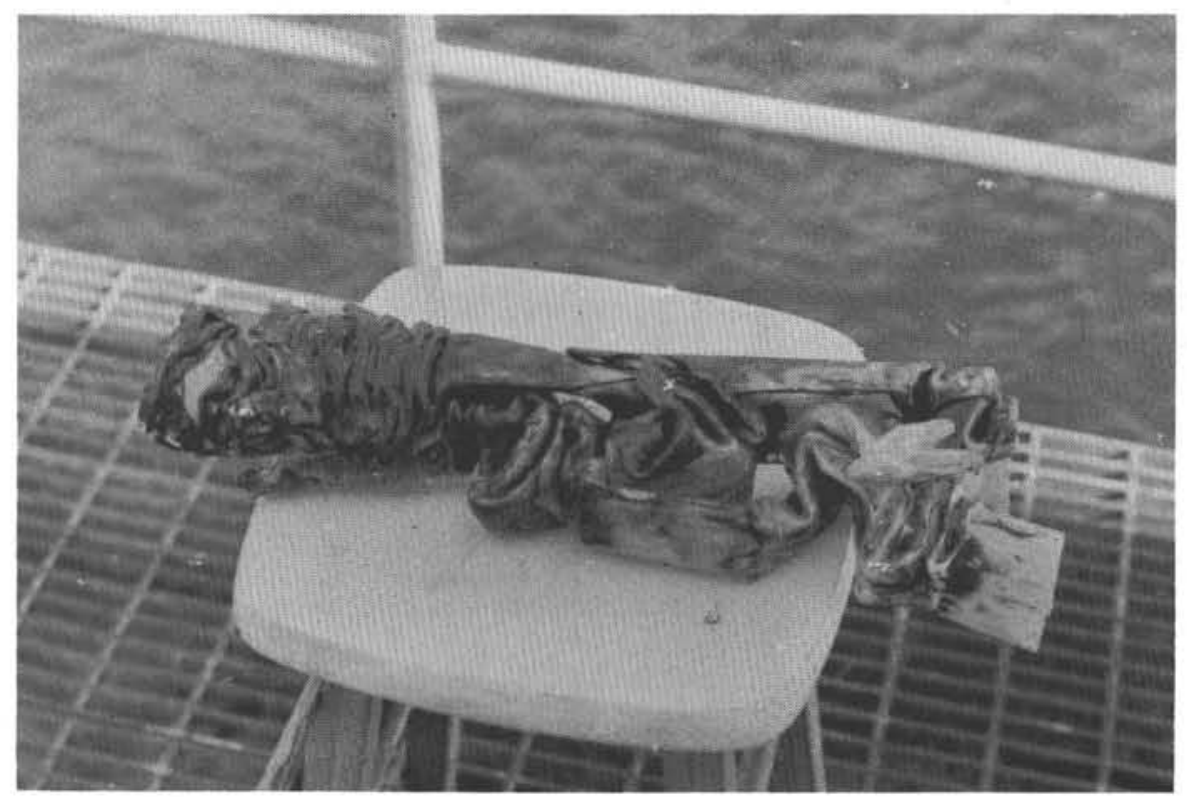

Plastic core liner collapsed and wadded up into the inner core barrel.

The clear buterate plastic liner has been a problem on several occasions. In addition to collapsing, the liner would wad inside the barrel. This was eliminated by reinforcing the lower or entrance end of the tube with a metal sleeve.

Many different sediments were drilled and cored during the first three years of operation. In general, these sediments have been soft and unconsolidated or very hard such as chert or limestone. Since both types were often encountered in the same hole, it has been difficult to build bits and core catchers that perform satisfactorily in such extremes. 
Some of the core bits used on Deep Sea Drilling Project:

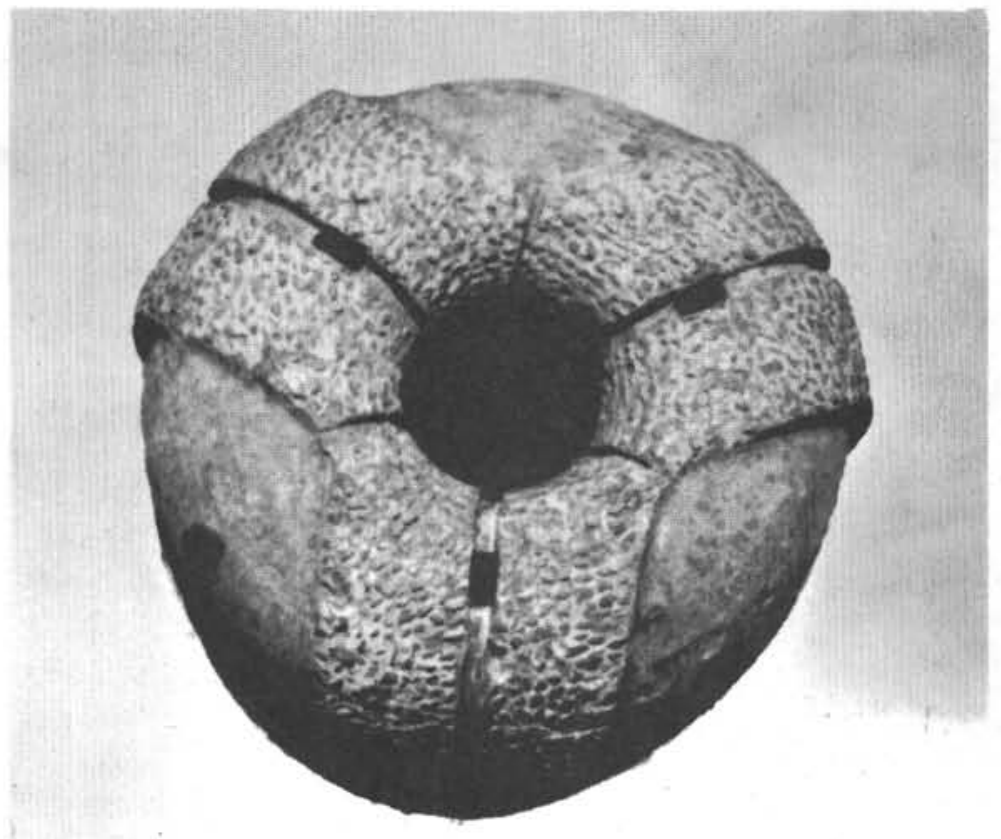

Sintered carbide.

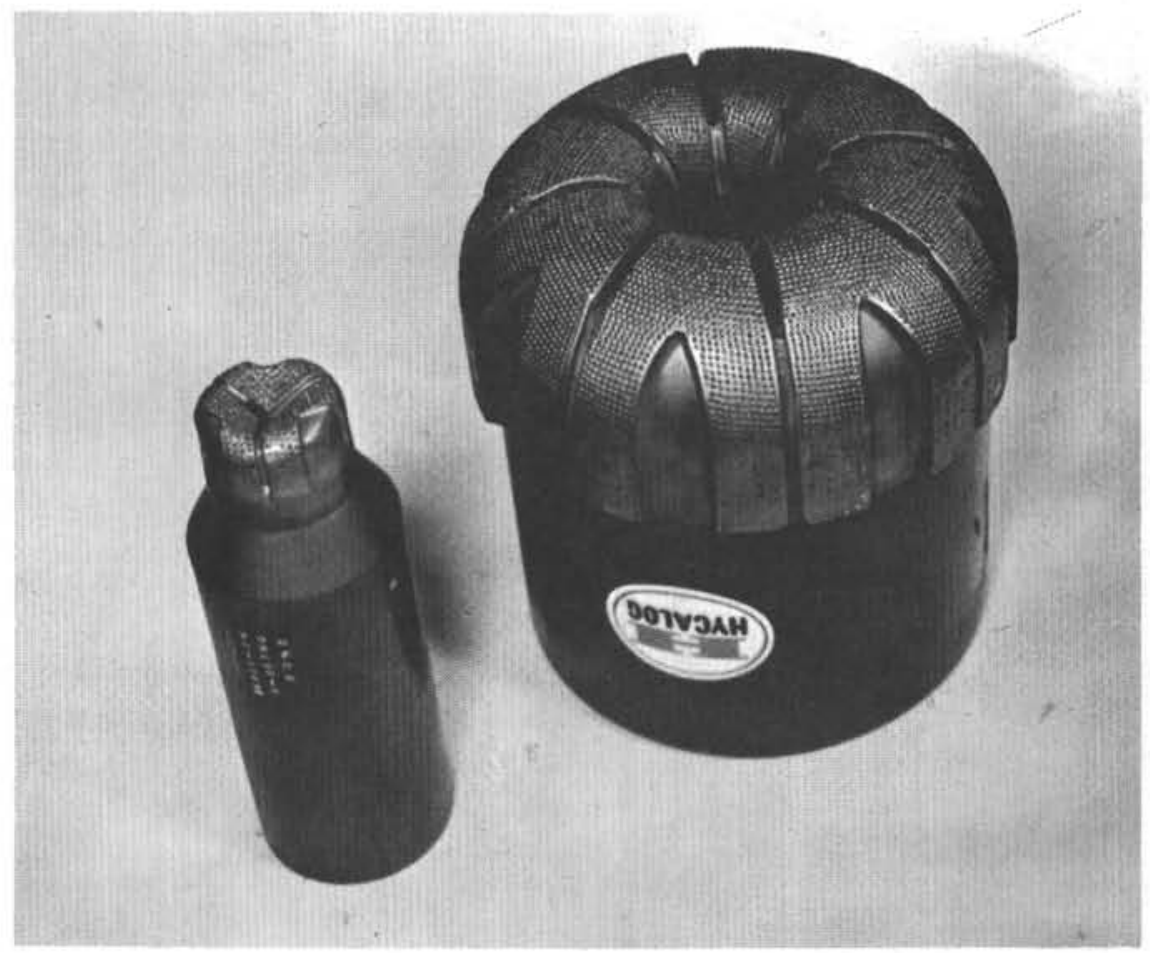

Massive set diamond bit with center bit. 


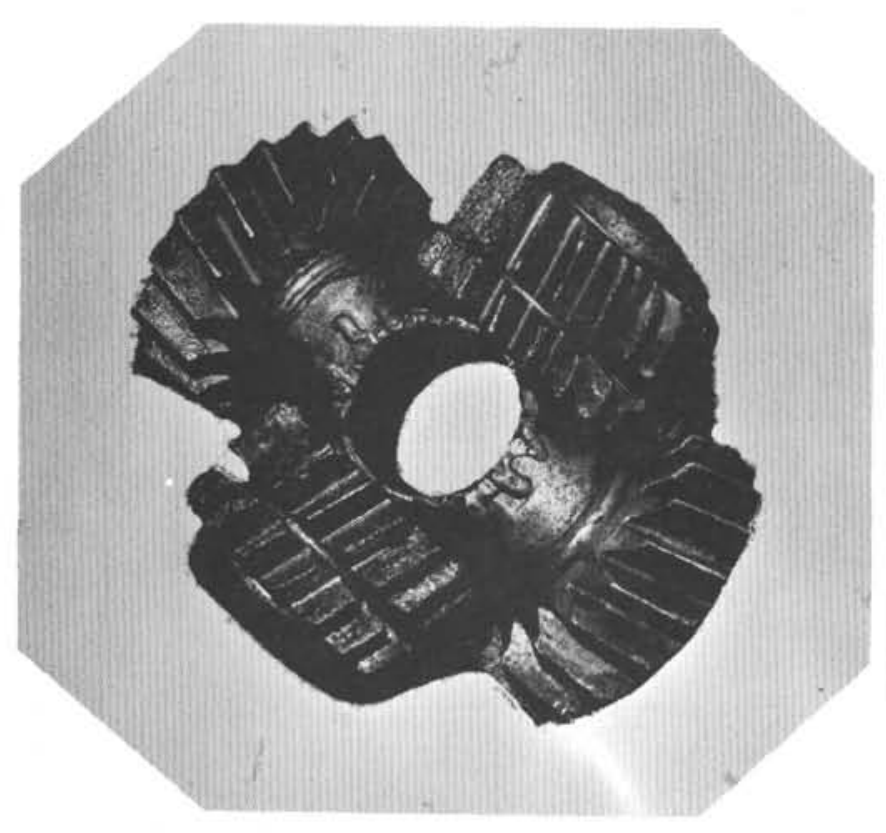

Cross section milled tooth roller bit.

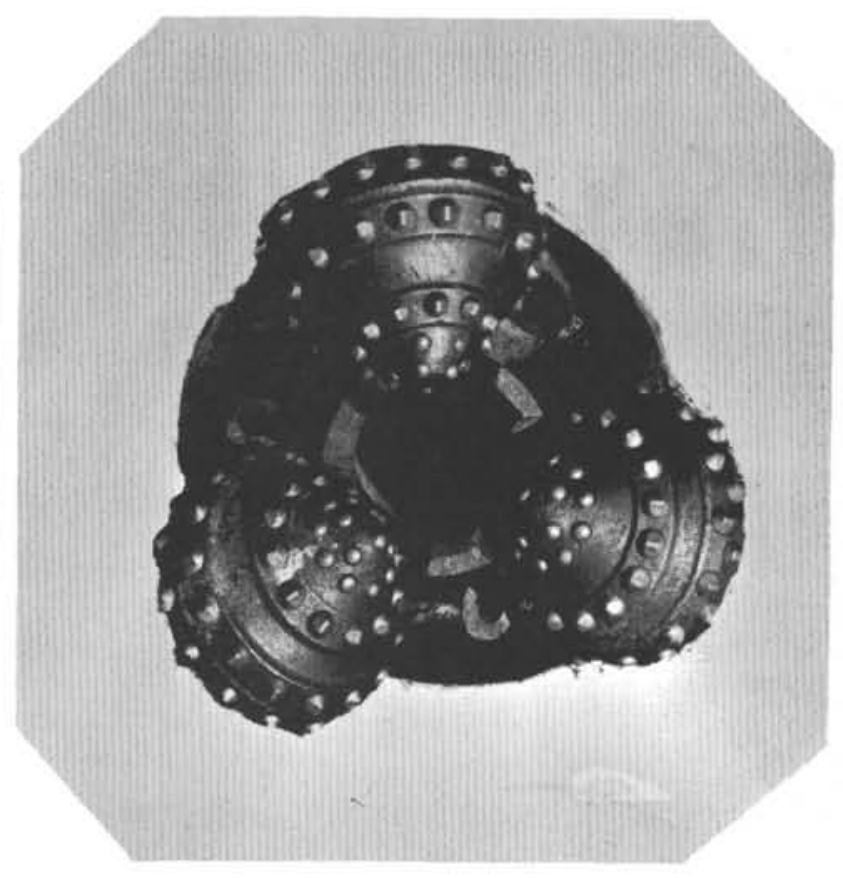

Three cutter carbide insert roller bit.

The tungsten carbide insert roller bit has turned in the best performance todate. (See upcoming Technical Report on Core Bits.)

Double dog-type core catchers are run more than any other combination. The inner core barrel is designed to run tandem catchers. Normally, a dog catcher is run above a hard formation collet catcher. However, the Deep Sea Drilling Project coring is done without stabilization of the bottom hole assembly. This increases the percent of hard formation core cut under gauge so the collet catcher can not hold it.

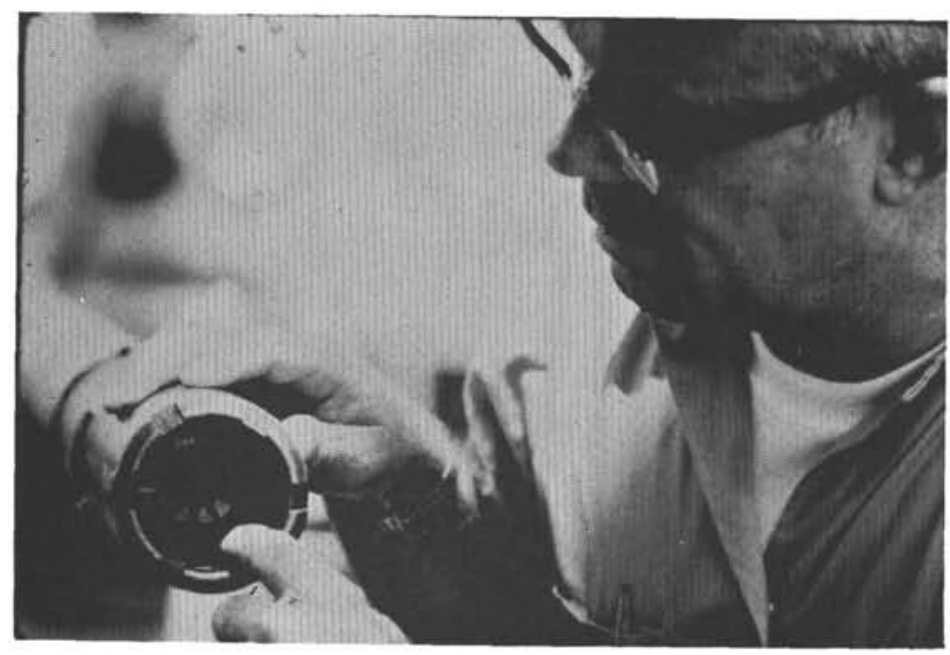

Dog type core catcher in place in the inner core barrel. 


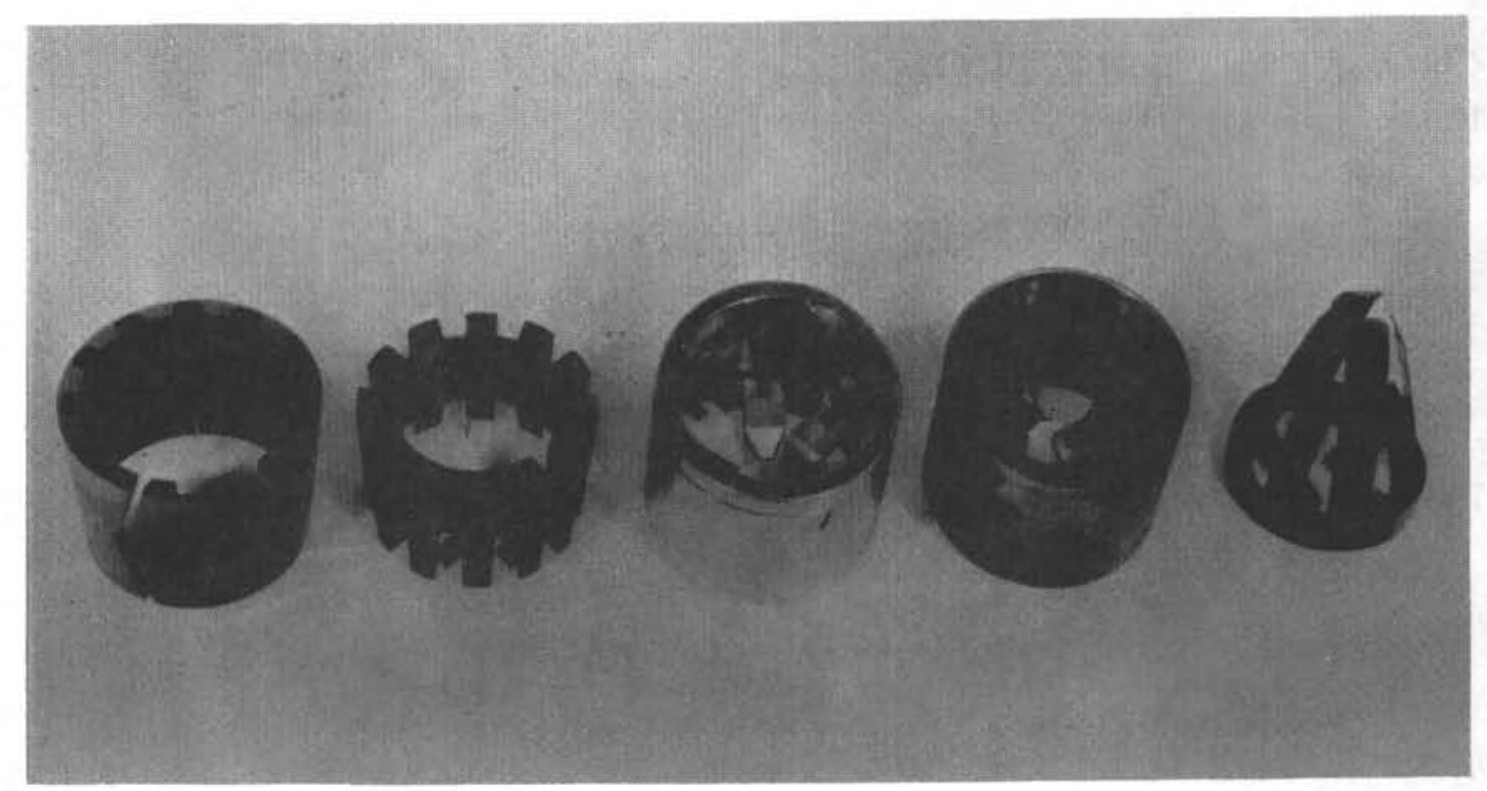

Core catchers used with wireline retrievable core barrel on Deep Sea Drilling Project.

During Leg 2, Dr. Melvin N.A. Peterson, the Project's Co-Principal Investigator who was a cruise co-chief scientist on the New York to Dakar expedition, added a pliofilm tubular catcher above the upper dog catcher. This allows sampling of very soupy sediments and has even held sea water.

The drilling crews have been constantly speeding up and improving coring and drilling operations. Coring technicians from oil well coring companies were used to supervise coring on the first nine legs. At this time, the Project thought the drilling crews were familar with the techniques necessary for maximum coring recovery, so the coring technician was replaced by adding a Global Marine Inc. crew member. His duties were to assist in coring, maintain the coring and other special equipment furnished by the Deep Sea Drilling Project.

Drilling and coring operations have followed rather closely to the procedures outlined in the Program Plan. The Project shipboard complement includes a cruise operations manager. This person may be a University of California at San Diego employee, or may be on loan from the Drilling Department of a major oil company. Either way, he is the Deep Sea Drilling Project's representative. Since these men have varied backgrounds, drilling techniques may vary. However, unless unusually adverse drilling conditions are encountered, core recovery is consistent.

The use of drilling mud has varied from leg to leg. Since there are no mud returns to 
D/N Glomar Challenger, it is difficult to evaluate what effect the mud has in cleaning the cuttings out of the hole.

Currently, the Deep Sea Drilling Project is engaged in designing and testing the following:

1. A piston core barrel for mud line cores.

2. Extended inner core barrel for less-disturbed cores.

3. Pressure core barrel for in situ sampling .

The results of these efforts will be subjects of later technical reports. 
See Bibliographies on Drill Pipe, Drill

Collars and Bumper Subs. 


\section{BIBLIOGRAPHY \\ (Coring Equipment)}

1. Deep Sea Drilling Project Initial Term Project Plan and Subsequent Revisions.

2. Subsurface Geologic Methods. Leroy Cold. School of Mines. CH. 6. Miscellaneous Subsurface Methods.

3. Drilling For Scientific Purposes International Upper Mantle Project. Sept. 1965.

(a) Core Drilling in South Africa. W.S. Garrett.

(b) Diamond Coring Techniques for Project Mohole. D. Sims.

4. Experimental Drilling in Deep Water at La Jolla and Guadalupe Sites.

National Academy of Sciences. Publication 914.

5. Stage A Report. Equipment Evaluation Test Well at Uvalde, Texas.

6. Stage A Report. Downhole Drilling Tools. National Science Foundation Contract C-260.

7. Coring Equipment for Ocean Drilling. Christensen Diamond Products Company.

8. Diamond Drilling Handbook. CDPC.

9. Proposal for Retrievable Wireline Coring-Hycalog, Inc.

10. Engineering Study (Deep Sea Drilling Project) Methods to Penetrate Hard Formations in Deep Ocean Basins. 


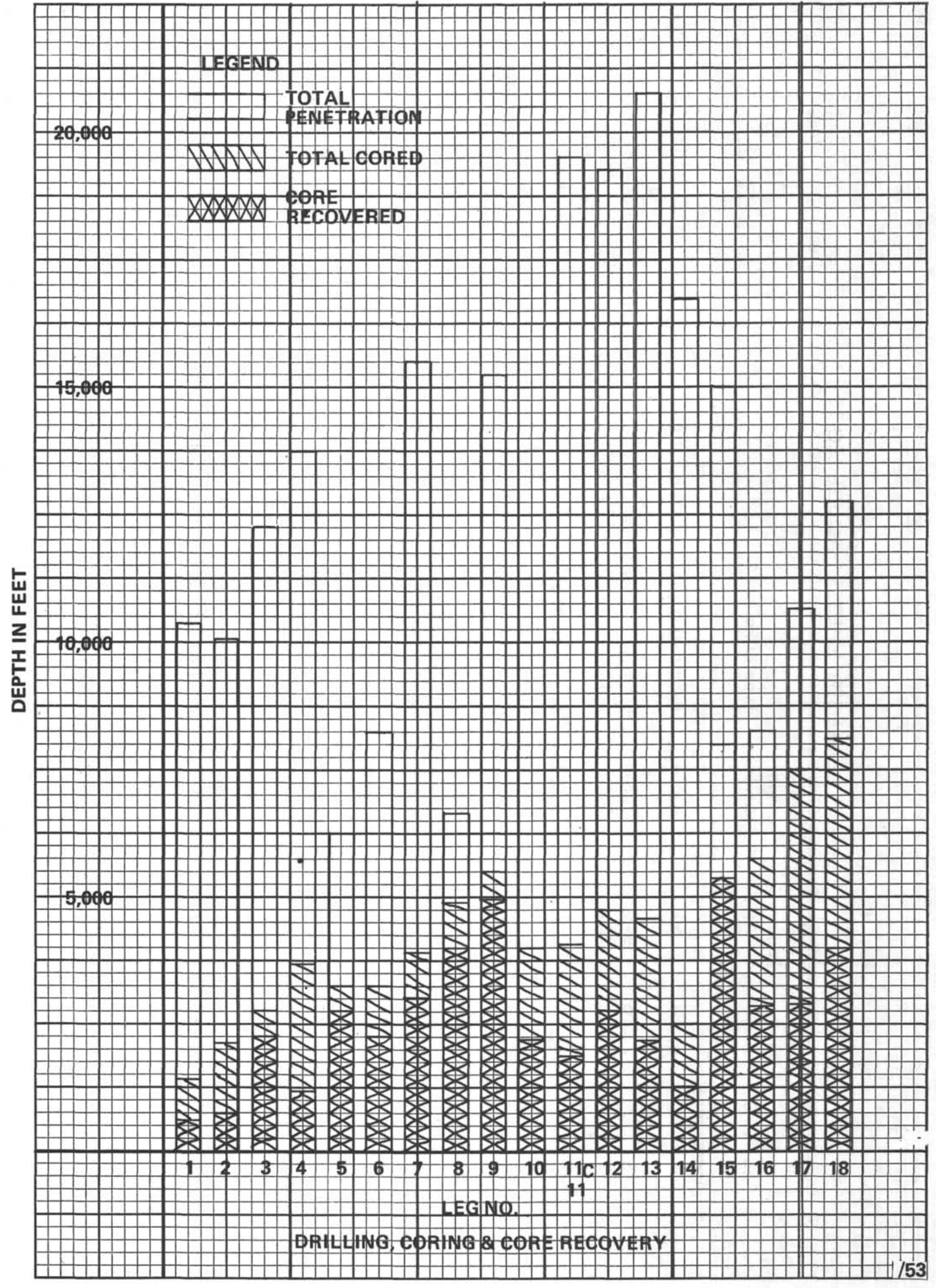


DRILL STRING LOSS THROUGH LEG 18

\begin{tabular}{|c|c|c|c|c|c|}
\hline Site & $\begin{array}{l}\text { Water } \\
\text { Depth } \\
\text { (ft.) }\end{array}$ & $\begin{array}{l}\text { Total } \\
\text { Penetration } \\
\text { (ft.) } \\
\end{array}$ & $\begin{array}{l}\text { String } \\
\text { Length } \\
(\mathrm{ft} .) \\
\end{array}$ & Type of Failure* & Remarks \\
\hline $\begin{array}{l}\text { Acceptance } \\
\text { Trials }\end{array}$ & 3,584 & 60 & 3,644 & (Bending) upper joint core barrel & $\begin{array}{l}\text { August } 1968 \\
\text { off station } \\
\text { Leg } 2\end{array}$ \\
\hline $\begin{array}{r}8 \\
12\end{array}$ & $\begin{array}{l}17,006 \\
14,936\end{array}$ & $\begin{array}{l}847 \\
220\end{array}$ & $\begin{array}{l}17,853 \\
15,156\end{array}$ & $\begin{array}{l}\text { upper joint core barrel } \\
\text { wobbled off second drill collar }\end{array}$ & $\begin{array}{l}\text { Hycalog thread } \\
\text { off station } \\
\text { Leg 3-January } 1969\end{array}$ \\
\hline 20 & 14,779 & 82 & 14,851 & service joint bumper sub & $\begin{array}{l}\text { high torque observed } \\
\text { Leg } 4\end{array}$ \\
\hline 24 & 16,924 & 770 & 17,694 & est. service joint bumper sub & $\begin{array}{l}\text { failure point dropped } \\
\text { with string }\end{array}$ \\
\hline 24 & 16,924 & - & 一 & $\begin{array}{l}\text { snapped off } 2 \text { feet below box } \\
479 \text { joints off bottom }\end{array}$ & $\begin{array}{l}\text { picked up elevators } \\
\text { with one link }\end{array}$ \\
\hline 25 & 6,355 & 252 & 6,607 & service ioint bumper sub & high torque \\
\hline 26 & 17,014 & 60 & 17,074 & tool joint between 1 and 2 drill collar & B.H.A. not buried \\
\hline 26 & 17,014 & 1,958 & 18,972 & upper joint core barrel & $\begin{array}{l}\text { Hycalog thread } \\
\text { Leg } 5\end{array}$ \\
\hline 35 & 11,063 & 1,279 & 12,332 & service joint top bumper sub & $\begin{array}{l}\text { (after logging) } \\
\text { Leg } 6\end{array}$ \\
\hline 44 & 4,872 & 269 & 5,131 & wobbled off top of sixth drill collar & pin bent \\
\hline 45 & 18,105 & 100 & 18,205 & service joint on bumper sub & \\
\hline 45 & 18,105 & 343 & 18,448 & torsion failure sixth joint above drill collar & no bumper subs \\
\hline 46 & 18,960 & 70 & 19,030 & pin first drill collar above bumper sub & $\begin{array}{l}\text { bumper sub above core } \\
\text { barrel }\end{array}$ \\
\hline 58 & 14,680 & 560 & 15,240 & parted by string shot middle bumper sub & $\begin{array}{l}\text { drill string stuck } \\
\text { Leg } 8\end{array}$ \\
\hline 68 & 17,936 & 49 & 17,975 & pin third drill collar above core barrel & shallow chert \\
\hline
\end{tabular}

*Resulting in loss of equipment below the keel. 
Drill String Loss Through Leg 18 concluded.

\begin{tabular}{|c|c|c|c|c|c|}
\hline Site & $\begin{array}{l}\text { Water } \\
\text { Depth } \\
\text { (ft.) }\end{array}$ & $\begin{array}{l}\text { Total } \\
\text { Penetration } \\
\text { (ft.) }\end{array}$ & $\begin{array}{l}\text { String } \\
\text { Length } \\
\text { (ft.) }\end{array}$ & Type of Failure & Remarks \\
\hline 76 & 15,085 & 90 & 15,175 & $\begin{array}{l}\text { tool joint second drill collar above core barrel } \\
\text { NOTE - Changed drill collar thread to NC61 }\end{array}$ & $\begin{array}{l}\text { Leg 9-January } 1970 \\
\text { shalliow chert }\end{array}$ \\
\hline & & & & & Leg 10 \\
\hline 87 & 12,350 & 2,285 & 14,635 & backed off 29 stands above drill collar & drill string stuck \\
\hline 93 & 10,015 & 5 & 10,020 & top service break bottom bumper sub & $\begin{array}{l}\text { lost beacon large } \\
\text { excursion }\end{array}$ \\
\hline $93 \mathrm{~A}$ & 10,040 & 26 & 10,066 & top service break top bumper sub & $\begin{array}{l}\text { shailow clay } \\
\text { Leg } 11 \text { A, B,C }\end{array}$ \\
\hline 99 & 16,123 & 1,276 & 16,399 & top service break second bumper sub & tight hole \\
\hline $99 \mathrm{~A}$ & 16,123 & 814 & 16,937 & top service break second bumper sub & firm formation \\
\hline 100 & 17,471 & 1,086 & 18,557 & top sub bottom bumper sub & cracked box (old crack) \\
\hline 106 & 14,764 & 1,184 & 15,948 & top service break middle bumper sub & $\begin{array}{l}\text { high current erratic } \\
\text { positioning }\end{array}$ \\
\hline 109 & 10,000 & - & 一 & re-entry equipment & $\begin{array}{l}\text { see re-entry report } \\
\text { Leg } 14\end{array}$ \\
\hline $143 C$ & 10,020 & 160 & 10,180 & top service break bottom bumper sub & sloping bottom \\
\hline 143D & 10,020 & 59 & 10,079 & top service break bottom bumper sub & $\begin{array}{l}\text { sloping bottom } \\
\text { Leg 15-January } 1971\end{array}$ \\
\hline 146 & 13,300 & - & - & re-entry equipment & $\begin{array}{l}\text { see re-entry report } \\
\text { Leg } 16 \\
\end{array}$ \\
\hline 163 & 17,500 & 958 & 18,458 & re-entry equipment & $\begin{array}{l}\text { see re-entry report } \\
\text { Leg } 17 \\
\end{array}$ \\
\hline 168 & 17,800 & 246 & 18,046 & sub $65 / 8$ double box top bottom bumper sub & Leg 18 \\
\hline 176 & 630 & 134 & 764 & service joint bumper sub & $\begin{array}{l}50 \text { foot excursion - } \\
\text { shallow water }\end{array}$ \\
\hline 177A & 7,000 & 1,670 & 8,670 & bumper sub packing nut backed off & test bumper sub \\
\hline
\end{tabular}


DEEP SEA DRILLING PROJECT

Drilling Status

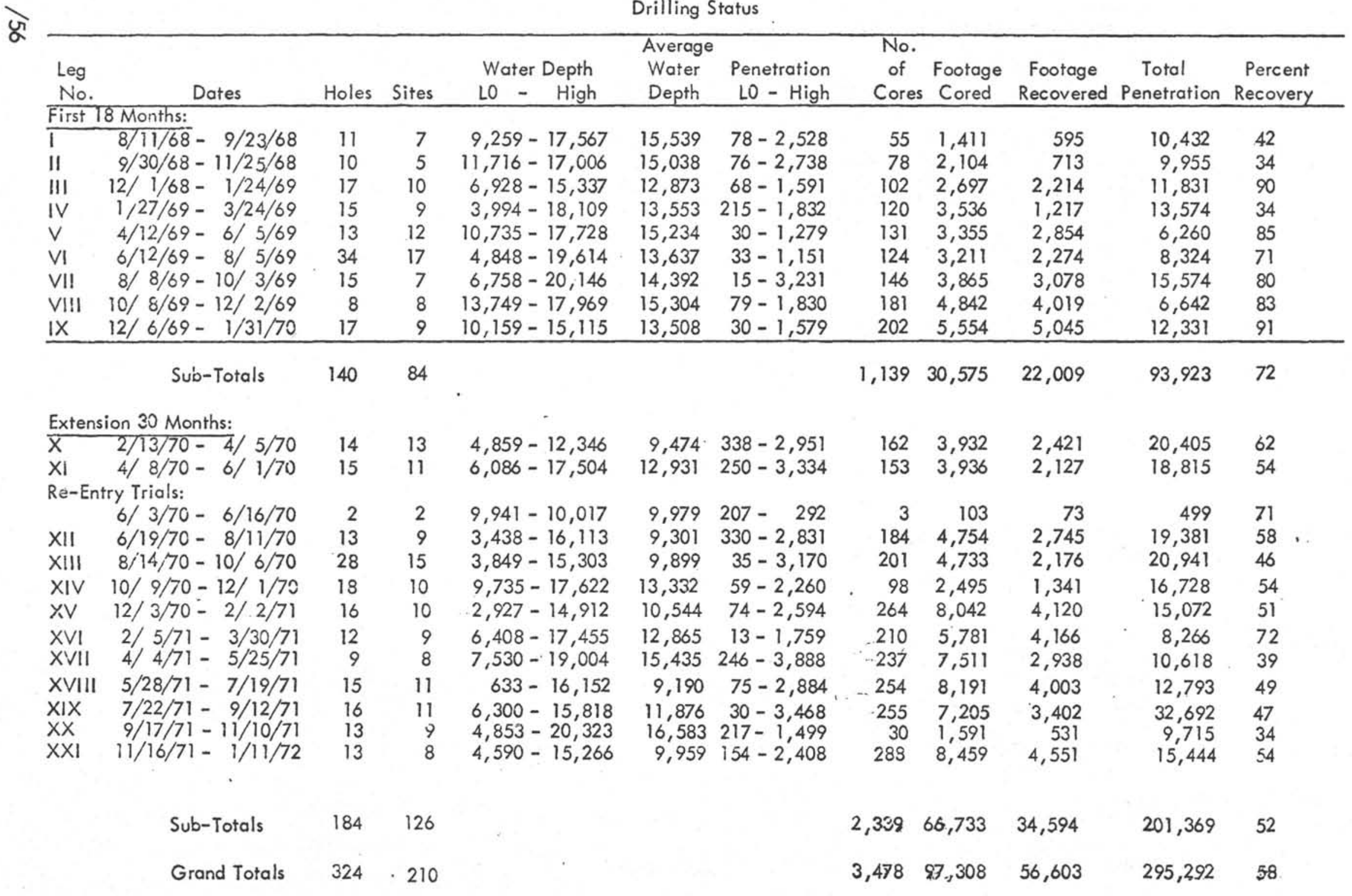

NOTE: All measurements are in feet. 


\section{APPENDIX A}

Metal Corrosion in Saline Waters 


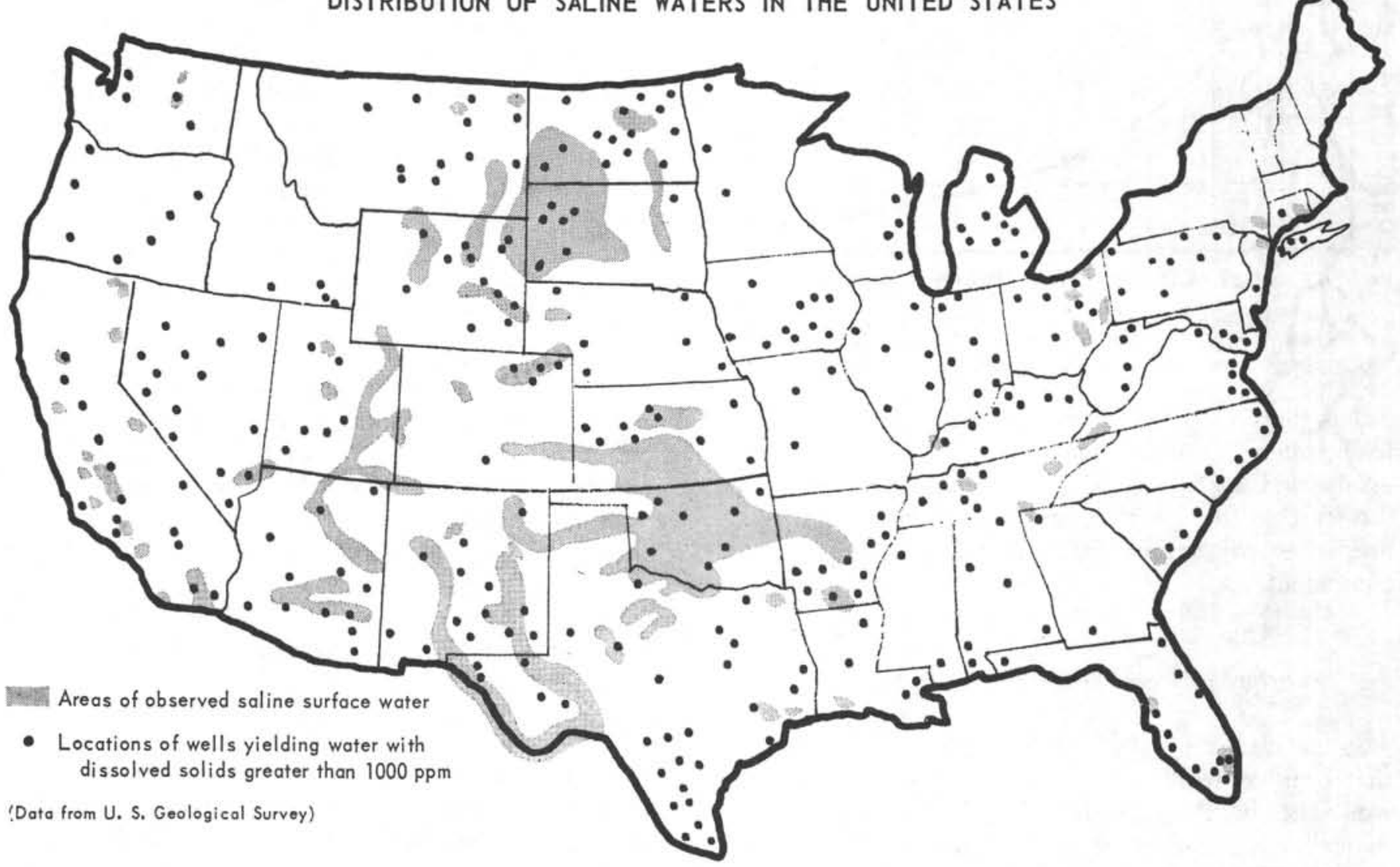

\section{METAL CORROSION IN SALINE WATERS}

The corrosion problems inherent in the handling and use of saline waters can be costly. The author discusses some of the mechanisms of such corrosion and suggests some stèps for countering saline-water attack on metals.

by Frederick W. FinK

IN MOST AREAS OF THE United States, as of many countries, problems associated with obtaining an adequate supply of fresh water are multiplying. Such conditions as rising urban populations, pollution of available supplies, and demands of agriculture and industry are forcing the exploitation of saline waters by a growing number of individuals, governments, and other organizations.

Saline waters, because of their wide distribution, are increasingly being considered for possible use in applications such as industrial cooling, fire protection services, street working and sanitation, and a rawwater source for conversion to potable water.

Waters containing $1000 \mathrm{ppm}$ or more of salt are usually referred to as saline or brackish waters. Such waters are available in many parts of the USA, sometimes as surface water and often from wells. ${ }^{1}$ In a few cases, wells produce brines that have industrial values as sources of chemicals. In the future, however, even fresh water sources can be expected to have increasing salt contents in some areas as a result of such developments as (1) greater pollution or water reuse, (2) use of salt for highway ice and dust control, (3) excessive pumping of wells (which in coastal areas allows infiltration of sea water), and (4) evaporation from large reservoirs, leaving the salts behind.

Saline waters, as a natural resource, pose many difficulties. Plants using saline water for cooling or as a source for conversion to fresh water, for example, have the problem of disposing of the salt-bearing effluent. In oil-producing fields the connate brines produced are disposed of by pumping them into a formation which precludes contamination of other underground values that may be present. ${ }^{2}$

The Office of Saline Water in Washington is conducting a wide range of experimental programs on methods of converting salt-bearing waters to fresh. It is confident that fresh water eventually can be produced from saline sources for well under $\$ 1.00$ per thousand gallons. Nevertheless, the economics of saline 


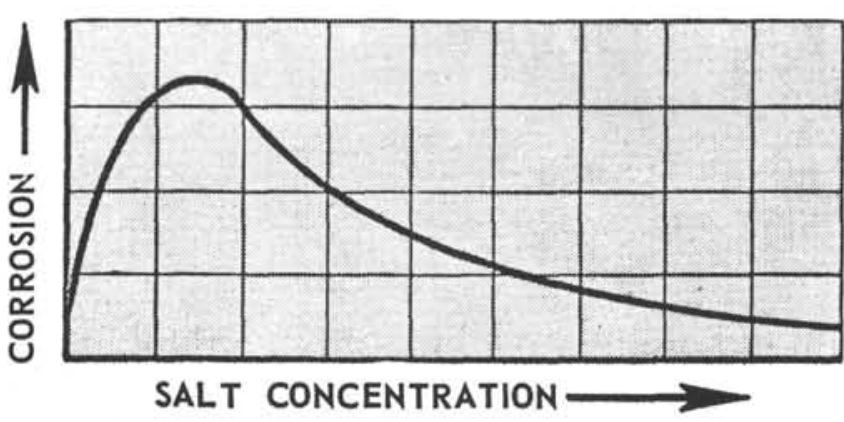

Corrosion increases with rising salt concentration. However, at some point ( 3 to 4 per cent for sodium chloride), the corrosion rate drops because oxygen is less soluble in the solution.

waters involve excessive expense when compared with fresh water. There are higher costs of handling, processing, and finally disposing of the salt residues. Not the least of these higher costs result from the steps needed to prevent excessive corrosion of pipes and equipment.

\section{Factors in Corrosion by Saline Waters}

Saline waters usually are more corrosive to metals than ordinary fresh waters. ${ }^{3}$ To predict whether saline well water will be corrosive to steel, it is necessary to understand the effects of such factors as (1) the salt content, (2) the dissolved gases, (3) the $\mathrm{pH},(4)$ the temperature, and (5) the tendency to form mineral scale. ${ }^{4}$ If the water contains several thousand parts per million of sodium and other chlorides, it is likely to be corrosive to steel and low-alloy steels. Stainless steels, copper alloys, aluminum alloys, and some nickelbase alloys also may be attacked, depending on conditions.

Salt Content. Distilled water in contact with air is corrosive to steel, probably because, in addition to oxy-

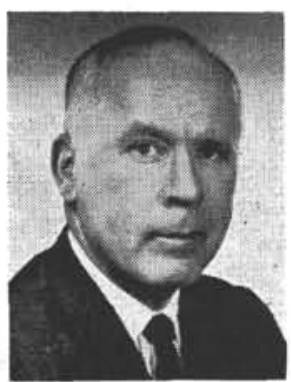

Backed by a broad knowledge of the properties of materials and of the characteristics of various environments, Frederick W. Fink has participated in and guided a broad spectrum of corrosion studies. Two of his current interests include studies involving the oil-ash problem in boilers and the deterioration of materials in marine service. In recent years, he has contributed to research on the mechanism of corrosion cracking in austenitic stainless steel, acid corrosion of cast stainless steel, and corrosion in nuclear reactors and rocket propellant systems. His interests at Battelle have included oil-well equipment corrosion, effects of flue-gas on metals, and development of alloys for chemical service. An important contributor to the work of professional societies, Fink has long been active in organizing the corrosion symposia of the National Association of Corrosion Engineers and The Electrochemical Society. acid. If a small amount of sodium chloride is added to such water, the corrosivity to steel is increased greatly. In fact, as sodium chloride is added, the corrosion rate increases up to a point at which a concentration of about 3 or 4 per cent is reached. Beyond this point, the corrosion rate starts to decrease (see figure at left). Thus, in a concentrated brine the corrosion rate is less than in, say a dilute salt solution, because of the much lower solubility of oxygen in the more concentrated solution.

After the chloride ion, the sulfate ion is most corrosive to steel. One explanation for the chloride ion's corrosiveness is that its smaller size enables it to penetrate protective films more readily than sulfate ions. Frequently, protective films form naturally on the surface of steel or other metals, or are developed by inhibitor additions. One can consider sodium and potassium ions as being corrosive, because they do not form protective mineral scales on the metal surface. On the other hand, calcium and magnesium ions are well known for their tendency to precipitate protective mineral scale on heated metal surfaces.

Corrosion Cell Mechanism. The attack on a metal such as steel immersed in a saline water is electrochemical in nature. Electric currents can be detected entering or leaving the solution at local sites in a corroding structure. Metal ions, e.g., iron, enter into solution at certain active areas referred to as "local anodes." The other electrodes of the local corrosion cells are known as "cathodes," where certain ions, usually hydrogen, tend to deposit from solution. Any process that interferes with the reaction going on either at the local anodes or cathodes tends to restrict the over-all operation of the corrosion cells.

Role of Oxygen and Other Gases. Corrosive attack on steel in saline well waters having a $\mathrm{pH}$ of about 5 to 9 , or higher, is usually controlled by the rate that oxygen, in solution, diffuses to the cathode. In the corrosion process, oxygen will remove the deposit of hydrogen at the local cathodes by forming water. In a flowing system containing plenty of oxygen, the cathodic areas receive an ample supply, and the local corrosion cells can continue to function at a fairly rapid rate. If oxygen or some other oxidizing medium is not present, the hydrogen film tends to accumulate on the cathode surfaces and the corrosion cells cease to function.

At the anode where the iron enters solution as ferrous ions, the presence of oxygen under some circumstances may promote protective oxide-film formation. Oxygen also can cause ferrous ions to oxidize to ferric ions. The latter can, in turn, attack a fresh steel surface. In general, oxygen is considered the most im- 
portant of the environmental factors in saline waters. In a saline water open to the atmosphere, oxygen is normally present up to $8 \mathrm{ppm}$ in solution at ordinary temperatures. If pressure is applied to the water, much larger amounts of oxygen can be maintained in solution.

In addition to carbon dioxide and oxygen, hydrogen sulfide can promote corrosion when present in saline water, even in small amounts. For example, as little as one ppm greatly accelerates the corrosive attack on steel. When hydrogen sulfide is present in a well water, it is often the result of bacterial action. Hydrogen sulfide is producing by sulfate-reducing bacteria and by bacteria which promote decomposition of organic sulfides.

Some connate brines, originating deep down in the earth and under high pressure, are found to have no oxygen present. If the $\mathrm{pH}$ is 6 or above, these oxygenfree brines are not corrosive to steel, even though the temperature may be as high as $250 \mathrm{~F}$. Occasionally a connate brine is found which not only is oxygen-free

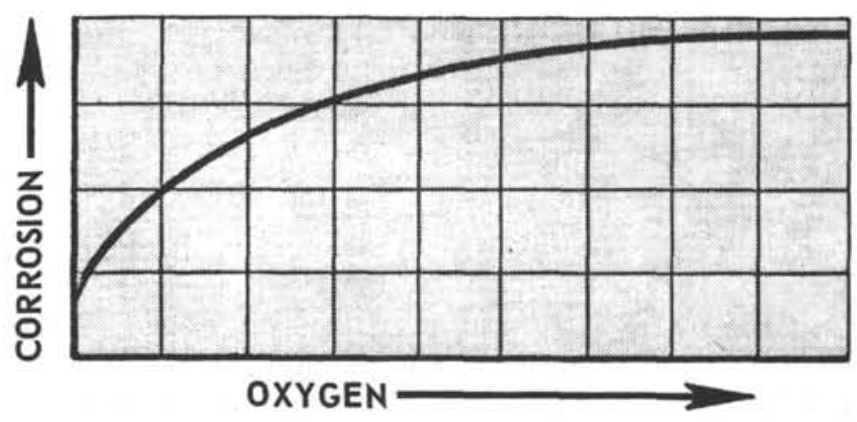

In saline waters above $5 \mathrm{pH}$, the greater the amount of oxygen diffusing to cathodic areas, the more tendency for corrosion to proceed.

but will also chemically react with small amounts of oxygen (air) that may be inadvertently introduced during handling. In other cases it is found desirable, when handling connate brines in steel piping, to add a scavenger of oxygen (such as sodium sulfite) to maintain the water oxygen-free and noncorrosive to steel.

Acid. Saline waters may be contaminated by mine water or other sources of acid. If the $\mathrm{pH}$ is much below 5, oxygen is not needed for corrosion of steel. For example, a direct reaction will occur between the metal and the solution, liberating hydrogen.

Temperature. Increasing the temperature of a saline water tends to accelerate its attack. At atmospheric pressure, however, oxygen solubility decreases as the temperature is raised, and at some point this becomes the dominating corrosion factor. For example, boiling saline water is normally less corrosive than water at some lower temperature, say 160 to $180 \mathrm{~F}$.

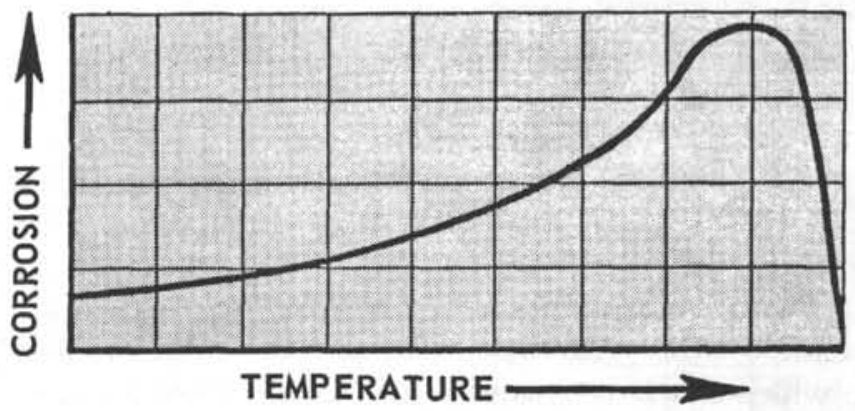

Saline solutions tend to become more corrosive with increasing temperature. At atmospheric pressure, however, oxygen solubility decreases with increasing temperature, and near and at the boiling point the solution's corrosivity is less than at lower temperatures.

Velocity and Cavitation. Any occurrence in a saline water which tends to break down the protective film on the metal is considered undesirable. Film breakdown may result from high velocity. Impingement is one type of velocity attack. Bubbles of air or other gas may be suspended in the water, carried along by the stream, and impinged at the metal surface. Turbulent flow also tends to promote removal of the protective film and allows local attack to occur. For steel in a dilute salt solution under ambient conditions, the increase in corrosion with velocity is shown diagrammatically in the graph below.

Another type of attack (also related to velocity) is cavitation. In this case, at some point on the metal surface, the velocity reduces the pressure locally so that the water boils. At some other point further downstream, these vapor bubbles suddenly collapse. They may do so with a tremendous shock and actually cause loss of metal at local sites after repeated hammering. Impellers in pumps driven at higher-than-rated speed will often fail from cavitation attack. A cavitated im. peller is extremely rough and often looks as if it had been eroded away. When a fresh metal surface is exposed by cavitation, considerable corrosion also may take place, especially in saline waters.

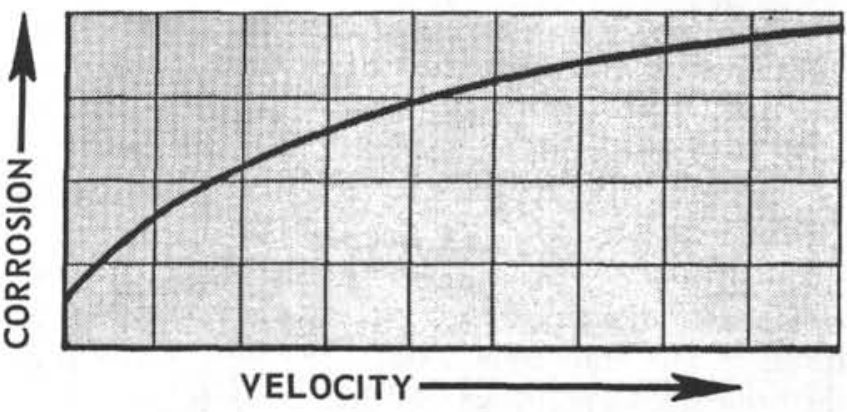

In general, the corrosion of steel tends to increase with the rate of flow of saline water at the metal surface. 
Deposit Attack. If in a stagnant solution, a uniform deposit of silt covers the entire surface of the metal, it may be protected against corrosion. Normally, only a portion of the metal surface is covered by a deposit and the remainder is exposed. Under these conditions, a rapid corrosive attack will occur under the deposit because of what is known as a "differential aeration cell." Corrosive attack often proceeds under deposits closest to the edge. Under a deposit, the protective film (which may have formed on the metal) is not repaired because it is shielded from the oxygen. It becomes the anode in the corrosion cell. Adjacent to the deposit, oxygen is available. This area usually will act as the cathode. Corrosion cells associated with deposits or local corrosion products will frequently result in pitting. Sometimes the pitting attack is cyclic, changing from active to passive and vice versa. Layers of rust, mineral scale, and silt may form a tubercle.

\section{IDENTIFying the Cause of Corrosion}

In view of the discussion so far, it is obvious that many factors enter into corrosion problems associated with well waters. To diagnose the problem and establish possible causes, several steps may be taken.

Experience has shown that examination of the well water at a laboratory distant from the source usually is not advisable. Bacteria, gas content, ferrous:ferric-ion ratio, and other such variables tend to change rapidly during transport. At least part of the analysis should be made at the location of the well, if possible. In any case, the sampling should be conducted by a person entirely familiar with both the corrosion and analytical problems. A chemical analysis of the brine usually is not sufficient to enable one to predict whether or not the water will be corrosive to the structure.

Similarly, the examination of a piece of rusted-out pipe in the laboratory usually does not allow conclusions to be made as to the cause of the attack. Both the environment and the metal structure must be studied together. By metallographic study, one can establish whether there is more than one phase in the metallic structure. Also, one can establish if there are minor harmful constituents in the metal, such as sulfur inclusions. Inclusions or contaminants in the metal can be the cause of local corrosion, but more often the environment holds the clue to the difficulty.

Some twenty years ago, in Battelle-conducted corrosion experiments, studies were made of samples of distillate and brine from a series of wells. In one test, the brine from a corrosive well and the distillate from a well in which corrosion was not serious were combined. It was found that the corrosion of the steel coupons by the brine was inhibited by the presence of the distillate from a noncorrosive well in the field. Further studies demonstrated that a corrosion inhibitor was naturally present in the distillate. On the other hand, if one took a brine from a noncorrosive well and combined it with a distillate from a corrosive well, the steel coupons would be badly corroded. The presence or absence of a natural inhibitor in the distillate was the principal factor in determining whether such wells would be corrosive to steel. Later experiments showed that the attack by a corrosive brine could be controlled by adding a suitable organic inhibitor to the well.

As our uses of saline waters increase, efforts to protect the equipment will have to be stepped up so as to make utilization of such waters economic. Based on knowledge of the mechanisms of corrosion and what we know of the effects of saline waters on various materials, designers can do much to limit corrosion attack and thus reduce the costs of handling saline waters.

In addition to the use of naturally corrosion-resistant materials, designers have access to other protective techniques. Thus, in some cases cathodic protection, protective coatings, or sacrificial metallic coatings can be utilized. Corrosion often can be controlled, too, through adjustment of the environment as by eliminating oxygen, carbon dioxide, and hydrogen sulfide; using inhibitors; or adjusting the $\mathrm{pH}$ of the waters.

Much, perhaps most, of today's research on corrosion is concerned with the correction of conditions that have arisen in existing structures. While water treatment, for example, is valuable in reducing costs of operations, the design of new installations to minimize corrosion is highly desirable. Because of the almost limitless combinations of factors that can play a part in corrosion problems, their solutions call for study by engineers and scientists experienced in the subject.

In the field of corrosion, as in others, continuing research is adding to the total of our knowledge. As our understanding of the mechanism of corrosion increases, new approaches to the solution of corrosion problems will emerge.

\section{REFERENCES}

1. R. A. Krieger, J. L. Hachett, and J. L. Pool, "Preliminary, Survey of the Saline-Water Resources of the United States," Geological Survey Water-Supply Paper 1374, 1957.

2. "Subsurface Salt-Water Disposal," published by Division of Production, American Petroleum Institute, Dallas, Texas, 1960.

3. F. W. Fink, "Saline-Water Development Poses Problems in Metal Corrosion," to be published in Ground Waler, October, 1963 (Journal of the National Water Well Association).

4. G. Butler and H. C. K. Ison, "Corrosion of Metals in Natural and Treated Waters," Corrosion Technology: Part I, June 1962, pp. 145-147; Part 2, July 1962, pp. 173-176; Part 3, August 1962, pp. 199-201. 


\section{APPENDIX B}

Evaluation of Methods to Alleviate Corrosion Fatigue in Type 135 Drill-Pipe Steel for

Offshore-Drilling Applications 

Authorized Reprint from
Special Technical Publication 462
Copyright
American. Society for Testing and Materiais
1916 Race Street, Philadelphia, Pa. 1910 3
1970
D. E. Pettit, ${ }^{1}$ D. W. Hoeppner," and W. S. Hyler ${ }^{1}$

\section{Evaluation of Methods to Alleviate \\ Corrosion Fatigue in Type 135 Driil-Pipe Steel for Offshore-Drilling Applications}

REFERI:NCE: Pettit, D. F.. Hecppner. D. W.. and Hy ler. W. S.. "livaluation of Methods to Alleviate Corrosion Fatigue in Type 135 Drill-l'ipe Steel for OffshoreDrilling Ipplications," Effects of Linsiromment and Complex Loud History on Fatiguc Life, AST.11 S7P 462 . Anterican Socicts for Testing and Materials. 1970, pp. 241-257.

ABSTR.ICT: Various methods of modifsing the drilling enviromment and changing the response of the matcral to the ensironment were examined as potential methods of alleviating corrosion fatigue in Type 1.35 drill-pipe steel for use in offshore-drilling applications. The fattigue hehavior of Type 135 steel specimens in seawater and in air was compared to the results ohtained in deaterated seawater. freshwater and seawater drilling mud. inhibited drilling mud. and drilling mud with an elevated $\mathrm{pH}$. No improvement in latigue life resulted for any of the modified environments examined. seteral actually proving detrimental. Cathodicprotection studies were then conducted on ypecimens subiected t: vatrious applied current densities during fatigue cycling in seawaier and a range of current densities that improved the fatigue behavior determined. The hall-cell potential was determined for the steel in seawater and zine selected as the sacriticial metal coating. Zinc-electroplated specimens fatigue tested in seanater showed a marhed increase in fatigue life compared to that of uncoated specimens in seawater. Bare regions up to ${ }^{3}$, in. wide were tolerated with no loss of protection and regions as large as $3_{4} \mathrm{i}$ in. wide still resulted in an improved fatigue-corrosion hehasior.

Thus, zinc electroplating of Type 135 drill-pipe steel resulted in a substantial improvement in fatigue hehavior in a seawater environment. Alteration of the chemical environment resulted in no improvement of the fatigue behavior of uncoated specimens over that ohtained in plain seawater.

KEY WORIS: fatiguc, corrosion latigue. Acsting. corrosion protection, steel. electroplating. surface coating. cathodic protection. inhibitors. Urilling. seawater

${ }^{1}$ Research Enginecr and Senwor Advisor. respectively. Structural Materials Engineering Division. Bätelle Nenorial Institute. Coltumbus Laboratories, $505 \mathrm{~K}$ ing Avenue. Columbus, Ohio +3201.

2Senior Scientist, Lochhed-California Company. Burbank. Calif. 


\section{Introduction}

In 1962, the National Science Foundation undertook a program designed to develop the equipment necessary for drilling a hole through the earth's crust and into the earth's mantle. The necessary equipment to accomplish this task was to be a refinement of the present-day offshore-drilling equipment used in oil ficlds.

One of the main considerations in any offshore-drilling operation is the selection of a material suitable for use in the drill-pipe string. Early test results revealed that orie of the main limitations of pipe performance was the corrosion-fatigue behavior of the material. While it is recognized that corrosion-fatigue tests conducted under laboratory conditions are not directly applicable to the design function, they are useful in providing information regarding a relative order of merit for various approaches. The determination of the relative effectiveness of several different methods of preventing corrosion-fatigue in drill pipe is the subject of this paper.

Conceptually. there are three basic approaches to the prevention of corrosion fatigue. First. the environment can be modified so that it is less reactive with the test material. Sicond. the response of the material to the environment can be modified. Finally, the environment and the material can be separated so that no interaction can occur.

In this investigation. variations of these three basic approaches to preventing corrosion-fatigue were used to determine the most promising manner of alleviating the corrosion-fatigue problem in the offshore-drilling environment. In the first part of this paper, several modifications of the drilling environment werc exammed. These included the use of deacrated scawater, various drilling muds, and seawater mud with an elevated pH. In the second portion of this paper. methods of changing the material response to the enviromment by means of eathodic protection and the application of a sacrificial metal coatting were examined. In the find section of the paper, results of the investigation are summarized and the more favorable methods discussicd.

\section{Experimental Program}

The material used in this investigation was Type 135 drill-pipe steel with the typical compusition given below:

\begin{tabular}{|c|c|c|c|c|}
\hline$\ldots c$ & $\mathrm{Mn}$ & $\mathrm{P}$ & $\mathrm{S}$ & $\mathrm{Si}$ \\
\hline Percentage .... 0.45 & 1.61 & 0.018 & 0.030 & 0.22 \\
\hline
\end{tabular}

This material wats selected because it represented one of the higher strength production-line drill-pipe materials. The material was obtained in the form of standard t-in. in ontside diameter drill pipe that had been given the standard 


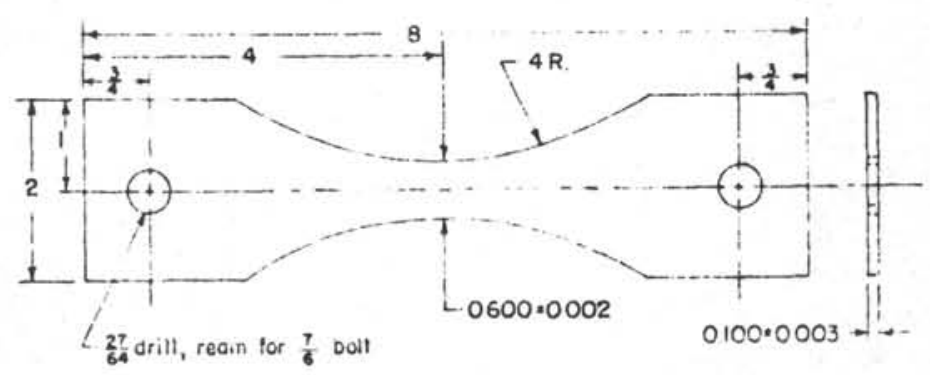

FIG. 1-Unnotched fatigue-specimen contiguration.

heat treatment consisting of a quench from 1550 to $1600 \mathrm{~F}$ at a quenching rate of $35 \mathrm{ft} / \mathrm{min}$ followed by tempering at $1025 \mathrm{~F}$. The average tensile propertics based on triplicate tests vere:

Ultimate strengtii, $159,200 \mathrm{psi}$

0.2 percent yield strength, $144,100 \mathrm{psi}$

Percentage elongation in 2-in. gage length, 12.5 percent.

All specimens were machined from the pipe section oriented parallel to the longitudinal axis of the pipe. The configuration of the unnotched fatigue specimens used in this program is shown in Fig. 1. The flat surfaces of the specimens were polished with 400 -grit emery paper and kerosene. The edges of the specimens werc polished on a wheel in steps using 240, 400, and 500grit emery paper with kerosene. The resulting finish had a surface roughness of approximately $10 \mu \mathrm{in}$. rnıs, with all final polishing marks oriented parallel to the specimen axis.

All fatigue tests were conducted in a Krouse 10,000-lb capacity axial-load fatigue machinc equipped with a mechanical speed reducer. This allowed the cyclic frequency of the test to be varied from 12 เo $1200 \mathrm{cpm}$. For the corrosion-fatigue tests, a lucite container was fitted around the specimen and sealed at the bottom with silicon grease. The environment was allowed to flow into the bottom of the container and exit at the top so that a minimum of 2 in. of the environment covered the specimen test section at all times. All fatigue tests were conducted at a mean stress of $75 \mathrm{ksi}$.

\section{Experimental Results}

\section{Control Test Results}

Control tests were conducted on unnotehed specimens in air and in seawater to provide baseline data against which to evaluate the effectiveness of the various protection methods. It has been demonstrated by Endo and Miyao [I]" that, because the corrosion process is time-dependent, the fatigue

${ }^{3}$ The italic numbers in brackets refer to the list of references appended to this paper. 
life obtained in a corrosive environment will be a function of the testing frequency. In order to assure that the frequency was slow enough to allow corrosion to be a factor, preliminary tests were conducted in seawater (see Appendix for composition) at frequencies varying from 12 to $1200 \mathrm{cpm}$. The results presented in Fig. 2 show only a slight difference between the results obtained at 12 and $60 \mathrm{cmm}$. The longer fatigue lives obtained at 1200 cpm; however. indicated the corrosion did not have sufficient time to show an effect due to the short duration of the test. On this basis, a frequency of $60 \mathrm{cpm}$ was selected for use in all the corrosion-fatigue tests. The air-fatigue tests were conducted at a speed of $1200 \mathrm{cpm}$. The final results of the control tests in air and seawater are shown in Fig. 3.

\section{Effect of Modified Environments}

The effect of environment on the corrosion behavior of a metal is obvious; if the environment can be made more neutral, the corrosion is expected to be reduced. However. the exact nature of corrosion fatigue as it occurs in drilling fluids is not a simple process. but instead is a combination of the effects of several contaminates including oxygen, hydrogen sulfide, carbon dioxide, and various acids [2]. The following modifications of environment were examined to determine the effect of various factors that could be expected to influence the corrosiveness of the environment.

Deaerated Seawater-The role of oxygen in seawater often has been suspected of accelsrating the corrusion-fatigue process [2]. To examine this possibility, fatigue tests were conducted using seawater deaerated with $1.6 \mathrm{~g}$

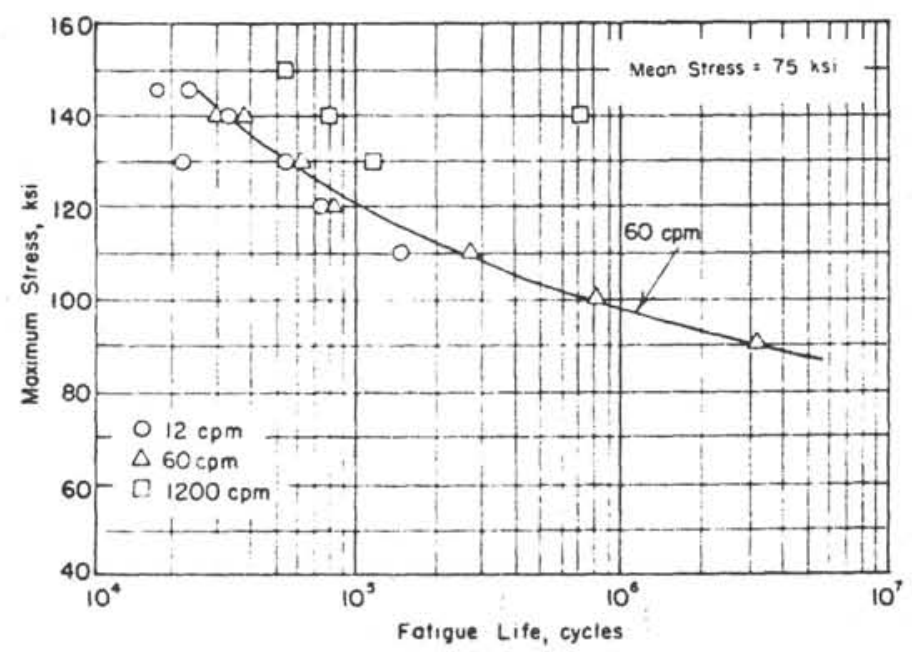

FIG. 2-The effect of test frequency on the corressim-futigue lives of unnotched Type 135 steel. 


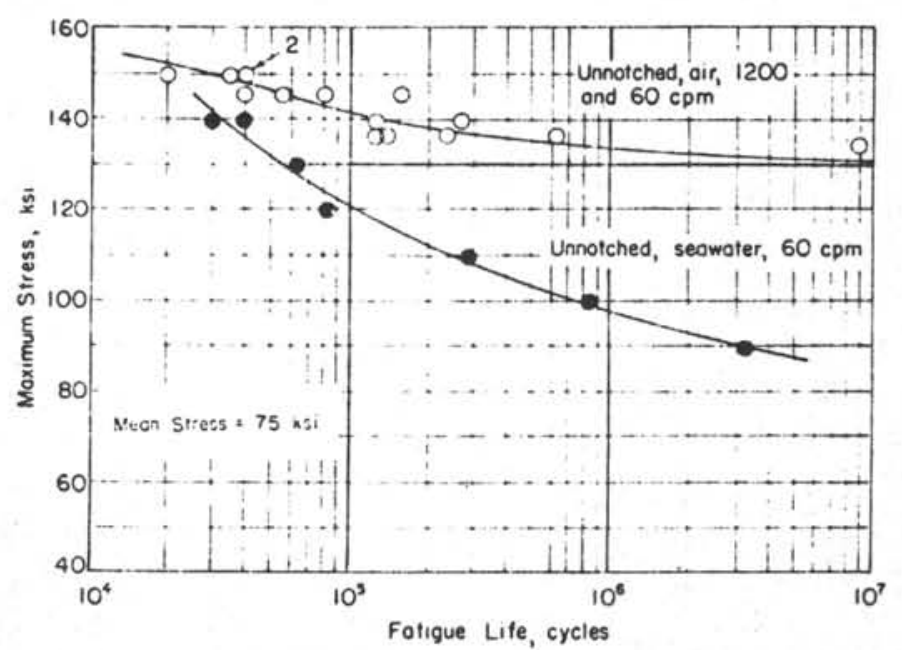

FIG. 3-Axial lead umnotched latigue results.

of K-91 (calcium sulfite catalyzed with cobalt chloride) for every 5 gal of seawater. Analysis of the freshly deacrated seawater showed less than 0.02 $\mathrm{ppm}$ of oxygen as compared with the 5 to $6 \mathrm{ppm}$ oxygen in the as-received seawater. Initial tests conducted in the open system showed no improvement of the fatigue properties. However. oxygen analysis of the seawater taken during the test inclieated that some oxygen was being absorbed from the air, so a completely closed system. shown schematically in Fig. 4, was subsequently constructed. Chacks of the oxygen lesel made during the tests in the closed system showed no change in the oxygen concentration from the initial value of less thin 0.02 ppm. As shown in Fig. 5, no difference between the deareated and the as-received scawater test results was observed, thus indicating that reducing the oxygen level from 6 to 0.02 ppm does not affect the corrosion-fatigue process in seitwater.

Drilling .Muds-Fatigue tests employing either freshwater or seawater drilling mud $(\mathrm{pH}=9 \pm 0.2$ ) were conducted in an open system in which the mud from the main reservoir wals continuously circulated around the specimen. More detailed information on these muds is presented in the Appendix.

For the initial tests, at pll of ') 1 as selected since some results [3] indicate this may be an optimum value for the protective effect of colloids. Unnotehed fatigue tests were conducted using freshwater mud with the pll of 9 and the fatigue results were found to be approximately equal to or slightly below the seawater-fatigue results. Similarly, tests conducted with the seatwater mud, $\mathrm{pH}=9$, also were found to yich fatigue lives below those obtained at the same stress level in seawater, as shown in Fig. 6. 

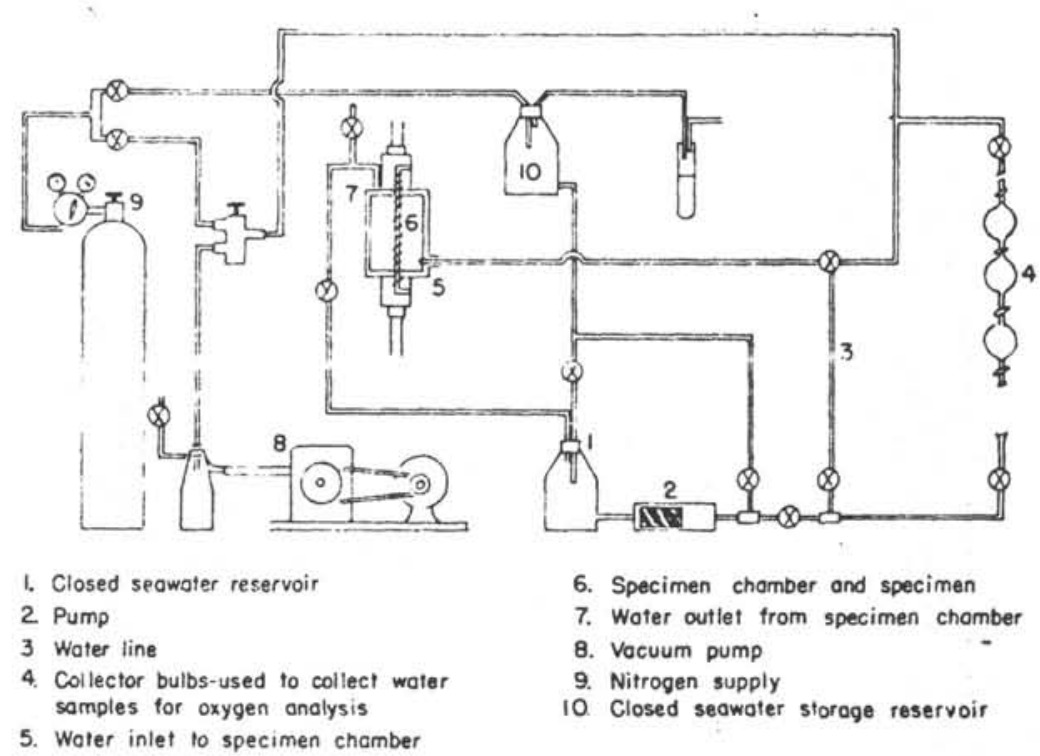

I. Closed seawater reservoir

2. Pump

3 Water line

4. Collector bulbs-used to collect water samples for oxygen analysis

5. Water inlet to specimen chamber
6. Specimen chamber and specimen
7. Woter outlet from specimen chomber
8. Vocuum pump
9. Nitrogen supply
10. Closed seawater storage reservoir

FIG. 4-Clased rirculating system used for the deaerated seawater futisue experiments.

It has been indicated [ 7 ] that improved corrosion-fatigue behavior may be obtained at high values of $\mathrm{pH}$. so tests were conducted using the seawater mud with the $\mathrm{pH}$ adjusted to 11.6 to 12 by the addition of sodium hydroxide. Again, as shown in Fig. 6, the resulting fatigue lives were shorter than those observed for regular seawater tests.

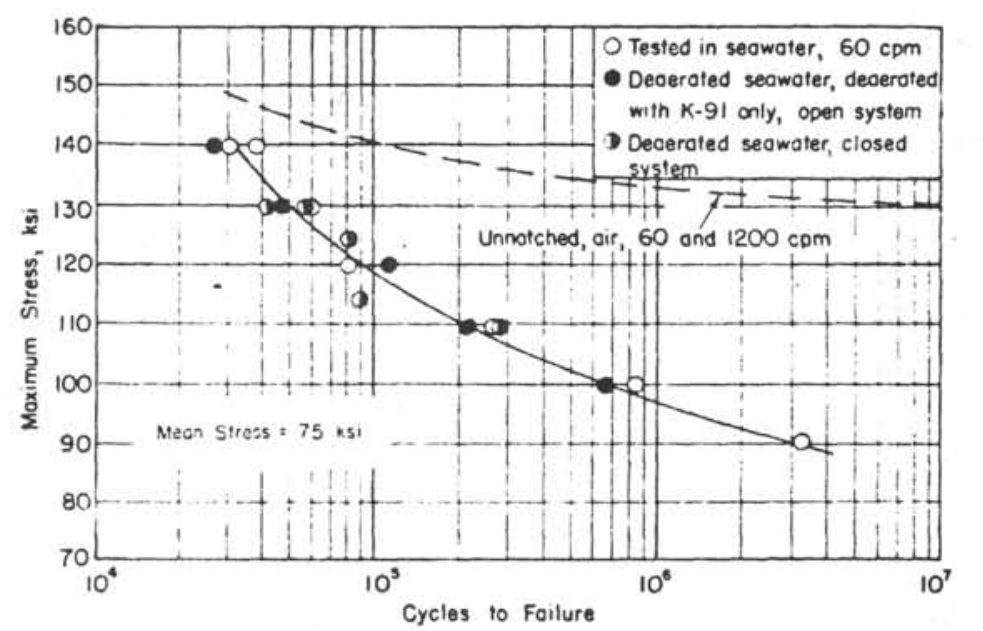

HG. 5-Fatigue behasior of unnotched specimens tested in deaerated seawater at $60 \mathrm{cpm}$. 


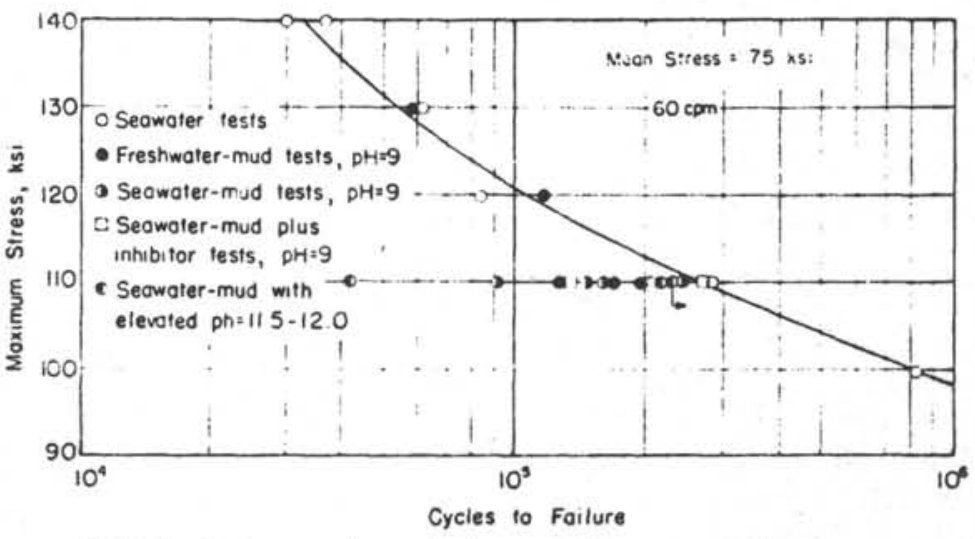

FIG. 6-Futigue results in fres/mater and seawater afrilling muds.

Because neither of the drilling muds tested was found to have any advantage over seawater, an inhibitor known as Cortron DF-18, an oil-soluble amine-type inhibitor, was added to the seawater mud. This type of inhibitor is designed to produce a non-conducting film of organic polar compounds on the surface of the material. Prior to starting the tests, a mixture of 1 part inhibitor to 10 parts cliescl oil was fed into the test chamber to cover the specimen. The chamber was then flushed with drilling mud and the test initiated. A one-to-ene mixture of diesel oil and inhibitor was added to the drilling mud every 6 hours during the test. However, the results, shown in Fig. 6, showed no substantial improsement in the fatigue behavior in the inhibited mud over that observed in the regular mud.

\section{Modifying Material Respense to the Environment}

Eflorts to change the corrosive nature of the drilling environment had met with no success. so attention was turned to the possibility of modifying the material response to the environment. Several possible methods including cathodic protection and the application of sacrificial metal coatings were examined.

Cathodic Protection-The application of current to a material to eliminate corrosion has long been recognized as a potentially useful approach since corrosion is primarily electrochemical in nature. Tests were conducted by applying different applied currents to fatigue specimens being tested in the recirculating seawater system. The current was applied through platinum anodes submerged in the electrolyte and continuously monitored with a Calomel reference eell. These tests were referred to as "unagitated tests." A mechinical stirrer wis then added to the system to produce increased velocities in the seawatcr. Thesc tests are relerred to as "agitated scawater tests." 
Specimens were tested in unagitated seatwater and the results obtained are shown in Fig. 7. As shown, fatigue lives equivalent to those obtained in air could be produced at current densitics from 40 to $100 \mathrm{~mA} / \mathrm{sq}$ it. During testing, it was observed that cakcureous deposits formed on the specinen surface, the thickness and extent of these coatings increasing with increasing current density. This calcareous deposit consisted principally of calcium carbonate ( $\mathrm{CaCO})$ and magnesium hydroxide $\left(\mathrm{Mg}(\mathrm{OH})_{2}\right)$ and is believed to oceur as a result of an increase in the $\mathrm{pH}$ of the electrolyte adjacent to the cathode [5]. The increase in pll presumably accompanies the flow of protective current.

Various factors govern the deposition of such coatings, and Humble [6] has studied the phenomenon in some detail. He concluded that the ratio of calcium carbonate to magnesium hydroxide in the coating is dependent on the applicil currem density, the composition of the water, and the amount of electrolyte tubtelence at the cathode. This is in agreement with the results found by Nichol [7] for mild stcel in scawater.

The effect of electrolyte velocity on the eurrent density required for protection can be seen from the results plotted in Fig. \&. Again, the results indi-

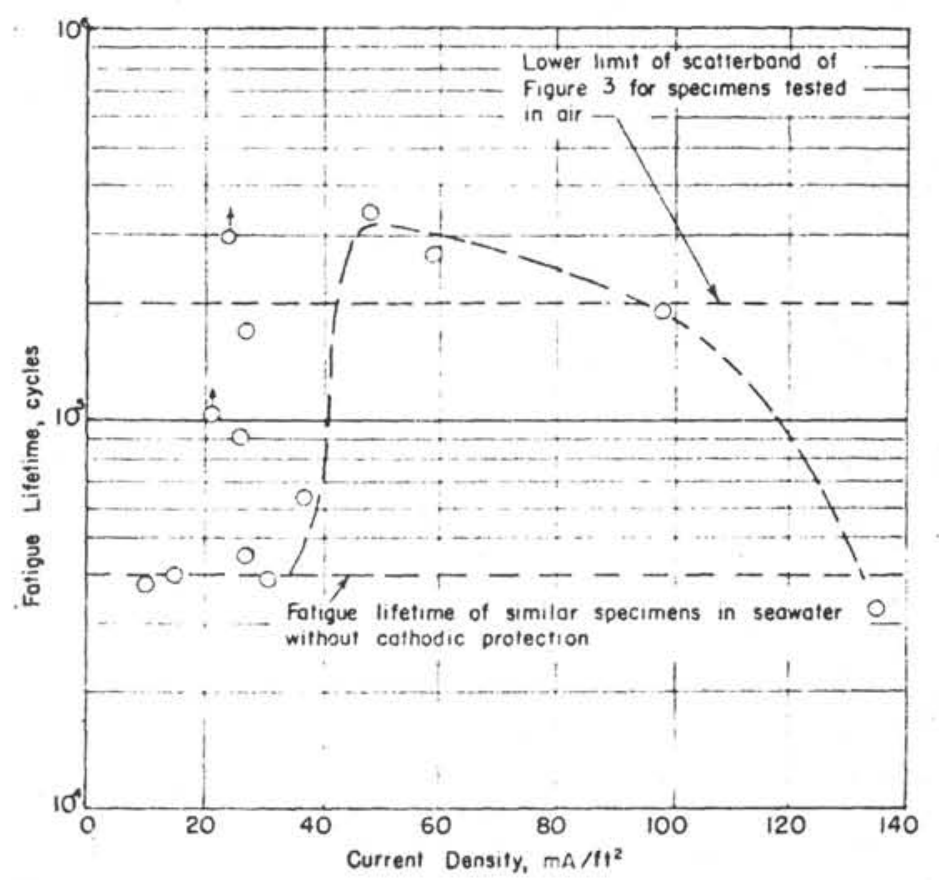

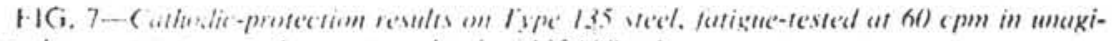
tated scasater at a mavimum stress lewel of $1.35,0(1)$ pis. 


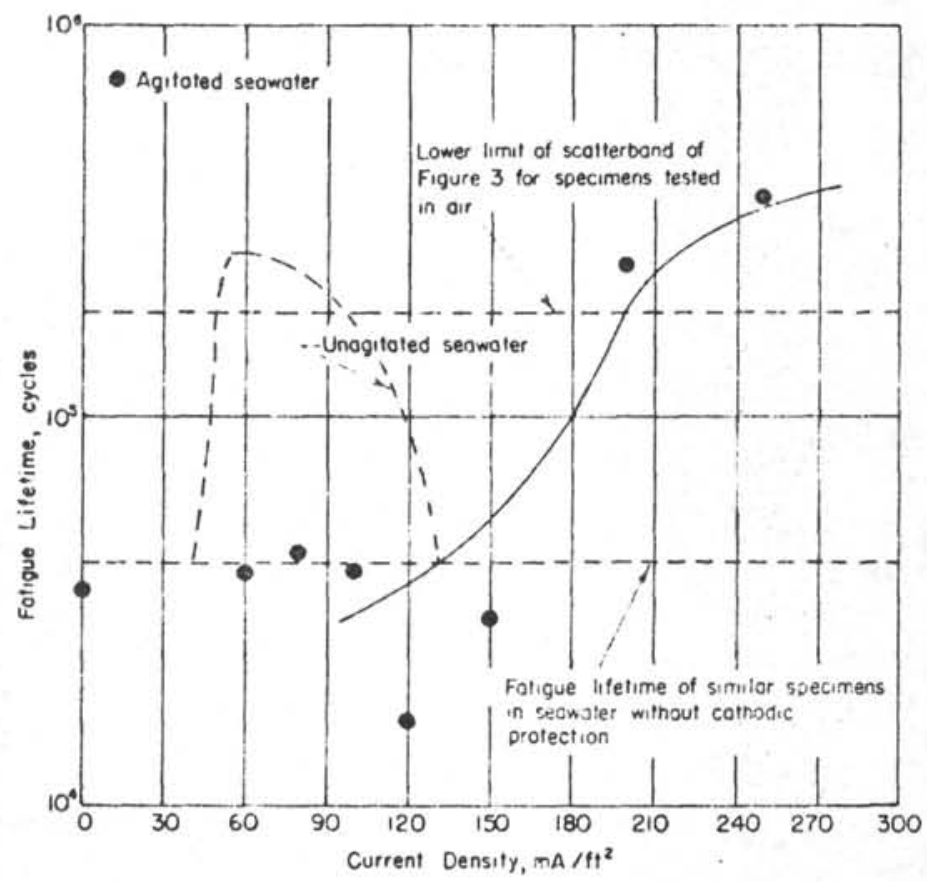

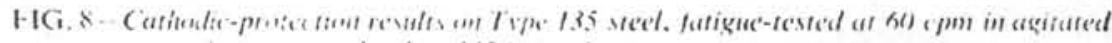

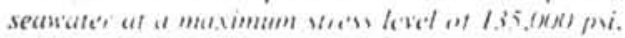

cate that a rather substantial increase in lifetime results from the application of cathedic protection. Hewcerer. under the condition of agitation. the current density repuired for protection has shifed from the $\$ 010100 \mathrm{~mA}$ sq fit range

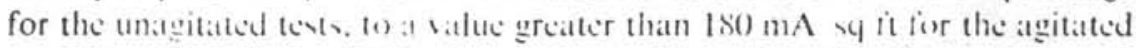
condition. The whersed is has ior is not readily explainable. It may be noted, however. that under agitated condition me calcarcous deponsts becine visible until a value of $200 \mathrm{~mA}$ s $\mathrm{ft}$ was reached. When the calcarcous deposit formed at $200 \mathrm{~mA}$ sc lit. it was of at different nature than the deposit formed in the unagitated tests. The importame result is, however, that even under high degrees of agifation, improsed fatigue behavior was achiesed by eathodic protection.

\section{Sacrificial Metal Coatings}

Normally. protective coatings, juch as paint, are designed to keep the corrodant from contacting the material. These coatings, howerer, have the inherent danger of becoming broken, thus allowing corrosion to proced. For this reasen, it was believed that as sateritical metal coating that is anodic to the base metal would be more reliable, since even if rupture of the coating did occur, cathodic protection would still exist over the exposid areat. In this 
manner. the inherent advantages of both the protective coating and cathodic protection could the employed.

As a means of xelecting a potential sacrificial metal coating, a specimen of Type 1.35 sted was exposed without stress in sciawater. A potential was established between the steel cathode and a platinum anode so that an applied current flowed between the platinum and the stecl. As the applied current was varied, potential measurements were made between the steel and a saturated Calomel half edl at various current values. From measurements for both increasing and decreasing current. Fig. 9 was prepared. This figure shows the half-cell potential as a function of the current density at the steel for the data in the range that appears to be of interest from a fatigue standpoint. The actual measurements encompassed a range of current densities from -1800 to $-600 \mathrm{~mA}$ sq ft. The vertical lines with solid circles at the end points represent specmens that were tested in fatigue under agitated eathodic-protection conditions at a constant current density. The solid circles represent the extremes in potential meatsured during the tests.

In Fig. 9, the range from 40 to 120$) \mathrm{mA}$ sy fit is eross-hatched and corresponds to the range where cathodic protection improved fatigue behavior. On the hasis of (1) the curve of Fig. 9. (2) the current densities required for protection against corrosion fatigue, and (3) the potentials required to produce these current densitics, the choice of metal coating for sacrificial protcetion is einc and possibly alloys of zinc. Also inclicated in Fig. 9. in the double-cross-hattched region, is the approximate range of the closed-circuit potential for the stcel-zinc couple.

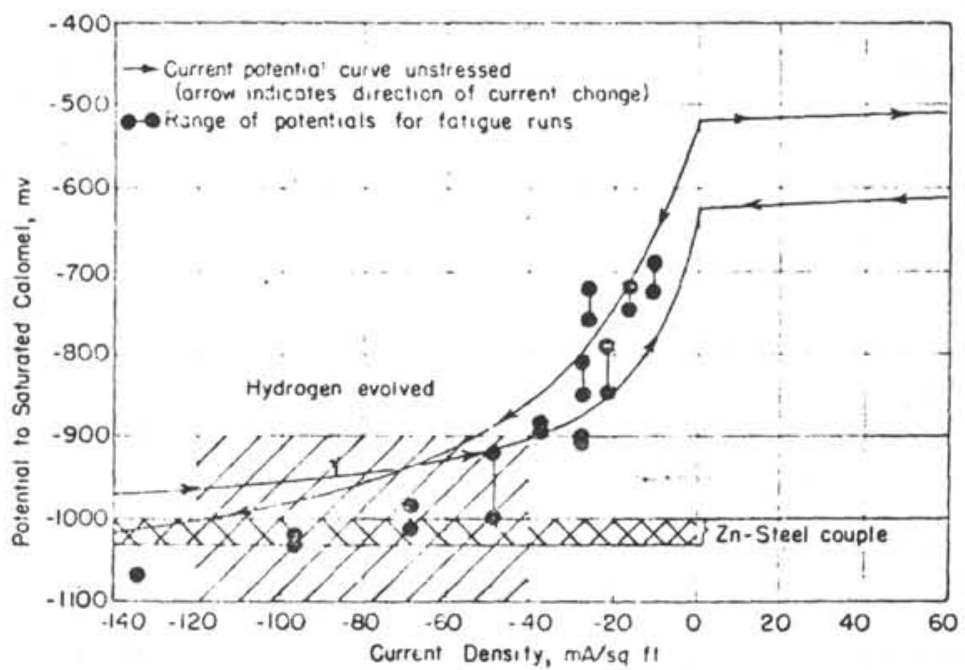

FIG. 9-Potential sersus current denstry retationship for Type 135 steel in seavcater. 
Also shown in Fig. 9 is an arrow pointing to one of the curves at the current density value of $80 \mathrm{~mA}$ sy ft. This indicates that hydrogen was evolved at this value. The important point is that, in these experiments, eathodic protection or protection by satrificial zinc coatings oceurs at current lensities where atomic hydrogen is relcased at the cathode. Consequently, hydrogen damage is a potential problem.

Flame-Sprayed Zinc-As a first approach to applying the zinc coating, a commercial zinc name-spraying procedure was used. Prior to the llame spraying, the specimen surfice was grit-blasted to did in bonding the zinc. For this reason, it was first necessary to determine the effect of grit-blasting per se on the fatigue behavior of Type 1.35 steel.

Results of the tests on grit-blasted and grit-blasted plus flame-sprayed speciniens are shown in Figs. 10 and 11, respectively. Figure 10 shows a marked decrease in the fatigue strength of the grit-blasted steel tested in air. A still further reduction in fatigue strength occurs for the grit-blatsted specimens when tested in seawater. The reduction in strength noted in scawater for the grit-blasted specimens is not surprising since the surfice damage produced by grit-blisting would be expected to be more susceptible to corrosion than unworked material. The reduction of the fatigue strength in air due to grit-blasting however, was not expected and indicates that the blasting treatment was very severe.

As seen in Fig. 11, the zinc coating does produce some increase in fatigue life in seawater ower that of the grit-blasted material. The results show no increase in fatigue life ower those obtained on bare specimens when tested in unagitated scatwater. and only a slight improwement at low stresses when tested in agitated seawater. The improvement, howeser, was not as much as had been expected. probably due to the severe grit-blasting preparation used prior to coating.

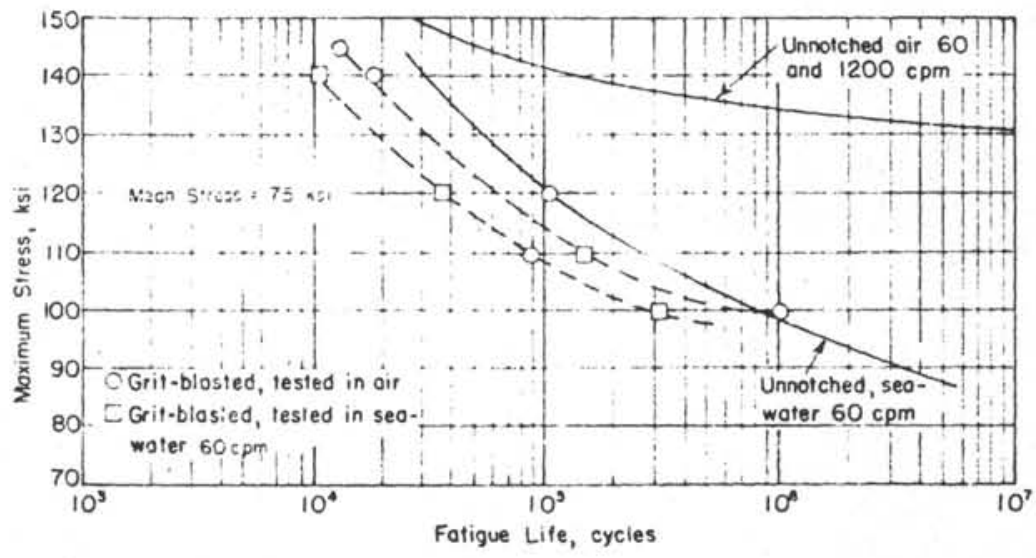

FI(. 10- Effect of stir-blustm: on the fatigne behasion of Type 135 sted. 


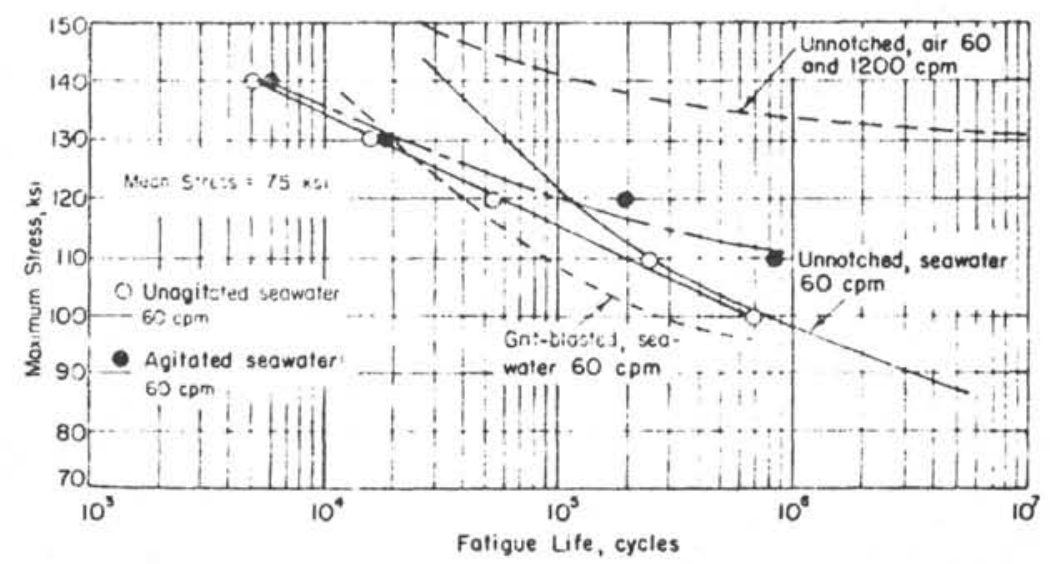

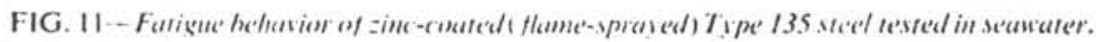

Electroplated Zinc-Since the flame-spraying procedure did not substantially improve the fatigue hehavior. the application of the zine coating by electroplating was examined. Unnotched fatigue specimens were electroplated with zinc using the following procedure.

The specimens were mounted in a plate rack built with non-conducting edge shields to reduce zine thickness at the specimen edges and improve the thickness uniformity. The specimens were then cleaned and plated as follows:

1. Immersed in a $180 \mathrm{~F}$ chelating-type sted cleaner for a few seconds.

2. Anodically eleaned in the same cleaner with at current density of approximatcly 100 amp sq it for 30 s.

3. Rinsed in tap water at 140 to $150 \mathrm{~F}$.

4. Rinsed in tap water at 65 to $70 \mathrm{~F}$.

5. Anodically trated in 10 percent (by weight) sulfuric acid solution at a current density of approximately $100 \mathrm{amp}$ sq it $(3.5 \mathrm{v})$ for $10 \mathrm{~s}$. A jumper contact was connected to cach specimen before immersion in the acid solution to avoid chemical attack of the stect that might create hydrogen that could be absorbed by the stect.

6. Rinsed in an overilowing tap-water bath $(65$ to $70 \mathrm{~F})$ while an anodic potential of $3.5 \mathrm{v}$ was maintained to prevent chemical attack.

7. Plated with $4.0 \pm 0.5$ mils of zine in a high-cfliciency zinc sulfate bath prepared with:

\begin{tabular}{|c|c|}
\hline Zinc sulfate $\left.(\mathrm{ZnSO}), 7 \mathrm{H}_{0} \mathrm{O}\right)$ & $365.0 \mathrm{~g} / \mathrm{l}$ \\
\hline Aluminum sulfate $\left(\mathrm{A} I S \mathrm{~S}_{1} \cdot 1811(\mathrm{O})\right.$. & $53.3 \mathrm{~g} / 1$ \\
\hline Zinc chloride $\left(\mathrm{ZnCl}_{2}\right) \ldots \ldots \ldots \ldots$ & $17.0 \mathrm{~g} 1$ \\
\hline Sodium sulfatc ( $\mathrm{Nat}_{\mathrm{SO}} \mathrm{S}_{3}$ ). & $75.0 \mathrm{~g} .1$ \\
\hline Wetting agent (Tergitol $0 S$ ) & $15.0 \mathrm{ml} 1$ \\
\hline pH (adjusted with $\mathrm{NaOH}$ ). & $3.7 \mathrm{pH}$ \\
\hline
\end{tabular}


The above bath was maintained at $85 \pm 2 \mathrm{~F}$ during the plating operation. A mechanical stirrer wats used to agitate the selution. and each specimen was plated for $70 \mathrm{~min}$ at a current density of $40 \mathrm{amp}$ sq fit to deposit the desired thickness. One of the piated specimens was sectioned to determine the coating thickness, which was found to be $4 \pm 0.5$ mils. A plitting thickness of 4 mils was selected because it could be expected to result in good adhesion and was commercially feasible.

The fatigue results obtained for the plated specimens in air and in seawater are shown in Fig. 12. From this figure, it can be seen that, while the electroplating results in severe degradation of the air fatigue results, a marked improvenent in the corrosion-fatigue behavior in seawater is produced.

Since the enating mat be broken during the pipe lifetime, several plated specimens were prepared with bare spots (hereafter referred to as "holidays"). This configuration is shown in Fig. 13. 110liday sizes ranging from 1, to 3 , in.

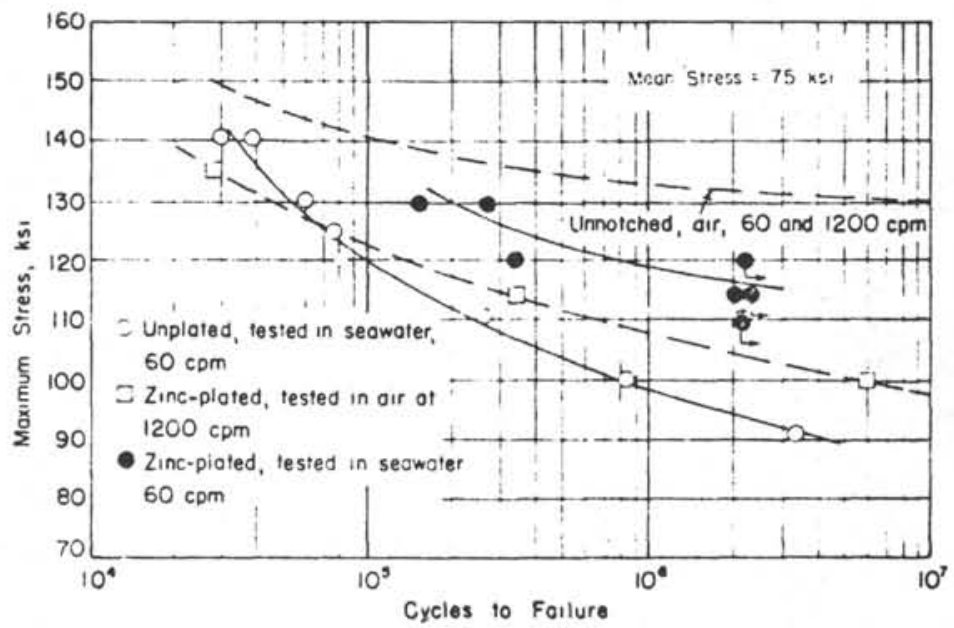

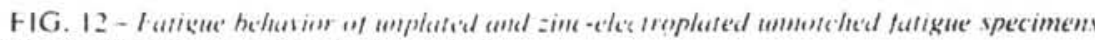
of Tipe 135 sted teved in wasterer and air.

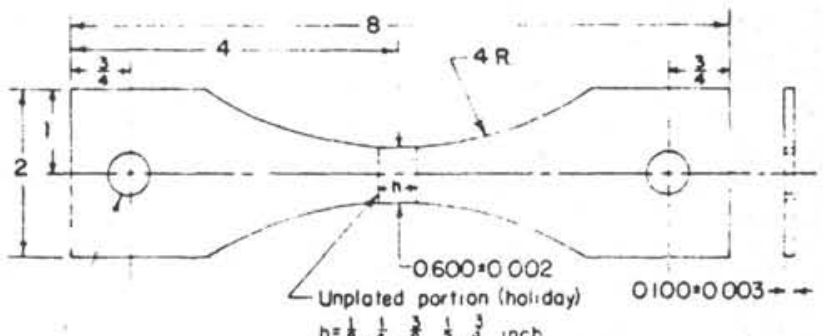

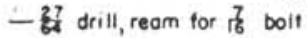

$n=\frac{1}{8}, \frac{1}{4}, \frac{3}{6}, \frac{1}{2}, \frac{3}{4}$ inch

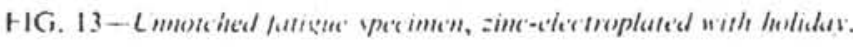




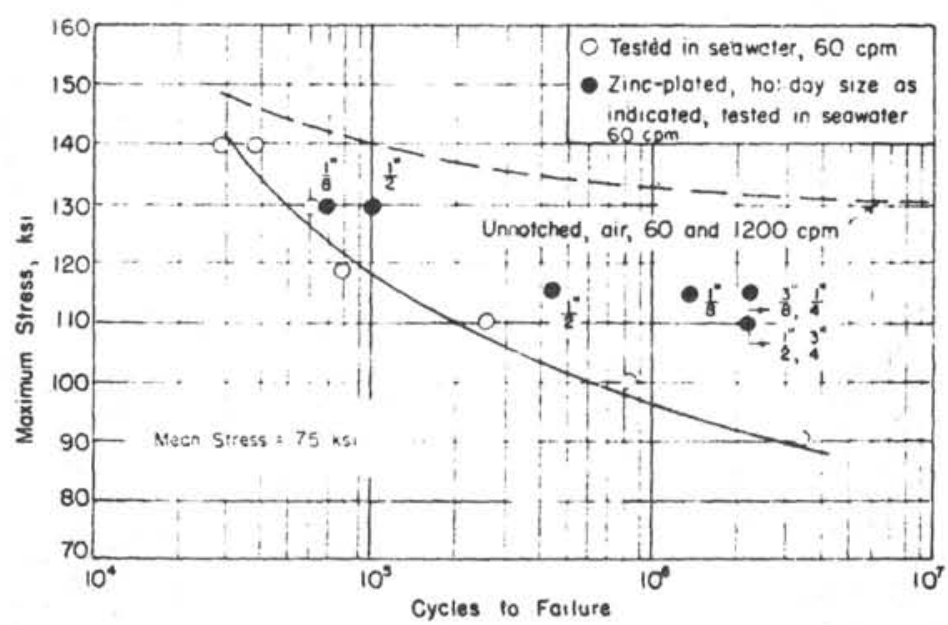

F1G. 14-Fatigue hehavior of zinc-electroplated unnotehed futigue specimens of Type 1.35 steel possessing varions size holictavs.

were tested in unagitated seawater to determine the maximum size defect tolerable in the zinc plating without a loss in fatigue strength. The results of these fatigue tests are shown in Fig. 14. If the results shown in Figs. 12 and 14 are compared, it can be seen that the presence of holidays up to $3.4 \mathrm{in}$. still result in nearly complete protection at a maximum stress of 110 or $115 \mathrm{ksi}$. At the higher stress of $130 \mathrm{ksi}$ maximum, some reduction in fatigue life does occur due to the holidays although the behavior is still superior to that of the unplated specimens.

\section{Summary}

The objective of this study was to examine a variety of approaches to the prevention of corrosion fatigue in drill pipe in the hope of determining the more promising procedures. For this reason, a variety of data was generated with the aim of determining the most promising direction for future efforts. On the basis of these results, the following trends are observed.

First, the use of certiin modified environments to control corrosion fatigue does not appear to be a promising avenue of exploration. While only a few of many inhibitors and drilling muds now alvailable were actually examined, no increase in fatigue life was observed for any of the methods examined. Second. a marked improvement in corrosion-fatigue life was noted with cathodic protection and with a sacrificial metal coating.

The results obtained with the sicrificial metal coating (zinc) indicate that this methud of protection is very promising. While the results obtained for the flame-sprayed zine coating were disappointing. they emphasize the importance of the method of application of the coating. On the other hand, the electroplated zinc couting was found to he quite effective in improving the 
corrosion-fatigue behavior. The tolerance of bare regions up to $3 / 8$ in. with no effect, and up to $3 / 4$ in. with little effect on the fatigue behavior indicates that the main benefit of the zinc coating lies in its electrochemical sacrificial nature.

The changes in the calcareous deposit produced by variations in the degree of agitation of the drilling fluid during cathodic protection do appear to have a bearing on the corrosion-fatigue behavior. In particular, the nature and effect of the deposit on possible hydrogen damage as related to the degree of agitation of the environment could prove to be extremely important, since the disadvantages produced by the hydrogen damage in the steel may outweigh the advantage obtained from the protection procedure. Further evaluation of this subject is needed to determine if hydrogen damage is a real problem in cathodic protection of drill pipe.

\section{Conclusions}

On the basis of the results obtained in this program, the following conclusions can be drawn:

1. The use of the following modified environments did not result in improvement in the corrosion-fatiguc behavior over that obtained in seawater.

(a) seawater deaerated with K-91

(b) freshwater drilling mud, $\mathrm{pH}=9$

(c) seawater drilling mud, $\mathrm{pH}=9$

(d) scawater drilling mud, $\mathrm{pH}=12$

2. The use of cathodic protection can result in corrosion-fatigue lives in seawater equivalent to those obtained in air.

3. The usc of an electroplated zinc coating results in an improvement in corrosion-fatigue life, but a decrease in the air-fatigue life.

4. Bare regions of steel up to $3 / 4$ in. can be tolerated in the zinc-coated specimens without appreciable loss of protection.

5. The use of a flame-sprayed zinc coating did not result in a general improvement in corrosion-fatigue behavior. This is believed to be partially the effect of the severe grit-blasting the material received prior to flame-spraying.

In future work the effectiveness of new methods such as plastic coatings, special surface treatments, new corrosion-resistant materials, new inhibitors, etc., should be examined in an effort to produce a more suitable corrosionresistant drill pipe.

\section{Acknowledgments}

The research program upon which this paper is based was funded by Brown \& Root Company under a subcontract from the National Science Foundation. Sincere thanks are given to Brown \& Root Company for their cooperation in the conduction of this program. 


\section{APPENDIX}

\section{Composition and Preparation of the Drilling Muds Employed}

The drilling muds employed were supplied by the Baroid Division of the National Lead Company.

\section{Composition}

Composition of $5 \mathrm{gal}$ of each of the two drilling muds is given in Table A1.

TABLE A1-Composition of drilling muds, per $5 \mathrm{gal}$.

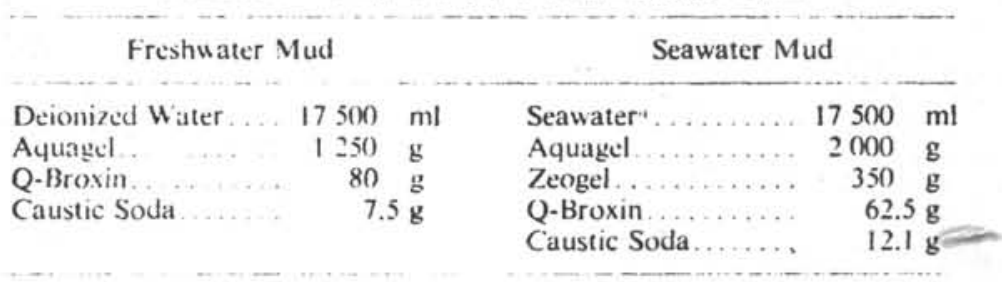

" $42 \mathrm{~g}$ "sea-salt" per liter of deionized water.

\section{Preparation}

Freslawater. Mht. The freshwater mud wats prepared in separate 5-gal batches. Each batch was prepared by adding $1250 \mathrm{~g}$ of Ayuagel to $17,50 \mathrm{~m} \mathrm{mi}$ of deionized water and stir ing at high veed with at dispersitor for $1 \mathrm{~h}$. The resulting slurry was

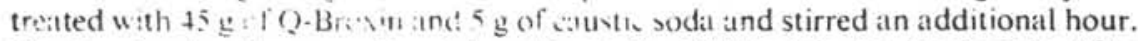

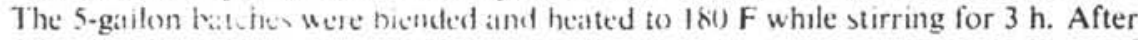
the mud had coo'sd, the pll and viscovity were adjusted with the addition of $35 \mathrm{~g}$ of Q-Broxin and 2.5 of wu with a dispersator.

Seawater Mad. The seiwater mud was prepared in separate 5-gal batches. Each 5 -gal batch was prepared by adding $20 \%(\mathrm{~g}$ of Ayuagel and $350 \mathrm{~g}$ of Zeogel to $17,500 \mathrm{ml}$ of seawater and stirring at high speed with a dispersator for 1 hour. The resulting slurry was treated with $62.5 \mathrm{~g}$ of $\mathrm{Q}$-Broxin and $6.1 \mathrm{~g}$ of caustic soda and stirred for an additional hour. The two batches of mud were blended and heated to $180 \mathrm{~F}$ while stirring for $3 \mathrm{~h}$. Alter the mud hatd cooled, the $\mathrm{pH}$ was adjusted by the addition of $6 \mathrm{~g}$ of citustic soda. The mud was then stirred for $3 \mathrm{~h}$ at high speed with a dispersator.

\section{References}

[I] Endo. ' $k$. and Miyao. Y.. "Effects of Cycle Frequency on the Corrosion Fatigue Strength." Bulletin of J.tpan Society of Mechanical Engineers, Vol. 1. No. 4, 1958, pp. $27+380$.

[2] Bush. H. E.. "Current Techniques for Combatting Drill Pipe Corrosion," The Drilling Contractor, July-August. 1966, pp. 53-61. 
[3] Lloyd, W. S. and Simpson, A. W., "Report of Special Subcommittee on Corrosion Fatigue of Drill Pipe," Corrosion Fatigue of Drill Pipe, Exhibit H, Topical Committee on Materials of the American I'etroleum Institute, 1939.

[4] "Improving the Performance of the Drill String," Battelle Memorial Institute Report to American Association of Drilling Contractors, 1946-19.47.

[5] Morgan, J. H., Cathudic Protectiom, Leonard Hill (Books) Limited, London, 1959, p. 170.

[6] Humble, H. A.. "Cathodic Protection of Steel in Seawater with Magnesium Anodes," Corrosion, Vol. 4, 1948, p. 51.

[7] Nichols, J. L.. "Cathodic Protection Reduces Corrosion Fatigue Cracking of Steel in Seawater," Muteriuls Protection, February, 1963, pp. 46-53. 


\section{APPENDIX C}

Mechanics of Long Drill Strings 


\title{
MECHANICS OF I.ONG DRILL STRINGS
}

P. H. Francis

P. A. Cox

FINAL REPORT

SwRI Project No. 02.2807

\author{
Prepared for \\ Deep Sea Drilling Project \\ Scripps Institution of Oceanography \\ La Jolla, California
}

August 17, 1970

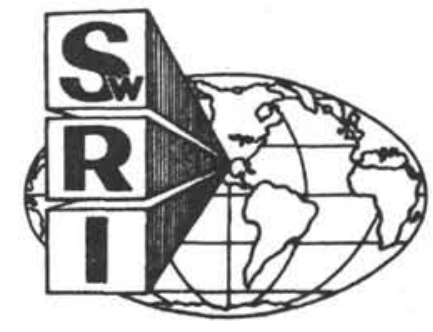

SOUTHWEST RESEARCH INSTITUTE SAN ANTONIO HOUSTON 
SOUTHWEST RESEARCH INSTITUTE

Post Office Drawer 28510, 8500 Culebra Road

San Antonio, Texas 78228

\section{MECHANICS OF LONG DRILL STRINGS}

P. H. Francis

P. A. Cox

FINAL REPORT

SwRI Project No. 02-2807

Prepared for

Deep Sea Drilling Project

Scripps Institution of Oceanography

La Jolla, California

August 17, 1970

Approved:

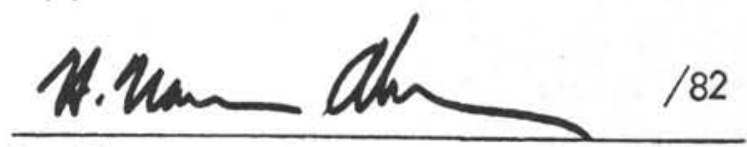

H. Norman Abramson, Director

Department of Mechanical Sciences 
LIST OF ILLUSTRATIONS . . . . . . . . . . . . . . . . . . . . . . . . . iv

NOMENCLATURE ......................... . . . . . . . . . . . . . . . . . . .

1. INTRODUCTION . . . . . . . . . . . . . . . . . . . . . . . . . 1

2. HEAVE DYNAMICS . . . . . . . . . . . . . . . . . . . . . . . . 3

2.1 Dynamic Response of Drill String . . . . . . . . . . . . . . . . . . . . 3

2.2 Ship Response to Swells . . . . . . . . . . . . . . . . . . . . . . . . . 5

2.3 Ship and String Response to a Random Sea . . . . . . . . . . . . . . . . . . . . . . . 6

2.4 Damping Calculations . . . . . . . . . . . . . . . . . . . . . . . . . 8

2.5 Fatigue Calculations . . . . . . . . . . . . . . . . . . . . . . . . . . 11

3. ROLL AND PITCH EFFECTS . . . . . . . . . . . . . . . . . . . . 15

3.1 Guide Shoe (Horn) System . . . . . . . . . . . . . . . . . . . . . 16

3.2 Picalo System . . . . . . . . . . . . . . . . . . . . . . . . . . . . . . 19

4. COMPUTED RESUltS . . . . . . . . . . . . . . . . . . . . . . . . . 23

4.1 Heave Dynamics . . . . . . . . . . . . . . . . . . . . . . . . . . . 23

4.2 Guide Shoe . . . . . . . . . . . . . . . . . . . . . . . . 29

4.3 Picalo . . . . . . . . . . . . . . . . . . . . . . . 31

5. CONCLUSIONS AND RECOMMENDATIONS . . . . . . . . . . . . . . . . . . 35

5.1 Conclusions . . . . . . . . . . . . . . . . . . . . . . 35

5.2 Recommendations for Current Operations . . . . . . . . . . . . . . . . . . . 36

5.3 Recommendations Regarding Future Operations . . . . . . . . . . . . . . . 37

6. COMPUTER PROGRAM DOCUMENTATION . . . . . . . . . . . . . . . . . . . 39

6.1 General . . . . . . . . . . . . . . . . . . . . . . . . . 39

6.2 Input Data . . . . . . . . . . . . . . . . . . . . . . . . . . . . . 40

6.3 Output Information . . . . . . . . . . . . . . . . . . . . . . . . . . . 42

6.4 List of Program Parameters . . . . . . . . . . . . . . . . . . . . . . . . 44

6.5 Program Listing . . . . . . . . . . . . . . . . . . . . . . . . . . . . . 48

6.6 Example Problem . . . . . . . . . . . . . . . . . . . . . . . 49

7. REFERENCES . . . . . . . . . . . . . . . . . . . 63

APPENDIX-DERIVATION OF HEAVE DYNAMICS MODAL SOLUTION . . . . . . . 65 


\section{LIST OF ILLUSTRATIONS}

Figure

Page

2.1.1 Schematic of Drill String . . . . . . . . . . . . . . . . . . . . . . 3

3.1 Section of Drill Pipe in Constrained Bending . . . . . . . . . . . . . . . 15

3.1.1 Schematic of Guide Shoe System and Estimation of Time of Contact . . . . . 17

3.2.1 Schematic of Picalo System ․ . . . . . . . . . . . . . . . . . . . . 19

4.1.1 Heave Stress Response to Sinusoidal Swells . . . . . . . . . . . . . . . . 24

4.1.2 Heave Stress Response to Sinusoidal Swells . . . . . . . . . . . . . . . . 24

4.1.3 Heave Stress Response to Sinusoidal Swells . . . . . . . . . . . . . . . . . 24

4.1.4 Heave Stress Response to Sinusoidal Swells . . . . . . . . . . . . . . . . 24

4.1.5 Heave Stress Response to Sinusoidal Swells . . . . . . . . . . . . . . . . 24

4.1.6 Heave Stress Response to Sinusoidal Swells . . . . . . . . . . . . . . . . 24

4.1.7 Heave Stress Response to Sinusoidal Swells . . . . . . . . . . . . . . . . 25

4.1.8 Heave Stress Response to Sinusoidal Swells . . . . . . . . . . . . . . . . 25

4.1.9 Dynamic Displacement Response to Sinusoidal Swells . . . . . . . . . . . 25

4.1.10 Dynamic Displacement Response to Sinusoidal Swells . . . . . . . . . . . 25

4.1.11 Dynamic Displacement Response to Sinusoidal Swells . . . . . . . . . . . 25

4.1.12 Dynamic Displacement Response to Sinusoidal Swells . . . . . . . . . . . 25

4.1.13 Dynamic Displacement Response to Sinusoidal Swells . . . . . . . . . . . 26

4.1.14 Dynamic Displacement Response to Sinusoidal Swells . . . . . . . . . . . 26

4.1.15 Fatigue Life for Sinusoidal Swells . . . . . . . . . . . . . . . . . . . 26

4.1.16 Fatigue Life for Sinusoidal Swells . . . . . . . . . . . . . . . . . . . 26

4.1.17 Fatigue Life for Sinusoidal Swells . . . . . . . . . . . . . . . . . . . 27

4.1.18 Fatigue Life for Sinusoidal Swells . . . . . . . . . . . . . . . . . . . 27

4.1.19 Fatigue Life for Sinusoidal Swells . . . . . . . . . . . . . . . . . . . 27 $/ 84$ 


\section{LIST OF ILLUSTRATIONS (Cont'd)}

Figure

4.1.20 Fatigue Life for Sinusoidal Swells . . . . . . . . . . . . . . . . . . . 27

4.1.21 Effect of Percent Maximum Stable Sinusoidal Swell on Fatigue Life . . . . . . 28

4.1.22 Heave Stress Response to Random Sea States . . . . . . . . . . . . . . . . . . 28

4.2.1 Fatigue Life of String with Guide Shoe . . . . . . . . . . . . . . . . . 29

4.2.2 Fatigue Life of String with Guide Shoe . . . . . . . . . . . . . . . . . 29

4.2.3 Fatigue Life of String with Guide Shoe . . . . . . . . . . . . . . . . . 30

4.2.4 Fatigue Life of String with Guide Shoe . . . . . . . . . . . . . . . . . 30

4.2.5 Fatigue Life of String with Guide Shoe . . . . . . . . . . . . . . . . . 30

4.2.6 Fatigue Life of String with Guide Shoe . . . . . . . . . . . . . . . . . 30

4.2.7 Effect of Angle of Deviation on Fatigue Life of String with Guide Shoe . . . . 30

4.3.1 Picalo Design Profiles . . . . . . . . . . . . . . . . . . . . . . . . 32

4.3.2 Bending Stresses in Picalo . . . . . . . . . . . . . . . . . . . . . . . 32

4.3.3 Fatigue Life of String with Picalo System . . . . . . . . . . . . . . . . 32

4.3.4 Fatigue Life of String with Picalo System . . . . . . . . . . . . . . . . 32

4.3.5 Fatigue Life of String with Picalo System . . . . . . . . . . . . . . . . 33

4.3.6 Fatigue Life of String with Picalo System . . . . . . . . . . . . . . . . 33

4.3.7 Fatigue Life of String with Picalo System . . . . . . . . . . . . . . . . 33

4.3.8 Fatigue Life of String with Picalo System . . . . . . . . . . . . . . . . 33 


\section{NOMENCLATURE}

Roman

A cross-sectional area of pipe

c damping force per unit length per unit velocity

distance from neutral axis to outer fiber (radius)

$c_{0} \quad$ defined by Eq. (2.14)

$c_{1} \quad$ defined by Eq. (2.9)

C concentrated damping force per unit velocity

$C_{D} \quad$ coefficient of drag

d diameter

D distributed damping force per unit length per unit velocity

cumulative damage

E elastic modulus

F defined by Eq. (2.8)

fractional fatigue damage

g gravitational acceleration

$h \quad$ height of guide shoe

$H \quad$ swell height, double amplitude

I second moment of area of drill pipe section

$k \quad$ added mass coefficient

K corrosion factor

$\ell \quad$ length of drill string

$L \quad$ fatigue life, hours

M concentrated end mass

bending moment

$n \quad$ number of reversed bending cycles number of drag (damping) disks 


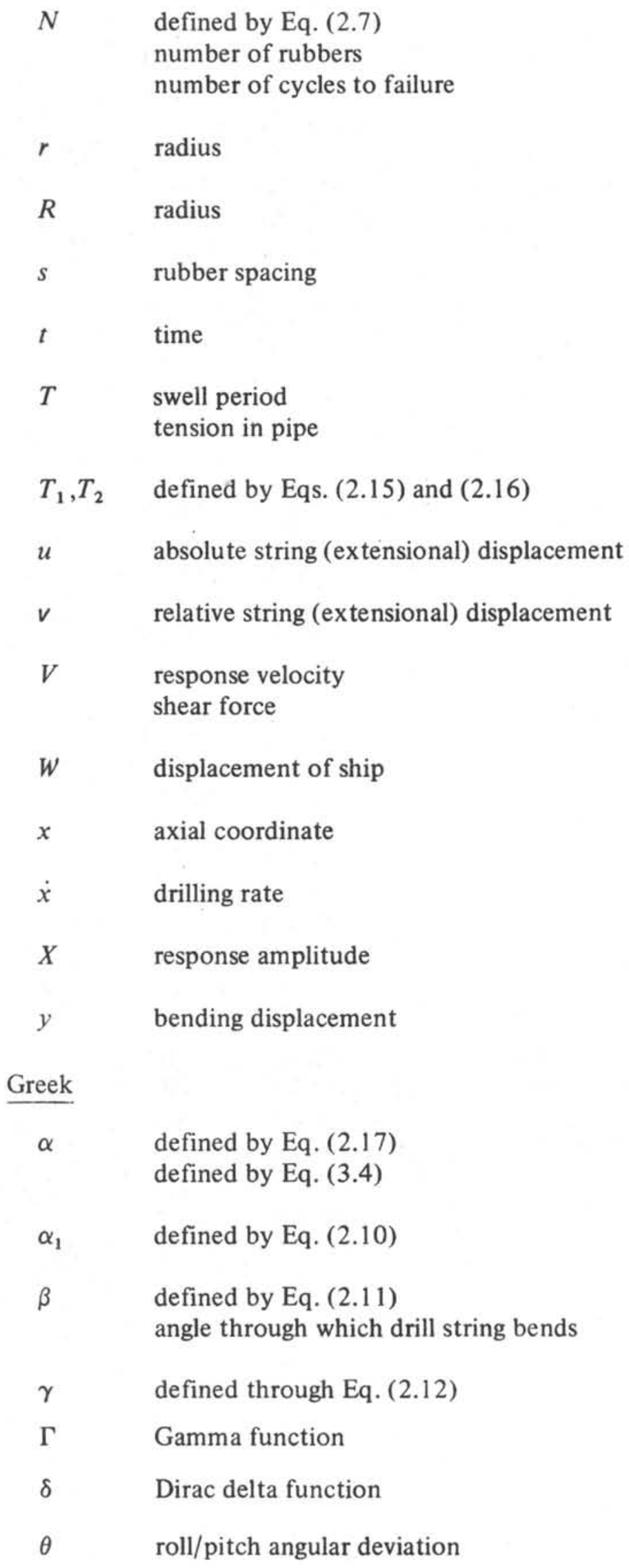




$\begin{array}{ll}\lambda & \text { swell wave length } \\ \mu & \text { distributed mass density of string } \\ \nu & \text { kinematic viscosity } \\ \rho & \text { mass density } \\ \sigma & \text { stress } \\ \varphi & \text { angle through which picalo bends } \\ \Phi & \text { power spectral density } \\ \omega & \text { frequency } \\ \omega_{1} & \text { defined by Eq. (2.13) } \\ \Omega & \text { ship response frequency }\end{array}$

\section{Subscripts}

$\begin{array}{ll}a & \text { added } \\ d & \text { design } \\ e, e q & \text { equivalent } \\ f & \text { fluid } \\ m & \text { maximum } \\ p & \text { pipe } \\ r & \text { rubber } \\ \text { rms } & \text { root mean square } \\ v & \text { vessel }\end{array}$




\section{SECTION 1. INTRODUCTION}

This report contains the final results of a study concerned with determining the dynamic stresses and fatigue life of the drill string system of the Glomar Challenger, Deep Sea Drilling Project. The Challenger as now in use operates with a guide sheet of about $51.7 \mathrm{ft}$ in height, which is installed just below the drilling platform, and which serves the purpose of limiting the bending stresses in the pipe as the ship rolls and pitches in response to sea motions. The guide shoe structure has thus far performed quite satisfactorily in regard to inhibiting excessive bending stresses in the pipe.

However, due to its physical size and "permanent" installation, the guide shoe has presented some rather difficult logistic problems in actual drilling operations. It is not possible to deploy or retract the drill string through the guide shoe with the re-entry tools and equipment at the lower end of the string, and it will frequently be necessary to keel-haul such equipment at drill sites where multiple core bit runs are required. This process of keel-hauling is both time-consuming and dangerous. Hence, it would be highly desirable to find an attractive solution which would make this phase of the operation unnecessary. This objective became the motivation of this program. It was desired to define as accurately as possible the loading environment on the drill string, the predicted fatigue life of the string under operating conditions, and to interpret these predictions in terms of alternative concepts for limiting the bending in the string.

The work of this program was based upon two reports submitted to Global Marine. Incorporated, by Dr. T. Vreeland, Jr. $(1.1,1.2)$, consultant to Global Marine. These reports dealt, respectively, with the Heave Dynamics of the drill string and with the effects of roll and pitch ship motions on the drill string. These reports, and the results therein contained, served as a basis for design assurance of the drill string/guide shoe concept now being employed on the Challenger operations.

The first objective of the present work was to review these reports and to see if it was possible to remove any unusual conservatism in the stress and life predictions. Then, computer programs were written to solve the resulting equations, and the computed results were assessed in terms of alternate concepts to the guide shoe configuration. The overall analysis procedures set forth in the reports by Vreeland were found to be quite thorough and satisfactory. The present report. in fact. adheres quite closely to his presentation, and the mathematical notation is very nearly identical to that employed by Vreeland. There were, however, a number of departures made in the theoretical work, and, hence, the final stress and life prediction equations differ rather substantially in some cases from those presented by Vreeland. As a result of these differences in the present analysis vis-a-vis Dr. Vreeland's, the present results differ somewhat from his. In general, however, the differences between the two sets of results are not substantial and at any rate do not lead to contradictions with any of Vreeland's overall study conclusions.

The analytical formulations of this study are presented in Section 2. Heave Dynamics. and Section 3, Roll and Pitch Effects. The mathematical calculations therein contained are given in rather complete detail. In order to facilitate the reading of these sections. much of the detail derivations and ancillary information are relegated to smaller print and are presented as they occur. Section 4 presents the computed results for the Heave Dynamics, and for roll and pitch effects with both the guide shoe and picalo systems. These results are summarized in Section 5 and, based upon these summaries, a number of recommendations are made concerning possible alternate concepts to 
the present guide shoe system used on the Glomar Challenger. Section 6 contains a complete computer program documentation. Also included in this section are sample runs which may be used in checking out the numerical program on other computer systems. Appendix A contains a detailed derivation of the modal solution to the Heave Dynamics problem of the drill string. This solution is rather lengthy and the resulting equations differ somewhat in form from those presented by Vreeland(1.1) 


\section{SECTION 2: HEAVE DYNAMICS}

In this section, there is presented an analysis of the dynamic response of the drill string to heave excitation. The dynamic stresses and displacements are computed both for deterministic and random sea states, and the fatigue life of the drill string is estimated on the basis of these stress computations.

The analysis is based on a model of the drill string assembly as a uniform elastic rod with a concentrated mass at the lower end representing the drill collars, drill, drag disks, and landing base. The string is excited harmonically at the upper end. Damping is included to account for the dissipation of the rod, rubbers, drag disks, and landing base. The modal solution of the differential equation of motion is deferred to Appendix A so as not to detract from the orderly presentation of results given in this section. Other derivations, all of which are short, are set in small print as encountered.

\subsection{Dynamic Response of Drill String}

The drill string is shown schematically in Figure 2.1.1.The string is excited at the top by a time-dependent displacement $W(t)$. The absolute displacement of a segment of the string is $u(x, t)$, where $x$ is the space coordinate measured from the top of the string. The rod is considered to be uniform along its length in modulus, cross-sectional area, density, and damping capacity. With these assumptions, the response is given by solutions of the differential equation.

$$
\rho A=\frac{\partial^{2} u}{\partial t^{2}}=A E \frac{\partial^{2} u}{\partial x^{2}}-c \frac{\partial u}{\partial t}
$$

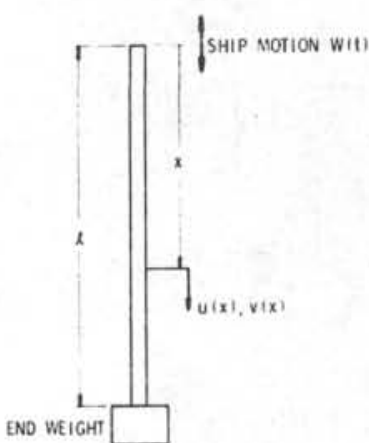

Figure 2.1.1-Schematic of Drill String

In this equation, $\rho, A, E$, and $c$ are, respectively, the mass density, cross-sectional area, modulus, and damping force of the string (see Nomenclature). To account for both distributed and concentrated mass and damping, the following quantities are defined:

$$
\begin{aligned}
\rho A & =\mu A+M \delta(x-\ell) \\
c & =D+C \delta(x-\ell)
\end{aligned}
$$

where $\delta(x-\ell)$ is the Dirac delta function. The boundary conditions which must be imposed on solutions of Eq. (2.1) are:

$$
\begin{gathered}
u(0, t)=W(t) \\
\left.\frac{\partial u}{\partial x}\right|_{x=\ell}=-\left.\frac{M}{A E} \frac{\partial^{2} u}{\partial t^{2}}\right|_{x=\ell}
\end{gathered}
$$

The first of these is to insure the prescribed displacement at the top of the string, while the second balances the internal and inertia forces at the end of the string, to which the concentrated mass is affixed.

The problem just posed has been solved by a modal analysis for the time-dependent and maximum displacement, and stress. The analysis uses only the first vibration mode of the string. 
This approximation is acceptable for a long string under low-frequency excitation, as in the case of the drill string. The derivation of the response equations given below is presented in Appendix A. Reference should be made to the damping calculations later in this section and to Table 2.4.1 for correct interpretations of the constants in the following equations.

$$
\begin{gathered}
\sigma_{m}(x)=\left(\frac{E N c_{1} \alpha_{1}}{\ell}\right) \cos \left(\frac{\alpha_{1} x}{\ell}\right) \\
v_{m}(x)=N c_{1} \sin \left(\frac{\alpha_{1} x}{\ell}\right) \\
u_{m}(\ell)=\left\{\left[W_{0}+\frac{N}{F}\left(T_{1} \cos \alpha-T_{2} \sin \alpha\right)\right]^{2}+\frac{N^{2}}{F^{2}}\left(T_{1} \sin \alpha+T_{2} \cos \alpha\right)^{2}\right\}^{1 / 2}
\end{gathered}
$$

where:

$$
\begin{aligned}
& W(t)=W_{0} \sin \Omega t \\
& N=F\left\{\left[\frac{M \omega_{1}^{2} c_{1}^{2}}{\beta}\left(\frac{1}{2}+\frac{1}{4 \alpha_{1}} \sin 2 \alpha_{1}\right)-\frac{\Omega^{2}}{\beta}\right]^{2}+C^{2} \Omega^{2} c_{1}^{4}\left[\frac{\gamma}{4}\left(2-\frac{1}{\alpha_{1}} \sin 2 \alpha_{1}\right)+\sin ^{2} \alpha_{1}\right]^{2}\right\}^{-1 / 2} \\
& F^{2}=W_{0}^{2} c_{1}^{2}\left\{\frac{M^{2} \Omega^{4}}{\beta^{2}}\left[\frac{1}{\alpha_{1}}\left(1-\cos \alpha_{1}\right)+\beta \sin \alpha_{1}\right]^{2}+C^{2} \Omega^{2}\left[\frac{\gamma}{\alpha_{1}}\left(1-\cos \alpha_{1}\right)+\sin \alpha_{1}\right]^{2}\right\} \\
& c_{1}=\left[M\left(\frac{1}{2}-\frac{1}{4 \alpha_{1}} \sin 2 \alpha_{1}+\beta \sin ^{2} \alpha_{1}\right)\right]^{-1 / 2} \\
& \operatorname{ctn} \alpha_{1}=\beta \alpha_{1} \\
& \beta=\frac{M}{\mu A \ell} \\
& \gamma=\frac{D \ell}{C} \\
& \omega_{1}=\frac{\alpha_{1} c_{0}}{\ell} \\
& c_{0}^{2}=\frac{E}{\mu} \\
& T_{1}=\frac{M W_{0} c_{1}^{2} \Omega^{2}}{\beta}\left[\frac{1}{\alpha_{1}}\left(1-\cos \alpha_{1}\right)+\beta \sin \alpha_{1}\right] \sin \alpha_{1} \\
& T_{2}=C W_{0} c_{1}^{2} \Omega\left[\frac{\gamma}{\alpha_{1}}\left(1-\cos \alpha_{1}\right)+\sin \alpha_{1}\right] \sin \alpha_{1} \\
& \alpha=\operatorname{Tan}^{-1}\left\{\frac{C c_{1}^{2} \Omega \beta\left\{(\gamma / 4)\left[2-\left(1 / \alpha_{1}\right) \sin 2 \alpha_{1}\right]+\sin ^{2} \alpha_{1}\right\}}{M \omega_{1}^{2} c_{1}^{2}\left[(1 / 2)+\left(1 / 4 \alpha_{1}\right) \sin 2 \alpha_{1}\right]-\Omega^{2}}\right\}
\end{aligned}
$$

These equations enable one to determine the dynamic stress and displacement for a harmonic sea state for any set of drill string parameters. 


\subsection{Ship Response to Swells}

Swells of height $H$ (double amplitude) and frequency $\Omega$ cause heave motions of the vessel which can be expressed as

$$
W(t)=H_{v}(\Omega) H \sin \Omega t
$$

where $H_{v}(\Omega)$ is the transfer function for the vessel. Model tests for vessel response to $45^{\circ}$ quartering swells (conservative design practice) have shown that a good approximation to the transfer function for the vessel is

$$
H_{v}(\Omega)=0.08(T-2), \quad 2<T<14
$$

where $T=2 \pi / \Omega$ is the swell period in seconds.

It is necessary now to derive an expression for the maximum swell height for a given swell period. There are two ways to proceed. Strictly speaking, the maximum swell height is to be found on the basis of a trochoidal wave form. Such an analysis gives the following relationship for the maximum stable swell height:

$$
H_{\mathrm{max}}=1.30 T^{2}
$$

This relationship, however, probably represents overly-conservative design practice, since drilling operations are not likely to be done in seas of trochoidal form ("rough" seas) with wave heights high enough to be damaging to the drill string. to be

Equation $(2.20)$ can be derived as follows. Lamb(2.1), p. 417, shows the finite-amplitude surface wave velocity

$$
\begin{aligned}
c & =\sqrt{\frac{g}{k}\left(1+k^{2} H_{\max }^{2}\right)} \\
& =\sqrt{\frac{\lambda g}{2 \pi}\left[1+\left(\frac{2 \pi H_{\max }}{\lambda}\right)^{2}\right], \quad \text { since } k=\frac{2 \pi}{\lambda}}
\end{aligned}
$$

In these expressions, $c$ is the wave velocity, $g$ the gravitational acceleration constant, $\lambda$ the wave length, and $H_{\max }$ the maximum wave amplitude. Now, since $\lambda=c T$ :

$$
\lambda=\frac{g T^{2}}{2 \pi}\left[1+\left(\frac{2 \pi H_{\max }}{\lambda}\right)^{2}\right]
$$

Finally, the ratio of wave amplitude to wave length, $H_{\max } / \lambda$, is to be found in the footnote on p. 418 of Lamb (due to a printing error, the decimal is missing):

$$
\frac{H_{\max }}{\lambda}=0.142
$$

for trochoidal wave profiles. Thus, on substituting,

$$
\begin{aligned}
& H_{\max }=0.142 \frac{g T^{2}}{2 \pi}-\left\{1+|2 \pi(0.142)|^{2}\right\} \\
& H_{\max }=1.30 T^{2}
\end{aligned}
$$

A somewhat more realistic relationship may be found by assuming a sinusoidal wave profile. For the sinusoidal wave, the maximum stable swell height is found to be

$$
H_{\max }=0.817 T^{2}
$$


This is the relationship which has been used as the basis of the heave dynamics loading environment for purposes of this report. It turns out, however, that the maximum stable sinusoidal swell is unconservative as a design criterion, for fractional values of the coefficient 0.817 lead to higher dynamic stresșes and shorter fatigue lives. This point is discussed in more detail in Section 4. Computed Results.

Equation $(2.21)$ can be found very simply by postulating that, at the crest of the maximum stable swell, the pressure is zero, so that the acceleration and gravitational forces exactly annihilate each other:

$$
\ddot{H}=g
$$

thus,

$$
\begin{gathered}
\Omega^{2} H_{\text {max }}=g \\
H_{\text {max }}=\frac{g}{\Omega^{2}}=\frac{g T^{2}}{(2 \pi)^{2}}=0.817 T^{2} \quad(\mathrm{ft})
\end{gathered}
$$

Combining Eqs. (2.18) and (2.21), there results the following expression for the maximum vessel response as a function of sea period:

$$
W_{\max }=0.0653(T-2) T^{2}
$$

The question arises as to whether or not one is justified in ignoring the force supplied by the drill string when computing the ship response to swells, as has been done in this report. A simple calculation will show that the ship displacement due to the drill string force is insignificant with respect to the ship displacement in swells, thus justifying the assumption. The dynamic force imparted to the vessel by the string is $F_{S}=\sigma A=5.80 \sigma$, where $\sigma$ is the dynamic stress and a $19.5 \mathrm{lb} / \mathrm{ft}$ string has been assumed. This force creates a vertical displacement of the ship, which can be estimated by

$$
W_{s}=\frac{F_{s}}{\left(M+M_{a}\right) \Omega^{2}}
$$

where $M$ and $M_{a}$ are, respectively, the actual mass and the added mass of the ship, and $\Omega$ is the ship frequency:

$$
\begin{gathered}
M=\frac{13.4 \times 10^{6}}{32.2}=0.416 \times 10^{6} \\
M_{a}=\pi \rho b^{2} \ell=\pi\left(\frac{64.4}{32.2}\right)(65)^{2}(400)=10.6 \times 10^{6} \\
\Omega=\frac{2 \pi}{T}=1.257 \quad(\text { for } T=5 \mathrm{sec} \text { ) }
\end{gathered}
$$

Thus, $w_{s}=3.34 \times 10^{-7} \sigma$. The vertical displacement as calculated without consideration of the drill string, $w_{a}$ is

$$
w_{a}=0.08(T-2)\left(0.817 T^{2}\right)=4.9 \mathrm{ft}=58.9 \text { inches }
$$

Thus, comparing $w_{s}$ with $w_{a}$ :

$$
\frac{w_{s}}{w_{a}}=5.67 \times 10^{-9} \sigma
$$

which is insignificant for any realistic value of $\sigma$. The same conclusion holds for other assumptions regarding $M_{a}$ and $T$ than those assumed here.

\subsection{Ship and String Response to a Random Sea}

In this section, expressions for the root mean square ( $\mathrm{rms}$ ) values of the maximum stress in the drill string, period of the stressing, and displacement of the bottom of the string, are presented. The following customary assumptions are used: 
(1) The sea motion is weakly stationary

(2) The sea motion is Gaussian

(3) The ship transfer function is linear.

Under these three assumptions, the excitation of the drill string is Gaussian and weakly stationary. The displacement, velocity, and acceleration power spectral densities of the vessel response are defined in terms of the power spectral density of the sea, $\Phi_{S S}$, as

$$
\begin{aligned}
& \Phi_{W W}(\omega)=\Phi_{S S}(\omega)\left|H_{v}(\omega)\right|^{2} \\
& \Phi_{\dot{w} \dot{w}}(\omega)=\omega^{2} \Phi_{S S}(\omega)\left|H_{v}(\omega)\right|^{2}
\end{aligned}
$$

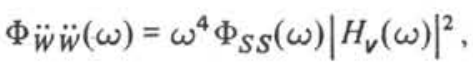

respectively. In these expressions, $\omega$ is the excitation frequency in radians/second. $\Phi_{S S}$ is the power spectral density of the sea wave height, and $H_{v}(\omega)$ is the ship transfer function. Eq. (2.19).

The power spectral density of the drill string response is obtained by finding $\Phi_{\eta \eta} \dot{w}$ and $\Phi_{\eta \eta} \ddot{w}$. respectively, the power spectral densities resulting from the $\dot{W}$ and $\ddot{W}$ excitations. These functions are:

$$
\begin{gathered}
\Phi_{\eta \eta \dot{w}}=c_{1}^{2} C^{2}\left[\frac{\gamma}{\alpha_{1}}\left(1-\cos \alpha_{1}\right)+\sin \alpha_{1}\right]^{2}\left|H_{S}(\omega)\right|^{2} \Phi_{\dot{w} \dot{w}}(\omega) \\
\Phi_{\eta \eta \ddot{w}}=\frac{c_{1}^{2} M^{2}}{\beta^{2}}\left[\frac{1}{\alpha_{1}}\left(1-\cos \alpha_{1}\right)+\beta \sin \alpha_{1}\right]^{2}\left|H_{S}(\omega)\right|^{2} \Phi_{\ddot{w} \ddot{w}(\omega)}
\end{gathered}
$$

where

$$
\begin{aligned}
\left|H_{S}(\omega)\right|^{2} & =\frac{N^{2}}{F^{2}} \\
& =\left\{\left[\frac{M \omega_{1}^{2} c_{1}^{2}}{\beta}\left(\frac{1}{2}+\frac{1}{4 \alpha_{1}} \sin 2 \alpha_{1}\right)-\frac{\omega^{2}}{\beta}\right]^{2}+C^{2} \omega^{2} c_{1}^{4}\left[\frac{\gamma}{4}\left(2-\frac{1}{\alpha_{1}} \sin 2 \alpha_{1}\right)+\sin ^{2} \alpha_{1}\right]^{2}\right\}^{-1}
\end{aligned}
$$

Note that $\Phi_{\eta \eta \dot{w}}$ and $\Phi_{\eta \eta \ddot{w}}$ are components of the response power spectral density and are not themselves the velocity and acceleration power spectral densities.

With these preliminaries, the rms values of top end stress, lower end relative displacement. and frequency are given as follows:

$$
\begin{gathered}
\sigma_{\mathrm{rms}}(0)=E \eta_{\mathrm{rms}} c_{1} \alpha_{1} / \ell \\
v_{\mathrm{rms}}(\ell)=\eta_{\mathrm{rms}} c_{1} \sin \alpha_{1} \\
\omega_{\mathrm{rms}}=\left[\int_{0}^{\infty} \omega^{2}\left(\Phi_{\eta \eta \dot{w}}+\Phi_{\eta \eta} \ddot{w}\right) \mathrm{d} \omega / \eta_{\mathrm{rm} \mathrm{s}}^{2}\right]^{1 / 2}
\end{gathered}
$$


where

$$
\eta_{\mathrm{rms}}^{2}=\int_{0}^{\infty}\left(\Phi_{\eta \eta \dot{w}}+\Phi_{\eta \eta} \ddot{w}\right) \mathrm{d} \omega
$$

These quantities are all determined completely from the known dynamic drill string response and ship transfer function, once the sea power spectral density has been specified.

The power spectral density of the sea state, $\Phi_{S S}$, may be described either by data taken directly from a spectral analysis, or by an approximating function which characterizes the main features of the sea states of interest. In this report, the second alternative has been chosen. Ochi(2.2) has presented power spectral density data typical of those encountered in moderate to heavy seas. The energy content of these spectra lies principally in the band $0.2<\omega<1.0$. A reasonable approximation to these data is the function

$$
\Phi_{S S}(\omega)=A\left\{1 .-\cos \left[\frac{5 \pi}{2}(\omega-0.2)\right]\right\}^{2}
$$

The constant $A$ corresponds to the maximum amplitude, in $\mathrm{ft}^{2} / \mathrm{rad}$ of the power spectral density and occurs at $\omega=0.6$. The integrated spectral energy is

$$
\int_{0.2}^{1.0} \Phi_{S S}(\omega) \mathrm{d} \omega=\frac{6 A}{5}
$$

so that $A$ is $5 / 6$ of the integrated spectral energy in units of $\mathrm{ft}^{2} \mathrm{sec}$.

\subsection{Damping Calculations}

Damping is introduced into the drill string system through the drag and added mass effects of the drill string, rubbers, drag disks, and end mass. Each of these effects has an important influence on the dynamic response of the string.

The differential equation of motion of the system, as given before [Eq. (2.1)], is

$$
\mu A \frac{\partial^{2} u}{\partial t^{2}}+M \delta(x-\ell) \frac{\partial^{2} u}{\partial t^{2}}=A E \frac{\partial^{2} u}{\partial x^{2}}-D \frac{\partial u}{\partial t}-C \delta(x-\ell) \frac{\partial u}{\partial t}
$$

The drag coefficient $D$ is composed of contributions $D_{1}$ and $D_{2}$ from the drill pipe and from the rubbers. In addition, the rubbers are considered to contribute an added mass effect to the first term in the differential equation above. The drag disks at the lower end of the string give rise both to the drag coefficient $C$ and an added mass effect to the second term in the differential equation.

Consider first the distributed damping coefficient $D: D=D_{1}+D_{2}$, where $D_{1}$ and $D_{2}$ are the velocity-damping coefficients of the drill string and the rubbers, respectively. The drill string is assumed to oscillate harmonically, so that at any point the displacement $X$ and velocity $V$ are. respectively,

$$
\begin{gathered}
X(t)=X_{o} \sin \omega t \\
V(t)=X_{o} \omega \cos \omega t
\end{gathered}
$$


It will be shown below that $D_{1}$ and $D_{2}$ are expressible as

$$
\begin{gathered}
D_{1}=\sqrt{2 \nu \omega} \pi r \rho_{f} \\
D_{2}=\frac{\rho_{f}}{2} n_{2} C_{D}\left(\frac{\pi d_{r}^{2}}{4}\right) X_{0} \omega
\end{gathered}
$$

In these expressions, $\nu$ is the kinematic viscosity, $r$ the radius of the drill pipe, $\rho_{f}$ the mass density of the sea water, $n_{2}$ the number of rubbers per unit length of pipe, $C_{D}$ the coefficient of drag of a flat disk, and $d_{r}$ the diameter of the rubber. From potential flow theory, the coefficient of $\operatorname{drag} C_{D}$ for a thin disk is $C_{D}=1.12$ for Reynold's numbers $N_{R}>10^{2}$, as in the present case.

To derive Eqs. (2.36) and (2.37), reference is made first to Lamb(2.1), who shows that the force/unit area $f(t)$ that a plate oscillating harmonically about the $x-y$ plane imparts to a semi-infinite pipe $y \geqslant 0$ is:

$$
f(t)=\rho_{f} \sqrt{\nu \omega} X_{0} \omega \cos \left(\omega t+\frac{\pi}{4}\right)
$$

The work/unit cycle done by the plate on the pipe is

$$
\begin{aligned}
\text { work } & =\int_{\text {cycle }} f(t) \mathrm{d} x=\int_{\text {cycle }} f(t) X_{0} \omega \cos \omega t \mathrm{~d} t \\
& =\int_{0}^{2 \pi / \omega} \rho_{f} \sqrt{\nu \omega}\left(X_{0} \omega\right)^{2} \cos \left(\omega t+\frac{\pi}{4}\right) \cos \omega t \mathrm{~d} t=\rho_{f} \sqrt{\nu \omega}\left(X_{0} \omega\right)^{2} \frac{\sqrt{2} \pi}{2 \omega}
\end{aligned}
$$

This work/unit cycle is to be identical with an "equivalent" in-phase damping:

$$
\rho_{f} \sqrt{\nu \omega}\left(X_{0} \omega\right)^{2} \frac{\sqrt{2 \pi}}{2 \omega} \equiv \int_{\text {cycle }} D_{e} X_{0} \omega \cos \omega t \mathrm{~d} x=D_{e}\left(X_{0} \omega\right)^{2} \int_{0}^{2 \pi / \omega} \cos ^{2} \omega t \mathrm{~d} t=\frac{\pi D_{e}\left(X_{0} \omega\right)^{2}}{\omega}
$$

Thus, $D_{e}=\sqrt{2} / 2 \rho_{f} \sqrt{\nu \omega}$. The damping coefficient per unit length, $D_{1}$, then is found by multiplying the damping coefficient per unit area, $D_{e}$, by the circumference of the drill pipe, $2 \pi r$. This gives the result

$$
D_{1}=\sqrt{2 \nu \omega} \pi r \rho_{f}
$$

stated as Eq. (2.36).

The rubbers are assumed distributed uniformly along the drill string length, and their effective damping coefficient, $D_{2}$, may be computed in the following manner. The damping force $F_{2}$ is customarily taken as proportional to the square of the velocity:

$$
\begin{aligned}
F_{2}=C_{D} \frac{1}{2} \rho_{f}\left(\frac{\pi d_{r}^{2}}{4}\right) v|V| & =C_{D} \frac{1}{2} \rho_{f}\left(\frac{\pi \mathrm{d}_{r}^{2}}{4}\right)\left(X_{0} \omega\right)^{2} \cos \omega t|\cos \omega t| \\
& \approx C_{D} \frac{1}{2} \rho_{f}\left(\frac{\pi d_{r}^{2}}{4}\right)\left(X_{0} \omega\right)^{2} \cos \omega t
\end{aligned}
$$

The indicated approximation is justified by the close similarity of the functions $\cos \theta|\cos \theta|$ and $\cos \theta$. For $N$ rubbers, the total damping force is $N F_{2}$, and the damping constant per unit length is, therefore,

$$
D_{2}=\left(\frac{N}{\ell}\right) \frac{F_{2}}{V}=n_{2} C_{D} \frac{1}{2} \rho_{f}\left(\frac{\pi d_{r}^{2}}{4}\right) x_{0} \omega
$$

where $n_{2}=N / \ell$

The rubbers also contribute an added mass effect because of the mass of water they must displace during oscillation. This added mass effect shows up as an added term to the 
coefficient $\mu A$ in the leading term of the differential equation of motion of the drill string. The acceleration force for one rubber is

$$
F_{3}=k \rho_{f} B \frac{\partial^{2} u}{\partial t^{2}}=k \rho_{f}\left(\frac{\pi d_{r}^{3}}{6}\right) \frac{\partial^{2} u}{\partial t^{2}}
$$

where the volume of the added mass effect is assumed to be that of a sphere having the same diameter as the rubber. The added mass coefficient $k$ is taken to be $2 / \pi$, and, hence, the added mass of the rubbers, $M_{a} \partial^{2} u / \partial t^{2}$, is

$$
M_{a} \frac{\partial^{2} u}{\partial t^{2}}=n_{2} \rho_{f} \frac{d_{r}^{3}}{3} \frac{\partial^{2} u}{\partial t^{2}}
$$

The added mass coefficient $k$ can be derived by considering the kinetic energy of the system

$$
F V=\frac{\mathrm{d} T}{\mathrm{~d} t}=M_{a} V \frac{\mathrm{d} V}{\mathrm{~d} t}
$$

where $F, V$, and $T$ are, respectively, the force, velocity, and kinetic energy of the added mass. The kinetic energy $T=$ $(4 / 3)\left(\rho_{f} r^{3} V^{2}\right)$ from Milne-Thompson ${ }^{(2.3)}$. Thus,

$$
M_{a}=\frac{1}{V} \frac{\mathrm{d} T / \mathrm{d} t}{\mathrm{~d} V / \mathrm{d} t}=\frac{1}{V} \frac{\mathrm{d} T}{\mathrm{~d} V}=2 \rho_{f} \cdot \frac{4}{3} r^{3}=\frac{2}{\pi} \cdot \text { (mass of sphere) }
$$

In terms of the earlier notation,

$$
M_{a}=\frac{2}{\pi} \cdot(\text { mass of sphere })=k \cdot(\text { mass of sphere })
$$

and, hence,

$$
k=\frac{2}{\pi}=0.637
$$

This, incidentally, corresponds with the value stated in the paper by Iversen and Balent ${ }^{(2.4)}$.

The drag disks at the lower end of the drill string also contribute damping and added mass effects. It is assumed that if more than a single drag disk is placed at the end of the string. they are separated enough so that their effects do not interact, yet they are close enough together so that they can be considered "lumped" with respect to the string length.

The coefficient of damping $C$ is computed exactly as before for the damping coefficient $D_{2}$ of the rubbers. The result is

$$
C=n C_{D} \frac{1}{2} \rho_{f}\left(\frac{\pi d_{d}^{2}}{4}\right) X_{0} \omega
$$

where $n$ is the number of drag disks and $d_{d}$ is the diameter (actual or effective) of the drag disks.

The added mass term, again, is computed just as was done for the rubbers. The added mass term is

$$
M_{a} \delta(x-\ell) \frac{\partial^{2} u}{\partial t^{2}}=n \rho_{f} \frac{d_{d}^{3}}{3} \delta(x-\ell) \frac{\partial^{2} u}{\partial t^{2}}
$$

From these results, the interpretations listed in Table 2.4.1 are to be given to the coefficients in the original differential equation of motion, Eq. (2.35). 
These are the values of the coefficients for the modal analysis solution, Eqs. (2.4) to (2.17).

It should be noted that the damping coefficients depend both upon frequency $\omega$ and amplitude $X_{o}$. Therefore, an iterative solution was used in the response calculations, wherein the damping for a particular frequency was first calculated using an assumed amplitude, the amplitude was calculated using the response analysis presented in this section, and the damping constant recalculated using the new value for amplitude. This process was found to converge rapidly. The effect of variation in amplitude along the string on the distributed damping (due to the amplitude dependence of damping) was taken into account by assuming a mean amplitude of $u(\ell) / \sqrt{2}$ for the case of swells, and $v(\ell) / \sqrt{2}$ for the case of the random sea.

\subsection{Fatigue Calculations}

The drill pipe employed on the Glomar Challenger drilling operations is Grade S-135 Drill Pipe. having average yield and ultimate strength values of about 145.0 and $159.3 \mathrm{ksi}$, respectively*. The fatigue properties of this type of material were discussed in an article by Rollins (2.5), who summarized much of the recent fatigue data generated for S-135 drill pipe material. The data presented in the article by Rollins are used as a basis for describing, quantitatively. the fatigue behavior of the drill string for purposes of this report.

Rollins notes that the endurance limit in reversed bending for S-135 drill pipe in air is about 80 $\mathrm{ksi}$, whereas there is no apparent endurance limit for specimens tested in sea water. For purposes of comparison, however, at $10^{6}$ cycles, the reversed bending fatigue strengths are about $88 \mathrm{ksi}$ in air and about $29 \mathrm{ksi}$ in sea water, a reduction of approximately $2 / 3$.

A conservative approximation to the data given by Rollins can be made for zero mean stress fatigue loading, assuming linearity between stress $\sigma$ and the logarithm of $N$, the number of cycles to failure. The expression used in this report is

$$
N(\sigma)=\left(\frac{11.023 \times 10^{5}}{\sigma}\right)^{3.82}
$$

To account for the fact that a mean stress does exist in the drill pipe, use is made of the well-known Goodman equation to define an "equivalent" stress level $\sigma_{\mathrm{eq}}$ having no mean stress: see Madayag(2.6):

$$
\sigma_{\mathrm{eq}}=\frac{\sigma}{K\left(1-\sigma_{s} / \sigma_{u}\right)}
$$

*These values were averages of nineteen specimens, whose strengths ranged from 136.6 to $153.6 \mathrm{ksi}$ in yield and from $153.7 \mathrm{ksi}$ to 166.4 in ultimate. 
In this expression, $\sigma$ is the alternating stress amplitude, $\sigma_{s}$ the mean (static) stress in the pipe, $\sigma_{u}$ the ultimate tensile strength, and $K$ an empirical factor to account for the corrosive nature of the sea water environment. For all calculations presented in this report, a factor $K=0.9$ was used. In view of Eq. (2.42). Eq. (2.41) becomes

$$
N(\sigma)=\left(\frac{11.023 \times 10^{5}}{\sigma_{\mathrm{eq}}}\right)^{3.82}
$$

If the ship operates in a sea having swells of essentially constant amplitude, the life in hours, $L$. may conveniently be calculated by means of the formula:

$$
L=\frac{2 \pi N(\sigma)}{3600 \omega_{1}}
$$

where $\omega_{\mathrm{i}}$ is given by Eq. (2.13).

For the random sea state, the analysis of Miles(2.7) provides a basis for computing the string life. Miles defines an equivalent stress of constant amplitude, $\sigma_{r}$ which produces the same fatigue damage as the root-mean-square stress $\sigma_{\mathrm{rms}}$ induced in the string by the random sea. This equivalent stress is found by adopting the linear cumulative damage concept ("Minér's rule") and takes the form

$$
\sigma_{r}=\sqrt{2}\left\{\Gamma\left(1+\frac{m}{2}\right)\right\}^{1 / m} \sigma_{\mathrm{rms}}
$$

where $\Gamma$ is the gamma function and $m$ is the exponent in Eq. (2.41). In the present study, where $m$ $=3.82$,

$$
\sigma_{r}=1.662 \sigma_{\mathrm{rms}}
$$

The number of fatigue cycles to failure is, then,

$$
N(\sigma)=\left[\frac{11.023 \times 10^{5} K\left(1-\sigma_{s} / \sigma_{u}\right)}{\sqrt{2} \sigma_{\mathrm{rms}}}\right]^{m}\left\{\Gamma\left(1+\frac{m}{2}\right)\right\}^{-1}
$$

and the fatigue life in hours is

$$
L=\frac{2 \pi N(\sigma)}{3600 \omega_{\mathrm{rms}}}
$$

where $\omega_{\mathrm{rms}}$ is found via Eq. (2.31).

When encountering sea states (deterministic or random) which are not constant in time but vary, the concept of damage accumulation is necessary to determine the life of the drill string. The simplest and most useful of the several damage theories proposed is the linear cumulative damage principle associated with the names Palmgren and Miner. In this theory, a damage ratio is defined as the ratio of cycles experienced at a given stress level, $n$, to the cycles required to fail the drill pipe at that same stress level, $N$. As stress cycles accumulate at various stress levels, the damage ratios are added up to yield the damage fraction $D$ :

$$
/ 100 \quad D=\sum_{i} \frac{n_{i}}{N_{i}}
$$


Failure is assumed to occur when the damage fraction $D$ reaches unity, $D=1$. (In practice, failures are found to occur for $D$ as little as 0.5 and as high as 5 , or more.) Thus, if the subscript $i$ denotes the ith of several different stress levels and associated number of applied cycles, the cumulative damage is

$$
\begin{gathered}
D=\frac{1}{\left(11.023 \times 10^{5}\right)^{3.82}} \sum_{i} n_{i} \sigma_{i}^{3.82}=8.47 \times 10^{-24} \sum_{i} n_{i} \sigma_{i}^{3.82} \\
D=\frac{2^{3.82 / 2} \Gamma[1+(3.82 / 2)]}{\left[11.023 \times 10^{5} K\left(1-\sigma_{s} / \sigma_{u}\right)\right]^{3.82}} \sum_{i} n_{i} \sigma_{\mathrm{rms}}^{3.82}=\frac{8.61 \times 10^{-23}}{\left(1-\sigma_{s} / \sigma_{u}\right)^{3.82}} \sum_{i} n_{i} \sigma_{\mathrm{rms}}^{3.82}
\end{gathered}
$$

for the deterministic and random seas, respectively. The concept of linear cumulative damage can be very useful in keeping records of the history of drill pipe segments, thereby to estimate the remaining useful life. 


\section{SECTION 3: ROLL AND PITCH EFFECTS}

As the ship rolls and pitches in response to wave action, the bending in the upper portion of the drill string must be controlled by some means to prevent string breakage due to excessive bending stresses. Bending of the drill string is also associated with the fact that the ship does not rest precisely over the drilling target. To limit the bending stresses in the string, a constraining system of some kind must be employed. This report considers the design parameters associated with two possible systems:

(1) Guide shoe (horn)

(2) Picalo.

Before considering each of these concepts in some detail, a few mathematical results common to both will be derived.

The drill pipe is considered as a uniform tubular Bernoulli-Euler beam, subject to tension and bending. The pipe is fitted with rubbers at a spacing $s$, so that only the rubbers may contact the bending constraint system. Within the usual assumptions of elementary beam theory, the deflection curve between each rubber is described by the differential equation

$$
E I_{p} \frac{\mathrm{d}^{2} y}{\mathrm{~d} x^{2}}-T y=M(x)
$$

together with the boundary conditions

$$
\begin{gathered}
\text { at } \quad x=0: \quad y=0, \frac{\mathrm{d} y}{\mathrm{~d} x}=0 \\
\text { at } x=s: \quad y=\frac{s^{2}}{2 R}, \frac{\mathrm{d} y}{\mathrm{~d} x} \simeq \frac{\mathrm{d} y}{\mathrm{~d} s}=\frac{s}{R}
\end{gathered}
$$

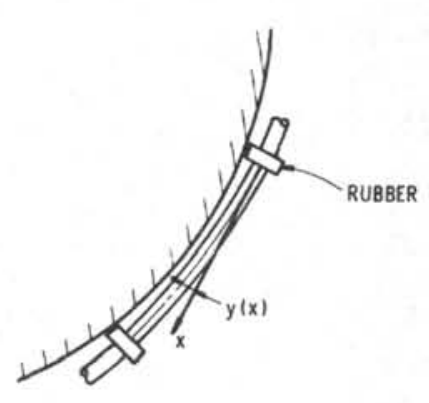

Figure 3.1-Section of Drill Pipe in Constrained Bending

In these expressions, $E I_{p}$ is the flexural rigidity of the drill pipe, $R$ is the radius (assumed constant) to which the pipe is bent, and $T$ is the tension and $M$ the moment developed in the drill pipe. The other symbols are defined in Figure 3.1. The solution to this system of equation: determines the maximum bending moment as

$$
M=\frac{E I_{p} \alpha s}{2 R} \frac{\sinh \alpha s}{\cosh \alpha s-1}
$$

where $\alpha^{2}=T / E I_{p}$.

$$
\begin{aligned}
& \text { To show this result, note that Eq. (3.1) can be expressed as } \\
& \begin{array}{l}
\frac{E I_{p} \mathrm{~d}^{4} y}{\mathrm{~d} x^{4}}-\frac{T \mathrm{~d}^{2} y}{\mathrm{~d} x^{2}}=\frac{\mathrm{d}^{2} M}{\mathrm{~d} x^{2}}=q=0, \\
\frac{\mathrm{d}^{4} y}{\mathrm{~d} x^{4}}-\frac{\alpha^{2} \mathrm{~d}^{2} y}{\mathrm{~d} x^{2}}=0 \\
\text { or } \\
\alpha^{2}=\frac{T}{E I_{p}}
\end{array}
\end{aligned}
$$


The general solution is

$$
y=A+B x+C \cosh \alpha x+D \sinh \alpha x
$$

Invoking the first two boundary conditions, Eqs. (3.2a), one finds

$$
\begin{aligned}
& C=-A \\
& D=-\frac{B}{\alpha}
\end{aligned}
$$

Invoking the second two boundary conditions, Eqs. (3.2b), there results

$$
\begin{gathered}
A=\frac{s}{2 R \alpha} \frac{\sinh \alpha s}{\cosh \alpha s-1} \\
B=\frac{s}{2 R}
\end{gathered}
$$

From Eq. (3.1),

$$
M=E I_{p} \frac{\mathrm{d}^{2} y}{\mathrm{~d} x^{2}}-T y=-T(A+B x)
$$

and, therefore, $M$ assumes a maximum value at $x=0, M=-T A$, the magnitude of which provides the result expressed as Eq. (3.3). This bending moment acts at each rubber or tool joint.

The maximum bending stress in the drill pipe, which occurs at the rubbers or tool joints. is

$$
\sigma=\frac{M r}{I_{p}}=\frac{E r \alpha s}{2 R} \frac{\sinh \alpha s}{\cosh \alpha s-1}
$$

while the peak tensile stress is

$$
\sigma=\frac{T}{A}+\frac{E r \alpha s}{2 R} \frac{\sinh \alpha s}{\cosh \alpha s-1}
$$

where $A$ is the net area of the drill pipe section. From the form of Eq. (3.5), one sees that increasing the radius $R$ correspondingly decreases the bending stress.

\subsection{Guide Shoe (Horn) System}

The Glomar Challenger is presently equipped with a guide shoe, a trumpet-shaped structure opening downward, of height $h$. The guide shoe has a constant radius $R$, to insure a uniform peak bending stress for all portions of the pipe in contact with the guide. If $\theta$ is the maximum design roll/pitch angle, then $h=R \sin \theta$, or

$$
R=\frac{h}{\sin \theta}
$$

The maximum stress experienced by the drill string as it bends to conform to the radius of the guide shoe is given by Eq. (3.5), where $R$ is given by Eq. (3.7). This bending stress adds to the direct tension stress $T / A$ to become the design criterion for the string under static loading.

As the drill string rotates and decends during drilling operations. that portion in the guide shoe which conforms to the radius accumulates fatigue damage due to the bending and tension stresses. As a segment of the pipe passes through the guide shoe, it is in contact with the guide for only a portion of the time, since the roll and pitch angles oscillate about a zero 
mean angle. In accounting for these factors, one arrives at the following expression for the expected number of reversed bending cycles, $n$, an element of the pipe experiences while passing through the shoe:

$$
n=\frac{0.637 R \theta(60)(\mathrm{RPM})}{\dot{x}}
$$

where RPM is the rotational speed of the string and $\dot{x}$ the drilling rate in feet/hour.

The numerical factor in this equation was derived by Vreeland(1.2), whose derivation is reproduced below. Following this derivation, it will be shown by a different train of thought that this factor is consistent with relatively close upper and lower bound estimates. Vreeland begins by postulating harmonic roll/pitch motion of period $T$

$$
\theta=\theta_{0} \sin \frac{2 \pi t}{T}
$$

The drilling rate is small compared to the rate of contact of the pipe with the guide, $\dot{x}<<R \theta_{o} / T$, and a segment is in contact with the guide for a time $t<R \theta_{o} / \dot{x}$. In following an element of the pipe as it passes downward from the top of the guide, one locates its position at any time $t$ by $x=\dot{x} t$, and finds that it comes in contact with the guide only if $x<$ $R \theta_{o}$. The element is not in contact from time $t=0$ to such time when $R \theta(t)=x$, i.e., when

$$
\frac{x}{R}=\theta_{0} \sin \frac{2 \pi t}{T}
$$

Thus,

$$
\frac{t_{n c}}{T}=\frac{2}{\pi} \operatorname{Sin}^{-1}\left(\frac{x}{R \theta_{0}}\right)
$$

where $t_{c}+t_{n c}=T$, with the subscripts denoting "contact" and "no contact," respectively. Averaging over the length of contact, there results

$$
\frac{t_{c}}{T}=1-\frac{2}{\pi R \theta_{0}} \int_{0}^{R \theta_{0}} \operatorname{Sin}^{-1}\left(\frac{x}{R \theta_{0}}\right) \mathrm{d} x=0.637
$$

which is the factor appearing in Eq. (3.8).

To justify this numerical estimate, it will now be shown that, within the assumptions presented above, the factor is bounded by 0.500 and 0.681 . To do this, first follow an element of the pipe as it descends with velocity $\dot{x}$ from the top of the guide and compare its position with the contact arc length $X$, Figure 3.1.1a. This comparison is illustrated in

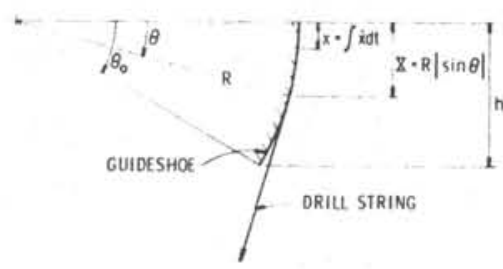

Figure 3.1.1a-Schematic of Guide Shoe System

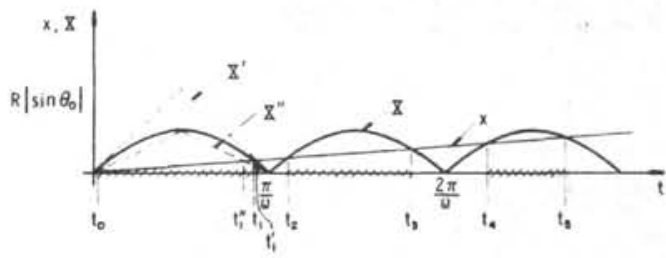

Figure 3.1.1.b-Estimation of Time of Contact

Figure 3.1.1b. The total contact time, $t_{c}$, is found by summing up the shaded portions of the abscissa, each of which indicates the proportion of a half-cycle of roll/pitch that the element in question contacts the guide shoe. One begins by writing

$$
\begin{gathered}
t_{0}=0 \\
t_{1}=\frac{R}{\dot{x}}\left|\sin \left(\theta_{0} \sin \omega t_{1}\right)\right|=\frac{R}{\dot{x}} \sin \left(\theta_{0} \sin \omega \bar{t}_{1}\right), \quad \bar{t}_{1}=\frac{\pi}{\omega}-t_{1} \\
t_{2}=\frac{R}{\dot{x}}\left|\sin \left(\theta_{0} \sin \omega t_{2}\right)\right|=\frac{R}{\dot{x}} \sin \left(\theta_{0} \sin \omega \bar{t}_{2}\right), \quad \bar{t}_{2}=t_{2}-\frac{\pi}{\omega} \\
t_{3}=\frac{R}{\dot{x}}\left|\sin \left(\theta_{0} \sin \omega t_{3}\right)\right|=\frac{R}{\dot{x}} \sin \left(\theta_{0} \sin \omega \bar{t}_{3}\right), \quad \bar{t}_{3}=\frac{2 \pi}{\omega}-t_{3} \\
\begin{array}{c}
\vdots \\
\text { etc. }
\end{array}
\end{gathered}
$$


where each of the $\bar{t}_{1}, \bar{t}_{2}$, etc., is less than $\pi / 2 \omega$. Since these expressions are nonlinear in the $t_{1}, t_{2}$, etc., it is expedient to resort to bounding approximations.

For an upper-bound estimate, the bilinear approximation denoted by $X^{\prime}$ in Figure $3.1 .1 \mathrm{~b}$ is introduced: $X=$ $R \theta_{0} \omega t, t<\pi / 2 \omega$. Then, one writes

$$
\begin{aligned}
& t_{0}^{\prime}=0 \\
& t_{1}^{\prime}=\frac{R \theta_{0}}{\dot{x}} \omega \bar{t}_{1}^{\prime}=\frac{R \theta_{0}}{\dot{x}} \omega\left(\frac{\pi}{\omega}-t_{1}^{\prime}\right), t_{1}^{\prime}=\frac{\pi R \theta_{0}}{R \theta_{0} \omega+\dot{x}} \\
& t_{2}^{\prime}=\frac{R \theta_{0}}{\dot{x}} \omega \bar{t}_{2}^{\prime}=\frac{R \theta_{0}}{\dot{x}} \omega\left(t_{2}^{\prime}-\frac{\pi}{\omega}\right), t_{2}^{\prime}=\frac{\pi R \theta_{0}}{R \theta_{0} \omega-\dot{x}} \\
& t_{3}^{\prime}=\frac{R \theta_{0}}{\dot{x}} \omega \bar{t}_{3}^{\prime}=\frac{R \theta_{0}}{\dot{x}} \omega\left(\frac{2 \pi}{\omega}-t_{3}^{\prime}\right), t_{3}^{\prime}=\frac{2 \pi R \theta_{0}}{R \theta_{0} \omega+\dot{x}} \\
& \vdots
\end{aligned}
$$

etc.

Thus,

$$
\begin{gathered}
t_{c}^{\prime}=\left(\dot{t}_{1}^{\prime}-t_{0}^{\prime}\right)+\left(t_{3}^{\prime}-t_{2}^{\prime}\right)+\left(t_{5}^{\prime}-t_{4}^{\prime}\right)+\ldots \\
=\left(\frac{\pi R \theta_{0}}{R \theta_{0} \omega+\dot{x}}-0\right)+\left(\frac{2 \pi R \theta_{0}}{R \theta_{0} \omega+\dot{x}}-\frac{\pi R \theta_{0}}{R \theta_{0} \omega-\dot{x}}\right)+\left(\frac{3 \pi R \theta_{0}}{R \theta_{0} \omega+\dot{x}}-\frac{2 \pi R \theta_{0}}{R \theta_{0} \omega-\dot{x}}\right)+\ldots \\
=\frac{\pi R \theta_{0}}{R^{2} \theta_{0}^{2} \omega^{2}-\dot{x}^{2}}\{R \theta_{0} \underbrace{(1+1+1+\ldots)}_{n \text { times }}-\dot{x}(\underbrace{1+3+5+\ldots+(2 n-1)}_{=n^{2}})\}
\end{gathered}
$$

where $n$ is here the number of half waves. Thus,

$$
\begin{aligned}
t_{c}^{\prime} & =\frac{n \pi R \theta_{0}}{R^{2} \theta_{0}^{2} \omega^{2}-\dot{x}^{2}}\left(R \theta_{0} \omega-n \dot{x}\right) \\
& \simeq \frac{n \pi}{R \theta_{0} \omega^{2}}\left(R \theta_{0} \omega-n \dot{x}\right)
\end{aligned}
$$

since $\dot{x} \ll R \theta_{0} / T$. To find $n$, note that

$$
\begin{gathered}
t_{\max }=n\left(\frac{\pi}{\omega}\right)=\frac{R}{\dot{x}} \sin \theta_{0} \\
\simeq \frac{R \theta_{0}}{\dot{x}}
\end{gathered}
$$

Thus, $n=R \theta_{0} \omega / \pi \dot{x}$, from which

$$
t_{c}^{\prime}=\frac{\pi-1}{\pi} \frac{R \theta_{0}}{\dot{x}}=\frac{0.681 R \theta_{0}}{\dot{x}}
$$

which serves as an upper-bound estimate.

The lower-bound estimate proceeds in exactly the same manner, this time with $X^{\prime \prime}$, as depicted in Figure 3.1.1 b. On replacing $X$ with $X^{\prime \prime}=(2 / \pi) R \theta_{0} \omega t$ and repeating the process just outlined, one concludes that

$$
t_{c}^{\prime \prime}=\frac{1}{2} \frac{R \theta_{0}}{\dot{x}}=\frac{0.5 R \theta_{0}}{\dot{x}}
$$

Inasmuch as $t_{c}^{\prime \prime}<t_{c}<t_{c}^{\prime}$, the estimate stated as Eq. (3.8) will be adopted in this report.

The fractional fatigue damage incurred by the element as it descends through the guide shoe is $F$ :

$$
F=n / N
$$

where $N$ is the number of cycles to failure as defined by Eq. (2.43) and $n$ is given by Eq. (3.8). The total life of the drill string in hours is $L$ :

$$
L=N /(60)(\mathrm{RPM}) \text {, hour's }
$$




\subsection{Picalo System}

An alternative system concept for limiting the bending radius of the drill string during $\mathrm{roll} / \mathrm{pitch}$ is through the use of a picalo, or flexible guide. Conceptually; the picalo is a tapered, hollow cantilevered beam through which the drill pipe is fed during drilling. The taper is designed so that a constant radius of curvature is achieved, which depends upon the string tension.

Recall the differential Eq. (3.1) for the deflection of a beam which, in general, has the form

$$
\frac{\mathrm{d}^{2}}{\mathrm{~d} x_{1}^{2}}\left(E I \frac{\mathrm{d}^{2} y_{1}}{\mathrm{~d} x_{1}^{2}}\right)=T \frac{\mathrm{d}^{2} y_{1}}{\mathrm{~d} x_{1}^{2}}
$$

The subscript 1 denotes the picalo, as described in Figure 3.2.1. For small curvatures, such as are encountered in the bending of the picalo, $\mathrm{d}^{2} y_{1} / \mathrm{d} x_{1}^{2} \simeq 1 / R$, which is required to be constant. Substituting, one arrives at

$$
\frac{\mathrm{d}^{2} I}{\mathrm{~d} x_{1}^{2}}=\frac{T}{E}
$$

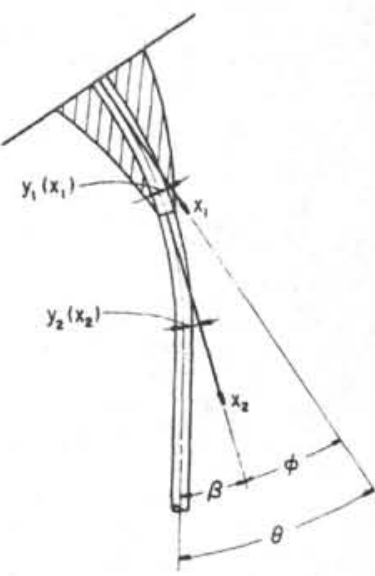

Figure 3.2.1-Schematic of Picalo System

whose complete solution is

$$
I=\frac{T x_{1}^{2}}{2 E}+c_{1} x_{1}+c_{2}
$$

where $c_{1}$ and $c_{2}$ are constants yet to be determined.

The bending displacements of the drill pipe are governed by the differential equation

$$
E I_{p} \frac{\mathrm{d}^{4} y_{2}}{\mathrm{~d} x_{2}^{4}}=T \frac{\mathrm{d}^{2} y_{2}}{\mathrm{~d} x_{2}^{2}}
$$

where the subscript 2 denotes the drill pipe. The boundary conditions are

$$
\begin{gathered}
\text { at } x_{2}=0: \quad y_{2}=0, \frac{\mathrm{d} y_{2}}{\mathrm{~d} x_{2}}=0, \frac{\mathrm{d}^{2} y_{2}}{\mathrm{~d} x_{2}^{2}}=\frac{M}{E I_{p}} \\
\text { as } x_{2} \rightarrow \infty: \frac{\mathrm{d} y_{2}}{\mathrm{~d} x_{2}} \text { is bounded }
\end{gathered}
$$

The solution is

$$
y_{2}=\frac{E I_{p}}{R T}\left(\mathrm{e}^{-\alpha x_{2}}-1\right)+\frac{x_{2}}{R \alpha}
$$

where $\alpha=\sqrt{T / E I_{p}}$ as before.

To show this, one begins with the general solution of Eq. (3.14)

$$
y_{2}=A+B x_{2}+C \cosh \alpha x_{2}+D \sinh \alpha x_{2}
$$


which reduces to

$$
y_{2}=A\left(1-\cosh \alpha x_{2}\right)+B x_{2}-\frac{1}{\alpha} \sinh \alpha x_{2}
$$

under imposition of the first two boundary conditions in Eq. (3.15a). The third boundary condition provides $A=$ $-M / T$. The remaining condition, Eq. $(3.15 b)$, requires bounded behavior as

$$
\lim _{x_{2} \rightarrow \infty} \frac{\mathrm{d} y_{2}}{\mathrm{~d} x_{2}}=\lim _{x_{2} \rightarrow \infty}\left[B+\frac{1}{2}\left(\frac{M \alpha}{T}-B\right) \mathrm{e}^{\alpha x}\right]
$$

From this, it follows immediately that $B=M \alpha / T$, and one is led to Eq. (3.16) above.

In order to complete the stress analysis of the drill string, the constants, $c_{1}$ and $c_{2}$ in Eq. (3.13) must be determined. The bending moment $M$ and the shear force $V$ at the point where the drill string emerges from the lower end of the picalo are, respectively,

$$
\begin{gathered}
M=E I_{p} \frac{\mathrm{d}^{2} y_{2}(0)}{\mathrm{d} x_{2}^{2}}=\frac{E I_{p}}{R} \\
V=-E I_{p} \frac{\mathrm{d}^{3} y_{2}(0)}{\mathrm{d} x_{2}^{3}}=\frac{E I_{p} \alpha}{R}
\end{gathered}
$$

It is necessary to maintain a smooth transition in both the bending moment and the shear in the drili string as it emerges from the end of the picalo. These two conditions suffice to determine $c_{1}$ and $c_{2}$, and the final expression for $I$, from Eq. (3.13), is

$$
I=I_{p}\left\{1-\alpha\left(h-x_{1}\right)+\frac{\alpha^{2}\left(h-x_{1}\right)^{2}}{2}\right\}
$$

This result derives directly from the stated boundary conditions

$$
\begin{aligned}
& \left.\frac{E I}{R}\right|_{x_{1}=h}=\frac{E I_{p}}{R} \quad \text { (moment continuity) } \\
& \left.\frac{E}{R} \frac{\mathrm{d} I}{\mathrm{~d} x_{1}}\right|_{x_{1}=h}=\frac{E I_{p} \alpha}{R} \quad \text { (shear continuity) }
\end{aligned}
$$

where Eqs. (3.17) and (3.18) have been used. Thus, from Eq. (3.13),

$$
\begin{gathered}
\frac{T h^{2}}{2 E}+c_{1} h+c_{2}=I_{p} \\
\frac{T h}{E}+c_{1}=I_{p} \alpha
\end{gathered}
$$

from which

$$
\begin{aligned}
& c_{1}=\frac{\left(E I_{p} \alpha-T h\right)}{E} \\
& c_{2}=I_{p}(1-\alpha h)+\frac{T h^{2}}{2 E}
\end{aligned}
$$

Using these constants, one is led to Fq. (3.19).

To compute the bending stresses at pipe elements within the picalo, the bending radius of the picalo needs to be determined in terms of the roll/pitch angle of the ship. The total roll/pitch angle. $\theta$, is the sum of the angle $\varphi$ through which the picalo bends and $\beta$, the angle through which the drill string bends: $\theta=\varphi+\beta$. The angle $\varphi$ is given simply by $h \simeq R \varphi$. $\beta$ is found by: 


$$
\begin{aligned}
\beta & =\lim _{x_{2} \rightarrow \infty} \frac{\mathrm{d} y_{2}}{\mathrm{~d} x_{2}}-\frac{\mathrm{d} y_{2}(\theta)}{\mathrm{d} x_{2}} \\
& =\lim _{x_{2} \rightarrow \infty}\left(-\frac{E I_{p} \alpha}{R T} \mathrm{e}^{-\alpha x_{2}}+\frac{1}{R \alpha}\right)=\frac{1}{R \alpha}
\end{aligned}
$$

Thus,

$$
R=\frac{h}{\varphi}=\frac{h}{\theta-\beta}=\frac{(h+1 / \alpha)}{\theta}
$$

The bending stress in the picalo is $\sigma$.

$$
\sigma=\frac{M c}{I}=\frac{E c}{R}=\frac{E c \theta}{h+1 / \alpha}
$$

where $c$ is the outer radius of the picalo at the position in question. The bending stress in the drill string contained in the picalo is given by combining Eqs. (3.5) and (3.20)*:

$$
\sigma=\frac{E r \theta \alpha s}{2(h+1 / \alpha)} \frac{\sinh \alpha s}{\cosh \alpha s-1}
$$

The maximum tensile stress is found by adding the direct tensile stress

$$
\sigma=\frac{T}{A}+\frac{E r \theta \alpha s}{2(h+1 / \alpha)} \frac{\sinh \alpha s}{\cosh \alpha s-1}
$$

The above equations are valid for a picalo system designed to a chosen value of tension $T$ (i.e.. a chosen $\alpha$ ). Thus, the system is designed to some string length, and corresponding $T$. which insures a constant bending radius $R$ for that string length. When drilling with a string of different length. the radius $R$ will not be constant along the picalo, and the effective new bending radius must be estimated. The effective bending radius may be estimated by the expression

$$
R=R_{d}+\sqrt{\frac{\overline{E I_{p}}}{T \theta^{2}}}\left(1-\sqrt{\frac{T}{T_{d}}}\right)
$$

where the subscript $d$ stands for the design condition, for which $R$ is everywhere constant. This expression predicts $R>R_{d}$ whenever $T<T_{d}$, and vice versa. For purposes of numerical computation, Eq. (3.24) can be used in place of Eq. (3.20) for all string lengths.

Eq. (3.24) is found by requiring $h / \theta \mid=R-(1 / \alpha \theta)]$ to be the same for the design string length condition as for any other length. Thus,

$$
R-\frac{1}{\alpha \theta}=R_{d}-\frac{1}{\alpha_{d^{\theta}}}
$$

which results in the foregoing expression.

An exact solution for the nonuniform curvature of the picalo under other than the design condition can be found, although it is tedious. One begins by writing

$$
\frac{\mathrm{d}^{2}}{\mathrm{~d} x^{2}}\left(I \frac{\mathrm{d}^{2} y}{\mathrm{~d} x^{2}}\right)=\frac{T}{E} \frac{\mathrm{d}^{2} y}{\mathrm{~d} x^{2}}
$$

*Refer to the discussion relating to Eq. (3.24). 
where $y \equiv y_{1}$ and $x \equiv_{x_{1}}$, and $I$ is defined by Eq. (3.19). On substituting for $I$, there results

$$
\frac{\mathrm{d}^{2} f}{\mathrm{~d} x^{2}}+\frac{2 I^{\prime}}{I} \frac{\mathrm{d} f}{\mathrm{~d} x}=0
$$

where $f=\mathrm{d}^{2} y / \mathrm{d} x^{2}$, and the superior prime denotes $\mathrm{d} / \mathrm{d} x$. By transforming from $f$ to $g$ via

$$
f=g \exp \left\{-\int \frac{I^{\prime}}{I} \mathrm{~d} x\right\}
$$

the differential equation reduces to the simpler form

$$
\frac{\mathrm{d}^{2} g}{\mathrm{~d} x^{2}}-\frac{I^{\prime \prime}}{I} g=0
$$

The quantity $I^{\prime \prime} / I$ is rational, whose numerator is a constant and whose denominator is a second-order polynomial in $x$. By making two successive linear transformations of the independent variable,

$$
\begin{aligned}
& z=a x+b \\
& \omega=c z+d
\end{aligned}
$$

The differential equation can be transformed to the canonical form

$$
\frac{d^{2} g}{d \omega^{2}}+\left[\frac{\nu(\nu+1)}{1-\omega^{2}}\right] \omega=0
$$

whose solution is expressed in terms of Legendre functions

$$
g=\sqrt{1-\omega^{2}}\left[A P_{\nu}(\omega)+B Q_{\nu}(\omega)\right]
$$

Transforming back, this result determines $\mathrm{d}^{2} y / \mathrm{d} x^{2}$ in terms of the constants $A$ and $B$. Integrating twice, $y$ is thus expressed in terms of four constants, whose values are fixed by the boundary conditions imposed on the picalo system. The final result is not given here in view of the adequacy of the approximation, Eq. (3.24).

In computing the fatigue damage inflicted in the pipe as it descends through the picalo. account must be taken of the fact that the picalo oscillates slowly in response to the roll and pitch motion of the ship. As an approximation to this effect, it is assumed that $\theta$ varies harmonically about a mean of zero: $\theta=\theta_{\mathrm{max}} \sin (2 \pi t / T)$. The effective value of $\theta$ is taken as the root mean square value

$$
\theta=\frac{\sqrt{2} \theta_{\max }}{2}
$$

This value of $\theta$ is to be used, for the purposes of fatigue calculations. in computing the bending stress, Eq. (3.22). This stress, in turn, is used to compute the number of cycles to failure $N$ from Eq. (2.43). The number of cycles, $n$, experienced by a segment of the pipe as it descends through the picalo is

$$
n=\frac{h(60)(\mathrm{RPM})}{\dot{x}}
$$

and the fraction of life expended is

$$
F=\frac{n}{N}
$$

This completes the fatigue analysis of the picalo system. 


\section{SECTION 4. COMPUTED RESULTS}

This section presents data computed on the basis of the equations developed in Sections 2 and 3 for heave response and for the guide shoe and picalo concepts under conditions of roll and pitch. The data cover a wide range of parameter variations which may be encountered in the Deep Sea Drilling Project. The results are grouped into three subsections, presenting, respectively. Heave Dynamics, the guide shoe system, and the picalo system. Each subsection is prefaced by a bricf commentary on the results, including major conclusions.

\subsection{Heave Dynamics}

Figures 4.1.1 through 4.1:22 present dynamic stress, maximum displacement, and fatigue life estimates for the drill string in response to heave motions. Most of these data correspond to sinusoidal swells, as random sea states were found to impart far less severe dynamic stresses on the string.

An important consequence of the mathematical model is that the dynamic response of the drill string is rather sensitive to the swell frequency. Thus, the ratio of wave height to wave length, which affects the swell frequency, enters as a basic program parameter in addition to wave height. The theoretical maximum sinusoidal wave height for a given wave length $\lambda$ is $0.0890 \lambda$. This valuc: however, is scarcely ever attained in practice and leads to dynamic stress predictions which are appreciably lower than are found with more typical wave height/wave length ratios. Ochi(2.2) shows that this ratio is commonly about 0.0286 for mild regular waves and 0.0500 for severe regular waves in Sea State 7 (very high seas). The data presented in the following curves accounted for this range of values by introducing the parameter "fraction of maximum stable sinusoidal swell" (FMSSS). The greatest permissible value of this parameter is unity, in which case the waveheight/wave-period relation is

$$
H_{\max }=0.817 T^{2}
$$

as derived in Section 2.2 of this report. The wave height/wave length which corresponds to this value is the aforementioned maximum value of 0.0890 . The data which follow are plotted for three values of the fraction of maximum stable sinusoidal swell (FMSSS) of 0.1. 0.5. and 1.0. The following table shows the corresponding ratios of wave height/wave length $(H / \lambda)$ and wave height $/$ period $^{2}\left(H / T^{2}\right)$.

TABLE 4.1. WAVE HEIGHT PARAMETERS

\begin{tabular}{c|c|c} 
FMSSS & $H / \lambda$ & $H / T^{2}$ \\
\hline 0.1 & 0.0089 & 0.0817 \\
0.5 & 0.0445 & 0.4085 \\
1.0 & 0.0890 & 0.8170
\end{tabular}

This range of FMSSS considered does include the estimates given by Ochi for Sea State 7. Until more definitive data are available regarding $H$ and $I / \lambda$ values actually experienced in the Glomar Challenger's drilling operations, an amount of uncertainty will exist in interpreting the data which follow. In the meantime, however, it would appear that an FMSSS of 0.5 should be reasonably representative of the heavier sea states, at least, and this fraction is therefore given somewhat more emphasis in the following curves than is either 0.1 or 1.0 . 


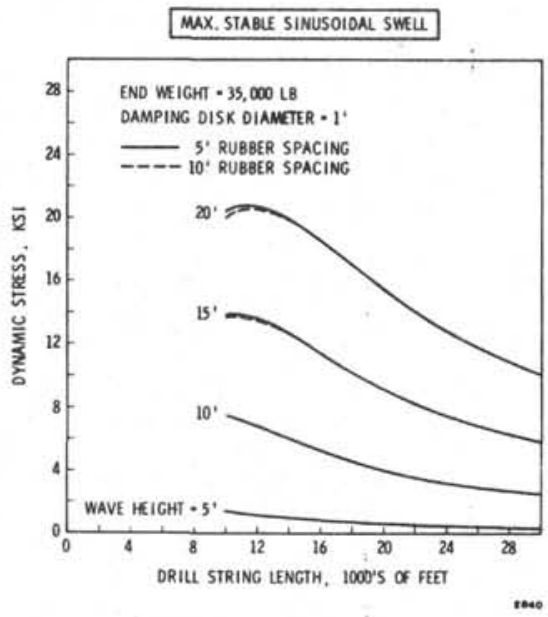

Figure 4.1.1-Heave Stress Response to Sinusoidal Swells

0.5 MUX. STABLE SINUSOIDAL SWEL

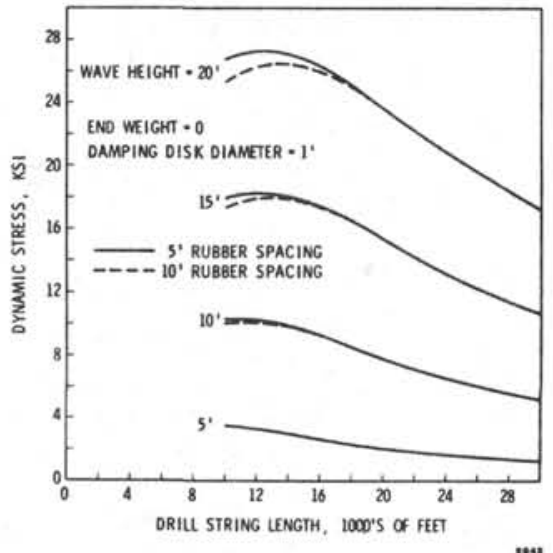

Figure 4.1.3-Heave Stress Response to Sinusoidal Swells

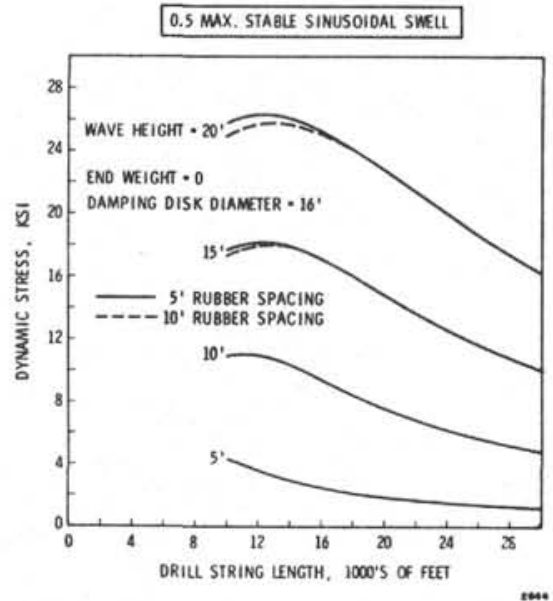

Figure 4.1.5-Heave Stress Response to Sinusoidal Swells

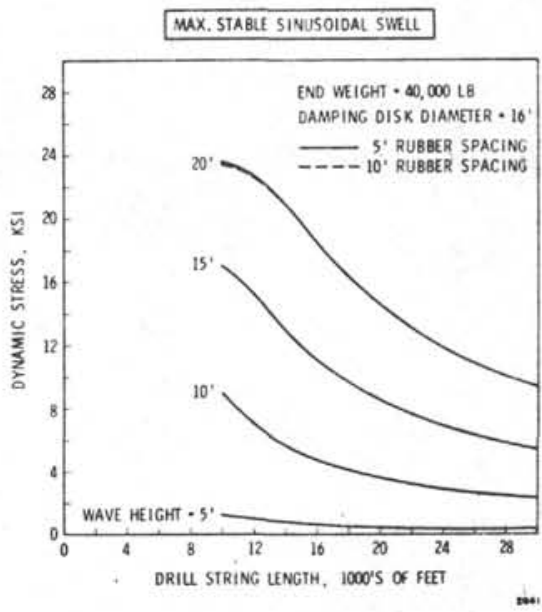

Figure 4.1.2-Heave Stress Response to Sinusoidal Swells

\subsection{MAX. STABLE SINUSOIDAL SWELL}

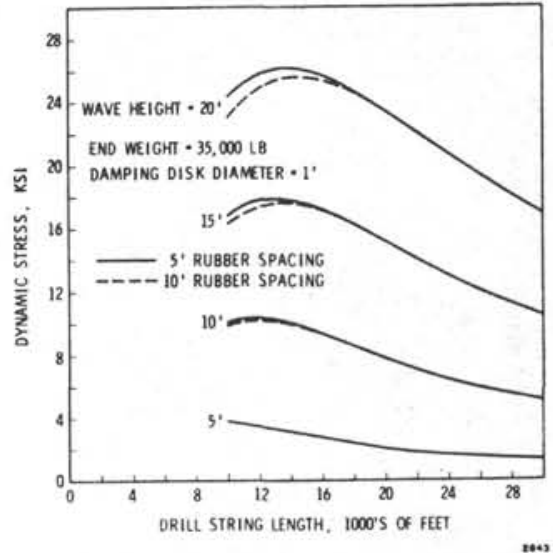

Figure 4.1.4-Heave Stress Response to Sinusoidal Swells

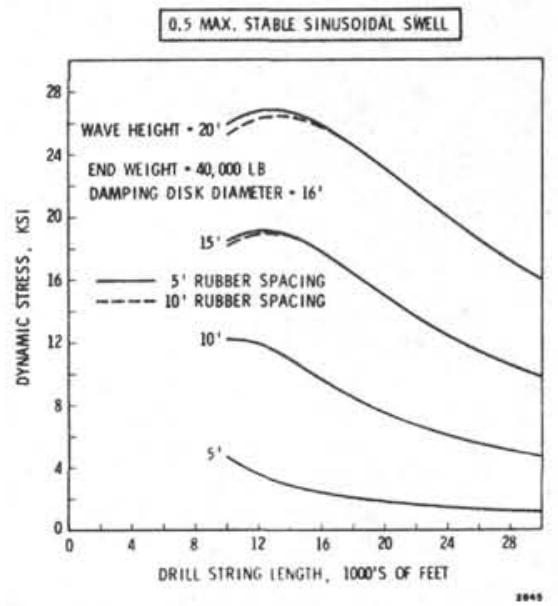

Figure 4.1.6-Heave Stress Response to Sinusoidal Swells 


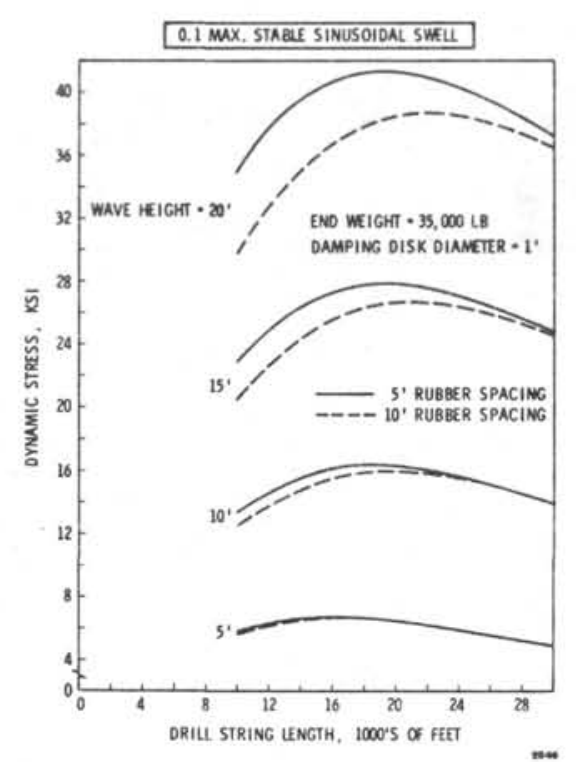

Figure 4.1.7-Heave Stress Response to Sinusoidal Swells

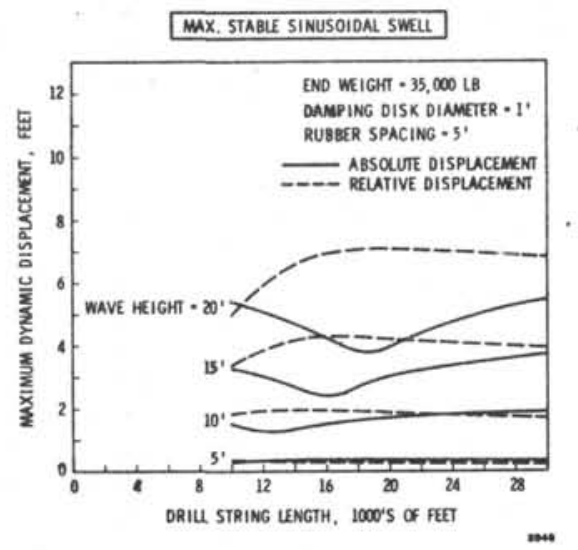

Figure 4.1.9-Dynamic Displacement Response to Sinusoidal Swells

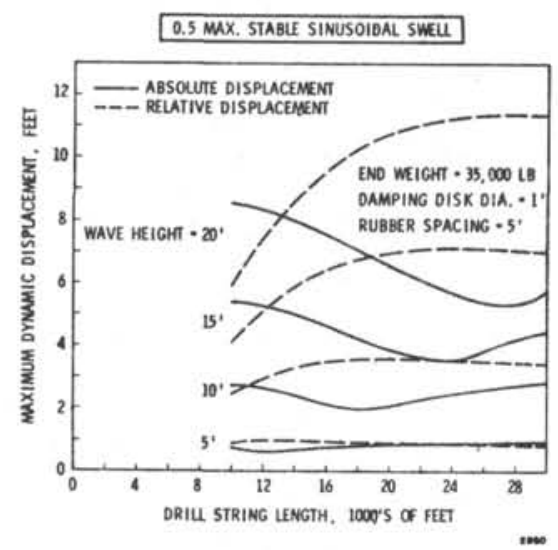

Figure 4.1.11-Dynamic Displacement Response to Sinusoidal Swells

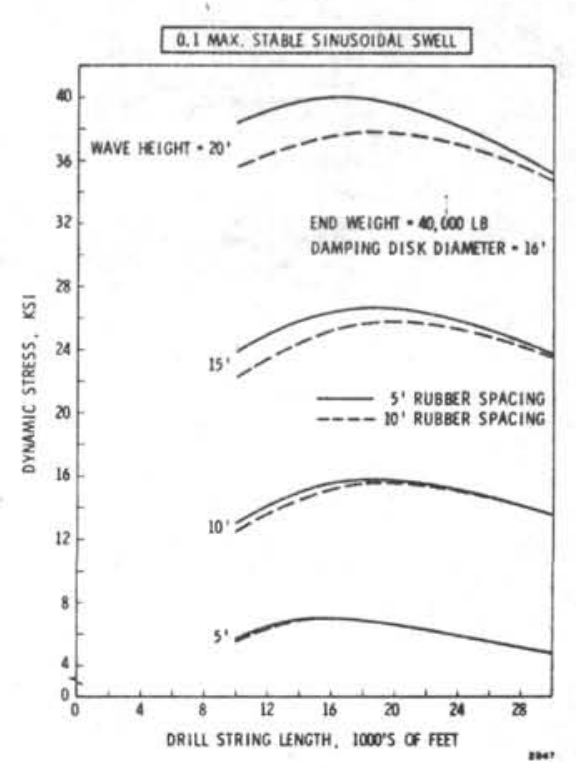

Figure 4.1.8-Heave Stress Response to Sinusoidal Swells

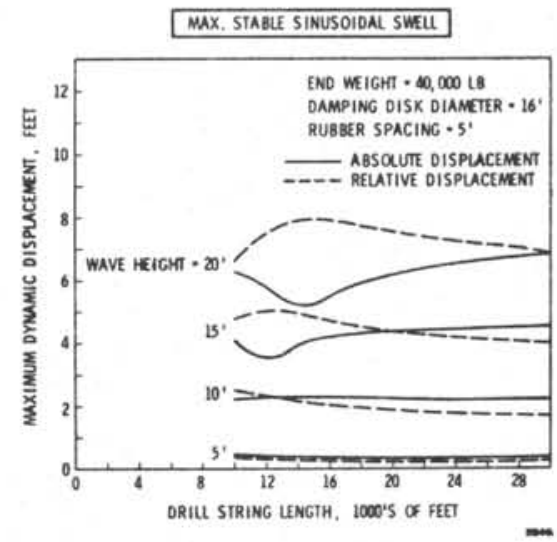

Figure 4.1.10-Dynamic Displacement Response to Sinusoidal Swells

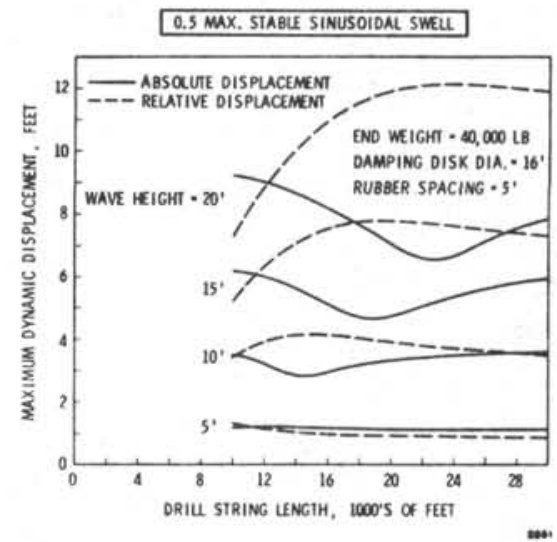

Figure 4.1.12-Dynamic Displacement Response to Sinusoidal Swells 


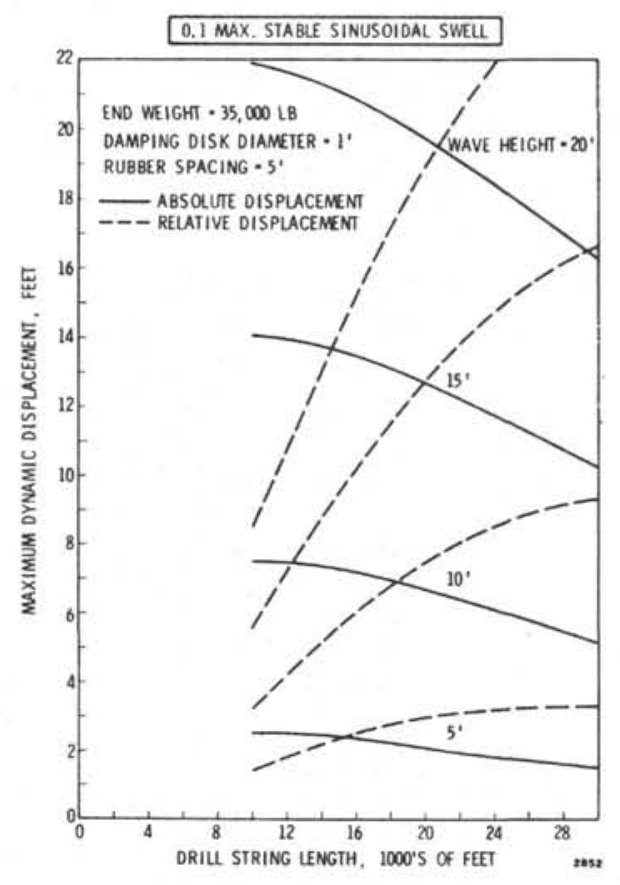

Figure 4.1.13-Dynamic Displacement Response to Sinusoidal Swells

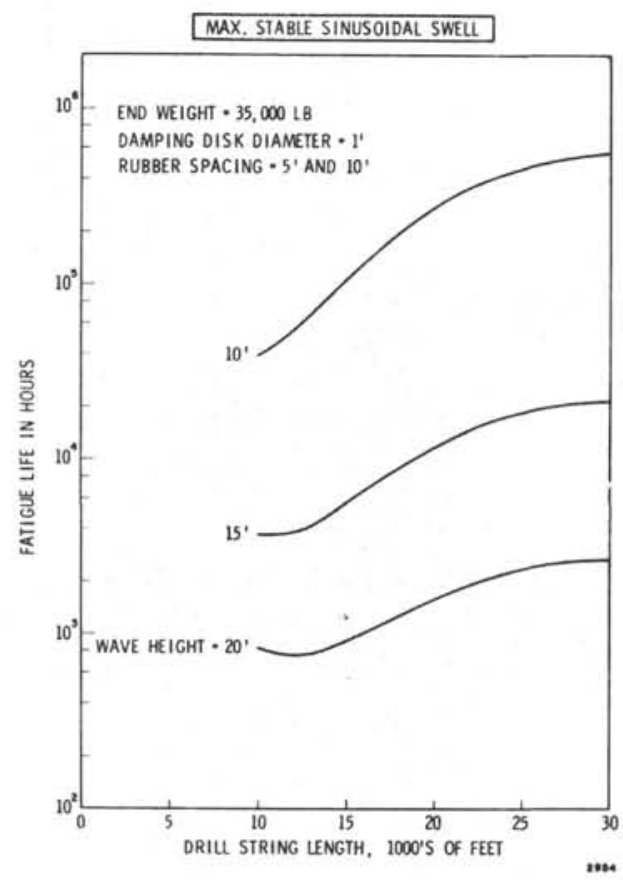

Figure 4.1.15-Fatigue Life for Sinusoidal Swells

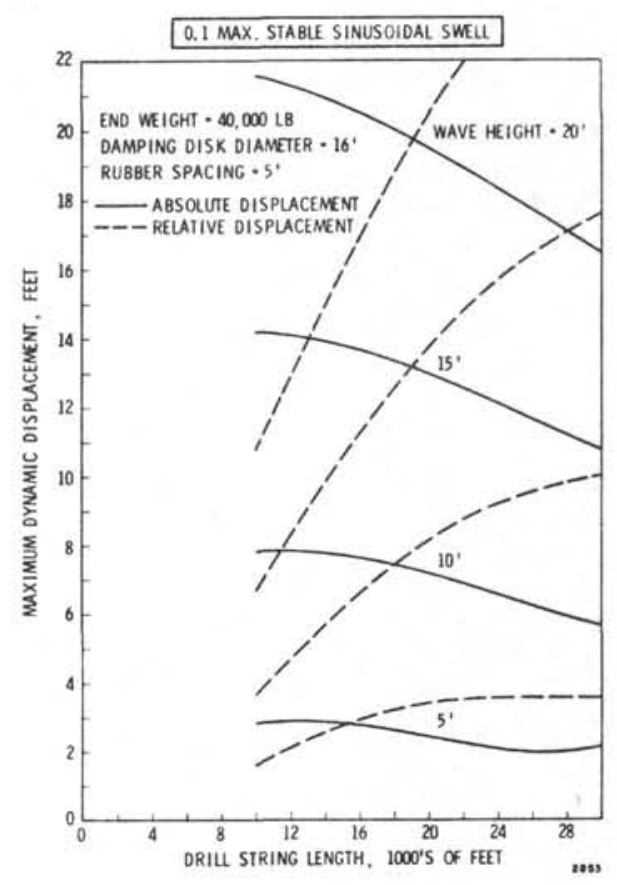

Figure 4.1.14-Dynamic Displacement Response to Sinusoidal Swells

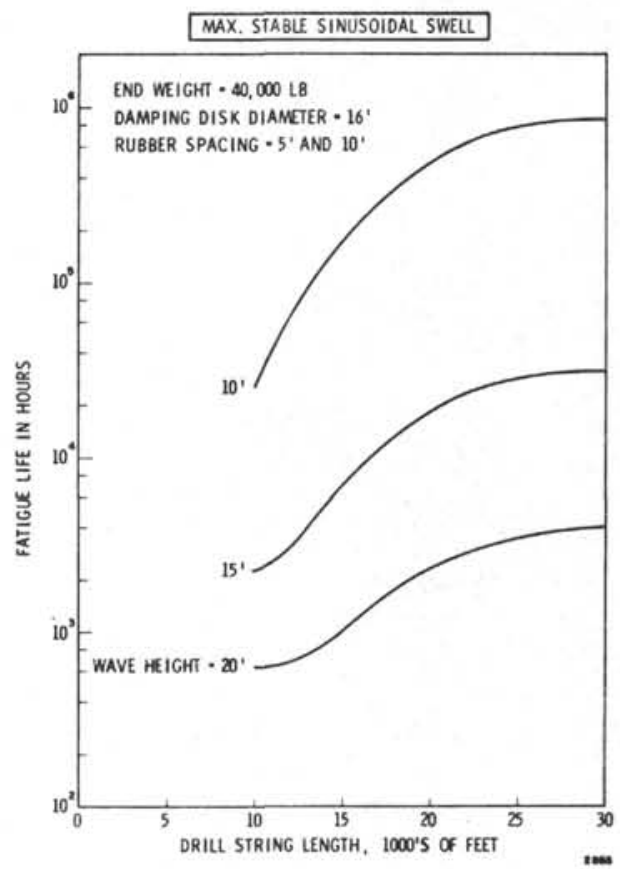

Figure 4.1.16-Fatigue Life for Sinusoidal Swells 


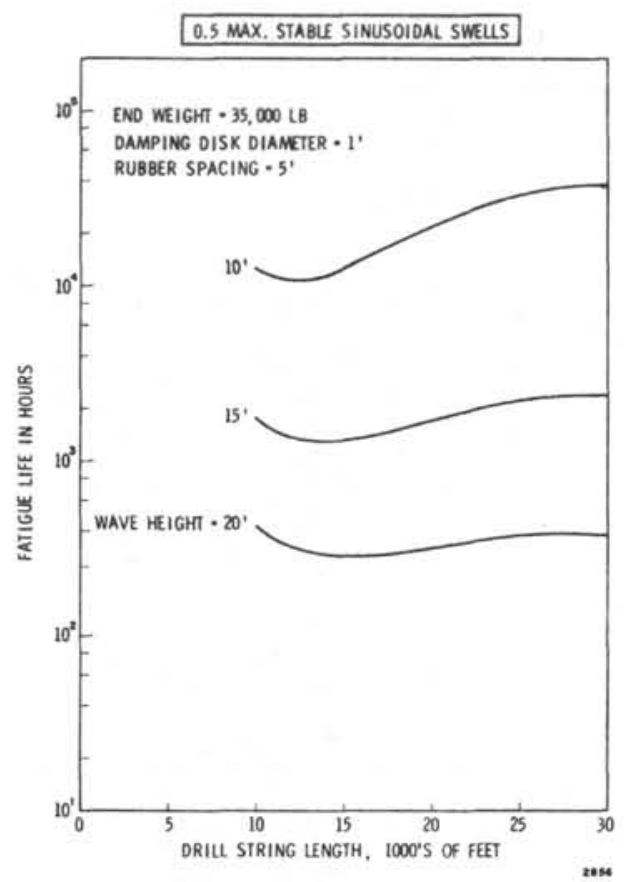

Figure 4.1.17-Fatigue Life for Sinusoidal Swells

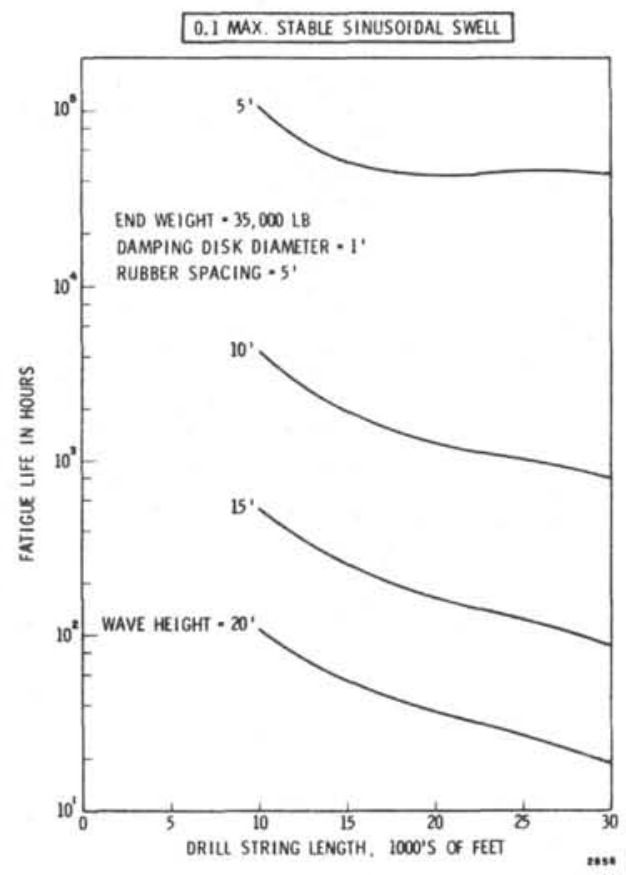

Figure 4.1.19-Fatigue Life for Sinusoidal Swells

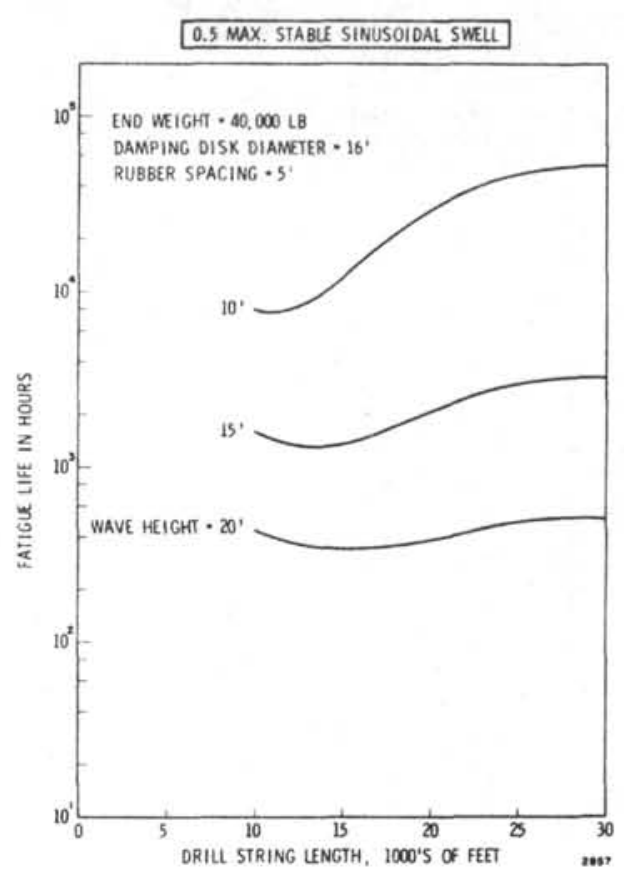

Figure 4.1.18-Fatigue Life for Sinusoidal Swells

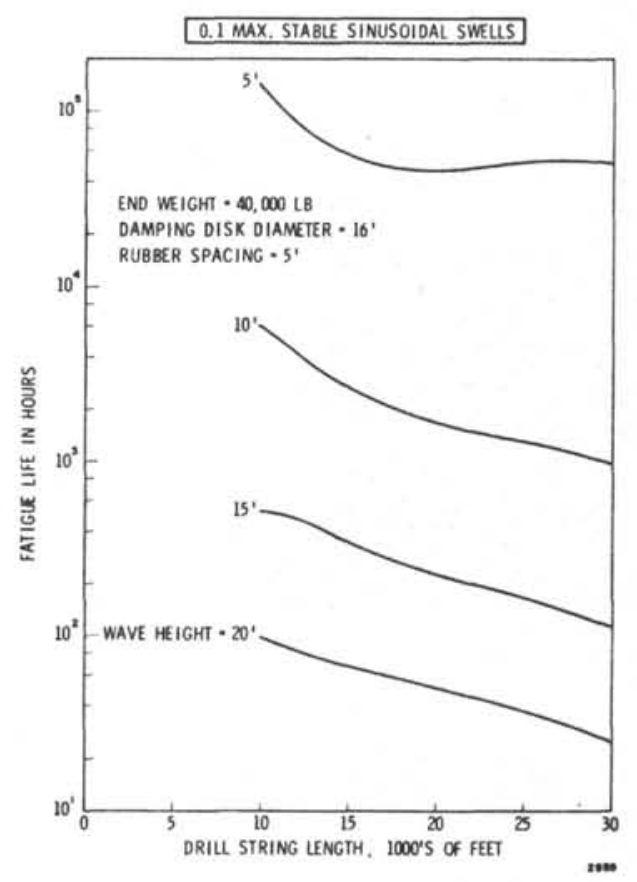

Figure 4.1.20-Fatigue Life for Sinusoidal Swells 


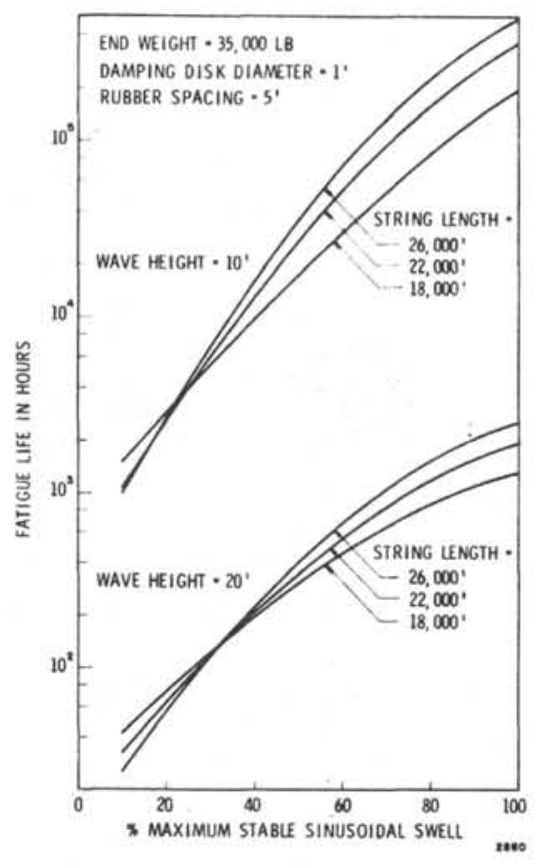

Figure 4.1.21-Effect of Percent Maximum Stable Sinusoidal Swell on Fatigue Life

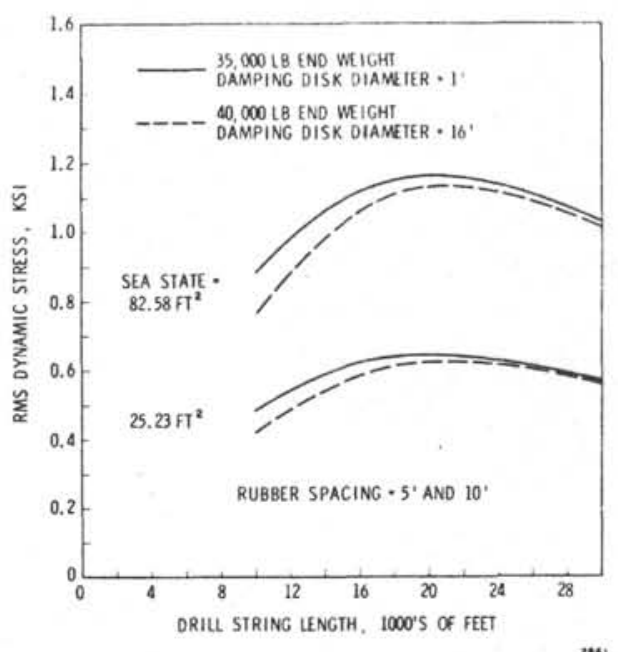

Figure 4.1.22-Heave Stress Response to Random Sea States

It should be borne in mind that the fatigue life estimates are valid for a pipe section at the top of the string which supports the full string length indicated. If, in service, a pipe section is placed sometimes near the bottom of the string and sometimes nearer the top, the fatigue damage it will accumulate will be much less than if it were always near the top. The fatigue life under varying stressing conditions such as these could be evaluated using the method outlined in Section 2.5, but would require record-keeping on each strand of drill pipe. In more practical terms, if a system of rotation were developed whereby a given pipe section were placed near the bottom, centrally, and near the top of the string on a fairly regular basis, the fatigue lives of all segments would be more nearly the same and would help to forestall any premature fatigue failures.

The dynamic stress data are all given for the top of the drill string, where these stresses are maximized. The dynamic stress in the pipe is reduced uniformly all the way down the string length, and achieves its minimum at the bottom where its value is reduced from the maximum value by a factor of $\cos \alpha_{1}$. Using this fact, the stresses (and hence the forces) in the region of the bumper subs can easily be estimated.

All results given in this report correspond to one damping disk at the bottom of the string. In the case of a re-entry system, this disk is taken to be $16 \mathrm{ft}$ in diameter to represent the landing base. Otherwise, a single damping disk $1 \mathrm{ft}$ in diameter was used.

The following general observations and conclusions follow from the data which are presented in this section:

(1) The dynamic stresses decrease with increasing string length, for strings greater than about $14,000 \mathrm{ft}$. (The static stress, however, increases with string length, and has a counteracting influence on the fatigue life.)

(2) The dynamic stresses are greater for a fraction of maximum stable sinusoidal swell (FMSSS) of 0.5 than for an FMSSS of unity. Moreoever, an FMSSS of 0.5 is more nearly typical of actual values encountered. 
(3) The effect of rubber spacing on the dynamic stresses is generally very small. The 10 -ft rubber spacing produces slightly lower stresses than does the 5 -ft spacing. Rubber spacing is less important at low wave heights and long string lengths.

(4) For a given string length (and FMSSS), the dynamic stress is relatively insensitive to end weight and disk diameter.

(5) The maximum relative displacement, $v_{\mathrm{m} a x_{2}}$ can exceed the maximum absolute displacement, $u_{\mathrm{max}} \cdot v_{\mathrm{max}}$ ranges up to about $12 \mathrm{ft}$ for long string lengths with 20 -ft swells: (Note that since these are maximum values, the times at which $u_{\mathrm{m} \text { ax }}$ and $v_{\mathrm{m} \text { ax }}$ occur are, in general, not the same.)

(6) The fatigue life generally remains constant or improves with increasing string length for strings longer than about $14,000 \mathrm{ft}$. [See (1) above.]

(7) The fatigue life is decreased approximately by a factor of 10 for each 5 -ft increase in wave height.

(8) The landing base (16-ft damping disk) improves the fatigue life for string lengths greater than $14,000 \mathrm{ft}$. The improvement can be as great as $50 \%$, depending upon the other system parameters.

(9) The random sea state produces negligible displacements and fatigue lives that can be considered indefinite. Thus, the sinusoidal swell sea state, not the random sea state, is the governing design condition.

(10) The response to the random sea state is insensitive to the end weight and rubber spacing, but is sensitive to the magnitude of the sea state and, to a lesser extent, to the damping disk diameter.

\subsection{Guide Shoe}

The following figures illustrate the type of fatigue behavior to be expected of the drill string when used in connection with the guide shoe system. Figures 4.2.1 through 4.2.7 show how the fatigue life is affected by the height of the guide shoe, and by the system parameters of angular deviation, rubber spacing, end weight, and string length. The fatigue life is expressed in terms of the ratio of the number of holes which can be drilled to the drilling rate $\dot{x}$. This is done for conciseness

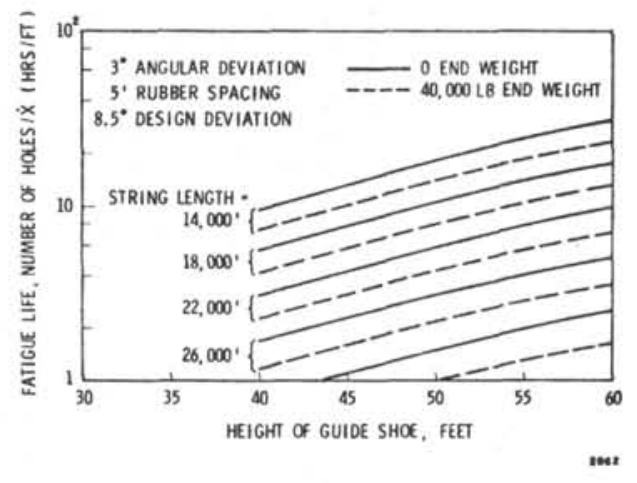

Figure 4.21-Fatigue Life of String with Guide Shoe

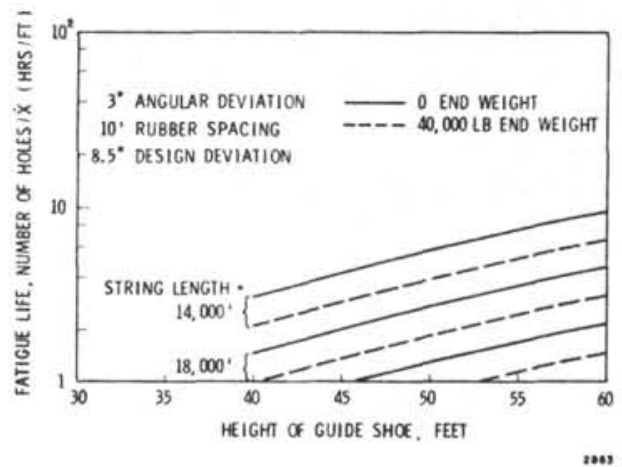

Figure 4.1.2-Fatigue Life of String with Guide Shoe 


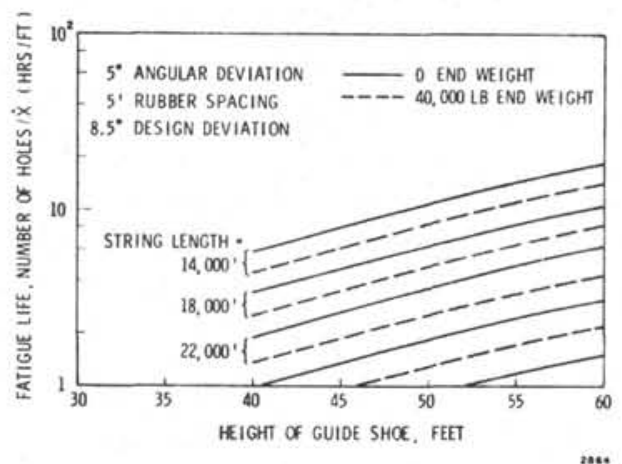

Figure 4.2.3-Fatigue Life of String with Guide Shoe

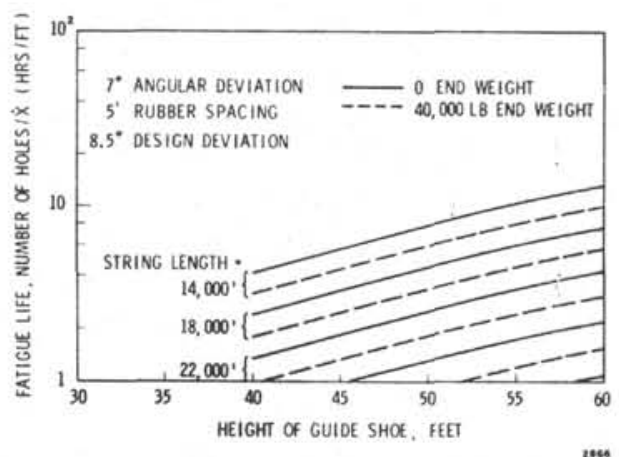

Figure 4.2.5-Fatigue Life of String with Guide Shoe

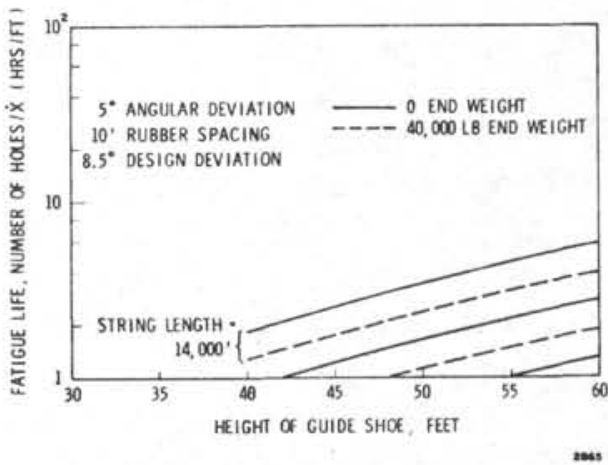

Figure 4.2.4-Fatigue Life of String with Guide Shoe

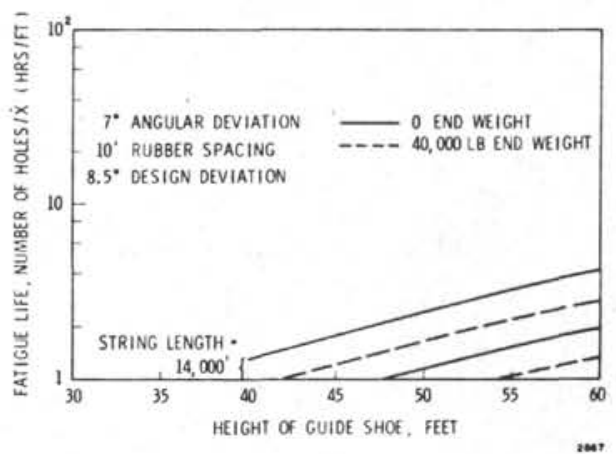

Figure 4.2.6-Fatigue Life of String with Guide Shoe

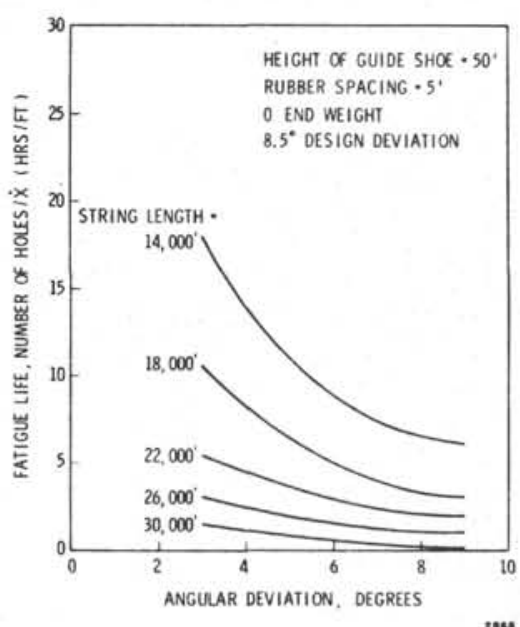

Figure 4.2.7-Effect of Angle of Deviation on Fatigue Life of String with Guide Shoe inasmuch as the fatigue life is directly proportional to $\dot{x}$. Thus, for a drilling rate of $20 \mathrm{ft} / \mathrm{hr}$, a 50 -ft guide shoe used with a 22,000 -ft drill string with 5 -ft rubber spacing, 40,000-lb end weight and $5^{\circ}$ angular deviation would yield an expected life of $(2.5)(20)$ or 50 holes.

All of the results presented for the guide shoe correspond to a design angular deviation of $8.5^{\circ}$. The design deviation is a critical factor in the design of the guide shoe, for it must be large enough to accommodate any conceivable roll/pitch angle (any angular deviation greater than the design value would lead to catastrophic failure due to the uncontrolled bending radius at the lower end of the shoe). On the other hand, the guide shoe radius $R$ varies inversely with the design angular deviation $\theta$ :

$$
R=\frac{h}{\sin \theta}
$$

so that large values of $\theta$ imply small bending radii and, hence, large bending stresses and small fatigue lives. This tradeoff between assured control of the bending radius and short fatigue life is the basic shortcoming of the guide shoe concept. In reviewing the accompanying figures for the guide shoe system, it should be borne in mind that the fatigue lives could be significantly improved by lessening the design angular deviation from $8.5^{\circ}$. However, clear justification for such practice would have to be provided in terms of data from severe drilling operations. 
It should be recognized that the following results apply to sections of the drill string which are supporting the full indicated string length below. The lower-most sections of the string, as they descend through the guide, support very little string length, and, hence, these sections incur appreciably less fatigue damage than sections higher up on the string. This fact is made clear by studying the preceding figures. If sections of the drill string are rotated about from hole to hole by being inserted near the bottom, centrally, or upper most on the string, these sections can be expected to enjoy uniformly long fatigue lives.

The data displayed in the foregoing figures lead to the following observations concerning fatigue life of the string with the guide shoe system:

(1) Rubber spacing of $5 \mathrm{ft}$ improves the fatigue life by a factor of about 3 over a 10 -ft rubber spacing, depending upon the string length.

(2) The fatigue life is degraded by about $30 \%$ for each additional degree of angular deviation in the range from 3 to $7^{\circ}$.

(3) The fatigue life is substantially improved (nearly exponentially) with increased height of guide shoe.

(4) The fatigue life for a $40,000-\mathrm{lb}$ end weight is about $70 \%$ of the life for a zero end weight.

\subsection{Picalo}

Figures 4.3.1 through 4.3.8 summarize the expected fatigue life of the drill string when used in conjunction with the picalo system. The fatigue lives are presented in terms of the ratio of the number of holes which can be drilled to the drilling rate $\dot{x}$, just as was done for the guide shoe system. This is done for the same reason as before, viz, that the fatigue life is directly proportional to $\dot{x}$. Thus, these data for the picalo system can be compared directly with those for the guide shoe. All of the data presented correspond to a design length of $18,000 \mathrm{ft} . *$

Several of the conclusions drawn from the guide shoe data are applicable for the picalo system, as well. Here also, for example, it should be recognized that these fatigue lives are valid for a pipe section which is always placed so as to support a string length of the indicated amount. The fatigue lives of the string segments can be measurably increased by following a program of rotation whereby all segments are employed at the lower, central, and upper end of the string from time-to-time. If such a program is followed, the following predicted lives severely underestimate the actual lives by a rather wide margin.

The following general conclusions result from the data presented:

(1) Rubber spacing of $5 \mathrm{ft}$ improves the fatigue life of the string by a factor of from 3 to 5 over a 10 -ft rubber spacing, depending on the string length.

(2) The fatigue life of the string is degraded by a factor of about 2 to 4 for each additional degree of angular deviation in the range from 3 to $7^{\circ}$.

(3) The fatigue life is improved with increased height of the picalo by a near exponential relationship.

(4) The fatigue life for a $40,000-\mathrm{lb}$ end weight is about $65 \%$ of the life for a zero end weight.

\footnotetext{
*Refer to Section 3.2 of this report for a discussion of the meaning and implications of the design length.
} 


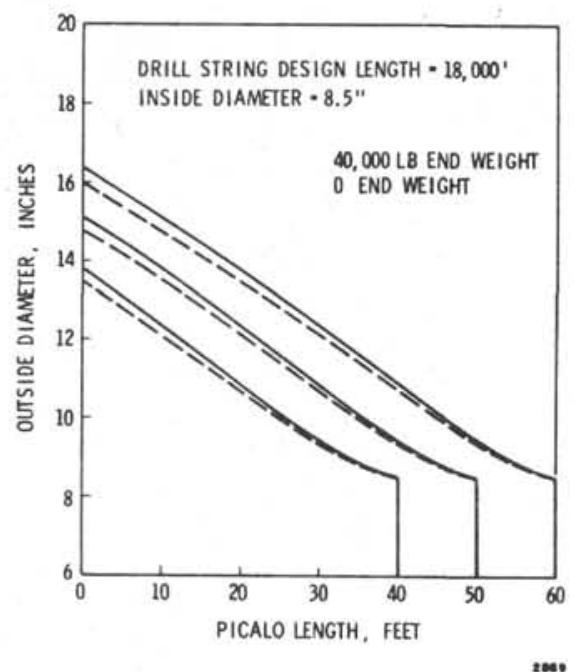

Figure 4.3.1-Picalo Design Profiles

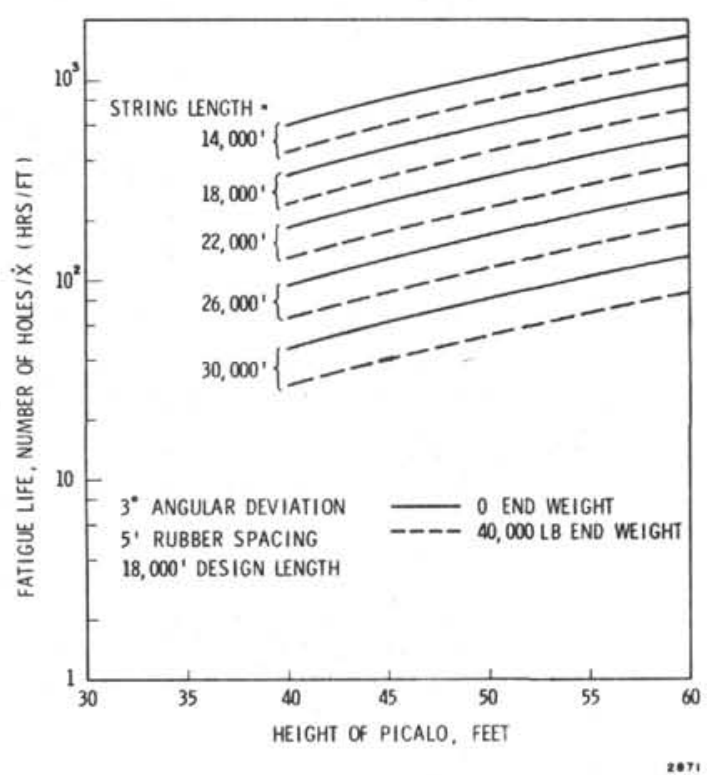

Figure 4.3.3-Fatigue Life of String with Picalo System

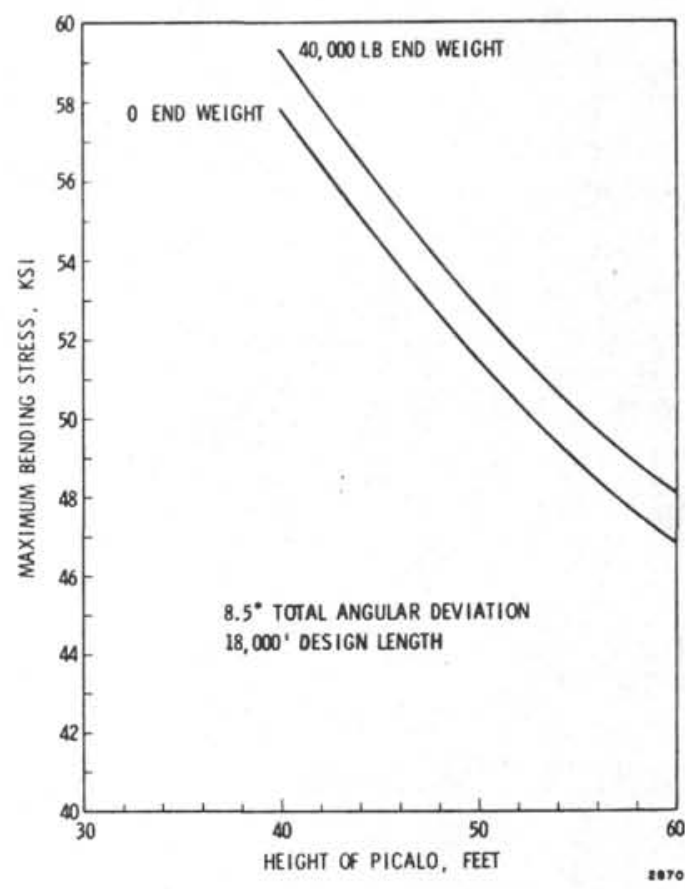

Figure 4.3.2-Bending Stresses in Picalo

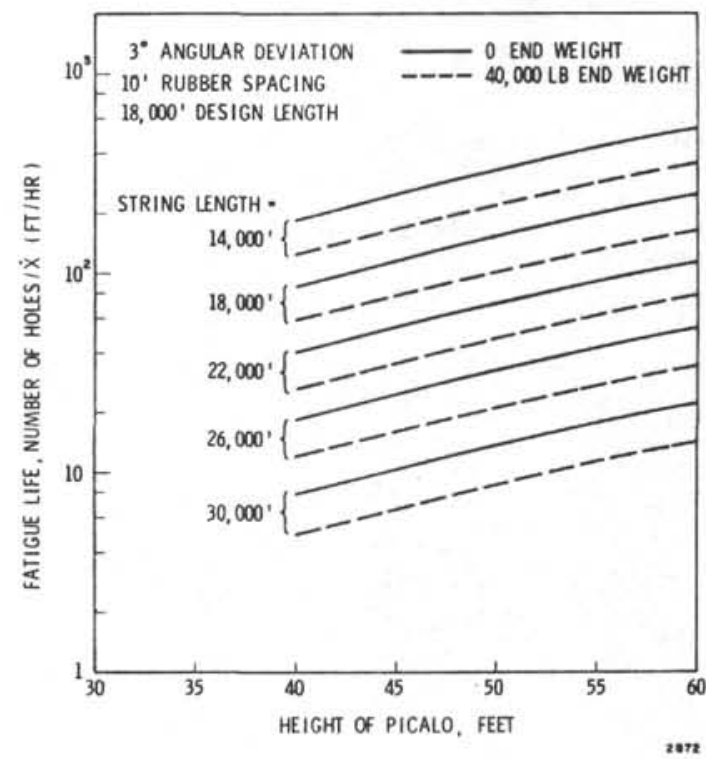

Figure 4.3.4-Fatigue Life of String with Picalo System 


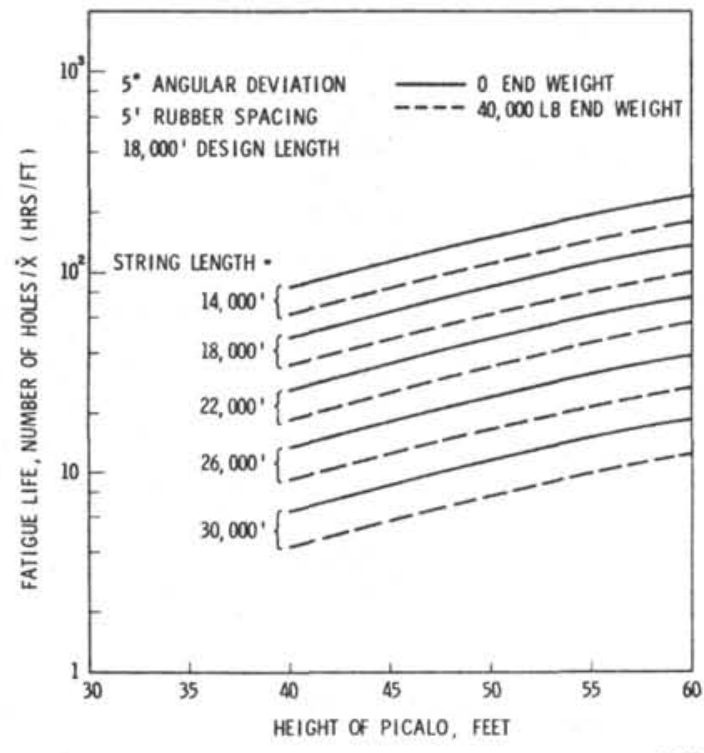

Figure 4.3.5-Fatigue Life of String with Picalo System

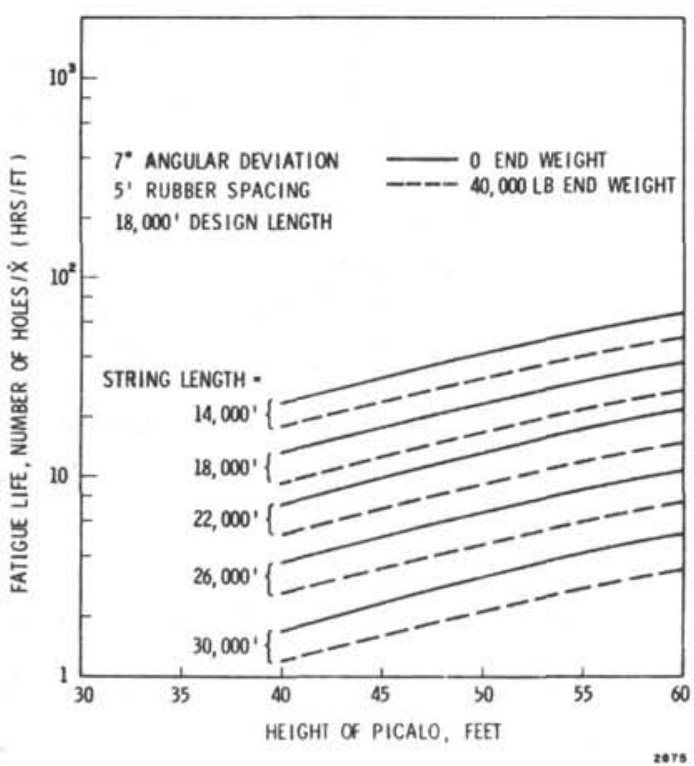

Figure 4.3.7-Fatigue Life of String with Picalo System

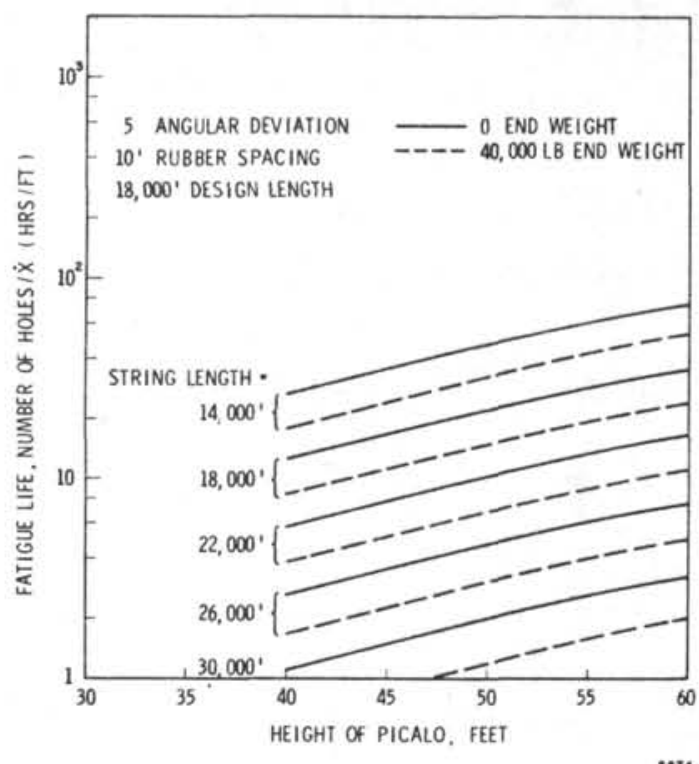

Figure 4.3.6-Fatigue Life of String with Picalo System

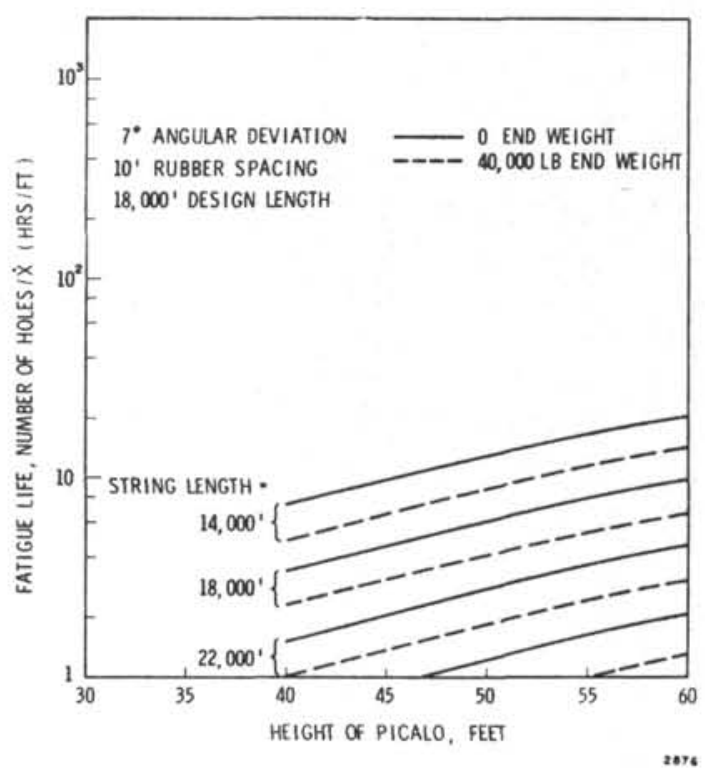

Figure 4.3.8-Fatigue Life of String with Picalo System 


\section{SECTION 5. CONCLUSIONS AND RECOMMENDATIONS}

This section presents the main conclusions and recommendations which follow from the results found in the present study. These remarks, therefore, are necessarily presented in the light of the limitations of this study, viz., only two of several potentially feasible guide systems were studied in detail, and the existing structural details of the Glomar Challenger were not investigated in sufficient depth to enable any recommendations to be made regarding specific design details. The ideas of this section are presented in three separate categories: Conclusions; Recommendations for Current Operations; Recommendations Regarding Future Operations.

\subsection{Conclusions}

A number of detailed conclusions are presented in Section 4, Computed Results, for heave dynamics effects and for the guide shoe and picalo systems. The conclusions presented below are of a more general nature and fall within the framework of the overall objectives of the present program. Earlier sections of this report should be consulted for further information related to the topics mentioned below.

The first conclusion drawn from this study is that fatigue life, and not peak stress. is the principal design criterion for the drill string under current operating conditions. Under the most adverse set of conditions that can realistically be supposed, the peak stresses are well within the yield strength of the S-135 drill pipe.

A guide system of some kind is essential to assure the structural integrity of the string. The fatigue life of the drill string is very sensitive to the magnitude of the bending deflections which arise in string deployment and operation, and these deflections must be adequately controlled.

Since much of the work presented in this report was based upon the earlier work of Vreeland $(1.1,1.2)$, it is appropriate to note certain comparisons between the two studies. In general. the present analysis predicts somewhat higher dynamic stresses under heave conditions than does the work of Vreeland. While there are differences in some of the mathematical relationships (in places, substantial), no unusually conservative assumptions were found in the earlier work which. if removed, would lead to increased life predictions. It was found here, as in the Vreeland study. that heave dynamics in response to random sea states is not a design condition. In fact. the present study predicts string stresses in a random sea which are somewhat lower than those predicted by Vreeland. Regarding the guide shoe and the picalo systems, the present results agree rather well with those given by Vreeland.

It may be concluded from the present study that the picalo system is much superior to the guide shoe system in terms of the fatigue life of the drill string. This conclusion follows by comparing the two under realistically severe operating conditions. Consider. for example. operations involving a $3^{\circ}$ angular deviation in response to roll and pitch motions. and a 20,000-ft string with rubbers spaced $5 \mathrm{ft}$ apart. For a drilling rate of $30 \mathrm{ft} / \mathrm{hr}$ and a $52-\mathrm{ft}$ guide shoe, the string will survive about $7(30)=210$ holes, whereas with a picalo of the same length, the string will survive about $400(30)=12,000$ holes. This substantial difference is due largely to the fact that the guide shoe must be designed to accommodate angular excursions of the largest magnitude which can conceivably occur. The picalo system, on the other hand, provides bending restraint for all angular deviations, and is a much more "efficient" system. 
It is useful to compare the life estimates given above with the life of the string under comparably severe heaving motions. Consider the same 20,000-ft drill string having rubbers spaced $5 \mathrm{ft}$ apart. Assume a sea having 10-ft swells, and a fraction of maximum stable sinusoidal swell (FMSSS) of 0.5 . The fatigue life of the string under these conditions will be about $2 \times 10^{4}$ hotirs. This will enable 1000 holes to be drilled to $600 \mathrm{ft}$ each at $30 \mathrm{ft} / \mathrm{hr}$. When compared with the fatigue life of the string with the picalo system, this calculation suggests that heave motions, not roll and pitch, may be the governing design criterion, depending, of course, on the specific picalo design. When compared with the guide shoe, roll and pitch may govern.

One popular restraining system that was not investigated in the present study is the kelly system. This system typically utilizes a specially-designed length of hex-pipe suspended from the top by a hook attached to a swivel bail. The kelly pipe passes through a gimbal-mounted bushing and attaches to the drill pipe. Hansford and Lubinski $(5.1)$ have investigated the fatigue life of grades $\mathrm{D}$ and $\mathrm{E}$ drill pipe using a particular kelly system for restraint. They estimated that the number of holes which the pipe can survive is about 1.85 times the drilling rate, for $5^{\circ}$ angular deviations and for a wide range of typical hook loads. This figure compares favorably with life estimates employing the guide shoe system for the present study, especially in view of the fact that S-135 drill pipe has a higher fatigue life than Grades D or E pipe. Thus, it is possible that a kelly-type restraint system would be an attractive alternative to the guide shoe or picalo. Such a system would render keelhauling unnecessary, although it makes deployment of the drill string a more time-consuming operation. Some detailed study, however, of the kelly system would have to be made in terms of the Glomar Challenger operations before meaningful comparisons could be made between these various systems.

\subsection{Recommendations for Current Operations}

The single major obstacle preventing more realistic estimates of the string fatigue life is the determination of the loading environments due to heave and to roll and pitch motions. Accordingly. it is recommended that procedures be effected to determine the (deterministic) sea state for typical. severe drilling environments. There are two equivalent ways of going about this:

(1) Measure the wave height $H_{\mathrm{m} \text { ax }}$ and the wave length $\lambda$ directly. From these data. the period $T$ may be calculated according to the equation

$$
T^{2}=\frac{2 \pi \lambda}{g}\left[1+\left(\frac{2 \pi H_{\mathrm{max}}}{\lambda}\right)^{2}\right]^{-1}
$$

given in Section 2.2 of this report. Once $T$ is known, the fraction of maximum stable sinusoidal swell (FMSSS) may be computed as

$$
\text { FMSSS }=\frac{H_{\mathrm{max}}}{0.8} \frac{1 T^{2}}{7 T^{2}}
$$

This would serve to determine the validity of the 0.5 fraction assumed for many of the results calculated in Section 4. Furthermore, the computer program could be rerun using as direct input the measured values of $H_{\mathrm{m} \text { ax }}$ and $H_{\mathrm{m} \text { ax }} / \lambda$.

(2) As an alternative to the procedure outlined above, the wave height $H_{\mathrm{m}}$ ax and the period $T$ could be measured directly. This approach would permit the FMSSS to be calculated directly from Eq. (5.2), and then compared with values suggested elsewhere in this report. In order to provide input to the computer program. the 
wave length $\lambda$ can be estimated from Eq. (5.1). This equation leads to a cubic expression for $\lambda$ :

$$
\lambda^{3}-\left(\frac{g T^{2}}{2 \pi}\right) \lambda^{2}-2 \pi g H_{\mathrm{max}}^{2} T^{2}=0
$$

which has the solution*

$$
\lambda=\frac{g T^{2}}{6 \pi}+(A+B)
$$

where

$$
\left(\begin{array}{l}
A \\
B
\end{array}\right)=\sqrt[3]{\frac{g T^{2}}{54}\left(\frac{g^{2} T^{4}}{4 \pi^{3}}+54 \pi H_{\mathrm{max}}^{2}\right) \pm \sqrt{\frac{g^{2} T^{4} H_{\mathrm{max}}^{2}}{108 \pi^{2}}\left(g^{2} T^{4}+108 \pi^{4} H_{\mathrm{max}}^{2}\right)}}
$$

Either of these two sets of measurements can be made with standard measurement tools generally available, and either procedure would lead to considerably more confidence in the fatigue life estimates of the drill string.

It is recommended that steps be taken to insure a uniform 5-ft rubber spacing on all lengths of drill pipe. While the pipe now is equipped nominally with this spacing, in fact. there is a great variability in rubber spacing due to slippage, etc. The results presented in this report show that the fatigue life of a pipe strand, with either the guide shoe or the picalo, is degraded by a factor of from three to five if there is any 10 -ft spacing between adjacent rubbers. This sensitivity of fatigue life to rubber spacing is too serious to be ignored, and some program of spacing maintenance should be begun.

\subsection{Recommendations Regarding Future Operations}

The scope of the present study was limited specifically to evaluation of the guide shoe and picalo restraint systems. It is known that the existing guide shoe system is satisfactory in terms of assuring the integrity of the drill string under operating conditions. Desirable modifications to the present guide shoe system can only be achieved by relaxing the angular deviation design criterion (presently $8.5^{\circ}$ ), which requires a much more definitive evaluation of the roll and pitch motions of the vessel under severe drilling environments. It is possible that an entirely new guide shoe system could be designed which would have an inside diameter large enough to accommodate the landing base. Such a system would be mounted inside the moon pool. It would suffer the disadvantages in that it would protrude a significant distance below the bottom of the ship hull, would be very massive, and could not be retrieved through the moon pool.

In light of all the conclusions drawn from the present study. it is recommended that work be started on the design of a picalo restraint system. An entirely satisfactory system could be based upon a design length of less than $50 \mathrm{ft}$. Two attractive structural concepts which are compatib!e with ready access to the landing base and other gear at the end of the string are:

(1) Retractable picalo

(2) "Clamshell" picalo.

*It can be shown that Eq. (5.3) has but one real root. 
Of these two, the first is the more attractive if it can be designed within the constraints of the existing ship structure. This coricept involves a picalo that, when in operation, is fixed at its upper end at the deck level immediately below the drilling platform and protrudes down into the moon pool. For purposes of access to the landing base and other gear. the picalo would be retracted upwards through the drilling platform to clear the area within and immediately above the moon pool. This could be done by means of an electric or hydraulic hoisting device.

The "clamshell" concept involves fixing the picalo permanently at the deck level immediately below the drilling platform. The picalo would be split vertically, so as to consist of two halves which would be bolted or otherwise fastened together during string deployment. For access purposes, the two halves would open apart at the hinge points and fold upward out of the way.

The determination of which of these two design concepts is the more attractive and technically feasible would depend upon a detailed study of the existing ship structure and its ability to accommodate a picalo structure of the size required.

If it is found that neither of the above-mentioned picalo concepts (or an equivalent) is technically feasible, it is recommended that a study of the kelly system vis-a-vis a modified guide shoe be undertaken. The present report gives all the analysis needed to evaluate a modified guide shoe system. The kelly system, on the other hand, would require some preliminary analytical study to determine whether an existing kelly would be adequate, or if a specially designed system (employing, perhaps, a Greyhound string) would be needed. Then, on the basis of a comparison between the kelly and the modified guide shoe systems, a new restraint system design would be undertaken. 


\section{SECTION 6. COMPUTER PROGRAM DOCUMENTATION}

\subsection{General}

The program SCRIPPS calculates the stresses in the drill string and the expected string life for drilling operations under the conditions of ship heave, and roll and pitch. The program will handle a wide variety of drilling conditions including variations in the sea state, the roll or pitch angle of the ship, the drill string configuration, and the drilling rates. In addition, for roll and pitch, the calculations can be performed with either a rigid guide (guide shoe) or a flexible guide (picalo).

To calculate the stresses in the drill string for ship heave, the equations governing the longitudinal motion of the string are solved to obtain the maximum displacement and dynamic stress. A solution can be obtained for heave motions of the ship due to swells of constant amplitude and period, or to random seas. For response to swells, the sea state is defined by the wave height. length, and period. Input to the program is in terms of the double amplitude of the wave height and the wave height to wave length ratio. An expression relating the period of the wave to its height and length is included in the program. The basis for the expression is explained in Section 2.2 of this report.

Because the response of the drill string is sensitive to the swell frequency, the ratio of the wave height to wave length, which affects the swell frequency, significantly affects the string response. Hence, for any given wave height, it may be necessary to vary the wave length over some reasonable range to find the maximum string response. If the relationship of wave height to wave length is fairly constant in the open seas, then such a procedure would not be warranted. For maximum stable sinusoidal swells, the ratio of wave height to wave length is 0.0890 . Ochi $(2.2)$ gives the ratio for mild regular and severe regular waves in Sea State 7 as 0.0286 and 0.050 , respectively. In the example problem, included at the end of the section, maximum stable sinusoidal swells were assumed.

For the response to random seas, the integrated spectral density of the sea (the area under the power spectral density plot) is the input parameter which defines the sea state. A trigonometric function is used by the program to approximate the shape of the power spectral density curve. Refer to Section 2.2 of the report for a description of this function.

In addition to the sea state, the longitudinal response of the string is affected by the length of the string, the concentrated mass at the end of the string, the number and size of the rubbers, and the number and size of the damping disks, all of which are included as input parameters.

For roll and pitch, the stresses in the string and the string life are determined for an assumed angular deviation of the ship in roll and/or pitch motions. These calculations can be performed for either the rigid or the flexible guide. When the flexible guide is specified, the guide stiffness parameters are calculated by the program and included in the printout. Since the flexible guide can be designed to provide constant radius for only one value of tension in the drill string. a design length must be specified which, together with the concentrated mass at the end of the string, determines the design tension load. For the rigid guide, the height of the guide and the maximum allowable angular deviation for which the guide is designed define the guide radius. In addition to the angular deviation of the ship in roll or pitch and the guide design parameters, the stresses in the drill string and the string life are affected by the string length, rubber spacing, concentrated mass at the end of the string. and the drilling rate. All of these parameters are included as input data. 
Standard pipe parameters are included as constants in the program, that is. parameters for a 5 -in. diameter S-135 steel pipe weighing $19.5 \mathrm{lb} / \mathrm{ft}$. In addition, an option is provided so that new pipe parameters can be inserted if desired. Other options permit the user to calculate the response of the string either to heave motion or roll and pitch of the ship, to select the type of guide to be used for roll and pitch, and the type of seas for heave response. Also, for a single run up to twenty different values of the string length, concentrated mass at the end of the string, swell height. random sea state, and angle of roll or pitch of the ship can be included. These multiple valued parameters are nested in "DO loops" in the program, as shown below:

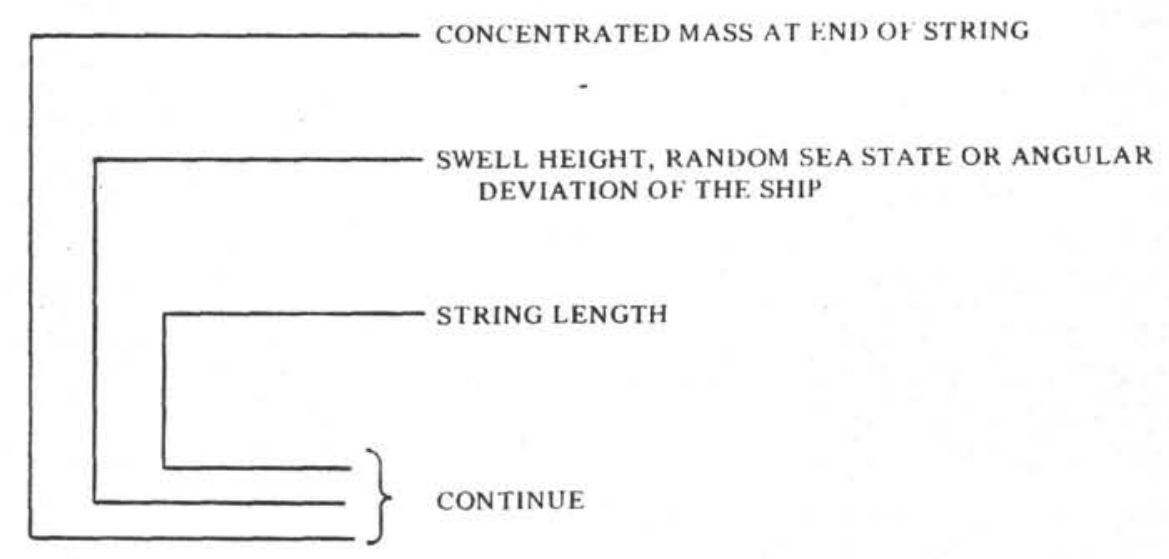

The input variable for the outer loop is always the concentrated mass at the end of the string, and for the inner loop, the string length. For the middle loop, the input variable depends upon the type of calculation and, thus, the subroutine being used in the program. (The subroutines and their functions are explained under the program listing.)

\subsection{Input Data}

1. HEADING CARD (10A8)

Cols. 1-80: HED

2. CONTROL CARD (8I5)

Cols. 1-5: IPP

6-10: IHEAVE

11-15: IPITCH

16-20: MXL
Heading to be printed with the output.

Index for pipe parameter option-punch 1 if new pipe parameters are to be input; otherwise leave blank.

Index for heave response options

blank - omit heave response

+1 - heave response to swells

+2 - heave response to random seas

$-1 \quad-$ heave response to both swells and random seas

Index for roll and pitch options

blank - omit roll and pitch calculation

$+1 \quad-$ roll and pitch with flexible guide

+2 - roll and pitch with rigid guide

$-1 \quad$ - roll and pitch with both the

flexible and rigid guides

Number of different string lengths to be included in the input data (20 maximum) 
21-25: MMC

26-30: MHMAX

31-35: MSTATE

36-40: MTHETA

3. GENERAL DATA (8E10.0)

Cols. 1-10: RSPACE

11-20: XL(1)

21-30: XL(2)

31-40: $\mathrm{XMC}(1)$

41-50: $\mathrm{XMC}(2)$
Number of different values of concentrated mass at the end of the string to be included in the input data $(20$ maximum)

Number of different wave heights to be included in the input data (for heave response to swells only) (20 maximum)

Number of different random sea states to be included in the input data (for heave response to random seas only) (20 maximum)

Number of different values of the angular deviation of the ship in pitch or roll to be included in the input data (for roll and pitch option only) (20 maximum)

Spacing of the rubbers along the string ( $\mathrm{ft}$ )

Length of drill string $(\mathrm{ft})$

Continue until $\mathrm{XL}(\mathrm{I}), \mathrm{I}=1, \mathrm{MXL}$ is satisfied

Mass at end of string (lb)

Continue until XMC(I), I = $1, \mathrm{MMC}$ is satisfied

4. ALTERNATE PIPE PARAMETERS [if IPP = 1] $(6 \mathrm{E} 10.0)$

Cols. 1-10: DP

11-20: AP

21-30: WTP

31-40: SU

41-50: E

51-60: DRUB
Outside diameter of the pipe (in.)

Pipe cross-sectional area $\left(\mathrm{in}^{2}\right)$

Weight of pipe $(\mathrm{lb} / \mathrm{ft})$

Ultimate tensile strength of the pipe (psi)

Elastic modulus of the pipe (psi)

Outside diameter of the rubbers (in.)

5. DAMPING DISKS [for heave response] (3E10.0)

Cols. 1-10: XN

11-20: DD

21-30: RATIO
Number of damping disks at end of string

Diameter of the damping disks ( $\mathrm{ft}$ )

Wave height divided by wave length (for response to swells only) 
6. SWELL HEIGHTS [for heave response to swells] (8E10.0)

Cols. 1-10: $\operatorname{HMAX}(1) \quad$ Double amplitude of swell height ( $\mathrm{ft}$ )

11-20: $\operatorname{HMAX}(2) \quad$ Continue until $\operatorname{HMAX}(1), \mathrm{I}=1$, MHMAX is satisfied

7. RANDOM SEA STATE [ for heave response to random seas] (8E10.0)

Cols. 1-10: STATE(1) Integrated spectral energy of the random sea $\left(\mathrm{ft}^{2}\right)$

11-20: STATE(2) Continue until STATE(I), I = 1, MSTATE is satisfied

8. ROLL AND PITCH (6E10.0)

Cols. 1-10: RPM Rotary drilling speed (rpm)

11-20: XDOT Linear drilling rate $(\mathrm{ft} / \mathrm{hr})$

21-30: $\mathrm{H} \quad$ Height of guide $(\mathrm{ft})$

31-40: DTOP Inside diameter at top of guide (in.)

41-50: THETAD Maximum angle for which the guide shoe is designed and the angle for which the stress in the flexible guide is calculated (degrees)

51-60: XLD Length of drill string for which the flexible guide design parameters are determined ( $\mathrm{ft}$ )

9. ANGULAR DEVIATION IN ROLL OR PITCH (8E10.0)

Cols. 1-10: THETA(1) Single amplitude angular roll or pitch angle of the ship (degrees)

11-20: $\operatorname{THETA}(2) \quad$ Continue until THETA(1), I = 1, MTHETA is satisfied

\subsection{Output Information}

1. HEADING-exactly as input on Card 1

\section{HEAVE RESPONSE}

a. Heading to identify the type of response, i.e.. heave response to swells or random seas

b. Input data which remain invariant for the run. i.c.. the rubber spacing. the number and diameter of the damping disks. the wave height to wave length ratio and the fraction of max. stable sinusoidal swells

c. Subheading to identify concentrated mass at end of string and the swell height or random sea state 
d. For each end mass and sea state combination, the following quantities are printed for each string length [ for random seas, quantities (1) and (6) are rms vilue]:

(1) Maximum dynamic stress [at top of string] (psi)

(2) Equivalent stress which provides for the effects on fatigue life of surface corrosion by the sea water and the mean stress level in the pipe (psi)

(3) Maximum static stress in the string which is equal to the string weight less buoyancy effects ( $p s i)$

(4) Cycles to failure of the string for continuous cycling at the maximum stress levels

(5) Life of the string for continuous operation at the maximum stress levels (hours)

(6) Maximum displacement of the end of the string relative to the ship ( $\mathrm{ft}$ )

(7) Maximum absolute displacement of the end of the string [response to swells only] (ft)

\section{ROLL AND PITCH}

a. Heading to identify type of guide, i.e., roll and pitch-rigid guide or flexible guide

b. Input data which remain invariant for the run, i.c.. the rubber spacing. height of guide, maximum design angle (for rigid guide), design length (for flexible guide), the rotary drilling rate and the linear drilling rate

c. If the flexible guide is used, the outside diameter and moment of inertia of the guide are printed for ten stations along its length. In addition, the maximum stress in the guide (at the top) for an angular deviation of THETAD and with tension in the string corresponding to the design length, XLD. is printed.

d. Subheading identifying the end mass on the string and the roll or pitch angle of the ship

e. For each combination of end mass and roll or pitch angle, the following quantities are printed for each string length:

(1) Maximum dynamic stress in string [bending stress in the pipe while inside the guide] (psi)

(2) Equivalent dynamic stress which provides for the effect upon the fatigue life of surface corrosion by the sea water and the mean stress level (psi)

(3) Maximum static stress in the string which is equal to the string weight less buoyancy effects (psi)

(4) Cycles to failure of the pipe for continuous cycling at the maximum stress levels 
(5) Life in hours-(4) converted to hours based on the rotary drilling rate

(6) Number of holes which can be drilled under the stated conditions-accounts for variations in the stress as ship rolls or pitches and the drilling rates

\subsection{List of Program Parameters}

\begin{tabular}{|c|c|c|c|}
\hline & $\begin{array}{l}\text { Fortran } \\
\text { Symbol }\end{array}$ & Definition & $\begin{array}{c}\text { Variable } \\
\text { Name }\end{array}$ \\
\hline \multicolumn{4}{|c|}{ 1. INPUT PARAMETERS } \\
\hline \multicolumn{4}{|c|}{ a. General } \\
\hline & RSPACE & Rubber spacing along the string ( $\mathrm{ft}$ ) & s \\
\hline & $\mathrm{XL}$ & String length (ft) & $\ell$ \\
\hline & $\mathrm{XMC}$ & Mass at end of string (lb) & M \\
\hline
\end{tabular}

b. Optional Pipe Parameters

\begin{tabular}{|c|c|c|}
\hline AP & Pipe cross-sectional area $\left(\mathrm{in}^{2}\right)$ & $A_{p}$ \\
\hline DP & Pipe outside diameter (in.) & $d_{p}$ \\
\hline DRUB & Outside diameter of rubbers (in.) & $d_{r}$ \\
\hline E & Elastic modulus of pipe (psi) & $\mathrm{E}$ \\
\hline SU & $\begin{array}{l}\text { Ultimate tensile strength of pipe } \\
\text { (psi) }\end{array}$ & $\mathrm{S}_{\mathrm{u}}$ \\
\hline WTP & Weight of the pipe $(\mathrm{lb} / \mathrm{ft})$ & $(\mu)(\mathrm{g})$ \\
\hline \multicolumn{3}{|c|}{ c. Heave Response } \\
\hline DD & Diameter of the damping disks (in.) & $d_{d}$ \\
\hline HMAX & Double amplitude of wave height (ft) & $\mathrm{H}_{\mathrm{max}}$ \\
\hline RATIO & $\begin{array}{l}\text { Ratio of wave height to wave length } \\
\text { (for swells only) }\end{array}$ & $\mathrm{H} / \lambda$ \\
\hline STATE & $\begin{array}{l}\text { Integrated spectral energy of the } \\
\text { random sea }\left(\mathrm{ft}^{2}\right)\end{array}$ & $\Phi_{\mathrm{ss}}(\omega)$ \\
\hline $\mathrm{XN}$ & $\begin{array}{l}\text { Number of damping disks at end of } \\
\text { string }\end{array}$ & $\mathrm{n}$ \\
\hline
\end{tabular}




\begin{tabular}{|c|c|c|}
\hline $\begin{array}{l}\text { Fortran } \\
\text { Symbol }\end{array}$ & Definition & $\begin{array}{l}\text { Variable } \\
\text { Name }\end{array}$ \\
\hline \multicolumn{3}{|l|}{ d. Roll and Pitch } \\
\hline DTOP & Inside diameter at top of guide (in.) & $d$ \\
\hline $\mathrm{H}$ & Height of guide ( $\mathrm{ft}$ ) & $\mathrm{h}$ \\
\hline RPM & Rotary drilling rate ( $\mathrm{rpm})$ & RPM \\
\hline THETA & $\begin{array}{l}\text { Roll or pitch angle of the ship } \\
\text { (degrees) }\end{array}$ & $\theta$ \\
\hline THETAD & $\begin{array}{l}\text { Maximum angle for which the rigid } \\
\text { guide is designed (degrees) }\end{array}$ & $\theta_{\mathrm{d}}$ \\
\hline XDOT & Linear drilling rate $(\mathrm{ft} / \mathrm{hr})$ & $\dot{x}$ \\
\hline XLD & $\begin{array}{l}\text { Length for which the flexible guide } \\
\text { is designed ( } \mathrm{ft} \text { ) }\end{array}$ & $\ell_{\mathrm{d}}$ \\
\hline \multicolumn{3}{|c|}{ 2. PROGRAM CONSTANTS } \\
\hline AP & Pipe cross-sectional area $=5.66 \mathrm{in}^{2}$ & $A_{p}$ \\
\hline DP & Outside diameter of pipe $=5.00 \mathrm{in}^{2}$ & $\mathrm{~d}_{\mathrm{p}}$ \\
\hline DRUB & Outside diameter of rubbers $=7.00 \mathrm{in}$ & $d_{r}$ \\
\hline $\mathrm{CD}$ & Coefficient of fluid drag $=1.12$ & $C_{D}$ \\
\hline $\mathrm{E}$ & Elastic modulus of pipe $=30 \times 10^{6} \mathrm{psi}$ & $\mathrm{E}$ \\
\hline EXPM & $\begin{array}{l}\text { Constant in fatigue life relationship }= \\
3.82\end{array}$ & $\mathrm{~m}$ \\
\hline G & $\begin{array}{l}\text { Acceleration due to gravity }= \\
386 \text { in. } / \mathrm{sec}^{2}\end{array}$ & $\mathrm{~g}$ \\
\hline PI & Universal constant $=3.1416$ & $\pi$ \\
\hline $\mathrm{RH} \emptyset$ & Density of sea water $=63.99 \mathrm{lb} / \mathrm{ft}^{3}$ & $\rho_{\mathrm{f}}$ \\
\hline SU & $\begin{array}{l}\text { Ultimate tensile strength of pipe } \\
=160,000 \mathrm{psi}\end{array}$ & $\mathrm{S}_{\mathrm{u}}$ \\
\hline WTP & Weight of pipe $=19.5 \mathrm{lb} / \mathrm{ft}$ & $(\mu)(\mathrm{g})$ \\
\hline $\mathrm{XK}$ & Constant in added mass term $=2 / \pi$ & $2 / \pi$ \\
\hline
\end{tabular}




\begin{tabular}{|c|c|c|}
\hline $\begin{array}{l}\text { Fortran } \\
\text { Symbol }\end{array}$ & Definition & $\begin{array}{c}\text { Variable } \\
\text { Name }\end{array}$ \\
\hline XKS & $\begin{array}{l}\text { Factor to account for effects of } \\
\text { surface corrosion on fatigue life } \\
\text { of pipe }=0.9\end{array}$ & K \\
\hline XO & $\begin{array}{l}\text { Assumed displacement at end of } \\
\text { string for initial damping calcu- } \\
\text { lation }=50 \mathrm{in.}\end{array}$ & $\mathrm{X}_{0}$ \\
\hline $\mathrm{XNU}$ & $\begin{array}{l}\text { Viscosity of sea water }=1.129 \\
\mathrm{lb}-\mathrm{sec} / \mathrm{ft}^{2}\end{array}$ & $\nu$ \\
\hline
\end{tabular}

3. CALCULATED QUANTITIES

\begin{tabular}{|c|c|c|}
\hline ALFA & Equation (2.17) & $\alpha$ \\
\hline ALFA 1 & Equation (2.10) & $\alpha_{1}$ \\
\hline BETA & Equation (2.11) & $\beta$ \\
\hline $\mathrm{C}$ & $\begin{array}{l}\text { Concentrated damping at end of } \\
\text { string due to damping disks-Table } 2.4 .1\end{array}$ & C \\
\hline $\mathrm{CO}$ & Equation (2.14) & $\mathrm{C}_{0}$ \\
\hline $\mathrm{CYC}$ & Fatigue life of string in cycles & $\mathrm{N}$ \\
\hline $\mathrm{Cl}$ & Equation (2.9) & $c_{1}$ \\
\hline D & Equivalent diameter of the rubbers & d \\
\hline DAMP & $\begin{array}{l}\text { Distributed damping due to fluid } \\
\text { drag on pipe and rubbers-Table 2.4.1 }\end{array}$ & D \\
\hline DBAR & $\begin{array}{l}\text { Equivalent diameter of the damping } \\
\text { disks }\end{array}$ & $\bar{d}$ \\
\hline DIP & Inside diameter of the pipe & d \\
\hline ETA & Equation (2.32) & $\eta$ \\
\hline $\mathrm{F}$ & Equation (2.8) & $\mathrm{F}$ \\
\hline GAMMAF & Gamma function & $\Gamma(1+m / 2)$ \\
\hline GAMA & Equation (2.12) & $\gamma$ \\
\hline HOLES & $\begin{array}{l}\text { Number of holes which can be drilled } \\
\text { under specified drilling conditions }\end{array}$ & $1 / \mathrm{F}$ \\
\hline
\end{tabular}




\begin{tabular}{|c|c|c|}
\hline $\begin{array}{l}\text { Fortran } \\
\text { Symbol }\end{array}$ & Definition & $\begin{array}{l}\text { Variable } \\
\text { Name }\end{array}$ \\
\hline HSSQ & Equation (2.28) & $\mathrm{H}_{\mathrm{S}}{ }^{2}$ \\
\hline HV & Transfer function of the ship & $\mathrm{H}_{\mathrm{V}}$ \\
\hline LIFE & $\begin{array}{l}\text { Life of the string in hours for con- } \\
\text { tinuous cycling at maximum stress }\end{array}$ & $\mathrm{L}$ \\
\hline $\mathrm{NN}$ & Equation (2.7) & $\mathrm{N}$ \\
\hline$\emptyset$ MEGA & Frequency of the forcing function (sea) & $\Omega$ \\
\hline$\emptyset$ MEGA 1 & $\begin{array}{l}\text { Fundamental frequency of the string } \\
\text { longitudinal response }\end{array}$ & $\omega_{1}$ \\
\hline PHEWD & Equation (2.26) & $\Phi_{\eta \eta \dot{w}}$ \\
\hline PHEWDD & Equation (2.27) & $\Phi_{\eta \eta} \ddot{w}$ \\
\hline PHISS & $\begin{array}{l}\text { Power spectral density of the sea- } \\
\text { Equation }(2.33)\end{array}$ & $\Phi_{\mathrm{ss}}$ \\
\hline RDES & $\begin{array}{l}\text { Radius of curvature of the flexible } \\
\text { guide for } \theta=8.5^{\circ} \text { and design } \\
\text { tension in string }\end{array}$ & $\mathrm{R}$ \\
\hline $\mathrm{RH} \emptyset \mathrm{RN}$ & Radius of the guide shoe & $\mathrm{R}$ \\
\hline SEQ & Equivalent stress in pipe & $\sigma_{\mathrm{eq}}$ \\
\hline SGMAX & $\begin{array}{l}\text { Maximum stress in flexible produced } \\
\text { by RDES }\end{array}$ & $\sigma$ \\
\hline SRMS & $\begin{array}{l}\text { Dynamic stress based on rms value of } \\
\text { ship roll or pitch angle }\end{array}$ & $\sigma_{\mathrm{rms}}$ \\
\hline SS & Static stress in string & $\sigma$ \\
\hline STRES & Maximum dynamic stress in string & $\sigma$ \\
\hline STRESR & $\begin{array}{l}\text { Equivalent stress for calculating } \\
\text { fatigue life due to random seas }\end{array}$ & $\sigma_{\mathrm{eq}}$ \\
\hline $\mathrm{T}$ & Period of ocean waves & $\mathrm{T}$ \\
\hline TDES & $\begin{array}{l}\text { Design tension in string for flexible } \\
\text { guide }\end{array}$ & $\mathrm{T}_{\mathrm{d}}$ \\
\hline TEN & Tension in string & $\mathrm{T}$ \\
\hline
\end{tabular}




\begin{tabular}{|c|c|c|}
\hline $\begin{array}{l}\text { Fortran } \\
\text { Symbol }\end{array}$ & Definition & $\begin{array}{c}\text { Variable } \\
\text { Name }\end{array}$ \\
\hline TRMS & Rms value of theta & $\theta_{\mathrm{rm} \mathrm{s}}$ \\
\hline $\mathrm{T} 3$ & Equation (2.15) & $\mathrm{T} 1$ \\
\hline T4 & Equation (2.16) & T2 \\
\hline UL & Absolute displacement at end of string & $\mathrm{u}(\ell)$ \\
\hline VL & $\begin{array}{l}\text { Displacement of string relative to the } \\
\text { ship }\end{array}$ & $\mathrm{v}(\ell)$ \\
\hline WMAX & Heave motion of the ship & W \\
\hline XDG & $\begin{array}{l}\text { Distance along guide measured from } \\
\text { bottom }\end{array}$ & $x, x_{1}$ \\
\hline XIG & Moment of inertia of the guide & I \\
\hline $\mathrm{XM}$ & $\begin{array}{l}\text { Total mass at end of string including } \\
\text { added mass due to the damping disks }\end{array}$ & M \\
\hline XMEAN & $\begin{array}{l}\text { Mean displacement of string for } \\
\text { calculating distributed damping }\end{array}$ & \\
\hline $\mathrm{XMU}$ & $\begin{array}{l}\text { Density of the pipe including } \\
\text { apparent mass effects due to rubbers }\end{array}$ & \\
\hline XMUP & Density of the pipe & $\mu$ \\
\hline $\mathrm{XN} 2$ & $\begin{array}{l}\text { Number of rubbers per unit length of } \\
\text { string }\end{array}$ & $\mathrm{n}_{2}$ \\
\hline
\end{tabular}

\subsection{Program Listing}

The program is composed of a main calling program and six subroutines. A brief explanation of the main program and subroutines is given below, followed by the program listing:

SCRIPPS Main or calling program. Reads heading card. control card and the common data cards. Prints heading and calls subroutines as directed by the control card data.

PAR Subroutine to calculate the string behavior for roll and pitch of the ship. Includes provisions for a rigid or flexible guide.

SUB Subroutine to calculate fatigue life of the string for ship roll or pitch and print output for each string length.

HEAVE Subroutine to calculate the response of the string to heave motions of the ship. 
COMUN Subroutine which contains statements common to the response calculations for both swells and random seas in the HEAVE subroutine.

FATIG Subroutine to calculate the fatigue life of the string for dynamic stresses due to heave motion of the ship.

GMMMA Subroutine to calculate the gamma function for different values of " $m$ " other than that included as a constant in the program.

\subsection{Example Problem}

The example problem uses every option and, therefore, contains, every input parameter in the program. For the multivalued parameters, two each have been included, although any number from 1 to 20 could have been used. Note, however, that if the maximum number of each multivalued parameter is used, particularly in the outer loops, the output becomes exceedingly large.

The input parameters used in the example problem were selected to represent a possible drilling condition with the Glomar Challenger. The ratio of the wave height to wave length is somewhat arbitrary and represents maximum stable sinusoidal swells. This condition may not produce maximum response in drill string. (See Section 4.1 for a more detailed discussion of this point.)

The input data are shown on a data sheet exactly as they would be punched in the data cards. The computer printout of the results follows the input data.

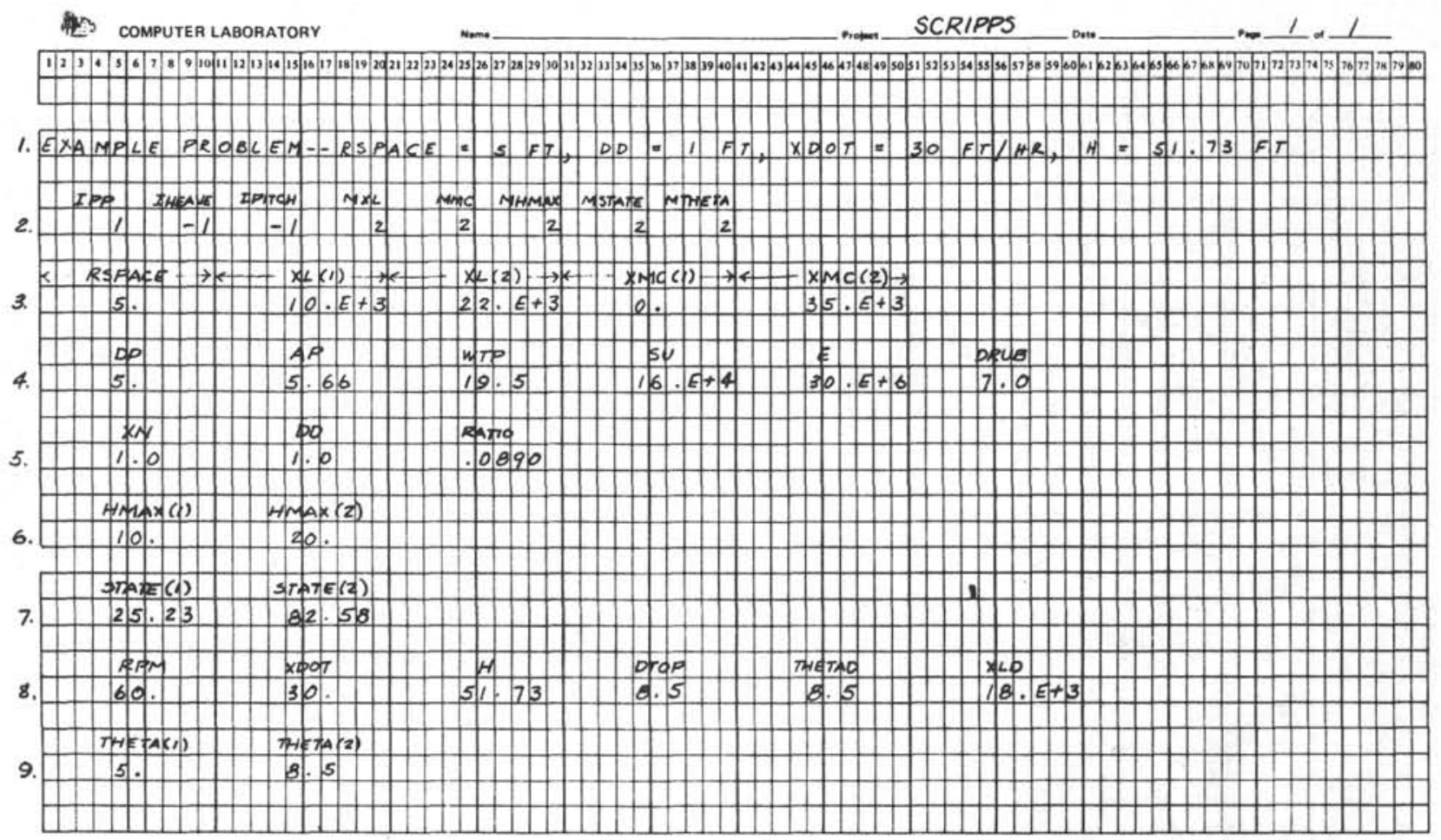



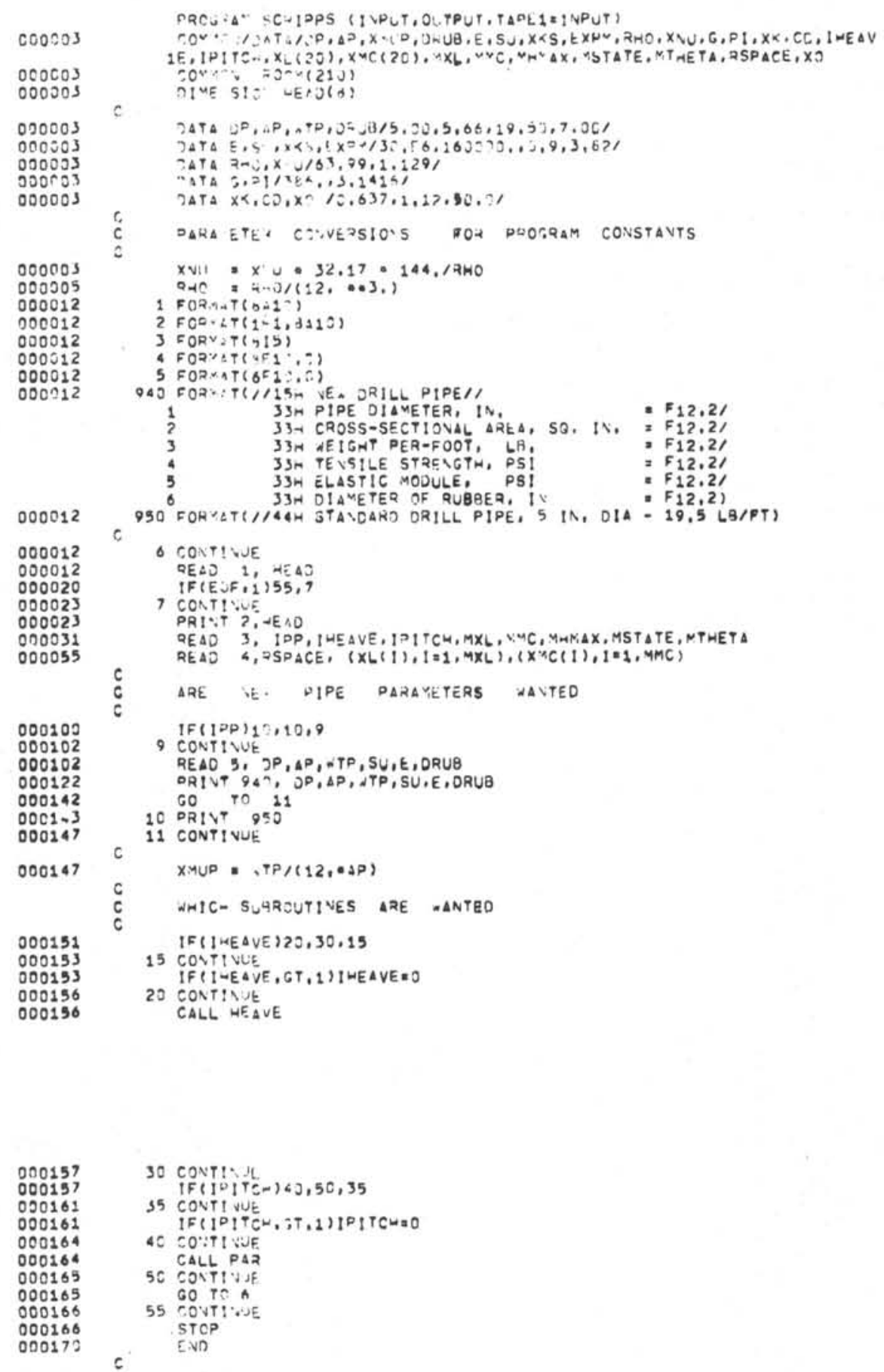
c

SUBROUTI'E PAR

000002

CIMERSSIO THETA(20)

000002

000002

$c$
$c$

IE, IPITCH, X: (20), XMC(20), 4XL, MMC, WHMAX, MSTATE, MTHETA, RSPACE, XO

000002

000002

000013

000020

000020

000024

000024

DARA:ETEA CO.VERSIONS FOR PROGRA COISTAVTS

REAL LIFF

DPI = SNRT $\{$ TP०O2, $* 4, \triangle A P / P I\}$

$X I P=(0: 164,10(D P \bullet 4: D P I \bullet 04)$

1111 FORNAT $(1-1)$

PRINT 1111

1010 FORMAT(BEI? O)

1012 FORMAT (BE 1$)$, O)

1020 FORMLTI/ISNH ROLL $\triangle N D$ PITCH - RIGIO RUIUE /

$122 \mathrm{~N}$ NEIGTH OF GUIDE, FT $=F 6,21$

000024

000024

2 $19 \mathrm{H}$ GUIDE DESIGIEO FDQ,F6,2,9H DEGREES

1052 FORMATE $1 / 36$ M $\triangle N G U L A R$ DEVIATION, DEG

O00024 IN30 FORMATS//4X,16H STRING LENGTH 16H BENDING STRESS.

000024

000024

000024

1 16H EQUIV, STRESS, $16 \mathrm{H}$ STATIC STRESS

16H

1000 FOHMATS/132H ROLL AND PITCH. FLEXIBLE GUIOE/

$122 \mathrm{H}$ HEIGTH CF GUIDE, FT 2 Fo, 21

1070 FORMATL 133 H FUEXE DESIGNED FOR, FIO, 2, 11H FT STRING)

PARAMETERS/6X,

1 18H OIST, FROM TIP ,10W OUTSIDE DIAMETER,

18. POMENT OF INERTIA/10(3F/18,2/)

45H VAX STRESS IN GUIDE FOR ANGULAR DEVIATION OF,FG, 2

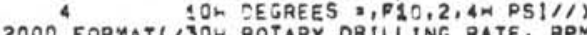

200 FORMATL $30 H$ DOTAPY DRILIING RATE, RPM $=510.21$ 30-. LINEAR ORILLING RATE, FT/HR $\cong F 10.21$
3OW RUBGER SPACING. FT

000024

000044

000057

000061

000062

(1)

000114

00012

000136

000137

000147

000161

000161

000163

REAO 1O1U, DPN, XOOT, H, DTOD, THETAD, XLO

READ 1012, (TNETA(1), 1 1 , MTHETA)

IF(IPITCW)97,98,99

97 CONTIVLE

PRINT 102O,H, THETAD

PRINT 1060,H, XLO

PRIVT $2000, R P Y$, XDOT, RSPACE

GO TO $10 \mathrm{C}$

QB PRINT $: 020, H$, THETAD

PRINT 2ONO, RPY, XกOT, ASPACE

GO TC 100

99 PRINT $1060, \mathrm{HI}$ XL

PRINT 2000, RPM, XOOT, RSPACE

100 CONTINIJE

c

PARAVETFE COUVERSIOVS FOR INPUT DATA

$4: 4 \cdot 12$

$X L O=\times L \div .12$.

000164

000166

THETLD THETAQ - PI/1AO,

DO 10001 1, MMC

PRINT 1:31, XMC(1)

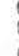

000176

00020

000210

00021

000215

0022

000222

000224

000234

000245

000247

00252

(1)

000301

000303

000311

000315

DESIGN PARAMETERS FOR FLEXIBLE GUIOE

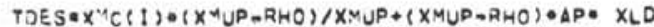

$A L F A D=53 R T$ (TDES/(EQXIP))

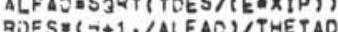

ELEM $=0,0$

ELEM $=0$,

$2 X=411 ?$.

So $35<1,10$

ELEN $=E L E^{4} * D X$

$X G(K)=E L E M$

$X I G(K)=T$ ES $\triangle X G(K) \bullet \bullet 2 /(2, \bullet E)+X 1 P \triangle A L F A D \bullet X G(K)$

$T G(K)=(64, * X I G(K) / P 1+(D T O P) \bullet 04) \bullet 0,25$

39 CONTINJE

$S G Y A X=E \cup D G(10) /(2, \bullet R O E S)$

SGNAXIE ODG(1,T)

PQ1 VT $1=70,(X G(K), O G(K), X 1 G(K), K=1,10)$, PHETAP, SGMAX

TO 1 TOO J: 1, VTMETA

PRTा 12S2, THETA(J)

$T$ TETSI $=$ TACTLCJ) O DI/18C,

DAIVT 1030

$001=0 ? \times 1,{ }^{M} \times 6$ 


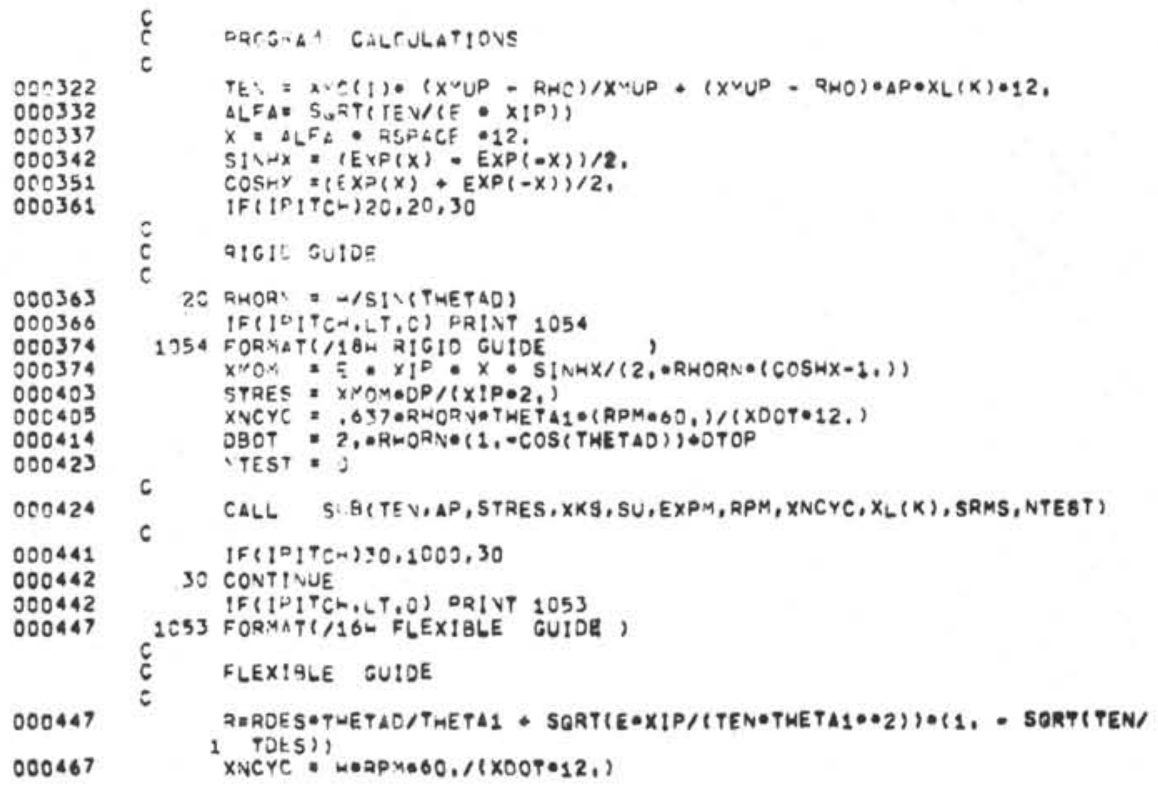

\begin{tabular}{|c|c|c|}
\hline $\begin{array}{l}000474 \\
000503\end{array}$ & & 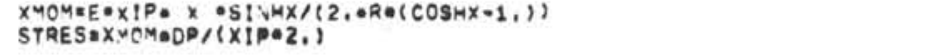 \\
\hline $\begin{array}{l}000505 \\
000507\end{array}$ & $c$ & 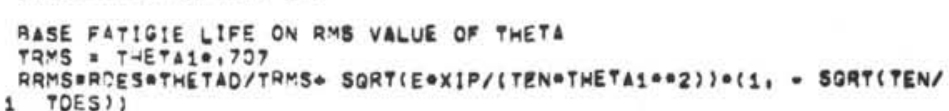 \\
\hline $\begin{array}{l}000527 \\
000536\end{array}$ & & 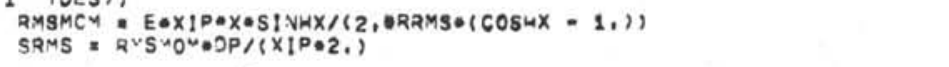 \\
\hline 000541 & 6 & NTEST $=1$ \\
\hline 000542 & C & CALL S: B(TEN, AP, STRES, XKB, SU, EXPM, DPM, XNCYC, XL (K), SRME, NTEST) \\
\hline $\begin{array}{l}000560 \\
000570 \\
000570\end{array}$ & $c_{1000}$ & $\begin{array}{l}\text { CONT:VUE } \\
\text { REPUPN } \\
\text { ENO }\end{array}$ \\
\hline
\end{tabular}




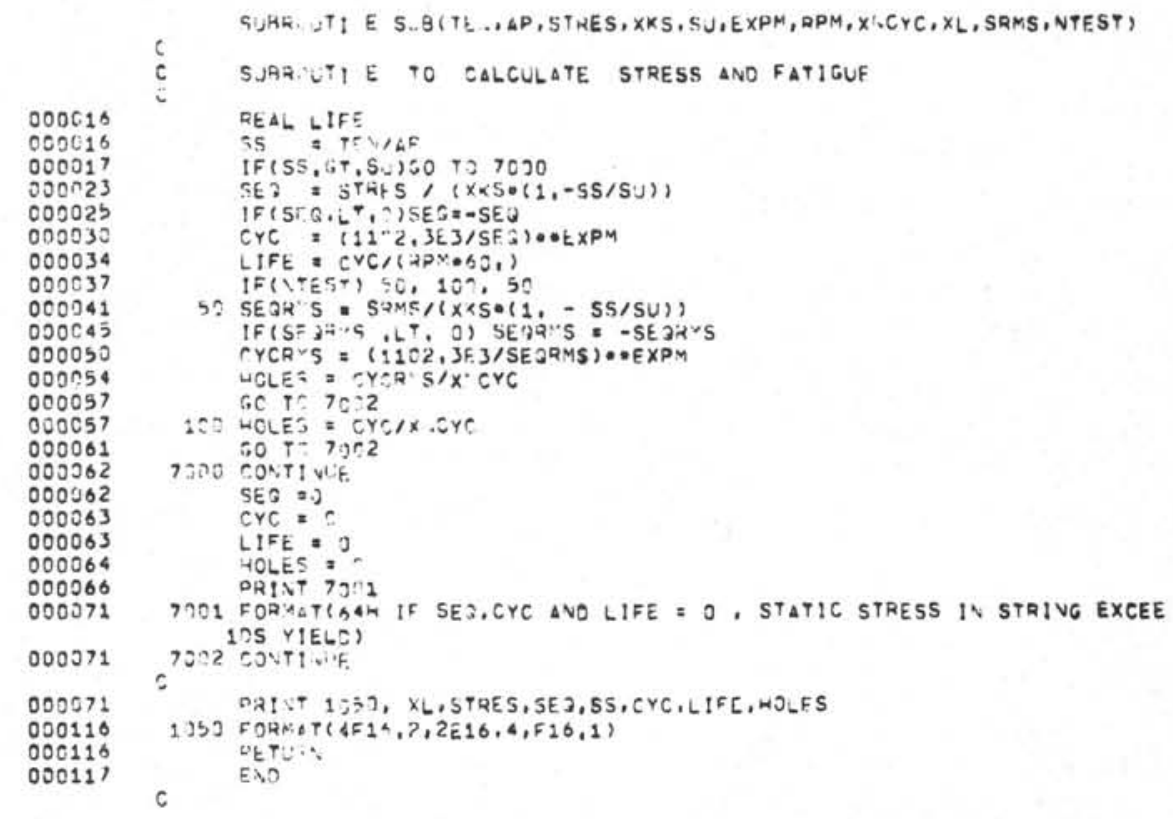



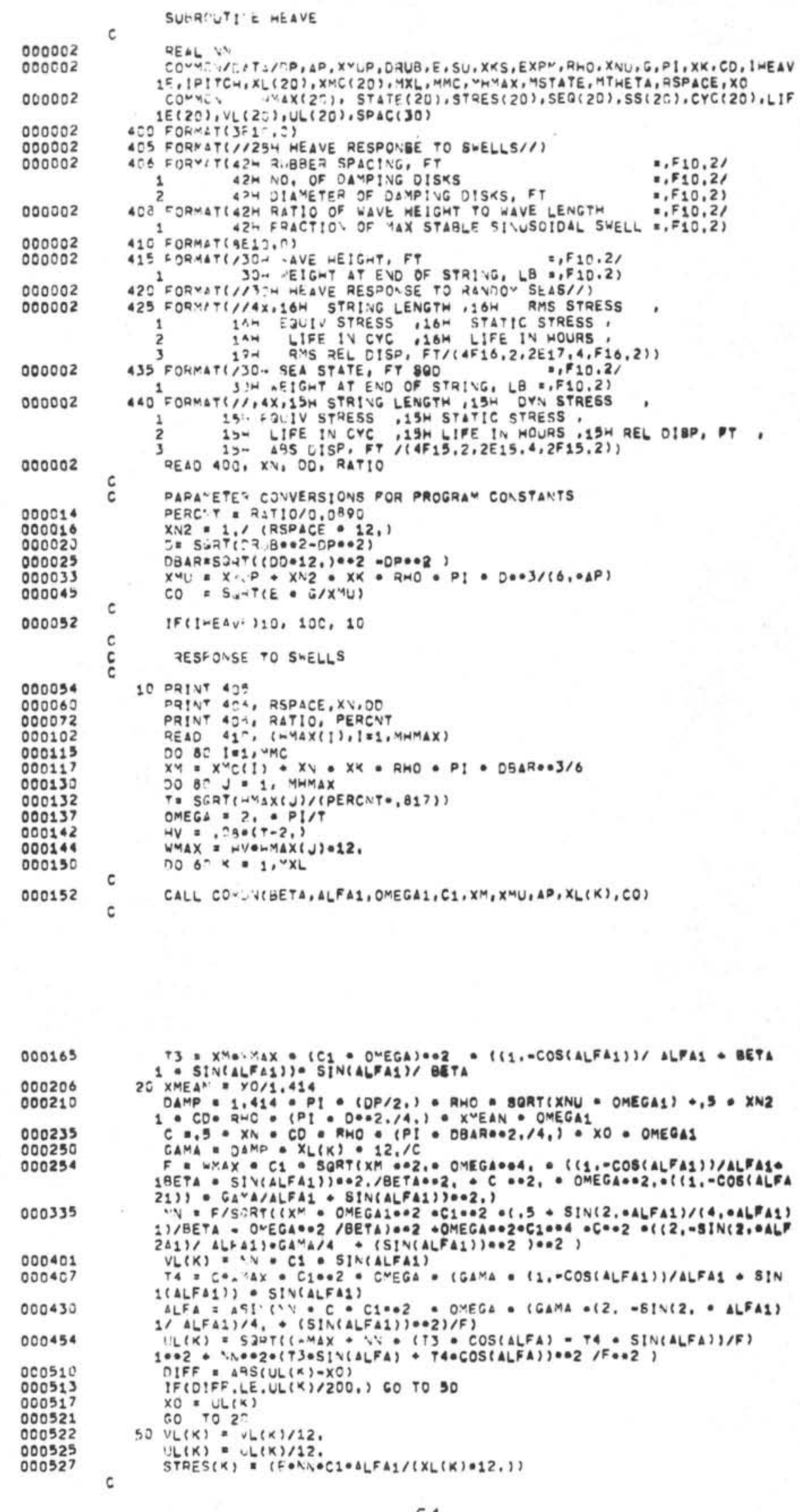

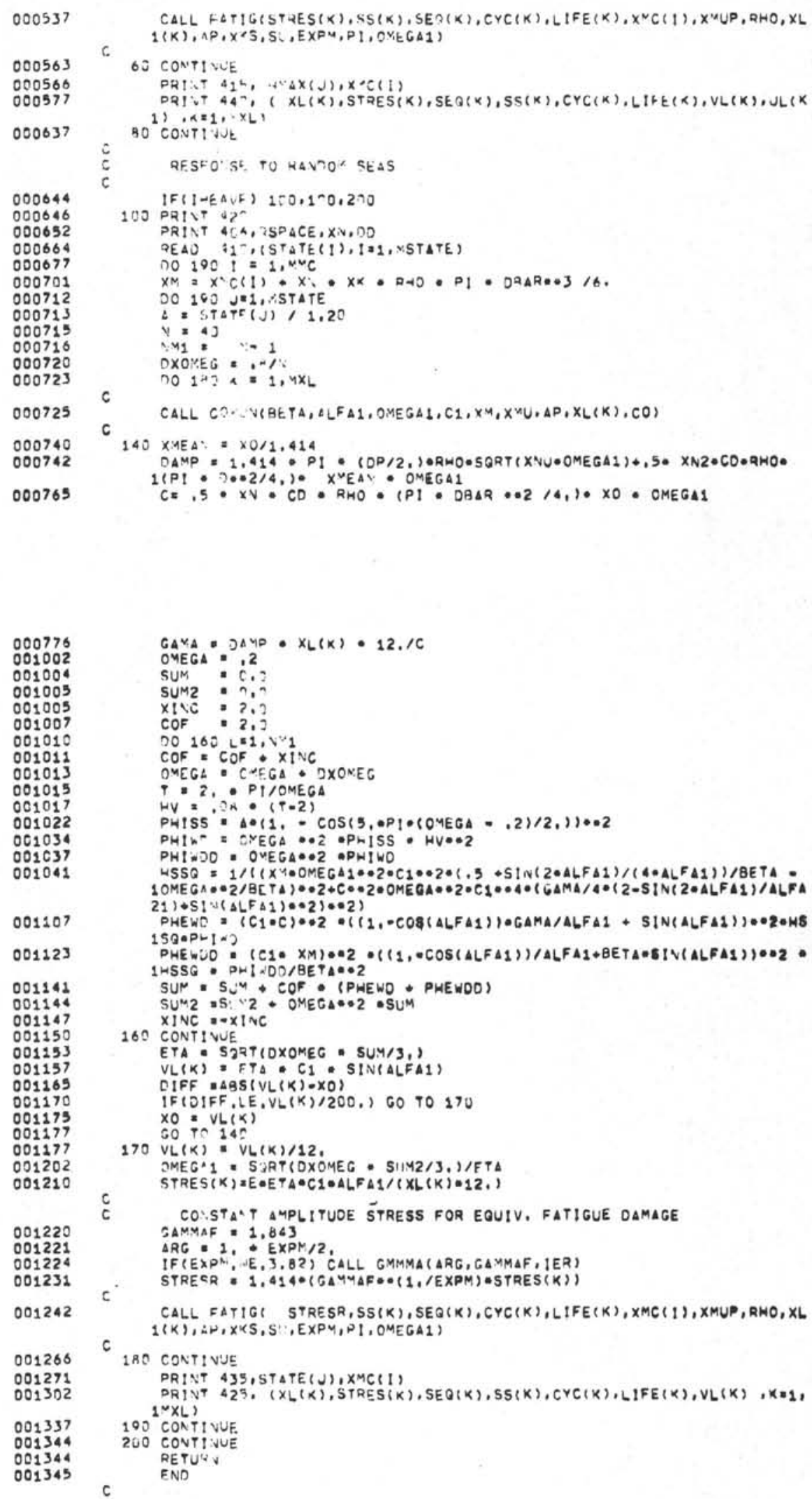


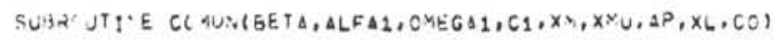

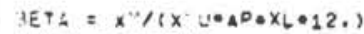

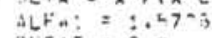

AETA = ?

ALL STC $-4 A S E C)$

4 DIFF = (TETA - BETAT)

IF(A:S( IFF), LE, AETA/2CJ, ) GN TC 23

$\triangle L F A:=\triangle L F A,=, 2$ OIFF

PETAT = (C.S( $\triangle L F A L) / S !)(\triangle L F A I)) / \angle L F A$

CALL SECAN-(YSEC)

IF (Y)

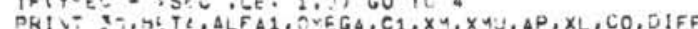

00005

000057

SO TOQ T TE

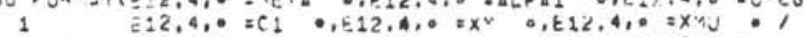

$? \quad \quad \because 2,4,0=: P \quad \because E 12,4,0=X L \quad 0, E 12,4,0=C O \quad \bullet$

$3 \quad F 12,4,0=2 F F+1$

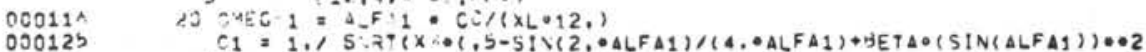

000157

1)

0001626 


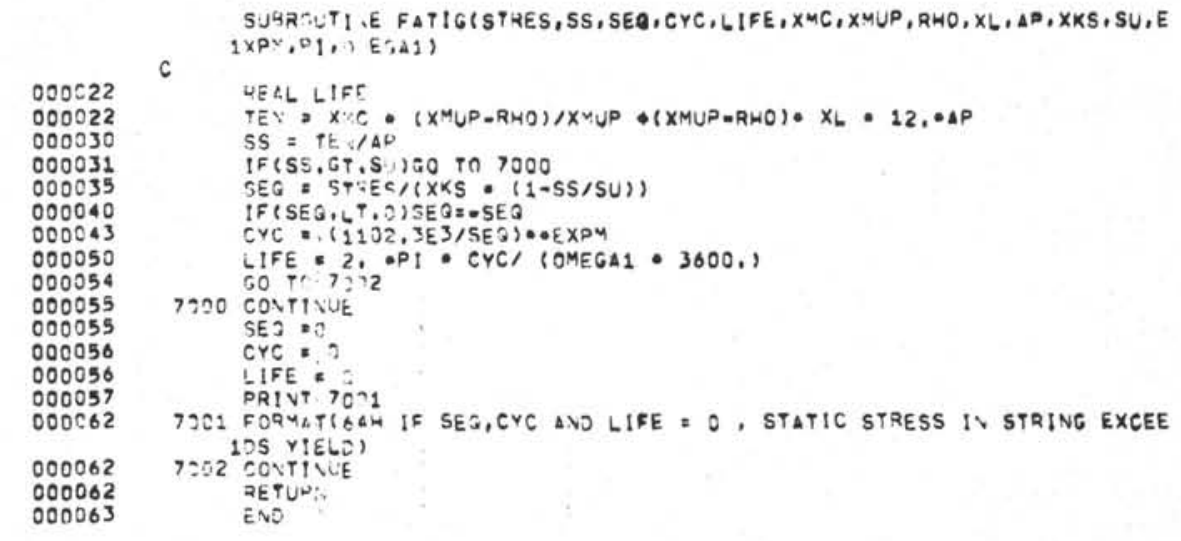




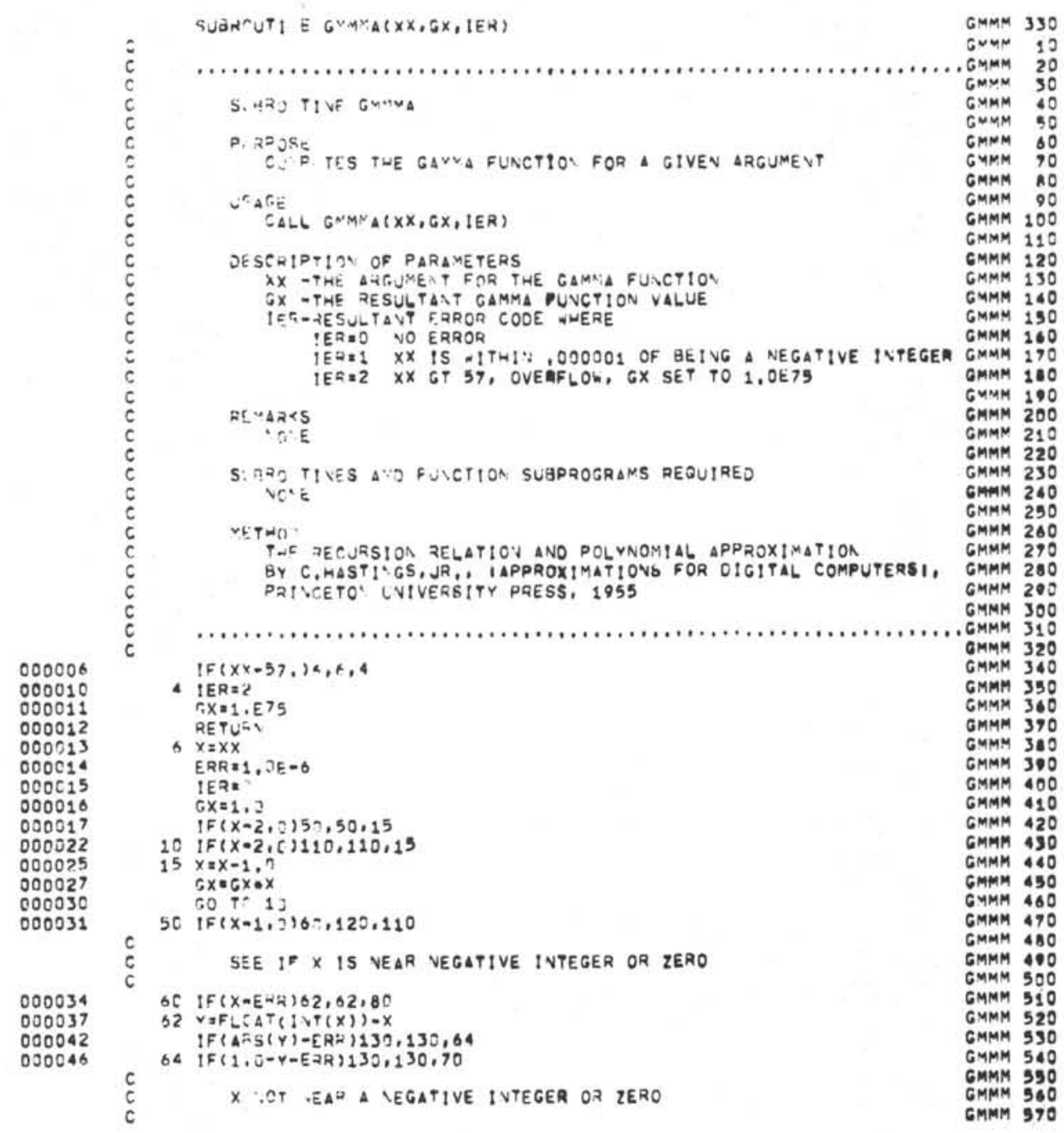

900052 


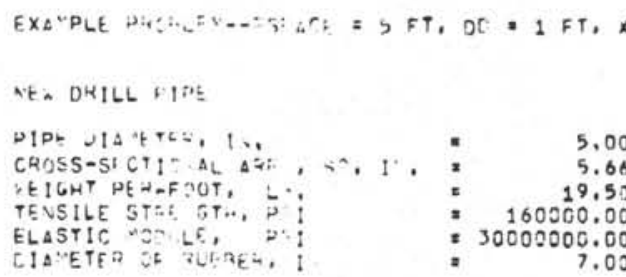

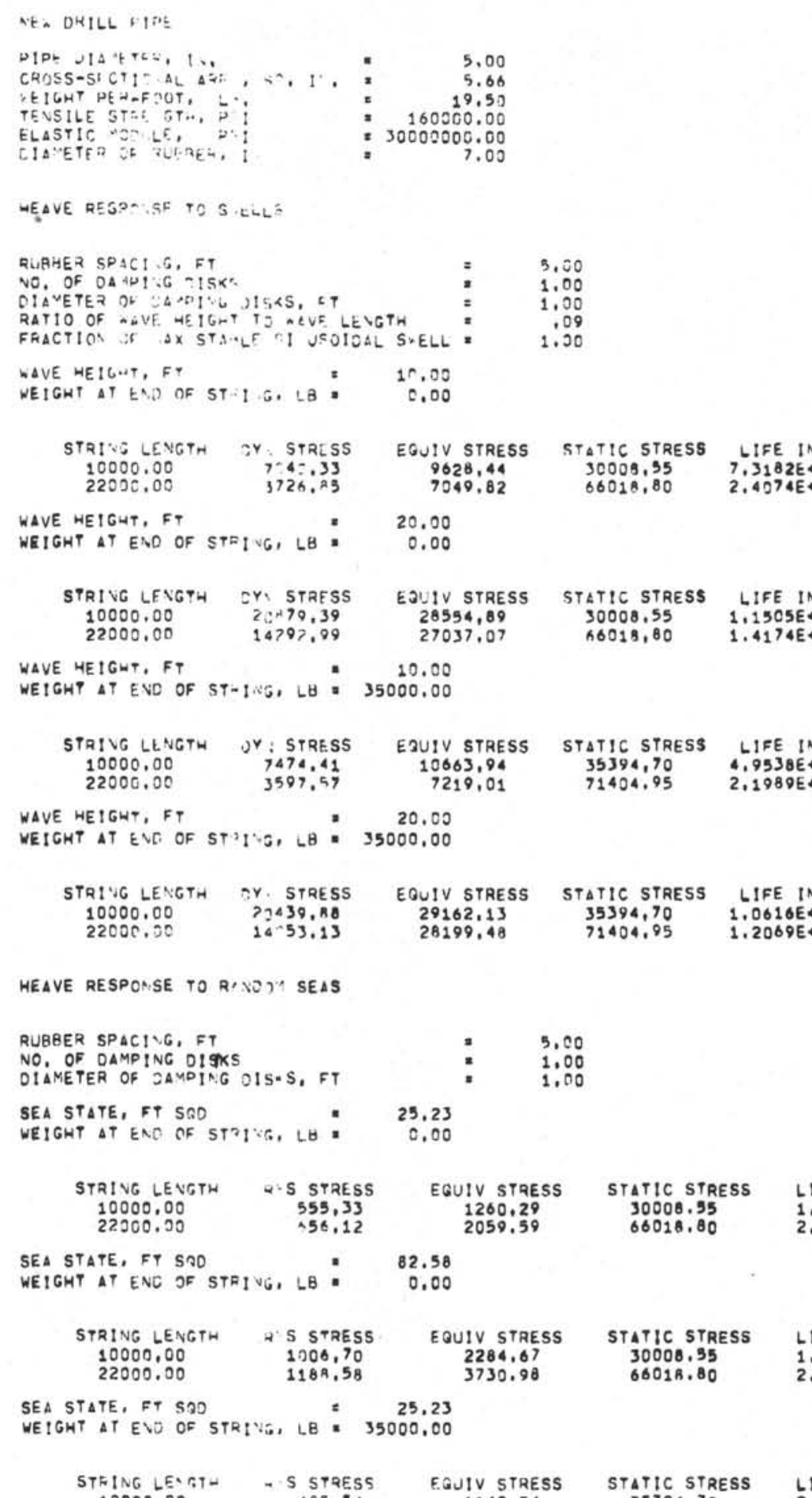

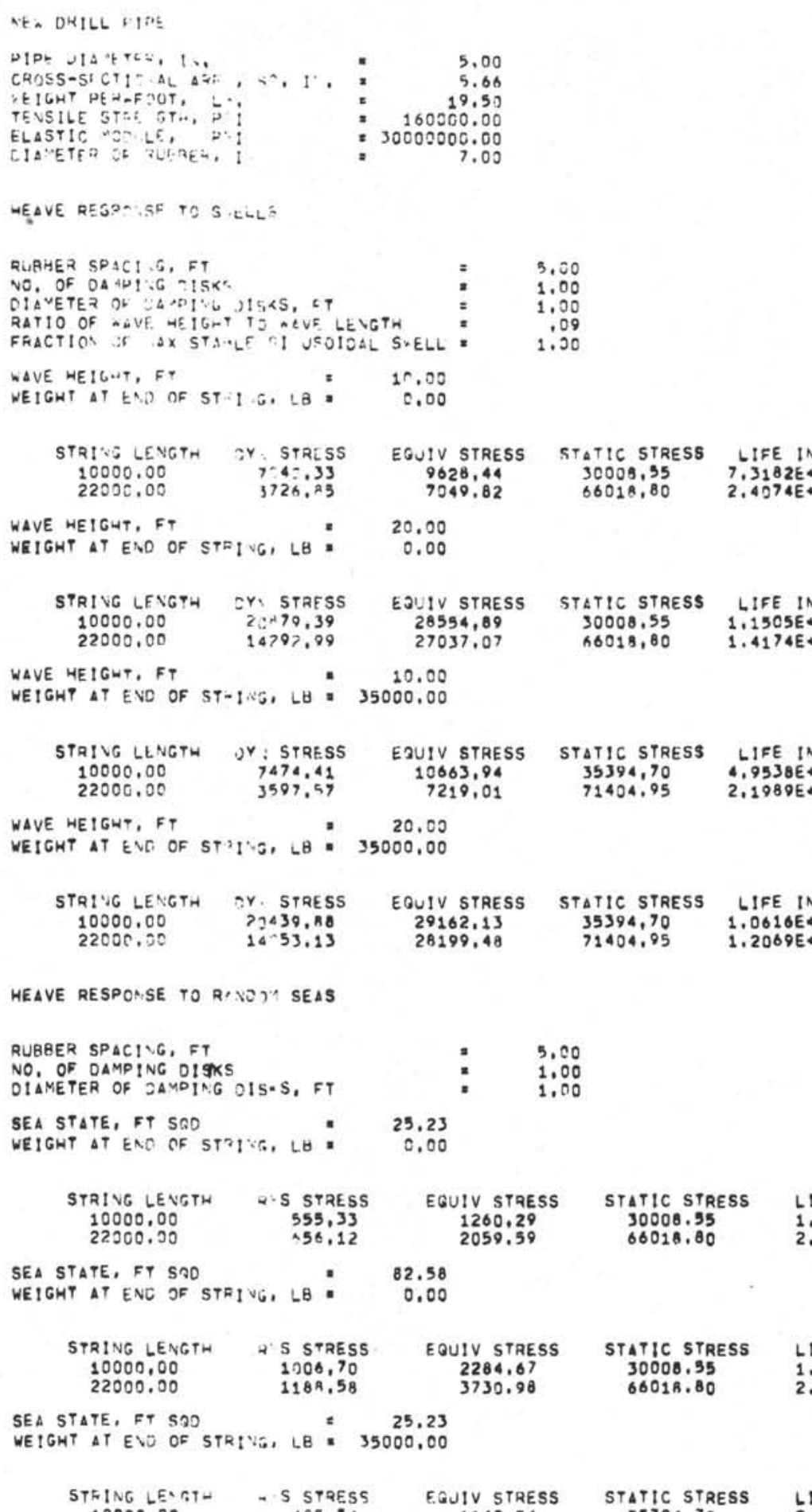

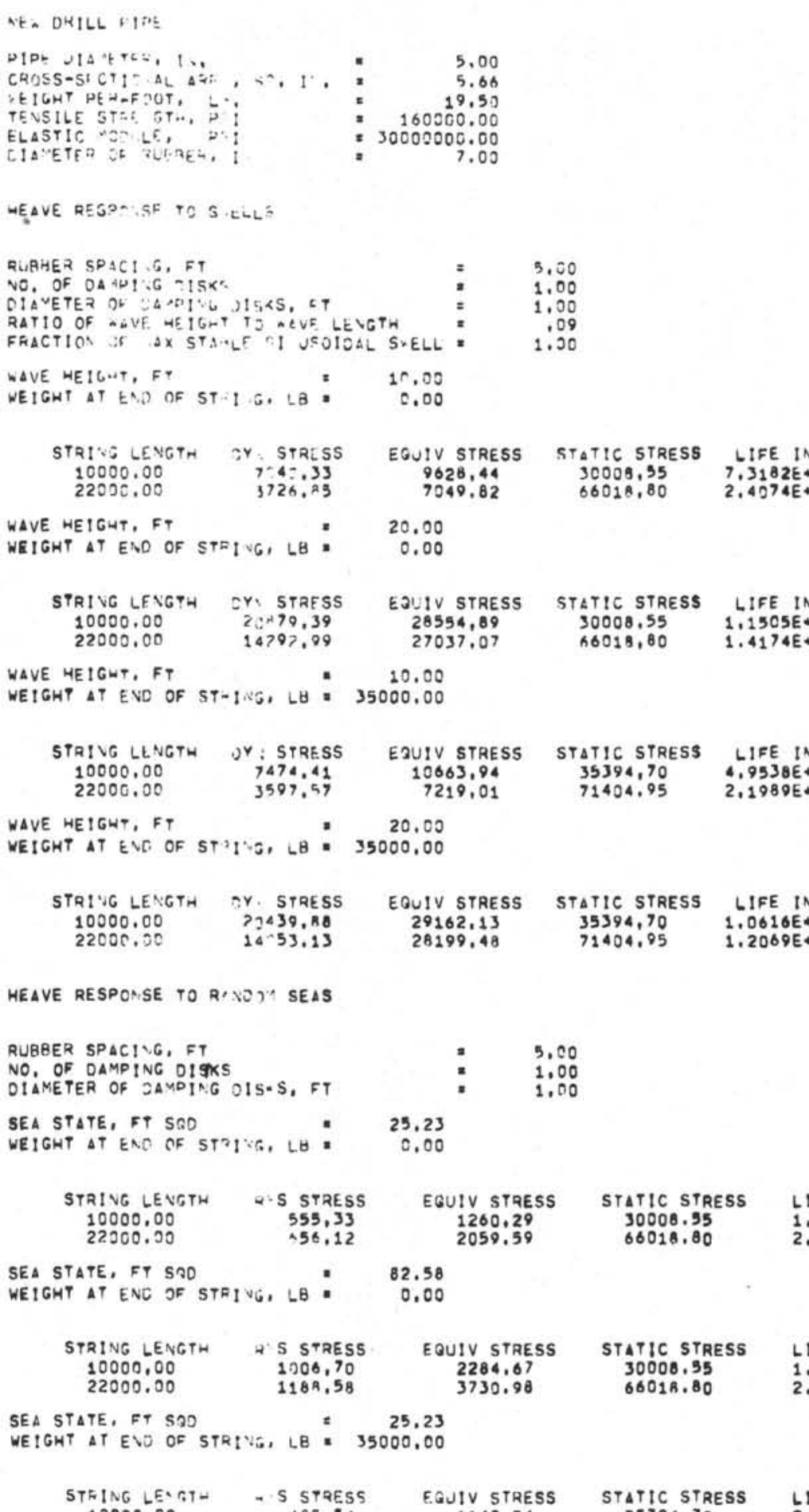

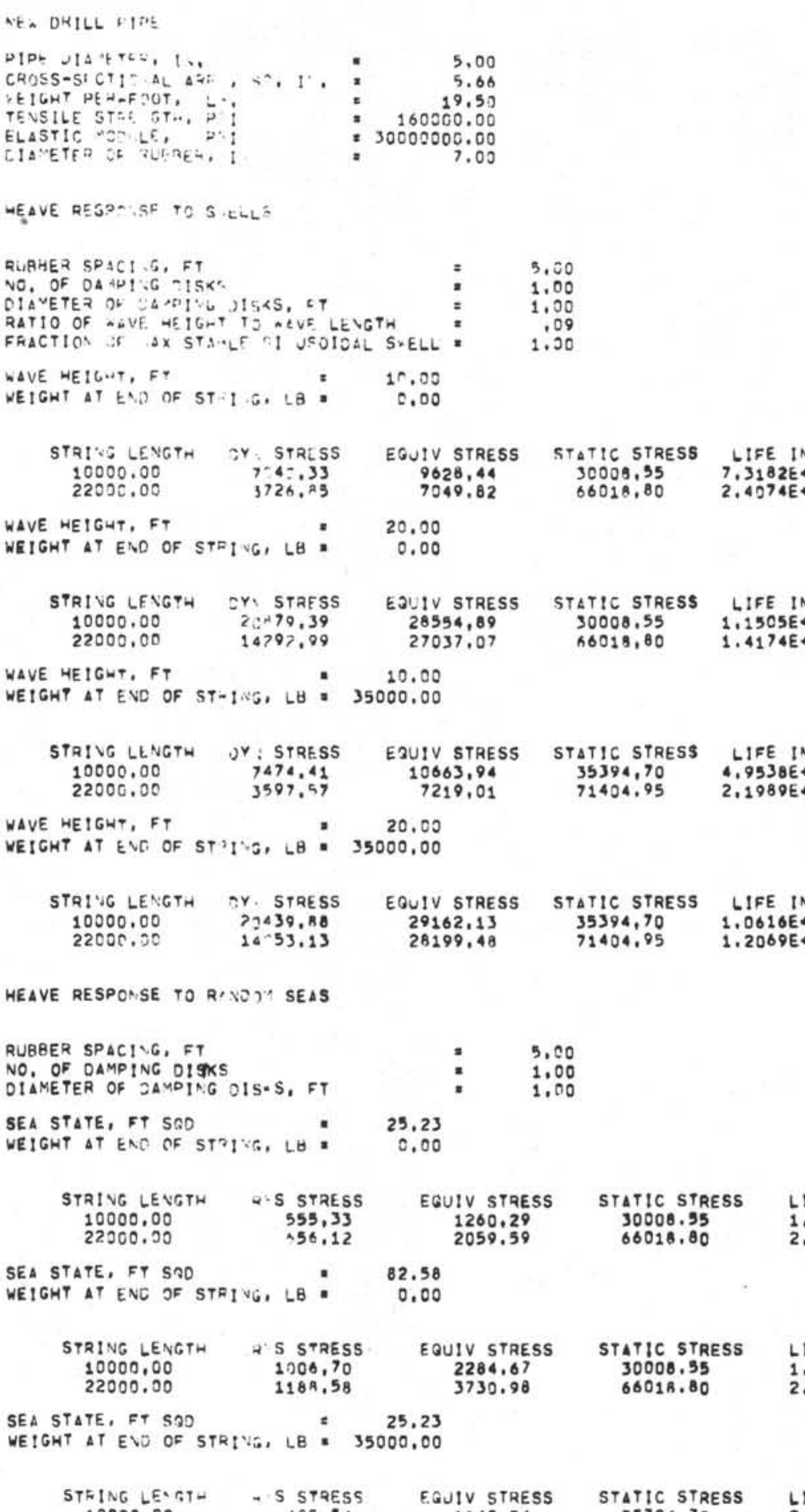

\begin{tabular}{|c|c|c|c|c|c|c|c|c|c|}
\hline $\begin{array}{l}\text { STRI:DE LENGTH } \\
10000.00 \\
22000.00\end{array}$ & $\begin{array}{c}\text { SY } \\
;-4 T R E S S \\
3726,23\end{array}$ & $\begin{array}{c}\text { EQUIV STRESS } \\
9628,44 \\
7049,82\end{array}$ & $\begin{array}{l}\text { STATIC STRESS } \\
30008,35 \\
66018,80\end{array}$ & $\begin{array}{l}\text { LIFE IN CYC } \\
7,3182 E+07 \\
2.4074 E+08\end{array}$ & $\begin{array}{l}\text { LIFE IN WOURS } \\
4,8950 E+04 \\
3,5424 E+05\end{array}$ & REL & $\begin{array}{l}\text { DISP, FT } \\
1.49 \\
1.74\end{array}$ & $\triangle B S$ & $\begin{array}{l}015 P \text {, } \\
1.24 \\
1.49\end{array}$ \\
\hline $\begin{array}{l}\text { WAVE HEIGHT, FT } \\
\text { WEIGHT AT ENO OF S }\end{array}$ & FIVG, LB $=$ & $\begin{array}{r}20.00 \\
0.00\end{array}$ & & & & & & & \\
\hline $\begin{array}{l}\text { STRIVG LENGTH } \\
10000.00 \\
22000.00\end{array}$ & $\begin{array}{l}\text { EY: STRESS } \\
2,470.39 \\
14797.09\end{array}$ & $\begin{array}{c}\text { EOUIV STRESS } \\
28554,89 \\
27037,07\end{array}$ & $\begin{array}{l}\text { STATIC STRESS } \\
30008,55 \\
66018,80\end{array}$ & $\begin{array}{l}\text { LIFE IN CYC } \\
1.1505 E+06 \\
1.4174 E+06\end{array}$ & $\begin{array}{l}\text { LIFE IN WOURS } \\
7.6935 E+02 \\
2.0857 E+03\end{array}$ & REL & $\begin{array}{c}\text { OISP, FT } \\
4.43 \\
6.67\end{array}$ & $\triangle B S$ & $\begin{array}{r}0 i s p \\
4,76 \\
3,48\end{array}$ \\
\hline $\begin{array}{l}\text { WAVE HEIGHT, FT } \\
\text { WEIGHT AT END OF } S\end{array}$ & $-1 \times G, L \theta=$ & $\begin{array}{r}10.00 \\
5000,00\end{array}$ & & & & & & & \\
\hline $\begin{array}{l}\text { STRIVG LENGTH } \\
10000.00 \\
22000.00\end{array}$ & $\begin{array}{c}\text { oY : STRESS } \\
7474.41 \\
3597.57\end{array}$ & $\begin{array}{c}\text { E3UIV STRESS } \\
10663,94 \\
7219,01\end{array}$ & $\begin{array}{l}\text { STATIC STRESS } \\
35394,70 \\
71404,95\end{array}$ & $\begin{array}{l}\text { LIFE IN CYC } \\
4.9538 E+07 \\
2.1980 E+08\end{array}$ & $\begin{array}{l}\text { LIFE IN WOURS } \\
3,8865 E \bullet 04 \\
3,4933 E+05\end{array}$ & REL & $\begin{array}{c}\text { OISP, FT } \\
1.81 \\
1.80\end{array}$ & $\triangle B S$ & $\begin{array}{l}015 p \\
1,49 \\
1,76\end{array}$ \\
\hline $\begin{array}{l}\text { WAVE HEIGHT, FT } \\
\text { WEIGHT AT ENE OF } S\end{array}$ & $3 \div 3, \angle B=$ & $\begin{array}{r}20,00 \\
5000,00\end{array}$ & & & & & & & \\
\hline $\begin{array}{l}\text { STRIVG LENGTH } \\
10000.00 \\
22000.00\end{array}$ & $\begin{array}{l}\text { OY. STRESS } \\
22439,80 \\
14.53 .13\end{array}$ & $\begin{array}{c}\text { EQUIV STRESS } \\
29162.13 \\
28199,48\end{array}$ & $\begin{array}{c}\text { STATIC STRESS } \\
35394,70 \\
71404,95\end{array}$ & $\begin{array}{l}\text { LIFE IN CYC } \\
1.0616 E+06 \\
1.2069 E+08\end{array}$ & $\begin{array}{l}\text { LIFE IN WOURS } \\
8,3290 E+02 \\
1,9173 E+03\end{array}$ & REL & $\begin{array}{c}\text { OtSP, FT } \\
7.95 \\
7.04\end{array}$ & $\triangle B S$ & $\begin{array}{l}01390 \\
5,41 \\
4,42\end{array}$ \\
\hline
\end{tabular}

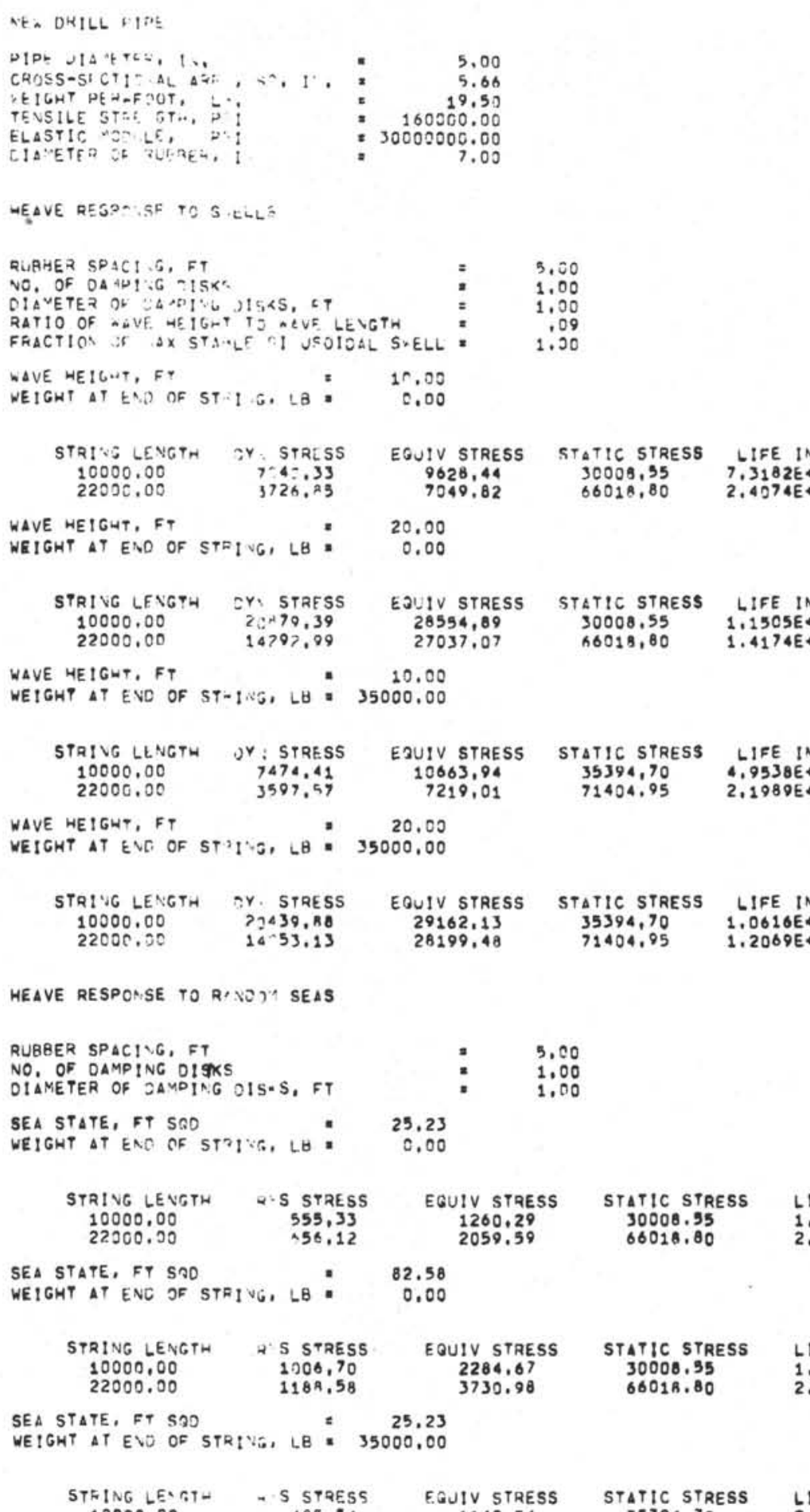

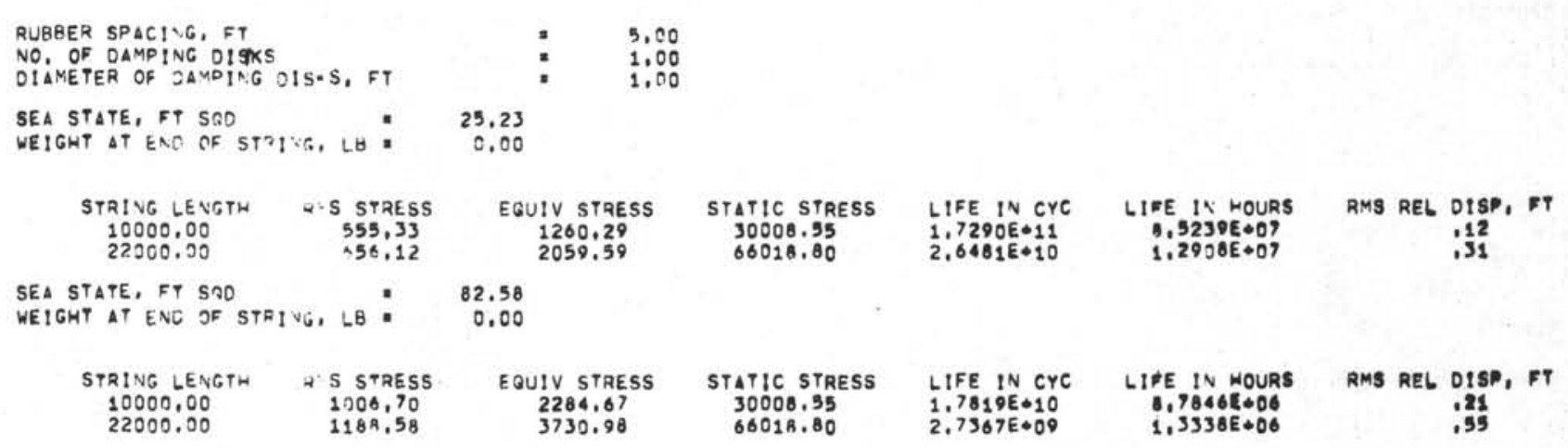

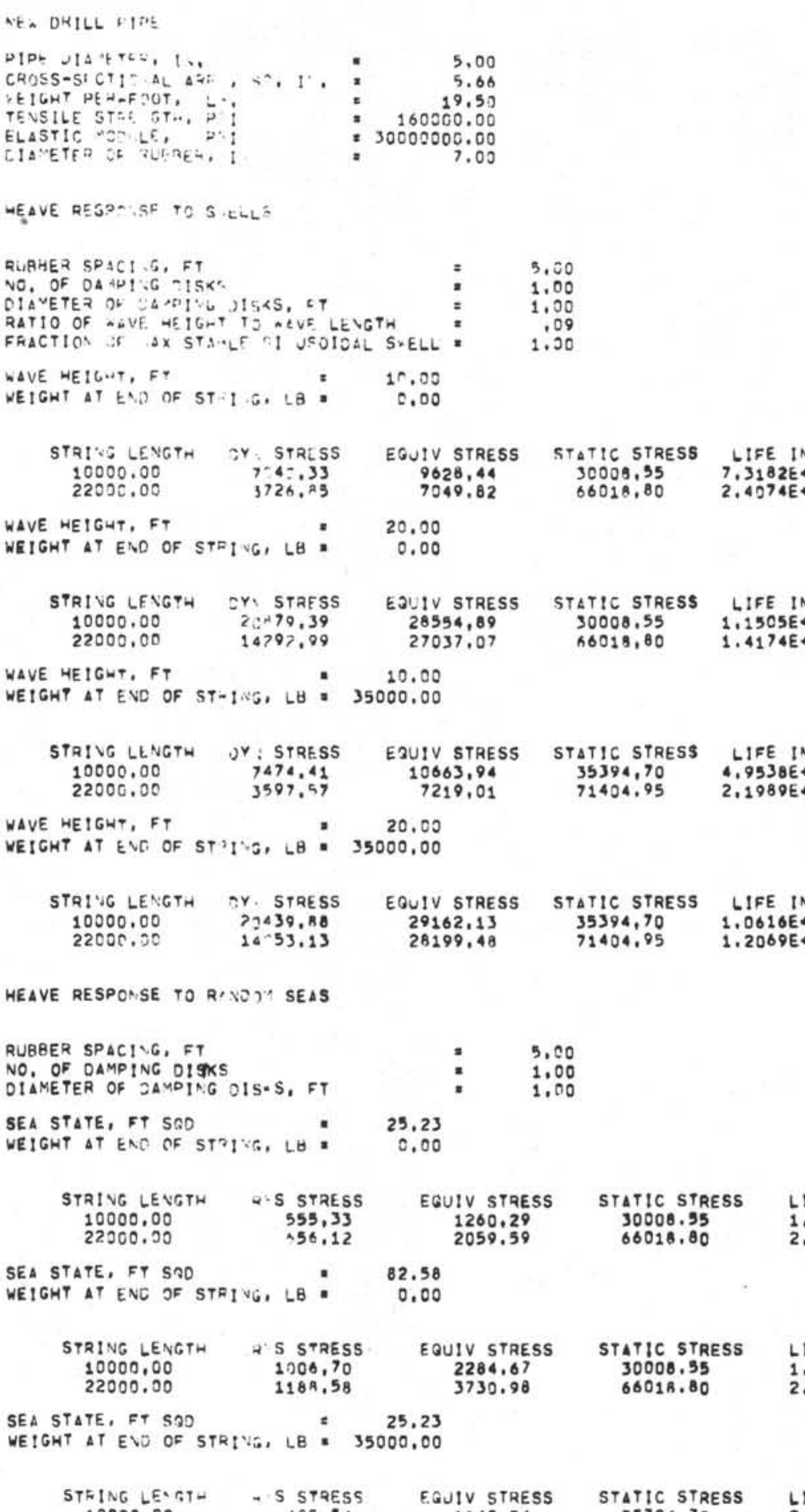

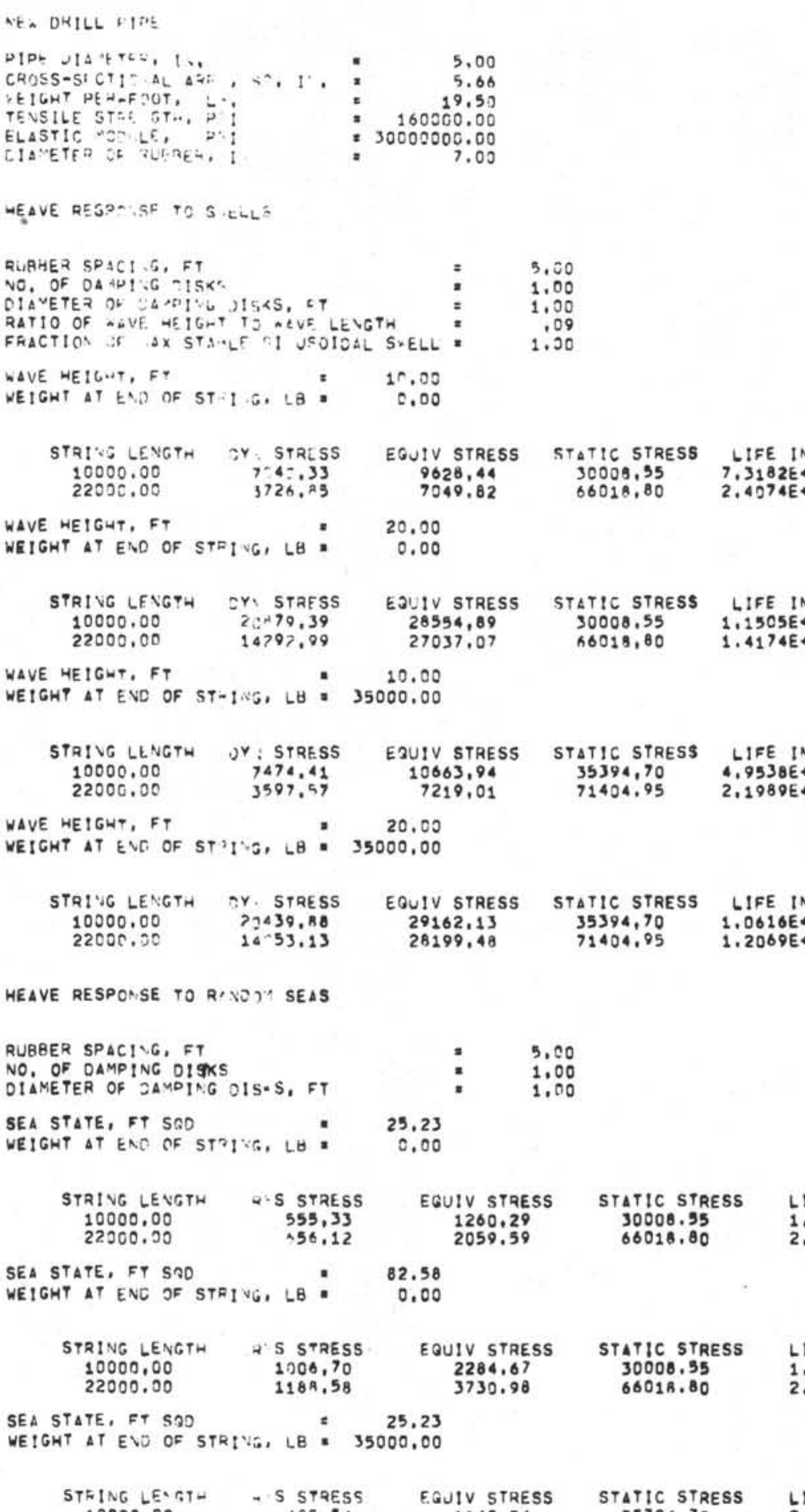

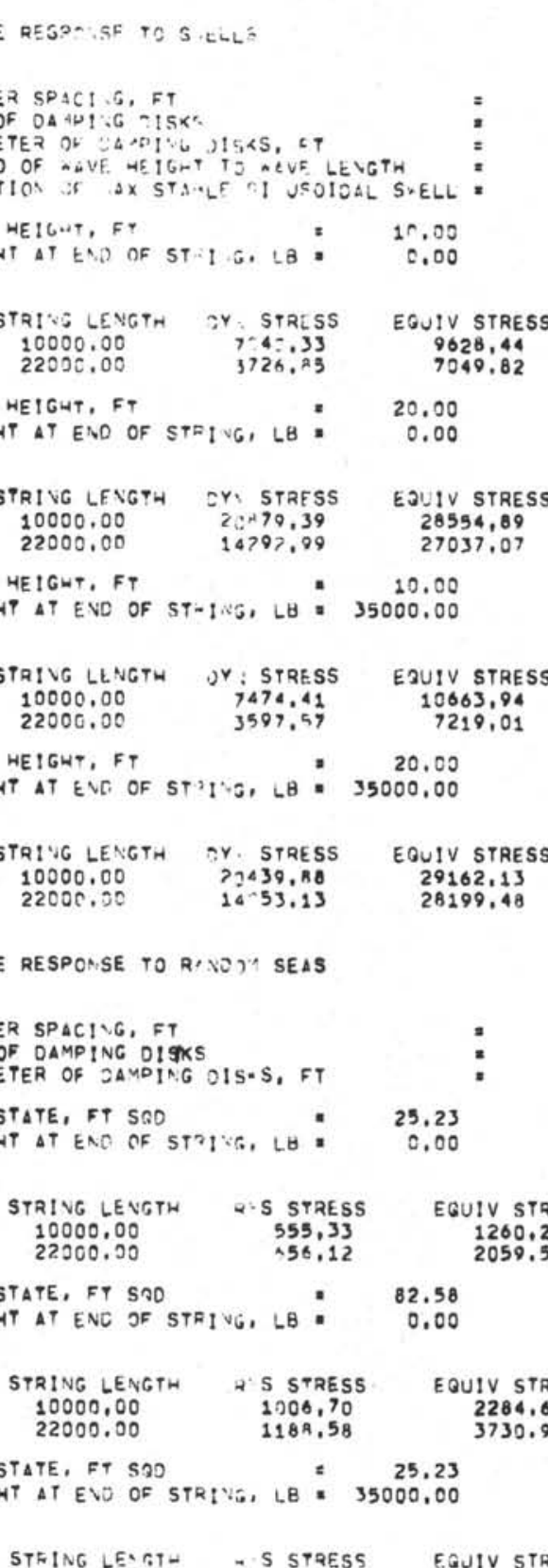

STE, FT $S 30=82.38$

WEIGHT AT ENO OF STATC, LB = 35000,00
STRING LENGTH $\rightarrow$ S STRESS 10000,00
22000,00
180.03
EQUIV STRESS
2083.51

35394,70
71404,95
LIDE IN HOURS
$1,2142 E+00$
$1.1523 E \bullet 07$

RMS REL OISP, PT

.12 


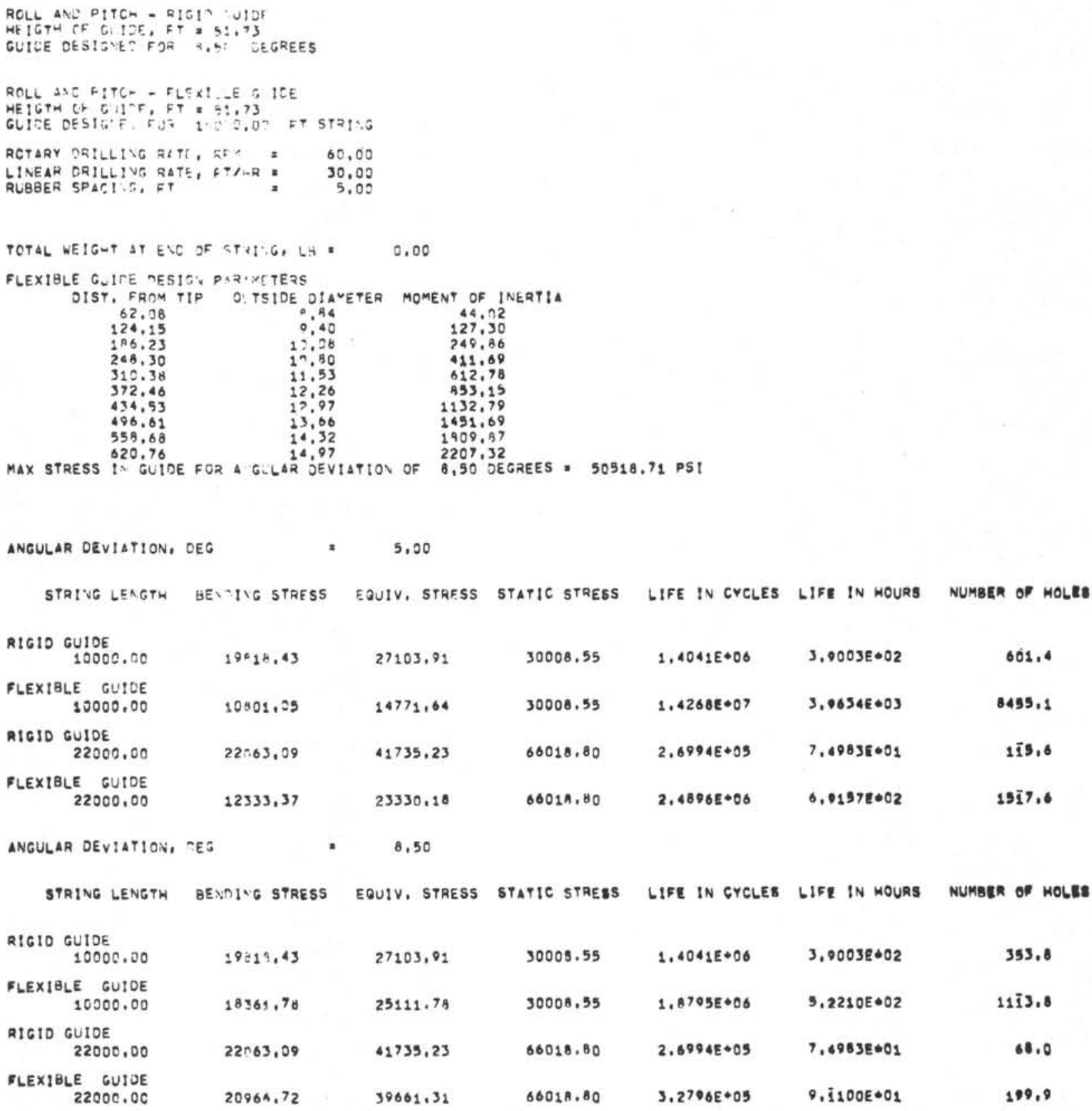

$9.1200 E \bullet 01$

109,9

TOTAL WEIGHT AT ENO OF STAI.G, LU a 35000,00

FLEXIBLE GUIDE DESIGN PARAMETERS DIST, FROM TIP OUTSIDE DIAMETER MCMENT OF INERTIA

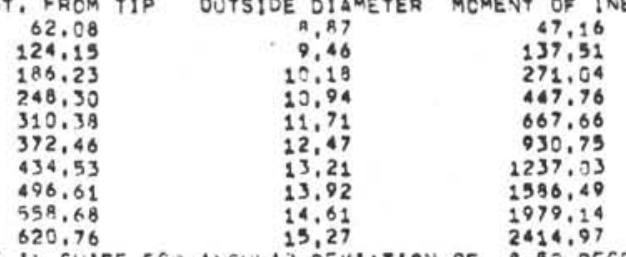

MAX STRESS I: GUIDE ECA AIGULAR OEVIATION OF 8,30 JEGREES = 31091.45 PS ? 


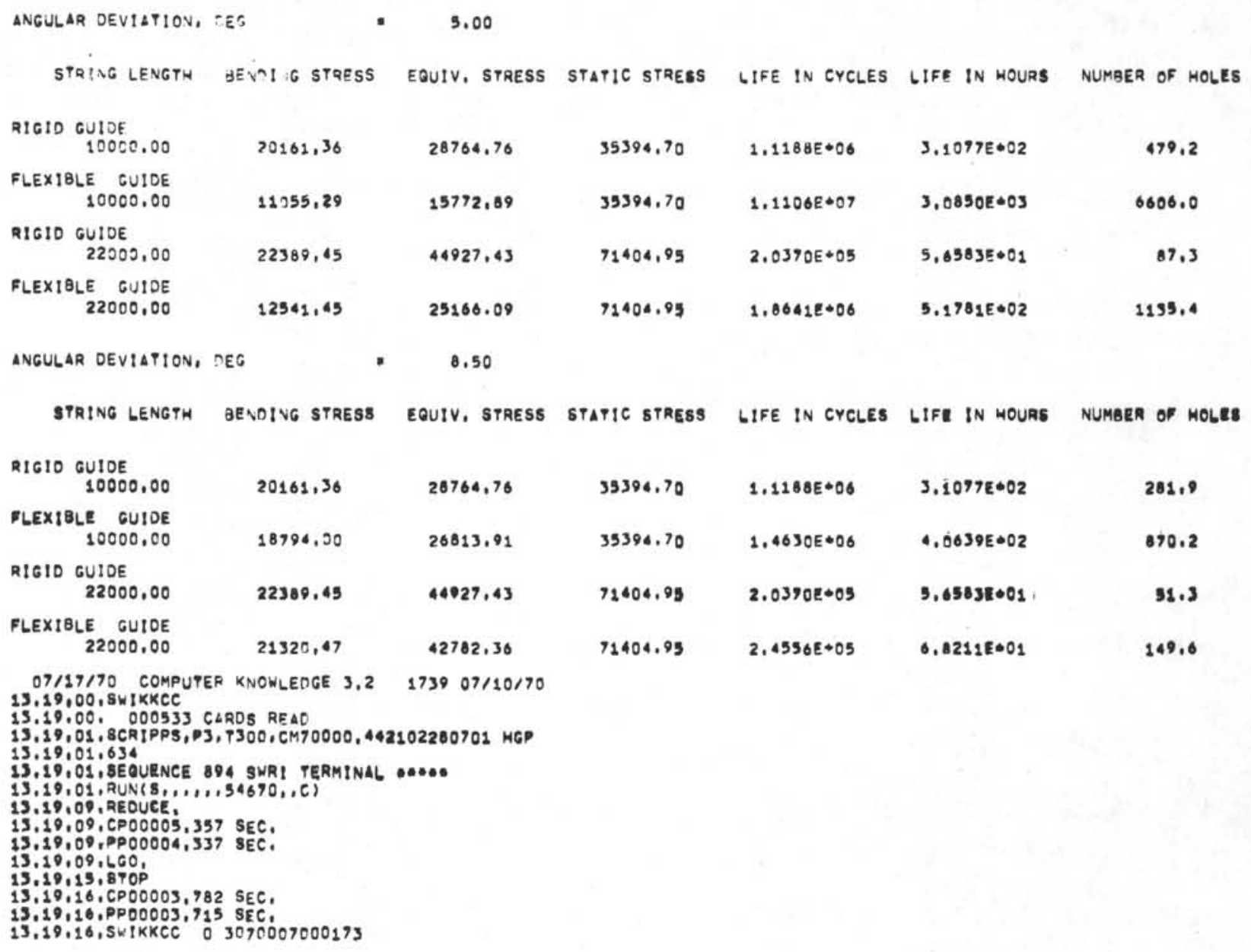




\section{SECTION 7. REFERENCES}

1.1 Vreeland, T., Jr., "Heave Dynamics of Long Drill Strings Suspended from a Floating Vessel." Report Submitted to Global Marine Exploration Co., December 29, 1967.

1.2 Vreeland, T., Jr., "Control of Bending Stresses in a Long Drill String Due to Ship Roll and Pitch,” Report Submitted to Global Marine Exploration Co., January 2, 1968.

2.1 Lamb, Sir Horace, Hydrodynamics, Sixth Edition, Dover Publications, New York, New York.

2.2 Ochi, Michel K., "Extreme Behavior of a Ship in Rough Seas," Presented at SNAME Annual Meeting, New York, New York, November 12, 1964.

2.3 Milne-Thompson, L. M., Theoretical Hydrodynamics, Second Edition, The MacMillan Co., New York, New York, 1950.

2.4 Iversen, H. W. and Balent, R., "A Correlating Modulus for Fluid Resistance in Accelerated Motion," Journal of Applied Physics, 22, 3, 324-328, March 1951.

2.5 Rollins, H. M., "Fatigue Failure Considerations in Drill Pipe Design," The Drilling Contractor, $35 \mathrm{ff}$, May-June 1966.

2.6 Madayag, A. F. (ed), Metal Fatigue: Theory and Design, Chapter 6, John Wiley and Sons. Inc.. New York, New York, 1969.

2.7 Miles, J. W., "On Structural Fatigue Under Random Loading," Jour. Aero. Sci.. 753-762, November 1954.

5.1 Hansford, J. E. and Lubinski, A., "Effects of Drilling Vessel Pitch or Roll on Kelly and Drill Pipe Fatigue," Journal of Petroleum Technology, 77-86, January 1964.

A-1 Timoshenko, S. P., Vibration Problems in Engineering, Third Edition, D. Van Nostrand Co.. Inc., Princeton, New Jersey, 1955. 
APPENDIX

DERIVATION OF HEAVE DYNAMICS MODAL SOLUTION 
In this Appendix, the modal solution for the heave response, Eqs. (2.4) to (2.17), is derived. The governing equations and boundary conditions are:

$$
\rho A \frac{\partial^{2} u}{\partial t^{2}}=A E \frac{\partial^{2} u}{\partial x^{2}}-c \frac{\partial u}{\partial t}
$$

where

$$
\begin{aligned}
\rho A & =\mu A+M \delta(x-\ell) \\
c & =D+C \delta(x-\ell)
\end{aligned}
$$

and

$$
\begin{gathered}
u(0, t)=W(t) \\
\left.\frac{\partial u}{\partial x}\right|_{x=\ell}=-\left.\frac{M}{A E} \frac{\partial^{2} u}{\partial t^{2}}\right|_{x=\ell}
\end{gathered}
$$

The beginning point is the solution to the free vibration problem, $\bar{u}(x, t)$, wherein $W(t)=0$. This is done by assuming a separable solution of the form

$$
\bar{u}(x, t)=X(x) T(t)
$$

whereupon Eq. (A.1) becomes

$$
\frac{\ddot{T}}{T}+\frac{D}{\mu A} \frac{\dot{T}}{T}=\frac{E}{\mu} \frac{X^{\prime \prime}}{X}=\text { constant }=-\frac{E \alpha_{1}^{2}}{\mu \ell^{2}}=-\frac{c_{0}^{2} \alpha_{1}^{2}}{\ell^{2}}
$$

In this expression, the superscripted primes and dots indicate, respectively. differentiation with respect to $x$ and $t$, and the form of the constant has been chosen for later convenience.

The mode functions are seen to be governed by

$$
X^{\prime \prime}+\left(\frac{\alpha_{1}}{\ell}\right)^{2} X=0
$$

The first mode solution to Eq. (A.6) is

$$
X(x)=a_{1} \sin \frac{\alpha_{1} x}{\ell}+a / 2 \cos \frac{\alpha_{1} x}{\ell}
$$

The constant $a_{2}$ vanishes by virtue of (A.3a). In satisfying boundary condition (A.3b), one is led to

$$
X^{\prime}(\ell) T(t)=-\frac{M}{A E} X(\ell) \ddot{T}(t)
$$

If the system is only lightly damped, the unknown time function is given approximately by solutions to

$$
\ddot{T}+\left(\frac{c_{0} \alpha_{1}}{\ell}\right)^{2} T=0
$$


The first mode solution to this equation is

$$
T(t)=b_{1} \sin \frac{c_{0} \alpha_{1} t}{\ell}+b_{2} \cos \frac{c_{0} \alpha_{1} t}{\ell}
$$

Substituting (A.10) into (A.8), one arrives at the frequency equation

$$
\operatorname{ctn} \alpha_{1}=\beta \alpha_{1}
$$

which defines $\alpha_{1}$ implicitly. In this expression, $\beta=M / \mu A \ell$.

Equation (A.11) is trancendental in $\alpha_{1}$ and defines an infinite set of $\alpha_{1}$ 's. For the first-mode solution of interest here, one is concerned only in the fundamental value of $\alpha_{1}$. The first-mode solution can thus be expressed as

$$
\bar{u}(x, t)=a_{1} T(t) \sin \frac{\alpha_{1} x}{\ell}
$$

The forced-vibration response can be constructed from the normal mode solution using the method of virtual work, as outlined by Timoshenko(A.1). The forced solution is sought in the form

$$
u(x, t)=W(t)+\phi_{1}(t) \sin \frac{\alpha_{1} x}{\ell}
$$

where $\phi_{1}$ is an undetermined function of time. A virtual displacement

$$
\delta u=a \sin \frac{\alpha_{1} x}{\ell}
$$

is imagined, and one proceeds to calculate the virtual work

(1) done by the inertia forces

(a) in the string $\left(W_{1 a}\right)$

(b) on the end mass $\left(W_{1 b}\right)$

(2) done by the elastic forces $\left(W_{2}\right)$

(3) of the exciting force $\left(W_{3}\right)$

(4) done by the damping forces

(a) in the string $\left(W_{4 a}\right)$

(b) on the end mass $\left(W_{4 b}\right)$.

These quantities are calculated below, using $u$ and $\delta u$ from Eqs. (A.13) and (A.14). 
$\underline{\text { Calculation of } W_{1 a}}$

$$
\begin{aligned}
W_{1 a} & =-\int_{0}^{\ell} \mu A \frac{\partial^{2} u}{\partial t^{2}} \delta u \mathrm{~d} x \\
& =-\frac{\mu A a \ell}{\alpha_{1}}\left(1-\cos \alpha_{1}\right) \ddot{w}-\frac{\mu A a \ell}{4 \alpha_{1}}\left(2 \alpha_{1}-\sin 2 \alpha_{1}\right) \ddot{\phi}_{1}
\end{aligned}
$$

Calculation of $W_{1 b}$

$$
\begin{aligned}
W_{1 b} & =-\left.M \frac{\partial^{2} u}{\partial t^{2}} \delta u\right|_{x=\ell} \\
& =-M a\left(\ddot{W}+\ddot{\phi}_{1} \sin \alpha_{1}\right) \sin \alpha_{1}
\end{aligned}
$$

Calculation of $W_{2}$

The strain energy $V$ is given by

$$
V=\frac{1}{2} \int_{0}^{\ell} A E\left(\frac{\partial u}{\partial x}\right)^{2} \mathrm{~d} x=\frac{A E \alpha_{1}}{8 \ell}\left(2 \alpha_{1}+\sin 2 \alpha_{1}\right) \phi_{1}^{2}
$$

The change in $V$ during the virtual displacement is

$$
\delta V=\frac{\partial V}{\partial \phi_{1}} \delta \phi_{1}=\frac{A E \alpha_{1}}{4 \ell}\left(2 \alpha_{1}+\sin 2 \alpha_{1}\right) \phi_{1} \delta \phi_{1}
$$

The work done is the negative of this quantity, with $\delta \phi_{1}$ replaced by $a$ :

$$
W_{2}=-\frac{A E \alpha_{1} a}{4 l}\left(2 \alpha_{1}+\sin 2 \alpha_{1}\right) \phi_{1}
$$

Calculation of $W_{3}$

The force acting at $x=0$ is

$$
\sigma A=\left.A E \frac{\partial u}{\partial x}\right|_{x=\ell}=\frac{A E \alpha_{1}}{\ell} \phi_{1}
$$

The virtual displacement at $x=0$, however, vanishes (the displacement is prescribed at $x=0$ ), so the virtual work vanishes:

$$
W_{3}=0
$$

Calculation of $W_{4 a}$

$$
\begin{aligned}
W_{4 a} & =-\int_{0}^{\ell} D \frac{\partial u}{\partial t} \delta u \mathrm{~d} x \\
& =-\frac{D a \ell}{\alpha_{1}}\left(1-\cos \alpha_{1}\right) \dot{W}-\frac{D a \ell}{4 \alpha_{1}}\left(2 \alpha_{1}-\sin 2 \alpha_{1}\right) \dot{\phi}_{1}
\end{aligned}
$$


Calculation of $W_{4 b}$

$$
W_{4 b}=-\left.C \frac{\partial u}{\partial t} \delta u\right|_{x=\ell}=-C a\left(\dot{W}+\dot{\phi}_{1} \sin \alpha_{1}\right) \sin \alpha_{1}
$$

The total work done during the virtual displacement must vanish in the physical system. Therefore, the expressions given by Eqs. (A.15) to (A.20) are summed and equated to zero. The present study is concerned only with harmonic excitation:

$$
W(t)=W_{0} \sin \Omega t
$$

Making this substitution and performing the indicated operations, one has

$$
\begin{aligned}
& \frac{1}{\beta c_{1}^{2}} \ddot{\phi}_{1}+C\left[\frac{\gamma}{4}\left(2-\frac{1}{\alpha_{1}} \sin 2 \alpha_{1}\right)+\sin ^{2} \alpha_{1}\right] \dot{\phi}_{1}+\frac{M \omega_{1}^{2}}{\beta}\left(\frac{1}{2}+\frac{1}{4 \alpha_{1}} \sin 2 \alpha_{1}\right) \phi_{1}= \\
= & \frac{M W_{0} \Omega^{2}}{\beta}\left[\frac{1}{\alpha_{1}}\left(1-\cos \alpha_{1}\right)+\beta \sin \alpha_{1}\right] \sin \Omega t-C W_{0} \Omega\left[\frac{\gamma}{\alpha_{1}}\left(1-\cos \alpha_{1}\right)+\sin \alpha_{1}\right] \cos \Omega t
\end{aligned}
$$

where

$$
\begin{aligned}
c_{1}=\left[M\left(\frac{1}{2}-\frac{1}{4 \alpha_{1}} \sin 2 \alpha_{1}+\beta \sin ^{2} \alpha_{1}\right)\right]^{-1 / 2} \\
\omega_{1}=\frac{\alpha_{1} c_{0}}{\ell} \\
c_{0}^{2}=\frac{E}{\mu} \\
\gamma=\frac{D \ell}{C}
\end{aligned}
$$

To discuss the solution of this differential equation for $\phi_{1}$, it is useful to digress momentarily and consider the canonical form

$$
m \ddot{\phi}+c \dot{\phi}+k \phi=F_{1} \cos \Omega t+F_{2} \sin \Omega t
$$

The general solution to this equation is given by a particular integral (i.e., any solution of the equation) plus the complete solution of the homogeneous equation (i.e., with $F_{1}=F_{2}=0$ ). The latter solution is a transient one, decaying exponentially. After this transient dies out, the particular integral prevails, so, for the present purposes, only the particular integral need be considered. It can be verified by direct substitution that a particular solution of Eq. (A.24) is

$$
\phi=\frac{F_{1} \cos (\Omega t-\alpha)+F_{2} \sin (\Omega t-\alpha)}{\sqrt{\left(k-m \Omega^{2}\right)^{2}+c^{2} \Omega^{2}}}
$$

where

$$
\alpha=\operatorname{Tan}^{-1}\left(\frac{c \Omega}{k-m \Omega^{2}}\right)
$$


To find the maximum (steady-state) response, $\phi_{m}$, one equates $\dot{\phi}=0$, whereupon

$$
\Omega t=\alpha+\operatorname{Tan}^{-1}\left(\frac{F_{2}}{F_{1}}\right)
$$

Substituting this value for $\Omega t$ into Eq. (A.25), there results

$$
\phi_{m}=\frac{\sqrt{F_{1}^{2}+F_{2}^{2}}}{\sqrt{\left(k-m \Omega^{2}\right)^{2}+c^{2} \Omega^{2}}}
$$

Returning now to the original problem, the maximum value of $\phi_{1}$ (and hence of $u$ ) can be determined by using Eq. (A.28) where, for the present problem.

$$
\begin{gathered}
F_{1} \equiv-C W_{0} \Omega\left[\frac{\gamma}{\alpha_{1}}\left(1-\cos \alpha_{1}\right)+\sin \alpha_{1}\right] \\
F_{2} \equiv \frac{M W_{0} \Omega^{2}}{\beta}\left[\frac{1}{\alpha_{1}}\left(1-\cos \alpha_{1}\right)+\beta \sin \alpha_{1}\right] \\
m \equiv \frac{1}{\beta c^{2}} \\
c \equiv C\left[\frac{\gamma}{4}\left(2-\frac{1}{\alpha_{1}} \sin 2 \alpha_{1}\right)+\sin ^{2} \alpha_{1}\right] \\
k \equiv \frac{M \omega_{1}^{2}}{\beta}\left(\frac{1}{2}+\frac{1}{4 \alpha_{1}} \sin 2 \alpha_{1}\right)
\end{gathered}
$$

With these substitutions and Eq. (A.25), Eq. (A.13) becomes

$$
\frac{\frac{M W_{0} c_{1}^{2} \Omega^{2}}{\beta}\left[\frac{1}{\alpha_{1}}\left(1-\cos \alpha_{1}\right)+\beta \sin \alpha_{1}\right] \sin (\Omega t-\alpha)-C W_{0} c_{1}^{2} \Omega\left[\frac{\gamma}{\alpha_{1}}\left(1-\cos \alpha_{1}\right)+\sin \alpha_{1}\right] \cos (\Omega t-\alpha)}{\left\{\left[\frac{M c_{1}^{2} \omega_{1}^{2}}{\beta}\left(\frac{1}{2}+\frac{1}{4 \alpha_{1}} \sin 2 \alpha_{1}\right)-\frac{\Omega^{2}}{\beta}\right]^{2}+C^{2} c_{1}^{4} \Omega^{2}\left[\frac{\gamma}{4}\left(2-\frac{1}{\alpha_{1}} \sin 2 \alpha_{1}\right)+\sin ^{2} \alpha_{1}\right]^{2}\right\}^{1 / 2} \sin \frac{\alpha_{1} x}{\ell}}
$$

In this expression, $\alpha$ is defined by Eq. (A.26) as

$$
\alpha=\operatorname{Tan}^{-1}\left(\frac{c \Omega}{k-m \Omega^{2}}\right)=\operatorname{Tan}^{-1}\left\{\frac{C c_{1}^{2} \Omega \beta\left[\frac{\gamma}{4}\left(2-\frac{1}{\alpha_{1}} \sin 2 \alpha_{1}\right)+\sin ^{2} \alpha_{1}\right]}{M \omega_{1}^{2} c_{1}^{2}\left(\frac{1}{2}+\frac{1}{4 \alpha_{1}} \sin 2 \alpha_{1}\right)-\Omega^{2}}\right\}
$$

To find the maximum response, it is useful first to consider the relative displacement $v(x, t)=$ $u(x, t)-W(t)$. Using Eq. (A.28), one finds the maximum, $v_{m}(x)$, to be given by

$$
v_{m}(x)=N c_{1} \sin \frac{\alpha_{1} x}{\ell}
$$


where

$$
\begin{gathered}
N=F\left\{\left[\frac{M \omega_{1}^{2} c_{1}^{2}}{\beta}\left(\frac{1}{2}+\frac{1}{4 \alpha_{1}} \sin 2 \alpha_{1}\right)-\frac{\Omega^{2}}{\beta}\right]^{2}+C^{2} \Omega^{2} c_{1}^{4}\left[\frac{\gamma}{4}\left(2-\frac{1}{\alpha_{1}} \sin 2 \alpha_{1}\right)+\sin ^{2} \alpha_{1}\right]^{2}\right\}^{-1 / 2} \\
F^{2}=W_{0}^{2} c_{1}^{2}\left\{\frac{M^{2} \Omega^{4}}{\beta^{2}}\left[\frac{1}{\alpha_{1}}\left(1-\cos \alpha_{1}\right)+\beta \sin \alpha_{1}\right]^{2}+C^{2} \Omega^{2}\left[\frac{\gamma}{\alpha_{1}}\left(1-\cos \alpha_{1}\right)+\sin \alpha_{1}\right]^{2}\right]
\end{gathered}
$$

The maximum dynamic stress is computed using Eq. (A.31):

$$
\begin{gathered}
\sigma_{m}(x)=E \epsilon(x)=E \frac{\partial u}{\partial x}=E \frac{\partial v}{\partial x} \\
\sigma_{m}(x)=\frac{E N c_{1} \alpha_{1}}{\ell} \cos \frac{\alpha_{1} x}{\ell}
\end{gathered}
$$

and the peak dynamic stress is seen to act at the upper end of the drill string.

The maximum absolute displacement, $u_{m}(\ell)$, is found by seeking stationary values of Eq. (A.29) with respect to time. This equation is first expressed in the more convenient form

$$
u(\ell, t)=W_{0} \sin \Omega t+\frac{N}{F}\left[T_{1} \sin (\Omega t-\alpha)-T_{2} \cos (\Omega t-\alpha)\right]
$$

where

$$
\begin{gathered}
T_{1}=\frac{M W_{0} c_{1}^{2} \Omega^{2}}{\beta}\left[\frac{1}{\alpha_{1}}\left(1-\cos \alpha_{1}\right)+\beta \sin \alpha_{1}\right] \sin \alpha_{1} \\
T_{2}=C W_{0} c_{1}^{2} \Omega\left[\frac{\gamma}{\alpha_{1}}\left(1-\cos \alpha_{1}\right)+\sin \alpha_{1}\right] \sin \alpha_{1}
\end{gathered}
$$

On equating the first-time derivative to zero, one finds

$$
\Omega t=-\operatorname{Tan}^{-1}\left[\frac{\left(F W_{0} / N\right)+T_{1} \cos \alpha+T_{2} \sin \alpha}{T_{1} \sin \alpha+T_{2} \cos \alpha}\right]
$$

Substituting (A.37) into (A.35) leads to the expression for $u_{m}(\ell)$ :

$$
u_{m}(\ell)=\left\{\left[W_{0}+\frac{N}{F}\left(T_{1} \cos \alpha-T_{2} \sin \alpha\right)\right]^{2}+\frac{N^{2}}{F^{2}}\left(T_{1} \sin \alpha+T_{2} \cos \alpha\right)^{2}\right\}^{1 / 2}
$$

This completes the derivation of all of the basic dynamic heave response equations stated as Eqs. (2.4) to (2.17) in Section 2. 


\section{APPENDIX D}

Hydrogen Movement in Steel-Entry, Diffusion, and Elimination 


\title{
HYDROGEN MOVEMENT IN STEEL- ENTRY, DIFFUSION, AND ELIMINATION
}

\author{
DEFENSE METALS INFORMATION CENTER \\ Battelle Memorial Institute \\ Columbus, Ohio 43201
}


The Defense Metals Information Center was established at Battelle Memorial Institute at the request of the Office of the Director of Defense Research and Engineering to provide Government contractors and their suppliers technical assistance and information on titanium, beryllium, magnesium, aluminum, refractory metals, high-strength alloys for high-temperature service, corrosion- and oxidation-resistant coatings, and thermal-protection systems. Its functions, under the direction of the Office of the Director of Defense Research and Engineering, are as follows:

1. To collect, store, and disseminate technical information on the current status of research and development of the above materials.

2. To supplement established Service activities in providing technical advisory services to producers, melters, and fabricators of the above materials, and to designers and fabricators of military equipment containing these materials.

3. To assist the Government agencies and their contractors in developing technical data required for preparation of specifications for the above materials.

4. On assignment, to conduct surveys, or laboratory research investigations, mainly of a short-range nature, as required, to ascertain causes of troubles encountered by fabricators, or to fill minor gaps in established research programs.

Contract No. AF 33(615)-1121

Project No. 8975

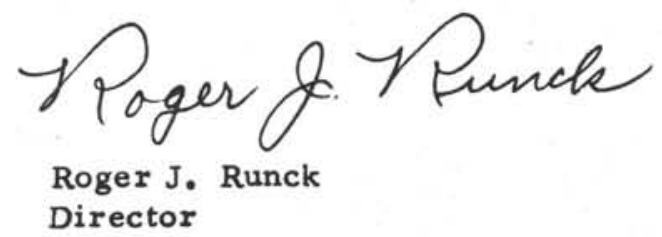

$\underline{\text { Notices }}$

When Government drawings, specifications, or other data are used for any purpose other than in connection with a definitely related Government procurement operation, the United State 8 Government thereby incurs no responsibility nor any obligation whatsoever; and the fact that the Government may have formulated, furnished, or in any way supplied the said drawings, specifications, or other data, is not to be regarded by implication or otherwise as in any manner licensing the holder or any other person or corporation, or conveying any rights or permission to manufacture, use, or sell any patented invention that may in any way be related thereto.

Qualified requesters may obtain copies of this report from the Defense Documentation Center (DDC), Cameron Station, Bldg. 5, 5010 Duke Street, Alexandria, Virginia, 22314. The distribution of this report is limited because the report contains technology identifiable with items on the strategic embargo lists excluded from export or re-export under U. S. Export Control Act of 1949 (63 STAT. 7), as amended (50 U.S. C. App. 2020.2031), as implemented by AFR 400-10.

Copies of this report should not be returned to the Research and Technology Division, Wright-Patterson Air Force Base, Ohio, unless return is required by security considerations, contractual obligations, or notice on a specific document. 
HYDROGEN MOVEMENT IN STEEL-ENTRY, DIFFUSION, AND ELIMINATION

\section{by}

E. E. Fletcher and A. R. Elsea

to

\section{OF FICE OF THE DIRECTOR OF DEFENSE RESEARCH AND ENGINEERING}


SUMMARY

INTRODUCTION

SOLUBILITY

Introduction

Preferred Lattice Sites for Hydrogen.

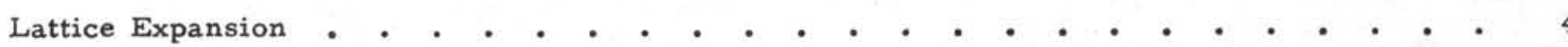

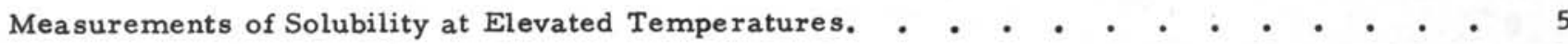

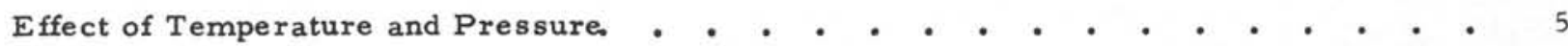

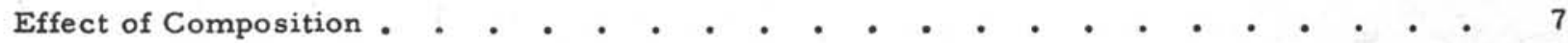

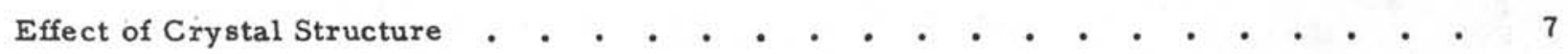

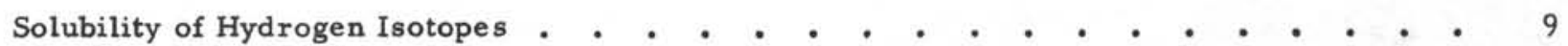

Measurements of Solubility at Lower Temperatures (750 F to Room Temperature) . . . 10

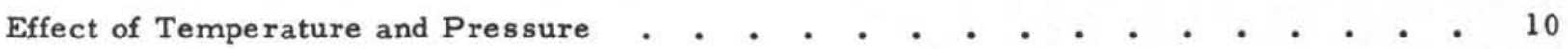

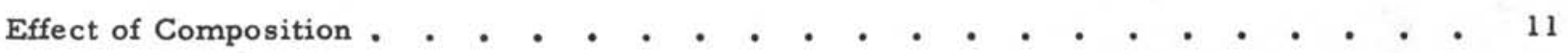

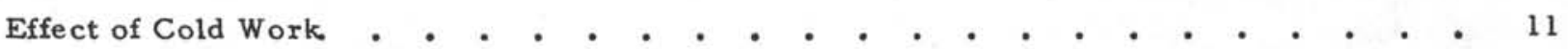

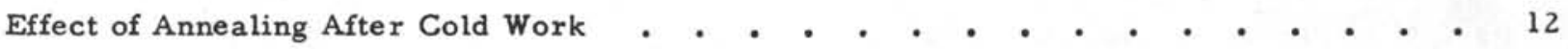

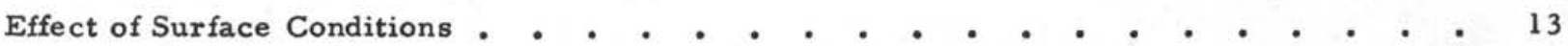

Estimates of Equilibrium Hydrogen Pressure in Steel. . . . • . . . . . . . . 13

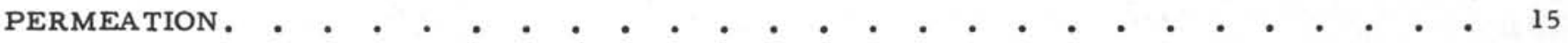

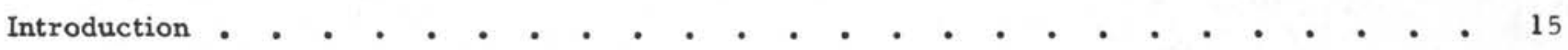

Hydrogen Entry • • • • • • • • • • • • • • • • • • • • • • • • 16

Entry by Corrosion Processes • • • • • • • • • • • • • • • • • • •

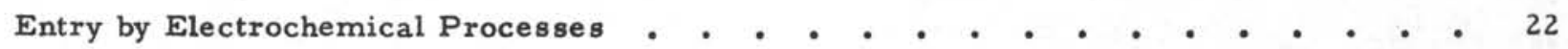

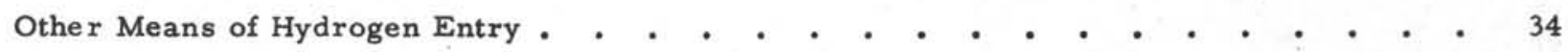

Effects of Surface Treatments and Environment • • • • • • • • • • • . 37

Diffusion • • • • • • • • • • • • • • • • • • • • • • • • • • 38

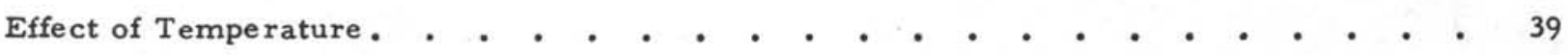

Effect of Pressure • • • • • • • • • • • • • • • • • • • • • • 45

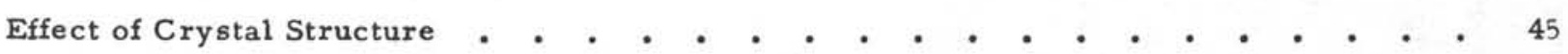

Effect of Steel Composition • • • • • • • • • • • • • • • •

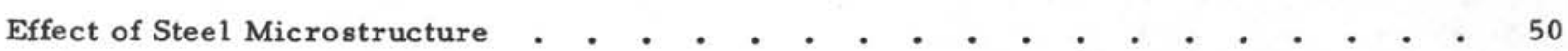


Effect of Metal Thickness . . . . . . . . . . . . . . . . . . . . 51

Effect of Cold Work . . . . . . . . . . . . . . . . . . . . 53

Diffusion of Deuterium . . . . . . . . . . . . . . . . . . . 56

Removal of Hydrogen . . . . . . . . . . . . . . . . . . . . . . 57

The Effects of Temperature, Section Size, and Steel Composition . . . . . . . 57

Effects of Environment and Surface Reactions . . . . . . . . . . . . . 61

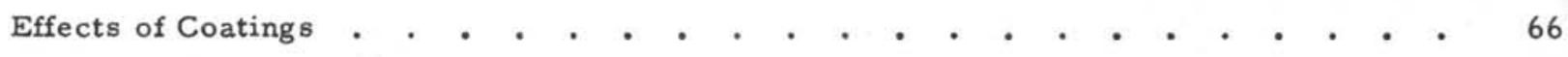

Residual, or Nondiffusible, Hydrogen . . . . . . . . . . . . . . . 69

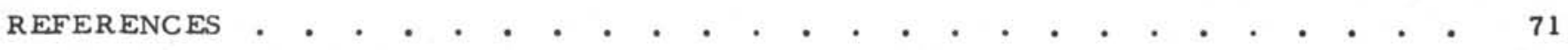

OTHER DMIC PUBLICATIONS ON HYDROGEN IN STEEL

"The Problem of Hydrogen in Steel"

DMIC Memorandum 180, October 1, 1965

"Hydrogen-Induced, Delayed, Brittle Failures of High-Strength Steels"

DMIC Report 196, January 20, 1964

"The Effects of High-Pressure, High-Temperature

Hydrogen on Steel"

DMIC Report 202, March 26, 1964 


\section{HYDROGEN MOVEMENT IN STEEL--ENTRY, DIFFUSION, AND ELIMINATION}

E. E. Fletcher and A. R. Elsea*

\section{SUMMARY}

Previous DMIC reports have described various problems associated with hydrogen in steel. The present report considers how hydrogen enters steel, moves through it, and is removed from it.

The solubility of hydrogen in iron and steel affects the entry of hydrogen into the material and its movement through the metal. The solubility also serves as an indication of the magnitude of the concentration gradients to be expected. Therefore, an understanding of the solubility of hydrogen is important in understanding other aspects of the behavior of hydrogen in steel.

Iron is a typical endothermic occluder of hydrogen. It is generally concluded that no hydrides are formed. The hydrogen atom, being the smallest atom, is the one most likely to form interstitial solid solutions. Apparently, it does so in iron, but X-ray data show no clear-cut evidence of solid solubility. The solubility of hydrogen in iron generally conforms to Sieverts' law for pressures up to at least 100 atmospheres. Therefore, it is concluded that hydrogen enters iron and steel only in the dissociated form, not as molecules. However, it is still uncertain whether this dissociated form is the atom or the proton, or both. Because the interstices in the $\alpha$-iron lattice are smaller than those in $\gamma$-iron, the solubility is lower in $\alpha$-iron than it is in $\gamma$-iron. Because the interstice $s$ in $\alpha$-iron are even smaller than the hydrogen atom, severe distortion of the $\alpha$-iron lattice results from interstitial solution. The lattice expansion apparently is below the limit of experimental error for detection by $\mathrm{X}$-ray methods. However, the bowing of a sheet specimen cathodically charged with hydrogen on only one surface and the elongation of a coil of iron wire upon being charged with hydrogen have demonstrated that ex pansion does accompany hydrogen solution.

At room temperature, the solubility of hydrogen in iron is very small (a few ppm), but the solubility increases with increasing temperature. A marked increase in solubility accompanies the transformation from body-centered cubic iron to the face-centered form on heating. Also, a large increase occurs on melting, the solubility in liquid iron being much greater than in the solid. In conformance with Sieverts' law, the solubility

*Senior Metallurgical Engineer and Associate Chief, Ferrous and High Alloy Metallurgy Division, Battelle Memorial Institute, Columbus, Ohio. generally is proportional to the square root of the external partial pressure of molecular hydrogen. Alloying elements have some effect on solubility, but the crystal structure has a far greater effect.

Measurements of the solubility (S), permeability (P), and diffusivity (D) of hydrogen in iron are individually reliable and, under conditions of steady-state diffusion, they are consistent with each other at temperatures above about $750 \mathrm{~F}$ (that is, they satisfy the relationship $P=S \cdot D$ ), but not at lower temperatures. Experimental difficulties have precluded obtaining as complete an understanding of the solubility of hydrogen in iron and steel for the temperature range from about $750 \mathrm{~F}$ to room temperature as has been obtained for the higher temperatures. Nearly all investigators have obtained abnormally high solubilities of diffusible hydrogen at temperatures below about $750 \mathrm{~F}$ as compared with the extrapolation of data for $\alpha$-iron at higher temperatures. There is strong evidence for the existence of traps in annealed material (as well as in cold-worked material) to account for the extra solubility. However, the dislocation density of annealed iron is far too low for the extra hydrogen to be trapped in dislocations. Some investigators suggest that other lattice defects, possibly vacancies, constitute the traps. Others suggest that the traps may be merely slightly widened planar lattice spacings. One group of investigators found that certain types of iron and steel treated at high pressure and high temperatures for prolonged periods will retain at ambient temperatures and pressures greater amounts of hydrogen than the usually indicated solubility. Furthermore, the hydrogen thus introduced can be extracted in two fractions, the "extra" hydrogen being much more difficult to remove. In this lowtemperature range, austenitic materials have higher solubilities for hydrogen than do the ferritic or martensitic materials, just as at higher temperatures.

A number of investigators have shown that cold work or subsequent annealing have little or no effect on hydrogen solubility in high-purity iron. However, in the case of SAE 1020 steel, for example, cold work may increase the solubility for hydrogen by a factor of as much as 100 or more for some conditions. Variations from this behavior 
have been reported, and there is no agreement even on the trends. Some of these discrepancies probably arose because of the use of different experimental conditions and because of variations in the methods used for the analysis for hydrogen, all of which are not equally effective in detecting both dissolved and trapped hydrogen. If the data indicate a general trend, it seems to be that cold work increases the solubility for hydrogen. Such increasing solubility is usually explained by hypothesizing the existence of "traps" in which that hydrogen in excess of the equilibrium lattice solubility is accommodated. Presumably, the concentration of such traps increases with increasing degree of plastic deformation. Apparently all such traps cannot be removed by annealing, but usually the large occlusive capacity of cold-worked material is markedly reduced by annealing.

Because the equilibrium solubility of hydrogen decreases with decreasing temperature, hydrogen tends to escape from surfaces, both external and internal. Atomic hydrogen depositing in internal voids will combine to form molecular hydrogen which cannot diffuse in steel, and thus high pressures of molecular hydrogen can build up in these internal voids, sometimes exceeding the yield strength of the steel so that blisters or other damage occurs.

The permeation of hydrogen through steel consists of interactions at both the entry and exit surfaces of the metal as well as diffusion through the bulk metal. Where diffusion is rate controlling and surface resistances to entry and exit are very small, permeation is equal to the product of the solubility and the diffusivity $(P=S \cdot D)$. This relationship usually applies at temperatures above about $750 \mathrm{~F}$.

Hydrogen can be introduced by corrosion processes, including acid pickling, corrosion in aqueous environments, and sulfide corrosion; electrochemical processes, such as electroplating, cathodic cleaning, electrolytic machining, and cathodic protection; exposure to high-pressure hydrogen or to hydrogen or water vapor at elevated temperatures; cyclotron proton irradiation; exposure to suitable flames; and glow discharge. Hydrogen introduced during steelmaking operations frequently is a factor in the delayed hydrogen cracking of steel. The report considers possible hydrogen-evolution reactions during corrosion or electrolytic processes; then the entry mechanism is discussed. Some of the important factors in hydrogen entry are the type of environment at the entry surface; the nature and concentration of the pickling bath, electrolyte or electroplating bath; $\mathrm{pH}$, external hydrogen pressure, or current density; the presence of cathodic poisons or pickling inhibitors; the structure of the steel; and the condition of the steel surface, cold work having a significant effect on hydrogen entry. A number of substances, such as phosphorus, sulfur, hydrogen sulfide, arsenic, and selenium (called cathodic poisons) serve to delay the recombination of atomic hydrogen liberated at the steel surface into the molecular form, and, hence, provide increased opportunity for atomic hydrogen to enter the steel.

Hydrogen pickup in steelmaking is minimized by careful drying of raw materials, slagmaking materials, and refractories, and by such processes as vacuum melting or vacuum degassing. Heat-treating atmospheres should be low in hydrogen partial pressure and in water-vapor content to minimize hydrogen pickup. No acid pickling, cathodic cleaning, or electroplating operations can be tolerated if the hydrogen content of steel is to be kept as low as possible.

The second major part of permeation is diffusion through the bulk solid. Most of the current theories explaining hydrogen embrittlement and hydrogen cracking depend on the diffusion of hydrogen. The diffusion of hydrogen in iron appears to be compatible with the relation $\mathrm{P}=\mathrm{S} \cdot \mathrm{D}$ at elevated temperatures, but anomalously low values of diffusivity are obtained at the lower temperatures, primarily below about 300 or $400 \mathrm{~F}$. The results of various investigators in determining the diffusion coefficient are in fairly good agreement for temperatures above $750 \mathrm{~F}$ and generally so above about $400 \mathrm{~F}$. However, experimental difficulties in measuring low rates of permeation have resulted in considerable discrepancy at temperatures near room temperature.

Experiments have shown that the diffusion of hydrogen in iron and steel occurs throughout the bulk material and not preferentially at grain boundaries as it does for many other materials. At higher temperatures, apparently hydrogen diffuses through the crystal lattice; at lower temperatures where anomalous solubility and diffusivity are encountered, it is possible that hydrogen diffuses through a nonconnecting "rift" network. As would be expected, the rate of diffusion increases rapidly with increasing temperature. This is the basis for the baking treatments designed to remove hydrogen from steel. Atomic hydrogen in steel will diffuse against very high back pressures of gaseous molecular hydrogen. Diffusion occurs at a barely perceptible rate at the temperature of dry ice $(-109 \mathrm{~F})$, and the rate is nil at the temperature of liquid nitrogen $(-320 \mathrm{~F})$.

Alloy additions of silicon and chromium to steel markedly decrease the diffusivity in $\alpha$-iron. Increasing the carbon content appreciably lowers the permeation rate at ambient temperatures. Steel microstructure has a marked effect on the permeation of hydrogen through steel. Carbide particles in any form appear to hinder passage of hydrogen through steel, even after steady-state conditions have been attained. High permeation rates are obtained when the iron carbide is in the globular (spheroidized) form, and minimum rates are associated with martensite. Annealed or normalized structures have appreciably higher 
rates than do martensitic structures. Coarse, lamellar pearlite offers more resistance to hydrogen passage than does fine pearlite. Where permeation is determined by the rate of diffusion and not by surface processes on the entry or exit surfaces, the rate of permeation is inversely proportional to the metal thickness.

Controversial results have been obtained in studying the effect of cold work on the occlusion of hydrogen and also on permeation. Some investigators have reported that cold work increases the rate of permeation of hydrogen, others state that it reduces permeation, and still others have observed no effect or different effects depending upon the amount of cold work. Much more work is needed to clarify the effect of cold work on permeation and on diffusion.

The rate of hydrogen removal from iron and steel depends on, and varies greatly with, such factors as temperature, thickness of material, crystal structure (whether austenitic or ferritic), the amount of cold work, the environment at the exit surface, and the presence of coatings such as oxide films or electroplates.

The loss of hydrogen from austenitic steels is imperceptible at room temperature, but ferritic or martensitic steels continually lose hydrogen at ambient temperatures until the equilibrium level has been reached. The rate of loss from all steels increases with increasing temperature, at least within a few hundred degrees of room temperature. Hydrogen removal is roughly 250 to 500 times faster at $400 \mathrm{~F}$ than at room temperature. However because of increased solubility of hydrogen in $\alpha$-iron with increasing temperature, baking temperatures should not be too high. The optimum temperature is about 400 to $500 \mathrm{~F}$, but frequently it must be limited to 375 to $400 \mathrm{~F}$ to prevent damage to electroplated coatings. Variation in crosssectional area has a large effect on diffusion, and hence on the removal of hydrogen. For a cylindrical bar, the time to remove a given fraction of the hydrogen from a saturated specimen increases as the square of the diameter. In one instance, where 60 days was required to reduce the hydrogen to the equilibrium level in 1-inch-square bars at room temperature, about 6 years was required for 4inch bars.
Practically all alloy additions retard the evolution of hydrogen from steel, silicon and chromium being particularly effective. The method of introducing hydrogen into the steel has practically no effect on the rate of removal of hydrogen or the rate of recovery of lost ductility.

Frequently, surface reactions, rather than diffusion through the bulk of the metal, control the entry and removal of hydrogen. The nature of the environment at the exit surface has been found to be very important in the removal. For example, immersion in hot water is more effective than exposure to hot air at the same temperature; moist air is more effective than dry air. Oxide films, which often form on steels during treatment, hinder the removal of hydrogen. The presence of a more or less impermeable coating, such as dense cadmium, makes the evolution of hydrogen from steel more difficult, and frequently baking is rather ineffective in reducing the propensity toward delayed, brittle failure when such coatings are present. Ductility is recovered much more slowly in a baking treatment when coating $s$ are present than when the steel surface is bare.

Re sidual or so-called "nondiffusible" hydrogen has been encountered many times in studies of hydrogen removal and in the analysis of steels for hydrogen. Frequently, the hydrogen can be extracted in two fractions, the one fraction requiring very high temperatures for its removal. This has led some investigators to suggest that hydrogen exists in steel in two forms, the one form being bound far more tenaciously than is indicated by the usual diffusion coefficient. Frequently, all of the hydrogen is not removed in warm-extraction analyses, but drastic vacuum treatment at temperatures in the austenitic region or even in the molten state is required.

Thus, removal is facilitated by elevated temperatures, clean surfaces free from oxide or other coatings, thin sections, low partial pressures of dissociated hydrogen in the external atmosphere, and by the presence of water or water vapor at the exit surface. 


\section{INTRODUCTION}

The effects of hydrogen on the ductility of steel and the phenomenon of hydrogen-induced delayed, brittle failure of high-strength steel at low applied stresses have been described in a previous report (DMIC Report No. 196). It was shown that the se phenomena depend not only on the presence of hydrogen, but also on the ability of hydrogen to diffuse, or move, in the steel while it is under load. This movement occurs either in response to a concentration gradient or a stress gradient. Since both the presence and the movement of hydrogen in steel are fundamental to the se serious problems, this report has been prepared to aid in understanding the movement of hydrogen in steel. It considers the ways in which hydrogen enters steel, how it moves through steel, and methods whereby it may be removed from steel. The various factors that affect each of the se phenomena are considered.

The person who is producing high-strength steel parts is interested in keeping hydrogen out of steel to as great an extent as possible, and in being able to remove most of that which enters unavoidably. Sometimes the research man desires to introduce hydrogen into steel intentionally in order to study the influence of hydrogen on the behavior of steel. Information is given to assist in both of the se approaches to the hydrogen problem.

First, the report deals with the solubility of hydrogen in iron and steel. Following this, the permeation of hydrogen through iron and steel is broken down into its component parts of entry, diffusion, and exit. A concluding section deals with the removal of hydrogen from production parts. 


\section{SOLUBILITY}

\section{Introduction}

The effect of hydrogen on the mechanical properties of any given metal depends upon the hydrogen-metal system, and, especially, on such factors as the solubility of hydrogen in the metal and the formation of a hydride phase. It is generally considered that metals and hydrogen react in one of the four following ways: (1) by forming salt-like, ionic hydrides, (2) by forming covalent hydrides that are gaseous at room temperature, (3) by forming alloys that exhibit negative heats of absorption (endothermic occlusion), or (4) by forming alloys that exhibit positive heats of absorption (exothermic occlusion), sometimes called "pseudo hydrides".

Iron, being a typical endothermic occluder, takes up hydrogen only in small quantities, even at elevated temperatures where such occluders exhibit their greatest solubilities. This behavior is in accordance with the positive temperature coefficient which, of necessity, corresponds to the negative heat of absorption. The alloy of iron and hydrogen, that is, the product of occlusion, consists of only one solid phase. This was long considered to be a true terminal solid solution of hydrogen in iron. Proponents of the viewpoint that endothe rmic occluders form true solid solutions with hydrogen cite the following as evidence: (1) the hydrogen solubility varies with the square root of the pressure (Sieverts' law), and (2) the solubility increases as the temperature increases. (1) Other investigators question whether solid solutions occur at all in endothermic metal-hydrogen systems, such as the iron-hydrogen system. (2) As will be shown later, the solubility of hydrogen in iron does not follow Sieverts' law perfectly. X-ray evidence, including some obtained recently, (3) fails to indicate solid solubility.

The exothermic occluders, which absorb hydrogen in much larger quantities than do the endothermic occluders, form alloys of greater complexity which exhibit unmistakable solid solutions and one or more secondary phases.

Although the products of occlusion of the exothermic occluders and endothermic occluders of the transition metals resemble the hydrides of the alkali and alkaline-earth metals in showing variable composition, the analogy appears to extend no further; the hydrogen alloys form either with expansion or without any volume change at all and are wholly metallic in character, while formation of the hydrides of the alkali and alkaline-earth metals is accompanied by marked contraction and the products are salt-like in nature. The changes in gross dimensions, brought about by absorption of hydrogen, are, in the cases of endothermically occluding metals (like iron), generally too small to be observed with certainty. The exothermically occluding metals, on the other hand, are expanded markedly by occlusion, as much as 15 percent or more.

Knowledge of the solubility of hydrogen in iron and steel is important in understanding the hydrogen problem, because the solubility affects the entry of hydrogen into the metal and also its movement through the metal. It serves to indicate the magnitude of the concentration gradients to be expected.

It will be shown later, in the section on permeability, that the measurements of solubility, permeability, and diffusivity of hydrogen in iron are individually reliable and, under conditions of steady-state diffusion, they are consistent with each other for temperatures above $750 \mathrm{~F}(400 \mathrm{C})$. However, at temperatures below about $750 \mathrm{~F}$, the experimentally measured solubility deviates from the extrapolation of the high-temperature behavior in the direction of greater solubility. Because of the se apparently anomalous results, the solubilities at high temperatures and low temperatures will be discussed separately.

The gas content in a solid or liquid may be expressed in a number of ways. The commonest are as follows:

Atomic concentration $=$ atoms of $\mathrm{H}$ per atom of metal

Relative volume $(R V)=$ volumes of $H$ per volume of metal

Weight percent $=\mathrm{g}$ of $\mathrm{H}$ per $100 \mathrm{~g}$ of metal

Gas volume per metal weight $=$ commonly, cc of $\mathrm{H}$ per $100 \mathrm{~g}$ of metal, or, less often, cc of $\mathrm{H}$ per $\mathrm{g}$ of metal

Parts per million by weight $(\mathrm{ppm})=0.0001 \mathrm{x}$ weight percent.

Conversion factors for interconversion of these units for iron are listed in Table 1.

\section{Preferred Lattice Sites for Hydrogen}

Interstitial solid solutions are formed when solute atoms of small radii are accommodated in the interstices, or "holes", of the lattice of a solvent. Because the size of the lattice interstices is restricted, only the smaller atoms hydrogen, boron, carbon, nitrogen, and oxygen are likely to form this type of solid solution. Of these, the hydrogen atom with an atomic radius of $0.46 \mathrm{~A}$ is the smallest, and, hence, the most readily accommodated interstitially. When a solvent accepts one of the se elements interstitially, solution is usually accompanied by expansion of the unit cell.

Diagrams of both of the iron lattices are shown in Figure 1. The largest holes in the 
TABLE 1. FACTORS FOR CONVERSION OF DIFFERENT UNITS OF HYDROGEN CONTENT IN IRON

(Mital density assumed $7.88 \mathrm{~g} / \mathrm{cc}$; atomic weight of iron 55.84 .)

\begin{tabular}{|c|c|c|c|c|c|}
\hline \multirow[b]{2}{*}{$\begin{array}{l}\text { Desired } \\
\text { Units }\end{array}$} & \multicolumn{5}{|c|}{ Factor } \\
\hline & $\begin{array}{c}\text { Atomic } \\
\text { Concentration }\end{array}$ & RV & $\begin{array}{l}\text { Weight } \\
\text { Percent }\end{array}$ & $\frac{\mathrm{Cc} \mathrm{H}_{2}}{100 \mathrm{~g} \mathrm{Fe}}$ & Ppm \\
\hline $\begin{array}{l}\text { Atomic Con- } \\
\text { centration }\end{array}$ & 1 & 0.000632 & 0.554 & 0.0000498 & 0.0000554 \\
\hline RV & 1,580 & 1 & 877 & 0.0788 & 0.0877 \\
\hline $\begin{array}{l}\text { Weight } \\
\text { Percent }\end{array}$ & 1. 805 & 0.00114 & 1 & 0.0000899 & 0.0001 \\
\hline$\frac{\mathrm{Cc} \mathrm{H}_{2}}{100 \mathrm{~g} \mathrm{Fe}}$ & 20,080 & 12.69 & 11,100 & 1 & 1.11 \\
\hline Ppm & 18,050 & 11.4 & 10,000 & 0.899 & 1 \\
\hline
\end{tabular}

Example of calculation:

Calculate the atomic concentration $(\mathrm{H} / \mathrm{Fe})$ when $\mathrm{RV}=94$

$94 \times 0.000632=0.0594$, i.e., about 0.06 atom $\mathrm{H}$ per 1 atom Fe.

close-packed face-centered cubic lattice are at the midpoints of the edges of the unit cell $(001 / 2$, etc.) and at $1 / 21 / 2 \frac{1}{2}$. The se are known as octahedral sites and are crystallographically equivalent positions; one example of the former type of site and the only latter site are illustrated in Figure la. Each of the se interstices is surrounded symmetrically by six iron atoms (radius $1.26 \AA$ ) at equivalent distances, giving a coordination number of 6. Smaller interstices exist at positions of the type $1 / 4 \frac{1}{4} 1 / 4$; the se are surrounded by a tetrahedral arrangement of four solvent atoms (coordination number $=4$ ), and hence, are known as tetrahedral sites. One of these sites is shown in the upper right portion of Figure la. In $\gamma$-iron, the larger (octahedral) interstices have room for a spherical atom of $0.52 \AA$ radius, and the smaller (tetrahedral) interstices for one of only $0.28 \AA$ without expansion of the lattice. The kind of site occupied by a given interstitial atom is that which will permit it to attain the highest coordination number compatible with its size. Larger interstitial atoms tend to occupy octahedral sites and smaller ones the tetrahedral sites, the maximum radius ratio being about 0.59 for $C N=6$ and 0.41 for $C N=4$. It is considered that the preferential location of the hydrogen atom is the smaller (tetrahedral) site of the face-centered cubic $\gamma$-iron lattice ${ }^{4)}$ the $\mathrm{H} / \mathrm{Fe}$ radius ratio being only 0.37 .

Body-centered cubic metals have their largest holes at $1 / 21 / 40$ and equivalent positions. A spherical atom here would touch four spherical atoms of the solvent. One of the se sites is shown in Figure 1b. In $\alpha$-iron, the re would be room in the se tetrahedral sites for an interstitial atom of $0.36 \AA$ radius, which is smaller than even the hydrogen atom. Smaller holes are found at the midpoints of the edges $(001 / 2$, etc. ) and at the equivalent positions at the centers of the faces $(1 / 21 / 20$, etc.). One of each of these small, octahedraltype sites is indicated in Figure lb. The se octahedral sites are surrounded by two close atoms and four slightly more distant ones and, thus, are asymmetrical ( In $\alpha$-iron, there would be room here for a sphere of only $0.19 \AA$ radius if the iron atoms are con-

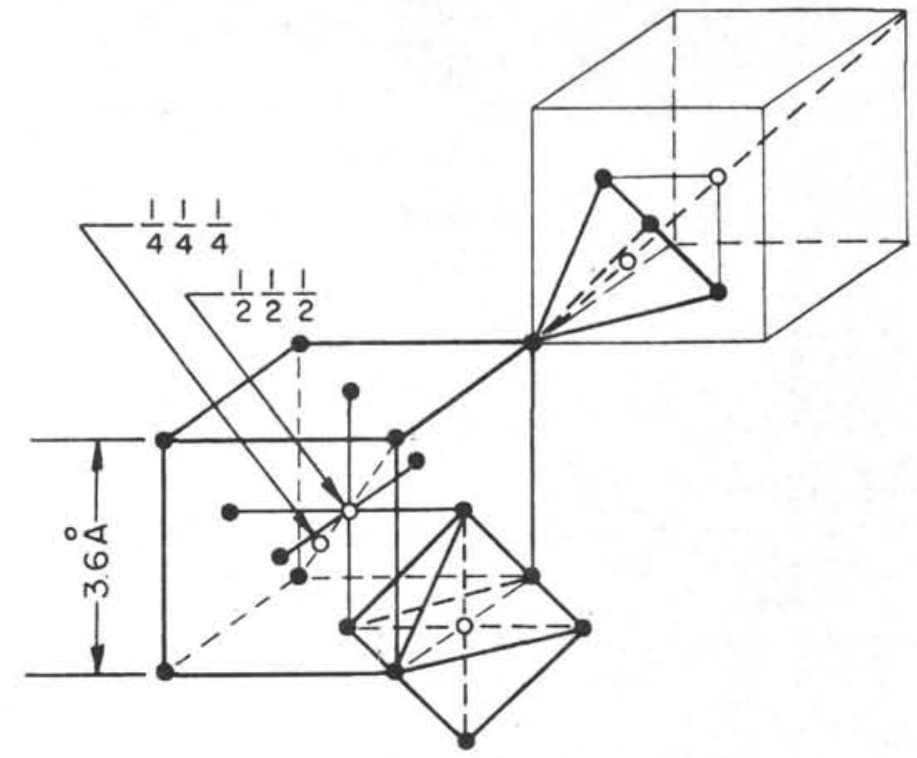

a. Interstitial Positions in Face-Centered Cubic $\gamma$-Iron

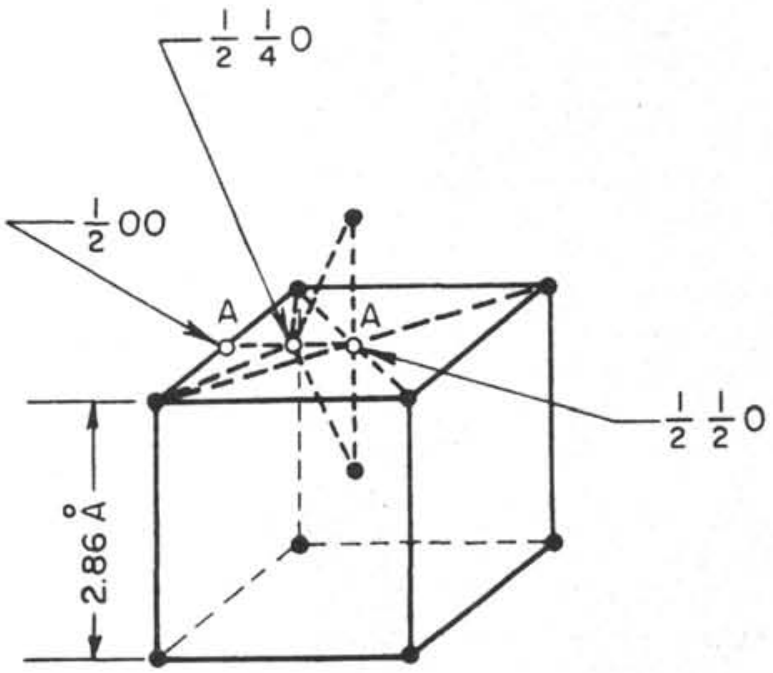

b. Interstitial Positions in Body-Centered Cubic $\alpha$-Iron

\section{FIGURE 1. SCHEMATIC REPRESENTATION OF $\alpha$ - AND $\gamma$-IRON LATTICES}

(Solid circles denote centers of iron atoms.)

sidered as spheres in contact with each other. The larger (tetrahedral) sites in $\alpha$-iron are regarded to be more stable for hydrogen than are the asymmetrical positions. $(5,6)$

Because the interstices in $\alpha$-iron are smaller than those in $\gamma$-iron, it appears that interstitial solid solution in $\alpha$-iron should be more difficult than in $\gamma$-iron, as is the case. Because the interstices in $\alpha$-iron are considerably smaller than even the hydrogen atom, one concludes that severe distortion of the $\alpha$-iron lattice should result from interstitial solution.

Plusquellec and co-workers $(7)$ have sugge sted that hydrogen is preferentially associated with 
lattice defects present in the $\{112\}$ crystal planes. From X-ray studies, Bastien $(8)$ concluded that the $\{112\}$ crystal planes in $\alpha$-iron are tilted slightly in the presence of hydrogen, but the parallelism of the planes is restored as the hydrogen diffuses out of the material. This conclusion was based on the observed broadening of the $\{112\}$ spots on Laue patterns obtained from steel charged with hydrogen. Heating the previously charged steel at temperatures high enough to drive the hydrogen out but too low to cause any recovery of the lattice caused the broadening to disappear. He attributed this effect to a local lattice distortion associated with hydrogen occupying and expanding the tetrahedral lattice interstices of body-centered cubic $\alpha$-iron. Recently, Tetelman, Wagner, and Robertson $(3)$ showed by $\mathrm{X}$-ray studies that cathodic charging of iron with hydrogen produces both distortion and anisotropic particle-size broadening. They concluded that the broadening of the X-ray reflections, that was found after charging, resulted from plastic deformation and was not due to preferential location of hydrogen in the lattice as Plusquellec and co-workers assumed.

Since, as will be shown later, the solubility of hydrogen in iron conforms to Sieverts' law at temperatures above $750 \mathrm{~F}(400 \mathrm{C})$, it has been concluded that hydrogen enters iron in a dissociated form, rather than as molecules. Furthermore, the relatively simple diffusivity behavior of hydrogen in iron at temperatures above $750 \mathrm{~F}(400 \mathrm{C})$ has been taken as indicating that hydrogen diffuses interstitially at these temperatures. This approach is verified by a consideration of interstitial diffusion theory in which Wert and Zener ${ }^{(9)}$ obtained theoretical values of $1.6 \times 10^{-3} \mathrm{~cm}^{2} / \mathrm{sec}$ for each of two interstitial models in which it was assumed that the hydrogen occupied either the octahedral or the tetrahedral sites of $\alpha$-iron. This value compares favorably with the experimental value of $1.4 \times 10^{-3} \mathrm{~cm}^{2} / \mathrm{sec}$ for the diffusion coefficient $\mathrm{D}_{\mathrm{o}}$ obtained recently by Johnson and Hill ${ }^{(10)}$ for temperatures above $390 \mathrm{~F}(200 \mathrm{C})$. This leaves little doubt as to the interstitial nature of the diffusion process, for, according to Zener, interstitial processes are the only diffusion processes in which the theoretical $D_{0}$ is of the order of $10^{-3} \mathrm{~cm}^{2} / \mathrm{sec}$. However, this method could not determine which site was preferred.

Although it has been demonstrated that hydrogen enters and diffuses through iron in a dissociated form, it is still uncertain whether this form is an atom or a proton. The extremely rapid diffusion rate of hydrogen in iron has led some to speculate that the dissociated particles are protons which have an extremely small radius $\left(10^{-5} \AA\right)$ with respect to the interatomic distance in iron. Bastien $(8)$ has presented evidence from electrolys is experiments which indicate that the hydrogen is present as ionized particles with a positive charge. He has speculated that the hydrogen probably does not exist as simple protons, but rathe $r$ as protons that are partially shielded or screened by electrons.
The effective size of such an ion could be near that of the hydrogen atom, big enough to conceivably lead to some lattice distortion and expansion. However, the state of ionization is not yet known. According to Bastien, (8) Darmois (11) has obtained additional evidence that the diffusion takes place at least partly in the form of protons.

Cottrell has shown that, for larger interstitial atoms, such as carbon and nitrogen, a significant decrease in lattice strain energy accompanies the transfer of an atom from an isolated interstitial site into one in the vicinity of a dislocation. This decrease in energy provides the driving force for the formation of atmospheres of such atoms around dislocations. Heller ${ }^{(12)}$ studied the hydrogen yield point and concluded that the corresponding strain interaction of hydrogen with dislocations is too small to lead to condensation around dislocations at room temperature.

Hill and Johnson(13) believe that the extremely rapid decrease in the diffusivity of hydrogen in annealed iron at temperatures below $390 \mathrm{~F}$ (200 C) is related to the existence of traps in which the hydrogen possesses lower energy than when it is in interstitial sites. Accordingly, diffusion at lower temperatures is presumed to be controlled by the rate of escape from such traps, thus accounting for the higher activation energy observed at these temperatures.

Hill and Johnson(13) have presented the following views on the physical nature of the traps for hydrogen. The traps in unalloyed iron that has not been cold worked seem qualitatively similar in certain respects to those in cold-worked iron-carbon alloys, which these investigators studied previously and which they suggested were cracks formed by piled-up dislocations in which the hydrogen is chemisorbed. (14) The present traps react with hydrogen endothermically, however, and so they do not appear to be chemisorption sites, in view of the fact that hydrogen chemisorption is exothermic in all known cases. Nevertheless, there might be some connection between the traps in $\alpha-$ iron and those that result from cold work in steel. During plastic straining of steel, the present traps might migrate through the ferrite lattice and coalesce at interfaces with $\mathrm{Fe}_{3} \mathrm{C}$ particles to form the larger and more energetic traps characteristic of deformed steel. They would thus serve as building blocks for the stronger traps in cold-worked steel.

This behavior of the traps suggests that they are dislocations. However, previous estimates of the strain interaction of hydrogen with dislocations are of the order of only $0.1 \mathrm{ev}$ or $2,000 \mathrm{cal} / \mathrm{g}$-atom. Such interactions would be detectable only at quite low temperatures, whereas the present trapping is detectable at $555 \mathrm{~F}(290 \mathrm{C})$ and the interaction energy is $4,800 \mathrm{cal} / \mathrm{g}$-atom. Hill and Johnson suggest that the hydrogen may be at least partially ionized and, therefore, has an electrostatic rather than a strain interaction with the dislocations. Also, a dislocation 
density several orders of magnitude higher than the usually accepted dislocation density in undeformed iron would be required if the traps are actually dislocations. Likewise, in the temperature range of interest, the concentration of vacancies is several orders of magnitude smaller than the number of trapped hydrogen atoms.

It is possible that the traps are another kind of lattice defect. This has been suggested in effect in many previous theories of hydrogen in metals. Smith $(2)$ has hypothesized that the hydrogen resides entirely in a network of interconnecting "rifts" created by the hydrogen itself. Hill and Johnson's view differs from that of Smith in holding that the hydrogen diffuses through the lattice, rather than through a rift network, and is situated wholly in the lattice interstices at higher temperatures. The possibility of nonconnecting "rifts" is admitted only at lower temperatures where the anomalous solubility and diffusivity (to be discussed later) are found. Other ideas of extra-lattice accommodation of hydrogen in steel include the planarpressure occlusion theory of $\operatorname{Zapffe}(15,16,17)$ and the theory that hydrogen is accommodated at subgrain boundaries suggested by Andrew et al. $(18,19)$

Hill and Johnson(13) pointed out that all the se views of hydrogen in metals have many points in common with their concept of traps. They suggested that a generally consistent conclusion might be that the traps are slightly widened planar lattice spacings that form only as the hydrogen-saturated iron lattice is cooled below a certain temperature. Such a mechanism does not require the presence of dislocations or vacancies, and there is virtually no limit to the number of traps that can be formed if the dissolved hydrogen concentration or the external pressure of molecular hydrogen is high enough.

\section{Lattice Expansion}

The exothermic hydrogen occluders exhibit considerable expansion of the crystal lattice as the result of hydrogen occlusion. From the data on iron available to $\mathrm{Smith}^{(2)}$ in 1948 , he concluded that expansion occurring as a result of hydrogen absorption is limited to exothermic occluders. However, it was shown in 1960 that this is not the case, because the face-centered cubic lattice of the endothermic occluder nickel is expanded by 6 percent as the result of cathodic charging with hydrogen.

Wever and Pfarr $(20)$ reported an increase in the lattice spacing of mild steel of about 0.017 percent as the result of prolonged charging with cathodically evolved hydrogen. The average hydrogen content after charging was $30 \mathrm{~cm}^{3} / 100 \mathrm{~g}$ of steel, itself a very high value, but the investigators believed that the hydrogen concentration in the surface layer was probably much higher. On standing at room temperature, the hydrogen gradually escaped and the lattice spacing was observed $/ 169$ to decrease, approaching the initial value after 15 days. Baukloh and Stromburg(21) observed a 0.03 percent increase in the lattice spacing as the result of cathodic charging for 24 hours under severe conditions. However, in other work $(22,23,3)$ no detectable influence of cathodic charging with hydrogen on the lattice spacing of iron was found. According to Smialowski(24) Lihl(25) observed changes in the lattice spacing similar to those reported by Wever and Pfarr. However, he concluded that high stresses arising in the surface layer of pickled or electrolytically charged specimens made a correction of the values of Wever and Pfarr mandatory. After making such a correction, he found that their values were below the limit of experimental error.

Some of the investigators who used $\mathrm{X}-\mathrm{ray}$ methods for studying the effects of hydrogen occlusion in iron or steel tried to evaluate the magnitude of the stresses introduced in the surface layers of the metal by charging with hydrogen either electrolytically or by pickling. For example, Lihl(25) reported surface compressive stresses as high as $27,000 \mathrm{psi}$. However, he suggested that these stresses are a secondary effect of corrosion and cannot be directly attributed to the presence of occluded hydrogen in the metal. Glikman and Snezhkova(26) cathodically charged one side of a 13 percent chromium steel strip with hydrogen. The charged side became convex, and its deflection was measured. The highest stresses calculated were $10,000 \mathrm{psi}$. Inasmuch as the deflection of charged specimens disappeared after they were baked at about 400 to $575 \mathrm{~F}$, these investigators concluded that the stresses were created by dissolved hydrogen, not by corrosion as Lihl suggested. Szklarska-Smialowska and Smialowski(27) also observed the bending of strips cathodically charged on one side only. They found that iron actually deformed plastically as the result of cathodic charging with hydrogen. Smialowski and SzklarskaSmialowska, (28) studying the elongation of iron wires as the result of cathodic charging with hydrogen, observed linear expansion when catalytic poisons were present in the electrolyte; the effect was a small fraction as great when no poison was added to the acid electrolyte. This work will be discussed further when the effect of poisons on hydrogen entry is considered. In studying the deformation of Cshaped specimens cut from cold-rolled steel tubing and charged only on the ID, the cold-worked steel did not become deformed under the influence of cathodic charging. However, with prior annealing, the width of the gap gradually expanded as cathodic charging progressed. The deformation was almost completely irreversible, the width of the gap decreasing very little on standing at room temperature. Metallographic examination of charged rings showed that blisters and cracks were present. After a certain period of electrolysis, both the wires and the rings reached a limiting degree of deformation, no further deformation being observed with continued electrolysis. 
Foryst and Smialowski $(29,24)$ studied the limiting expansion and relative embrittlement of two Armco iron rods cathodically charged with hydrogen. One of the irons was unkilled and contained many sulfide and oxide inclusions; the other iron was Si-Al killed and had a much lower inclusion content. Some of the data for these two irons are included in the following tabulations:

$\frac{\text { Iron }}{\text { Unkilled Killed }}$

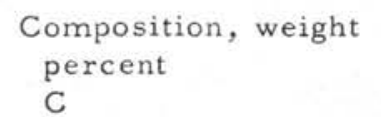

$\mathrm{Mn}$

$\mathrm{Si}$

$\mathrm{P}$

S

A1

Oxides

$\begin{array}{ll}0.02 & 0.03 \\ 0.05 & 0.06 \\ 0.03 & 0.15 \\ 0.007 & 0.011 \\ 0.031 & 0.004 \\ 0.00 & 0.07 \\ 0.061 & 0.039\end{array}$

Limiting Expansion, percent

0.021

0.004

Relative Embrittlement, percent

The unkilled iron with the high inclusion content showed about five times greater expansion when cathodically charged with hydrogen than did the killed iron. However, these irons did not differ in their susceptibility to embrittlement by cathodically evolved hydrogen. Thus, embrittlement and deformation or expansion do not seem to be quantitatively related to each other. The explanation advanced for this difference in behavior was that embrittlement depends on the degree of impregnation of the metal phase with atomic or ionic hydrogen, whereas expansion is due to the production of voids filled with gaseous hydrogen under high pressure. It was concluded that the presence of internal voids and defects is essential for the occurrence of elastic and plastic deformations in iron cathodes as the result of being charged with hydrogen. Embrittlement is a property of the metal phase, while expansion depends on the quantity and distribution of voids, nonmetallic inclusions, and other defects in the metallic structure. Since Foryst (30) later found that oxide inclusions did not influence the expansion of iron, it seems likely that the expansion attributed to inclusions is associated with sulfides.

The present authors have detected bowing of thin sheet specimens of a number of irons and mild steels cathodically charged with hydrogen on one surface. The bowing, measured with a dial indicator, was convex on the charged surface.

Although direct measurements of lattice expansion and stresses resulting from charging iron and steel with hydrogen have given controversial results, the bowing of sheet specimens charged on one side and the elongation of a spiral are evidence of expansion.

$\frac{\text { Measurements of Solubility at }}{\text { Elevated Temperatures }}$

Effect of Temperature and Pressure

At room temperature, the solubility of hydrogen in iron and other endothermic occluders is very small. However, the solubility increases with increasing temperature, and sometimes becomes considerable at temperatures of $1200 \mathrm{~F}$ or above.

Several investigators have measured the solubility of hydrogen in annealed or hot-worked iron and steel. $(31,32,33,34,35,36,37,38,13)$ Usually, the method employed was to measure the change in volume of gaseous hydrogen in contact with the sample at a given temperature and pressure.

At room temperature, the solubility of hydrogen in body-centered cubic $\alpha$-iron is very small, but it increases slowly with increasing temperature. A marked increase in solubility accompanies the transformation from bodycentered cubic $\alpha$-iron to face-centered cubic $\gamma$-iron at about $1670 \mathrm{~F}$. The solubility in $\gamma$-iron also increases slowly with increasing temperature until the $\gamma-0$ transformation temperature is reached, where the solubility drops markedly. In the body-centered cubic $\delta$-form, the solubility again gradually increases with increasing temperature up to the melting point, where a large increase occurs. Thus, for a given temperature, the solubility of hydrogen in face-centered cubic iron is appreciably greater than that in body-centered cubic iron. This is a consequence of the larger interstices in the face-centered cubic lattice of $\gamma$-iron as compared with those in the body-centered cubic $\alpha$ - and $\delta$-iron lattices. Also, the solubility in liquid iron is much greater than that in solid iron. These relationships are shown by several solubility isobars in Figure 2. For a given isobar, the solubility of $\delta$-iron may be considered as an extension of the solubility of $\alpha$-iron, since both forms have the same crystal lattice.

In both the liquid and the solid states for iron and steel, the solubility of hydrogen generally follows Sieverts' law for diatomic gases and varies as the square root of the gas pressure:

$$
\mathrm{S}=\mathrm{k}\left(\mathrm{p}_{\mathrm{H}_{2}}\right)^{1 / 2} \text {. }
$$

Actually, the solubility of hydrogen in steel is proportional to the partial pressure of atomic hydrogen, the only form of hydrogen that is soluble in steel. The partial pressure of atomic hydrogen formed by dissociation of molecular hydrogen is proportional to the square root of the pressure of molecular hydrogen. 


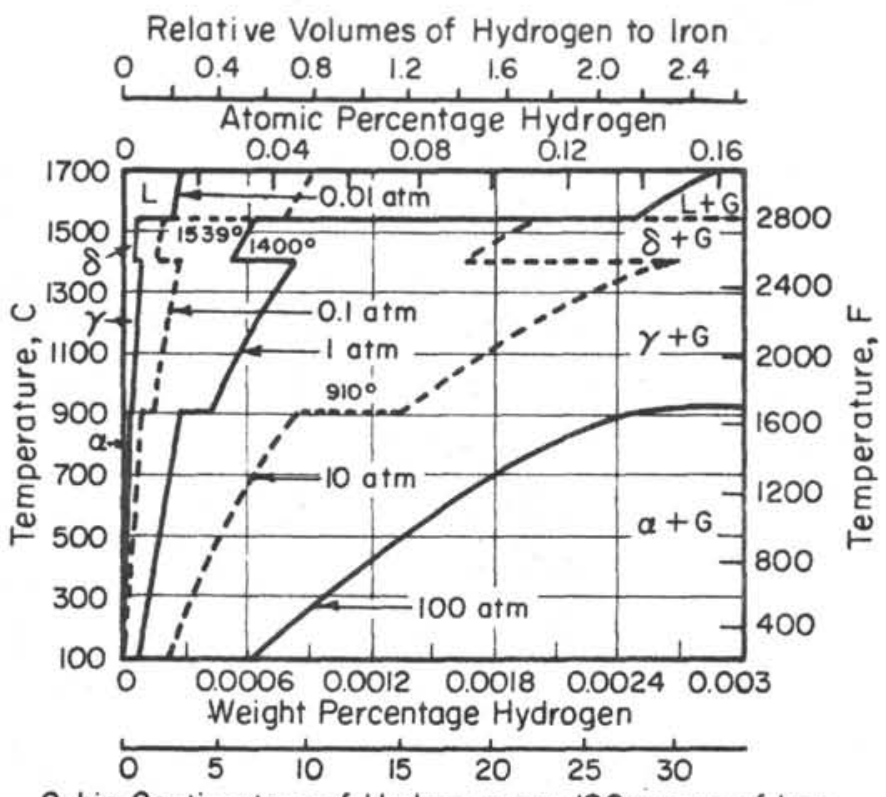

Cubic Centimeters of Hydrogen per 100 grams of Iron

\section{FIGURE 2. Fe-H IRON-HYDROGEN CONSTITU- TIONAL DIAGRAM AFTER ZAPFFE (39)}

Sieverts and co-workers showed the relationship expressed in Equation 1 to be generally applicable to endothermic hydrogen occluders, including iron, at all except high pressures and at all temperatures investigated (they were working at elevated temperatures). Armbruster (37) determined the solubility of hydrogen in iron, nickel, and several steels at low pressures that ranged from 0.001 to $1.5 \mathrm{~mm} \mathrm{Hg}$ and temperatures of 750,930 , and $1110 \mathrm{~F}(400,500$, and $600 \mathrm{C})$, and verified the applicability of the pressure-solubility relationship given by Equation 1 .

However, deviations from Sieverts' law have been observed, chiefly at lower temperatures than were used by Sieverts and by Armbruster. Hill and Johnson(13) found positive deviations for the pressure exponent, $n$, from the Sieverts' law value of 0.5 , as follows:

\begin{tabular}{|c|c|c|}
\hline \multicolumn{2}{|c|}{ Temperature } & \multirow[b]{2}{*}{$\mathrm{n}$} \\
\hline $\mathrm{C}$ & F & \\
\hline 585 & 1085 & 0.57 \\
\hline 538 & 1000 & 0.54 \\
\hline 490 & 914 & 0.52 \\
\hline 390 & 734 & 0.63 \\
\hline 290 & 554 & 0.55 \\
\hline 210 & 410 & 0.56 \\
\hline 145 & 293 & 0.75 \\
\hline
\end{tabular}

Ham and Rast(40) reported that different specimens exhibited different values of $\mathrm{n}$ as high as 0.555 at $930 \mathrm{~F}(500 \mathrm{C})$; $\mathrm{n}$ increased with decreasing temperature to as high as 1.08 at $390 \mathrm{~F}(200 \mathrm{C})$. Chang and $/ 171$
Bennett(41) reported an increase from 0.5 to as much as 1.0 with decreasing temperature. Thus, in all these investigations, the solubility would appear to be anomalously high at low temperatures.

The solubility, $\mathrm{S}$, as a function of temperature, T, was measured by Sieverts (32) for iron; Fowler and Smithells(42) showed that the results were described by an equation of the following type:

$$
\mathrm{S}=\alpha \mathrm{p}^{1 / 2} \mathrm{e}^{-\beta / T}
$$

where $\alpha$ and $\beta$ are constants. Armbruster(37) found that an equation of the same form accurately expressed the temperature relation of the solubility of hydrogen in pure iron in her experiments at temperatures in the range of 750 to $1110 \mathrm{~F}$ $(400$ to $600 \mathrm{C})$. What appears to be the best equation for the solubility of hydrogen in $\alpha$-iron at temperatures above $\sim 750 \mathrm{~F}(400 \mathrm{C})$ is that given by Geller and Sun:(38)

$$
S_{(p p m)}=42.7 p^{1 / 2} e^{-3280 / T}
$$

This equation is based on the average of several reliable measurements made independently by various investigators. $(33,34,35)$ The results for a pressure of 1 atmosphere are shown graphically in Figure 3.

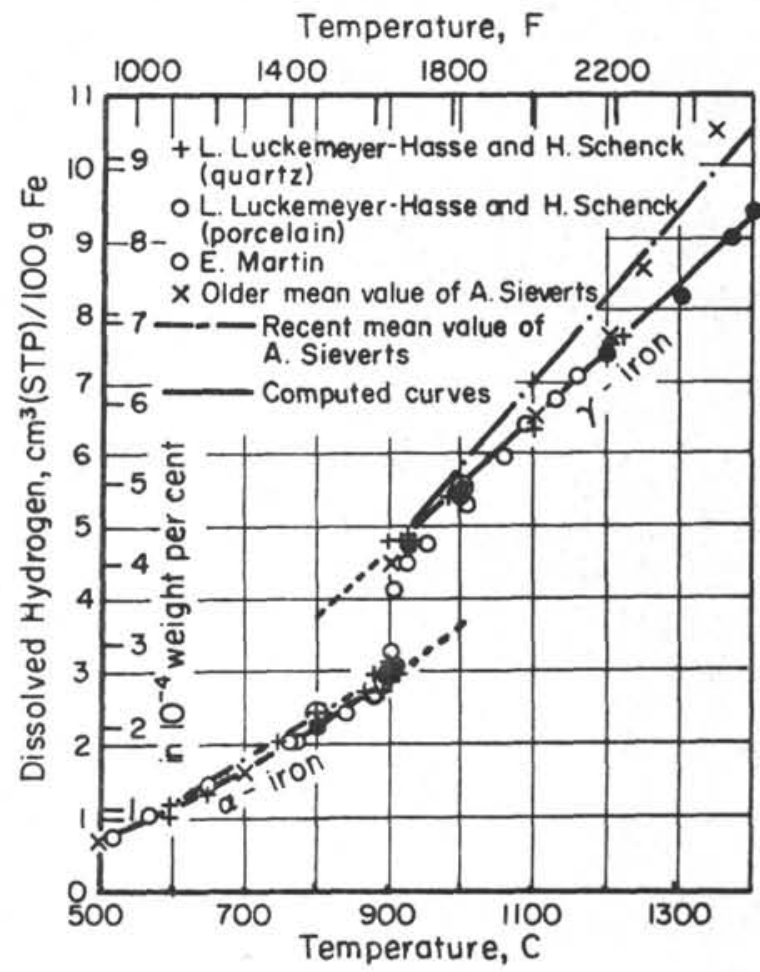

FIGURE 3. SOLUBILITY OF HYDROGEN IN PURE $\alpha$ - AND $\gamma$-IRON AS A FUNCTION OF TEMPERATURE( 38 )

$\left(\mathrm{p}_{\mathrm{H}_{2}}=1\right.$ atmosphere $=760$ torr. $)$ 
Dyakonov and Samarin ${ }^{(43)}$ computed equilibrium constants and energy changes for hydrogensolubility data obtained for iron by various investigators. When they plotted the logarithm of the equilibrium constant, $\mathrm{K}$, for the reaction

$$
1 / 2 \mathrm{H}_{2} \text { gas } \rightleftharpoons[\mathrm{H}] \text { in } \mathrm{Fe}
$$

against $1 / T$ (the term $[\mathrm{H}]$ being the equilibrium concentration of atomic hydrogen dissolved in iron under constant gas pressure), a straight-line relationship was found for each form of iron, including liquid iron. From the four straight lines obtained, they calculated the standard free-energy changes and the heats of hydrogen absorption for the various forms of iron $-\alpha, \gamma, \delta$, and liquid. The results showed that the values of the thermodynamic properties do not differ greatly for the different forms of solid iron.

\section{Effect of Composition}

Many investigators have studied the effects of different alloying elements on the solubility of hydrogen in iron and steel. Much of this work is for the molten state, and, hence, is of relatively little interest to those concerned with delayed, brittle failure of steel. This area has been reviewed by Smialowski(24) in Chapter 2. Only a few data available for the solid state will be presented to illustrate that there is an effect of composition on hydrogen solubility.

Armbruster( 37 ) determined the solubility of hydrogen in iron, nickel, and 13 steels of vastly different composition, including both austenitic and ferritic steels. The samples are described in Table 2. Her results are shown in Table 3 and in Figure 4. $\mathrm{S}$ is the solubility in micromoles of hydrogen per $100 \mathrm{~g}$ of metal, and $\alpha$ is the slope of the plot of micromoles of hydrogen per millimeter of pressure versus the reciprocal of the square root of the pressure. From the solubility of hydrogen at $1.0 \mathrm{~mm}$ pressure in the steels at the various temperatures investigated, which is represented by the values of $\alpha$ in Table 3, it is apparent that the steels fall into three groups, namely, (I) ferritic, low in alloying elements, (II) an intermediate group, high in alloying elements, and (III) austenitic, the solubility of hydrogen in this group being several times as great as in the ferritic group. The magnitude of the differences among these groups is shown by the curves in Figure 4 .

Luckemeyer-Hasse and Schenck (35) determined the solubility of hydrogen in iron, nickel, chromium, and a number of iron-nickel, ironchromium, and iron-nickel-chromium alloys. Their results are shown in Figures 5, 6, and 7 .

Smialowski(24) has summarized many of the data regarding the effects of other alloying elements on hydrogen solubility in solid steel (see Chapter 2).

\section{Effect of Crystal Structure}

Although alloying elements have some effect on the solubility of hydrogen in iron, this effect is overshadowed by the influence of crystal structure on hydrogen solubility. It is clearly shown by Armbruster $(37)$ that body-centered cubic iron and ferritic steels (Numbers 2 through 10 ) dissolve less hydrogen than do the face-centered cubic austenitic steels (Numbers 11 through 14) and nickel (see Figure 4 and Table 3). The results of Luckemeyer-Hasse and Schenck(35) that were presented above also support the same conclusion. These latter investigators apparently were the first to associate this effect of structure on the solubility of hydrogen with the size of the interstices, recognizing that there are larger empty spaces in the center of a model of a face-centered

TABLE 2. DESCRIPTION OF SAMPLES USED BY ARMBRUSTER(37)

\begin{tabular}{|c|c|c|c|c|c|c|c|c|c|c|c|c|c|}
\hline \multirow[b]{2}{*}{ Number } & \multirow[b]{2}{*}{ Material } & \multicolumn{9}{|c|}{ Composition, percent } & \multirow{2}{*}{$\begin{array}{l}\text { Weight, } \\
\text { g }\end{array}$} & \multirow{2}{*}{$\begin{array}{l}\text { Thick- } \\
\text { ness, } \\
\text { mm }\end{array}$} & \multirow{2}{*}{$\frac{\text { Area }}{\text { Volume }}, \mathrm{cm}^{-1}$} \\
\hline & & $\mathrm{C}$ & $\mathrm{Mn}$ & $\mathrm{s}$ & $\mathrm{P}$ & $\mathrm{Si}$ & $\mathrm{C}_{\mathrm{r}}$ & $\mathrm{Ni}$ & \multicolumn{2}{|c|}{ Other } & & & \\
\hline 1 & Carbonyl iron & 0.011 & -- & -- & -- & -- & -- & -- & & & 516.6 & 0.34 & 65 \\
\hline 2 & Mild steel & 0.39 & 0.73 & 0.032 & 0.022 & 0.19 & 0.048 & 0.012 & & & 439.6 & 2.45 & 10 \\
\hline 3 & Mild steel & 0.39 & 0.70 & 0.049 & 0.016 & 0.128 & -- & -- & & & 382.1 & 0.076 & 255 \\
\hline 4 & Mild steel & 0.12 & 0.47 & 0.041 & 0.016 & 0.003 & -- & - & & & 366.7 & 0.038 & 530 \\
\hline 5 & Mild steel & 0.10 & 0.39 & 0.032 & 0.015 & 0.007 & -- & -- & & & 499.5 & 0.27 & 80 \\
\hline 6 & $1.5 \% \mathrm{Mn}$ steel & 0.20 & 1.46 & 0.022 & 0.027 & 0.205 & -- & -- & & & 510.7 & 0.26 & 82 \\
\hline 7 & $3 \%$ Si Steel & 0.05 & 0.23 & 0.013 & 0.010 & 3.17 & -- & -- & Al & 0.27 & 624.9 & 0.28 & 74 \\
\hline 8 & $4 \% \mathrm{Ni}$ Steel & 0.32 & 0.64 & 0,020 & 0.023 & 0.245 & -- & 3.64 & $\mathrm{Al}_{2} \mathrm{O}$ & 0.03 & 504.7 & 0.26 & 78 \\
\hline 9 & $13 \mathrm{Cr}, 0.3 \mathrm{C}$, ferritic & 0.32 & 0.47 & - & -. & 0.28 & 12.78 & - & & & 508.3 & 0.74 & 28 \\
\hline 10 & $16 \% \mathrm{Cr}$ steel & 0.09 & 0.46 & 0.014 & 0.012 & 0.395 & 15.60 & 0.33 & & & 552.3 & 0.25 & 80 \\
\hline 11 & $28 \% \mathrm{Ni}$ steel & 0.025 & 0.18 & -- & -- & 0.06 & -- & 27.88 & & & 475.5 & 0.15 & 137 \\
\hline 12 & $13 \%$ Mn steel & 1.40 & 12.98 & 0.019 & 0.048 & 0.32 & - & -. & & & 523.8 & 0.96 & 22 \\
\hline 13 & $13 \mathrm{Cr}, 0,3 \mathrm{C}$, austenitic & 0.32 & 0.47 & - & -- & 0.28 & 12.78 & -- & & & 508.3 & 0.74 & 28 \\
\hline 14 & $18 \mathrm{Cr}-8 \mathrm{Ni}$ steel & 0.07 & 0.37 & 0.005 & 0.006 & 0.47 & 18. 30 & 9.92 & & & 362.2 & 0.097 & 209 \\
\hline \multirow[t]{2}{*}{15} & Nicke1 & 0.13 & 0.13 & -- & -- & 0.04 & -- & 99.52 & $\mathrm{Cu}$ & 0.06 & 377.7 & 0.14 & 152 \\
\hline & & & & & & & & & $\mathrm{Fe}$ & 0.09 & & & \\
\hline
\end{tabular}


TABLE 3. VALUES OF $\alpha$, THE SOLUBILITY OF HY DROGEN AT 1.0 MM PRESSURE, FOR CERTAIN STEELS AT 750 TO $1110 \mathrm{~F}(400$ TO $600 \mathrm{C})$ (37)

\begin{tabular}{|c|c|c|c|c|c|c|}
\hline $\begin{array}{l}\text { Sample } \\
\text { Number }\end{array}$ & $\begin{array}{l}\frac{\text { micromg }}{752 \mathrm{~F}} \\
(400 \mathrm{C})\end{array}$ & $\frac{\mathrm{s} / 1^{\alpha} 0_{0} \mathrm{~g} \mathrm{a}}{932 \mathrm{~F}}$ & 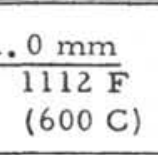 & $\begin{array}{c}\text { Total Number of } \\
\text { Measurements }\end{array}$ & $\begin{array}{l}\text { Average Deviation } \\
\text { in Solubility }\end{array}$ & $\begin{array}{l}\text { Heat of Solution }(\Delta \mathrm{H}) \text {, } \\
\mathrm{cal} / \mathrm{g} \text {-mole }\end{array}$ \\
\hline 1 & 0.60 & 1.16 & 1.93 & 108 & \pm 0.03 & 13,300 \\
\hline 2 & 0.45 & 0.97 & 1.58 & 39 & \pm 0.02 & 14,200 \\
\hline 3 & 0.79 & 1.29 & 2.18 & 74 & \pm 0.03 & 13,600 \\
\hline 4 & 0.69 & 1. 35 & 2.15 & 36 & \pm 0.04 & 13,100 \\
\hline 5 & 0.45 & 1.00 & 1.79 & 36 & \pm 0.03 & 16,200 \\
\hline 6 & 0.58 & 1.21 & 2.07 & 40 & \pm 0.04 & 14,800 \\
\hline 7 & 0.46 & 1.52 & 2.42 & 43 & \pm 0.05 & 18,600 \\
\hline 8 & 0,50 & 1.09 & 2.02 & 76 & \pm 0.02 & 16,200 \\
\hline 9 & 0.33 & 0.73 & 1.46 & 38 & \pm 0.04 & 16,400 \\
\hline 10 & 0.40 & 0.84 & 1.56 & 47 & \pm 0.03 & 15,900 \\
\hline 11 & 1.51 & 2.44 & 3.54 & 48 & \pm 0.03 & 9,700 \\
\hline $12 \mathrm{a}(40 \%)$ & 1.63 & 2.54 & 3.25 & 40 & \pm 0.04 & 8,000 \\
\hline $12 \mathrm{~b}(85 \%)$ & 2. 45 & -- & -- & 16 & \pm 0.03 & -- \\
\hline 13 & 4.37 & 5.20 & 6.18 & 29 & \pm 0.04 & 4,200 \\
\hline 14 & 5.24 & 6.37 & 7.55 & 40 & \pm 0.03 & 4,300 \\
\hline 15 & 5.93 & 7.94 & 9.83 & 45 & \pm 0.03 & 5,900 \\
\hline
\end{tabular}

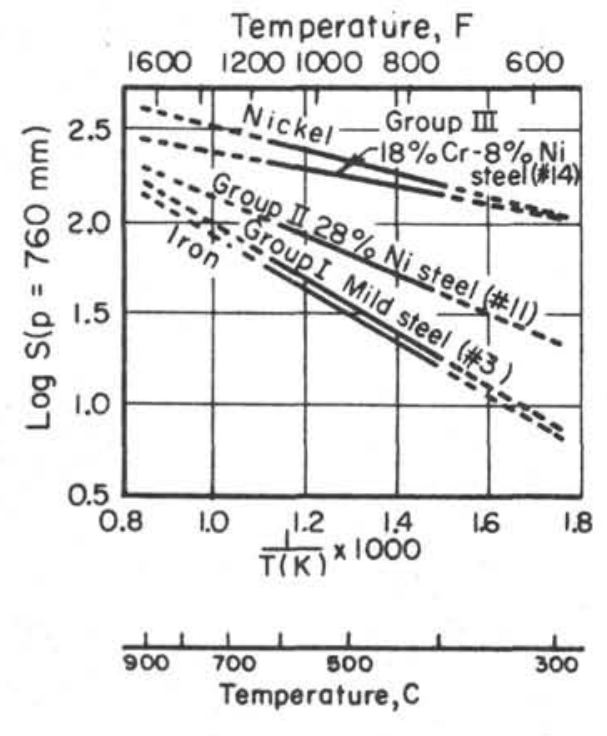

FIGURE 4. SOLUBILITY OF HYDROGEN AT 1 ATMOSPHERE IN IRON, NICKEL, AND A TYPICAL STEEL FROM EACH OF THREE GROUPS, AT 572 TO $1652 \mathrm{~F}$ $(300 \text { TO } 900 \mathrm{C})^{(37)}$

( $\mathrm{S}=$ solubility in micromoles of $\mathrm{H}$ per 100 g of metal.)

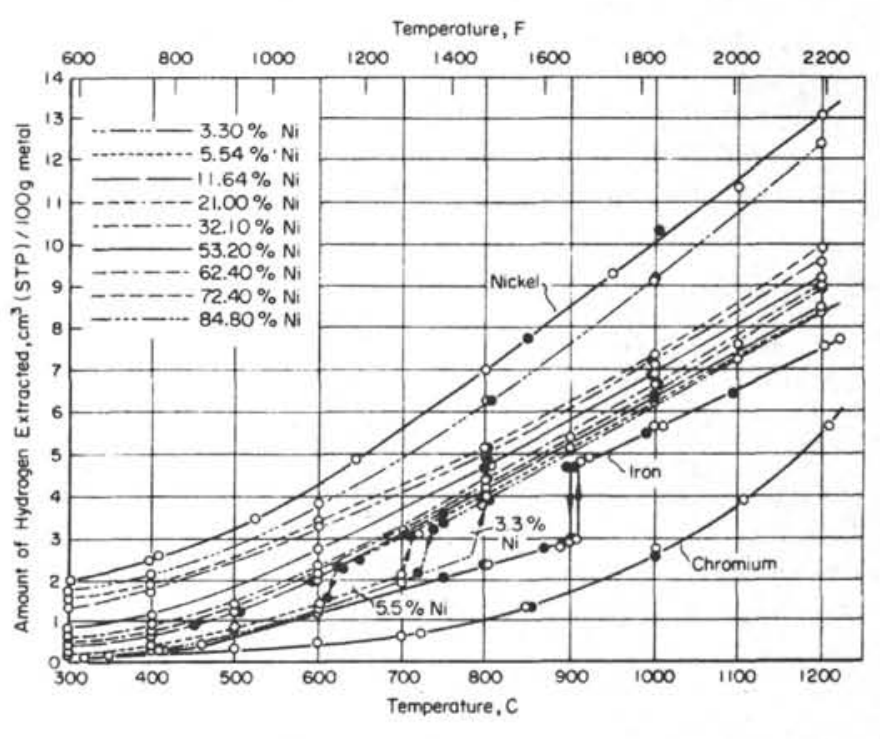

FIGURE 5. INFLUENCE OF TEMPERATURE ON THE SOLUBILITY OF HYDROGEN IN IRON, NICKEL, CHROMIUM, AND SEVERAL IRON-NICKEL ALLOYS( 35 ) 


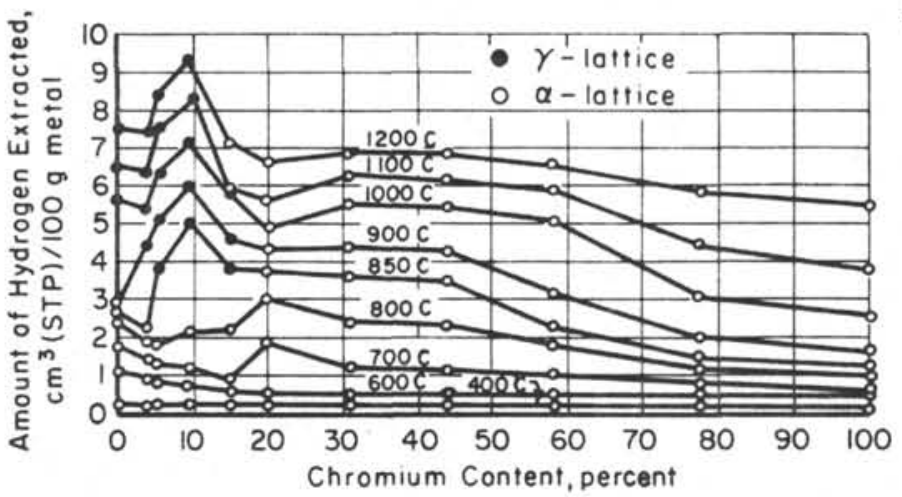

FIGURE 6. SOLUBILITY OF HYDROGEN IN IRONCHROMIUM ALLOYS AT VARIOUS TEMPE RATURES (35)

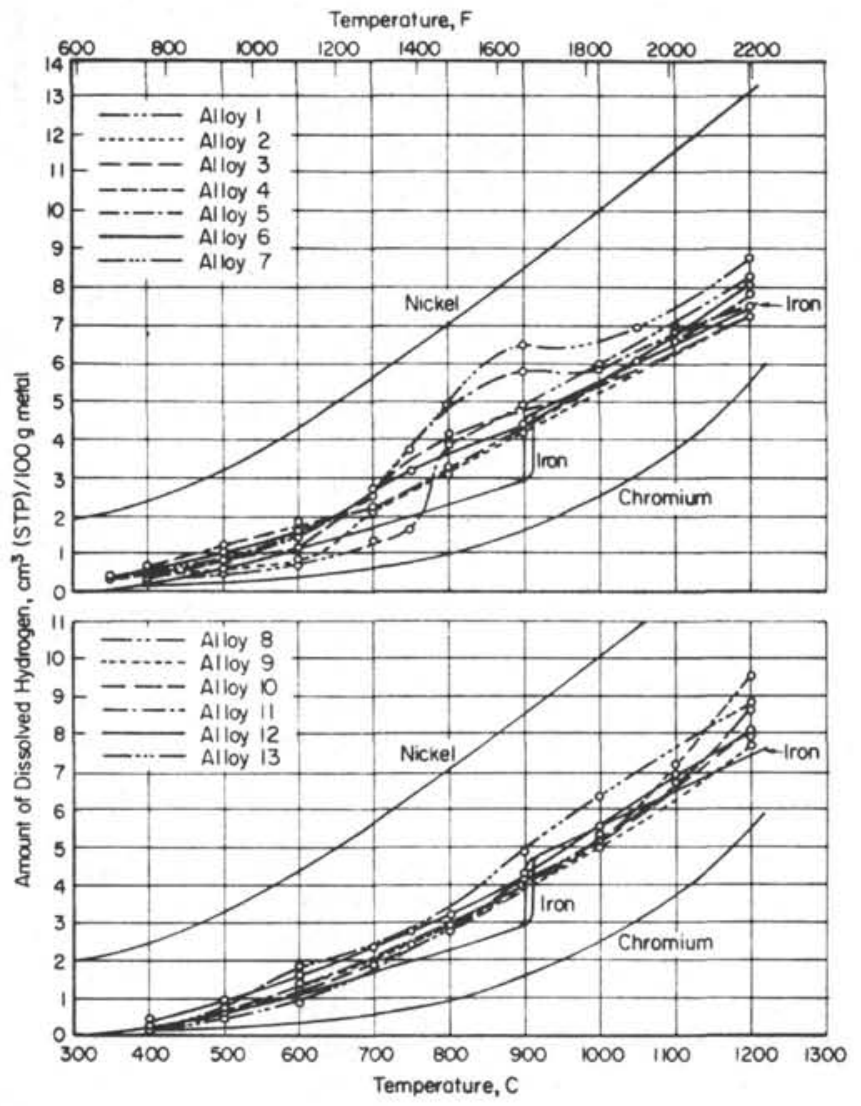

FIGURE 7. DISSOLVING CAPACITY OF VARIOUS $\mathrm{Fe}-\mathrm{Ni}-\mathrm{Cr}$ ALLOYS FOR HYDROGEN WITH INCREASING TEMPERATURE(35)

\begin{tabular}{cccr}
\multicolumn{3}{c}{ Composition of the Fe-Cr-Ni Alloys } & Investigated \\
\hline Alloy & $\mathrm{C}, \%$ & $\mathrm{Ni} \%$ & \multicolumn{1}{c}{$\mathrm{Cr}}$, \\
\cline { 2 - 2 } 1 & 0.01 & 3.1 & 2.57 \\
2 & 0.01 & 8.12 & 4.43 \\
3 & 0.01 & 11.4 & 3.02 \\
4 & 0.01 & 26.4 & 2.79 \\
5 & 0.01 & 5.1 & 4.65 \\
6 & 0.01 & 10.0 & 4.63 \\
7 & 0.01 & 5.16 & 9.53 \\
8 & 0.01 & 20.3 & 9.66 \\
9 & 0.01 & 15.1 & 14.6 \\
10 & 0.01 & 10.0 & 29.5 \\
11 & 0.02 & 2.04 & 44.1 \\
12 & 0.02 & 5.1 & 44.2 \\
13 (a) & 0.05 & 9.02 & 17.5
\end{tabular}

cube formed by spheres than in the body-centered cube. Sieverts and Hagen(44) compared the solubilities of hydrogen in iron, nickel, and cobalt and concluded that they are determined by the crystal structure. The solubility is greatest in the facecentered cubic lattices of $\gamma$-iron and nickel, less in the body-centered cubic lattice of $\alpha$-iron, and smallest in the close-packed hexagonal structure of cobalt. In studying a 13 percent manganese steel treated so as to have different amounts of untransformed austenite, Armbruster( 37 ) concluded that manganese per se has little influence on the solubility of hydrogen in iron, the higher solubilities in the 13 percent manganese steel being related to the amount of retained austenite.

\section{Solubility of Hydrogen Isotopes}

The solubility of the hydrogen isotopes also has been studied. Sieverts et al(33) determined the 1-atmosphere isobars for hydrogen and deuterium in two types of iron (ingot iron and iron made by the carbonyl process) for temperatures above $915 \mathrm{~F}$. The solubility of deuterium in iron was found to be a little less than that of hydrogen, and the difference increased with increasing temperature.

Hawkins (45) has compared the solubilities of hydrogen, deuterium, and tritium in an austenitic stainless steel $(18.8 \mathrm{Cr}, 10.66 \mathrm{Ni})$ at temperatures in the range from 570 to $1380 \mathrm{~F}$ ( 300 to $750 \mathrm{C}$ ) at pressures of 0.1 to $2.5 \mathrm{~mm} \mathrm{Hg}$. The solubilities were given in the following form:

$$
\log \mathrm{S}=-\frac{\mathrm{A}}{\mathrm{T}}+\mathrm{B}
$$

where $\mathrm{S}$ is the solubility in micromoles per $100 \mathrm{~g}$ of steel at $1 \mathrm{~mm} \mathrm{Hg}$, and $\mathrm{T}$ is degrees Kelvin. The experimental values were as follows:

\begin{tabular}{|c|c|c|c|}
\hline Isotope & A & B & $\begin{array}{c}\Delta \mathrm{H}, \\
\mathrm{cal} / \mathrm{mole} \\
\end{array}$ \\
\hline Hydrogen & 366,9 & 1.314 & 3370 \\
\hline Deuterium & 382.2 & 1. 259 & 3520 \\
\hline Tritium(a) & 400.2 & 1. 267 & 3680 \\
\hline
\end{tabular}

(a) $\mathrm{T}=96 \%, \mathrm{H}=4 \%$.

The solubility of 100 percent tritium was calculated and reported also.

Frank, Lee, and Williams (46) calculated the ratio of the solubilities of hydrogen and deuterium over the temperature range from 79 to $187 \mathrm{~F}(26$ to $86 \mathrm{C)}$ from opserved permeation and diffusion rates. They used the relationship

$$
\mathrm{P}_{\mathrm{H}} / \mathrm{P}_{\mathrm{D}}=\left(\mathrm{D}_{\mathrm{H}} / \mathrm{D}_{\mathrm{D}}\right)\left(\mathrm{S}_{\mathrm{H}} / \mathrm{S}_{\mathrm{D}}\right) \text {, }
$$

where $\mathrm{P}=$ permeation rate, $\mathrm{D}=$ diffusion rate, and $\mathrm{S}=$ solubility. $D_{\mathrm{H}} / \mathrm{D}_{\mathrm{D}}$ was taken as 1.37 (a value determined experimentally and found to be invariant with temperature). The results follow: 


\begin{tabular}{|c|c|c|}
\hline \multicolumn{2}{|c|}{ Temperature } & \multirow{2}{*}{$\begin{array}{c}\text { Solubility Ratio } \\
\left(\mathrm{S}_{\mathrm{H}} / \mathrm{S}_{\mathrm{D}}\right)\end{array}$} \\
\hline $\mathrm{C}$ & $F$ & \\
\hline 86 & 187 & 6.9 \\
\hline 80 & 176 & 7.8 \\
\hline 79 & 174 & 7.4 \\
\hline 60 & 140 & 4.4 \\
\hline 60 & 140 & 5.0 \\
\hline 52 & 126 & 3.2 \\
\hline 52 & 126 & 3.4 \\
\hline 50 & 122 & 4.9 \\
\hline 42 & 108 & 4.2 \\
\hline 34 & 93 & 3.6 \\
\hline 26 & 79 & 3.3 \\
\hline 26 & 79 & 3.5 \\
\hline
\end{tabular}

indicates that Sieverts' law is followed reasonably well at pressures up to at least 100 atmospheres at these higher temperatures. At temperatures below $735 \mathrm{~F}(390 \mathrm{C})$, the experimentally measured solubility deviated markedly from the extrapolation of the high-temperature behavior in the direction of greater solubility. In a detailed analysis of the data, these investigators found this deviation to result chiefly from a change in the heat of solution and only secondarily from deviations from Sieverts' law. This experimentally observed abnormally high solubility of diffusible hydrogen below $735 \mathrm{~F}$ ( $390 \mathrm{C})$ tends to confirm the hypothesis of hydrogen trapping that Johnson and Hill presented earlier, in Reference (10). They believe that the traps for hydrogen in iron form suddenly on cooling. This

They concluded that, although permeation-rate data are not always highly reliable, there appears to be a trend toward greater difference between the solubilities of hydrogen and deuterium at higher temperatures.

These differences in solubility and diffusivity of the hydrogen isotopes, particularly those obtained by the latter investigators, indicate that tagged, or tracer, experiments would be of limited value for obtaining solubility or rate data for ordinary hydrogen.

\section{Measurements of Solubility at Lower Temperatures (750 F to Room Temperature)}

Experimental difficulties have made it impossible to date to obtain as complete an understanding of the solubility of hydrogen in iron and steel for the temperature range between $750 \mathrm{~F}(400 \mathrm{C})$ and room temperature as has been obtained for the higher temperatures. This is unfortunate, because the behavior in this lower temperature range is important to problems of hydrogen embrittlement and delayed, brittle failure. In this lower temperature range, the behavior of hydrogen often is changed greatly by variations in impurity content, mechanical and thermal processing, and the method used in preparing the specimen surfaces. Also, the effects of strain and cold work upon the occlusive capacity of metals, including iron, are still controversial.

\section{Effect of Temperature and Pressure}

Hill and Johnson(13) measured equilibrium concentrations of hydrogen in iron at hydrogen pressures up to about 150 atmospheres and temperatures down to $295 \mathrm{~F}(145 \mathrm{C})$. Some of the results are shown in Figure 8, where the 100atmosphere isobar for the solubility of hydrogen in one of the heats of iron is shown. The dashed line in the figure was obtained by applying Sieverts' law to the solubility data which Geller and Sun(38) reported for temperatures above $750 \mathrm{~F}(400 \mathrm{C})$ at a pressure of 1 atmosphere. The agreement between the 100-atmosphere isobar and that given by Sieverts' law is quite good above $735 \mathrm{~F}(390 \mathrm{C})$; this

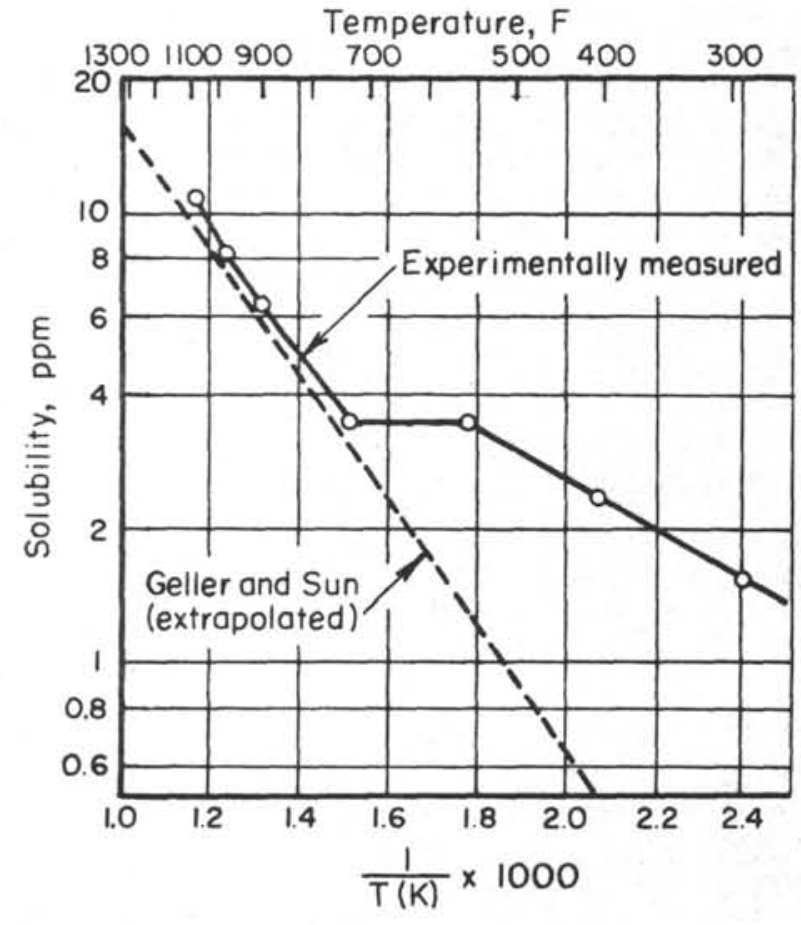

FIGURE 8. SOLUBILITY ISOBARS AT 100 ATM FOR HYDROGEN IN IRON(13)

Hill and Johnson $(47,10,13)$ also found that certain, but not all, grades of iron, when treated for periods of several days at high pressures and at temperatures between 840 and $1200 \mathrm{~F} \mathrm{(450} \mathrm{and}$ $650 \mathrm{C})$, will absorb considerably more hydrogen than is indicated by the solubility data shown in Figure 8. The hydrogen thus introduced can be extracted in two separate fractions, one of which is evolved in accordance with the usual diffusion coefficient for annealed $\alpha$-iron*. The second, or extra, fraction is much more difficult to remove and requires extreme extraction conditions. This will be discussed further when the removal of hydrogen from steel is considered.

* For example, see Figure 28 (page 40) and Equations 38 and 43 (pages 40 and 44 ) to be presented later in further discussion of the work of these investigators. 
By using enthalpy and heat-of-solution data for trapped and interstitial hydrogen, Hill and Johnson (13) were able to estimate the solubility of hydrogen in iron at room temperature. Extrapolating their measurements of solubility at 100 atmospheres and $295 \mathrm{~F}(145 \mathrm{C})$ indicated that the 100atmosphere solubility at $77 \mathrm{~F}(25 \mathrm{C})$ is between 0.5 and $1.0 \mathrm{ppm}$, of which less than $0.02 \mathrm{ppm}$ is interstitial hydrogen. Using the directly measured solubility data for hydrogen in iron at elevated temperatures obtained by Armbruster, (37) Darken and Smith(48) estimated by extrapolation that the solubility at 1 atmosphere and $95 \mathrm{~F}(35 \mathrm{C})$ is between $0.9 \times 10^{-3}$ and $0.9 \times 10^{-4} \mathrm{ppm}$.

Bryan and Dodge,(49) in studying the solubility of hydrogen in annealed, high-purity iron, obtained excellent agreement between the 1-atmosphere solubilities calculated from permeability and diffusivity on the one hand and from degassing data on the other, throughout the temperature range from 259 to $1279 \mathrm{~F}$ (126 to $693 \mathrm{C})$.

\section{Effect of Composition}

Few data are available to show the effect of steel composition on hydrogen solubility for the lower temperature range. Hudson, Magor, and Stragand $(50)$ charged six commercial enameling steels, six experimental rimmed steels, and ten commercial steels of quite diverse compositions with hydrogen by acid charging in $2 \mathrm{~N} \mathrm{H}_{2} \mathrm{SO}_{4}$ at $100 \mathrm{~F}$ (38 C). They obtained hydrogen solubilities, determined by warm extraction under mercury at $320 \mathrm{~F}(160 \mathrm{C})$, as follows:

\begin{tabular}{|c|c|}
\hline Steel ${ }^{(a)}$ & $\begin{array}{c}\text { Hydrogen } \\
\text { Solubility, } \\
\mathrm{cm}^{3} / 100 \mathrm{~g} \text { of steel }\end{array}$ \\
\hline
\end{tabular}

Six commercial enameling steels

Six experimental rimmed steels

USS Man-Ten

USS Vitrenamel

Vanadium-alloyed rimmed steel

Silicon steel

Rimmed steel

Bessemer steel

Aluminum-killed steel

Ferritic stainless steel (Type 430)

Titanium-alloyed killed steel

Austenitic stainless steel (Type 302)

(a) All contained less than 0.20 percent carbon.

It is presumed that the apparent solubility of the austenitic stainless steel was low because of resistance to attack during pickling or because of incomplete extraction. With thermally charged specimens and a higher temperature range, Armbruster(37) showed that austenitic stainless steels had higher solubilities for hydrogen than did ferritic high-chromium steels.
A number of investigators have shown that for the best available grades of high-purity iron there is little or no effect of cold deformation or of subsequent annealing on the hydrogen solubility or the density. $(51,14)$ However, in the case of SAE 1020 steel, cold work greatly increases the solubility for hydrogen. For example, Darken and Smith (48) and Hudson, Riedy, and Stragand(52) found that cold work greatly increased both the saturation value of solubility and the time required to reach saturation (see Figure 9). Keeler and Davis (51) found that cold work increased the hydrogen occlusion at $480 \mathrm{~F}(250 \mathrm{C})$ by a factor of about 100 and lowered the density, the latter effect ascribed to the formation of voids. Hill and Johnson(14) observed that changes in solubility increased in magnitude with increases in carbon content and with increased degree of deformation.

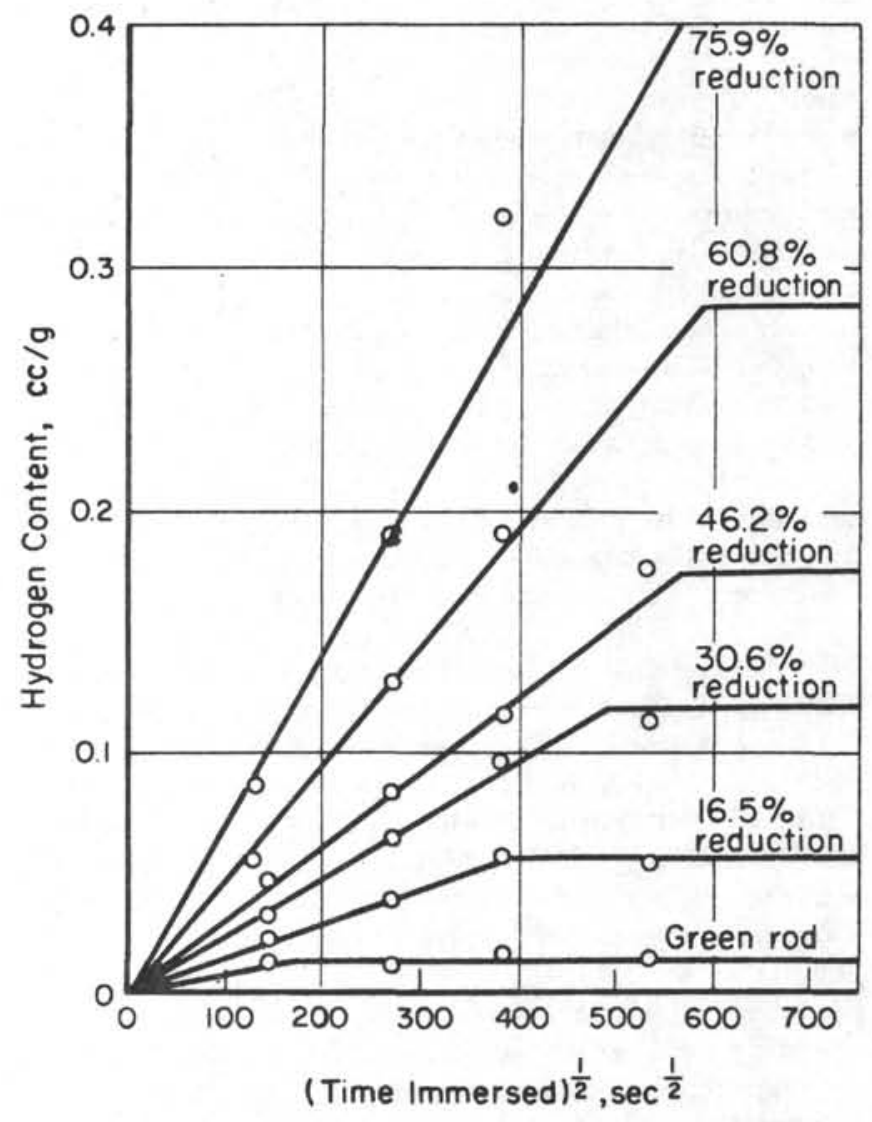

FIGURE 9. EFFECT OF COLD REDUCTION ON RATE OF HYDROGEN ABSORPTION AND ON THE SATURATION VALUE OF HYDROGEN CONTENT; WIRE STOCK IMMERSED IN $\mathrm{N} \mathrm{H}_{2} \mathrm{SO}_{4}$ AT $95 \mathrm{~F}$ ( $35 \mathrm{C})$; GREEN ROD $1 / 2$-IN. DIAMETER(48)

( 1 cc NTP per gram $=0.00899$ percent $H_{\text {. }}$ )

The effects of cold work on the solubility of hydrogen in steel usually are explained by hypothesizing the existence of "traps" in which hydrogen in excess of the equilibrium lattice solubility can be 
accommodated. $(51,14,48)$ Presumably, the concentration of such traps increases with increased degree of plastic deformation. Apparently, all of the traps cannot be removed by annealing the coldworked steel, since, as will be shown later, such a treatment does not necessarily yield a material with the same characteristics toward hydrogen occlusion as were possessed by the original hotworked steel.

The main conclusions that Keeler and Davis(51) drew regarding the observed effect of cold work in increasing the solubility of hydrogen in SAE 1020 steel were as follows: (1) impurities must be present if the density is to decrease upon cold reduction, (2) the observed hydrogen occlusion is not compatible with the theory of occlusion by the storage of molecular hydrogen in the traps, and (3) two kinds of voids probably result from imperfect plastic flow of ferrite about inclusions or other phases during cold working. Regarding Conclusion (3), they conjectured that hydrogen may be stored in the gaseous form in the larger of the two kinds of voids, which do not disappear on annealing, but it is apparently associated in some other way with narrower imperfections that are eliminated by annealing or recrystallizing. Hill and Johnson(14) proposed that much of the hydrogen contained in cold-worked steels in this lower temperature range is contained in cracks. The apparent heat of solution that they calculated for the cold-worked alloys was similar to the heat of chemisorption of hydrogen on iron powder reported by Emmett and Harkness. (53) Therefore, Hill and Johnson suggested that the traps in cold-worked iron-carbon alloys are cracks, formed by piled-up dislocations, in which the hydrogen is chemisorbed.

Other investigators have reported variations from the behavior just described. For example, Bryan and Dodge(49) found that the solubility of hydrogen in cold-worked high-purity iron (26 percent reduction) was about 40 percent higher than it was in the annealed material. However, the solubility calculated from permeability and diffusivity was about the same for the two materials. This suggested to them that, even in high-purity iron, some hydrogen is trapped in a nondiffusible form, possibly by chemisorption on walls of cracks or as some chemical compound with carbon or other impurities. Duflot $(54,55)$ and Naumann and Carius $(56)$ working with iron and low-alloy steel, respectively, found first a decrease in the capacity of the metal for hydrogen with increasing deformation, followed by a considerable increase at high deformations. Contrary to these findings, Schuetz and Robertson $(57)$ found that the saturation hydrogen content of steel passed through a maximum with increasing cold deformation. Raczynski and Smialowski $(58)$ observed that cold reduction reduced the occlusive capacity of mild steel. These examples have been cited to show that it is hazardous to try to compare the results of the various investigators because of different experimental conditions or the lack of published information on the conditions used.
Another source of discrepancies is variation in the methods of analysis for hydrogen, which ranged from warm extraction at relatively low temperatures to vacuum fusion. Residual, or "nondiffusible", hydrogen has been widely known in connection with the analysis of steels for hydrogen. It is chiefly responsible for the lack of acceptance in this country of warm extraction as an analytical method for determining hydrogen; in the warmextraction method, only the hydrogen evolved during heating in the alpha range is measured. The residual hydrogen is not all removed from the steel by this technique, so preference has been given to analytical techniques whereby it is possible to recover all the hydrogen, an example being the tinfusion method. Residual, or "nondiffusible", hydrogen will be discussed further in a subsequent section on the removal of hydrogen from steel.

Smialowski(24) pointed out that experiments with steels quite similar in composition but which differ in the distribution of impurities often show great differences in the occlusive capacity for hydrogen. He is of the opinion that this effect of impurity distribution is probably of greater importance than the amount of cold work.

Podgurski(59) studied the anomalously high solubility reported for hydrogen in cold-worked steel at temperatures somewhat above $390 \mathrm{~F}$ $(200 \mathrm{C})$. He attributed this to methane formed by a reaction between hydrogen and cementite; he quantitatively isolated this methane from steel. Furthermore, the calculated volume needed to accommodate the amount of methane found was approximately equal to the volume corresponding to the measured density change resulting from the cold work. Thus, he concluded that the methane formed is accommodated in microvoids in the metal. However, isotope experiments ruled out the possibility that methane is produced in steel at room temperature by acid charging.

Effect of Annealing After Cold Work

Although annealing a steel after cold deformation may eliminate the density loss and reduce the large occlusive capacity, it does not necessarily yield a material with the same characteristics toward hydrogen occlusion as those possessed by the original hot-worked steel (see Figure 10). Apparently, all of the traps for hydrogen cannot always be removed by annealing the cold-worked steel. Keeler and Davis (51) found that the traps in cold-worked SAE 1020 steel persisted to temperatures up to about $750 \mathrm{~F}(400 \mathrm{C})$. This is the same temperature as that below which anomalously large solubilities are found for hot-worked or annealed materials.

Hudson, Riedy, and Stragand(52) studied the influence of cold work on hydrogen absorption rate into, solubility level in, and desorption rate from low-carbon steel sheet. In one part of the study, samples of a commercial steel were obtained in 


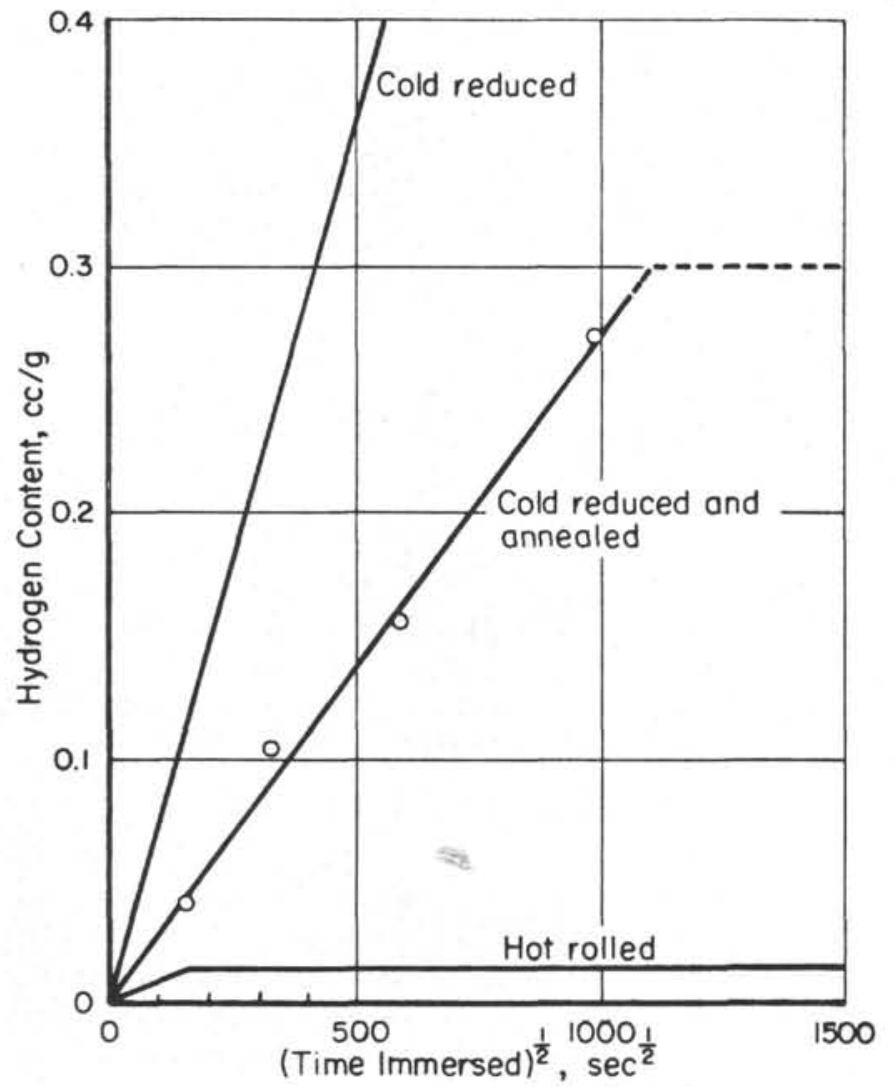

FIGURE 10. THE EFFECT OF COLD DRAWING $(75.9 \%)$ AND OF SUBSEQUENT ANNEAL [64 HOURS AT $1470 \mathrm{~F}$ (800 C)] ON HYDROGEN ABSORPTION AND THE SATURATION VALUE OF HYDROGEN CONTENT; WIRE STOCK IMMERSED IN $\mathrm{N} \mathrm{H}_{2} \mathrm{SO}_{4}$ AT $95 \mathrm{~F}(35 \mathrm{C})(48)$

( 1 cc NTP per gram $=0.00899$ percent $H_{\text {. }}$ )

the as-cold-reduced, as-continuously-annealed, and as-box-annealed conditions from the same original coil. The box-annealing operation involved 4 hours at a temperature of $1200 \mathrm{~F}$, whereas the continuous strip anneal involved a period of less than 1 minute at this temperature. The effects of these treatments on the time for hydrogen to reach the saturation level and on the saturation concentration were as follows:

\begin{tabular}{|c|c|c|}
\hline Condition & $\begin{array}{c}\text { Time to Reach } \\
\text { Saturation } \\
\text { Level, } \\
\text { minutes } \\
\end{array}$ & $\begin{array}{c}\text { Hydrogen } \\
\text { Saturation } \\
\text { Concentration, } \\
\mathrm{cc} / 100 \mathrm{~g} \text { steel } \\
\end{array}$ \\
\hline Cold reduced & $>50$ & $>78$ \\
\hline $\begin{array}{l}\text { Continuously } \\
\text { annealed }\end{array}$ & 10 & 12 \\
\hline Box annealed & 19 & 5 \\
\hline
\end{tabular}

Note that the longer annealing time associated with the box anneal reduced the saturation level for subsequent hydrogen charging considerably.
Darken and Smith(48) also showed that increased annealing time (and increased temperature too) lowered the hydrogen saturation concentration reached during subsequent pickling of the steel.

In a continuation of the work reported in Reference (52), Hudson et al $(60)$ found that the effect of cold reduction on hydrogen solubility in mild steel persisted through subsequent heat treatment and later cold reduction as well. This was not true, though, for hydrogen permeability.

\section{Effect of Surface Conditions}

As one might expect, the surface conditions of the steel have no effect on the hydrogen saturation level, but instead, they affect the rate of entry. This is illustrated by the work of Hudson, Magor, and Stragand $(50)$ in which they found that, for a given steel, the rate of hydrogen absorption during acid pickling was greater for a heavily sandblasted surface than for a lightly sandblasted specimen, although the saturation level was not affected by the difference in surface conditions. This behavior, shown in Figure 11, illustrates the need for obtaining reproducible surface conditions when permeabilities are to be measured and compared.

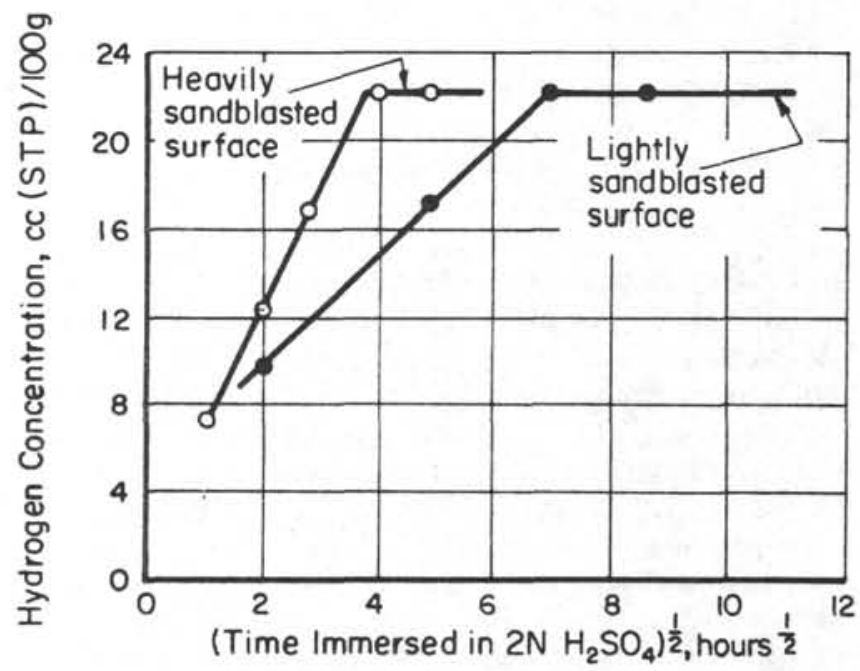

FIGURE 11. INF LUENCE OF SURFACE CONDITION ON HYDROGEN CHARGING RATE(50)

Estimates of Equilibrium Hydrogen Pressure in Steel

As was shown in preceding sections, when a piece of steel cools, the hydrogen solubility changes. The solubility of atomic hydrogen in steel under a given pressure of molecular hydrogen decreases with decreasing temperature. As the equilibrium solubility is reduced, the hydrogen tends to escape from surfaces. Microshrinkage cavities, gas holes, and other voids and discontinuities in the steel provide internal surfaces, and atomic hydrogen in the surrounding steel will precipitate in them as molecular hydrogen and become trapped, since molecular hydrogen cannot diffuse in steel. 
As the steel adjacent to the void becomes lower in hydrogen, a concentration gradient is created which results in continued flow of hydrogen toward the void and continued precipitation there. At room temperature, atomic hydrogen can diffuse and precipitate against considerable pressure of molecular hydrogen. However, there is disagreement as to the magnitude of these pressures. For years, it was considered that very high equilibrium pressures prevailed. It is well known that iron or steel is readily blistered at high temperatures by molecular hydrogen that forms in voids. The very fact that a blister forms shows that the pressure is greater than the yield strength of the steel. Also, analyses of gas extracted from blisters have shown the gas to be hydrogen. In cases where the steel is attacked by hydrogen and becomes decarburized, methane $\left(\mathrm{CH}_{4}\right)$ is found. The attack of steel by hydrogen at elevated temperatures and high hydrogen pressures is the subject of a separate DMIC report (DMIC Report No. 202).

Many investigations have shown that hydrogencontaining steel, on cooling to ordinary temperatures, is highly amenable to supersaturation with hydrogen, and consequently, to internal accumulations of hydrogen under high pressure. Pickling and cathodic electrolysis also are means of producing a high degree of supersaturation, because these processes create concentrations of atomic hydrogen on the surface of the steel that are equal to, or greater than, the concentrations occurring in hydrogen gas at high temperatures. On a number of occasions, the present authors have observed blistering of steel during cathodic charging with hydrogen at room temperature, and other instances of such behavior have been reported in the technical literature. This is visual evidence that high pressures are produced at room temperature.

Taking into consideration the fact that hydrogen does not behave as a perfect, or ideal, gas at high pressures, Carney, Chipman, and Grant (61) calculated the equilibrium hydrogen pressures shown in Table 4. For a hydrogen content in the steel of 0.00050 percent, or 5 ppm (an amount commonly found in steel not deliberately charged with hydrogen), an equilibrium hydrogen pressure of 184,000 psi was indicated at room temperature. Luckemeyer-Hasse and Schenck(35) used the squareroot-of-the-pressure law to calculate equilibrium pressures of molecular hydrogen necessary at an internal surface to prevent atoms of the gas dissolved at some higher temperature from precipitating during cooling. They, too, showed that normal hydrogen contents in steel (as determined by analysis) might be expected to provide very high stresses in voids in the steel. For example, their results indicated that, with molten steel with hydrogen contents in the order of 0.0010 percent ( $10 \mathrm{ppm}$ ) and above, pressures exceeding the tensile strength of the casting are reached before the steel has cooled to room temperature.
TABLE 4, EQUILIBRIUM PRESSURES OF HYDROGEN IN STEEL(61)

\begin{tabular}{cccc}
\hline \hline $\begin{array}{c}\text { Hydrogen } \\
\text { in Steel, } \\
\%\end{array}$ & $\begin{array}{c}\text { Fugacity, } \\
\text { atm }\end{array}$ & $\begin{array}{c}\text { Pressure of } \\
\text { Hydrogen, } \\
\text { atm }\end{array}$ & $\begin{array}{c}\text { Pressure of } \\
\text { Hydrogen, } \\
\text { psi }\end{array}$ \\
\hline
\end{tabular}

At Room Temperature

$\begin{array}{rrrr}0.00100 & 30,800,000 & 14,500 & 218,500 \\ 0.00050 & 7,720,000 & 12,250 & 184,000 \\ 0.00020 & 1,240,000 & 9,325 & 140,000 \\ 0.00009 & 250,000 & 6,850 & 103,000\end{array}$

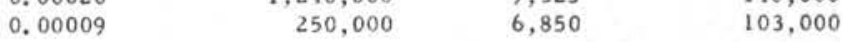

At $390 \mathrm{~F}(200 \mathrm{C})$

$\begin{array}{rrrr}0.00100 & 2,580 & 1,430 & 21,450 \\ 0.00050 & 647 & 520 & 7,800 \\ 0.00020 & 103 & 99.4 & 1,490 \\ 0.00009 & 20.9 & 20.9 & 314\end{array}$

0,00009

At $750 \mathrm{~F}(400 \mathrm{C})$

$\begin{array}{rrrr}0.00100 & 820 & 665 & 9,970 \\ 0.00050 & 205 & 193 & 2,900 \\ 0.00020 & 32.6 & 32.6 & 409 \\ 0.00009 & 6.6 & 6.6 & 99\end{array}$

Experiments with hollow cathodes have produced pressures of 200 to 300 atmospheres (about 3,000 to $4,500 \mathrm{psi}),(62,63)$ but these fall short of being equilibrium values, since the experiments were discontinued when the limits of the pressure-measuring equipment were reached. Smialowski and co-workers have used a method for estimating the pressure that is based on the measured expansion of iron when charged cathodically in an acid electrolyte with cathodic poison. They believe that the expansion is caused by molecular hydrogen that is trapped in cavities formed at nonmetallic inclusions, microporosity, and lattice defects. (24) The magnitude of the expansion observed suggests that the pressures developed exceed $10^{5}$ atmospheres $(1,470,000$ psi), possibly reaching $10^{7}$ atmospheres $(147,000,000 \mathrm{psi})$.

According to Evans, (64) the pressures attained experimentally are small compared with those theoretically possible. From studies of hydrogen overvoltage in cathodic charging, one might conclude that the pressure might be of the order of $10^{7}$ atmospheres. However, this assumes that the electrochemical laws continue to apply at high levels of overvoltage and that there is no leakage of molecular hydrogen - conditions that are not likely to be met. More refined calculations by Ubbelohde and co-workers $(65,66)$ suggest that pressures of about $6.6 \times 10^{18}$ atmospheres theoretically ought to be obtained.

Experiments have shown that before such high pressures could be developed, passageways would have been opened that would permit the escape of molecular hydrogen, and the pressure would no longer rise. Both Bridgman $(67,68)$ and Poulter and Uffelman(69) conducted experiments which demonstrated that molecular hydrogen under high pressure can open pathways in steel through which molecular hydrogen can diffuse. Bridgman 
found that a hollow steel cylinder containing hydrogen gas under pressure allowed the gas to escape with explosive violence when the pressure reached $128,000 \mathrm{psi}$, but without visibly damaging the cylinder. Poulter and Uffelman subjected a cylinder, which withstood 20,000 atmospheres $(294,000$ psi) oil pressure, to hydrogen gas pressure of 4,000 atmospheres $(59,000 \mathrm{psi})$. After only 5 minutes, there was a rapid evolution of hydrogen through the cylinder wall. Upon filling with oil at only 4,000 atmospheres (59,000 psi), oil passed through the wall and the pressure dropped to 500 atmospheres $(7,350 \mathrm{psi})$ in 2 hours. Examination under a low-power microscope revealed no flaws. However, when filled with hydrogen at 100 psi and immersed in water, small bubbles soon appeared over the entire outer surface.

At the other extreme, Hill and Johnson(13) purportedly showed that the pressure of molecular hydrogen in equilibrium with an atomic hydrogen concentration in the steel of $5 \mathrm{ppm}$ at room temperature must be several orders of magnitude lower than the value usually extrapolated from above $750 \mathrm{~F}(400 \mathrm{C})$. By their method of calculation, these hydrogen pressures are less than 1000 atmospheres, that is, below 14,700 psi. Thus, they suggest that the common theory that hydrogen embrittlement of steel results from extremely high equilibrium pressures of molecular hydrogen is incorrect. Of course, hydrogen contents much higher than 5 ppm can be introduced into steel by suitable charging techniques, and these would correspond to higher equilibrium pressures than 1000 atmospheres, which might account for the blistering observed.

\section{PERMEATION}

\section{Introduction}

Sometimes the terms "permeation" and "diffusion" have been used more or less interchangeably in describing the penetration of gases through metal walls. However, a number of writers concur in the belief that it is better to make the following distinction between the two. The overall process from bulk gas phase on one side of the metal wall, through the metal, to the bulk gas phase on the other side is best termed permeation. This consists of interactions at both the entry and the exit surfaces of the metal, as well as the actual transport through the metal. The term diffusion strictly applies only to transport through the metal. In the usual experiment with hydrogen, the permeation, rather than the diffusion, is measured, because one is dealing with the overall driving force of gas pressure.

Since the presence of hydrogen (sometimes as little as $1 \mathrm{ppm}$ ) may have a significant effect on the properties of steel and on the tendency toward delayed cracking of steel under sustained load, knowledge of the processes by which it enters and leaves steel is desirable. For convenience,
Darken and Smith(48) divided the processes into two classes which they termed "stationary" and "nonstationary".

The stationary state may be associated with the passage of hydrogen through a diaphragm. If conditions are maintained constant, the rate of passage of hydrogen through the diaphragm usually becomes constant (stationary) after sufficient time. This steady-state condition is described by the permeability constant, or permeability.

The nonstationary state is associated with the rate at which a solid steel object absorbs hydrogen from a suitable environment or loses hydrogen after it has been removed from that environment. This nonstationary diffusion phenomenon usually is described by the boundary conditions and the diffusion constant, or diffusivity.

For linear, steady-state diffusion with a concentration gradient as the driving force, the coefficient of diffusivity, D, may be defined by the equation

$$
J=-D \frac{\left(c_{1}-c_{2}\right)}{\Delta x},
$$

while permeability, $P$, is usually defined by

$$
J=\frac{-P}{\Delta x},
$$

where $\mathrm{J}$ is the diffusion current per unit of area and $\left(c_{1}-c_{2}\right) / \Delta x$ is the concentration gradient in the metal wall of thickness $\Delta x$. The permeability depends upon the gas-pressure difference on the two sides of the wall, so a permeation coefficient could be defined based on a pressure gradient. However, the usual values of $P$ have been obtained with a pressure difference of 1 atmosphere. Inasmuch as it has been established that the concentration of hydrogen in steel is proportional to the square root of the pressure, the permeability, $P$, also might be defined by the equation

$$
J=-P \frac{\sqrt{p_{1}}-\sqrt{p_{2}}}{\Delta x} .
$$

Permeability may be expected to depend on temperature, the nature of the metal, the boundary conditions, and the thickness of the diaphragm; there are indications that it may also depend on the nature of the environment surrounding the exit surface. For the permeation of hydrogen through steel, the boundary conditions include the nature of the steel surface and such things as the type and concentration of the acid in contact with one side of the diaphragm in pickling, the partial pressure of hydrogen in the gas used in pressure charging, and the nature of the electrolyte and the current density in cathodic charging from one surface. The presence or absence of a poison in pickling or in cathodic charging is another factor which is very important. Thus, many variables affect the rate at which hydrogen permeates metals, and, since apparently conflicting results have been 
obtained, the process is not completely understood. For example, consider the effect of pressure. It has been established reasonably well that the permeation rate of hydrogen through steel is proportional to the square root of the pressure (except at very low pressures). This indicates that it is only atomic hydrogen that penetrates steel and permeates through it. However, according to Dodge $(70)$ with many steels the permeation rate becomes constant when a hydrogen pressure of about 100 atmospheres is reached, and no further increase in permeation rate is obtained with further increases in hydrogen pressure. Apparently, as yet there is no satisfactory explanation of this behavior:

Dodge $(70)$ has given the following equation as being the one usually accepted as expressing the effect of pressure and temperature on permeation:

$$
J=\frac{K}{\Delta x}\left(p_{1}^{1 / 2}-p_{2}^{1 / 2}\right) e^{-E /(R T)},
$$

where $J=$ rate of permeation per unit area

$$
\begin{aligned}
\mathrm{K}= & \text { a constant that depends on the metal } \\
& \text { and probably on several factors re- } \\
& \text { lated to the state of the metal }
\end{aligned}
$$

Although this law of pressure and temperature dependence is supposedly general, the limits within which it applies and the effect of variables on $\mathrm{K}$ are not well established.

A number of investigators have measured the amount of hydrogen permeating through a thin tube and agreed that the following equation holds:

$$
\mathrm{P}(\operatorname{or} \mathrm{Z})=\mathrm{Kp}^{1 / 2} \mathrm{e}^{-\mathrm{B} / \mathrm{T}} \text {, }
$$

where $\mathrm{p}$ is the pressure, $\mathrm{T}$ is the absolute temperature, and $\mathrm{K}$ and $\mathrm{B}$ are constants. For the pressure in $\mathrm{mm}$ and temperature in degrees Kelvin, Smithells and Ransley(71) gave the following values for the constants for iron:

$$
\mathrm{K}=1.63 \times 10^{-3} \text { and } \mathrm{B}=4800 \text {. }
$$

Borelius and Lindblom(72) obtained

$$
K=1.60 \times 10^{-3} \text { and } B=4700
$$

for high-purity iron. The effect of pressure on hydrogen permeation will be discussed in more detail in the section dealing with hydrogen entry. Because the greatest effect of temperature on permeation is through its effect on diffusion, further consideration will be given to temperature in the section on diffusion.

The permeability, $\mathrm{P}$, is related to the solubility, S, and the diffusivity, D, as follows:

$$
\mathrm{P}=\mathrm{S} \cdot \mathrm{D} \text {. }
$$

A number of investigators have used this relationship to calculate the diffusivity of hydrogen in iron or steel from permeability data obtained experimentally. However, Bryan and Dodge(49) indicated that this relationship holds only for the case where the diffusion through the bulk metal is the controlling rate, and surface resistances to permeation are negligible. It will be shown later that these three properties are mutually consistent for hydrogen permeating through iron or steel at temperatures above about $750 \mathrm{~F}(400 \mathrm{C})$.

Many investigators have studied the rate at which hydrogen permeates metals, and a large number of these studies have been performed on iron and steel. For that matter, a permeation experiment is the usual method used to study the movement of hydrogen in steel. However, because of the great number of factors that influence permeation, the analysis of the results is complicated. Actually, the person dealing with hydrogen in steel usually is interested in hydrogen entry, hydrogen diffusion through the bulk solid, and the removal of hydrogen. Although these processes are all part of permeation, it will be more convenient for the purposes of this report to consider them separately.

\section{Hydrogen Entry}

Hydrogen enters steel only when it is presented to the steel surface as atomic hydrogen, as has been discussed previously in the section on solubility. Those ways in which hydrogen enters steel subsequent to its manufacture are of special interest to the defense contractor who is concerned about hydrogen embrittlement and delayed brittle failure. These are corrosion, electrolytic processes, and dissociation of hydrogen gas at elevated temper atures.

\section{Entry by Corrosion Processes}

Atomic hydrogen can be liberated at the surface of iron or steel as a result of direct attack by corrosive media or galvanic corrosion. Important examples of the former are acid attack as in acid pickling, attack by hydrogen sulfide, and corrosion by water such as has resulted in hydrogen cracking of pressure vessels being pressure tested with water. Galvanic corrosion is the accelerated electrochemical corrosion that occurs when two dissimilar metals are joined electrically and are in the same corroding medium or electrolyte. This type of 
corrosion usually produces a higher rate of corrosion on the less noble of the two metals and tends to protect the more noble metal; hydrogen may be evolved on the latter. Thus, hydrogen may be evolved on iron or steel when it is coupled with a more active metal, such as magnesium, aluminum, or cadmium.

In any diffusion or permeation problem, the boundary conditions are of great importance. Therefore, it is desirable to have some measure of the driving force of hydrogen; this usually is given in terms of pressure or concentration, When atomic hydrogen is liberated at the surface of steel by chemical attack (for example, by immersion in a suitable acid solution), no actual gage pressure (above atmospheric) of hydrogen is developed on the steel surface. If the pressure concept is adopted for this situation, it must be considered to be a virtual pressure. For an ideal gas, the driving force may be considered to be the fugacity, a thermodynamic quantity which may be regarded as a potential or virtual pressure. Three irdependent methods of calculating fugacity for hydrogen on iron immersed in $1 \mathrm{~N} \mathrm{H}_{2} \mathrm{SO}_{4}$ all give values that lie between $10^{6}$ and $10^{8}$ atmospheres, (48) pressures far higher than the bursting strength of steel. As Sims $(73)$ has stated, such reactions as those of water vapor, pickling in acid, or cathodic precipitation may create an atmosphere at the steel surface, which, in terms of hydrogen-atom concentration, may be equivalent to thousands of atmospheres of hydrogen gas at room temperature or to lowpressure hydrogen at very high temperatures. In this way, the high concentrations of hydrogen that may be obtained in steel by pickling or other chemical attack or by cathodic charging may be accounted for. The fugacity varies with the electrical potential developed in the acid, and this depends on which acid is used, and on its concentration and temperature. (48)

Acid Pickling. It is necessary to remove mill scale or rust from steel before applying a metallic coating, and such removal is advantageous before applying paint. Although this can be done by mechanical means, such as grit blasting or grinding, it often is carried out by pickling in acid solutions. Part of the action of pickling consists of an undermining of the scale which results, in part, from attack of the steel itself by the acid. Electrochemically, iron is a less "noble" element than hydrogen, and thus, it replaces hydrogen from solutions of its ions (acids). Thus, iron is corroded in acid solutions with a pH less than about 4 . When a piece of iron or steel is placed in a solution of a nonoxidizing acid with which it reacts, as in pickling, there are local anodes and cathodes acting, and atomic hydrogen is released at the local cathodes on the steel surface, according to the reaction

$$
2 \mathrm{H}^{+}+\mathrm{Fe} \longrightarrow \mathrm{Fe}^{++}+2 \mathrm{H} \text {. }
$$

A portion of this liberated nascent hydrogen enters into the steel. The portion that does not enter the steel almost immediately, then combines to form molecular hydrogen which is not soluble in metals. The fraction of the hydrogen atoms that recombine and thus escape from the steel surface without entering is greatly affected by inhibitors or by promoters (promoters are commonly called cathodic poisons). When a piece of steel which has been pickled is removed from the acid solution and held in air, the hydrogen which it contains tends to effuse slowly out of the steel.

Entry of hydrogen into the steel is highly undesirable because it may produce blisters in the steel, or hydrogen cracking may occur, either during pickling or afterwards when the part is placed under load. Acid pickling may introduce more hydrogen into steel than is introduced by electroplating operations.

One method used to reduce destruction of valuable metal, minimize surface roughening, and reduce unnecessary consumption of acid is to make the workpiece a cathode by means of an external potential source, rather than merely dipping it in the acid. However, problems related to the absorption of atomic hydrogen by the steel are likely to become more severe when pickling is performed cathodically. Blistering and cracking become even more severe if arsenic or selenium, which are common impurities in acids, are present during cathodic pickling. However, by adding a trace of tin salt to the acid, it is possible to realize the advantages of cathodic pickling while minimizing the disadvantages. A very thin layer of metallic tin is deposited on any portion of the metal which becomes bare of scale. This layer hinders evolution of hydrogen because of the high overvoltage of tin, and it also imposes a barrier to retard the entry of atomic hydrogen into the steel.

One way to reduce the evolution of hydrogen resulting from attack of the metal is to make the steel the anode during acid pickling (anodic pickling). It should effectively prevent the evolution of hydrogen on the steel and, therefore, its entry into steel. However, sometimes anodic pickling increases both the attack on the metal and the roughening, and it may increase acid consumption. Therefore, this procedure is used most frequently for material from which the scale previously has been removed mechanically, the object being to produce a surface suitable for electropolishing.

The method most frequently used to reduce the problems related to metal attack and hydrogen liberation at the same time is to add to the sulfuric or hydrochloric acid pickling bath a substance that will restrain the attack on the metal while still permitting the scale to be undermined. Such substances usually are called "inhibitors". However, Evans $(64)$ has pointed out that the corrosion rate is not brought down to so low a level as to justify use of this term, the corrosion rate being tolerated only because the time of immersion in the acid is 
comparatively short. He prefers use of the term "restrainer". Restrainers are commonly used in ordinary acid pickling baths without an external applied electric current. However, a combination of restrainer and cathodic current can be a very economical procedure. With this arrangement, the current required is much lower than in the absence of a restrainer, and the restrainer concentration required is far below that needed in the absence of current. It is claimed that the combination avoids the chief difficulties encountered with each method, that is, the problem of hydrogen embrittlement and delayed cracking associated with cathodic treatment at high current densities, and the loss of time associated with the use of restrainers, some of which appreciably retard the removal of scale. The current density can be reduced to $1 / 100$ that needed when no restrainer is used, and the restrainer concentration can be reduced to $1 / 10$ that needed when no current is employed. (74)

Evans, (64) in describing the use of restrainers, pointed out that if the only objective in using a restrainer is to cut down the destruction of metal and the consumption of acid, any substance can be used which obstructs any one of the essential steps of the corrosion process. It would make little difference whether the step obstructed is the anodic reaction or one stage of the cathodic reaction. A large number of substances are known to appreciably diminish the corrosion rate, including such cheap materials as glue, size, gelatin, and molasses. However, in practice a restrainer must meet other requirements. Reducing the total corrosion, that is, the total hydrogen production, does not suffice. It is particularly necessary to reduce that fraction of the hydrogen which enters the metal and causes either blistering or cracking. A restrainer which poisoned the second stage of the cathodic reaction without interfering with the first stage of the cathodic reaction or with the anodic reaction would be harmful in many instances, because it would cause a concentration of atomic hydrogen to be built up and thus actually would promote a diffusion of hydrogen into the metal. For example, glue additions greatly reduce the amount of hydrogen gas (molecular form) evolved from the pickling bath but have little effect on the risk of cracking.

Formerly, many commercial restrainers were used which did not meet all these requirements. Zapffe and Haslem(75) tested 14 of them and found that on stainless steel 11 of them actually increased hydrogen embrittlement, and none of them reduced it appreciably. On mild steel, some of the restrainers produced considerable improvement. Some recent work on the effect of restrainers on the evolution of hydrogen during pickling is discussed in Reference (76).

Many of the restrainers used today are organic substances that contain nitrogen and sulfur. It is believed that these polar atoms serve to attach the molecules to the metal surface at points where otherwise some essential step in the corrosion process would occur. The proprietary restrainers now available contain such compounds as diorthotolyl-thio-urea or dihydro-thio-ortho-toluidine. Substances with nitrogen in the ring, such as quinoline and its derivatives, also are effective restrainers. Generally, the efficiency of the restrainer increases as the length and number of side chains attached to the polar atom increase. However, some small molecules, such as formaldehyde, can act as restrainers. Most of the present effective restrainers interfere mainly with the anodic reaction, although the cathodic reaction usually is retarded somewhat also.

A list of pickling inhibitors, including information on the amounts required, may be found in Reference (77).

The use of restrainers, or inhibitors, has been discussed for the person who desires to use pickling in processing his steel and still reduce the amount of hydrogen introduced into the steel. However, for high-strength steels, which are especially susceptible to hydrogen-induced delayed brittle failures, it is best to avoid pickling and all cathodic cleaning processes. For these materials, scale is best removed mechanically, and only alkaline or anodic cleaning processes should be used.

For the person in the laboratory who is studying the effects of hydrogen on steel, it may be desirable to introduce hydrogen into steel intentionally. Sometimes this is done by acid pickling, though more frequently it is done electrolytically by cathodic charging. In either instance, the entry of hydrogen is greatly facilitated by the presence of substances known as cathodic poisons. Such substances as sulfur, phosphorus, arsenic, $\mathrm{H}_{2} \mathrm{~S}, \mathrm{PH}_{3}, \mathrm{AsH}_{3}$, and low-oxidixed compounds of sulfur, phosphorus, and arsenic greatly enhance hydrogen penetration into metals. Also, it is believed that sulfur and phosphorus contained in iron and steel act in a manner similar to that of their compounds added to the acid solution, because, with acid attack of sulfide and phosphide inclusions present at the surface of the sample, $\mathrm{H}_{2} \mathrm{~S}$ and $\mathrm{PH}_{3}$ are formed. (78) This subject will be discussed further in the section dealing with entry of hydrogen by cathodic charging, since most of the investigations have utilized this method of hydrogen charging.

Darken and $\operatorname{Smith}^{(48)}$ carried out a comprehensive study of the behavior of hydrogen in steel during and after immersion in acid. They studied the rate of absorption, saturation solubility, and permeation of hydrogen in steel. The method of investigation consisted of exposing one side of a thin steel diaphragm to an acid solution and collecting and measuring the hydrogen which diffused through and passed out the other side. The solubility of hydrogen was determined by both warm 
extraction and vacuum extraction at temperatures up to $1470 \mathrm{~F}(800 \mathrm{C})$. As one might expect, they found that the amount of hydrogen passing through a steel disc in contact with acid depended on the $\mathrm{pH}$ of the acid, as is illustrated in Figure 12. The amount of hydrogen absorbed by the steel also depended on $\mathrm{pH}$, as is shown in Figure 13. In experiments with cylinders of various diameters immersed in a buffered acid solution of $\mathrm{pH}=3.2$, the rate at which hydrogen was absorbed was found to be related to the dimensions in the manner to be expected from the usual diffusion laws. That is, a plot of the square root of time for saturation versus specimen diameter gave a straight line. Cold work markedly increased the absorption rate, the time to reach saturation, and the saturation concentration or amount of absorbed hydrogen. For a given material, the amount absorbed increased linearly with the square root of time until a limiting amount was absorbed. After this saturation value was reached, no further hydrogen was absorbed for longer immersion times. The saturation value was very small for hot-rolled steel, but increased markedly with cold work. The effect on absorption of annealing after cold work was less than had been anticipated, inasmuch as the annealed material did not behave toward hydrogen at all like the original hot-rolled material (see Figure 10).

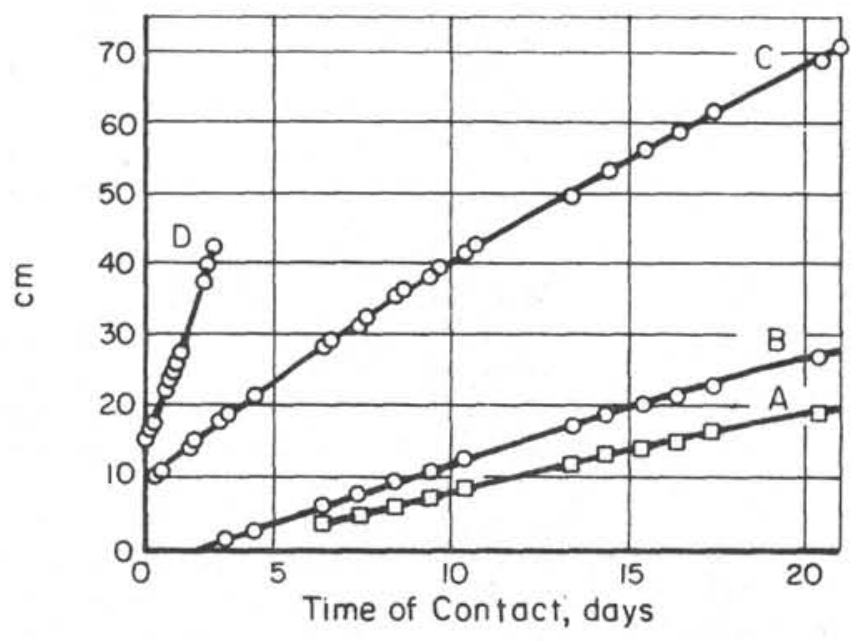

FIGURE 12. AMOUNT OF HYDROGEN $(1 \mathrm{~cm}$ on scale $=4.27 \mathrm{cc})$ PASSING THROUGH AN SAE 1020 STEEL DISC IN CONTACT WITH AN ACID SOLUTION PLOTTED AGAINST TIME IN DAYS(48)

\begin{tabular}{|c|c|c|c|}
\hline \multirow[b]{2}{*}{ Curve } & \multirow[b]{2}{*}{ Solution } & \multicolumn{2}{|c|}{ Disc } \\
\hline & & $\begin{array}{c}\text { Original } \\
\text { Thickness, } \\
\mathrm{mm} \\
\end{array}$ & $\begin{array}{l}\text { Diameter } \\
\text { In Contact, } \\
\mathrm{mm}\end{array}$ \\
\hline A & $\mathrm{pH} \quad 6.25$ & 0.965 & 27.6 \\
\hline B & 5.47 & 0.965 & 29.0 \\
\hline C & 4.33 & 0.960 & 27.5 \\
\hline $\mathrm{D}$ & $10 \mathrm{~N} \mathrm{H}_{2} \mathrm{SO}_{4}$ & 0.957 & 27.0 \\
\hline
\end{tabular}

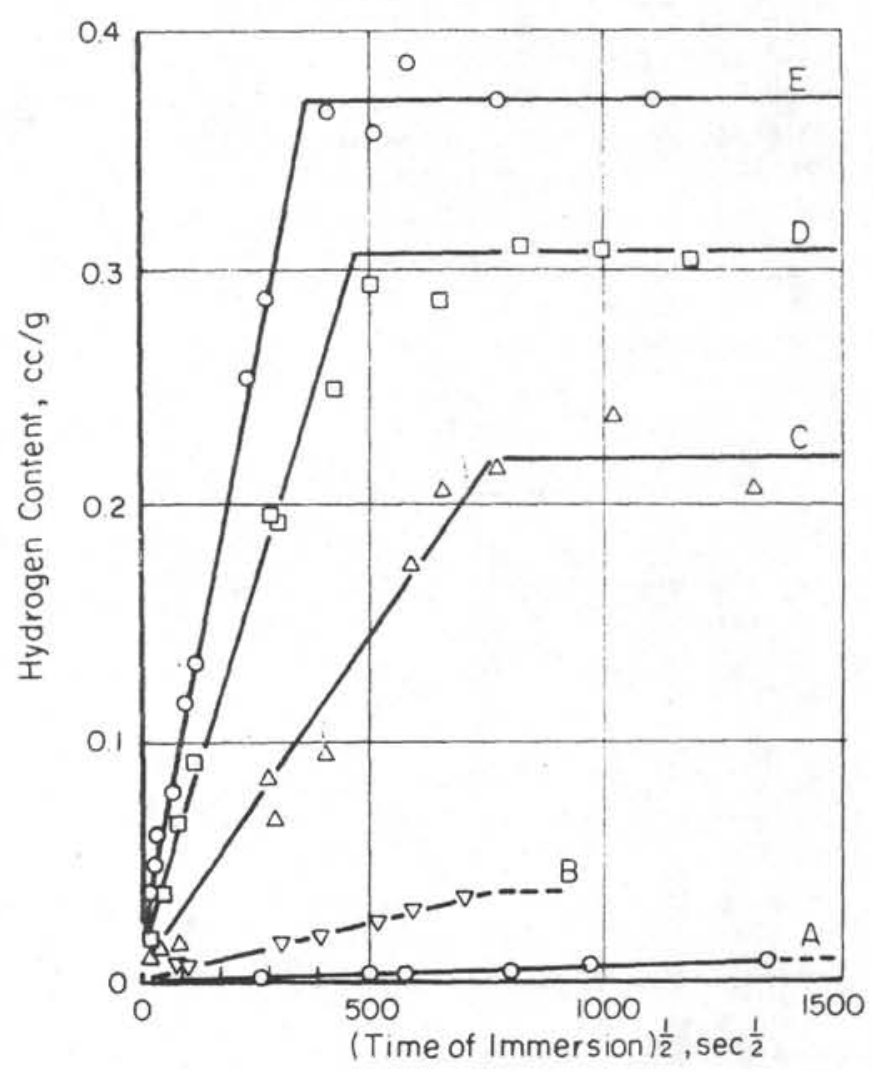

FIGURE 13. AMOUNT OF HYDROGEN ABSORBED BY SIMILAR SPECIMENS IMMERSED IN A SOLUTION OF pH (A) 7.92; (B) 7.09 ; (C) 5.43 ; (D) 3.14 ; (E) 1.38 , PLOTTED AGAINST SQUARE ROOT OF TIME OF IMMERSION(48)

( 1 cc NTP per gram $=0.00899$ percent H. )

Nitric acid, an oxidizing acid, has been regarded as causing no hydrogenation. $(79,64)$ Most of the base metals that liberate hydrogen from hydrochloric acid are attacked also by nitric acid. However, the hydrogen atoms react with nitric acid to form salts of ammonia or hydroxylamine $\left(\mathrm{NH}_{2} \mathrm{OH}\right)$; these compounds are rich in hydrogen. The more noble metals that cannot liberate hydrogen from hydrochloric acid or sulfuric acid are unlikely to produce hydrogen or hydrogen-rich products such as ammonia salts. Instead, they produce compounds rich in oxygen, such as $\mathrm{NO}_{2}$, $\mathrm{HNO}_{2}$, or NO. Iron shares the properties of both groups and produces both ammonium salts and nitrous acid, besides the gases $\mathrm{NO}_{2}$ and NO. Evans $(64)$ pointed out that it may seem remarkable that a simple dip in an oxidizing acid bath which would pickle a surface without introducing hydrogen is not more widely adopted as a simple means of avoiding hydrogen troubles without demanding an external potential. However, he states that practically every oxidizing acid or acidic mixture introduces some new objection. Nitric acid, for instance, is unpleasant owing to the fumes evolved and the action on the skin. It was used in one situation where spring clips were found to become 
embrittled on pickling in hydrochloric acid or sulfuric acid followed by electrotinning; the problem was solved by using nitric acid for pickling and applying the tin by hot dipping. (80) However, Hudson, Norris, and Stragand $(81)$ found that, at least under some conditions, treatment of steel with nitric acid can introduce hydrogen into the steel. This is shown in the following tabulation:

\begin{tabular}{|c|c|c|c|c|}
\hline \multirow[b]{2}{*}{ Solution } & \multirow{2}{*}{$\begin{array}{c}\text { Concen- } \\
\text { tration, } \\
\mathrm{M} \\
\end{array}$} & \multirow[b]{2}{*}{$\mathrm{pH}$} & \multicolumn{2}{|c|}{$\begin{array}{l}\text { Hydrogen Content, (a) } \\
\mathrm{cc} / 100 \mathrm{~g}\end{array}$} \\
\hline & & & $\begin{array}{c}\text { Warm } \\
\text { Extraction } \\
\end{array}$ & $\begin{array}{l}\text { Vacuum } \\
\text { Fusion }\end{array}$ \\
\hline Uncharged & -- & -- & 0.1 & 1.3 \\
\hline $\begin{array}{l}\mathrm{H}_{2} \mathrm{O} \text {, deoxy- } \\
\text { genated }\end{array}$ & -- & 6.6 & 0.1 & -- \\
\hline $\mathrm{HNO}_{3}$ & 0.1 & 1.3 & 3.6 & -- \\
\hline $\mathrm{HNO}_{3}$ & 15.6 & $<0.0$ & 1. 0 & -- \\
\hline
\end{tabular}

(a) Content after treatment by immersion in the indicated solution at $100 \mathrm{~F}(38 \mathrm{C})$ for 4 hours.

When fully charged to saturation by immersion in $2 \mathrm{~N} \mathrm{H}_{2} \mathrm{SO}_{4}$ at $100 \mathrm{~F}(38 \mathrm{C})$ for 24 hours, average hydrogen contents of $12.7 \mathrm{cc} / 100 \mathrm{~g}$ and $16.0 \mathrm{cc} /$ $100 \mathrm{~g}$ were obtained by warm extraction and vacuum fusion, respectively.

Smialowski(79) has devoted Chapter 15 to hydrogen in pickling of steel, and he gives $61 / 2$ pages of references on the subject.

Other Corrosion Processes. Another source of hydrogen in steel arises from the corrosion of steel in aqueous environments. Time-dependent delayed failures have been observed in rocketmotor cases when tested at constant pressure and exposed to aqueous environments. $(82,83)$ In a series of experiments with small-size pressure vessels, it was proved that the water used in hydrostatic testing was the cause of the delayed, brittle failures, and that these failures were induced by hydrogen. This type of failure is not encountered when oil is used as the pressurizing medium, or when water is prevented from contacting the steel by use of a primer on the steel. However, when water contacts the bare metal, the burst strength is lowered (by $130,000 \mathrm{psi}$ in the experiments mentioned above). The water serves as a medium for localized galvanic action which releases the essential atomic hydrogen. Pressure testing with oil is an effective preventative measure against embrittlement, provided that the pressure-vessel steel has not already been loaded with hydrogen prior to hydrostatic testing. (83)

Hydrogen will permeate steel at room temperature because of corrosion that occurs as a result of exposure to air and liquid water. The corrosion reaction occurring on bare steel under these conditions may be written

$$
\mathrm{Fe}+\mathrm{H}_{2} \mathrm{O} \longrightarrow \mathrm{FeO}+2 \mathrm{H} \text {. }
$$

Experiments with heavy water $\left(D_{2} O\right)$, in which permeation was detected with a mass spectrometer, showed that the source of the hydrogen is the water that participates in the initial corrosion reaction (Equation 14), rather than the hydrogen present in the steel prior to corrosion. $(84)$ When air was removed from the environment surrounding the entry surface, only $\mathrm{D}_{2} \mathrm{O}$ being left, the rate of permeation was reduced markedly; this shows that oxygen from the air is involved in the process.

Using a metal radio tube, having an $S A E$ 1010 carbon steel shell, as an ionization gage, Norton $(85)$ measured the permeation of hydrogen through the steel shell into the interior. The hydrogen was generated by corrosion that occurred when the tube was dipped into water. A bare, sandblasted, steel surface admitted hydrogen at the rate of $0.13 \mathrm{micron} /$ hour with the shell in water at $77 \mathrm{~F}$ (25 C). With a protective paint on the tube, the rusting reaction was essentially stopped, and very little hydrogen entered the steel ( 0.008 micron) hour). When 0.1 percent sodium chromate, a corrosion inhibitor, was added to the water, entry of hydrogen into even the bare steel was virtually stopped, the entry rate being $<0.001 \mathrm{micron} /$ hour. Of the various coatings examined, one coating, zinc (a more active metal than steel), gave an increased rate of hydrogen entry.

With this technique, many hours of immersion were required for the experiments in the case of water rusting the shell. Also, it was a passive system, that is, the tube was turned on only after the diffusion had occurred. McCaldin(86) developed a method, using a different tube, to continuously determine hydrogen permeating through the shell of the tube. He was able to use this device to measure hydrogen permeation during electroplating, sandblasting, abrading, and chemical cleaning treatments. Lawrence(87) used this same type of equipment to continuously monitor hydrogen sorption during the entire electroplating procedure, during stress corrosion, and during exposure to gaseous and aqueous media. As a result of his experiments, the low-embrittlement cadmiumplating process for high-strength steel used by his company was altered materially. It was found that the rinses following pickling or plating were a source of considerable extra hydrogen in the plated parts. The new process now requires that the parts be rinsed in overflow tanks, and that the rinse water be changed at least once each hour to avoid damaging acid buildup. Because it was observed that vapor-honing operations resulted in sufficient hydrogen pickup to cause embrittlement, dry honing, which gives less hydrogen, was recommended.

Exposure to water vapor also introduces hydrogen into steel. Exposure to superheated sieam has resulted in measurable hydrogen permeation in both a plain-carbon ferritic steel and austenitic Type 304 stainless steel. (88) The results for ST 37 steel (plain carbon) exposed to steam 
at 1 atmosphere and temperatures in the range from 350 to $575 \mathrm{~F}$ are shown in the top part of Table 6. For comparison, these investigators also listed the permeation rate of hydrogen from water through steel which they computed from Norton's data(85). By extrapolating their data for steam to temperatures at which Norton determined the permeation rate for water, the results indicated that the permeability of hydrogen from water does not differ greatly from the permeability of hydrogen from steam of the same temperature and pressure, though the density of water is in the order of 2000 times the density of steam. Grinding or abrading steel causes hydrogen pickup, apparently from water vapor in the air or from the cutting fluid when the latter is used. $(89,90)$ A method has been devised to introduce hydrogen into steel for diffusion studies at room temperature and slightly elevated temperatures that consists of abrading steel under water under controlled conditions. (91)

TABLE 6. PERMEATION RATE OF HYDROGEN FROM WATER OR STEAM THROUGH ST 37 PLAIN-CARBON STEEI $0.1 \mathrm{~mm}$ THICK( 88$)$

\begin{tabular}{ccccc}
\hline \hline \multicolumn{2}{c}{ Temperaturc } \\
\hline $\mathrm{K}$ & $\mathrm{F}$ & $\begin{array}{c}\text { Environ- } \\
\text { ment }\end{array}$ & Investigators & $\begin{array}{c}\text { Permeation Rate, } \\
\mathrm{cm}^{3}(\mathrm{STP}) /\left(\mathrm{cm}^{2}-\mathrm{sec}\right)\end{array}$ \\
\hline 575 & 575 & Steam & Boeschoten et al & $274 \times 10^{-8}$ \\
525 & 485 & St am & Ditto & $10 \times 10^{-8}$ \\
450 & 350 & Steam & $"$ & $1 \times 10^{-8}$ \\
373 & 212 & Water & Norton $(85)$ & $9 \times 10^{-10}$ \\
298 & 77 & Water & Ditto & $1.5 \times 10^{-10}$ \\
\hline
\end{tabular}

Steel ball bearings have been found to pick up hydrogen from a hydrocarbon lubricant. (92) Another application of the radio-tube ionization gage involved a study of the problem of hydrogen generated by paint strippers which often are used on high-strength steel parts, (87) The stripper being used gave a hydrogen input equivalent to that which might have been experienced if the part had been soaked in a $\mathrm{H}_{2} \mathrm{SO}_{4}$ solution of $\mathrm{pH} 2$ at room temperature. Since it was the practice to allow the stripper to remain on some parts for as long as 24 hours, this aerospace company now requires that all high-strength steel parts exposed to this particular stripper be baked to drive out absorbed hydrogen before further processing.

It is rather generally agreed that the phenomenon of sulfide-corrosion cracking of steel is the result of the penetration of atomic hydrogen into the steel. $(57,93,94)$ That is, sulfide-corrosion cracking is identical with hydrogen cracking. The only part played by corrosion in this phenomenon seems to be to supply the nascent hydrogen to the surface of the steel. Since the sulfide ion is one of the most effective poisons of the hydrogenrecombination reaction, its presence serves not only to corrode the steel and supply the atomic hydrogen, but to make it possible for much of this atomic hydrogen to enter the steel. Inasmuch as only very small quantities of hydrogen embrittle steel and serve to make it susceptible to delayed brittle failure, enough hydrogen to embrittle the steel may be introduced at an insignificant corrosion rate. Both martensitic and ferritic structures fail when the strength level of the steel, the magnitude of the applied stress, and the hydrogen content introduced by sulfide corrosion are high enough, but austenite has not cracked under similar conditions - just as with failures where hydrogen is introduced by cathodic charging or thermal charging. $(57,93,94)$ For a given strength level, there appears to be a minimum stress necessary to produce failure. (93) A number of investigators have concurred in the finding that cold work increases the susceptibility of ferritic steel to sulfide-corrosion cracking and decreases the time to fracture. $(57,93,94)$ In recent years, Bastien and co-workers and Herzog have published the results of a large number of studies of sulfide-corrosion cracking. A number of other investigators have studied the hydrogen embrittlement and delayed brittle fracture of steel resulting from exposure to $\mathrm{H}_{2} \mathrm{~S}$; some of these studies will be found in References (95) to (101).

Certain $\mathrm{Cr}-\mathrm{Mo}-\mathrm{Al}$ and $\mathrm{Cr}-\mathrm{Mo}-\mathrm{V}$ steels, when properly heat treated, perform better in severe production service in sour-gas fields than does the conventional API Grade N-80 steel, and the same superiority is exhibited in laboratory sulfide-corrosion tests. $(102,103,104)$ A minimum susceptibility to cracking in constructional $\mathrm{Cr}-\mathrm{Mo}-$ $\mathrm{V}$ steels occurs after tempering the steel at elevated temperatures so as to produce a structure of fine spheroidal carbides. (94) Ferritic steels containing about 12 percent chromium are less susceptible to general corrosion than are steels with only 2 percent or so chromium, but they also show sulfide-corrosion cracking when heat treated to high strength levels. A 9 percent nickel steel was particularly susceptible to this type of cracking. (94) Fraser and co-workers $(105,106)$ studied 104 different alloys in the laboratory and under field conditions and derived empirical equations for rating the cracking susceptibility from composition, yield-strength, ductility, hardness, and heat-treatment data.

Water is an essential factor in the corrosion of iron by $\mathrm{H}_{2} \mathrm{~S}$. (107) Dry $\mathrm{H}_{2} \mathrm{~S}$ and saturated solutions of $\mathrm{H}_{2} \mathrm{~S}$ in benzene do not result in cracking of stressed steel specimens.(101) Various investigators have observed that the corrosion rate of steel in dry $\mathrm{H}_{2} \mathrm{~S}$ at elevated temperatures is minimized by the presence of oxygen, unlike acid solutions where the presence of oxygen accelerates corrosion. The rate of sulfide corrosion may be reduced considerably by lowering the acidity of the environment, even though the same amount of sulfide is present; (108) however, this apparently occurs only in the presence of oxygen. $(109,110)$ Cathodic protection and galvanic contact with less 
noble metals frequently are not adequate solutions to the problem of sulfide corrosion, because more hydrogen, not less, is supplied to the steel under these conditions. A little information is available to indicate that inhibitors can reduce the corrosion and lower the chance of failure of steels when stressed and immersed in $\mathrm{H}_{2} \mathrm{~S}$ solutions. (111,112,93) It has been suggested that copper coatings might present certain advantages.(108) Coating with aluminum (either aluminizing or calorizing) generally is considered to protect steel sufficiently against attack by $\mathrm{H}_{2} \mathrm{~S}$ at high temperatures, but it is doubtful whether the se coatings will prevent delayed cracking under the influence of moist $\mathrm{H}_{2} \mathrm{~S}$. Warren and Beckman (93) found that a nickel electroplate $0.127 \mathrm{~mm}(0.005 \mathrm{inch})$ thick provided protection for heat-treated AISI 4140 steel bolts against sulfide-corrosion cracking, but coatings of cadmium, zinc, lead, and brass did not give reliable or consistent protection.

A number of other corrosion reactions can introduce hydrogen into steel. For example, Bloom(113) has described the corrosion-generated hydrogen cracking of martensitic and other hardened stainless steels; Hudson, Norris, and Stragand(81) found the fairly high hydrogen content of $7.6 \mathrm{cc} /$ $100 \mathrm{~g}$ of steel after treatment for 4 hours in a $1 \mathrm{M}$ solution of $\mathrm{K}_{2} \mathrm{~S}_{2} \mathrm{O}_{8}$; and Uhlig(114) found that hardened 13 percent chromium steel failed rapidly when coupled to aluminum in 3 percent $\mathrm{NaCl}$ solution (a galvanic couple). Steigerwald(115) carried out an investigation to systematically evaluate the influence of liquid environments (primarily aqueous) on the delayed-failure characteristics of high-strength steel in the presence of very sharp notches (fatigue cracks). All the aqueous solutions and all the nonaqueous solutions except carbon tetrachloride (the only solvent that contained no hydrogen) consistently caused delayed failure. However, the times to failure for the nonaqueous solvents were considerably longer than those produced by the aqueous environments. The solvents with closed-ring structures and low dielectric constants, benzene and carbon tetrachloride, were capable of sustaining the applied load for the greatest periods of time.

It is possible that protective coatings such as zinc, cadmium, or aluminum may result in the introduction of hydrogen into steel during service. Since these metals are more anodic (that is, more active) than steel under most service conditions, at breaks in the coating the steel could become a cathode in an electrolytic cell, and this might result in hydrogen being introduced into the steel. This is one form of galvanic corrosion.

\section{Entry by Electrochemical Processes}

Cathodic protection is based on the principle that if an anodic current promotes corrosion, then a suitable cathodic current will prevent it. Cathodic protection of steel is accomplished in two ways. In the sacrificial-anode system, no external current is required. Anodes of zinc or of a magnesium or aluminum alloy are connected by a conductor to the steel structure to be protected. Electrochemical action alone (whereby the anode is slowly consumed) generates an electric current and provides the potential needed to protect the structure. With nonsacrificial anodes (such as a large ground bed of graphite for large steel structures), an external current must be supplied. With either system, atomic hydrogen is liberated at the surface of the steel (the cathode). Upon entering the steel, this atomic hydrogen is a potential source of hydrogen cracking or of blistering.

When steel is cleaned cathodically, machined electrolytically, electroplated, or purposely charged with hydrogen by cathodic treatment, cations of hydrogen are liberated on the steel surface (the cathode). Since free atoms or charged ions of hydrogen can exist at the steel surface only briefly, either they enter the metal lattice quickly or they form hydrogen molecules that cannot enter the steel. High hydrogen concentrations can be obtained in steel from the se various processes, frequently with serious consequences. Furthermore, the presence of certain elements or compounds in the electrolyte, which are known as cathodic poisons, greatly increases the likelihood that hydrogen will enter the steel. Their presence is an aid to the laboratory worker who is studying the effects of hydrogen in steel and desires to charge the steel with hydrogen under conditions that are as reproducible as possible. However, in producing parts for service, it is necessary to take steps to minimize hydrogen entry in such processes as those listed above, and to remove most of that hydrogen which is picked up during processing.

The driving force for hydrogen entry when atomic hydrogen is liberated by electrochemical processes is the fugacity of hydrogen at the steel surface. This has been discussed previously in the section that deals with entry by corrosion processes.

Cathodic Charging. Cathodic charging is the method most widely used to charge specimens with hydrogen for the purpose of studying the delayed-brittle-failure phenomenon. Numerous examples of this procedure have been discussed in a previous report ty the present authors (DMIC Report No. 196). One of two procedures usually is followed. A notched specimen may be charged under standard conditions (standard electrolyte, cathodic poison, current density, time, and specimen geometry) and then placed under load when a fixed time has elapsed after cathodic charging. With smooth specimens, it usually is not possible to obtain failures when they are charged prior to being placed under load. This type of specimen may be studied by charging under standard conditions continuously while under load. In either case, the hydrogen content may be varied by changing the current density. With prior charging, the hydrogen content also can 
be varied by using different charging times and by holding for different times after charging but prior to placing the specimens under load, allowing hydrogen effusion to various degrees. Baking treatments also may be used to vary the hydrogen content. All of these procedures have been discussed in the previous report in regard to their effect on delayed brittle failures of steel.

Some variables in the cathodic charging process, such as the effect of specimen thickness, will be discussed in the section of the present report on diffusion. Others, such as current density and cathodic poisons, are especially important to cathodic charging and are related to hydrogen entry, and, therefore, are considered here.

Possible Mechanisms. Chapter 4 of Smialowski's book(116) is devoted to a discussion of the cathodic evolution of hydrogen on metals which occlude this element. According to Smialowski, the electrolytic evolution of hydrogen from acid electrolytes consists of two main stages:

(1) Discharge of hydrated protons (the hydronium ion) and adsorption of neutral hydrogen atoms

$$
\mathrm{H}_{3} \mathrm{O}^{+}+\mathrm{e} \longrightarrow \mathrm{H}_{\text {ads }}+\mathrm{H}_{2} \mathrm{O} \text {. }
$$

(2) Desorption, that is, detachment of hydrogen atoms from the cathode and production of molecular hydrogen. Two alternative mechanisms are considered probable. Either the hydrogen atoms combine directly

$$
\mathrm{H}_{\mathrm{ads}}+\mathrm{H}_{\mathrm{ads}} \longrightarrow \mathrm{H}_{2} \text {, }
$$

or a hydrated proton discharges near an adsorbed hydrogen atom and gives molecular hydrogen as follows:

$$
\mathrm{H}_{\mathrm{ads}}+\mathrm{H}_{3} \mathrm{O}^{+}+\mathrm{e} \longrightarrow \mathrm{H}_{2} \mathrm{O}+\mathrm{H}_{2} \text {. }
$$

Reaction 16 is commonly called "catalytic desorption", because its rate is generally believed to depend upon the catalytic activity of the metal surface for recombination of hydrogen atoms into molecules. Reaction 17 is called "electrochemical desorption".

Either the discharge of hydrogen ions (15) or one of the two possible desorption mechanisms (16) or (17) determines the velocity of the overall process of hydrogen evolution from acids.

In neutral and alkaline solutions, water molecules supply the hydrogen evolved at the cathode. Smialowski writes the sequence of cathodic processes as follows:

$$
\begin{aligned}
& \mathrm{H}_{2} \mathrm{O}+\mathrm{e} \longrightarrow \mathrm{H}_{\mathrm{ads}}+\mathrm{OH}^{-} \\
& \mathrm{H}_{\mathrm{ads}}+\mathrm{H}_{\mathrm{ads}} \longrightarrow \mathrm{H}_{2}
\end{aligned}
$$

$$
\mathrm{H}_{\mathrm{ads}}+\mathrm{H}_{2} \mathrm{O}+\mathrm{e} \longrightarrow \mathrm{H}_{2}+\mathrm{OH}^{-}
$$

As in the preceding case, one of the above stages may be slow and rate determining.

Hydrogen evolved cathodically from alkaline electrolytes, such as $\mathrm{NaOH}$, shows much less ability to enter iron and steel specimens than that evolved from acid electrolytes or neutral solutions.

Barton(117) recently discussed in considerable detail the mechanisms whereby hydrogen finds its way across solution-metal interfaces and undergoes a change in its oxidation state. As a first approximation, Barton views hydrogen entry as a side reaction to the evolution reaction. Therefore, the various mechanisms of hydrogen evolution are considered in detail. Then the factors, such as surface coverage, which may affect the rate at which hydrogen enters the metal are considered. Finally, the factors involved in hydrogen release from metals are discussed.

It is unusual for a chemical reaction to occur in a single step. Generally, a number of consecutive or parallel steps or, frequently, a complex combination of parallel and consecutive steps constitute the mechanism. One of these steps will be the slowest, and it is called the rate-determining step. If it is enough slower than all the preceding or following steps so that the products and reactants of the other steps can attain equilibrium, it will completely control the rate of reaction.

In the hydrogen-evolution reaction, a number of steps are necessary in order to transfer or transform a proton from some proton-containing species in the bulk of the electrolyte solution to a hydrogen molecule in the gas phase. The following series of consecutive steps is a simplified presentation of the main features of the process.

(1) A proton-containing species must diffuse from the bulk of the solution to the outer boundary of the double layer surrounding the electrode. Hydrogen discharge, particularly from aqueous solutions, usually is not diffusion controlled at this step.

(2) The proton must be transferred across the charged double layer; this is probably a diffusion-controlled process.

(3) The proton species then may be adsorbed on the electrode. The deleterious effects of impurities on the hydrogen-electrode reaction, which frequently plague research in this area, often result from specific adsorption of impurities on the metal surface that results in a blocking action to either the adsorption of the reactant or to a subsequent step. However, an adsorbed layer does not necessarily prevent hydrogen reduction. 
(4) The charge transfer from the electron sea of the metal to the proton may be the slow step in the process in some cases. This reduction step leaves an adsorbed layer of hydrogen atoms on the electrode surface. These atoms either enter the metal or combine to form hydrogen molecules which are not capable of entering the metal.

(5) The direct combination of two adsorbed atoms to form an adsorbed hydrogen molecule has been the traditionally accepted slow step in the evolution reaction. Another combination process, the electrochemical one, involving the simultaneous combination of an adsorbed atom, a proton, and an electron from the metal has been shown to be important in many cases.

(6) The hydrogen molecules must be desorbed and diffuse away from the electrode surface. If this is a slow step, the hydrogen molecules can have a blocking effect on the active electrode area, with a consequent reduction in the rate of either the adsorption or the charge transfer.

(7) The final step, at least under conditions of high current density, is the formation of bubbles.

Many mechanisms have been proposed to account for the charge transfer, atom formation, and molecule formation. Barton discusses the few that have been widely accepted, both for acid and alkaline electrolytes. The equations for these reactions are listed in Table 7.

In highly acid solutions, where the source of of the proton is $\mathrm{H}_{3} \mathrm{O}^{+}$, these three mechanisms have gained wide acceptance:

(1) Rate determination by atomic combination.

(2) Rate determination by proton discharge. This consists of a slow discharge step followed by one of two fast combination steps ( $2 \mathrm{a}$ and $2 \mathrm{~b})$.

(3) Rate determination by electrochemical desorption. For the slow electrochemical desorption, there are two cases, one with low surface coverage and one with complete coverage.

In strongly alkaline solutions, the same three mechanisms also occur, but with the proton source being $\mathrm{H}_{2} \mathrm{O}$, along with one additional mechanism involving the solution cation. Step 4 in alkaline solutions is rate determination by alkali-metal amalgam reaction with water, followed by either

$$
\mathrm{H}_{\mathrm{ads}} \stackrel{\text { fast }}{=} \mathrm{H}_{2}
$$

TABLE 7. EQUATIONS FOR THE HYDROGENEVOLUTION-REACTION MECHAN$\operatorname{ISMS}(117)$

Mechanism ( -5 - Indicates Slow Reaction)

Acid Solutions

(1) $\mathrm{H}_{3} \mathrm{O}^{+}+\mathrm{e} \rightleftharpoons \mathrm{H}_{\mathrm{ads}}+\mathrm{H}_{2} \mathrm{O}$

$\mathrm{H}_{\text {ads }} \stackrel{\mathrm{s}}{\longrightarrow}-\mathrm{H}_{2}$

(2a) $\mathrm{H}_{3} \mathrm{O}^{+}+\mathrm{e} \stackrel{\mathrm{s}}{\longrightarrow}-\mathrm{H}_{\mathrm{ads}}+\mathrm{H}_{2} \mathrm{O}$

$\mathrm{H}_{\mathrm{ads}} \rightleftharpoons \mathrm{H}_{2}$

(2b) $\mathrm{H}_{3} \mathrm{O}^{+}+\mathrm{e} \stackrel{\mathrm{s}}{\longrightarrow} \mathrm{H}_{\mathrm{ads}}+\mathrm{H}_{2} \mathrm{O}$

$\mathrm{H}_{\mathrm{ads}}+\mathrm{H}_{3} \mathrm{O}^{+}+\mathrm{e} \rightleftharpoons \mathrm{H}_{2}+\mathrm{H}_{2} \mathrm{O}$

(3) $\mathrm{H}_{3} \mathrm{O}^{+}+\mathrm{e}=\mathrm{H}_{\mathrm{ads}}+\mathrm{H}_{2} \mathrm{O}$

$\mathrm{H}_{\text {ads }}+\mathrm{H}_{3} \mathrm{O}^{+}+\mathrm{e} \stackrel{\mathrm{s}}{-}-\mathrm{H}_{2}+\mathrm{H}_{2} \mathrm{O}$

Alkaline Solutions

(1) $\mathrm{H}_{2} \mathrm{O}+\mathrm{e} \rightleftharpoons \mathrm{H}_{\mathrm{ads}}+\mathrm{OH}^{-}$

$\mathrm{H}_{\text {ads }} \stackrel{\mathrm{s}}{\longrightarrow} \mathrm{H}_{2}$

(2a) $\mathrm{H}_{2} \mathrm{O}+\mathrm{e} \stackrel{\mathrm{s}}{\longrightarrow} \mathrm{H}_{\mathrm{ads}}+\mathrm{OH}^{-}$

$\mathrm{H}_{\mathrm{ads}}=\mathrm{H}_{2}$

(2b) $\mathrm{H}_{2} \mathrm{O}+\mathrm{e}-\mathbf{s}-\mathrm{H}_{\mathrm{ads}}+\mathrm{OH}^{-}$

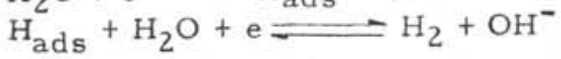

(3) $\mathrm{H}_{2} \mathrm{O}+\mathrm{e} \rightleftharpoons \mathrm{H}_{\text {ads }}+\mathrm{OH}^{-}$

$\mathrm{H}_{\mathrm{ads}}+\mathrm{H}_{2} \mathrm{O}+\mathrm{e} \stackrel{\mathrm{s}}{\longrightarrow} \mathrm{H}_{2}+\mathrm{OH}^{-}$

(4) $\mathrm{M}^{+Z}+\mathrm{Ze} \rightleftharpoons \mathrm{M}$

$\mathrm{M}+\mathrm{ZH}_{2} \mathrm{O} \stackrel{\mathrm{s}}{\longrightarrow} \mathrm{M}^{+\mathrm{Z}}+\mathrm{ZH}_{\mathrm{ads}}+\mathrm{ZOH}^{-}$

or

$$
\mathrm{H}_{\text {ads }}+\mathrm{H}_{2} \mathrm{O}+\mathrm{e} \stackrel{\text { fast }}{=} \mathrm{H}_{2}+\mathrm{OH}^{-} \text {. }
$$

The mechanisms of hydrogen evolution in both strongly acid and strongly alkaline solutions are fairly well known for many metals. Knowledge is much less complete for the region of intermediate $\mathrm{pH}$. The reader is referred to Barton's paper for a discussion of each of these mechanisms and for additional references.

It has been realized for some time that the nature of the cathode surface is of prime importance in determining the mechanism of the hydrogen-electrode reaction and the mode of hydrogen entry. The nature of the surface is not well understood, even though some work has been done in which the surfaces have been prepared carefully enough to give reproducible results. The rate of the hydrogen-electrode reaction depends upon such variables as alloy composition, porosity, heat treatment (including annealing), and surface treatments such as electropolishing or anodic 
activation. Appreciable differences occur between different crystallographic faces prepared in the same way.

Barton analyzed the entry process as a side reaction to the evolution process, assuming that one of the hydrogen-containing species present in the evolution process either is or leads to the entry species. It is to be expected that the entry species would be adsorbed on the surface and that it is present in reasonably high concentrations. The mechanisms listed previously are associated with various amounts of hydrogen atoms adsorbed on the surface. Barton considered each one in turn. If it is hypothesized that the entering species is adsorbed hydrogen atoms, the entry rate should correlate with the extent of surface coverage by hydrogen. Data are presented which support this hypothesis. Also, the low coverage in alkaline solutions compared to acid solutions is reflected in the relative permeabilities of hydrogen introduced into steel from these solutions, as will be discussed in the section dealing with the electrolyte. The concentration of hydrogen molecules adsorbed on the surface is believed to be negligible for all mechanisms for iron and steel. Thus, molecular hydrogen does not appear to be a likely species to supply the entering hydrogen. This is supported by gas-phase studies (referred to previously) which indicate that the species in the metal is monatomic. Also, Barton presented arguments against the hypothesis that adsorbed molecular hydrogen and water furnish the entering hydrogen.

If an approximately linear relation exists between the overvoltage and the fraction of the surface that is covered with hydrogen, and if the Tafel relation between overvoltage and current density is employed, the coverage should vary as the log of the current density and so should the permeation rate if coverage is the determining factor. As will be discussed in the next section, the dependence of permeation rate on current density has been investigated many times and usually is given as a square-root function.

It has been suggested that the effects of mechanical processes such as shot peening, polishing, or grit blasting possibly should not be attributed to mechanical working of the mital surface layer but may be due to alterations in the state of the surface.

Current Density. One of the major variables in the entry and permeation of cathodically evolved hydrogen in and through steel is the current density. In 1922, Bodenstein found that permeation of hydrogen followed the relationship

$$
\mathrm{P}=\mathrm{k} \mathrm{i}^{1 / 2},
$$

where $i$ is the cathodic current density and $k$ is a constant. The relationship between permeation and current density is the same as the relationship between permeation and pressure given earlier in the present report. Because of this similarity, a number of investigators concluded that the phenomena of hydrogen flow through metals from the gas phase (pressure charging and thermal charging) and from an electrolyte (electrolytic charging) are governed by identical laws and have similar mechanisms. However, a permeation rate that is attained readily at rather low values of the cathodic current density may be attained by pressure charging only with very large pressure differences, frequently thousands of atmospheres.

A number of investigators have observed hydrogen behavior different from that expressed by Equation 23. For example, Elsea and coworkers (118) performed a series of experiments with high-strength SAE 4340 steel in which the composition of the electrolyte, the current density, and the thickness of the permeation specimen were varied. Part of the results of these experiments are shown in Figure 14. In this figure, the log of the steady-state permeation rate is plotted as a function of the log of the current density for two different electrolytes, 4 percent $\mathrm{H}_{2} \mathrm{SO}_{4}$ with phosphorus poison and $1 / 2$ percent $\mathrm{NaOH}$ containing no cathodic poison. In all cases, the data fit a straight line reasonably well. Thus, an equation of the form

$$
\mathrm{P}=k \mathrm{i}^{\mathrm{n}}
$$

is indicated. Since the experiments were performed under steady-state permeation conditions, in which the quantities of hydrogen entering and leaving the specimen would be the same, this equation also expresses the relationship between entry rate and current density. The variation in the slopes of the lines shows that the exponent $\mathrm{n}$ was not constant. It varied from about 0.54 for the $0.040-i n$, -thick specimen charged in the $\mathrm{H}_{2} \mathrm{SO}_{4}$ electrolyte to 1.0 for the specimen of the same thickness that was charged in the $\mathrm{NaOH}$ electrolyte and a little over 1.0 for the thinner specimen charged in $\mathrm{NaOH}$.

At very low current densities, Raczynski (as described by Smialowski(119)) found that the permeation rate of hydrogen through an iron membrane was proportional to the current density, whereas at somewhat higher current densities it was proportional to the square root of the current density. In his plot of permeation rate versus the square root of the current density (see Figure 15), he identified four regions as follows:

Region $a$, in which $P$ is nearly propor-
tional to $i$ Region $b$, in which $P$ is proportional
to $i \frac{1}{2}$

Region c, in which a more complicated relationship exists between $P$ and $i$

Region d, in which $\mathrm{P}$ is independent of $\mathrm{i}$. 


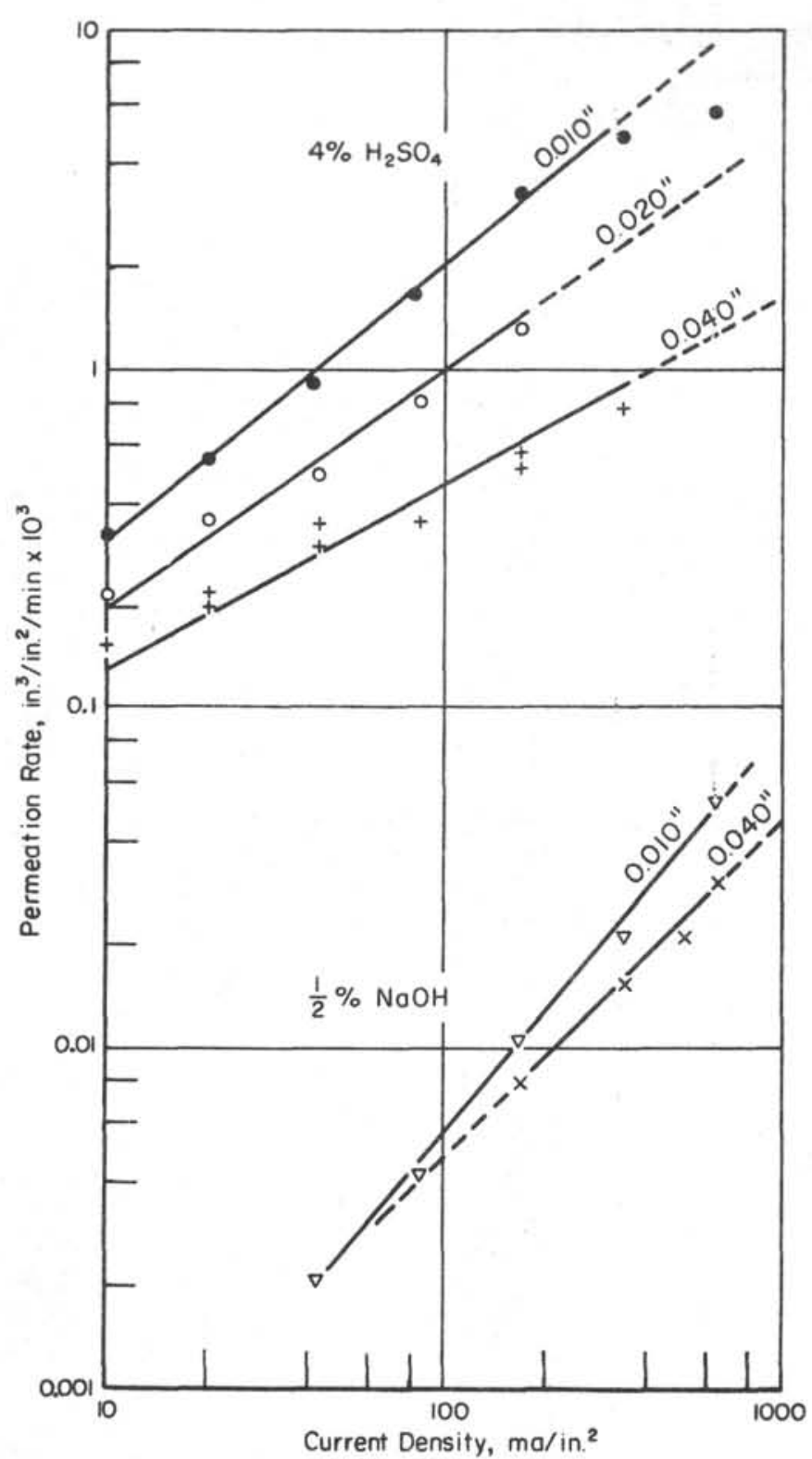

FIGURE 14, PERMEATION RATE OF HYDROGEN AS A FUNCTION OF CURRENT DENSITY FOR BOTH 4 PERCENT $\mathrm{H}_{2} \mathrm{SO}_{4}$ AND $1 / 2$ PERCENT NaOH ELECTROLYTES AND FOR VARIOUS THICKNESSES OF SPECIMENS(118)

(SAE 4340 steel.)

Since this analysis was for steady-state permeation, the hydrogen-entry rate showed the same relationships with current density. Barrer ${ }^{(120)}$ also showed that at high current densities it is possible to reach a condition such that the rate of entry (permeation rate under steady-state conditions) no longer increases as the current density is increased. According to Barrer, it is necessary to achieve Raczynski's Condition d if a diffusion coefficient is to be determined from permeation data.
26

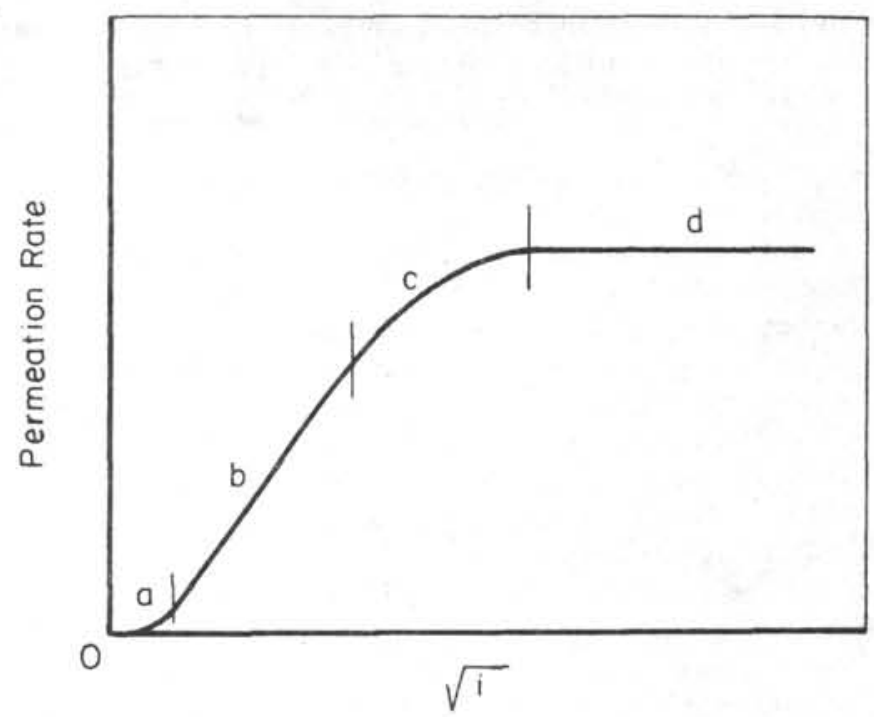

FIGURE 15. PERMEATION RATE VERSUS SQUARE ROOT OF CURRENT DENSITY (AFTER RACZYNSKI)
Raczynski showed that the d-region for mild steel may be reached at different values of the minimum current density. The critical currentdensity value, at which the permeation rate begins to be independent of the current, density, is lower for thicker membranes, at lower temperatures, and in the presence of cathodic poisons. For annealed mild-steel membranes 0.1 and $0.2 \mathrm{~mm}$ thick, charged cathodically at $68 \mathrm{~F}(20 \mathrm{C})$ in $1 \mathrm{~N}$ $\mathrm{H}_{2} \mathrm{SO}_{4}$ containing $\mathrm{As}_{2} \mathrm{O}_{3}$ cathodic poison, the following critical values were obtained:

$\begin{array}{cc}\begin{array}{c}\text { Thickness, } \\ \mathrm{mm}\end{array} & \begin{array}{c}\text { Critical Current } \\ \text { Density, amp } / \mathrm{cm}^{2}\end{array} \\ 0.1 & 0.15 \\ 0.2 & 0.05\end{array}$

The constant permeation rates for higher current densities are shown in Figure 16. For a given membrane, the effect of temperature on the critical value of the current density for attaining constant permeation rate was as follows:

\begin{tabular}{|c|c|c|}
\hline \multicolumn{2}{|c|}{ Temperature } & Critical Current \\
\hline $\mathrm{C}$ & $\mathrm{F}$ & Density, amp $/ \mathrm{cm}^{2}$ \\
\hline 30 & 86 & 0.15 \\
\hline 80 & 176 & 0.35 \\
\hline
\end{tabular}

Although Borelius and Lindblom ${ }^{(72)}$ obtained data which suggested that there is a threshold value of current density below which no permeation 


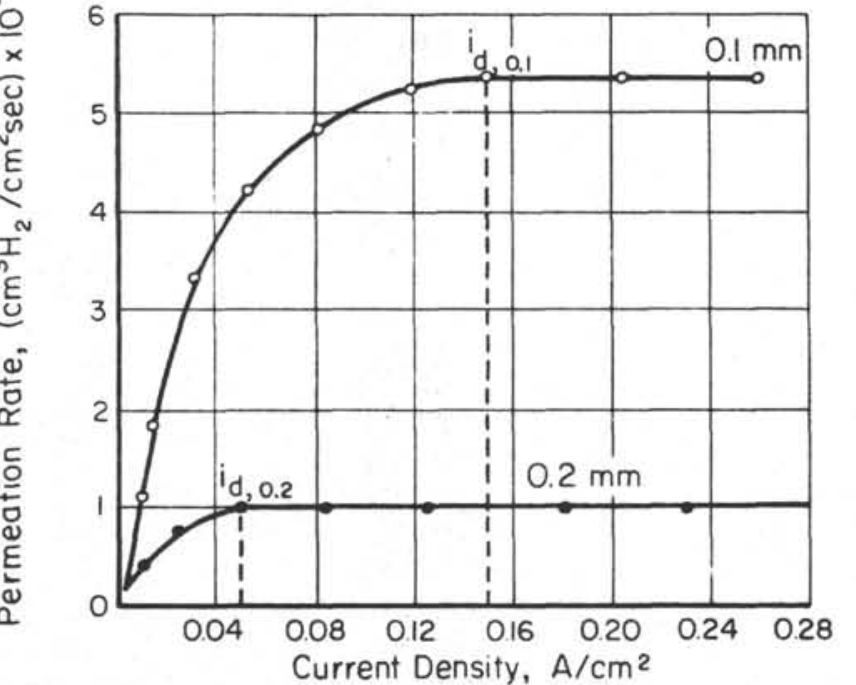

FIGURE 16. PERMEATION RATE VERSUS CURRENT DENSITY FOR 0.1 - AND 0.2MM-THICK MEMBRANES (AFTER RACZYNSKI) (119)

is possible, the majority of later investigators failed to confirm its existence. For example, according to Smialowski, (119) Raczynski observed permeation through an iron membrane $0.1 \mathrm{~mm}$ thick at a current density of only $0.2 \mathrm{ma} / \mathrm{cm}^{2}$.

For a hardened alloy steel cathodically charged in a very weak acid electrolyte (buffered solution of $\mathrm{pH}=4.0$ ) at low current densities, Bolton and Shreir (121) found a linear relationship between the hydrogen content (not the entry rate) and the logarithm of the current density, at least for current densities between 0.1 and $2.0 \mathrm{ma} / \mathrm{cm}^{2}$. These results, which were obtained for a fixed charging time which in all cases was less than that required to reach saturation, are shown in Figure 17.

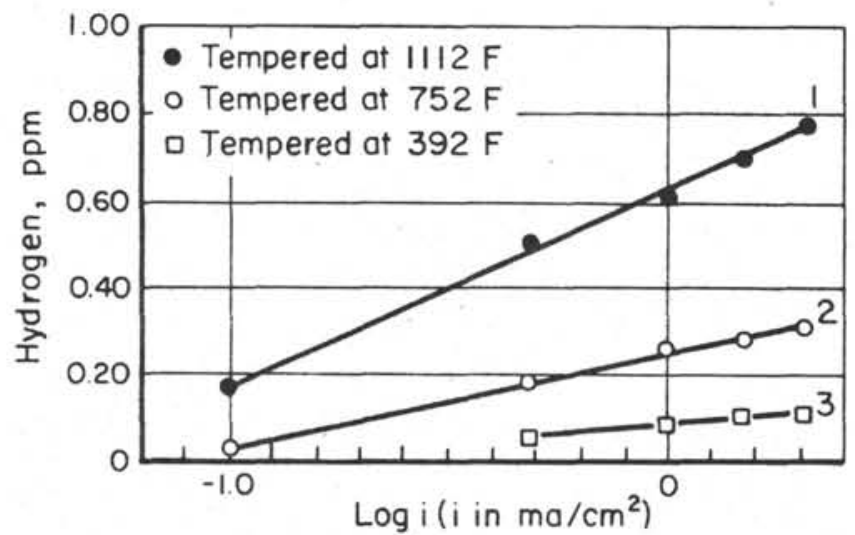

FIGURE 17. RELATIONSHIP BETWEEN HYDROGEN ABSORBED AND LOG I (HARDENED REX 539, ACETATE BUFFER pH 4. 0 , POLARIZED $3 \mathrm{HR})(121)$
Electrolyte. Apparently, quantitative information regarding the ability of hydrogen cathodically evolved from different acids to penetrate into iron are not available. Smialowski(119) suggests that the following is probably the decreasing order for the strong inorganic acids: orthophosphoric, sulfuric, and hydrochloric. Nitric acid, an oxidizing acid, has long been regarded as causing no hydrogenation. However, as was discussed in the section on acid pickling, Hudson, Norris, and Stragand $(81)$ found that nitric acid can result in hydrogen being charged into steel, at least under some conditions.

Many investigations have been carried out on absorption of hydrogen from strongly acid and strongly alkaline solutions. Many of these investigations have been for the purpose of developing cleaning and electroplating procedures to minimize hydrogen absorption during electrolysis. Also, a number of workers have purposely introduced hydrogen into steel by cathodic charging in strong acid solutions so as to determine the effects of hydrogen on mechanical properties and on the propensity toward delayed brittle failurt under static load. Many of these investigations have been described in a previous report on hydrogen in steel by the present authors (DMIC Report No. 196). When the acid contains a cathodic poison, large amounts of hydrogen (far above the solubility at room temperature) can readily be charged into steel. The importance of such factors as the nature of the surface of the cathode and the presence of impurities in the electrolyte often have been overlooked in such studies, with the result that reproducibility has not always been what might be desired. The presence of the poison in the electrolyte is of such importance that it will be considered separately in the next section of this report. The problems of accurately determining the quantities of hydrogen absorbed are so great that most investigators have evaluated the results of charging variables by their effect on mechanical properties, and particularly, on the susceptibility to delayed brittle failure.

In most of these experiments, it was desired that hydrogen be introduced into the steel at an appreciable rate. Therefore, the composition of the acid electrolyte was not of too much importance so long as it was constant for a given series of experiments. The liberation of hydrogen at the surface of the specimen was controlled by controlling the current density, as was discussed above. However, in experiments in which it is desired to introduce hydrogen at low rates so as to simulate conditions that could arise in service (for example, cathodically protected structures or steel coated with galvanically less noble metals), the composition of the electrolyte is highly important. At the very low current densities necessary, it is difficult to find an electrolyte that will provide cathodic protection for the specimen (the cathode). If cathodic protection is not maintained, corrosion 
of the specimen will introduce an additional and uncontrolled amount of hydrogen. One approach is to use weakly ionized acids, such as acetic acid, oxalic acid, or lactic acid. To provide sufficient conductivity, it may be necessary to substitute a solvent such as ethylene glycol for the water used conventionally. One problem that the present authors have found in their investigations with such electrolytes is that side reactions may occur at one or both electrodes. Frequently, therefore, the amount of hydrogen liberated at the specimen surface is far less than is calculated from the time and current, using Faraday's law. The authors have successfully used an electrolyte consisting of three parts by volume ethylene glycol and one part of a 5 percent (by weight) aqueous oxalic acid solution with mild steel at a current density of $1 \mathrm{ma} /$ in. ${ }^{2}$ in a number of experiments.

Hydrogen also can be introduced into steel by electrolysis in alkaline electrolytes. Such electrolytes offer the advantage of providing cathodic protection at low current densities. However, low permeation rates are obtained when they are used. ( The relationship between hydrogen absorption and cathode overvoltage is different for acid electrolytes and alkaline electrolytes. This behavior probably is the result of a change in the mechanism of the hydrogen-evolution reaction in this range where the $\mathrm{pH}$ at the cathode may be sufficiently high for water as well as the hydronium ion, $\left(\mathrm{H}_{3} \mathrm{O}\right)$; to be reduced to hydrogen. (121) Barton(122) suggested that the tendency for some metals to change to a slow-hydrogen-discharge mechanism in alkaline solutions with a resultant low coverage of the specimen surface may also explain the lower entry rate of hydrogen at high $\mathrm{pH}$ values.

The common effects observed at a cathode during electrolysis are (1) the discharge of a positive ion when the ion is below hydrogen in the electromotive series, (2) the formation of a negative ion from a reducible material such as chlorine gas, (3) the reduction of an insoluble salt with the formation of a negative ion into solution, and (4) the evolution of hydrogen gas when the positive ion lies above hydrogen in the electromotive series. In acid solutions, electrolysis is accompanied by the loss of hydrogen ions from solution as shown by the reaction

$$
\mathrm{H}^{+}+\mathrm{e}^{-}=\mathrm{H}^{\circ}
$$

and in neutral or alkaline solutions, it is accompanied by the formation of hydroxyl ions and the decomposition of water as shown by the reaction

$$
\mathrm{H}_{2} \mathrm{O}+\mathrm{e}^{-}=\mathrm{H}^{\circ}+\mathrm{OH}^{-} \text {. }
$$

Thus, one would expect the entry and permeation of hydrogen to be different when electrolysis is carried out in acid solutions than it is when carried out in neutral or alkaline solutions. The mechanisms of cathodic evolution of hydrogen on metals has been discussed in a previous section of the report.
Poisons and Inhibitors. Some elements of Groups V andVI of the periodic table act as poisons or "negative catalysts" for the hydrogen recombination reaction. These are phosphorus, arsenic, antimony, sulfur, selenium, and tellurium. There are indications that the elements bismuth, mercury, lead, and tin and the $\mathrm{CN}^{-}$ion have a similar effect. By slowing down the rate at which hydrogen atoms combine to form molecular hydrogen and thus increasing the lifetime of the atoms, these catalytic poisons promote the entry of hydrogen into iron, steel, and other metals during cathodic charging or pickling. Alexeev and Polukarov reported this effect in 1926 and apparently were the first to observe it.

Smialowski and Szklarska-Smialowska $(123,124)$ established the following order for decreasing ability to promote hydrogen entry into iron cathodes: phosphorus, sulfur, arsenic, selenium, antimony, tellurium, and bismuth. The anions $\mathrm{SO}_{4}{ }^{-2}$ and $\mathrm{PO}_{4}{ }^{-3}$ have a high degree of oxidation and stability and are not reduced at the cathode. Therefore, they do not poison the hydrogen recombination process at the steel surface. However, lower oxides, such as $\mathrm{SO}_{2}$, and oxides and oxidized anions of other elements mentioned above are reduced at the cathode to give free elements and hydrides. For example:

$$
\mathrm{As}_{2} \mathrm{O}_{3} \underset{\text { reduction }}{\longrightarrow} \text { As } \overrightarrow{\text { reduction }} \mathrm{AsH}_{3} \text {. }
$$

According to Smialowski, (119) the formation of a volatile hydride is essential for the poisoning effect. Also, certain organic compounds, for example thiourea, decompose at the cathode and form $\mathrm{H}_{2} \mathrm{~S}$, a potent catalytic poison. It has been demonstrated that part of the lack of reproducibility of results of various investigators using cathodic charging has been due to the fact that sulfuric and hydrochloric acids, unless they have been especially purified, usually contain traces of arsenic, selenium, and other elemunts that act as cathodic poisons. Smialowski and Szklarska-Smialowska(125) found that arsenic distinctly promotes the penetration of hydrogen into iron cathodes when present at a concentration as small as $4 \times 10^{-8}$ mole $/ 1$. Selenium is effective when as little as $3 \times 10^{-6}$ mole/ 1 is present. Since during prolonged electrolysis these elements escape into the atmosphere as hydrides, the cathodic poison content of the solution may be depleted.

Specimens of iron and the various steels always contain a certain amount of phosphorus and sulfur. If the specimen is allowed to contact the acid before the current is turned on, the acid is invariably contaminated. The extent of contamination depends on such factors as the composition and structure of the sample, the acidity of the solution, the elapsed time before the external current is applied so that the sample becomes cathodically protected, and the temperature.

The rate of hydrogen entry is very low when iron or steel is charged cathodically in pure acid 
solutions; however, when a cathodic poison is added to the acid electrolyte, the quantity of hydrogen absorbed is much greater. $(28,123-128)$ This is illustrated by some of the results Smialowski and Szklarska-Smialowska $(28,124,125)$ obtained in their study of the effects of cathodic poisons, performed in conjunction with studies of the dimensional changes in iron during cathodic charging in acids. Figure 18 summarizes the results obtained in one experiment in which the elongation of annealed mild-steel wires was measured as a function of the time of cathodic charging. The first portion of Curve 1 shows the behavior of the steel wire when treated cathodically for 310 minutes in pure $1 \mathrm{~N}$ $\mathrm{H}_{2} \mathrm{SO}_{4}$ solution at a current density of $0.15 \mathrm{amp} /$ $\mathrm{cm}^{2}$ and at a temperature of $37 \mathrm{~F}(3 \mathrm{C})$. The rate of elongation resulting from hydrogen penetration was comparatively low under these conditions. However, the rate rose markedly after an addition of $1 \mathrm{~g}$ of thiourea per liter of solution was made in the 311 th minute (indicated on the curve as Th. u.). Thiourea is decomposed at the cathode and $\mathrm{H}_{2} \mathrm{~S}$ is formed which acts as a poison and results in increased penetration of hydrogen into the steel cathode, the penetration being accompanied by plastic deformation of the wire. Curve 2 represents the behavior exhibited by a wire treated for 130 minutes in $1 \mathrm{~N} \mathrm{H}_{2} \mathrm{SO}_{4}$ that contained $0.16 \mathrm{~g}$ dibenzyl sulphoxide per liter. This compound is a corrosion inhibitor which becomes strongly chemisorbed on the surface of the polarized cathode at certain potential values, and the penetration of hydrogen into the iron cathode is greatly reduced. The subsequent addition of thiourea caused only a slight increase in hydrogen penetration rate when dibenzyl sulphoxide was present in the electrolyte. Curve 3 shows the behavior in acid containing $1 \mathrm{~g}$ $\mathrm{As}_{2} \mathrm{O}_{3}$ per liter at $86 \mathrm{~F}(30 \mathrm{C})$. Curve 4 shows the elongation of the wire in the same arseniccontaining electrolyte at $122 \mathrm{~F}(50 \mathrm{C})$, but $5 \mathrm{~min}-$ utes after the beginning of the electrolysis, $0.1 \mathrm{~g}$ dibenzyl sulphoxide (dbs) per liter of solution was added. This caused an immediate drop in the elongation rate. Different organic compounds produce effects like one or the other of these two compounds, thiourea and dibenzyl sulphoxide. Therefore, the electrolyte should always be maintained free from organic impurities if reliable experimental results are to be obtained.

Because the elongations in a straight wire were difficult to measure, these investigators developed another technique of coiling up a long length of wire for immersion in the electrolyte. Elongation of the coil (not the wire itself) was much larger and easy to measure. Using this technique they studied the effects of the different poisons on the deformation effect associated with hydrogen absorption. The experiments were performed with mild-steel wire, annealed after winding. The coils did not exhibit any deformation when subjected to cathodic conditions in a solution of pure $\mathrm{H}_{2} \mathrm{SO}_{4}$. However, when the electrolyte contained a cathodic poison, rapid elongation of the coil occurred until a limiting elongation was reached.

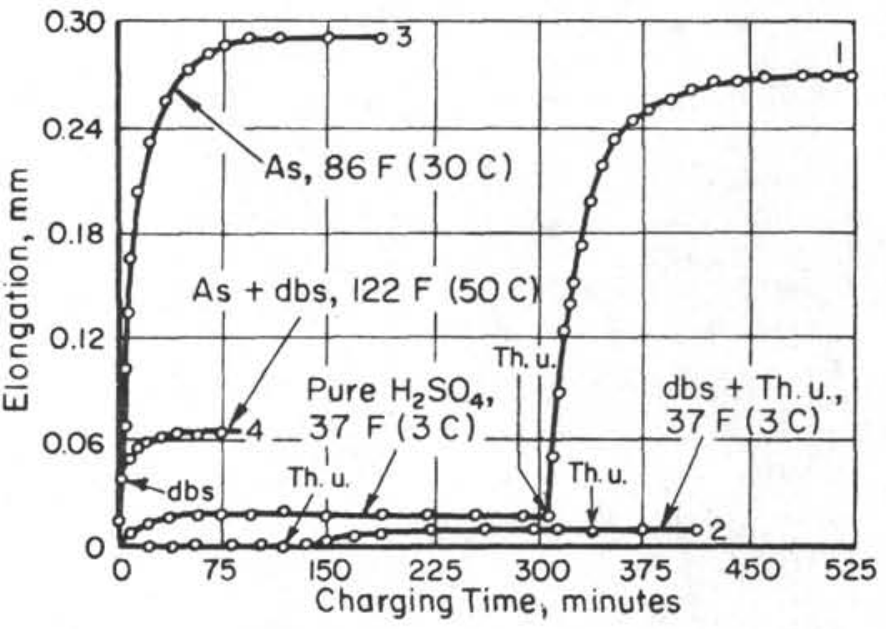

FIGURE 18. ELONGATION OF IRON WIRE AS A FUNCTION OF TIME OF CATHODIC CHARGING(125)

$$
\text { (Original length of wire }=180 \mathrm{~mm} \text {.) }
$$

Sometimes the elongation of the coil amounted to as much as 10 times the original coil length (actually a very small elongation of the wire itself). The effect of poison concentration is illustrated by the results obtained for arsenic, shown in Figure 19. Other data they obtained showed that the poison content of the electrolyte must exceed some rather critical amount, if the poison is to be very effective.

Figure 20 shows the relationship the se investigators found between the limiting values of elongation and the atomic number of the elements from Groups V-B and VI-B of the periodic system used as poisons. These data were obtained from coils with a cathodic current density of $0.036 \mathrm{amp} /$ $\mathrm{cm}^{2}$ at $68 \mathrm{~F}(20 \mathrm{C})$. The concentration of additions in the $1 \mathrm{~N} \mathrm{H}_{2} \mathrm{SO}_{4}$ electrolyte was always greater than the critical amount. Bismuth, selenium, tellurium, and antimony were added in the form of oxides, sulfur was added as $\mathrm{H}_{2} \mathrm{~S}$, and phosphorus was added in the form of hydrogen phosphide. Neither $\mathrm{SO}_{4}^{-2}$ or $\mathrm{PO}_{4}^{-3}$ ions caused penetration of hydrogen into iron cathodes, as measured by the elongation of coils.

It appears that a relationship exists between the deformation effect observed in the presence of any given poisoning element in the electrolyte and the binding force of the respective hydride that was computed by Siebert (see Table 8). (125) Oxygen and nitrogen, which form compounds with binding-force constants higher than in the hydrogen molecule itself, exhibit no measurable poisoning effect. Among the other elements listed, the strongest bond is with the sulfide ion, and it resulted in the greatest deformation as the result of hydrogen penetration of the steel cathode. Antimony makes a relatively weak bond and had a feeble poisoning effect. Selenium showed a weaker poisoning effect than was expected from its bindingforce constant. 


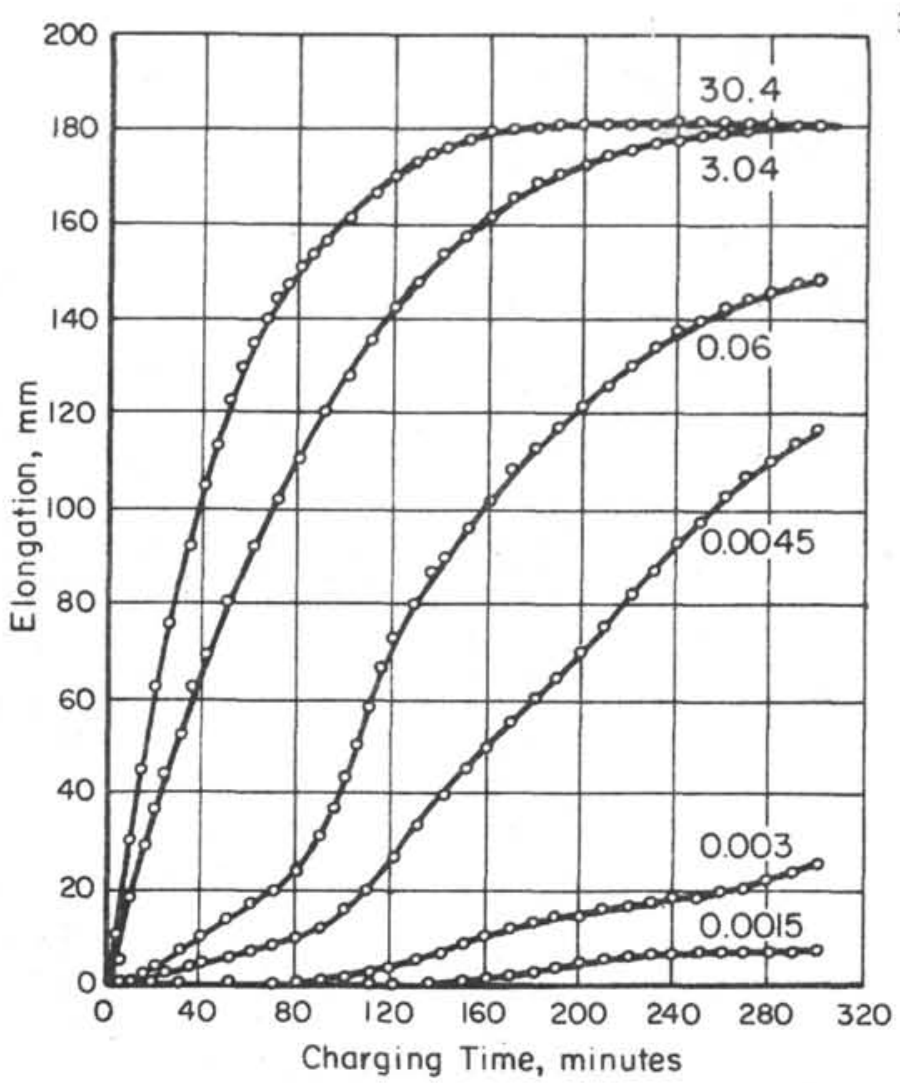

FIGURE 19. ELONGATION OF IRON COILS CHARGED CATHODICALLY IN $1 \mathrm{~N}$ $\mathrm{H}_{2} \mathrm{SO}_{4}$ WITH THE ADDITION OF DIF FERENT AMOUNTS OF ARSENIC EXPRESSED AS mg As/l BUT ADDED AS $\mathrm{As}_{2} \mathrm{O}_{3}(125)$

(Original length of coil immersed in acid $=l_{\text {。 }}$ $=50 \mathrm{~mm}$. Length of wire in coil $=L=1000$ mm.)

Darken and $\operatorname{Smith}(48)$ also studied the effect of inhibitors on hydrogen permeability and found a marked effect. Only two inhibitors--quinoline ethiodide ( 0.1 percent) and Nep No. 22--were investigated, both used with $1 \mathrm{~N} \mathrm{H}_{2} \mathrm{SO}_{4}$. Both of these inhibitors reduced the permeability of several steels to very low values, compared to those obtained with the uninhibited acid.

Structure. From measurements of overvoltage, Bolton and Shreir(121) obtained data which suggested that it is easier kinetically to discharge hydrogen on hardened steel tempered at low temperatures than on the same material tempered at high temperatures (see Figure 21). This, they stated, was in agreement with the results of galvanostatic (constant current) experiments, the results of which are shown in Figure 17. However, for a constant current density, the specimens absorbed hydrogen in the order of increasing tempering temperature, that is, martensite-like structures had a lower hydrogen absorption rate than did tempered structures. This is shown in Figures 17 and 22. For each of the tempered structures investigated, the relationships between the amount of
30

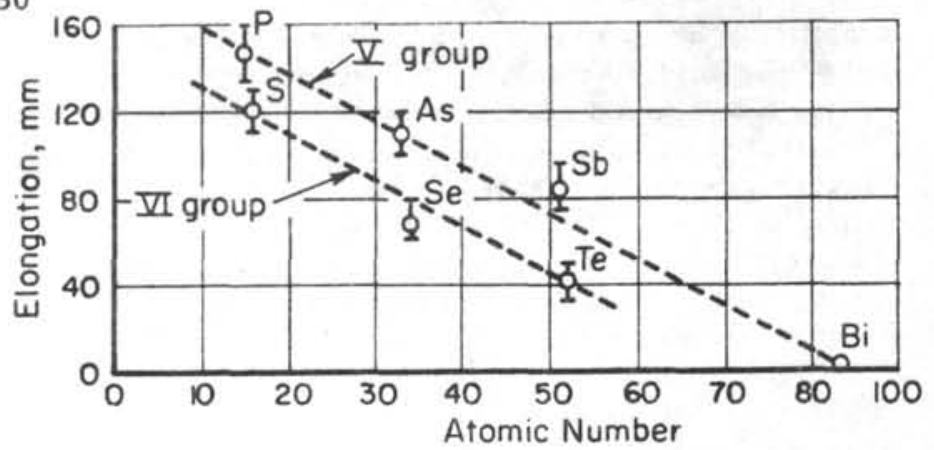

FIGURE 20. LIMITING ELONGATION OF IRON COILS VERSUS ATOMIC NUMBER OF THE ELEMENT USED AS POISON DURING CATHODIC POLARIZATION(125)

TABLE 8. COMPARISON OF THE LIMITING ELONGATION OF IRON COILS WITH THE BINDING FORCE OF THE HYDRIDES(125)

\begin{tabular}{|c|c|c|c|c|c|c|}
\hline Element & $\begin{array}{l}\text { Atomic } \\
\text { Number }\end{array}$ & $\begin{array}{c}\text { Valence } \\
\text { (n) }\end{array}$ & Hyclride & $\begin{array}{c}\text { Binding } \\
\text { Force } \\
\text { Constant } \\
\text { _, dynes } / \mathrm{A}\end{array}$ & $\begin{array}{l}\text { Mear. } \\
\text { Limiting } \\
\text { Elongation, } \\
\mathrm{mm}(\Delta)\end{array}$ & $\begin{array}{c}\text { Elongation } \\
\text { per Atom } H \text {, } \\
\frac{\Delta \ell}{n}\end{array}$ \\
\hline $\mathrm{H}$ & 1 & 1 & $\mathrm{H}_{2}$ & 5.76 & -- & - \\
\hline $\mathrm{N}$ & 7 & 3 & $\mathrm{NH}_{3}$ & 7.00 & - & - \\
\hline o & 8 & 2 & $\mathrm{H}_{2} \mathrm{O}$ & 8.41 & - & - \\
\hline $\mathrm{P}$ & 15 & 3 & $\mathrm{PH}_{3}$ & 3.47 & 148 & 49.3 \\
\hline $\mathrm{s}$ & 16 & 2 & $\mathrm{H}_{2} \mathrm{~S}$ & 4,31 & 121 & 60.5 \\
\hline As & 33 & 3 & $\mathrm{AsH}_{3}$ & 2.91 & 111 & 37.0 \\
\hline Se & 34 & 2 & $\mathrm{H}_{2} \mathrm{Se}$ & 3. 31 & 68 & 34.0 \\
\hline $\mathrm{Sb}$ & 51 & 3 & $\mathrm{SbLH}_{3}$ & 2.26 & 84 & 28.0 \\
\hline $\mathrm{Te}$ & 52 & 2 & $\mathrm{H}_{2} \mathrm{Te}^{\circ}$ & $?$ & 42 & 21.0 \\
\hline $\mathrm{Bi}$ & 83 & 3 & $\mathrm{BiH}_{3}$ & $?$ & 2 & 0.7 \\
\hline
\end{tabular}

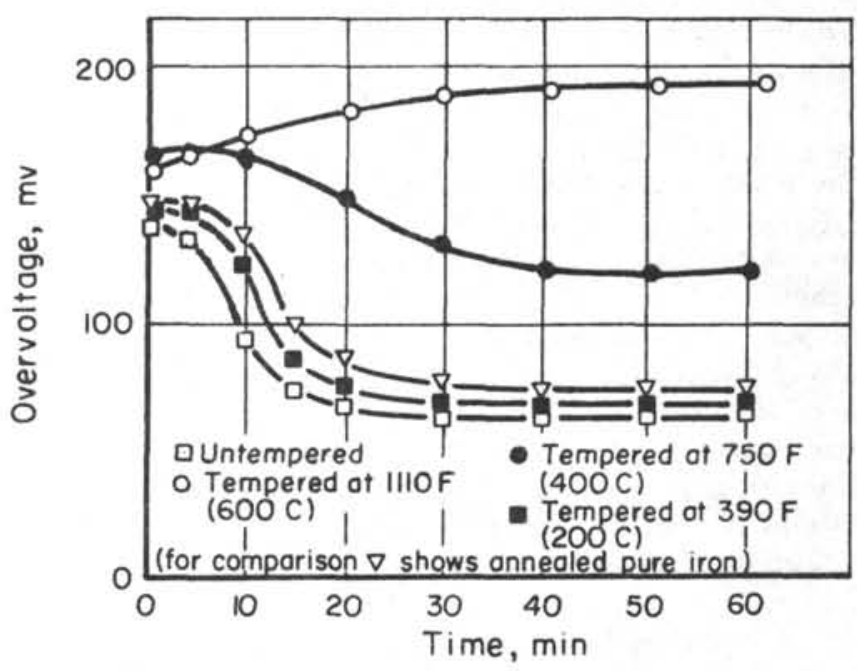

FIGURE 21. OVERVOLTAGE-TIME CURVES AT CONSTANT CURRENT(121)

(Hardened REX 539 steel, acetate buffer $\mathrm{pH} 4.0$, c. d. $0.20 \mathrm{ma} / \mathrm{cm}^{2}$.)

hydrogen absorbed and the cathode overvoltage and, likewise, hydrogen absorption and the log of the current density were linear over the limited range of conditions investigated. 


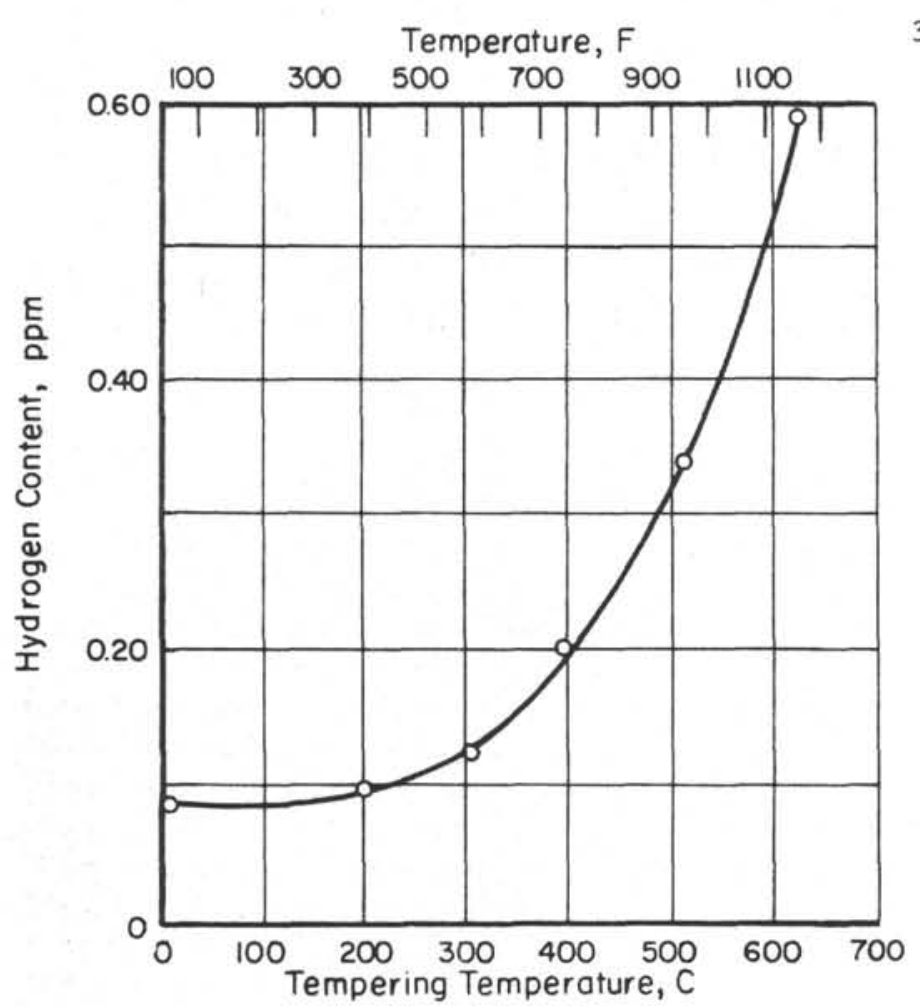

FIGURE 22, EFFECT OF TEMPERING TEMPERATURE ON ABSORPTION OF HYDRO GEN BY HARDENED STEEL(121)

(REX 539 steel, acetate buffer $\mathrm{pH} 4.0$, overvoltage $100 \mathrm{mv}$, charging time $16 \mathrm{hr}$.)

Electroplating. The ductility of steel may be markedly reduced and its propensity toward delayed brittle failure under static load may be markedly increased as the result of an electroplating process. These effects result from hydrogen that is plated concurrently with the metal, part of the hydrogen being absorbed by the steel. This has been a serious problem with high-strength steel parts. The electroplated coating is required for corrosion resistance, yet its application makes the part susceptible to failure by another mechanism - hydrogen cracking. Furthermore, the presence of the plate makes the removal of hydrogen from the steel much more difficult.

Early studies showed that the embrittlement becomes more severe as the hardness level of the steel is increased. $(129,130,131)$ Steel is embrittled by virtually all of the electroplating processes, including cadmium, chromium, zinc, tin, nickel, lead, copper, and silver. $(132-139)$ Hydrogen introduced into specimens during cadmium electroplating may be as high as that introduced through severe cathodic charging. (139) One investigation showed that the delayed-failure behavior was almost identical for commercial cadmium-plated steel and the same steel cathodically charged with hydrogen under a standard charging condition that was much used in studies of hydrogen-induced delayed brittle failure. (140)
31

As a result of these various investigations, it is apparent that sufficient hydrogen is introduced into steel during a commercial-type electroplating process to cause substantial embrittlement and to cause delayed brittle failure of steel under many conditions. Other work has shown that frequently more hydrogen is introduced in acid pickling to remove scale or in cathodic cleaning prior to electroplating than is introduced in electroplating itself. (141)

The method for estimating the hydrogen input to a workpiece during electrolysis that has been used most widely consists of determining the "efficiency" of the plating bath. This is done by measuring the quantity of electricity passed during plating, then using Faraday's laws of electrolysis to determine what weight of metal should have been plated on the cathode. By comparing the weight of metal actually deposited with that predicted by Faraday's laws, a measure of the efficiency of the plating bath being monitored is obtained. Efficiencies of 99.8 percent have been obtained. If it is assumed that the remaining 0.2 percent of the plating current deposits hydrogen instead of metal, it has been calculated that the amount of hydrogen plated at a plating current density of 50 amperes per square foot is approximately $6 \times 10^{17}$ hydrogen atoms per square foot per second. This method suffers from being low in its sensitivity to hydrogen estimation, and other drawbacks have been pointed out by McGraw et al(142) as a result of their study of hydrogen entry into metals during chemical and electrochemical processing.

Some investigators formerly attempted to evaluate hydrogen absorption during plating or the hydrogen remaining after a baking treatment indirectly by its effect on the tensile properties, particularly reduction in area. However, a number of instances have been reported in which hydrogen contents low enough to have no effect on the tensile properties have resulted in delayed brittle failure under static loads. After considerable study, it is now generally agreed that the sustained-load test of notched specimens is the only satisfactory mechanical test for evaluating hydrogen absorption. The common method of applying the test is to subject plated notched specimens to stresses of 70 to 90 percent of the notched tensile strength of unplated specimens for 100 hours or more. Rupture within 100 hours is generally taken as being indicative of embrittlement problems. However, brittle failures have occurred in triaxially stressed, cold-worked, plated test samples after 13,000 hours. (87) Thus, even this test is not sensitive enough or fast enough to be completely satisfactory for evaluating the absence of excess hydrogen in processed parts. These aspects have been discussed more fully in the section on test methods in a previous report by the present authors (DMIC Report No. 196).

Some very precise information on the entry and permeation of hydrogen through steels in contact with liquid media has been obtained using mass 
spectrometers to count the ions of hydrogen as they are desorbed by the surface of the steel not in contact with the liquid. $(91,46)$ However, the elaborate apparatus and the highly trained scientists required prohibit using this method to monitor plating lines. Use of the metal vacuum tube as a means of monitoring hydrogen, particularly when. the recently developed active system $(87)$ is employed, offers considerable promise for monitoring plating lines. The technique has been discussed a little more fully in a previous section of this report.

Lawrence(87) used the metal vacuum tube in an active system as a means of monitoring hydrogen absorption during the entire plating procedure. The results obtained with this hydrogen-detection gage were used to alter materially the lowembrittlement cadmium-plating process for highstrength steel. It was found that the rinses following pickling or plating added considerable extra hydrogen to the plated parts. The new process now requires that the parts be rinsed in overflow tanks, the rinse water being changed at least once each hour. A reduction of more than a factor of a thousand in hydrogen input rate during the plating process itself was achieved by lowering the voltage across the plating tank to 1 volt maximum. This was done with no decrease in cathode current density by raising the anode-to-cathode surface-area ratio to $6: 1$, and by keeping the anode-to-cathode distance small. By keeping sulfide concentration in the bath to a minimum of less than $1 \mathrm{ppm}$, both hydrogen sorption rates and sulfide stress corrosion were reduced greatly (sulfide is believed to be the most potent cathodic poison of the hydrogen recombination reaction). Deionized water with $0.5 \mathrm{ppm}$ maximum impurity content is required both for rinses and for the plating solution. The porosity of the plating is judged both by observing the hydrogen sorption rate during plating and by leaving the plated tube in the plating solution after the plating current has been turned off. With porous plating, hydrogen input does not cease with current shut off. Because of the cadmium-iron galvanic cell, the presence of the electrolyte provides the proper coupling so that the cadmium dissolves and is replaced by hydrogen from the solution. With nonporous plating, the hydrogen input rate is so low that it is difficult to detect even with this sensitive hydrogen-detection gage.

It has been widely recognized for a decade now that hydrogen-induced delayed brittle failure, as a potential source of fallure of steel, is a serious problem. Failures most frequently occur under sustained-load conditions at locations where stress concentrations exist, and they may occur at stresses far below the yield strength of the material. Electroplating processes are recognized as being the most common source of this detrimental hydrogen, and cadmium electroplating processes are considered to be among the worst offenders. Hydrogen cracking became a serious problem when steels were first used in aircraft at tensile strength levels above about 200,000 psi, for structural parts such as landing gear and fasteners. Steels are used now at strengths up to at least $280,000 \mathrm{psi}$, and further increases in strength are anticipated. A few years ago, the Air Force found it necessary to prohibit cadmium electroplating of certain steels having strengths greater than 220,000 psi. Thus, it was necessary for manufacturers to resort to other methods of providing corrosion protection that were inferior to cadmium electroplating in this respect. Therefore, many studies of cadmium electroplating processes were carried out to determine if one or more could be used safely for electroplating ultrahigh-strength steel. The reader is directed to References (143), (144), (145), (146), and (147) for descriptions of some of the se studies.

Among the cadmium electroplating baths studied were the conventional cadmium cyanide plating bath with and without brightener, the highefficiency cyanide plating bath with and without brightener, the cadmium fluoborate plating bath with various grain refiners and with none at all, and the cadmium sulfamate plating bath containing various grain refiners. Reference is made to the work of Geyer, Lawless, and Cohen $(145,146)$ to illustrate some of the results obtained. They used notched specimens of SAE 4340 steel heat treated so as to have an average notched tensile strength of $435,000 \mathrm{psi}$. All unplated specimens withstood 300,000 psi for 400 hours without failure, and the single specimen loaded at 400,000 psi withstood 100 hours without failure. A maximum applied stress of 300,000 psi was arbitrarily selected as the basis for a test used to determine if any detrimental hydrogen embrittlement had occurred in the plated specimens. A criterion was established that if one specimen of a group failed, then the entire group would be considered as having failed. All plated specimens were baked at $375 \mathrm{~F}$, generally for 23 hours, prior to testing.

Detrimental hydrogen embrittlement was obtained from the conventional cyanide bath, as was expected. Most specimens failed to sustain even 220,000 psi. At least one specimen from each group plated in the fluoborate bath failed. No detrimental hydrogen embrittlement occurred when the high-efficiency cyanide bath was used without a brightener. Since the coating was granular in appearance, a brightener was added to the bath to improve the surface finish. It was shown previously that this bath with a brightener had a higher cathode current efficiency than the bath without a brightener. However, specimens plated with the brightener failed in the sustained-load test, so efficiency was not the controlling factor. It appeared that the significant difference in these two deposits with respect to hydrogen embrittlement was in the physical structure of the cadmium electrodeposits. Granular deposits have greater porosity than smooth deposits, thereby allowing the hydrogen to be driven out to a greater extent during the baking treatment after plating. No failures occurred in 
1150 hours at 300,000 psi for specimens plated in the cadmium sulfamate bath with standard catechol grain refiner. However, the deposit was coarse grained and it was necessary to add additional grain refiners. When this was done, all specimens failed in 73 hours or less, even though the bath operated at approximately 100 percent cathode current efficiency over the entire plating range of current density, either with or without the additional grain refiners. Therefore, the pronounced differences in hydrogen embrittlement obtained with this bath were attributed solely to differences in the structures of the electrodeposits. Thus, it was shown that residual detrimental hydrogen embrittlement obtained from a cadmium electroplating bath is a function of cathode efficiency, which controls the entry of hydrogen, and of the structure of the coating, which controls the rate of removal of hydrogen during the postplating baking treatment.

A specimen coated with cadmium from a proprietary cadmium immersion solution (nonelectrolytic) failed after only 46 hours when stressed at 300,000 psi.

Four specimens were coated commercially with cadmium by a vacuum-metallizing technique. All withstood 300,000 psi for 300 hours without failure. Then three of them were exposed to salt fog for 192 hours, which resulted in light rusting. They again sustained a load of 300,000 psi for 300 hours without failure. The sustained-load test after exposure to salt fog was performed to determine if any detrimental hydrogen embrittlement resulted from the corrosion, since cadmium, being anodic to steel, would result in release of hydrogen at the cathodic areas during the corrosion process.

To determine whether cadmium is a barrier to hydrogen penetration, Geyer, Lawless, and Cohen took one of the specimens that had been vacuum metallized with cadmium and had been loaded ior 300 hours at 300,000 psi without failure and subsequently electroplated it with cadmium from the fluoborate bath. The specimen was not baked after plating and broke upon loading to $300,000 \mathrm{psi}$. It was concluded that the vacuum-metallized cadmium did not serve as a barrier to hydrogen.

Apparently, cadmium can serve as a barrier to hydrogen in some instances. Perhaps this depends on the structure of the cadmium coating. Elsea and co-workers(148) performed an experiment to study the effect of cadmium plate on the absorption of hydrogen by steel during cathodic charging. A tubular specimen was cadmium plated on the exterior surface only and then was baked at $340 \mathrm{~F}$ to remove the hydrogen introduced by plating. Cathodic charging of this specimen for 24 hours with the poisoned sulfuric acid electrolyte in contact only with the cadmium-plated surface resulted in no measurable accumulation of hydrogen within the specimen. In another experiment,(118) a cadmium plate approximately 0.0003 inch thick was electrodeposited on the entrance side of permeability specimens. Both the cyanide and the fluoborate plating processes were used, and several specimens of each type of plate were tested. Without exception, when the cadmium plate was on the entrance surface or electrolytic cell side, there was no absorption of hydrogen, not even after several hours of charging with current densities of 10 to several hundred ma/in. 2 with the poisoned 4 percent sulfuric acid electrolyte, or $500 \mathrm{ma} / \mathrm{in} .2$ with the sodium hydroxide electrolyte. The behavior was the same whether the cadmium plate was applied by the cyanide or the fluoborate process. Thus, hydrogen did not diffuse through a cadmium plate at temperatures close to room temperature. Other investigators have shown that the dense cadmium plate that has been used widely for corrosion protection of high-strength steel parts markedly hinders effusion of hydrogen, and low hydrogen contents are not obtained by aging at room temperature or at the elevated temperatures normally used for baking treatments (about 375 F). However, a suitable porous cadmium plate permits hydrogen effusion while still providing appreciable corrosion protection.

Somewhat along the same line, investigators at Case Institute of Technology developed a cadmium electroplating procedure that consisted of plating a flash of cadmium on the specimen, baking to remove the hydrogen (which they claimed was feasible through such a thin cadmium layer), then plating to build the cadmium plate up to the desired thickness. This method did not provide complete insurance against failures and apparently has not been adopted commercially.

Beck and Jankowsky(147) investigated the effectiveness of Watts-type bright nickel and pyrophosphate copper (both electroplated coatings) as undercoats in minimizing the embrittlement induced by overplating with cyanide cadmium or conventional chromium electroplates. Both undercoats resulted in some decrease in the susceptibility to delayed failure under sustained load when the undercoats were thick enough. Since other workers purportedly have shown recently that neither hydrogen atoms nor protons diffuse through thin nickel layers, Beck and Jankowsky concluded that the beneficial effect of nickel and other metallic undercoats is the result of their action as diffusion barriers, and barrier effectiveness apparently is related to the thickness of the undercoat. They suggested that deficiencies in effectiveness of the barrier coating, as revealed by the sensitive delayedfailure test, is the result of plating imperfections.

The present authors have observed that a nickel flash (applied chemically to the entrance surface), such as is used in preparing a surface for vitreous enameling, resulted in very low, but measurable hydrogen permeation rates. However, when the nickel-flashed specimen was baked for several hours at $375 \mathrm{~F}$ prior to the permeation 
experiment, rather high permeation rates were obtained through the enameling iron.

\section{Other Means of Hydrogen Entry}

High hydrogen concentrations can be obtained in steel from the various reactions listed above. In addition, there are several other ways in which hydrogen can enter steel.

Exposure of steel to high-pressure hydrogen, especially at slightly elevated temperatures, or heating steel in hydrogen at lower pressures but at high temperatures introduces hydrogen into the steel because some dissociation of the molecular hydrogen occurs under these conditions.

In pressure charging, the pressure of hydrogen is the driving force for hydrogen entry into steel. In general, the rate at which a gas passes through a diaphragm is greater, the greater the pressure on the inlet side or the greater the difference in pressure between the inlet and outlet sides. Since gases dissolve in metals as atoms, not molecules, the rate is expected to be proportional to the square root o the pressure (at least for pressures low enough that the ideal gas laws are obeyed). This is well established for hydrogen in iron at elevated temperatures, as has been discussed previously. Hill and Johnson, (13) using the pressure-charging method, obtained solubilities of hydrogen in $\alpha$-iron at 100-atmospheres pressure of hydrogen gas as follows:

\begin{tabular}{|c|c|c|}
\hline \multicolumn{2}{|c|}{ Temperature } & \multirow{2}{*}{$\begin{array}{l}\text { 100-Atmosphere } \\
\text { Solubility, ppm }\end{array}$} \\
\hline $\mathrm{C}$ & $F$ & \\
\hline 585 & 1085 & 10.98 \\
\hline 538 & 1000 & 8.08 \\
\hline 490 & 914 & 6.13 \\
\hline 390 & 734 & 3. 44 \\
\hline 290 & 554 & 3.19 \\
\hline 210 & 410 & 2. 36 \\
\hline 145 & 293 & 1.57 \\
\hline
\end{tabular}

Other investigators recently reported the embrittlement of heat-treated 0.7 percent carbon steel by an external hydrogen atmosphere at room temperature. (149) Exposure of bars to hydrogen at 1,990 psi hardly affected the tensile strength, but the reduction in area became almost nil and the notch tensile strength $(0.0028$-inch notch radius) was reduced by 50 percent.

Actually in pressure charging and in thermal charging in a hydrogen-bearing atmosphere as well, the driving force is the partial pressure of dissociated (atomic) hydrogen. Hydrogen dissociates according to the reaction, $\mathrm{H}_{2} \longrightarrow 2 \mathrm{H}$, and it is the dissociated part of the gas that controls its solubility in metals. Because this dissociation produces an increase in volume, the reaction is pressure sensitive; increased pressure reduces the degree of dissociation. In effect,
Sievert's law states that although the total number of hydrogen molecules present in a given volume increases directly as the pressure, the number of dissociated atoms increases only as the square root of the pressure.

Relatively little work has been done to determine the effect of elevated pressures on the permeation of hydrogen through steel, through its effect on the entry process. Conflicting results are found in the intormation that has been published. Baukloh and Guthmann(150) found that the hydrogen permeation rate at constant temperature for various steels increased linearly with the square root of the hydrogen partial pressure up to 40 to 100 atmospheres, and then it became virtually constant. At low pressures, well below 1 atmosphere, the results departed from the linear relationship, as has been observed by most investigators. On the other hand, Naumann(151) investigated the permeation of hydrogen through several steels at pressures up to 1000 atmospheres over a wide temperature range and found a linear relationship between permeation rate and the square root of the pressure up to the highest pressure investigated (except for the deviation at very low pressures).

Smithells and Ransley (71) studied the "diffusion" of hydrogen through iron as a function of pressure (pressure charging in the pressure range from 0.094 to $142 \mathrm{~mm} \mathrm{Hg}$ ) at two temperatures, 775 and $1339 \mathrm{~F}$ (686 and $999 \mathrm{~K})$. Their plot of rate of "diffusion" as a function of the square root of the pressure is shown in Figure 23. Although they called the effect diffusion, they actually were considering permeation and not diffusion through the bulk material, since surface variations markedly affected the results under some conditions. Their permeation values represented the volume of gas in $\mathrm{cm}^{3}$ at STP passing per second through $1 \mathrm{sq} \mathrm{cm}$ of surface of $1-\mathrm{mm}$ thickness. At the higher pressures in the range studied, the observed data lay on straight lines; however, there was a definite departure from this relation at low pressures, where the rate of permeation was less than that required by the Richardson equation for permeation, P:

$$
P=k \sqrt{ } \text { P. }
$$

The straight-line portions of the curves, if extended, cut the $\sqrt{ } \mathrm{p}$ axis at small positive values corresponding to the "threshold" values (below which diffusion did not occur) described previously by Borelius and Lindblom. (72) However, Smithells and Ransley found that this threshold does not exist because some permeation was observed at lower pressures. According to these investigators, all published data at the time exhibited the same deviation.

Smithells and Ransley then studied the effect on hydrogen entry of gas adsorbed on the surface of the iron. They considered that at low pressures 


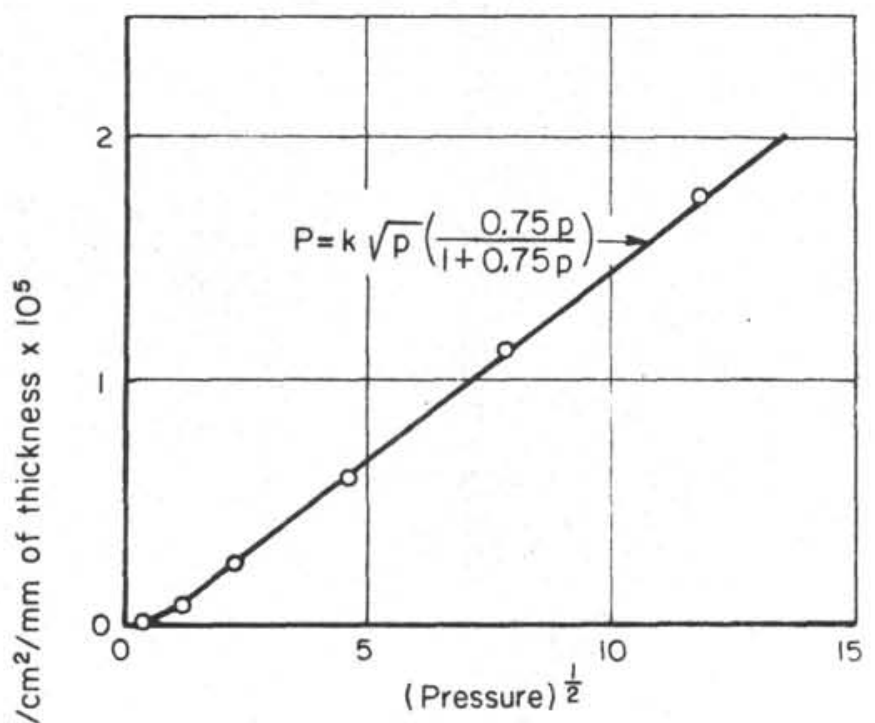

a. $775 \mathrm{~F}(686 \mathrm{~K})$.

है

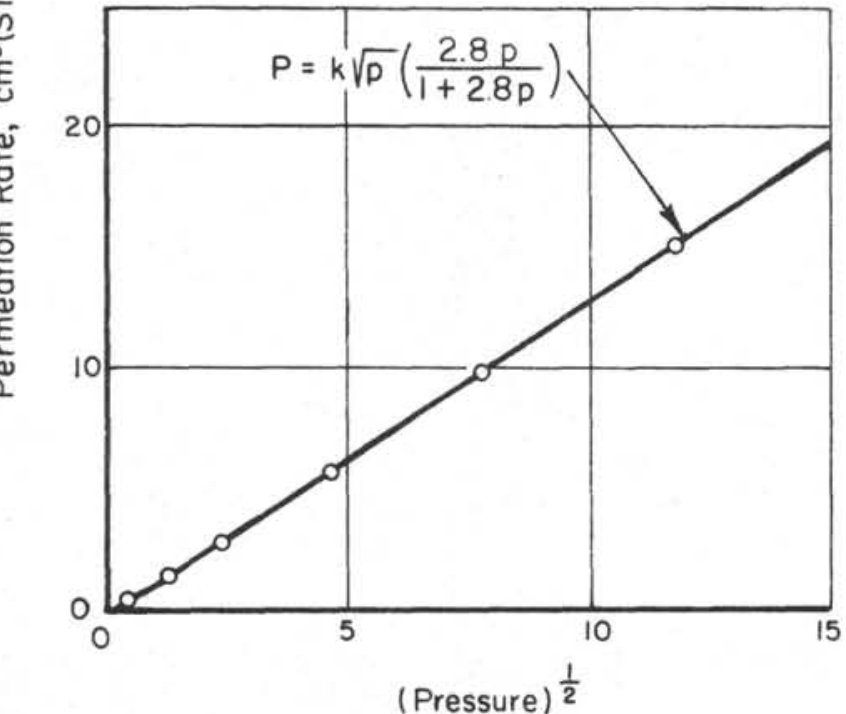

b. $1339 \mathrm{~F}(999 \mathrm{~K})$.

FIGURE 23. PERMEATION OF HYDROGEN THROUGH IRON (ETCHED SUR FACE)(71)

(Note change in the ordinate scales for the two figures by a factor of 10.)

and at temperatures where "diffusion" (permeation) could be measured, the amount of adsorbed gas is usually only a small fraction of a unimolecular layer. Therefore, at any given instant, hydrogen can enter only through those parts of the surface that are covered by adsorbed gas, the effective area of the metal surface being $\theta x$, where $x$ is the total area of the surface and $\theta$ is the fraction of the surface covered by adsorbed hydrogen. They introduced the concept that as the pressure, p, increased, $\theta$ increased according to the equation

$$
\theta=\frac{\text { ap }}{1+\text { ap }} \text {, }
$$

where a is a constant for a gas-metal system. Thus, at low pressures, $\theta$ increases rapidly and at high pressures it approaches unity. Introducing this adsorption isothe $\mathrm{rm}$ into the permeation equation (for constant temperature) gave

$$
\mathrm{P}=k \sqrt{\mathrm{p}}\left(\frac{\mathrm{ap}}{1+\mathrm{ap}}\right) .
$$

At high pressures, the term in parentheses approaches unity and the equation approximates Equation 28. According to this equation, the rate of permeation would fall off at low pressures in the manner observed experimentally by a number of workers. Published permeation-rate data for several metals were plotted against the square root of pressure. Then, the curve for Equation 30 was drawn in after selecting suitable values for the constants $\mathrm{a}$ and $\mathrm{k}$. The results Borelius and Lindblom obtained for iron at four temperatures have been treated in this way in Figure 24. The experimental points of Borelius and Lindblom are well represented by Smithells and Ransley's Equation 30.

Bryan and Dodge(49) studied the permeation rate of hydrogen in a highly purified iron (Ferrovac E) by maintaining a constant pressure of hydrogen inside a tubular specimen placed in an evacuated jacket and measuring the increase of pressure in the jacket. Permeation was studied for various pressures over the range from $1 / 30$ to 300 atmospheres and for temperatures over the range from 259 to $1279 \mathrm{~F}$ (126 to $693 \mathrm{C}$ ). Although the generally accepted equations for solubility, diffusivity, and permeability indicate that all three properties vary as the square root of the pressure, Bryan and Dodge presented evidence that at high pressures the pressure should be replaced by the fugacity. They found that the permeation rate was linear with the square root of the fugacity rather than of the pressure, although the difference was not very great at the maximum pressure they used. These results are shown in Figures 25 and 26.

The dissociation of hydrogen is strongly endothermic. Therefore, dissociation is promoted by high temperatures, and this is the basis of thermal charging. Giauque(152) used spectrographic data to calculate the dissociation values of hydrogen for various temperatures, shown in Table 9. Although the dissociation is very small at room temperature, it becomes appreciable at steelmaking temperatures (about $2900 \mathrm{~F}$ ). In the electric arc, hydrogen may be highly dissociated. Thermal charging is more effective if it is carried out in wet rather than dry hydrogen.

Both pressure charging and thermal charging with hydrogen have been discussed in more detail in another report dealing with the effects of hydrogen on steel at elevated temperatures and pressures (DMIC Report No. 202).

For some metals, hydrogen has been introduced by cyclotron proton irradiation. Exposure 


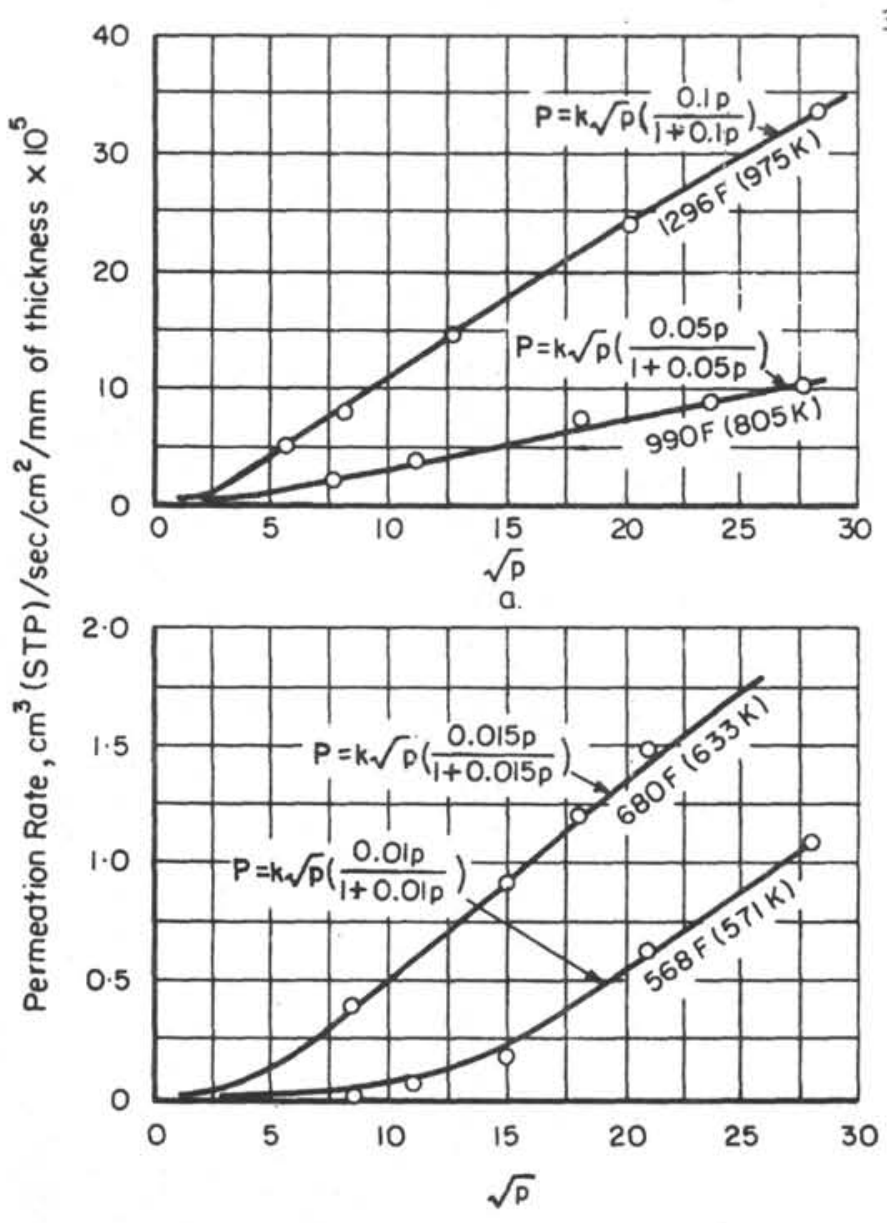

b.

FIGURE 24. PERMEATION OF HYDROGEN

THROUGH IRON, SHOWING SMITHELLS AND RANSLEY'S EQUATION APPLIED TO BORELIUS AND LINDBLOM'S DATA POINTS(71)

(Note that the permeation scales in $\mathrm{a}$ and $\mathrm{b}$ differ by a factor of 20.)
36

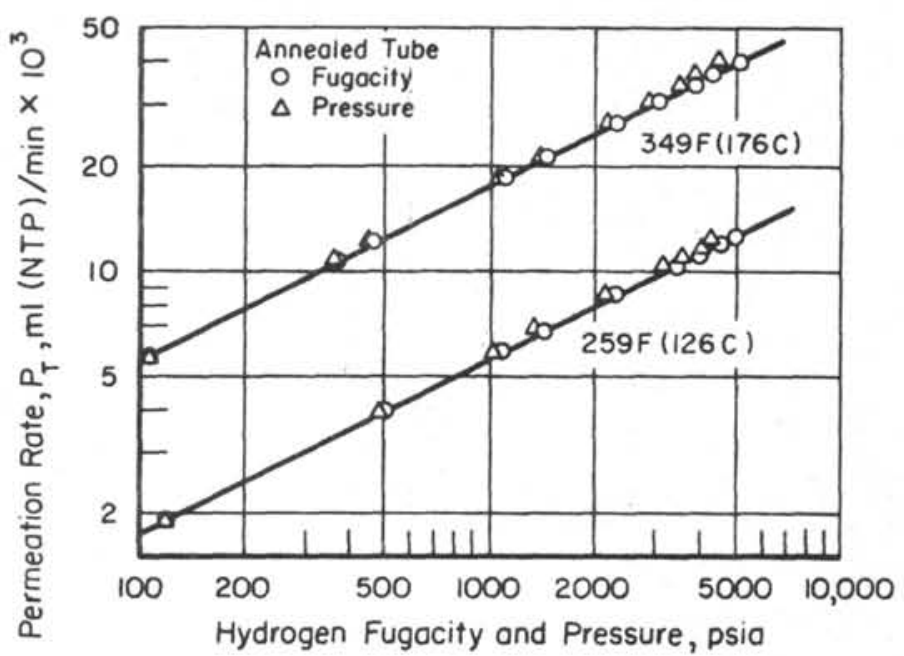

FIGURE 25. LOGARITHMIC PLOT OF PERMEATION RATE VERSUS PRESSURE AND FUGACITY, RUNS 103-121(49)

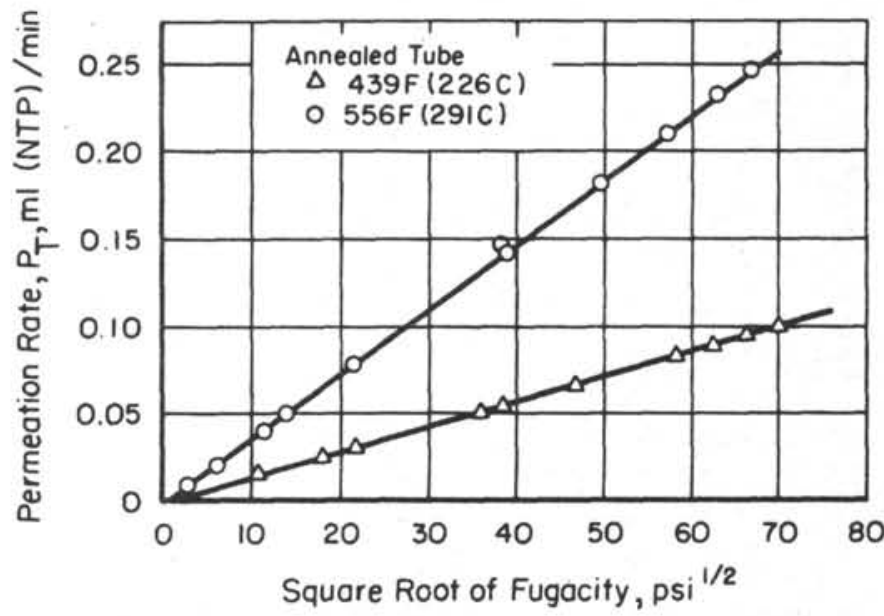

FIGURE 26. PERMEATION RATE VERSUS SQUARE ROOT OF FUGACITY, ANNEALED TUBE, RUNS 103-121(49)

TABLE 9. DISSOCLATION CONSTANTS FOR H $2=2 \mathrm{H}$ (AFTER GIAUQUE) $^{(152)(\mathrm{a})}$

\begin{tabular}{|c|c|c|c|c|}
\hline \multicolumn{3}{|c|}{ Temperature } & \multirow{2}{*}{$\mathrm{K}=\frac{\left(\mathrm{P}_{\mathrm{H}^{\prime 2}}\right.}{\mathrm{P}_{\mathrm{H}_{2}}}$} & \multirow{2}{*}{$\begin{array}{l}\text { Percent Dissociation } \\
\text { at } 1 \text { Atmosphere }\end{array}$} \\
\hline $\mathrm{K}$ & $\mathrm{C}$ & $\bar{F}$ & & \\
\hline 298 & 25 & 77 & 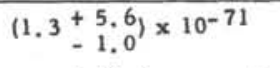 & $(1.8+2.4) \times 10^{-34}$ \\
\hline 500 & 225 & 435 & $\begin{array}{c}\left(7.7^{+13.5}\right) \times 10^{-41} \\
-4.9\end{array}$ & 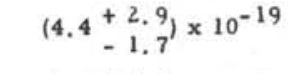 \\
\hline 1000 & 725 & 1335 & $(6.5+4.3) \times 10^{-18}$ & $(1.3 \pm 0.4) \times 10^{-7}$ \\
\hline 1500 & 1225 & 2235 & $(3.6 \pm+1.4) \times 10^{-10}$ & $(9.5+1.7) \times 10^{-4}$ \\
\hline 2000 & 1725 & 3135 & $\begin{aligned}(2.97 & +0.85 \\
& -0.66\end{aligned}$ & $\begin{aligned} 0.086 & +0.011 \\
& -0.010\end{aligned}$ \\
\hline 2500 & 2225 & 4035 & $\begin{array}{c}\left(6.93^{+1.54}-1.27\right. \\
-1.27\end{array}$ & $\begin{array}{r}1.32+0.14 \\
-0.13\end{array}$ \\
\hline 3000 & 2725 & 4935 & $\begin{aligned}(2.66 & +0.49) \times 10^{-2} \\
& -0.41\end{aligned}$ & $\begin{array}{r}8.1+0.7 \\
-0.6\end{array}$ \\
\hline 3500 & 3225 & 5830 & 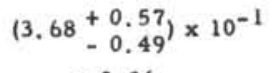 & $\begin{array}{r}29.0+2.0 \\
-1.8\end{array}$ \\
\hline 4000 & 3725 & 6740 & $2.68+0.36$ & $63.3+2.4$ \\
\hline 5000 & 4725 & 7630 & $\begin{array}{r}43.6+4.7 \\
-4.1\end{array}$ & $95.7+0.4$ \\
\hline
\end{tabular}

(a) Giauque made an error in calculating the precision of both the values of the equilibrium constant and the percent dissociation. The present authors have recalculated the values representing the precision, using Giauque's tabulated data, and these new values have been used in this table. 
to suitable flames is another method. Also, hydrogen has been charged into iron by glow discharge from a hydrogen atmosphere ionized by a directcurrent potential. $(153,154,155)$

Also, especially for heavy sections, hydrogen introduced during steelmaking operations may be a factor in delayed failures unless suitable vacuum processing has been used to minimize hydrogen pickup from such sources as water in the charge and in the refractories, including the ladle lining. Other sources of hydrogen during steelmaking are the scrap, hot metal, ferroalloys, and slag-making constituents. In fuel-fired melting furnaces, such as the open-hearth furnace, hydrogen and hydrocarbon gases usually are present in the furnace atmosphere. However, the most common source of hydrogen in liquid steel is water vapor which comes in contact with the liquid steel after it has been deoxidized.(156) This water vapor can originate in the air, furnace atmosphere, refractories, and slags. Thus, appreciable quantities of hydrogen are present in virtually all steel poured unless it is properly vacuum processed. Measures taken to minimize hydrogen defects include drying of raw materials (including slagmaking materials); careful drying of refractories in runners, ladles, and modes; and slow cooling and annealing of semifinished steel products. The use of oxygen during melting helps eliminate hydrogen. Today, considerable quantities of steel for high-strength applications are melted by the consumable-electrode vacuum-melting process, and these steels are virtually free of hydrogen in the ingot stage. Also, steel in thin sections loses hydrogen at an appreciable rate upon storage, so long as additional hydrogen is not being introduced by a corrosion process. However, hydrogen which enters the steel during melting can be held effectively in massive sections because the diffusion path to the surface is long. The hydrogen content in liquid low-alloy steel at the time of tapping may range from less than $1 \mathrm{ppm}$ to at most 10 to $12 \mathrm{ppm}$; frequently the content is 4 to $6 \mathrm{ppm}$. Using the procedures listed above, the amount of hydrogen present may be limited to the extent deemed necessary.

Hydrogen also can be introduced into steel during heat-treating operations, although it is more likely that solid steel will absorb hydrogen from the steam reaction $\left(\mathrm{Fe}+\mathrm{H}_{2} \mathrm{O} \longrightarrow \mathrm{FeO}+2 \mathrm{H}\right)$ than from dissociation of molecular hydrogen gas.

For careful processing to minimize the hydrogen content of steel, the heat-treating atmosphere should not be conducive to hydrogen pickup from the steam reaction. Therefore, the watervapor content should be low; also, the partial pressure of hydrogen should be low. It will be remembered that treatment at elevated temperatures in a wet-hydrogen atmosphere is one method used to intentionally introduce hydrogen into steel. Frequently, a dry argon atmosphere is used in laboratory investigations. No acid pickling, cathodic cleaning, or electroplating operations can be tolerated, as these operations usually introduce hydrogen into steel. Vapor honing introduces more hydrogen into steel than does dry honing. Abrasion can introduce hydrogen into steel from water vapor in the air or from a cutting fluid. Also, the part must be protected from corrosion, including protection from rusting in moist air.

\section{Effects of Surface Treatments and Environment}

If the entry of hydrogen, rather than diffusion, is the controlling factor in permeation of hydrogen through steel, as appears to be the case under most conditions, then variations in the nature of the steel surface will influence hydrogen permeation.

It is well known that the specific surface of an adsorbent is usually larger than the measured projected surface; early estimates indicated that the two areas differ by a factor in the range of 1. 5 to 20. Roughening the surface by etching or by alternate oxidation and reduction increases the area available for adsorption and also increases the proportion of the surface that is active. Thus, such treatments should affect the rate of permeation of hydrogen through steel at low pressures, and experiments have shown that this is so.

Smithells and Ransley(71) early studied the effects of such treatments on iron and nickel, and the results for iron are summarized as follows:

\begin{tabular}{|c|c|c|c|c|}
\hline Treatment & $\frac{\text { Temp }}{K}$ & $\frac{\text { ature }}{F}$ & $\begin{array}{l}\text { Hydrogen } \\
\text { Pressure, }\end{array}$ & $\begin{array}{c}\text { Hydrogen } \\
\text { Permeation Rate, } \\
\mathrm{cm}^{3} / \mathrm{sec} / \mathrm{cm}^{2(a)}\end{array}$ \\
\hline Polished & 673 & 752 & 0.77 & $0,47 \times 10^{-7}$ \\
\hline Etched & 673 & 752 & 0.77 & $4.4 \times 10^{-7}$ \\
\hline Polished & 863 & 1094 & 0.073 & $1.28 \times 10^{-7}$ \\
\hline $\begin{array}{l}\text { Oxidized and reduced } \\
\text { at } 1110 \mathrm{~F}(600 \mathrm{C})\end{array}$ & 863 & 1094 & 0.073 & $0.76 \times 10^{-7}$ \\
\hline $\begin{array}{l}\text { Further reduced at } \\
1470 \mathrm{~F}(800 \mathrm{C})\end{array}$ & 863 & 1094 & 0.073 & $1.54 \times 10^{-7}$ \\
\hline
\end{tabular}

The oxidation was accomplished by introducing a small amount of oxygen into the permeation apparatus and heating the tubular specimen to form a thin oxide film. In the case of iron, great difficulty was experienced in removing the adsorbed oxygen, even when the specimen was heated in hydrogen at $1110 \mathrm{~F}(600 \mathrm{C})$, and the adsorbed oxygen reduced the rate of permeation. Such an oxidation-andreduction treatment doubled the hydrogenpermeation rate of nickel as compared to a polished surface. Removal of the adsorbed oxygen from the iron by a special treatment at $1470 \mathrm{~F}$ (800 C) resulted in a higher permeation rate than was obtained for the polished tube. Etching a polished surface with acid had a far more marked effect, increasing the permeation rate by a factor of 10 . 
That this etching increased the absorption of hydrogen into the specimen was indicated by a much larger value of the constant a in Equation 30 that was obtained for etched surfaces. This behavior also is shown by comparing Figures 23 and 24 .

The present authors have observed that variations in the mechanical preparation of the surface (for example, grit blasting, vapor blasting, surface grinding, mechanical polishing, or electropolishing) can affect the hydrogen permeation rate considerably. At least a portion of this effect is undoubtedly the result of variations in surface roughness and, hence, gross surface area. However, the data obtained suggest that other factors also are involved, as the hydrogen entry rate was not always directly related to surface roughness.

Surface treatments such as activation or poisoning that are accomplished by exposure to suitable environments are known to affect adsorption, and hence hydrogen entry. Consequently, they affect hydrogen permeation, too. As was discussed in detail in a previous section, chemisorbed films of inhibitors or cathodic poisons can greatly reduce or increase the rate of hydrogen entry, respectively. Inasmuch as the effects of cathodic poisons, the nature of the electrolyte, and variations in current density are of major importance in the introduction of hydrogen into steel by cathodic charging, they have been discussed previously in the section dealing with cathodic charging. The effect of the environment on the entry of hydrogen also was discussed in the sections dealing with acid pickling and with other corrosion processes. The presence of moisture often is a factor; for example, thermal charging with hydrogen is much more effective when it is carried out in wet rather than dry hydrogen.

Recent laboratory work by Hudson and coworkers $(81)$ concerning the influence of oxidizing and other environments on the rate of desorption of hydrogen from steel that had been precharged with hydrogen showed that environmental conditions have considerable influence on the rate of desorption, and hence, on the permeation rate as well. This will be discussed more fully in a subsequent section dealing with the removal of hydrogen from steel.

Cold work can have a large effect on hydrogen permeation through steel. One might expect that part of the differences in permeation rate observed for different methods of mechanical surface treatment would be the result of differences in the depth of the thin cold-worked layer that most of them produce at the steel surface. However, since the effect of cold work on hydrogen permeation through iron and steel results primarily from its influence on hydrogen diffusion and the trapping of hydrogen inside the steel, rather than an effect on hydrogen entry, it will be discussed in the next section of this report, the one dealing with diffusion.
Diffusion

Most of the current theories of hydrogen embrittlement and hydrogen-induced delayed brittle failure of steel depend on diffusion of hydrogen in one way or another. Proper testing of these theories can only be accomplished when the diffusion process itself is properly understood. Although much work has been done recently on the diffusion of hydrogen in steel, the phenomenon still is not completely understood, and certain apparent discrepancies remain to be resolved. Unfortunately, as far as an understanding of delayed hydrogen cracking of steel is concerned, most of the serious discrepancies have been encountered at the lower temperatures in the vicinity of room temperature. The fact that relatively good agreement is beginning to be achieved for measurements in the general vicinity of room temperature would seem to indicate that there is hope of being able to treat the problem of hydrogen in steel from a scientific standpoint before long.

As was discussed previously, the entry and diffusion of hydrogen in metals occurs as atoms dissociated from the molecule, or perhaps as positively charged ions (protons) as suggested by Barrer(157) or partially shielded protons as suggested by Bastien. (8) In any event, molecular hydrogen $\left(\mathrm{H}_{2}\right)$ does not diffuse in metals, nor do the molecules of any of the other diatomic gases. The chief evidence supporting this conclusion is the experimental finding that the rate of permeation of a diatomic gas through a metal under steadystate conditions generally is proportional to the square root of the pressure. This would be expected if the diffusion through the bulk solid were due solely to the movement of atoms, as follows from the equilibrium relationship

$$
\mathrm{K}=\frac{\mathrm{P}_{\mathrm{H}}}{\sqrt{\mathrm{P}_{\mathrm{H}_{2}}}}
$$

where $\mathrm{K}$ is the equilibrium constant of the dissociation reaction $\left(1 / 2 \mathrm{H}_{2}=\mathrm{H}\right)$, and $\mathrm{pH}$ and $\mathrm{pH}_{2}$ are the partial pressures of atomic and molecular hydrogen, respectively. The experimentally demonstrated exponential relationship between permeation and temperature also indicates the importance of dissociation into atoms. This is the effect one would expect if the rate-controlling process were an activated adsorption on the surface that resulted in some dissociation. Additional evidence is the observation that nascent hydrogen will diffuse in a metal against a high pressure of molecular hydrogen.

Apparently St. Claire Deville and Troost in 1863 were the first to observe that hydrogen diffuses through solid steel. The diffusivity of hydrogen depends upon the temperature, the nature of the steel, and the amount of hydrogen present in the steel at the time. The driving force for diffusion of hydrogen in steel can be either a hydrogenconcentration gradient or a stress gradient. Most 
diffusion processes occur in response to a concentration gradient. However, it was shown in studies of hydrogen-induced delayed brittle failure of steel that hydrogen also can diffuse in responsc to a stress gradient. For example, in a region of uniform hydrogen content, hydrogen can diffuse to the region of maximum stress just in front of a crack tip in a part under load. This has been discussed more fully in DMIC Report No. 196.

\section{Effect of Temperature}

The values of permeability, solubility, and diffusivity are consistent with the relationship $\mathrm{P}=\mathrm{S} \cdot \mathrm{D}$ at elevated temperatures, but discrepancies arise at lower temperatures. Also, what appear to be anomalously low values of diffusivity are obtained at the lower temperatures, so diffusion in the two temperature ranges will be discussed separately.

Elevated Temperatures. The effect of temperature on the rate of diffusion can generally be expressed by

$$
D=k \cdot e^{-Q / R T} \text {, }
$$

where $\mathrm{T}$ is the absolute temperature in degrees Kelvin, Q is the activation energy (calories per gram mole) necessary for diffusion, $R$ is the gas constant ( 1.987 for the units given), and $k$ is a constant. With these units, the diffusion coefficient $D$ has the units $\mathrm{cm}^{2} / \mathrm{sec}$. Since this theoretical equation linking diffusivity and absolute temperature is exponential in form, a plot of $\log _{10} \mathrm{D}$ against $1 / T_{\text {abs }}$ (Arrhenius-type plot) should be linear. This follows from the alternate form of Equation 32 , a form which also is often used to express the results of diffusion experiments:

$$
\log \mathrm{D}=-\frac{\mathrm{Q}}{4.574 \mathrm{~T}}+\text { Const. }
$$

Bennek and Klotzbach(158) found a linear relationship between $1 / T$ and the log of the permeability down to $570 \mathrm{~F}(300 \mathrm{C})$ for several steels. Hobson(159) found no anomaly in the permeability of a $3 \mathrm{Cr}-\mathrm{Mo}$ steel down to $285 \mathrm{~F}(140 \mathrm{C})$. In other work, using specimens cut from large forgings, Hobson( $(160)$ showed that the evolution of hydrogen did not follow the predictions of the accepted exponential equation for diffusion at temperatures below about $300 \mathrm{~F}(150 \mathrm{C})$. Discontinuities in plots of hydrogen permeation through a thin diaphragm versus temperature have been observed by several workers. For example, Ham and Rast, (40) working with nearly pure iron, found anomalously low permeation at temperatures of 243 to $600 \mathrm{~F}$ (117 to $315 \mathrm{C}$ ). Chang and Bennett,(41) studying iron alloyed with chromium, nickel, or molybdenum, found anomalous permeability developing slowly at temperatures below $750 \mathrm{~F}(400 \mathrm{C})$ in Armco ingot iron and ironnickel alloys; they attributed this to a change in the mechanism of permeation, the rate being controlled by diffusion at higher temperatures but by surface processes (entry) as the temperature fell to the
570 to $750 \mathrm{~F}(300$ to $400 \mathrm{C}$ ) range. On the other hand, an Arrhenius-type plot (the log of the permcability plotted versus the reciprocal of the absolute temperature) of the results of the permeation experiments performed by Bryan and Dodge(49) yielded an excellent straight line throughout the temperature range studied, as is shown in Figure 27. There was no evidence of a change in slope of the plot down to the lowest temperature that they studied ( $259 \mathrm{~F}$ or $126 \mathrm{C}$ ). Their. equation for the temperature dependence of the permeability of hydrogen through pure iron was

$$
\psi(\operatorname{or} P)=0.0227 \mathrm{e}^{-8120 / R T},
$$

where $\mathrm{R}$ is in gram-calories per gram-mole of hydrogen and $\mathrm{T}$ is degrees Kelvin.

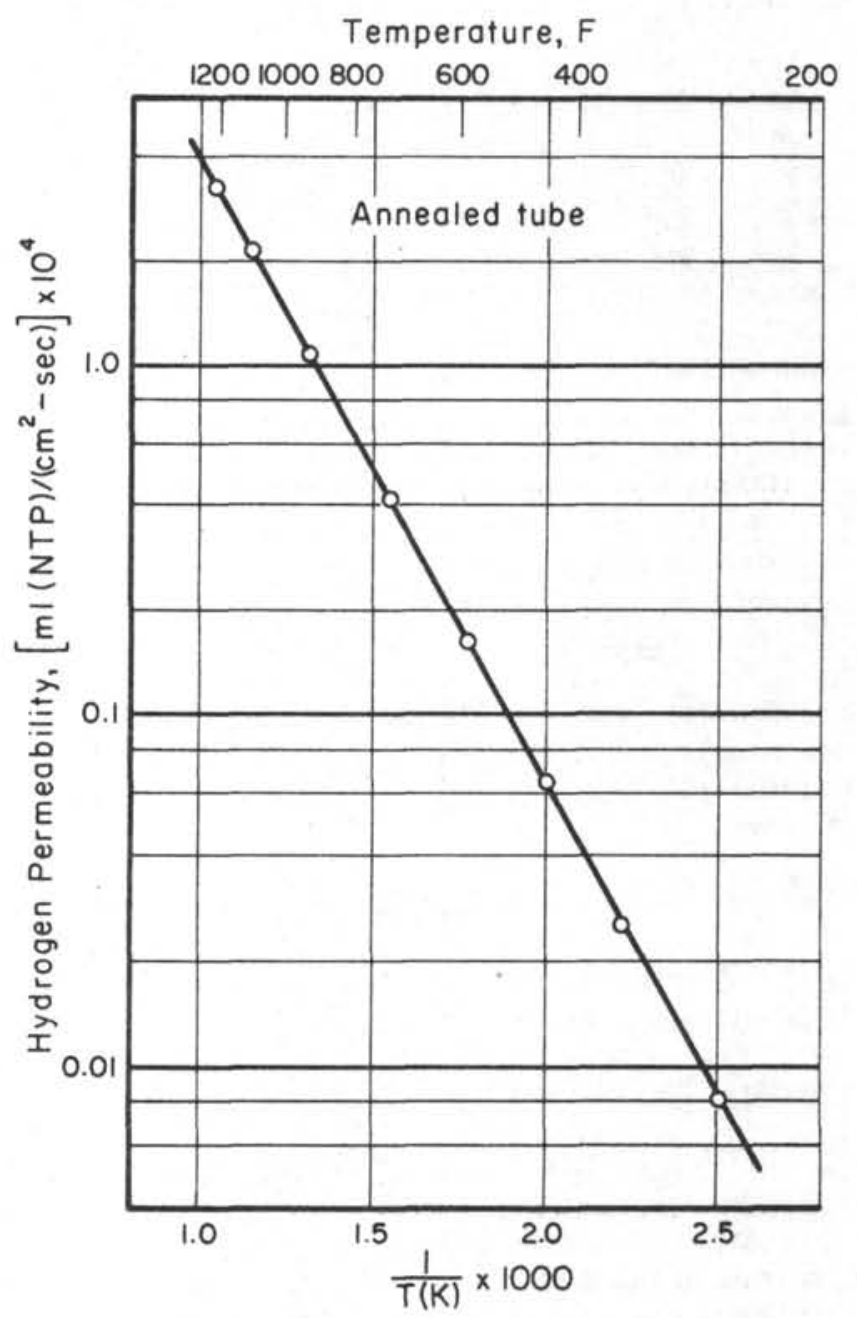

FIGURE 27. ARRHENIUS PLOT SHOWING VARIATION OF PERMEABILITY WITH TEMPERATURE (49)

Using Smithells and Ransley's permeability results $(71)$ and Sieverts' solubility results, $(32,33)$ 
Sykes, Burton, and Gegg(161) calculated the diffusivity, $D$, for $\alpha$-iron. The results, listed in Table 10 , are compared with the permeability results obtained by Bennek and Klotzbach for a Ni-Cr-W steel. It is seen that the change in diffusivity of hydrogen in $\alpha$-iron with change in temperature is relatively small. Over the temperature range from 570 to $1110 \mathrm{~F}$ ( 300 to $600 \mathrm{C}$ ), the diffusivity changed by a factor of 2 while the permeability changed by a factor of about 20. Thus, the major factor in improving the permeability is the increase in solubility with increasing temperature.

\section{TABLE 10. COMPARISON OF DIFFUSIVITY AND PERMEABILITY FOR IRON IN THE $\alpha-\operatorname{STATE}^{(161)}$}

\begin{tabular}{|c|c|c|c|}
\hline \multicolumn{2}{|c|}{ Temperature } & \multirow{2}{*}{$\begin{array}{l}\text { Diffusivity, D, } \\
\mathrm{sq} \mathrm{cm} / \mathrm{sec}\end{array}$} & \multirow{2}{*}{$\begin{array}{c}\text { Permeability, } \\
N(a)\end{array}$} \\
\hline C & $\mathrm{F}$ & & \\
\hline 20 & 68 & $1.5 \times 10^{-5}$ & -- \\
\hline 100 & 212 & $3.5 \times 10^{-5}$ & 0.00026 \\
\hline 200 & 390 & $6.7 \times 10^{-5}$ & 0.0045 \\
\hline 300 & 570 & $1.00 \times 10^{-4}$ & 0.029 \\
\hline 400 & 750 & 1. $38 \times 10^{-4}$ & 0.11 \\
\hline 500 & 930 & $1.70 \times 10^{-4}$ & 0.26 \\
\hline 600 & 1110 & $2.04 \times 10^{-4}$ & 0.59 \\
\hline 700 & 1290 & 2. $34 \times 10^{-4}$ & 1.00 \\
\hline 800 & 1470 & $2.69 \times 10^{-4}$ & -- \\
\hline
\end{tabular}

(a) $\mathrm{N}$ is the number of cc of gas at NTP diffusing through $1 \mathrm{sq} \mathrm{cm}$ of a plate $1 \mathrm{~mm}$ thick in $1 \mathrm{hr}$ at a pressure of $1 \mathrm{~atm}$, as determined by Bennek and Klotzbach. N corresponds to Sykes, Burton, and Gegg's $\mathrm{Z}$ and to $\mathrm{P}$ used by most investigators.

Geller and Sun(38) determined the diffusion coefficient for high-purity $\alpha$-iron at elevated temperatures. Their expression for hydrogen diffusion was

$$
\log D=-\frac{637}{T}-2.663,
$$

where $D$ is the diffusion coefficient with units of $\mathrm{cm}^{2} / \mathrm{sec}$ and $\mathrm{T}$ is degrees Kelvin. To facilitate comparisons to be made later, this equation can be rewritten as follows:

$$
\mathrm{D}=0.0022 e^{-2914 / R T} \text {. }
$$

More recently, Stross and Tompkins(162) determined the diffusion coefficient of hydrogen in $\alpha$-iron for the temperature range from 300 to $1650 \mathrm{~F}$ $(150$ to $900 \mathrm{C})$ from measurements of the rate of evolution into a vacuum from an iron cylinder saturated with hydrogen under various conditions. They found that at temperatures above $300 \mathrm{~F}$ (150 C) diffusivity in $\alpha$-iron conforms to the relationship

$$
\mathrm{D}_{\left(\mathrm{cm}^{2} / \mathrm{sec}\right)}=8.8 \times 10^{-4} \mathrm{e}^{-3050 / \mathrm{RT}} \text {. }
$$

Essentially the same values of $D$ have been determined by Eichenauer, Kunzig, and Pebler(163) and by Johnson and Hill. (10) The latter workers studied the diffusivity in $\alpha$-iron by measuring evolution rates over the temperature range from 77 to $1435 \mathrm{~F}$ $(25$ to $780 \mathrm{C}$ ). Irons were prepared by air melting and by vacuum melting, and both pressure-charging and thermal-charging methods were used to introduce hydrogen. The different melting and charging methods gave comparable results, as is shown in Figure 28. Above $392 \mathrm{~F}(200 \mathrm{C})$, the diffusivity, $\mathrm{D}$, in $\mathrm{cm}^{2} / \mathrm{sec}$ was represented by

$$
\mathrm{D}=0.0014 \mathrm{e}^{-3200 / \mathrm{RT}} \text {. }
$$

However, below $392 \mathrm{~F}(200 \mathrm{C})$, the diffusivity was anomalously low, as will be discussed in the next section.

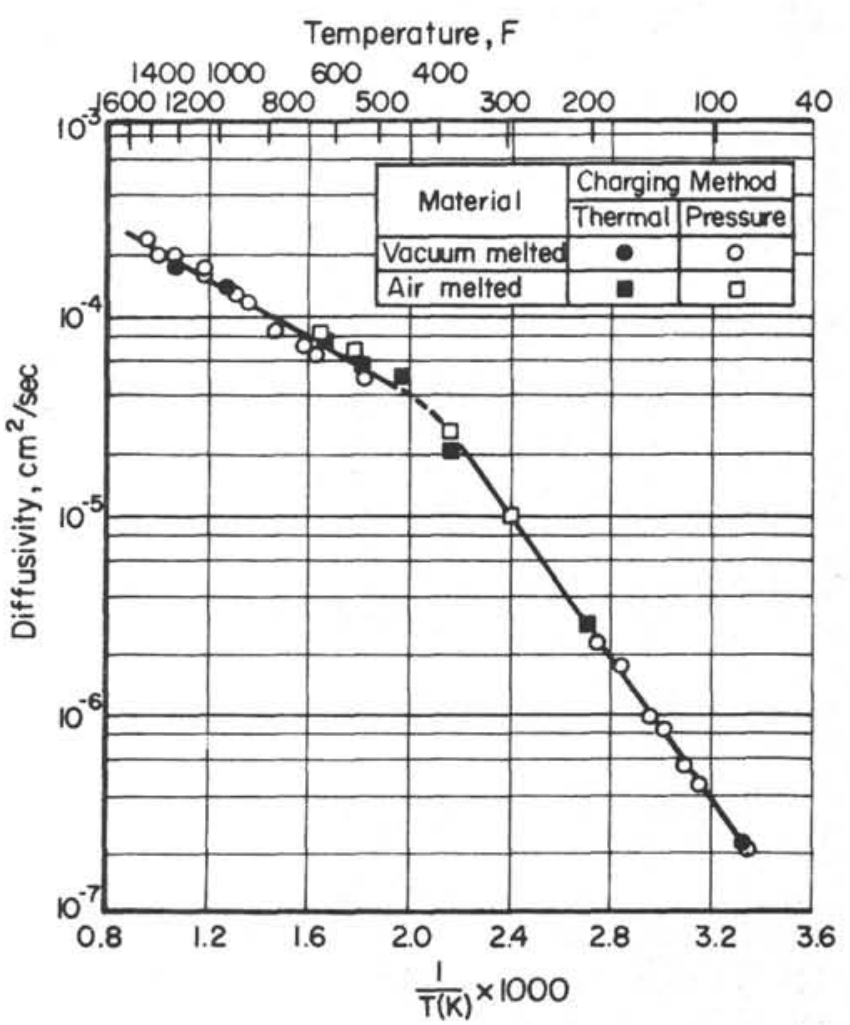

FIGURE 28. DIFFUSION COEFFICIENT OF HYDROGEN IN IRON $(10)$

As was discussed previously, the permeability, solubility, and diffusivity generally are related as follows:

$$
P=S \cdot D,
$$

(also see Equation 8). This is the relationship that Sykes et al(161) used to calculate the diffusivity from the permeability data for $\alpha$-iron obtained by Smithells and Ransley (71) and solubility data obtained by Sieverts. $(32,33)$ Their results for the diffusivity constant for $\alpha$-iron, expressed as $\mathrm{cm}^{2} / \mathrm{sec}$, were as follows: 
$D=7.6 \times 10^{-4} e^{-2285 / R T}$.

This equation agrees reasonably well with that which Stross and Tompkins subsequently determined experimentally (see Equation 37 ). This agreement indicates that the measurements of these three properties (permeability, solubility, and diffusivity) are individually reliable, and that the results are mutually consistent and in agreement with the relationship $\mathrm{P}=\mathrm{S} \cdot \mathrm{D}$ for temperatures above about $750 \mathrm{~F}(400 \mathrm{C})$.

Lower Temperatures (Below About 750 F). Although a number of investigations have been made of the diffusivity of hydrogen in iron and steel at room temperature and slightly elevated temperatures, the various values obtained are in poor agreement. For example, for five investigations, values reported for the diffusion coefficient at $77 \mathrm{~F}$ (25 C) ranged from about $1 \times 10^{-9}$ to $1 \times 10^{-5} \mathrm{~cm}^{2}$ / sec; the se values differ by a factor of 10,000 . However, the various results are in accord in one respect--all follow the trend for experimentally determined coefficients for temperatures below about $390 \mathrm{~F}(200 \mathrm{C})$ to be considerably lower than would be predicted by extrapolation of high-temperature measurements for $\alpha$-iron. This observed behavior of hydrogen in ferrite is just the reverse of its behavior in most other metal systems where lowtemperature deviations in the diffusion coefficient have been in the direction of higher values than are predicted by extrapolation of high-temperature data. These deviations in metals other than iron or iron alloys have been explained as resulting from preferentially rapid diffusion along grain boundaries or dislocations.

Because considerable controversy existed as to whether hydrogen diffuses through the lattice of metal crystals, through the grain boundaries, or through faults in the crystals, Smithells and Ransley $(7 \mathrm{I})$ conducted an experiment to obtain direct evidence on the effect of grain boundaries. They performed diffusion measurements on a singlecrystal tube and on another piece of the same tube of iron treated so as to have a normal grain size of 100 grains per $\mathrm{mm}^{2}$. The effect of grain size on the rate of diffusion of hydrogen through iron is shown in the following tabulation:

\begin{tabular}{|c|c|c|c|c|}
\hline \multicolumn{2}{|c|}{ Temperature } & \multirow{2}{*}{$\begin{array}{c}\text { Pressure } \\
\mathrm{mm} \\
\end{array}$} & \multicolumn{2}{|c|}{ Diffusion Rate(a) } \\
\hline $\mathrm{K}$ & $\mathrm{F}$ & & Fine Grain & Single Crystal \\
\hline 518 & 473 & 140 & $2.4 \times 10^{-6}$ & $1.2 \times 10^{-6}$ \\
\hline 686 & 775 & 140 & $17.6 \times 10^{-6}$ & $17.1 \times 10^{-6}$ \\
\hline 894 & 1150 & 140 & $92.8 \times 10^{-6}$ & $89.5 \times 10^{-6}$ \\
\hline 1052 & 1434 & 140 & $203.0 \times 10^{-6}$ & $205.0 \times 10^{-6}$ \\
\hline
\end{tabular}

(a) Units not stated.

The results show that the presence or absence of grain boundaries had no appreciable effect on the rate of diffusion of hydrogen through iron. Edwards (164) also had found the diffusion rates to be the same in a single crystal as in the same material in fine-grain polycrystalline form. Thus, it is accepted that the penetration of hydrogen into iron occurs throughout the lattice.

Using specimens cut from large forgings of $2-1 / 2 \mathrm{Ni}-\mathrm{Cr}-\mathrm{Mo}$ steel, Hobson $(160)$ showed that the diffusion of hydrogen in steel does not follow the predictions of the accepted exponential equations for $\alpha$-iron (for example, see Equations 39 and 37 , derived from data obtained at elevated temperatures) at temperatures below about $300 \mathrm{~F}(150 \mathrm{C})$. Instead, the diffusion rate and the diffusion coefficient are anomalously low at the lower temperatures, as is shown in Figure 29 and in the following tabulation:

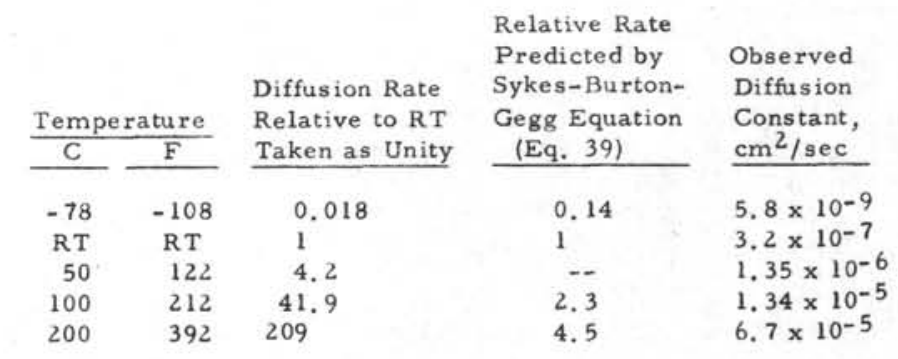

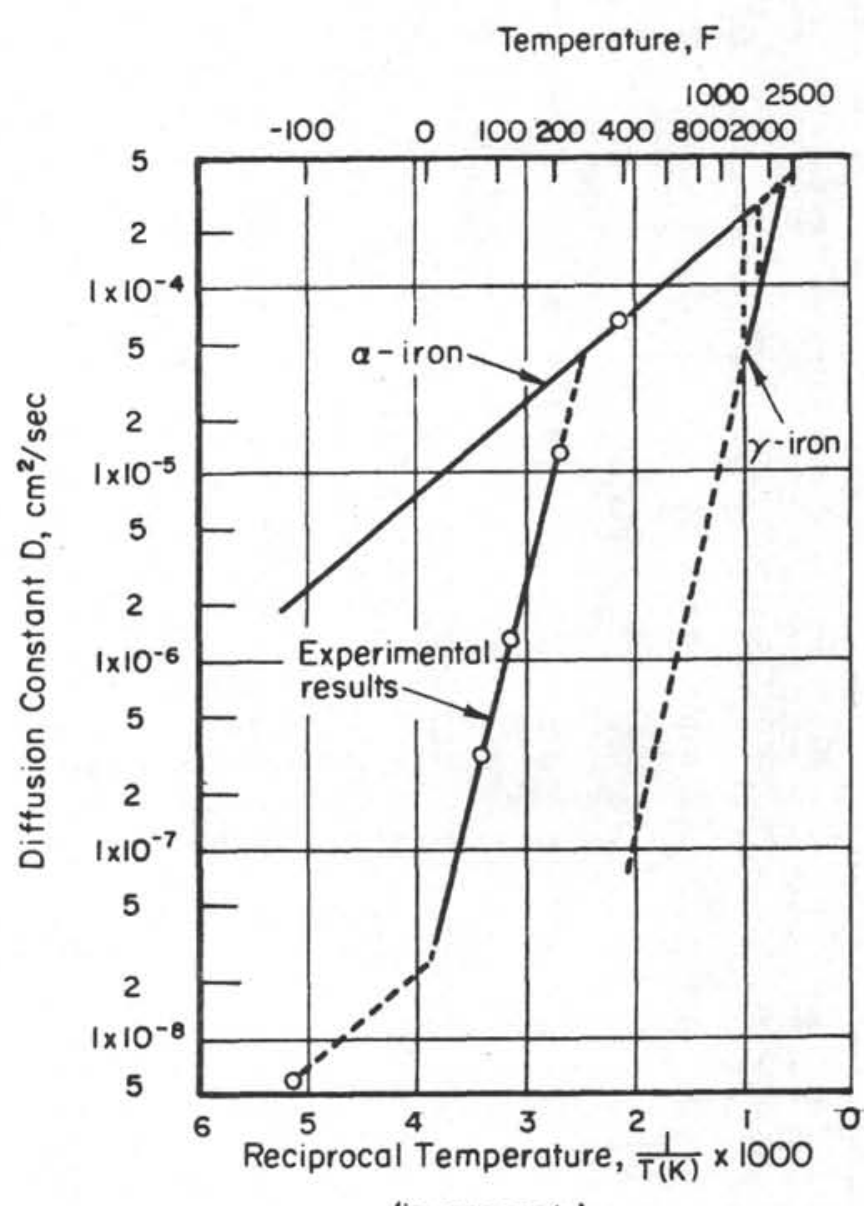

(inverse scale)

FIGURE 29. OBSERVED AND CALCULATED RATES OF DIFFUSION OF HYDROGEN IN IRON(160)

[Showing anomalously low diffusion of hydrogen in alpha iron at low temperatures - below about $390 \mathrm{~F}$ $(200 \mathrm{C})$ in this instance.] 
Hobson suggested that the diffusion experiments revealing anomalously low rates of hydrogen diffusion in steel below about $390 \mathrm{~F}(200 \mathrm{C})$ and a great reduction in diffusion rate below $212 \mathrm{~F}(100 \mathrm{C})$ (see Figure 29) make the continuation of slow cooling below the latter temperature of little value in reducing the hydrogen content of large forgings. Yet numerous investigators in sampling steel for hydrogen analysis have shown that for small specimens serious losses occur at room temperature.

Darken and Smith $(48)$ measured the effect of temperature on the permeability of hydrogen introduced into SAE 1020 steel by acid charging. The results may be summarized as follows:

Permęability at Indicated Temperature, $\mathrm{cm}^{3} / \mathrm{sec} / \mathrm{cm}^{2}$ for $1 \mathrm{~mm}$ thickness

\begin{tabular}{|c|c|c|c|c|}
\hline Solution & $32 \mathrm{~F}(0 \mathrm{C})$ & $95 \mathrm{~F}(35 \mathrm{C})$ & $131 \mathrm{~F}(55 \mathrm{C})$ & $167 \mathrm{~F}(75 \mathrm{C})$ \\
\hline $1 \mathrm{~N} \mathrm{H}_{2} \mathrm{SO}_{4}$ & $5.2 \times 10^{-6}$ & $23 \times 10^{-6}$ & -- & $78 \times 10^{-6}$ \\
\hline $\begin{array}{l}1 \text { molal } \\
\text { citric } \\
\text { acid }\end{array}$ & - & $6 \times 10^{-6}$ & -- & $34 \times 10^{-6}$ \\
\hline H 4.4 & -- & $1.04 \times 10^{-6}$ & $1.31 \times 10^{-6}$ & $1.46 \times 10^{-6}$ \\
\hline
\end{tabular}

The permeability doubled for about 36 F (20 C) rise in temperature (except for the $\mathrm{pH} 4.4$ solution where there was a large change in potential). Bardenheuer and Thanheiser $(62)$ found about the same temperature coefficient for a steel exposed on one side to sulfuric acid ( $387 \mathrm{~g} / 1)$, as follows:

\begin{tabular}{|c|c|c|}
\hline C & $\mathrm{F}$ & Permeability $\times 10^{6}$ \\
\hline 20 & 68 & 2.03 \\
\hline 30 & 86 & 2.56 \\
\hline 40 & 104 & 3.93 \\
\hline 50 & 122 & 5.16 \\
\hline 60 & 140 & 9.1 \\
\hline 70 & 158 & 11.8 \\
\hline 80 & 176 & 18.6 \\
\hline
\end{tabular}

Frank, Swets, and Fry(91) recently determined the diffusion rates of hydrogen in mild steel at low temperatures ( 77 to $194 \mathrm{~F}$ or 25 to $90 \mathrm{C}$ ) where the diffusion rates are relatively low. A mass spectrometer was used to study the movement of hydrogen through thin steel plates of different thicknesses. One surface of the plate faced the inside of the mass spectrometer and hydrogen was introduced into the other (outside) surface. Hydrogen was introduced by abrasion of the steel under water, the most satisfactory of several methods tried. Two methods of measuring diffusion were used: (1) the rate of approach to equilibrium when hydrogen was supplied to the steel plate, and (2) the rate of outgassing when the source of hydrogen was removed. Two markedly different sets of diffusion coefficients were obtained by the two methods. The first method gave diffusion coefficients that agreed very well with values obtained by others at somewhat higher temperatures.
The outgassing method, which was the more reproducible method, gave considerably lower values, as shown in Figure 30. The results are compared with those of other investigators in Figure 31. For the curves shown in Figure 30, the equation which fits the upper curve ("build-up" method) is

$$
D=5.0 \times 10^{-3} e^{-3400 / R T} \text {, }
$$

and that for the lower curve (decay method) is

$$
\mathrm{D}=1.90 \times 10^{-2} \mathrm{e}^{-6320 / \mathrm{RT}},
$$

where the activation energy is in calories per mole and the value of $\mathrm{D}$ is $\mathrm{cm}^{2} / \mathrm{sec}$. The decay method resulted in higher values of activation energy and higher $D_{0}$ values (the constants before the "e" terms in the two equations) than did the build-up method.

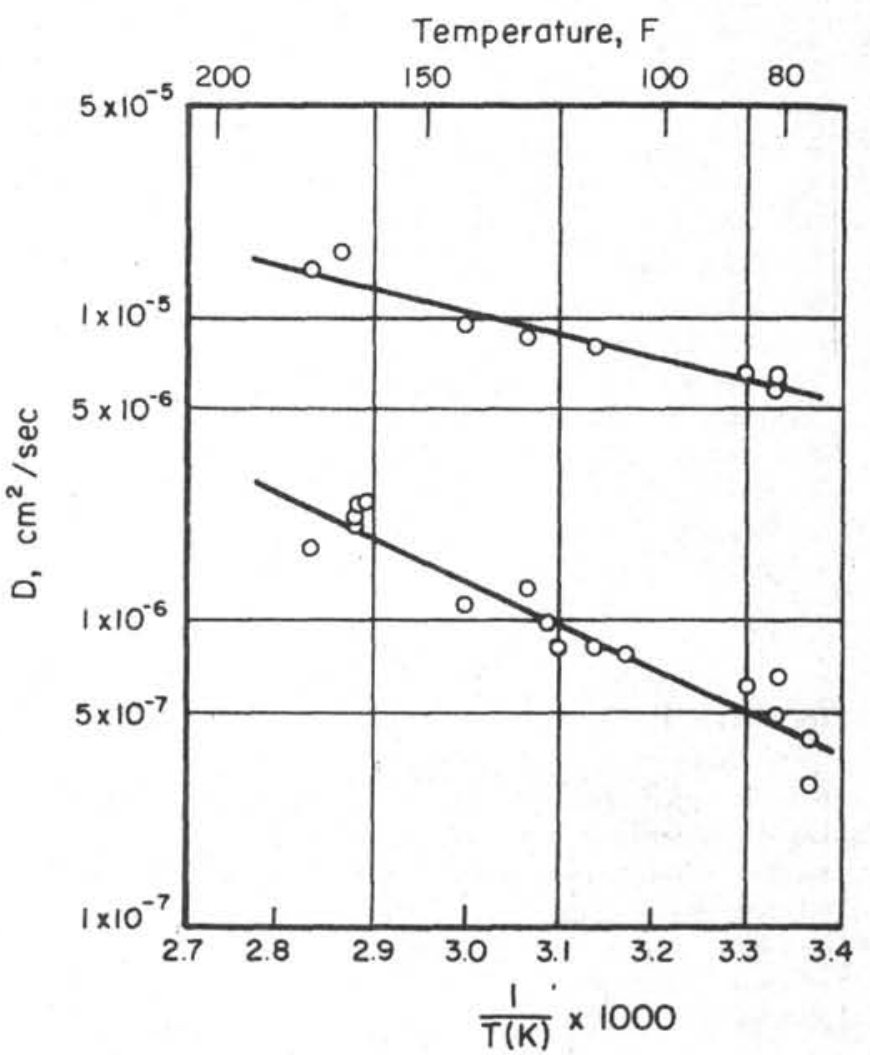

FIGURE 30. PLOTS OF InD VERSUS $1 / \mathrm{T} \times 1000$ FOR THE DIF FUSION OF HYDROGEN IN MILD STEEL(91)

[For the "build-up" method (upper) and the decay or outgassing method (lower) applied to the annealed specimen.]

In the experiments that involved making measurements from the decay curves, the effect of concentration was investigated through doubling the maximum permeation rate by increasing the load on the abrasive paper in one case and increasing the concentration of citric acid in the other. No significant change was detected in the decay rate, and hence, none in the diffusivity. This indicated 


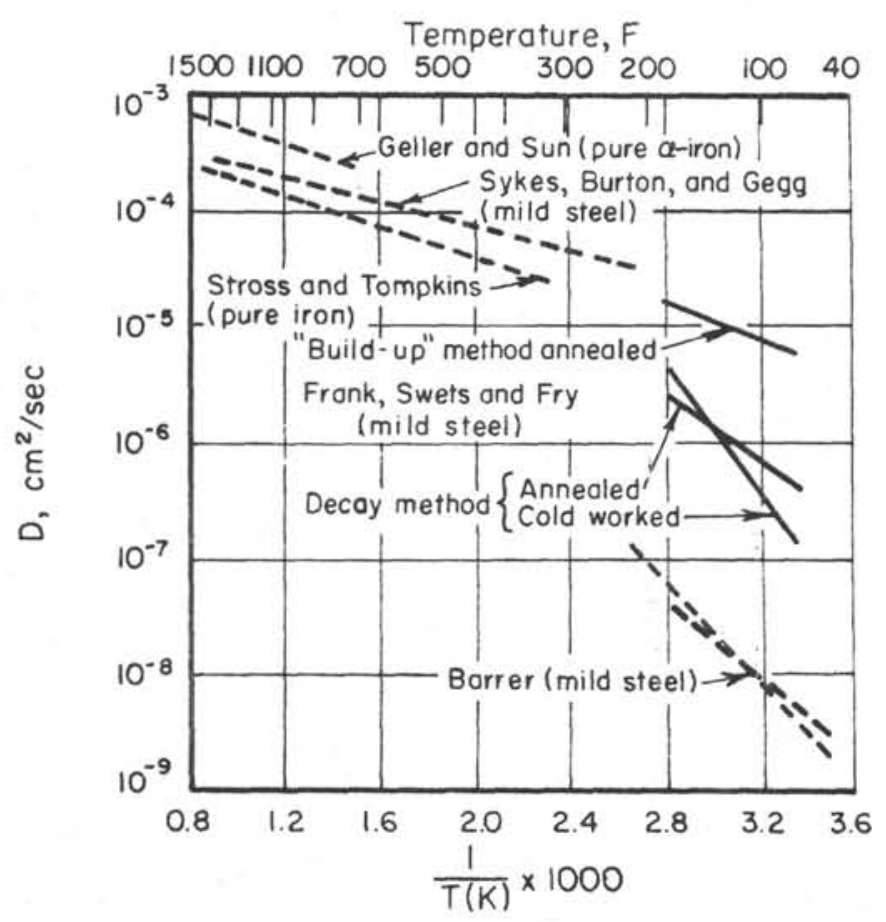

FIGURE 31. A COMPARISON OF THE WORK OF FRANK, SWETS, AND FRY ON THE DIF FUSION OF HYDROGEN IN STEEL AT LOW TEMPERATURES WITH THE WORK OF OTHERS(91)

that if there was a concentration effect, it was at least very small compared to other effects. Two observations indicated that the difference between the two sets of diffusion coefficients was not the result of surface effects. First, there was no significant difference in diffusion coefficients obtained from plates of different thickness, a result which would not be expected if surface effects were controlling. Second, when extensive changes were made in the character of the surfaces, by acid attack and other means, only minor differences in the decay rate resulted; these differences were small compared to the difference between the two sets of diffusion coefficients. Also, the difference between the two sets of coefficients cannot be attributed to the abrasion process because the same effect was observed when hydrogen was introduced by immersion in citric acid. The authors listed several facts which tentatively point to a time effect. Part of these were: (1) the "build-up" process preceded the decay process in time and gave the higher diffusion coefficients, (2) if hydrogen introduction was stopped early, before steady-state conditions were achieved, the decay rate was faster, and (3) if the hydrogen-introducing process was maintained a longer time after steady state was reached, the decay rate was always slightly lower. It was suggested that the one set of diffusion coefficients (from "build-up" measurements) were possibly associated with the simple, interstitial diffusion process, while the other set, which appeared after the hydrogen had been in the steel for awhile, apparently was associated with a more complex process. In a subsequent note, Frank $(165)$ discussed a similar effect observed by Weiner and Gensamer(166) who used internal-friction measurements to study hydrogen in mild steel in the very low-temperature range (subzero). Weiner and Gensamer also found that there were two processes of hydrogen movement and that they involved different activation energies. Furthermore, the process involving the higher activation energy occurred only after the hydrogen had been in the steel for some time, just as observed by Frank and co-workers.

Frank then presented the summary of the status of measurements of the diffusion coefficients of hydrogen in iron and steel that is shown in the top part of Table 11. In this type of work, as he pointed out, one is concerned primarily with whether the diffusion coefficients obey the law

$$
D=D_{0} \cdot e^{-E / R T},
$$

and if they do, one would like to know what the values of $E$ and $D_{O}$ are, $E$ being considered the activation energy of the diffusion process. The seven sets of measurements in the table cover the temperature range from -369 to $1650 \mathrm{~F}(-223$ to $900 \mathrm{C})$; all were made on high-purity iron or annealed mild steel, and several different methods were ui ed.

TABLE 11. SUMMARY OF STATUS OF MEASUREMENTS OF DIFFUSION COEFFICIENTS OF HYDROGEN IN IRON AND STEEL

\begin{tabular}{|c|c|c|c|c|}
\hline \multirow[b]{2}{*}{ Investigators } & \multicolumn{2}{|c|}{ Temperature Range } & \multirow{2}{*}{$\begin{array}{c}\mathrm{D}_{\mathrm{o}}, \\
\mathrm{cm}^{2} / \mathrm{sec}\end{array}$} & \multirow{2}{*}{$\begin{array}{c}\text { E, } \\
\mathrm{cal} / \mathrm{mole}\end{array}$} \\
\hline & C & $\mathbf{F}$ & & \\
\hline $\begin{array}{l}\text { Stross and } \\
\text { Tompkins (1956) }\end{array}$ & $150-900$ & $300-1650$ & $\begin{array}{c}8.85 \pm 0.83 \\
\times 10^{-4}\end{array}$ & $3050 \pm 100$ \\
\hline $\begin{array}{l}\text { Geller and Sun } \\
(1950)\end{array}$ & $400-900$ & $750-1650$ & $4.6 \times 10^{-2}$ & 2900 \\
\hline $\begin{array}{l}\text { Sykes, Burton, } \\
\text { and Gegg (1947) }\end{array}$ & $100-800$ & $210-1470$ & $7.6 \times 10^{-4}$ & 2290 \\
\hline $\begin{array}{l}\text { Frank, Swets, and } \\
\text { Fry (1958) }\end{array}$ & $\begin{array}{l}25-90 \\
25-90\end{array}$ & $\begin{array}{l}77-195 \\
77-195\end{array}$ & $\begin{array}{l}5.0 \times 10^{-3} \\
1.9 \times 10^{-2}\end{array}$ & $\begin{array}{l}3400 \\
6300\end{array}$ \\
\hline $\begin{array}{l}\text { Weiner and Gensame } \\
\text { (1957) }\end{array}$ & $\begin{array}{r}-223 \\
-168\end{array}$ & $\begin{array}{l}-369 \\
-270\end{array}$ & $\begin{array}{l}4 \times 10^{-4} \\
9 \times 10^{-5}\end{array}$ & $\begin{array}{l}3000 \\
6000\end{array}$ \\
\hline $\begin{array}{l}\text { Bryan and Dodgc(a) } \\
\quad(1963)\end{array}$ & $126-693$ & $259-1279$ & $3.9 \times 10^{-4}$ & 1080 \\
\hline $\begin{array}{l}\text { Johnson and Hill(a) } \\
(1960)\end{array}$ & $\begin{array}{r}200-750 \\
25-200\end{array}$ & $\begin{array}{c}392-1382 \\
77-392\end{array}$ & $\begin{array}{c}1.4 \times 10^{-3} \\
0.12\end{array}$ & $\begin{array}{l}3200 \\
7820\end{array}$ \\
\hline
\end{tabular}

(a) This work was performed subsequent to Frank's summary.

In the upper temperature region, there appears to be only the interstitial diffusion process with an activation energy of approximately 3000 cal/mole. However, there appear to be two diffusion processes in the lower temperature range. When hydrogen is first introduced into steel, it moves around relatively freely, and the diffusion process has an activation energy of about $3000 \mathrm{cal} /$ moie. But, with the passage of time, the hydrogen 
appears to be partially trapped by some lattice defect, and the diffusion of this hydrogen takes more energy to become activated (approximately 6000 $\mathrm{cal} / \mathrm{mole}$ is required) and takes place at a lower rate. Although there are differences in the values of $\mathrm{D}_{\mathrm{o}}$ in the table, when one considers that they are extrapolations of the measured values to infinite temperature (that is, $1 / \mathrm{T}=0$ ) and thus are sensitive to inaccuracies in the measurements, they agree with each other amazingly well.

Other recent work on the diffusion of hydrogen in iron and in iron-carbon alloys has been that of Hill and Johnson. $(10,14,13,167)$ All the results shown in Figure 32 were obtained from measurements of the nonsteady evolution of hydrogen that had been introduced into specimens by heating them in hydrogen gas at various pressures up to 150 atmospheres. The uppermost curve in the figure shows the diffusivity of hydrogen in annealed, pure $\alpha$-iron at temperatures from 77 to $1380 \mathrm{~F}$ ( 25 to $750 \mathrm{C})$. Rather than showing the straight line one expects to find in this type of plot $(\log D$ versus $1 / \mathrm{T})$, the curve shows a distinct break in the vicinity of $390 \mathrm{~F}(200 \mathrm{C})$. Above $390 \mathrm{~F}$, the diffusivity, $\mathrm{D}$, in $\mathrm{cm}^{2} / \mathrm{sec}$ was shown earlier in this report to be represented by

$$
\mathrm{D}=0.0014 \mathrm{e}^{-3200 / \mathrm{RT}} \text {. }
$$

However, below $390 \mathrm{~F}$, the diffusivity was anomalously low, being represented by

$$
\mathrm{D}=0.12 \mathrm{e}^{-7820 / R T} \text {. }
$$

At room temperature (77 F or $25 \mathrm{C})$, this yields a value of $\mathrm{D}$ of $2.2 \times 10^{-7} \mathrm{~cm}^{2} / \mathrm{sec}$.

As was dissussed in the preceding section, the results obtained above $390 \mathrm{~F}(200 \mathrm{C})$ agreed fairly well with those of other recent investigations. These results of Johnson and Hill(10) were obtained with several heats of iron which varied in total impurity content between 0.02 and 0.1 percent. In the higher temperature range, measurements of $D$ were found to be quite reproducible in spite of variations in impurity content, grain size, thermal and mechanical history, and original hydrogen content. The investigators were satisfied that surface processes were not controlling factors in the evolution of hydrogen and that the values reported were in fact volume-diffusion coefficients.

The anomalously low values of $D$ that Johnson and Hill obtained for temperatures below $390 \mathrm{~F}$ (200 C) were not entirely unexpected because they are in agreement with the general behavior observed by some of the other recent investigators (for example, Schuetz and Robertson, (57) Ham and Rast, (40) Hobson, (160) and Frank, Swets, and Fry(91)]. The abnormally low diffusion rates found by Ham and Rast at low temperatures are illustrated in Figure 33. These anomalously low values are not fully understood. Johnson and Hill hypothesized that at low temperatures the hydrogen in the metal is "trapped" with an energy $4800 \mathrm{cal} / \mathrm{g}$-atom below that of the interstitial hydrogen.

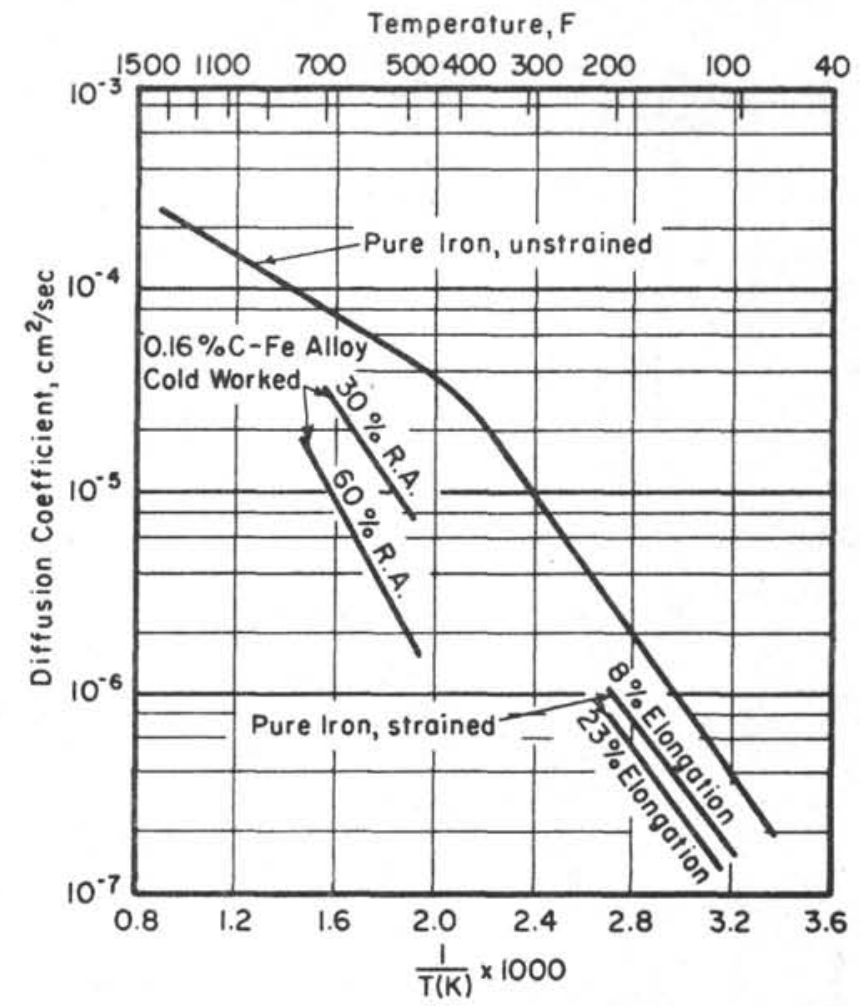

FIGURE 32. DIFFUSION OF HYDROGEN IN IRON AND IN AN IRON-CARBON ALLOY(167)

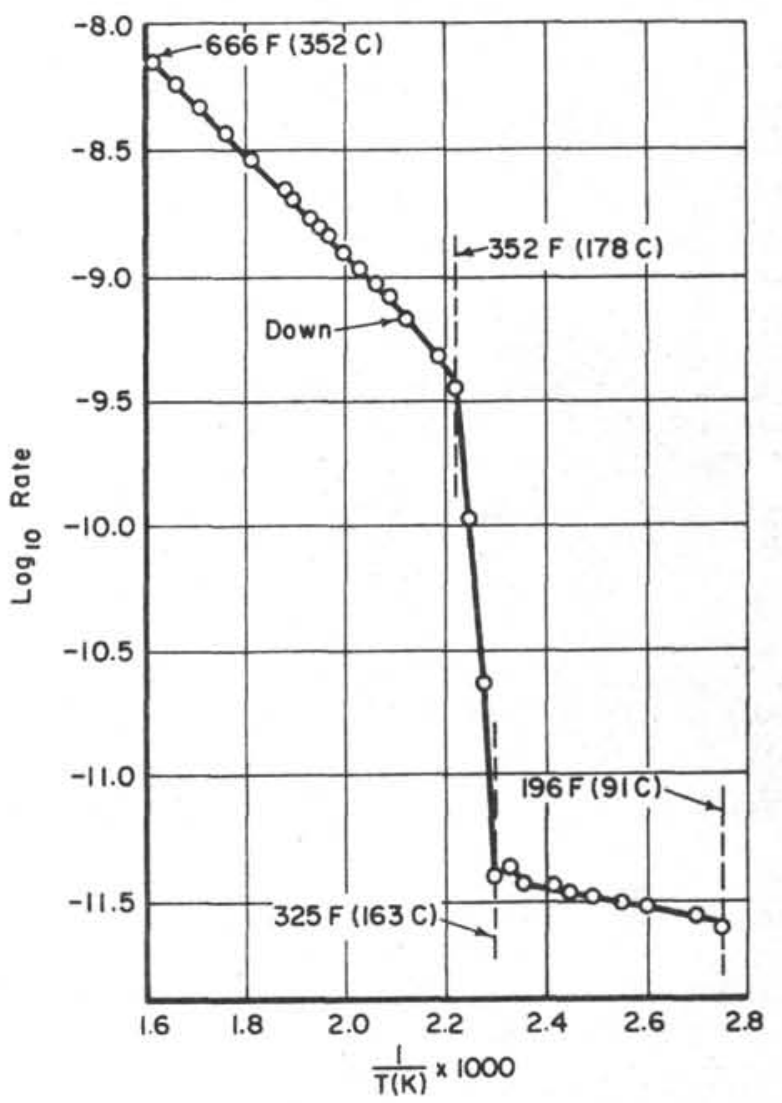

FIGURE 33. DIFFUSION ISOBAR [666-196 F (35291 C)] AT ATMOSPHERIC PRESSURE FOR CARBONYL IRON BAKED 5 HOURS

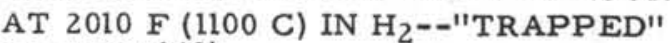
METHOD(40)

(Rates are measured in $\mathrm{g} / \mathrm{sec}$ through sample. Area $=2.8 \mathrm{~cm}^{2}$. Thickness $\left.=0.155 \mathrm{~cm}.\right)$ 
Bastien and co-workers have performed many investigations to learn more about the behavior of hydrogen in steel. Recently, Veysseyre, Azou, and Bastien $(168)$ determined the diffusion coefficient, D, of hydrogen in iron at $77 \mathrm{~F}(25 \mathrm{C})$ by measuring the amount of hydrogen that passed into the interior of a hollow soft-iron tube which was the cathode during electrolysis in a $\mathrm{N} \mathrm{HCl}$ solution. The hydrogen was drawn off under vacuum and its volume measured. They obtained a value of $D$ of approximately $3.0 \times 10^{-6} \mathrm{~cm}^{2} / \mathrm{sec}$ at this temperature.

The results of recent determinations of the diffusion coefficient at room temperature $(77 \mathrm{~F}$ or $25 \mathrm{C})$ are compared in the following tabulation:

\begin{tabular}{|c|c|}
\hline Investigators & $\mathrm{D}, \mathrm{cm}^{2} / \mathrm{sec}$ \\
\hline Johnson and Hill & $2.2 \times 10^{-7}$ \\
\hline $\begin{array}{c}\text { Frank, Swets, and Fry } \\
\text { ("build-up" method) }\end{array}$ & $1.6 \times 10^{-5}$ \\
\hline $\begin{array}{l}\text { Frank, Swets, and Fry } \\
\text { ("decay" method) }\end{array}$ & $4.5 \times 10^{-7}$ \\
\hline $\begin{array}{l}\text { Veysseyre, Azou and } \\
\text { Bastien }\end{array}$ & $\sim 3.0 \times 10^{-6}$ \\
\hline
\end{tabular}

Although the maximum and minimum values in the tabulation differ by a factor of 74 , the agreement is encouraging, considering the much wider variation obtained in earlier work and the difficulties encountered in measuring diffusivity at room temperature.

On the other hand, Bryan and Dodge, (49) in studying the permeation of hydrogen through highly purified iron, found no break in an Arrhenius-type plot of $\log D$ versus $1 / \mathrm{T}$ when the temperature went below some temperature in the range of 750 to $390 \mathrm{~F}$ ( 400 to $200 \mathrm{C}$ ). Instead, their data point for $259 \mathrm{~F}(126 \mathrm{C})$ fit the straight line through the data points for higher temperatures very precisely. However, their activation energy was lower than other values reported in the literature. Also, Stross and Tompkins(162) carried their experiments down to $302 \mathrm{~F}(150 \mathrm{C})$ and found no change in slope of an Arrhenius-type plot of the results. Evidently, more work is needed to understand the reason for these differences from the observations of Johnson and Hill and of Frank, Swets, and Fry.

One of the most recent analyses of the diffusion of hydrogen in iron and ferritic steel to be reported in the literature is that of McNabb and Foster. (169) They reported that a consideration of the literature shows the inadequacy of Fick's laws to describe the diffusion of hydrogen in steels below $750 \mathrm{~F}(400 \mathrm{C})$. Therefore, McNabb and Foster modified these laws on the assumption that hydrogen is delayed at fixed sites in the lattice. In a highly mathematical treatment, approximate and exact solutions of the resulting nonlinear system were derived for simple geometrical shapes. The results purportedly account qualitatively for the observed anomalous behavior. Experimental methods for verifying the theory were suggested.

Anomalous decreases in permeation rate at low temperatures also have been found by several investigators, and it is believed that they are related to anomalous changes in the diffusivity.

\section{Effect of Pressure}

A number of investigators showed that, for elevated temperatures, the solubility of hydrogen in iron is proportional to the square root of the hydrogen partial pressure, as was discussed previously. Since the rate of diffusion (in the case where a concentration gradient is the driving force) depends on the concentration of gas in the metal, one might expect that diffusion also would be proportional to the square root of the gas pressure, $\mathrm{p}$, according to the Richardson equation:

$$
\mathrm{D}=\mathrm{k} / \mathrm{p} \text {. }
$$

However, as early as 1912-1913, Charpy and Bonnerot showed that hydrogen diffuses in steel against a back-pressure of molecular hydrogen greater than 14 atmospheres. Bardenheuer and Thanheiser $(62)$ found that diffusion was still taking place when the back-pressure of molecular hydrogen reached 300 atmospheres, the limit of their equipment. Theoretically, the equilibrium back-pressure at room temperature is far higher than this for ordinary hydrogen contents, as has been discussed previous ly in considering the effect of pressure on solubility.

Since the effect of hydrogen partial pressure on permeation is an effect on hydrogen entry rather than on diffusion in the bulk solid, it has been discussed previously in the section dealing with hydrogen entry into iron and steel.

\section{Effect of Crystal Structure}

Chang and Bennett $(41)$ determined the diffusion constant for hydrogen in an iron-4. 36 percent nickel alloy in both the ferritic and the austenitic condition; the results are shown in Figure 34. Note that, for a given temperature, the diffusion constant for $v$-iron was much smaller than that obtained for $\alpha$-iron.

Equations 35 and 36 give the results that Geller and Sun(38) obtained for the diffusion coefficients for high-purity iron in the $\alpha$-form. The expression that they obtained for this same iron in the $\gamma$ form was as follows:

$$
\log D=-\frac{2174}{T}-1.971 \text {. }
$$

For ease of comparison, this equation can be rearranged as follows:

$$
\mathrm{D}=0.0107 \mathrm{e}^{-9944 / \mathrm{RT}} \text {. }
$$




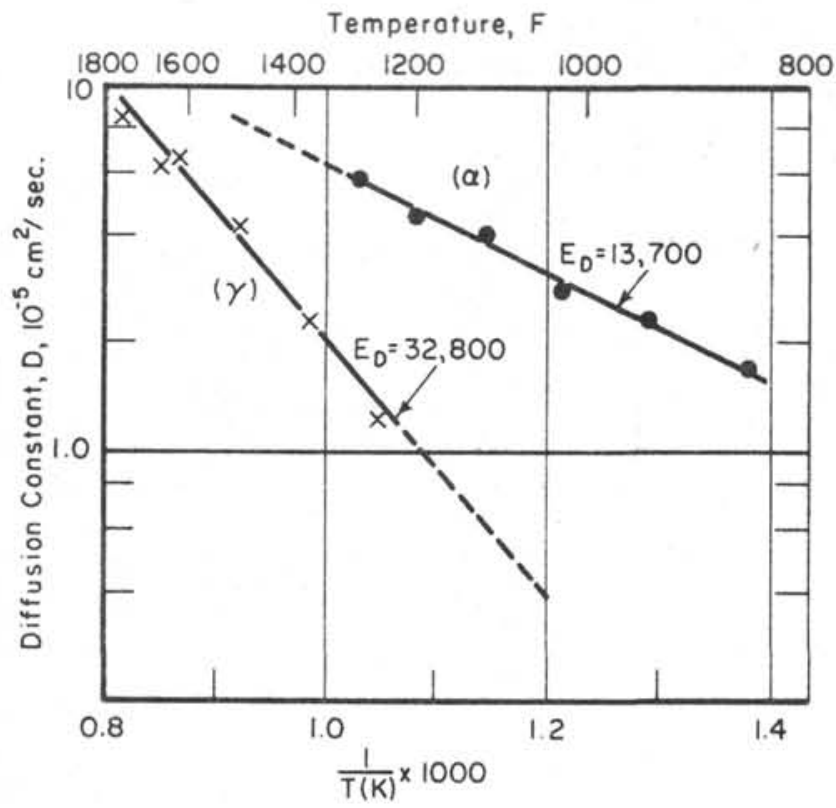

FIGURE 34. DIF FUSION CONSTANT FOR HYDROGEN OBTAINED BY TIME-LAG METHOD FOR IRON-4. 36\% NICKEL ALLOY (41)

(Showing the effect of crystal structure on diffusion.)

These results are plotted in Figure 35, along with the results for $\alpha$-iron (and for several iron alloys as well). This figure, too, shows that the diffusivity of hydrogen is markedly lower in $\gamma$-iron than it is in $\alpha$-iron at the same temperature. In the case of $\alpha-i$ ron, even though the hydrogen solubility is appreciably lower than it is in $\gamma$-iron at the same temperature, the passage of a hydrogen atom from one site in the iron lattice to another is much easier, and, therefore, the activation energy for diffusion in $\alpha$-iron is lower.

Sykes, Burton, and Gegg(161) calculated the diffusivity of hydrogen in austenite using the method described previously for ferrite. Sieverts' solubility data $(32,33)$ and Bennek and Klotzbach's data for permeability(158) were used for the austenitic state. The results of their calculations are shown in Table 12. If these results are compared with those obtained for the $\alpha$-condition shown in Table 10, one finds that only when the temperature reaches about $2100 \mathrm{~F}(1150 \mathrm{C})$ does the diffusivity in $\gamma$-iron reach that determined for $\alpha$-iron at $1200 \mathrm{~F}(650 \mathrm{C})$.

Hobson, (160) in studying diffusion in specimens cut from large forgings of an alloy steel, also obtained data that show that the diffusivity in austenite is much lower than in ferrite for a given temperature. Part of his findings are shown in Figure 29.

Bennek and Klotzbach(158) measured the permeation of hydrogen through 10 steels of widely

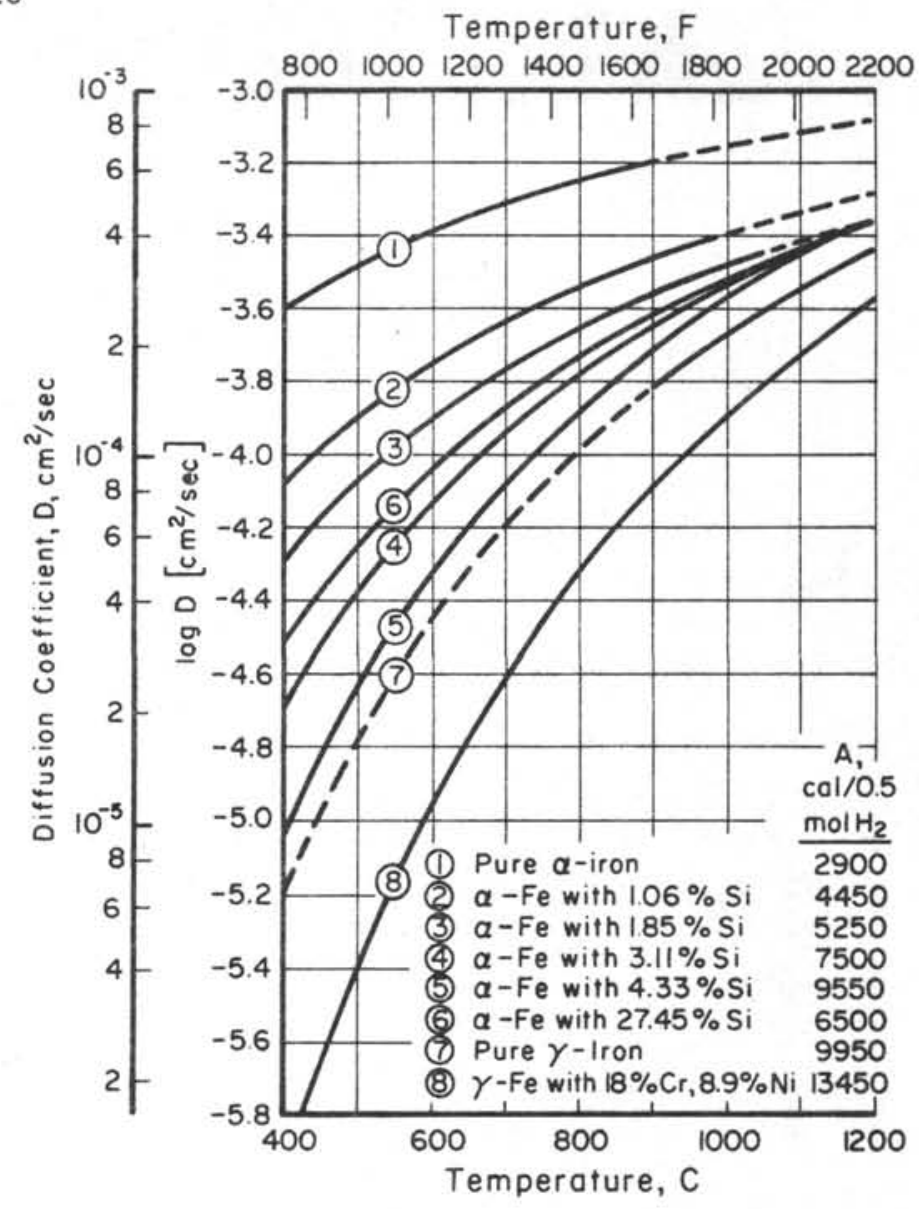

FIGURE 35. DIF FUSION COEFFICIENT OF HYDROGEN IN IRON AS A FUNCTION OF TEMPERATURE, CRYSTAL STRUCTURE, AND ALLOY ADDITION(38)

TABLE 12. DIFFUSIVITY AND PERMEABILITY OF HYDROGEN IN IRON IN THE Ү-STATE(161)

\begin{tabular}{|c|c|c|c|}
\hline \multicolumn{2}{|c|}{ Temperature } & \multirow{2}{*}{$\begin{array}{c}\text { Diffusivity, D }(\mathrm{a}) \\
\mathrm{sq} \mathrm{cm} / \mathrm{sec}\end{array}$} & \multirow{2}{*}{$\begin{array}{l}\text { Permeability, } \mathrm{Z}, \\
\text { volume } / \mathrm{hr}\end{array}$} \\
\hline $\mathrm{C}$ & $F$ & & \\
\hline 1200 & 2190 & $2.5 \times 10^{-4}$ & 6.5 (calculated) \\
\hline 1100 & 2010 & $1.9 \times 10^{-4}$ & 3.9 (calculated) \\
\hline 1000 & 1830 & $1.3 \times 10^{-4}$ & 2.4 \\
\hline 900 & 1650 & $8.7 \times 10^{-5}$ & 1.2 \\
\hline 800 & 1470 & $6.0 \times 10^{-5}$ & 0.55 \\
\hline
\end{tabular}

(a) There are not so many permeability data available for the $\gamma$-condition as for the $\alpha$-condition, so the diffusivity figures may not be so reliable.

varying composition, over a wide temperature range (limits of about 570 and $2310 \mathrm{~F}$ or 300 and $1265 \mathrm{C})$ for a plate thickness of $1 \mathrm{~mm}$. The compositions of their steels are listed in Table 13. The results obtained for four carbon steels of widely varying carbon content and five alloy steels, including $18 \mathrm{Cr}-8.9 \mathrm{Ni}$ austenitic stainless steel, are shown in Figure 36. Steel composition had some 
Temperature, $\mathrm{F}$

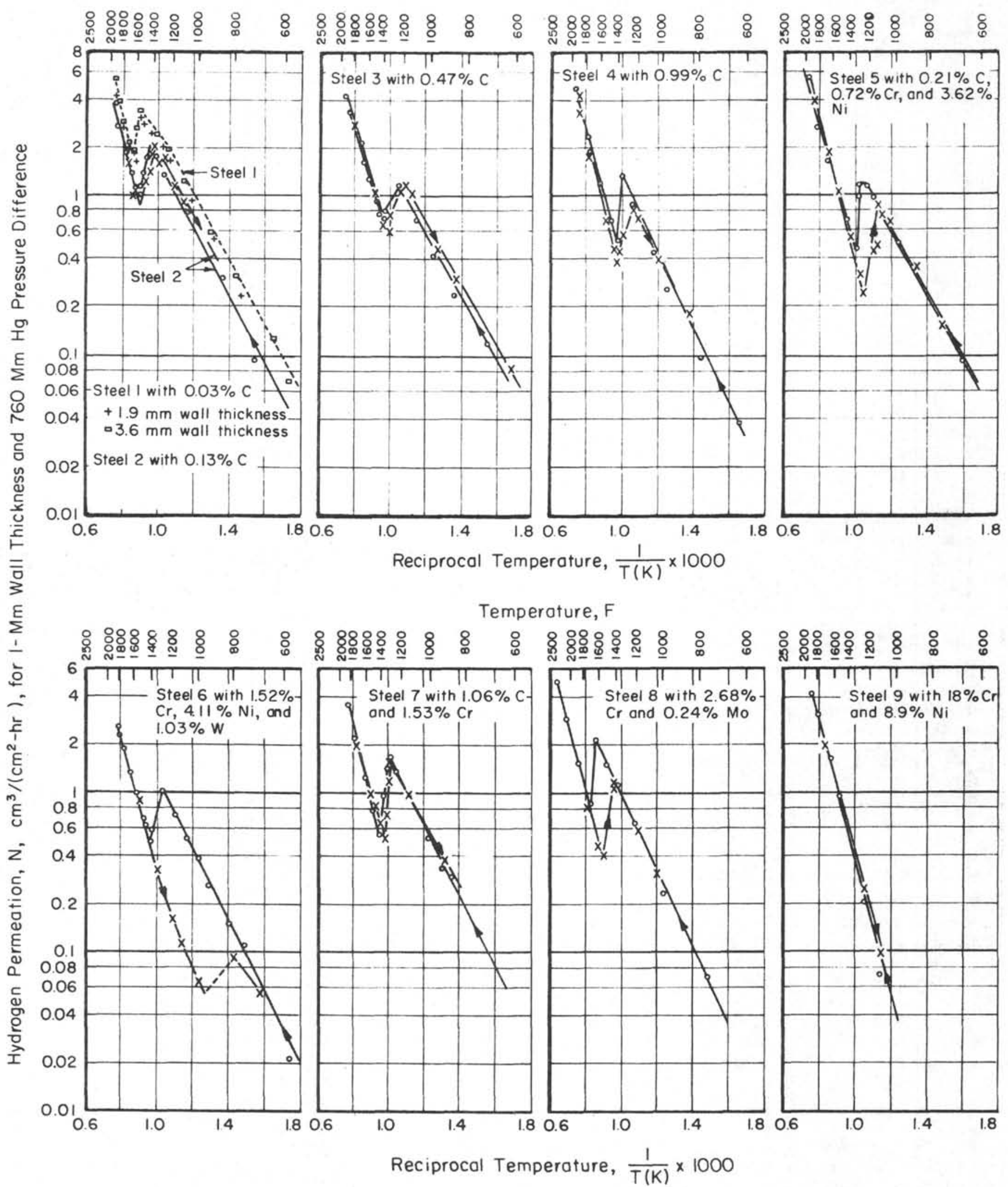

FIGURE 36. HYDROGEN PERMEABILITY OF NINE STEELS INVESTIGATED AS A FUNCTION OF TEMPERATURE FOR BOTH HEATING AND COOLING(158) 
TABLE 13. CHEMICAL COMPOSITION AND HYDROGEN SOLUBILITY OF THE STEELS INVESTIGATED BY BENNEK AND KLOTZBACH(158)

\begin{tabular}{|c|c|c|c|c|c|c|c|c|}
\hline \multirow[b]{2}{*}{ Steel } & \multicolumn{7}{|c|}{ Composition, percent } & \multirow{2}{*}{$\begin{array}{l}\text { Hydrogen Dissolved at } 1470 \mathrm{~F} \\
(950 \mathrm{C}) ; \mathrm{cm}^{3} / 100 \mathrm{~g}\end{array}$} \\
\hline & $\mathrm{C}$ & $\mathrm{Si}$ & $\mathrm{Mn}$ & $\mathrm{Cr}$ & Mo & $\mathrm{Ni}$ & Other & \\
\hline 1 & 0.03 & 0.01 & 0.12 & -- & -- & -- & -- & -- \\
\hline 2 & 0,13 & 0.14 & 0.35 & -- & -- & -- & -- & 5.64 \\
\hline 3 & 0.47 & 0.26 & 0.71 & -- & -- & -- & -- & -- \\
\hline 4 & 0.99 & 0.31 & 0.45 & -- & -- & - & -- & 4.97 \\
\hline 5 & 0.21 & 0.24 & 0.47 & 0.72 & -- & 3.62 & -- & -- \\
\hline 6 & 0.13 & 0.30 & 0.40 & 1.52 & -- & 4.11 & 1.03 & 5.56 \\
\hline 7 & 1.06 & 0.42 & 0.30 & 1.53 & -- & -- & -- & 5.61 \\
\hline 8 & 0.25 & 0.24 & 0.90 & 2.68 & 0.24 & -- & -- & 5.70 \\
\hline 9 & 0.10 & 0.67 & 0.40 & 18.0 & - & 8.9 & -- & 7.60 \\
\hline 10 & 0.24 & 0.28 & 0.90 & 2.72 & 0.26 & -- & 0.52 & 5.84 \\
\hline
\end{tabular}

influence on permeability, as will be discussed in the next section of this report. However, the most noteworthy result was the big drop in permeability that accompanied the $\alpha-$ to $-\gamma$ transformation on heating, and the corresponding sharp increase for the reverse transformation on cooling. The data for the austenitic stainless steel are consistent with the data obtained for the other eight steels for temperatures at which they were in the austenitic state. The difference in permeability between the $\alpha$ - and $\gamma$-states for the same temperature is shown clearly in Figure 37 for the $\mathrm{Cr}-\mathrm{Ni}-\mathrm{W}$ steel (Steel 6) and the mild steel, where the curves have been extrapolated to lower temperatures. Numerically, the following values were obtained from the extrapolated curves for the $\mathrm{Cr}-\mathrm{Ni}-\mathrm{W}$ steel (Steel 6) for the amount of hydrogen passing through a membrane 1$\mathrm{mm}$ thick under a pressure differential of $760 \mathrm{~mm}$ of mercury:

\begin{tabular}{|c|c|c|c|}
\hline \multicolumn{2}{|c|}{ Temperature } & \multicolumn{2}{|c|}{ Permeation, $\mathrm{N}, \mathrm{cm}^{3} / \mathrm{hr} / \mathrm{cm}^{2}$} \\
\hline $\mathrm{C}$ & $\mathrm{F}$ & In the $\gamma$-Region & In the $\alpha$-Region \\
\hline 1000 & 1832 & 2.4 & -- \\
\hline 900 & 1652 & 1.2 & -- \\
\hline 800 & 1472 & 0.55 & -- \\
\hline 700 & 1292 & 0.24 & 1.0 \\
\hline 600 & 1112 & 0.085 & 0.59 \\
\hline 500 & 932 & 0.018 & 0.26 \\
\hline 400 & 752 & 0.0032 & 0.11 \\
\hline 300 & 572 & 0.00027 & 0.029 \\
\hline 200 & 392 & 0.000008 & 0.0045 \\
\hline 100 & 212 & 0.000000034 & 0.00026 \\
\hline
\end{tabular}

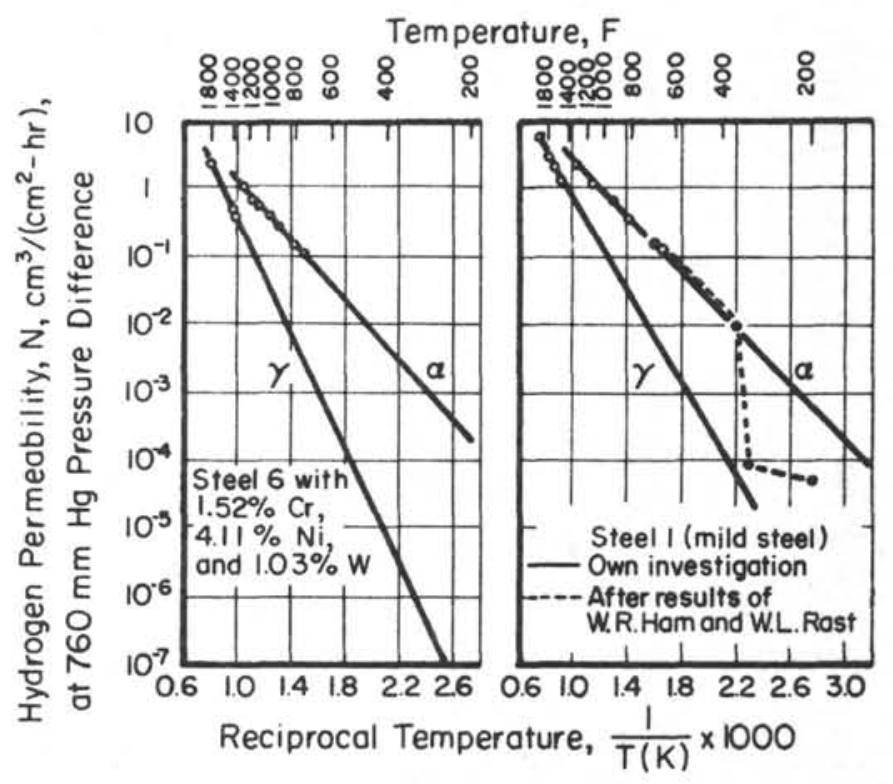
FIGURE 37. COMPARISON OF THE HYDROGEN PERMEABILITY OF AUST ENITE AND FERRITE AT VARIOUS TEM- PERATURES (CURVES EXTRAPOLA- TED) (158)

Effect of Steel Composition

Steel composition, if it has an effect on the movement of hydrogen in steel, might be expected to affect the diffusion of hydrogen through the bulk solid and, thereby, affect permeation. A few investigations have attempted to show the effect of steel composition on the diffusivity of hydrogen in steel. Most of the rest have merely examined the effect on overall permeation rate.

Geller and Sun(38) studied the effects of alloy additions upon the diffusivity of hydrogen in iron. The results, shown in Figure 35, indicate that alloy additions of silicon, chromium, or nickel decrease the diffusivity in either the $\alpha$ - or the $\gamma$ modification of iron. In measurements at room temperature, these investigators observed much smaller hydrogen-evolution rates for a supersaturated alloy containing 4.33 percent silicon than for a 25. 37 chromium-iron alloy. Specimens of alloys 
with 5.34 and 8.0 percent silicon (balance iron) showed no hydrogen evolution at all at room temperature.

Hobson(160) observed very low diffusion rates for a 14 percent chromium, ferritic stainless steel, as is shown by the following comparison:

\begin{tabular}{|c|c|c|c|}
\hline \multirow[b]{2}{*}{ Steel } & \multicolumn{3}{|c|}{$\begin{array}{l}\text { Approximate Diffusion Constant at Indicated } \\
\text { Temperature }, \mathrm{cm}^{2} / \mathrm{sec}\end{array}$} \\
\hline & $-108 \mathrm{~F}(-78 \mathrm{C})$ & Room Temp & $212 \mathrm{~F}(100 \mathrm{C})$ \\
\hline $2 \frac{1}{2} \mathrm{Ni}-\mathrm{Cr}-\mathrm{Mo}$ & $5.8 \times 10^{-9}$ & $3.2 \times 10^{-7}$ & 1. $34 \times 10^{-5}$ \\
\hline $3 \mathrm{Cr}-\mathrm{Mo}$ & $\sim 2.5 \times 10^{-9}$ & $\sim 5.0 \times 10^{-8}$ & - \\
\hline $14 \mathrm{Cr}$ & -- & $\sim 2.8 \times 10^{-9}$ & $\sim 3.2 \times 10^{-7}$ \\
\hline
\end{tabular}

It appears that the presence of chromium causes a large reduction in the rate of diffusion of hydrogen in iron. The high-chromium steels, though ferritic, are considered to be less susceptible to hydrogen defects than are chromium-free ferritic steels. This behavior may result from the much lower hydrogen-diffusion rates in the high-chromium steels as compared to steels low in chromium. Thus, one would expect the induction period before the onset of hydrogen cracking under sustained load to be much longer in high-chromium steels.

Chang and Bennett(41) studied the effects of chromium, nickel, and molybdenum on the rate of hydrogen permeation in iron. They found that chromium had little effect on permeation in the $\gamma$-range, but greatly reduced the rate of permeation in the $\alpha$-range. Nickel and molybdenum had little effect. Permeation in an Fe-4.25Cr alloy was less than one-tenth the rate obtained for Armco ingot iron over the temperature range from 750 to $1380 \mathrm{~F}$ ( 400 to $750 \mathrm{C}$ ), as is indicated in Figures 38 and 39. Note the anomalously low permeation rates obtained for the ingot iron at the lower temperatures, a finding which is consistent with observations by other investigators and which reflects the anomalously low diffusion rates obtained in the same temperature range (for example, see Figures $29,31,32$, and 33). The effect of chromium on permeation reflected the reduction in diffusivity by chromium.

Bhat and Lloyd(170) also observed that the addition of chromium effected a sizable reduction in permeation rate, as is shown in the following tabulation of the results of permeation during cathodic charging:

\begin{tabular}{|c|c|c|c|c|c|c|}
\hline$\frac{\text { Steel }}{\mathrm{C}}$ & $\begin{array}{c}\mathrm{ompos} \\
\mathrm{Ni} \\
\end{array}$ & $\frac{\mathrm{on}_{1} \%}{\mathrm{Cr}}$ & Treatment & $\begin{array}{r}\text { Hard- } \\
\text { ness, } \\
\text { Vickers } \\
\end{array}$ & $\begin{array}{l}\text { Time to } \\
\text { Start of } \\
\text { Evolu- } \\
\text { tion, min }\end{array}$ & $\begin{array}{c}\text { Rate of } \\
\text { Permea- } \\
\text { tion, } \\
\mathrm{cm}^{3} / \mathrm{hr}\end{array}$ \\
\hline 0.36 & 3.28 & - & $\begin{array}{l}\text { Water quenched from } \\
1560 \mathrm{~F} \text { and tempered } \\
\text { at } 1200 \mathrm{~F}\end{array}$ & 245 & 42 & 0.42 \\
\hline 0.32 & 3.29 & 0.87 & Ditto & 302 & 50 & 0.18 \\
\hline
\end{tabular}

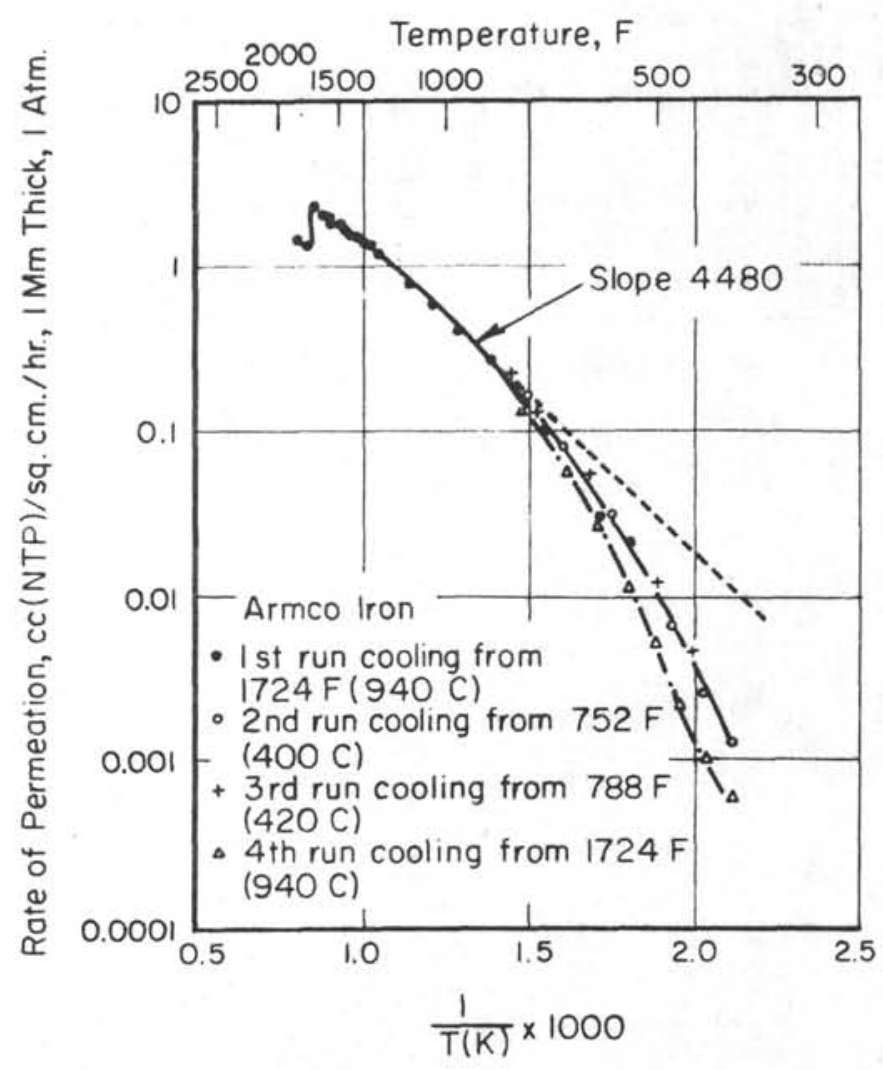

FIGURE 38. PERMEATION ISOBARS OF ARMCO $\operatorname{IRON}(41)$

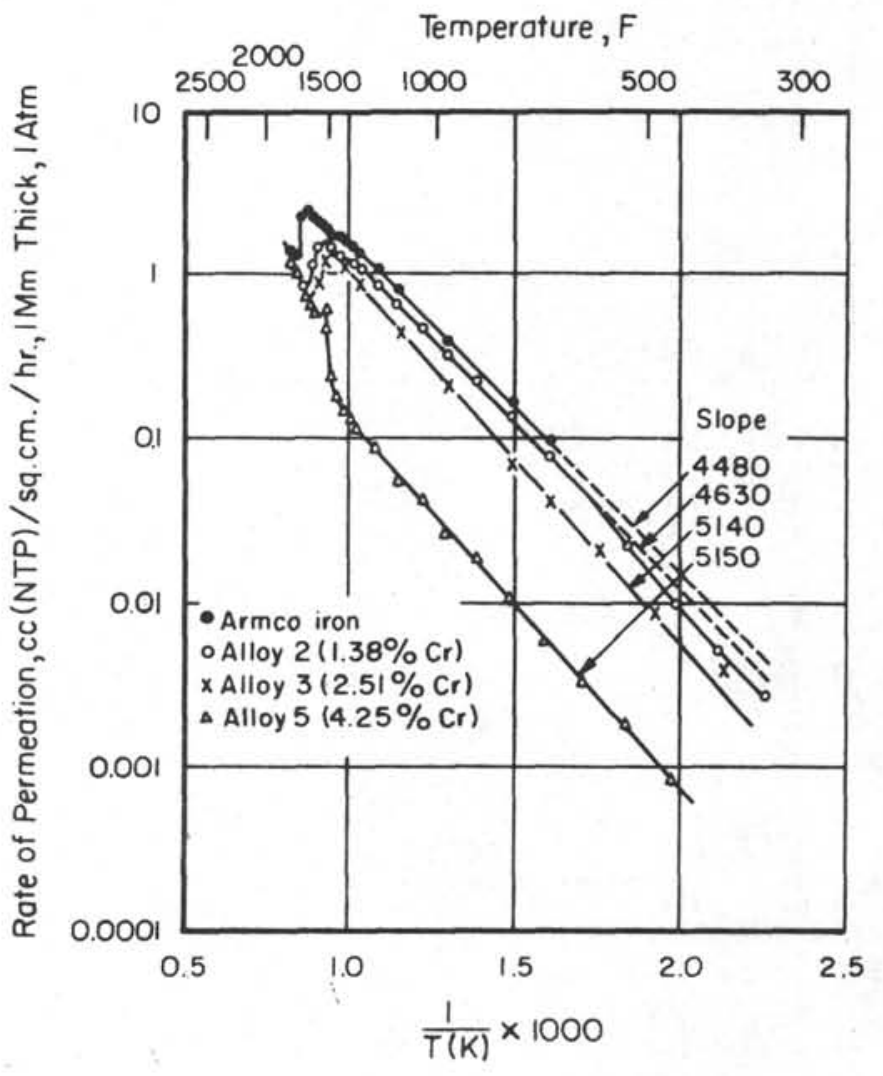

FIGURE 39. PERMEATION ISOBARS OF Fe-Cr ALLOYS(41) 
These investigators also determined the effect on permeation of variation in carbon content for normalized structures charged with hydrogen electrolytically. The results were as follows:

\begin{tabular}{cccccc}
$\begin{array}{c}\text { Carbon } \\
\text { Content } \\
\%\end{array}$ & & Treatment & $\begin{array}{c}\text { Hard- } \\
\text { ness, } \\
\text { Vickers }\end{array}$ & $\begin{array}{c}\text { Time to } \\
\text { Start of } \\
\text { Evolu- } \\
\text { tion, min }\end{array}$ & $\begin{array}{c}\text { Rate of } \\
\text { Permea- } \\
\text { tion, } \\
\mathrm{cm}^{3} / \mathrm{hr}\end{array}$ \\
\cline { 1 - 1 } 0.06 & & Normalized from 1705 F & 98 & 18 & 0.44 \\
0.31 & Normalized from 1650 F & 156 & 25 & 0.28 \\
0.59 & Normalized from 1560 F & 202 & 39 & 0.22
\end{tabular}

Their results indicated that increasing the carbon content decreased the permeation rate at room temperature considerably. According to Smialowski, (119) all opinions are now consistent with the statement first made by Bardenheuer and Thanheiser in 1929 that the presence of carbon considerably diminishes the hydrogen-permeation rate at ordinary temperatures. However, as will be shown subsequently in this report, the structural form of cementite ( $\mathrm{Fe}_{3} \mathrm{C}$ ) greatly influences the permeability of hydrogen through steel. At high temperatures, the effect of carbon content on hydrogen permeation through steel appears to be just the reverse of the above behavior, as is indicated by the results of Lewkonja and Baukloh's(171) experiments that are summarized in Figures 40 and 41. At the temperatures they used, hydrogen attack produces decarburization in time, and this phenomenon could have complicated the experiment.

As was discussed in the section dealing with the effect of crystal structure, Bennek and Klotzbach(158) measured the permeation of hydrogen through 10 steels of widely varying composition over a wide temperature range. The steels investigated were listed in Table 13. Steel composition had some influence on the permeability of hydrogen

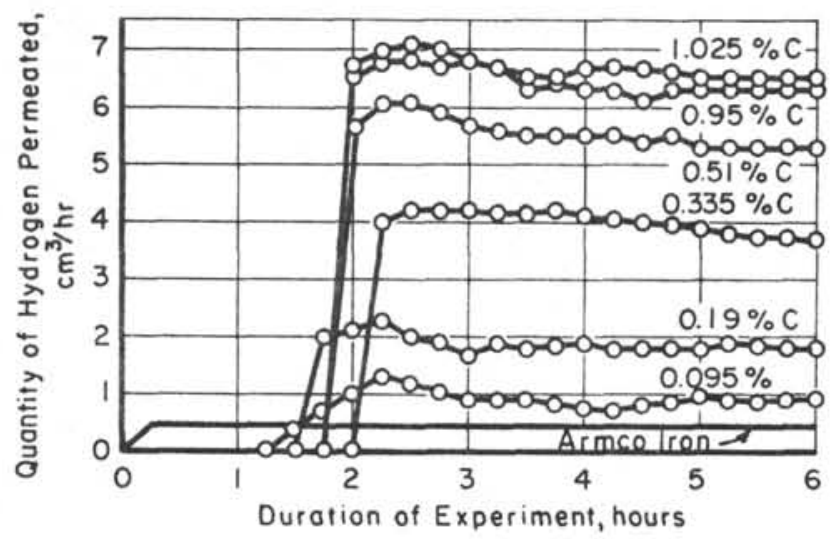

FIGURE 40. HYDROGEN PERMEATION OF PLAINCARBON STEELS AT 1562 F (850 C) AS A FUNCTION OF TIME (5-MM WALL THICKNESS) ${ }^{(171)}$ in a-iron, as can be seen from Figure 36. For the temperature range from 1380 to $750 \mathrm{~F}(750$ to $400 \mathrm{C})$, the results they reported for eight of the nine ferritic steels (including four carbon steels with $0.03,0.13,0.47$, and 0.99 percent $\mathrm{C}$, and four alloy steels including $0.72 \mathrm{Cr}-3.62 \mathrm{Ni}, 1.52 \mathrm{Cr}-$ $4.11 \mathrm{Ni}-1.03 \mathrm{~W}, 1.53 \mathrm{Cr}$, and $2.68 \mathrm{Cr} .0 .24 \mathrm{Mo})$ gave an average value of $5000 \pm 300$ for the constant $B$ in Equation 11 (page 16). Thus, the alloy additions had little if any effect on the activation energy for permeation $(B \cdot R)$ and, consequently, on the activation energy for diffusion, since the se experiments were performed at elevated temperatures where diffusion was rate controlling.

\section{Effect of Steel Microstructure}

Not only does the presence of carbon have considerable influence on the permeation of hydrogen through iron or steel, as was discussed in the preceding section of this report, but the physical form of the carbide particles exerts a very considerable influence, too. This effect arises largely from the effect of microstructure on diffusivity. Bardenheuer and Thanheiser $(62)$ investigated the effect of microstructure in a study of the acid pickling of steels that contained from 0.7 to 1.3 percent carbon. They observed 12 times greater hydrogen permeation rates when the cementite (iron carbide) was in globular form than when it was in the form of coarse lamellar pearlite. They also found that quenched steels had a lower permeability than annealed ones exhibited.

Smialowski(119) has described experiments that Nosyreva reported in 1948 in which the structure dependence of hydrogen permeation through a 0.84 percent carbon steel was studied. Nosyreva compared the permeation rates of cathodically evolved hydrogen at room temperature after various thermal treatments. The results of these experiments are given in Table 14. Nosyreva obtained

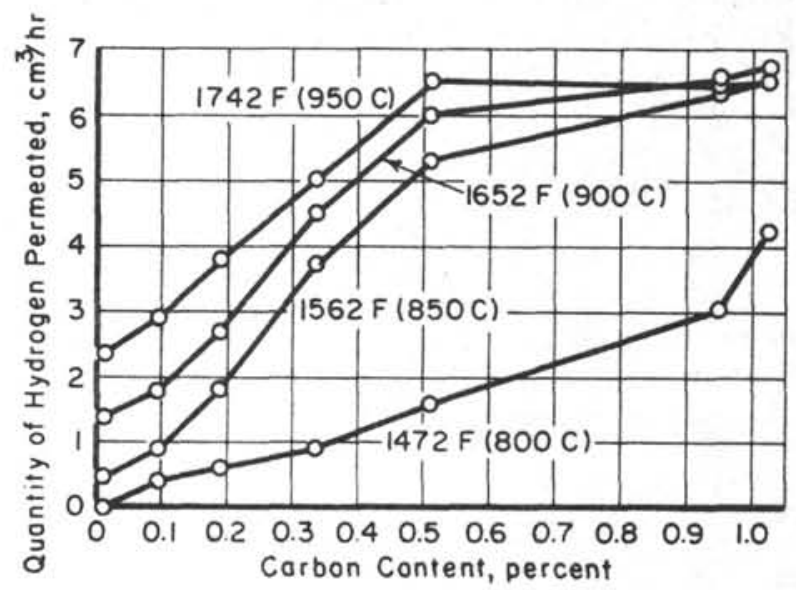

FIGURE 41. HYDROGEN PERMEATION OF PLAINCARBON STEELS AT VARIOUS TEMPERATURES AS A FUNCTION OF CARBON CONTENT ${ }^{(171)}$ 
a maximum permeability for the normalized condition. Bhat and Lloyd,(170) using electrolytic charging, compared the hydrogen permeation rates of various structures for a 0.59 percent carbon steel (as well as studying the effect of various carbon contents). As is shown in Table 15, martensite exhibited the maximum (a normalized ferrite gave the somewhat higher permeation rate of $0.44 \mathrm{~cm}^{3} / \mathrm{hr}$, but it had a low carbon content, of course). In 1957, Amiot reported the results of a thesis study of the effect of microstructure on the permeation of hydrogen through an a!loy steel $(0.26 \mathrm{C}, 0.25 \mathrm{Ni}, 1.02 \mathrm{Cr}, 0.30 \mathrm{Mo})$. His results have been summarized by Smialowski. (119) The results given in Table 16 show once again a minimum for martensite, but the maximum permeability observed was associated with the globular cementite, or spheroidite.

Thus, it appears that carbide particles in any form hinder the passage of hydrogen through steel, even after steady-state conditions have been reached. Cementite in the coarse spheroidized form appears to have the least effect on permeability; coarse lamellar pearlite offers more resistance to permeation than does fine pearlite; and martensite, in which the carbon atoms are present in the iron lattice but in which there is considerable strain, exhibits the lowest permeability of all.

\section{Effect of Metal Thickness}

If the rate of hydrogen flow is determined by the rate of diffusion, then under given conditions, the permeation should be inversely proportional to the thickness of the metal wall. Such a relationship was found by Edwards $(164)$ and by Darken and Smith (48) who studied the permeation of hydrogen through mild steel during acid pickling. Lewkonja and Baukloh(171) found the same relationship in studying hydrogenflow at high temperatures. According to Smialowski, (119) Raczynski in 1958 studied the permeation of cathodically evolved hydrogen through mild steel membranes of different thicknesses. Raczynski obtained the relation between permeation and the reciprocal of the thickness that is shown in Figure 42. No straightline relationship was observed for sheets less than $1-\mathrm{mm}$ thick. Such deviations from the law of inverse proportionality could be expected for the thinner membranes if surface processes on the entry and exit surfaces were influencing the permeation rate. In addition, using the time-lag method, Raczynski measured the apparent diffusion coefficient (D) of cathodically evolved hydrogen as a function of the thickness of the membrane. These results for mild steel at $194 \mathrm{~F}(90 \mathrm{C})$ are shown in Figure 43. For a wall thickness of $0.1 \mathrm{~mm}$, the apparent $D$-value was of the order of $0.7 \times 10^{-8}$ $\mathrm{cm}^{2} / \mathrm{sec}$. It increased rapidly with increasing thickness until at a thickness of about $0.9 \mathrm{~mm}$, a D-value of about $2 \times 10^{-5} \mathrm{~cm}^{2} / \mathrm{sec}$ was reached; no further increase was observed for thicker walls. This latter value agrees fairly well with that obtained by extrapolation from high-temperature

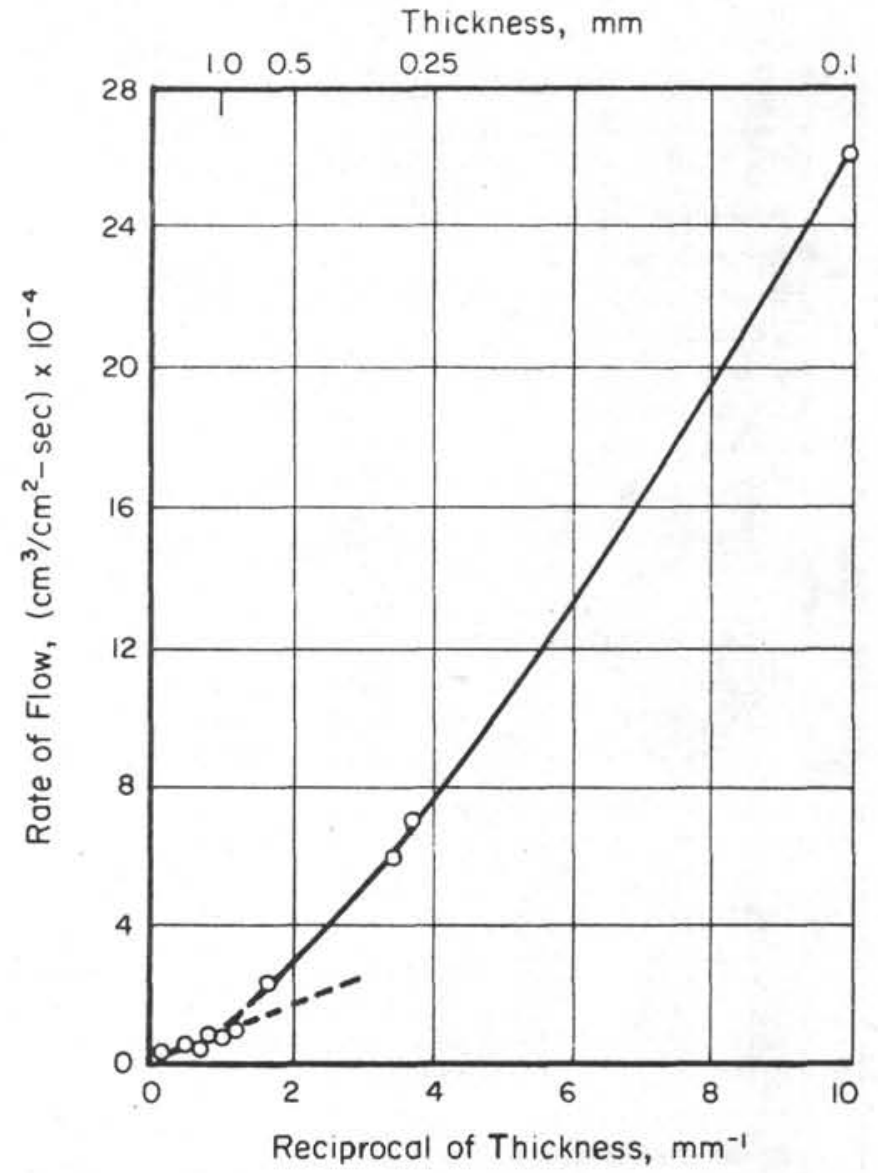

FIGURE 42. VARIATION OF THE RATE OF HYDROGEN FLOW WITH THE THICKNESS OF A MILD-STEEL MEMBRANE AT $194 \mathrm{~F}$ (90 C)(AFTER RACZYNSKI) (119)

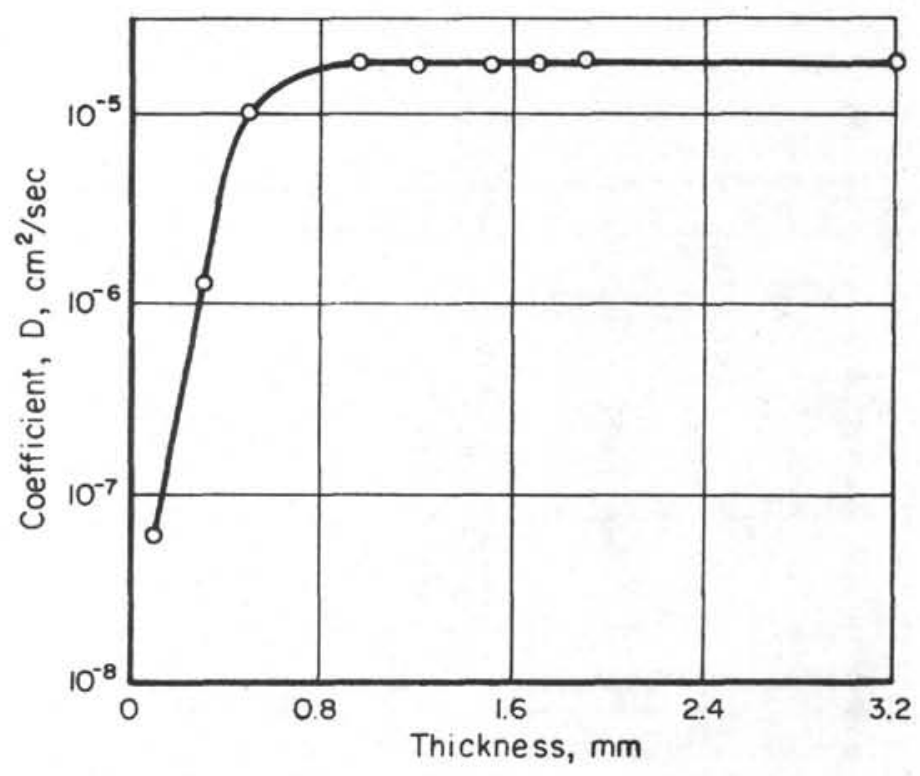

FIGURE 43. EFFECT OF PLATE THICKNESS ON THE VALUES OF D DETERMINED BY TIME-LAG METHOD FOR MILD STEEL CHARGED CATHODICALLY AT 194 F ( 90 C)(AFTER RACZYNSKI) (119) 
TABLE 14. VOLUMES OF HYDROGEN PERMEATING VARIOUS STRUCTURAL MODIFICATIONS OF 0.84 PERCENT CARBON STEEL (AFTER NOSYREVA)(119)

Structure

Volume of Hydrogen Permeated During 72 Hours, (a) $\mathrm{cm}^{3}$

Martensite

Products of isothermal decomposition at $392 \mathrm{~F}(200 \mathrm{C})(\mathrm{b})$

Troostite(c)

Sorbite(c)

Normalized steel

Annealed steel

1.10

1.11

2. 84

7.70

8.16

5.26

Globular cementite

3.95

(a) Electrolyte: 0.1 $\mathrm{N} \mathrm{H}_{2} \mathrm{SO}_{4}$; Temperature: 62.5-64.5 F (17-18 C); Cathodic Current Density: 0.014 amp/ $\mathrm{cm}^{2}$; Membrane Thickness: $0.5 \mathrm{~mm}$.

(b) Lower bainite.

(c) A term, no longer used in the United States, the meaning of which is somewhat vague. This term was used formerly to designate various types of structures including intermediate transformation products of austenite decomposition and some tempered martensites.

TABLE 15. HYDROGEN-PERMEATION RATES THROUGH 0.59 PERCENT CARBON STEEL TUBES TREATED TO GIVE DIFFERENT MICROSTRUCTURES(170)

Cathodically charged at room temperature with a cathodic current density of $0.3 \mathrm{amp} / \mathrm{cm}^{2}$.

\begin{tabular}{|c|c|c|c|c|}
\hline Treatment & Structure & $\begin{array}{l}\text { Hardness, } \\
\text { Vickers }\end{array}$ & $\begin{array}{l}\text { Time to Start } \\
\text { of Evolution, } \\
\text { minutes }\end{array}$ & $\begin{array}{c}\text { Permeation } \\
\text { Rate, } \\
\mathrm{cm}^{3} / \mathrm{hr}\end{array}$ \\
\hline $\begin{array}{l}\text { Normalized from } 1560 \mathrm{~F} \\
(850 \mathrm{C})\end{array}$ & $\begin{array}{l}\text { Coarse lamellar pearlite and } \\
\text { ferrite }\end{array}$ & 202 & 39 & 0.22 \\
\hline $\begin{array}{l}\text { Isothermally treated at } \\
895 \mathrm{~F}(480 \mathrm{C})\end{array}$ & Very fine pearlite and ferrite & 290 & 35 & 0.39 \\
\hline $\begin{array}{l}\text { Water quenched from } \\
1560 \mathrm{~F}(850 \mathrm{C})\end{array}$ & Martensite & 850 & 45 & 0.14 \\
\hline
\end{tabular}

TABLE 16. EFFECT OF STRUCTURE ON THE PERMEATION OF CATHODICALLY EVOLV ED HYDROGEN THROUGH AN ALLOY STEEL (AFTER AMIOT)(119)

\begin{tabular}{|c|c|c|}
\hline Treatment $^{(a)}$ & Structure & $\begin{array}{c}\text { Permeation Rate, (b) } \\
\mathrm{cm}^{3} / \mathrm{sec} / \mathrm{cm}^{2}\end{array}$ \\
\hline Oil quenched & Martensite & $3.7 \times 10^{-7}$ \\
\hline Water quenched, tempered at $1020 \mathrm{~F}(550 \mathrm{C})$ & Tempered martensite & $3.8 \times 10^{-7}$ \\
\hline Isothermally transformed at $660 \mathrm{~F}(350 \mathrm{C})$ & Fine bainite & $5.8 \times 10^{-7}$ \\
\hline Isothermally transformed at $840 \mathrm{~F}(450 \mathrm{C})$ & Coarse bainite & $7.2 \times 10^{-7}$ \\
\hline Isothe rmally transformed at $1110 \mathrm{~F}(600 \mathrm{C})$ & Fine lamellar pearlite & $11 \times 10^{-7}$ \\
\hline Isothermally transformed at $1335 \mathrm{~F}(725 \mathrm{C})$ & Coarse lamellar pearlite & $8 \times 10^{-7}$ \\
\hline Spheroidized at 1380 and $1255 \mathrm{~F}(750$ and $680 \mathrm{C})$ & Spheroidite & $12 \times 10^{-7}$ \\
\hline
\end{tabular}

(a) Austenitized for 30 minutes at $1605 \mathrm{~F}(875 \mathrm{C})$ in each case prior to the treatment listed.

(b) Electrolyte: $1 \mathrm{~N} \mathrm{HCl}$; Temperature: room temperature; Cathodic Current Density: 0.015 amp/cm². 
measurements. Smialowski has suggested that the reason that false $D$-values are obtained when using the time-lag method for thin iron walls is probably that the cathodically evolved hydrogen changes or damages the metal structure in the surface layer and this damaged layer constitutes an appreciable proportion of the total thickness in a thin membrane.

\section{Effect of Cold Work}

A number of investigators have studied the effects of elastic and plastic deformation on the rate at which hydrogen permeates steel at.room temperature, but only a few have studied their effect on the diffusion of hydrogen. From preceding sections, it is obvious that controversial opinions exist concerning the effect of cold work upon the occlusion of hydrogen in iron and steel. It will be shown in the following discussion that the results obtained for permeability likewise are controversial. Since the majority of investigators have studied permeation of hydrogen in iron and steel by the steady-state permeation-rate method which depends on solubility and diffusivity, it is to be expected that results obtained for diffusivity would be controversial, too.

Chaudron and Moreau(172) observed that cold work accelerated the permeation of hydrogen during pickling. However, Bastien $(173,174)$ reported that the permeation of hydrogen is faster for annealed steels than for cold-worked ones during cathodic charging, even though the cold-worked steels absorbed twice as much hydrogen. Rather similar results were obtained by Bhat and Lloyd, (170) who investigated the effects of cold work on the rate at which hydrogen permeated a number of ferritic steels. Although the magnitude of the effects varied from steel to steel, in all cases severe plastic deformation caused a decrease in the permeation rate. Without exception, increasing severity of cold work in the range of 0 to 70 percent reduction resulted in a decrease in permeation rate. A decrease by a factor of 10 as the result of about 70 percent reduction in area was not uncommon. This was accompanied by an increase in the quantity of hydrogen occluded during their cathodic charging. Still another viewpoint was the conclusion arrived at by Darken and $\mathrm{Smith}(48)$ that cold work had no effect on the permeability, though the maximum amount of hydrogen absorbed during pickling and the rate of absorption increased with the amount of cold deformation. When cathodically charging hydrogen through low-carbon steel sheet by the stationary-flow method, Schumann and Erdmann-Jesnitzer (175) observed that the permeation rate first increased with increasing cold work and passed through a maximum at about 10 to 20 percent cold reduction, then decreased rapidly with further deformation; for sheets cold worked 60 to 90 percent, the permeability was nearly zero (see Figure 44). Thus, four markedly different behaviors for the effect of cold work on the permeation of hydrogen through steel have been described.

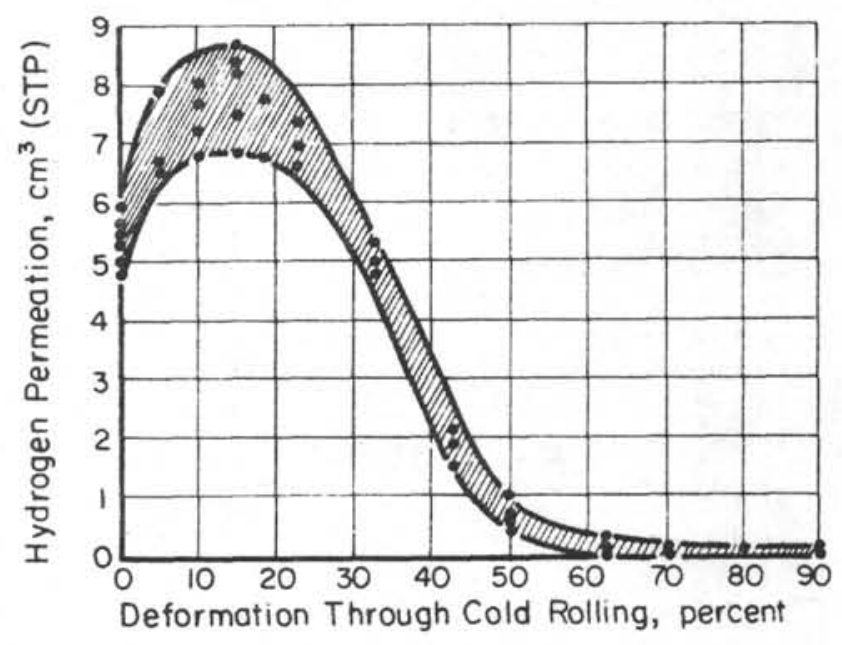

\section{FIGURE 44. HYDROGEN PERMEATION AS A FUNCTION OF THE DEGREE OF COLD ROLLING(175)}

Previously, the work of Hudson et al $(52,60,176)$ on the effects of cold reduction and heat-treating conditions on the hydrogen solubility $\left(C_{s}\right)$ in mild steel was discussed. These investigators also reported the change in hydrogen permeability, $\mathrm{P}$, produced by these variables. The hydrogensolubility values were taken from the saturation plateaus obtained on the hydrogen-absorption curves they determined. They defined hydrogen permeability, P, as the quantity of hydrogen (cc at standard temperature and pressure) transferred in 1 second through a diaphragm $1 \mathrm{~mm}$ thick and $1 \mathrm{~cm}^{2}$ in cross section. The values reported were calculated using the equation

$$
P=1.25 \rho \frac{\lambda^{2} b^{2}}{C_{s}}
$$

derived by Darken and Smith, (48) but changing the units to fit their experiment. This gave the equation

$$
\mathrm{P}=2.73 \times 10^{-7} \frac{\lambda^{2} \mathrm{~b}^{2}}{\mathrm{C}_{\mathrm{s}}},
$$

where $\lambda$ is the slope of the hydrogen-absorption curve (the hydrogen concentration in the steel plotted against the square root of the time in hours), that is, $\mathrm{cm}^{3} / 100 \mathrm{~g} /(\mathrm{hr})^{1 / 2} ; \mathrm{C}_{\mathrm{s}}$ is the hydrogen solubility in $\mathrm{cm}^{3} / 100 \mathrm{~g}$; b is the thickness of the specimen in $\mathrm{mm}$; and the density of the steel $(\rho)$ was taken as $7.8 \mathrm{~g} / \mathrm{cm}^{3}$. The effects of cold-reduction and heat-treatment combinations on hydrogen permeability are shown in Table 17 and in Figure 45. Increasing the amount of cold reduction increased the hydrogen solubility for the entire range of reductions used. Increasing the cold reduction also increased the hydrogen permeability until a maximum was reached (below 30 percent reduction for initially hot-rolled steel), after which the permeability decreased as the amount of cold work increased further. These results are rather similar to 

BILITY AND HYDROGEN PERMEABILITY IN STEEL(60)

\begin{tabular}{|c|c|c|c|c|}
\hline $\begin{array}{l}\text { Initial Cold } \\
\text { Reduction, } \\
\text { percent }\end{array}$ & $\begin{array}{l}\text { Box Anneal } \\
{[4 \mathrm{Hr} \text { at } 1200 \mathrm{~F}(650 \mathrm{C})]}\end{array}$ & $\begin{array}{l}\text { Second Cold } \\
\text { Reduction, } \\
\text { percent }\end{array}$ & $\begin{array}{l}\text { Hydrogen } \\
\text { Solubility, } \\
\text { cc/100 g }\end{array}$ & $\begin{array}{c}\text { Hydrogen } \\
\text { Permeability, (a) } \\
\text { P } \times 10^{6}\end{array}$ \\
\hline 3.7 & No & in & 4.7 & 6.3 \\
\hline 28.3 & No & No & 7.1 & 8.1 \\
\hline 47.3 & No & No & 10.2 & 4.5 \\
\hline 67.6 & No & No & 20.0 & 2.6 \\
\hline 78.2 & No & No & 20.9 & 2.0 \\
\hline 2.1 & Yes & No & 2.1 & 1.2 \\
\hline 28.3 & Yes & No & 6.2 & 0.43 \\
\hline 47.0 & Yes & No & 7.3 & 0.61 \\
\hline 67.6 & Yes & No & 9.0 & 1.1 \\
\hline 78.0 & Yes & No & 4.8 & 0.75 \\
\hline 3.2 & Yes & 60 & 21.2 & 0.19 \\
\hline 28.3 & Yes & 60 & 14.2 & 0.44 \\
\hline 45.2 & Yes & 60 & 17.9 & 0.46 \\
\hline 66.8 & Yes & 60 & 20.2 & 0.09 \\
\hline 78.1 & Yes & 60 & 23.0 & 0.09 \\
\hline 78.0 & Yes & 0 & 4.8 & 0.75 \\
\hline 78.3 & Yes & 15 & 5.2 & 4.5 \\
\hline 78.6 & Yes & 30 & 7.7 & 1.6 \\
\hline 78.0 & Yes & 45 & 12.8 & 0.18 \\
\hline 78.1 & Yes & 60 & 23.0 & 0.09 \\
\hline
\end{tabular}

(a) Permeability was defined as the quantity of hydrogen $\left(\mathrm{cm}^{3}\right.$ at standard temperature and pressure) transferred in 1 second through a diaphragm $1 \mathrm{~mm}$ thick and $1 \mathrm{sq} \mathrm{cm}$ in cross section.

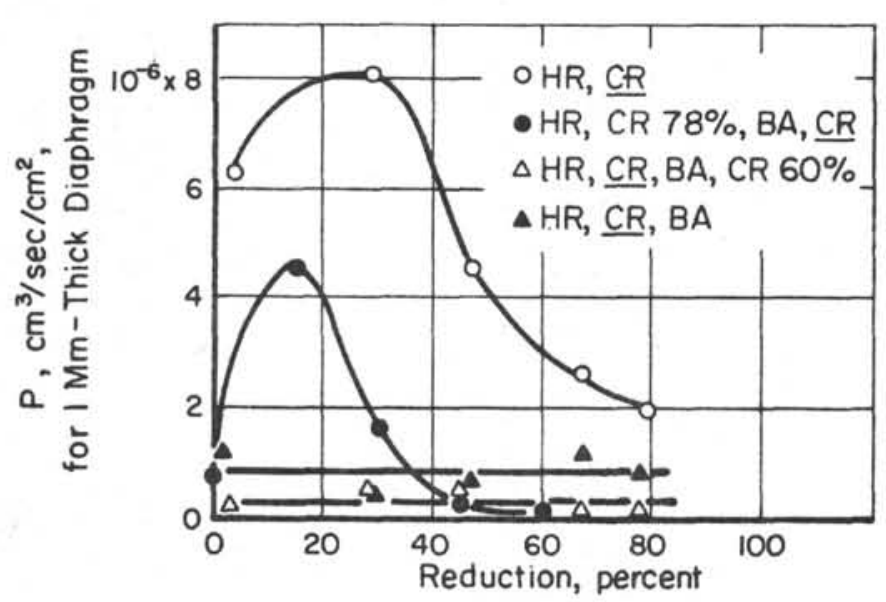

FIGURE 45. EFFECT OF COLD-REDUCTION AND HEAT-TREATMENT COMBINATIONS ON HYDROGEN PERMEABILITY IN $\operatorname{STEEL}(60)$

[HR $=$ hot rolled; $\mathrm{CR}=$ cold rolled $\mathrm{BA}=\mathrm{box}$ annealed $4 \mathrm{hr}$ at $1200 \mathrm{~F}(650 \mathrm{C})$ in a dry atmosphere containing 5 percent hydrogen and 95 percent nitrogen: $\underline{C R}=$ cold-rolling stage in which various reductions (as plotted in the figure) were used.] those obtained by Schumann and Erdmann-Jesnitzer (mentioned on the preceding page).

De Kazinczy ${ }^{(177)}$ imposed a variable, axial tensile stress on cylindrical tubes that were immersed in an electrolytic cell. He used the steadystate method. The tubes originally were evacuated and the buildup of the pressure of accumulating hydrogen was measured. At stresses below the yield point, there was a reversible change in the permeation rate that was proportional to the applied tensile stress (see Figure 46). The maximum increase in permeation rate due to elastic stress was about 6 percent; it occurred at stresses just below the yield point. An increased rate of flow almost proportional to the applied tensile stress was observed for stresses up to just about 0.2 percent offset yield strength. However, when the specimens were stressed beyond the yield point to at least 0.6 percent plastic elongation, the plastic flow caused the permeation rate to be increased appreciably above the straight-line relationship observed for elastic stresses, as is shown in Figure 47. After the applied stress was removed, specimens that had been permanently strained about 7 percent were found to have acquired a permanent increase in permeability of about 3 to 5 percent. On the 
basis of thermodynamic calculations, De Kazinczy concluded that the increased permeation rate resulting from elastic strain was almost entirely due to an increase in solubility in the lattice and not to an increase in diffusivity. * The additional increase in permeation rate accompanying plastic deformation was attributed to stress multiplication in certain zones (probably along slip planes) in which the hydrogen flow was increased.

Elsea and co-workers(148) performed a permeation experiment which indicated that a uniaxial tensile stress of 50,000 psi had no measurable effect on either the diffusion coefficient or the solubility of hydrogen in high-strength SAE 4340 steel. This behavior was shown as follows: an unstressed tubular specimen with a 0.037-inch wall thickness was charged cathodically at a current density of $10 \mathrm{ma} /$ in. $^{2}$ for 24 hours. The current then was charged abruptly to produce a current density of $30 \mathrm{ma} / \mathrm{in}^{2}$ with the specimen remaining unstressed. After a steady-state flow of hydrogen had been obtained, the current was lowered to again produce a current density of $10 \mathrm{ma} / \mathrm{in} .^{2}$, and a tensile stress of 50,000 psi was applied. After an extended period, the current again was raised abruptly to produce a current density of $30 \mathrm{ma} / \mathrm{in} .2$ The steady-state flow rates of hydrogen at the high and low current densities and the times to obtain a steady-state flow rate of hydrogen following the abrupt change of current were unaffected by the stress, within the limits of experimental accuracy.

Hill and Johnson $(14,167)$ found that the diffusivity in an iron-carbon alloy was decreased manyfold in the temperature range 480 to $750 \mathrm{~F}$ ( 250 to 400 C) by cold working. Since cold working increased the absorption by about the same factor, the permeability should have remained approximately constant. The experiments were performed with iron-carbon alloys that contained 0.16 percent carbon. These investigators found that cold work decreased the diffusivity at temperatures throughout the range from 390 to $750 \mathrm{~F}(200$ to $400 \mathrm{C})$. Also, the effect increased as the severity of the *This constitutes further evidence that hydrogen diffuses in annealed steel homogeneously through the lattice.

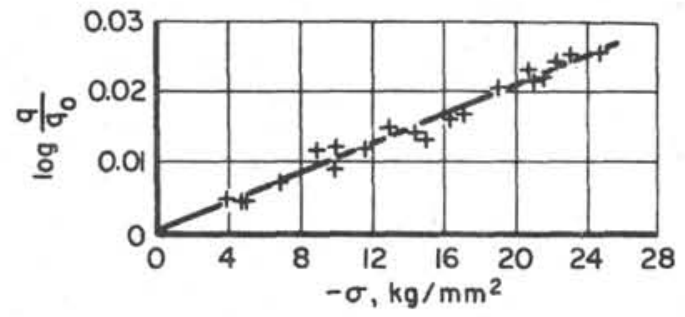

FIGURE 46. INCREASE OF HYDROGEN FLOW IN ANNEALED STEEL STRESSED ELASTICALLY (177)

(Note: $q$ is the amount of hydrogen that passed through a unit length of cylindrical tube per unit time under steady-state conditions.) cold work increased, just as these investigators found for hydrogen solubility in the same alloy. (14) Part of these results are shown in Figure 32. These workers hypothesized that the effect of cold work on diffusivity would become more severe with increasing carbon content because this trend was found in the solubility measurements. The two short curves in the temperature range 77 to 212 F (25 to $100 \mathrm{C}$ ) in Figure 32, when compared with the curve for unstrained pure iron, show the effect of cold work on the diffusivity in pure iron. These curves represent the diffusivity in samples that had been strained plastically 8 and 23 percent in uniaxial tension at room temperature after introduction of hydrogen by pressure charging. Again, as was found for the ironcarbon alloy, the effect of cold work was to reduce the value of the diffusion coefficient. The early stages of strain were proportionately more effective in lowering the coefficient.

These results for cold-worked iron were obtained with samples that had been strained at room temperature. A significant difference was observed when samples were strained at $-240 \mathrm{~F}$ $(-150 \mathrm{C})$ prior to measurement of the diffusivity. Such deformation had little or no effect on the diffusion coefficient, the values being essentially the same as those obtained from unstrained samples.

In a previous section, work of Darken and Smith(48) was discussed in which they showed that cold work had a pronounced effect on the solubility of hydrogen introduced into steel by acid charging (pickling). A 0.15 percent carbon steel rod was hot worked, being above $1650 \mathrm{~F}(900 \mathrm{C})$ in all hotworking operations. This was called "green rod". It was pickled and then baked to remove the hydrogen introduced by the pickling treatment. It was then cold drawn through wire-drawing dies in five steps, with no intermediate anneal. Cold work markedly increased the absorption rate, the time to reach saturation, and the saturation concentration or amount of absorbed hydrogen. Although cold reduction markedly affected absorption, it did not affect the permeability, as calculated from the slope $(\lambda)$ of the plot of hydrogen concentration

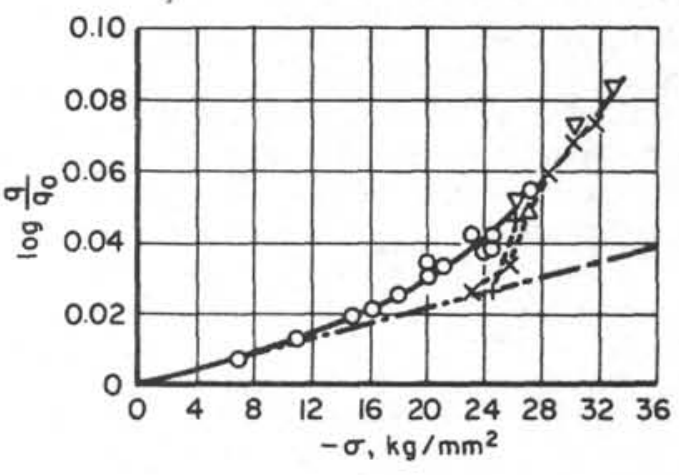

FIGURE 47. INCREASE OF HYDROGEN FLOW IN STEEL SUBJECTED TO PLASTIC DEFORMATION(177) 
versus the square root of the time, using the relation

$$
P=9.8 \lambda_{a^{2}} /\left(t_{s}\right)^{1 / 2},
$$

which they derived ( $a$ is the radius of the wire and $t_{s}$ is the time required to reach saturation). This is shown as follows:

\begin{tabular}{|c|c|c|c|}
\hline Sample Designation & $\begin{array}{c}\begin{array}{c}\text { Diameter, } \\
\text { inch }\end{array} \\
\end{array}$ & $\begin{array}{c}\text { Reduction } \\
\text { in Area, } \\
\text { percent }\end{array}$ & $\begin{array}{l}\text { Permeability, } \\
\mathrm{P}(\mathrm{a})\end{array}$ \\
\hline Green rod & 0.503 & 0 & $1.28 \times 10^{-6}$ \\
\hline After 1st reduction & 0.460 & 16.5 & $1.26 \times 10^{-6}$ \\
\hline After 2 nd reduction & 0.419 & 30.6 & $1.36 \times 10^{-6}$ \\
\hline After 3 rd reduction & 0.369 & 46.2 & 1. $18 \times 10^{-6}$ \\
\hline After 4th reduction & 0.315 & 60.8 & $1.29 \times 10^{-6}$ \\
\hline After 5 th reduction & 0.249 & 75.9 & $1.23 \times 10^{-6}$ \\
\hline & & Av & $1.26 \times 10^{-6}$ \\
\hline $\begin{array}{l}\text { Annealed after } 5 \text { th } \\
\text { reduction }\end{array}$ & 0.249 & 0 & $<0.24 \times 10^{-6}$ \\
\hline
\end{tabular}

(a) In $\mathrm{N} \mathrm{H}_{2} \mathrm{SO}_{4}$.

Thus, although cold reduction did not alter the permeability, annealing the cold-worked material decreased it by a factor of at least 5 .

Some of the most recent work is that of Bryan and Dodge. (49) They studied the permeation rate by maintaining a constant pressure of hydrogen inside a tubular specimen which was placed inside an evacuated jacket. The rate of permeation of hydrogen through a highly purified iron (Ferrovac E) was measured over the pressure range of $1 / 30$ to 300 atmospheres and the temperature range from 259 to $1279 \mathrm{~F}$ (126 to $693 \mathrm{C})$. No difference was observed in the permeability or diffusivity between the tube that had been cold reduced 26 percent and the same tube subsequently annealed. This is in sharp contrast to the case of carbon steels where the diffusivity is sharply decreased by cold working.

\section{Diffusion of Deuterium}

Frank, Lee, and Williams (46) determined the diffusion coefficients of hydrogen and deuterium in SAE 1010 steel for the temperature range from 79 to $187 \mathrm{~F}$ ( 26 to $86 \mathrm{C}$ ). A mixture of the two gases was introduced into the steel by abrasion in a mixture of 15 percent normal water $\left(\mathrm{H}_{2} \mathrm{O}\right)$ and 85 percent heavy water $\left(D_{2} O\right)$; this composition was selected because it provided nearly equal permeation rates for hydrogen and deuterium. A mass spectrometer was used to measure simultaneously the rates of evolution of $\mathrm{H}_{2}, \mathrm{HD}$, and $\mathrm{D}_{2}$ from the steel. The diffusion coefficients were measured by observing the rates of decay of the diffusion rates as a function of elapsed time after the process of introducing the isotopes was stopped. A plot of the diffusion coefficients for hydrogen and deuterium in the steel is shown in Figure 48. The ratio of the diffusion coefficient of hydrogen to that of deuterium was found to be constant within the limits of experimental error over the entire temperature range investigated; it had a value of $1.37 \pm 0.02$, which is very close to the square root of the ratio of the masses (1.414) which one might expect to get on the basis of simple kinetic theory. This ratio held, even at the lower temperatures where the curves in Figure 48 showed some deviation from a straight line. However, the ratio of the permeation rates varied with variation in temperature (see the tabulation below), reflecting the variation in the ratio of the solubilities of hydrogen and deuterium with temperature.

\begin{tabular}{|c|c|c|}
\hline C & $F$ & $\underline{P}_{H} / P_{D}$ \\
\hline 86 & 187 & 9.5 \\
\hline 80 & 176 & 10.7 \\
\hline 79 & 174 & 10.1 \\
\hline 60 & 140 & 6.1 \\
\hline 60 & 140 & 6.8 \\
\hline 52 & 126 & 4.4 \\
\hline 52 & 126 & 4.6 \\
\hline 50 & 122 & 6.7 \\
\hline 42 & 108 & 5.8 \\
\hline 34 & 93 & 4.9 \\
\hline 26 & 79 & 4.5 \\
\hline 26 & 79 & 4.8 \\
\hline
\end{tabular}

Within the limits of experimental error, there was no difference in the activation energies for hydrogen and deuterium diffusion (the two curves in Figure 48 having the same slope). In a previous paper, Frank and co-workers pointed out that the evolution of hydrogen from steel may not result from simple interstitial diffusion. If it does not, then one need not expect to get a difference in activation energies for hydrogen and deuterium as other authors have suggested. The results of these experiments indicated that, whatever the mechanism of the diffusion process at and near room temperature, the principal difference in the diffusion coefficients of hydrogen and deuterium is the result of the mass effect, and this does not vary with temperature.

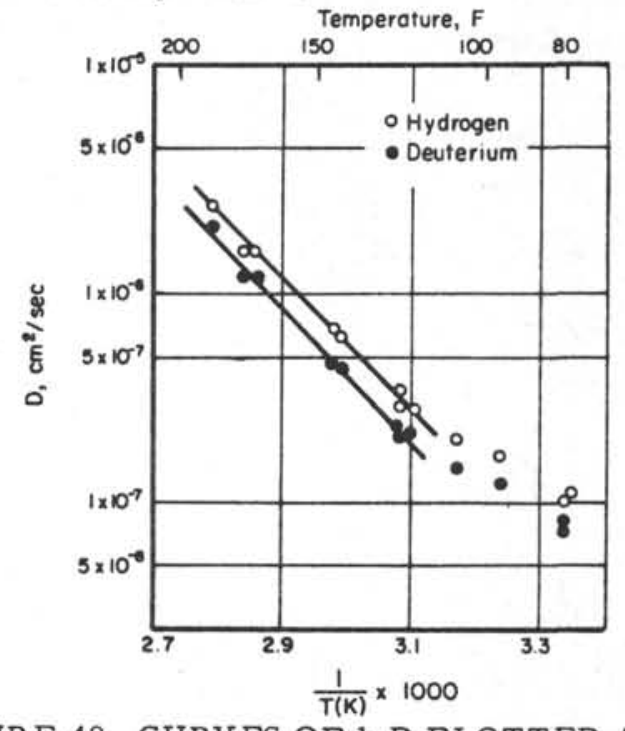

FIGURE 48. CURVES OF InD PLOTTED AGAINST 1/T x 1000 FOR HYDROGEN AND DEUTERIUM(46) 
Apparently, no data for the diffusivity of the third isotope, tritium, in steel are generally available.

\section{Removal of Hydrogen}

Although under certain corrosive conditions the hydrogen content of steel will increase during storage, in normally dry air hydrogen is constantly being lost from a piece of ferritic or martensitic steel until the hydrogen content of the steel reaches equilibrium with its environment. The rate of loss depends on, and varies greatly with, such factors as temperature, thickness of the material, whether the steel is ferritic or austenitic, and the amount of cold work.

\section{The Effects of Temperature, Section Size,} and Steel Composition

The loss of hydrogen from an austenitic steel is imperceptible at room temperature. Carter(178) found that no measurable quantity of hydrogen escaped at room temperature from austenitic samples in a period of 3 months, even though they contained 2 to 5 times as much hydrogen as the ferritic samples from which as much as 61 percent of the total hydrogen content was evolved in 10 days.

In general, the rate of hydrogen evolution from all steels increases with increasing temperature, at least within a few hundred degrees of room temperature. Hydrogen has been observed escaping from 5/8-inch-diameter cylinders of chill-cast ferritic steel at room temperature within 10 to 15 minutes after casting. (179) In 2 weeks at room temperature, such specimens lost as little as 10 percent or as much as 80 percent of their total hydrogen. The rest of the hydrogen evolved extremely slowly, if at all. $(180,181)$ From these latter investigations, it appears that aging to remove hydrogen from ferritic steel is roughly 250 to 500 times faster at $400 \mathrm{~F}$ than it is at room temperature, and that the aging time increases as the $3 / 2$ power of specimen size. This means that the time increases directly with increasing volume and inversely with increase in surface area. Therefore, for a cylindrical bar, the time increases as the square of the diameter. Hence, removal from large masses is very slow. For 1 -inch-square cast coupons of carbon steel, 60 days at room temperature was required to reduce the hydrogen to the "equilibrium" level, whereas it was estimated that 6 years would be required for 4 -inch coupons. $(180,181,182)$ At $400 \mathrm{~F}$, the time required to accomplish the same results were 6 hours and 100 hours, respectively.

Hobson $(160,183)$ has studied the removal of hydrogen from steel, with particular attention to its removal from large masses. The marked effects of temperature and the effects of holding time at a given temperature on the residual fraction (U) of hydrogen remaining in the steel are shown in
Figure 49. Note that two different time scales have been used to show the extremes of rate. Based on the time to reach $U=0.5$, and taking the rate at room temperature as unity, the rate at $392 \mathrm{~F}(200 \mathrm{C})$ was 209 times faster and the rate at $-110 \mathrm{~F}(-78 \mathrm{C})$ was $1 / 50$ as fast (as is shown in Table 18). From these results, it is obvious that the theoretical equation (of Sykes) is extremely misleading at temperatures below $392 \mathrm{~F}(200 \mathrm{C}) *$. The effects of section size (cylinder diameter) are shown in Figures 50 and 51 for two different steels. In Figures $50 \mathrm{a}$ and $5 \mathrm{la}$, the residual fraction of hydrogen has been plotted directly against time. In Figures $50 \mathrm{~b}$ and $5 \mathrm{lb}$, the residual fraction has been plotted directly against time reduced to a common diameter of $11.25 \mathrm{~mm}$. Theory predicts that for the latter arrangement the curves for a given steel should coincide. In practice, there was considerable scatter of the evolution curves, but this scatter was random for the different sizes of steel. It was concluded that the square law is followed approximately. Comparison of the two steels of Figures 50 and 51 shows that for a specimen of a given size the evolution was slower by a factor of about 40 for the $14 \mathrm{Cr}$ steel than for the 2. $5 \mathrm{Ni}-\mathrm{Cr}-\mathrm{Mo}$ steel. Table 19 compares the results for all 9 steels studied.

*See the section dealing with the effect of temperature on diffusion of hydrogen in steel in which it is shown that anomalously low diffusivities are encountered at temperatures below $750 \mathrm{~F}(400 \mathrm{C})$.

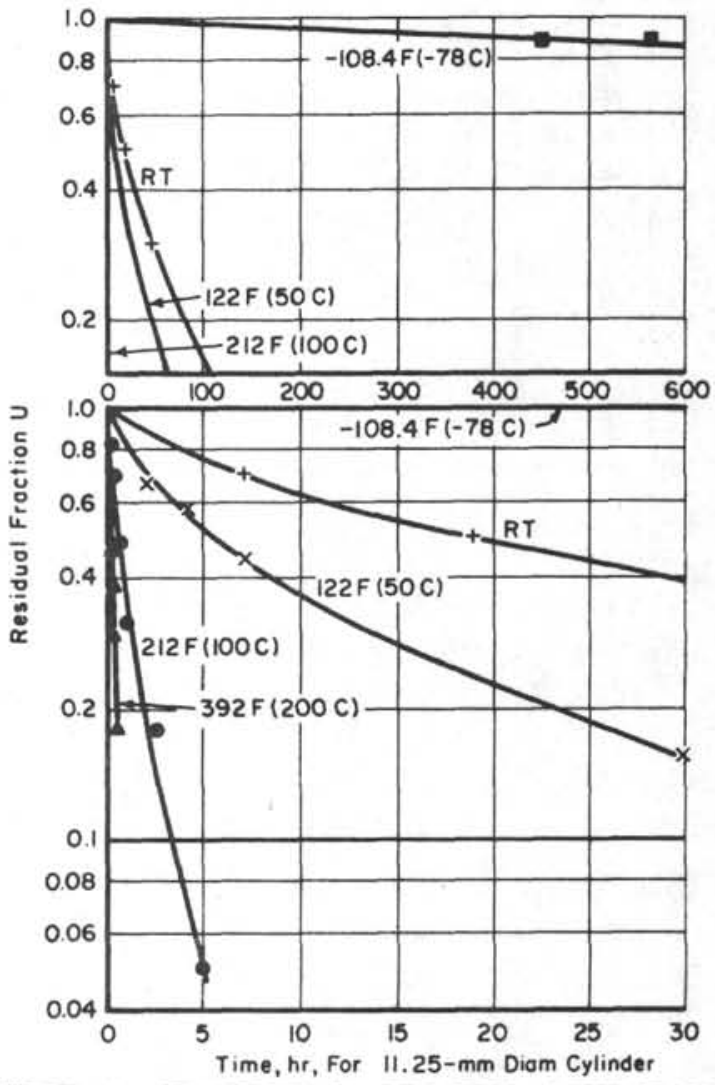

FIGURE 49. EFFECT OF TEMPERATURE ON RATE OF HYDROGEN EVOLUTION FROM 2. $5 \mathrm{Ni}-\mathrm{Cr}-\mathrm{MO}$ STEEL A(160) 


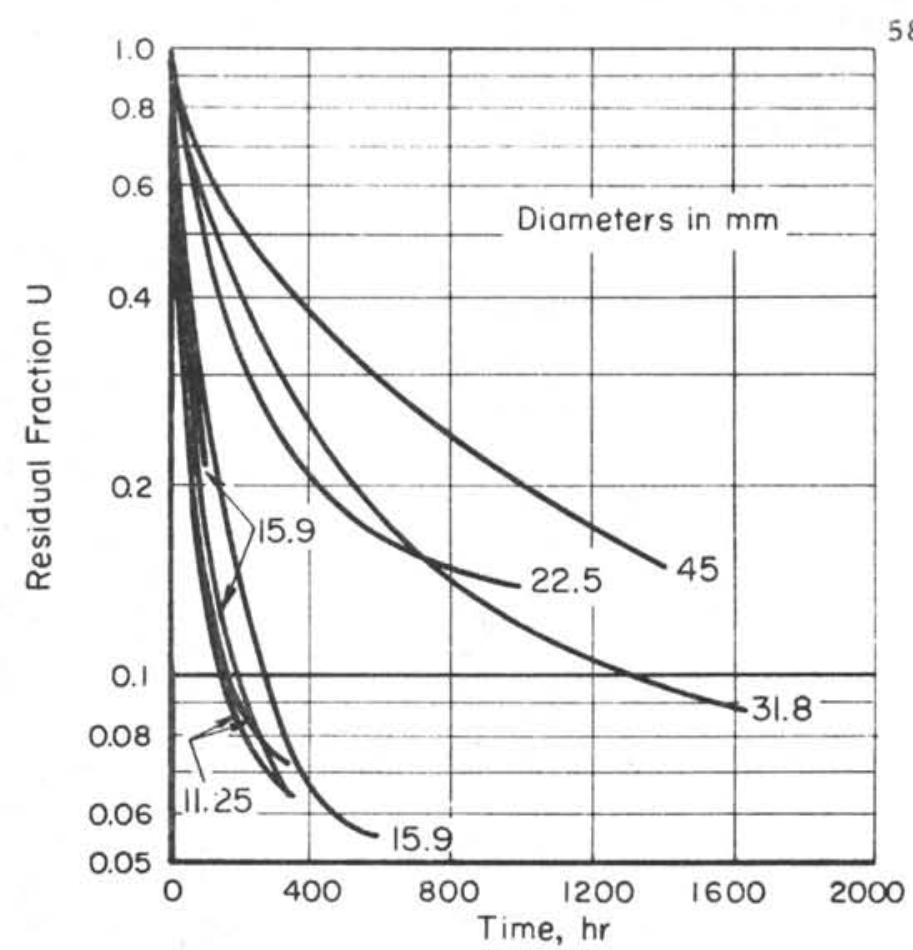

a.

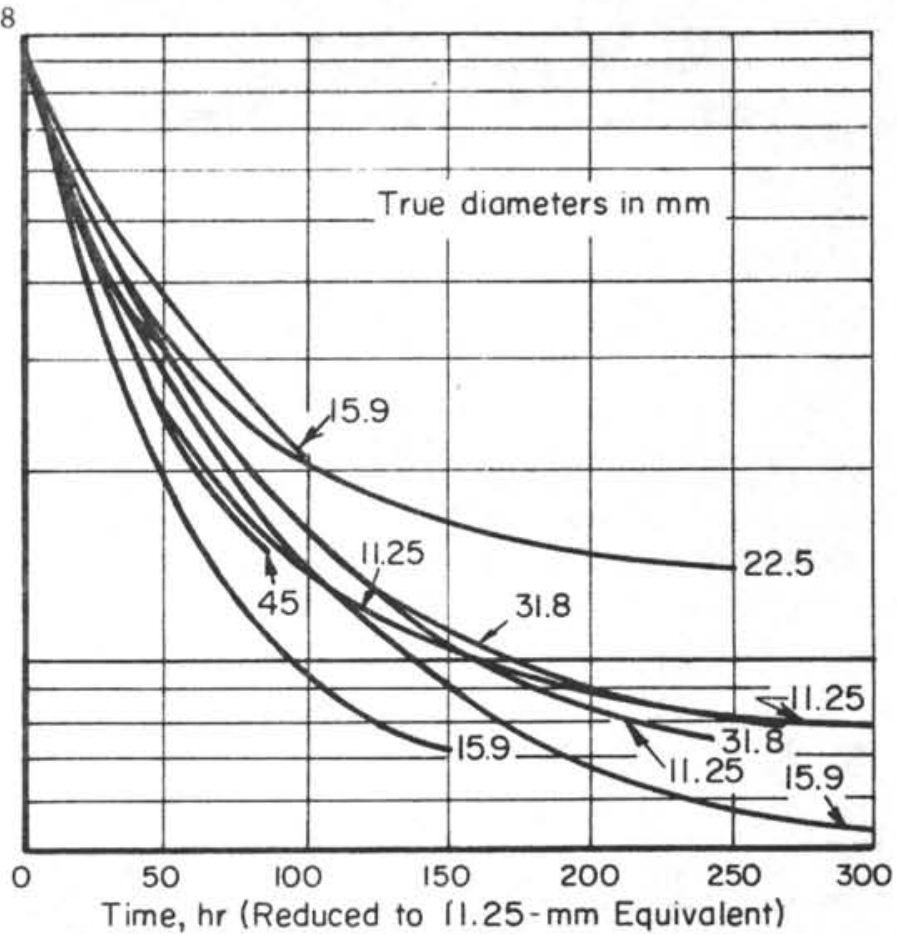

b.

FIGURE 50, (a) EFFECT OF CYLINDER DIAMETER ON EVOLUTION RATE FOR 2.5\%Ni-Cr-Mo STEEL

(b) EVOLUTION CURVES REDUCED BY INVERSE SQUARE LAW TO COMMON TIME SCALE(160)

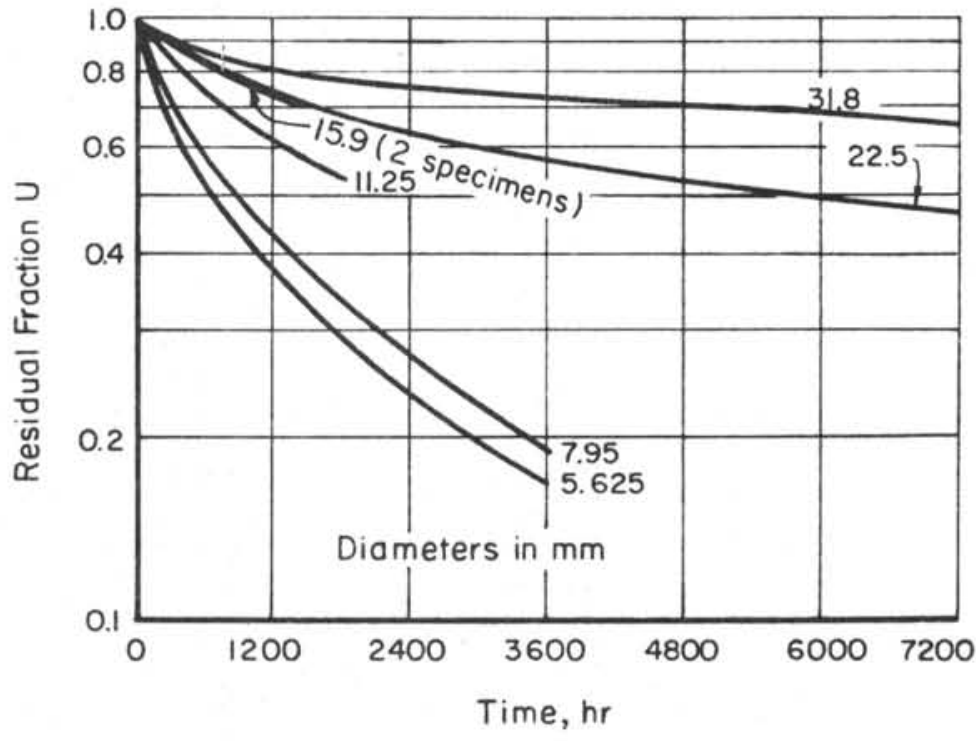

a.

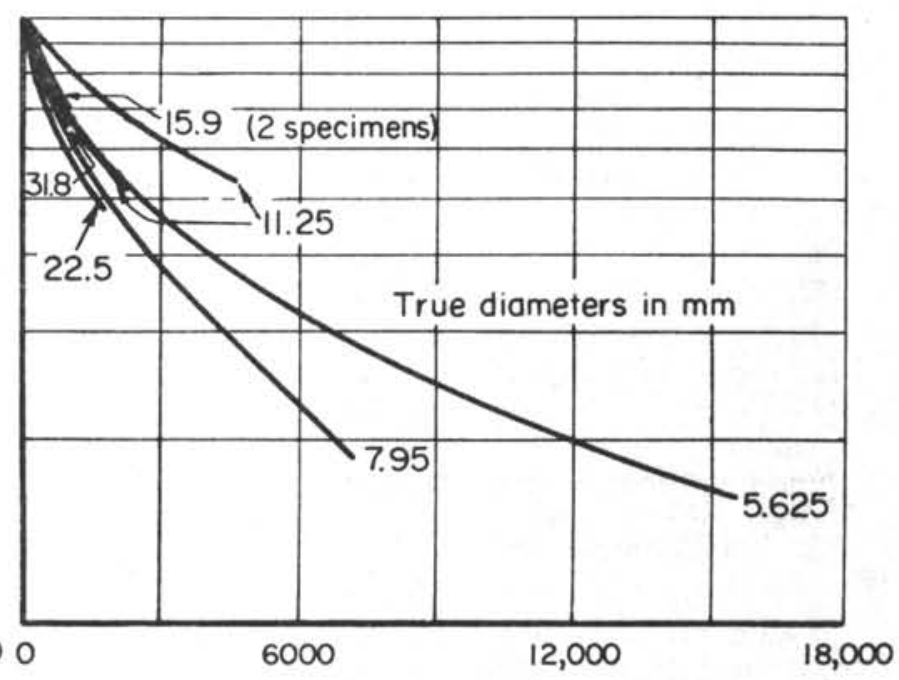

Time, hr (Reduced to II.25 - Mm Equivalent)

b.

FIGURE 51. (a) EFFECT OF CYLINDER DIAMETER ON EVOLUTION RATE FOR 14\%Cr STEEL

(b) EVOLUTION CURVES REDUCED BY INVERSE SQUARE LAW TO COMMON TIME SCALE(160)

TABLE 18. EFFECT OF TEMPERATURE ON THE RATE OF HYDROGEN DIFFUSION IN 2. $5 \% \mathrm{Ni}-\mathrm{Cr}-\mathrm{MO}$ STEEL A(160)

\begin{tabular}{|c|c|c|c|c|c|}
\hline \multicolumn{2}{|c|}{ Temperature } & \multirow{2}{*}{$\begin{array}{l}\text { Time to Reach } \\
\mathrm{U}=0.5, \mathrm{hr}(\mathrm{a})\end{array}$} & \multirow{2}{*}{$\begin{array}{l}\text { Rate Relative to RT } \\
\text { Taken as Unity }\end{array}$} & \multirow{2}{*}{$\begin{array}{l}\text { Relative Rate Predicted } \\
\text { by Sykes' Equation }\end{array}$} & \multirow{2}{*}{$\begin{array}{l}\text { Diffusion } \\
\text { Constant }\end{array}$} \\
\hline $\mathrm{C}$ & $F$ & & & & \\
\hline-78 & -172 & $\sim 1250$ & 0.018 & 0.14 & $5.8 \times 10^{-9}$ \\
\hline RT & RT & 23 & 1 & 1 & 3. $2 \times 10^{-7}$ \\
\hline 50 & 122 & 5. 5 & 4.2 & -- & 1. $35 \times 10^{-6}$ \\
\hline 100 & 212 & 0.55 & 41.9 & 2. 3 & 1. $34 \times 10^{-5}$ \\
\hline 200 & 392 & 0.11 & 209 & 4.5 & $6.7 \times 10^{-5}$ \\
\hline
\end{tabular}

(a) For $11.25-\mathrm{mm}$ cylinder; $45-\mathrm{mm}$ results are divided by 16 to be comparable. 
TABLE 19. CALCULATED TIMES FOR CYLINDERS OF 11.25 MM DIAMETER OF STEELS A-I TO REACH VARIOUS VALUES OF RESIDUAL HYDROGEN FRACTION U(160)

\begin{tabular}{|c|c|c|c|c|c|c|c|c|c|c|c|}
\hline \multirow[b]{3}{*}{ Steel } & \multirow[b]{3}{*}{ Type } & \multirow{3}{*}{$\begin{array}{c}\text { Number of } \\
\text { Experiments }\end{array}$} & \multicolumn{9}{|c|}{ Time to Reach Residual Hydrogen Fraction $U$, hours } \\
\hline & & & \multicolumn{3}{|c|}{$\mathrm{U}=0.7$} & \multicolumn{3}{|c|}{$\mathrm{U}=0.5$} & \multicolumn{3}{|c|}{$\mathrm{U}=0.3$} \\
\hline & & & Mean & $\operatorname{Max}$ & Min & Mean & Max & Min & Mean & Max & Min \\
\hline A & $2.5 \% \mathrm{Ni}-\mathrm{Cr}-\mathrm{Mo}$ & 10 & 7 & 10 & 5 & 19 & 24 & 14 & 44 & 58 & 33 \\
\hline B & $14 \% \mathrm{Cr}$ & 7 & 690 & 1320 & 310 & 2080 & 2960 & 1500 & 5640 & 6720 & 4560 \\
\hline $\mathrm{C}$ & $2.5 \% \mathrm{Ni}-\mathrm{Cr}-\mathrm{Mo}$ & 1 & 11 & -- & -- & 28 & -- & -- & 78 & -- & -- \\
\hline D & $0.34 \% \mathrm{C}$ & 1 & 32 & -- & -- & 63 & -- & -- & 108 & -- & -- \\
\hline $\mathrm{E}$ & $0.8 \% \mathrm{C}-1.0 \% \mathrm{Cr}$ & 2 & 11 & 12 & 10 & 27 & 31 & 22 & 72 & 88 & 56 \\
\hline$F$ & $0.8 \% \mathrm{C}-\mathrm{Cr}-\mathrm{Mo}$ & 1 & 26 & -- & -- & 62 & -- & -- & 150 & -- & -- \\
\hline G & $0.8 \% \mathrm{C}-\mathrm{Cr}-\mathrm{Mo}$ & 1 & 20 & -- & -- & 35 & -- & -- & 85 & -- & -- \\
\hline $\mathrm{H}$ & $3 \% \mathrm{Cr}-\mathrm{Mo}$ & 2 & 48 & 60 & 35 & 108 & 140 & 76 & 250 & 360 & 145 \\
\hline I & $3 \% \mathrm{Cr}-\mathrm{Mo}$ & 1 & 85 & -- & -- & -- & -- & -- & -- & -- & -- \\
\hline
\end{tabular}

In the section of the present report on solubility, it was shown that the solubility of hydrogen in alpha iron increases rapidly with increasing temperature. Therefore, baking or aging treatments to remove hydrogen from ferritic steel must be a compromise between greater permeability or rate of diffusion obtained at increased temperatures, so as to shorten the treatment time, and the lower solubility prevailing at lower temperatures. For parts that are not too thick, a baking treatment of 24 hours at about $375 \mathrm{~F}$ frequently is used. Retained austenite has a high equilibrium solubility for hydrogen, so hydrogen tends to concentrate in this constituent. This hydrogen cannot be removed by baking unless the treatment also transforms the retained austenite.

Moore and Smith (184) have presented a review of the early work on occlusion and evolution of hydrogen in and from iron and steel. They also studied the evolution of hydrogen from carbonyl iron strips cold rolled to a thickness of 0.06 $\mathrm{mm}$. When this material was exposed to pure hydrogen at 1 atmosphere and $77 \mathrm{~F}(25 \mathrm{C})$ for 55 days, it was found that 200 times as much hydrogen was occluded as could be accounted for by true lattice solubility. The hydrogen then was evolved from the foil in an evacuated container by holding first at room temperature and then by heating to successively higher temperature levels and holding isothermally at each temperature until the evolution slowed down perceptibly. The results of such a test are shown in Figure 52. They found that at each temperature level there was rapid evolution at first, but it then slowed down and practically stopped. When the temperature was raised, the pattern was repeated, except that more gas was evolved with each successive temperature level up to $1965 \mathrm{~F}(1075 \mathrm{C})$. This behavior is contrary to what might be expected in view of the fact that solid solubility increases with increasing temperature. However, heavily cold-worked iron or steel is capable of occluding very large contents of hydrogen, above the true solubility limit, and these investigators suggested that these data indicated that it is held occluded in rifts rather than in lattice solution.

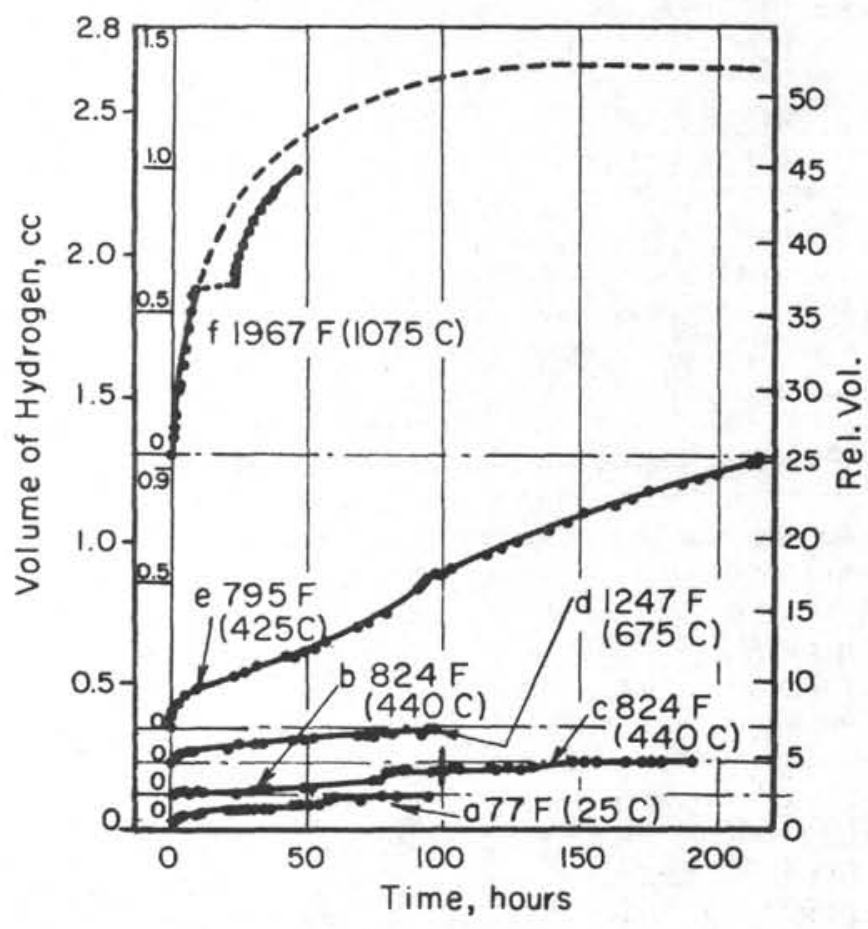

FIGURE 52. ISOTHERMAL EVOLUTION FROM PURE IRON FOIL (184)

Geller and Sun(38) investigated the effusion of hydrogen at room temperature. They found no evolution at all from austenitic steels, and they concluded that practically all alloy additions to ferrite retard the effusion of hydrogen and that structure also plays a big part. The effect of increasing amounts of silicon and of a high chromium content in retarding the effusion of hydrogen from ferrite is shown in Figure 53.

The effects of temperature on hydrogen removal also are indicated by the results of an experiment performed by Zapffe and Sims. (185) 
A group of 0.505-inch-diameter, mild-steel tensile specimens was heated in hydrogen for 3 hours at $2010 \mathrm{~F}(1100 \mathrm{C})$ and then quenched in water to retain a maximum amount of hydrogen. These charged specimens were then treated for varying periods of time at temperatures from 212 to $1470 \mathrm{~F}$ $(100$ to $800 \mathrm{C})$ by $180 \mathrm{~F}(100 \mathrm{C})$ increments. At the end of the treatment, each specimen was again quenched so that hydrogen loss on cooling would not affect the results. The specimens were immediately tested in tension. The embrittlement, as measured by loss in reduction in area, disappeared faster as the temperature was raised. Ductilities of the hydrogen-free control group heat treated at the same temperatures served as endpoint ductilities for the hydrogen-removal studies. The curve in Figure 54 shows the variation with temperature of the length of anneal necessary to obtain relief from hydrogen embrittlement, that is, for obtaining near-maximum ductility.

The early investigations of hydrogen embrittlement induced by pickling in acid solutions or by electrolysis also showed that aging at room temperature or heating to moderately elevated temperatures (known as baking) causes a gradual recovery of the original ductility. Some investigators reported that complete recovery had been obtained, while others found that recovery was incomplete at either room temperature or at elevated temperatures. However, this early work was done largely with low-carbon steel.

The method of introducing hydrogen into the steel has been found to have little effect on the rate of recovery at room temperature. For example, it was found to be only slightly different for lowcarbon steel wire embrittled by cathodic treatment from that for wire embrittled by heating in hydrogen. (186) However, variation in the crosssectional area of the test piece has a large effect on the rate of recovery at either room temperature or a given elevated temperature because the recovery depends on the diffusion of hydrogen. For this reason, elevated temperatures are increasingly more effective. A severely embrittled low-carbon steel wire 0.040 inch in diameter was found to recover 50 percent of the initial bending capacity in about 1 week, while a wire of the same composition

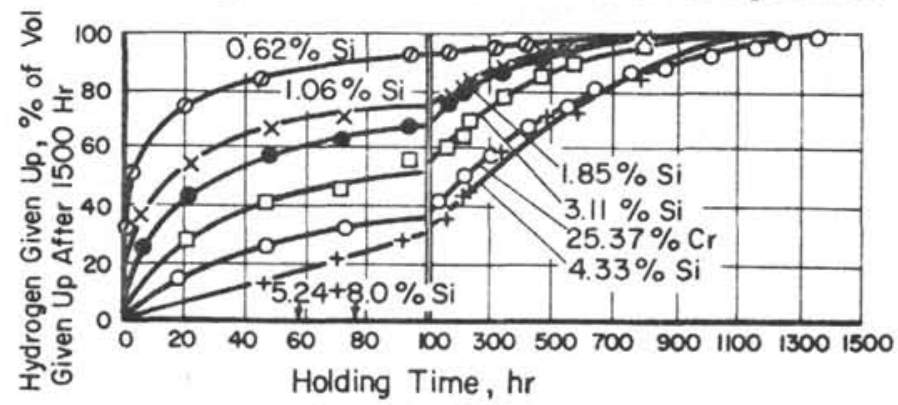

FIGURE 53. INFLUENCE OF SILICON AND CHROMIUM IN FERRITE ON EFFUSION OF HYDROGEN AT ROOM TEMPERATURE( 38 ) but 0.160 inch in diameter recovered to only 40 percent of the original bend value in 3 months. (

Apparently, low-alloy steels, heat treated to high strength levels, completely recover the ductility lost by hydrogen introduced by acid pickling if they are stored for a long time before use, or if they are baked at a sufficiently high temperature, provided that they are not electroplated after pickling. For example, tensile tests of SAE 4340 steel, heat treated to a hardness of Rockwell C 47 , indicated that complete recovery from the effects of pickling in $\mathrm{HCl}$ for 1 hour was accomplished by aging at room temperature for 5 hours or more (see Figure 55).

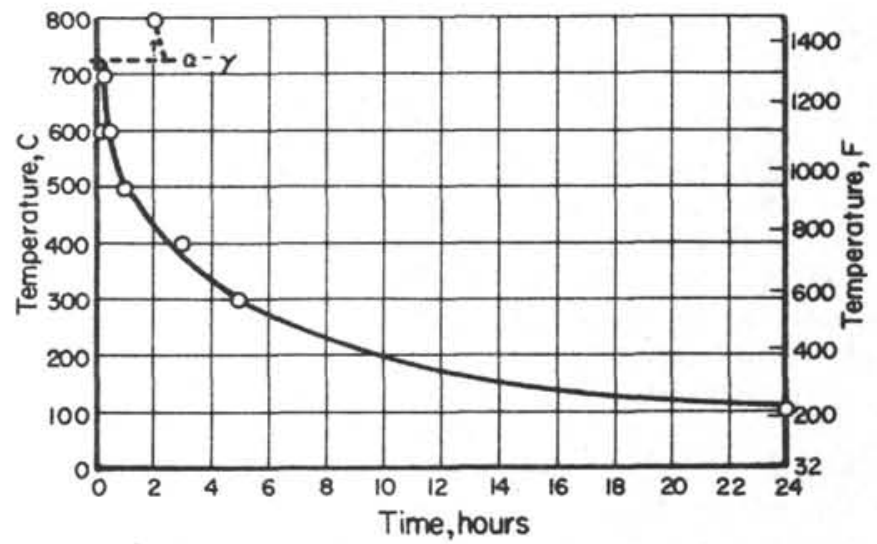

FIGURE 54. RELATION OF TEMPERATURE TO ANNEALING TIME NECESSARY FOR REMOVING HYDROGEN EMBRITTLEMENT FROM MILD-STEEL SPECIMENS(185)

(Tensile specimens 0.505 inch in diameter.)

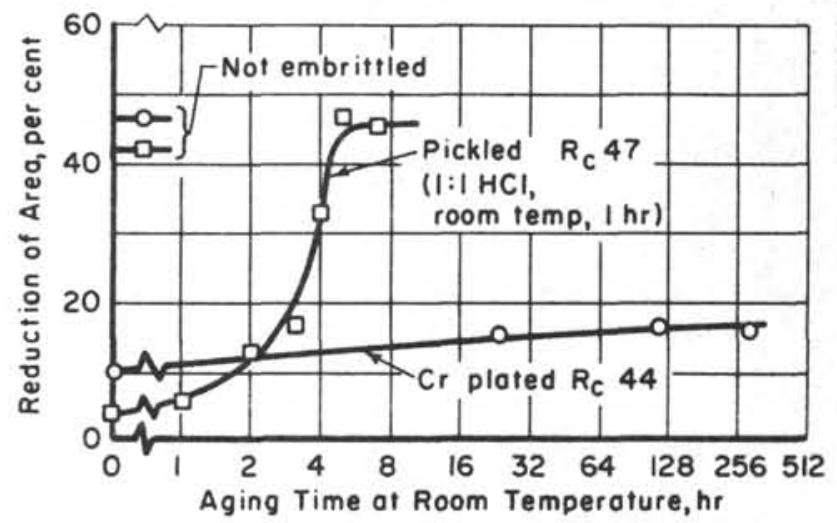

FIGURE 55. EFFECT OF AGING ON THE HYDROGEN EMBRITTLEMENT OF PICKLED AND CHROMIUM-PLATED TENSION SPECIMENS OF 4340 STEEL (0.505-IN. DIAM.)(DATA BY NORTH AMERICAN AVIATION)(187) 
passage of hydrogen generated on the other surface by reaction with acid. The rate of recovery of chromium- and cadmium-plated stainless steel

One way of looking at diffusivity, D, is that it is a measure of the time required for a specimen of given size under given conditions to absorb a given fraction of the hydrogen it would absorb in a very long time. In the case of constant boundary conditions and zero initial hydrogen content in the steel, the solution of Fick's diffusion equation (for specimens of similar shape) shows that the hydrogen concentration at any given point is a function $\mathrm{Dt} / \mathrm{a}^{2}$, where $\mathrm{t}$ is time and $\mathrm{a}$ is a linear dimension of the specimen (for example, the radius of a sphere or of a long cylinder, or the thickness of a slab or sheet). From this relation, it is clear that, for constant diffusivity, the time required for a specimen to absorb a given fraction, say half, of the total amount of hydrogen that it would absorb in a very long time (independent of that amount) would be proportional to the square of the dimension. For example, one would expect that it would take 4 times as long to half-saturate a 1 -inch rod than it would to half-saturate a $1 / 2$-inch rod. Likewise, for constant diffusivity, the reverse process (removal of hydrogen from the saturated specimen) would be expected to be similar, and the time required for the removal of any given percentage of the saturation amount of hydrogen should be the same as that required for the absorption of the same percentage by the same specimen at the same temperature. However, surface reactions, rather than diffusion through the bulk of the metal, may be controlling the entry and removal of hydrogen; the reactions may be different in the two cases. A number of studies have shown that environment is important in the removal of hydrogen from steel.

Bastien(188) studied the influence of the environment on the recovery of the bend characteristics of steel specimens embrittled by pickling in HC1. Figure 56 shows the markedly faster rate of recovery achieved when the specimens were immersed in water or were in air saturated with water vapor, than when they were in dry air. Immersing the specimens in water to which 0.01 percent of $\mathrm{Na}_{2} \mathrm{~S}$ was added retarded recovery the most. In this latter instance, corrosion may have occurred to provide an opposing reaction (hydrogen entry). The addition of $\mathrm{Na}_{2} \mathrm{~S}$ poison to the pickling acid increased the brittleness of the steel and it also increased the time required for complete recovery after a given pickling time.

Evans (64) stated that immersion in water is more effective in removing hydrogen from pickled steel than is exposure to hot air. Of course, both are considerably more effective than storage in air at room temperature. Slater(189) pointed out the marked superiority of an environment of water at $212 \mathrm{~F}(100 \mathrm{C})$ over air at the same temperature as a means of eliminating hydrogen. Other reports of a qualitative nature have indicated that hydrogen removal is more rapid in water than in air. Morris(128) showed that an oxide film on a steel surface not in contact with acid solution resists the (17Cr-1C) wire from the embrittled condition was shown by Zapffe and Haslem $(132)$ to be more rapid at $212 \mathrm{~F}(100 \mathrm{C})$ for specimens stored in water or 3 percent $\mathrm{NaOH}$ solution than for those stored in oil or dry argon.

Darken and Smith(48) studied hydrogen absorption during acid pickling and evolution of hydrogen on removing the steel from the acid and holding at the same temperature used for charging. The evolution rate of absorbed hydrogen was slower than the rate of absorption for several experiments which involved at least three different charging conditions. In one instance, 5 days' aging time was required for loss of half the hydrogen at $95 \mathrm{~F}$ (35 C), whereas only 7 hours' charging was required for the absorption of the same amount of hydrogen. Another comparison is shown in Figure 57. The difference between water-treated and air-treated specimens was not large, which was attributed to the fact that considerable time was required to heat the specimens up to $212 \mathrm{~F}(100 \mathrm{C})$ in air.

Darken and Smith explained the observed lower rate of evolution of hydrogen as compared with the rate of absorption on this basis. They assumed that the permeability is proportional to the gradient of the lattice-dissolved hydrogen and not the total hydrogen content. In these acidcharged specimens, the total hydrogen content was much greater than the portion dissolved in the lattice. As the amount of hydrogen in the steel decreased by effusion, the amount of lattice-dissolved hydrogen (the gradient of which is the driving force) decreased much more rapidly, and thus escape was very slow. They hypothesized that the observed variation does not correspond to a change of the diffusivity of lattice-dissolved hydrogen atoms in a perfect iron lattice, but, rather, that the change is caused by a "trapping" of a fraction of the hydrogen

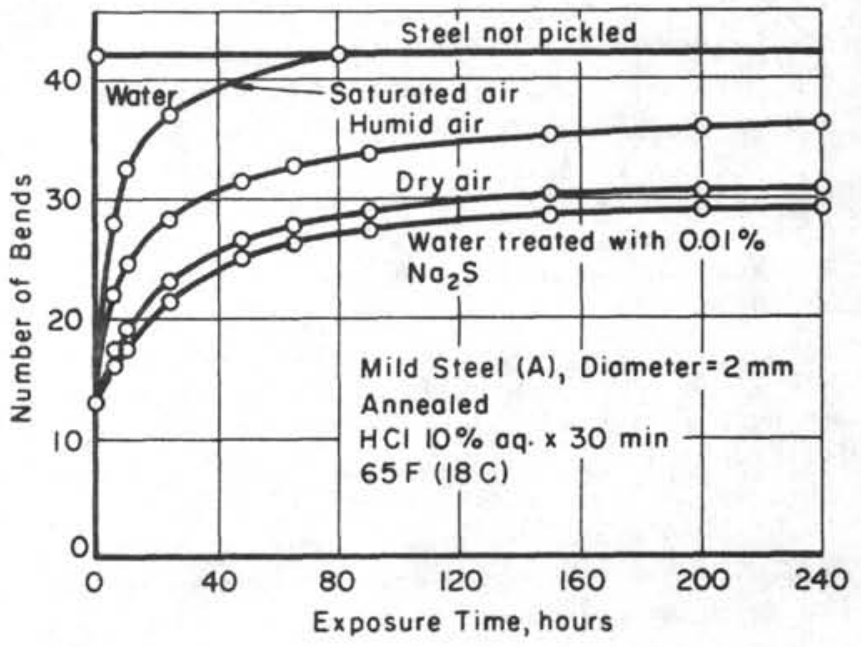

FIGURE 56. INFLUENCE OF THE NATURE OF THE EXTERNAL MEDIUM ON THE RECOVERY OF THE BEND CHARACTERISTICS AFTER PICKLING(188) 
atoms in imperfections of the iron lattice. They pointed out that it might be thought that the observed phenomena could be accounted for by the supposition that gaseous (molecular) hydrogen at high pressure accumulates in macroscopic voids. If this were so, they reasoned that the "amount" so accumulated would be proportional to the square of the concentration of lattice-dissolved hydrogen (Sieverts' law), and, hence, the "amount" in the voids would be a negligibly small fraction of the total hydrogen at low concentrations and the diffusivity would be greater than at higher concentrations. * This is contrary to observed behavior which indicates definitely that diffusivity is greater at higher concentrations than at lower. This conclusion of theirs that a large part of the hydrogen is somehow trapped is strengthened by the observed large increase of absorbed hydrogen resulting from prior cold work.

Hudson, Norris, and Stragend(81) studied the effect of environment on the rate of removal of hydrogen from a commercial, low-carbon steel. Their work involved specimens precharged with hydrogen only by acid pickling in $2 \mathrm{~N} \mathrm{H}_{2} \mathrm{SO}_{4}$ at $100 \mathrm{~F}(38 \mathrm{C})$ for 24 hours, a time found to be sufficient to ensure saturation with hydrogen. Postcharging treatments included treatment in deoxygenated distilled water at $39,100,147$, and $201 \mathrm{~F}(4,38,64$, and $94 \mathrm{C})$, distilled water saturated with oxygen used at $100 \mathrm{~F}$, and aqueous solutions of the following oxidizing agents used at $100 \mathrm{~F}$ :

*The present authors do not fully agree with this reasoning. Sievert's law expresses an equilibrium relationship between the concentration of atomic hydrogen in the lattice and the pressure of molecular hydrogen external to the iron lattice. This relation usually is expressed in the form: the concentration or solubility is proportional to the square root of the pressure of molecular hydrogen, but it may also be expressed in the form: the pressure is proportional to the square of the concentration or solubility (see Equation 1, page 5). Since Darken and Smith made no mention of the size and number of the voids other than that the voids are macroscopic in size, there is no way of knowing what the "amount" of hydrogen in the voids will be. Therefore, the relationship between the "amount" in the voids and the amount in the lattice also is unknown. Where the volume of the voids is a very small fraction of the volume of the iron (as might be expected to be the case in wrought products of high quality), Darken and Smith's statement about amount probably is correct, since a low pressure in a very small volume would correspond to a small "amount" of hydrogen gas. When one considers that the amount in the lattice is measured in terms of a few ppm by weight, it is apparent that the size and number of the voids for which the statement will apply is strictly limited. The equilibrium statement does imply that at low concentrations the pressure in the voids will be very low.

\begin{tabular}{|c|c|c|c|}
\hline Solution & M & Solution & M \\
\hline $\mathrm{KMnO}_{4}$ & 0.01 & $\mathrm{~K}_{2} \mathrm{~S}_{2} \mathrm{O}_{8}$ & 0.1 \\
\hline $\mathrm{KMnO}_{4}$ & 0.1 & $\mathrm{NaNO}_{2}$ & 0.1 \\
\hline $\mathrm{KMnO}_{4}$ & 0.25 & $\mathrm{HNO}_{3}$ & 0.1 \\
\hline $\mathrm{K}_{2} \mathrm{Cr}_{2} \mathrm{O}_{7}$ & 0.1 & $\mathrm{HNO}_{3}$ & 15.6 \\
\hline $\mathrm{KCrO}_{4}$ & 0.1 & $\left(\mathrm{NH}_{4}\right)_{2} \mathrm{Ce}\left(\mathrm{NO}_{3}\right)_{6}$ & 0.1 \\
\hline $\mathrm{KClO}_{3}$ & 0.1 & $\mathrm{Fe}_{2}\left(\mathrm{SO}_{4}\right)_{3}\left(\mathrm{NH}_{4}\right)_{2} \mathrm{SO}_{4}$ & 0.1 \\
\hline $\mathrm{KBrO}_{3}$ & 0.1 & $\mathrm{~K}_{3} \mathrm{Fe}(\mathrm{CN})_{6}$ & 0.1 \\
\hline $\mathrm{KIO}_{3}$ & 0.1 & $\mathrm{H}_{2} \mathrm{O}_{2}$ & 3. 0 \\
\hline $\mathrm{KClO}_{4}$ & 0.1 & $\mathrm{NaAsO}_{2}$ & 0.1 \\
\hline $\mathrm{KIO}_{4}$ & 0.1 & $\mathrm{NaHAsO}_{4}$ & 0.1 \\
\hline $\mathrm{NaBO}_{3}$ & 0.1 & & \\
\hline
\end{tabular}

Other environments studied included water-dioxane mixtures (containing 2, 10, 20, 40, 60, and 80 percent water), dioxane, methanol, dry nitrogen, humidified nitrogen ( 0.63 and 1.86 percent water), dried hydrogen gas, and a vacuum. For all of the se environments, removal-rate studies were performed at $100 \mathrm{~F}$. Additional temperatures from 32 to $212 \mathrm{~F}(0$ to $100 \mathrm{C}$ ) were investigated for some of the environments so as to permit estimates to be made of activation energies. Following all treatments, residual hydrogen was determined by the warm-extraction technique.

The effects of postcharging treatments with aqueous solutions at $100 \mathrm{~F}$ on the rate of removal of hydrogen from steel are summarized in Table 20. The rate of removal was highest when the steel was immersed in water. These investigators stated that this observed behavior agrees with the findings of Lewis and Ubbelohde.(190) For aqueous solutions of oxidizing agents, no treatment was better than deoxygenated water for hydrogen removal. These

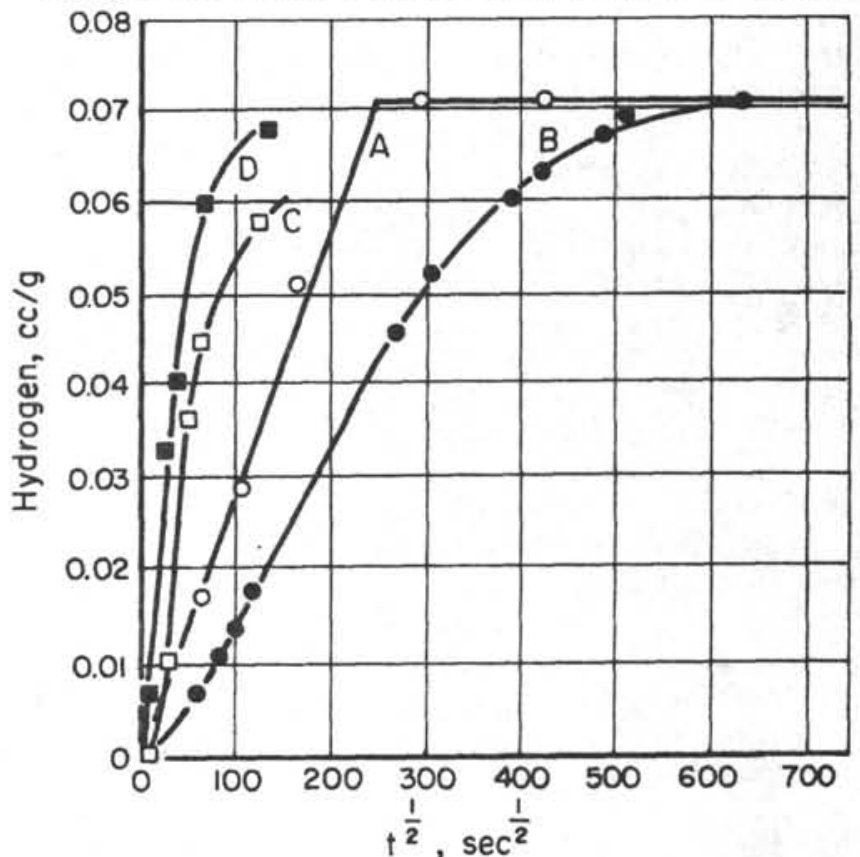

FIGURE 57. COMPARISON OF RATE OF ABSORPTION (CURVE A) AT 95 F (35 C) WITH RATE OF EVOLUTION (CURVE B) AT 95 F INTO MERCURY AND (CURVE C) INTO AIR AT 212 F (100 C) AND (CURVE D) WATER BATH AT $212 \mathrm{~F}(48)$ 
TABLE 20, EFFECT OF THE ENVIRONMENT (CONSISTING OF AQUEOUS SOLUTIONS OF VARIOUS OXIDIZING AGENTS AND DEOXYGENATED WATER) ON THE RATE OF REMOVAL OF HYDROGEN FROM LOW-CARBON $\operatorname{STEEL}(81)$

\begin{tabular}{|c|c|c|c|}
\hline \multirow[b]{2}{*}{ Treating Solution } & \multirow[b]{2}{*}{ M } & \multicolumn{2}{|c|}{$\begin{array}{l}\text { Hydrogen Removed, } \\
\text { percent }\end{array}$} \\
\hline & & $2 \mathrm{hr}$ & $4 \mathrm{hr}$ \\
\hline $\mathrm{K}_{2} \mathrm{CrO}_{4}$ & 0.1 & 15 & 14 \\
\hline $\mathrm{K}_{2} \mathrm{Cr}_{2} \mathrm{O}_{7}$ & 0.1 & 7 & 14 \\
\hline $\mathrm{KBrO}_{3}$ & 0.1 & 17 & 15 \\
\hline $\mathrm{H}_{2} \mathrm{O}_{2}$ & 3. 0 & 17 & 18 \\
\hline $\mathrm{KMnO}_{4}$ & 0.25 & 18 & 22 \\
\hline $\mathrm{KIO}_{3}$ & 0.1 & 15 & 23 \\
\hline $\mathrm{NaBO}_{3}$ & 0.1 & 20 & 24 \\
\hline $\mathrm{NaAsO}_{2}$ & 0.1 & 21 & 24 \\
\hline $\mathrm{Fe}_{2}\left(\mathrm{SO}_{4}\right)_{3}\left(\mathrm{NH}_{4}\right)_{2} \mathrm{SO}_{4}$ & 0.1 & 28 & 25 \\
\hline $\mathrm{KMnO}_{4}$ & 0.1 & 16 & 27 \\
\hline $\mathrm{NaNO}_{2}$ & 0.1 & 18 & 30 \\
\hline $\mathrm{K}_{3} \mathrm{Fe}(\mathrm{CN})_{6}$ & 0.1 & 20 & 32 \\
\hline $\mathrm{K}_{2} \mathrm{~S}_{2} \mathrm{O}_{8}$ & 0.1 & 49 & 42 \\
\hline $\mathrm{KIO}_{4}$ & 0.1 & 18 & 44 \\
\hline $\mathrm{KClO}_{3}$ & 0.1 & 34 & 62 \\
\hline $\mathrm{KMnO}_{4}$ & 0.01 & 58 & 66 \\
\hline$\left(\mathrm{NH}_{4}\right)_{2} \mathrm{Ce}\left(\mathrm{NO}_{3}\right)_{6}$ & 0.1 & 59 & 74 \\
\hline $\mathrm{Na}_{2} \mathrm{HAsO}_{4}$ & 0.1 & 56 & 74 \\
\hline $\mathrm{KClO}_{4}$ & 0.1 & 65 & 81 \\
\hline $\mathrm{HNO}_{3}$ & 15.6 & 64 & 84 \\
\hline $\mathrm{HNO}_{3}$ & 0.1 & 49 & 85 \\
\hline $\mathrm{H}_{2} \mathrm{O}\left(\mathrm{O}_{2}\right.$-saturated $)$ & & 68 & 80 \\
\hline $\mathrm{H}_{2} \mathrm{O}$ (deoxygenated) & & 72 & 85 \\
\hline
\end{tabular}

data indicate that the oxide films which often form in visible amounts on the steel surface during treatment hinder the removal of hydrogen from steel. The linear relationship obtained for hydrogen removal in a water environment when $1 / \mathrm{c}$ (where $c=$ concentration of hydrogen in steel) was plotted against time shows that a second-order rate law applies for this treatment (see Figure 58), that is, dc/dt $=-\mathrm{k}_{2} \mathrm{c}^{2}$. Note how much more rapid the removal rate became at slightly elevated temperatures. The rate constant more than doubled for a $36 \mathrm{~F}(20 \mathrm{C})$ rise in temperature. Removal of hydrogen in water-dioxane mixtures depended directly on the amount of water present in the medium.

The marked effect of environmental conditions on the rate of hydrogen removal from steel is well demonstrated by a comparison of the rates from steel immersed in water and steel held in a vacuum, both at $100 \mathrm{~F}$, as shown in Figure 59. The behavior in the two environments indicated that the hydrogen removal responded to different rate laws. The difference between the initial slopes was significant, that for vacuum being very small. The time required to remove 50 percent of the

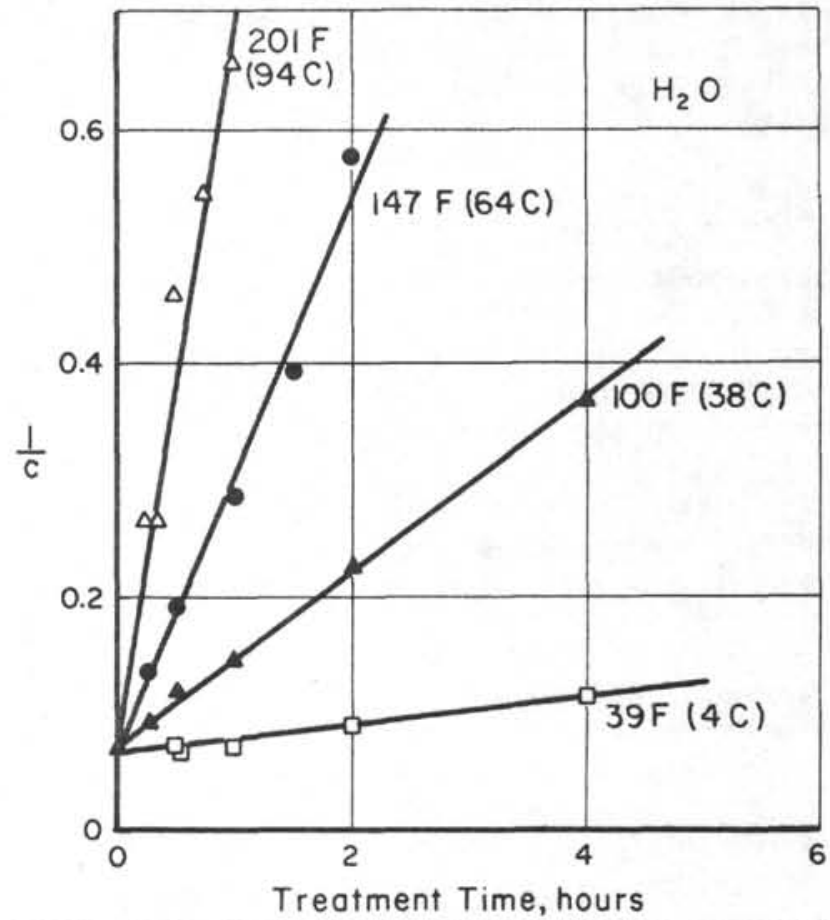

FIGURE 58. THE EFFECTS OF VARIATIONS IN TEMPERATURE ON THE REMOVAL OF HYDROGEN FROM LOW-CARBON STEEL EXPOSED TO A WATER ENVIRONMENT(81)

(The linear relationship shows that a secondorder rate law applies for hydrogen removal in a water environment; $\mathrm{c}=$ concentration of hydrogen in steel.)

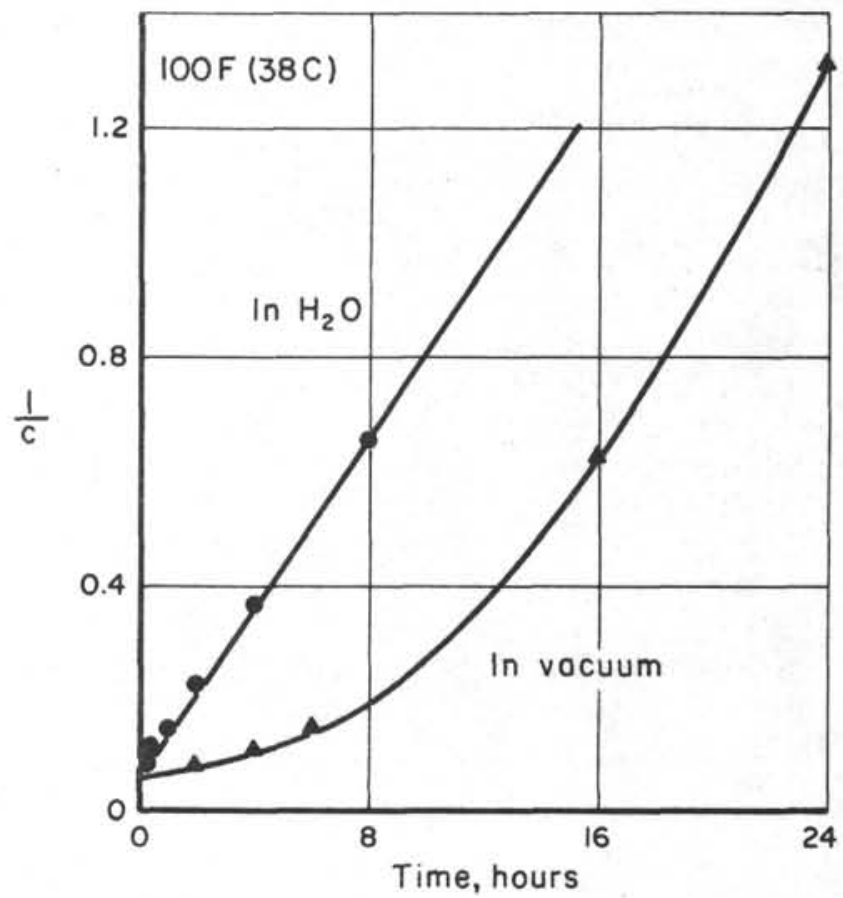

FIGURE 59. PLOT SHOWING THAT THE REMOVAL OF HYDROGEN FROM STEEL IN WATER AND IN A VACUUM OBEYS DIFFERENT RATE LAWS(81)

(The difference between initial slopes is significant; $c$ = concentration of hydrogen in steel.) 
hydrogen from the steel investigated was only 1 hour for specimens immersed in water and 5.8 hours for specimens held in a vacuum at the same temperature.

The fact that such large differences in hydrogen removal rate do exist shows that surface reactions can be rate determining. If the process were simple and diffusion controlled, the amount of moisture present on the steel surface could not affect the rate because it cannot affect the rate of hydrogen diffusion within the iron lattice.

For environments containing appreciable moisture, a second-order rate law was found to apply for the process of hydrogen removal from steel, as was discussed above. However, for environments containing extremely small amounts of moisture, a first-order rate law applied, as indicated by linear plots obtained when In $(1 / \mathrm{c})$ was plotted versus $t$. Such plots were obtained for dried hydrogen and dried nitrogen at several different temperatures, for storage in a vacuum at $100 \mathrm{~F}$, and for treatment in dioxane and methanol at various temperatures. A plot showing part of these results is given in Figure 60 (removal of hydrogen from steel in water, a second-order reaction, is shown for comparison). Note that hydrogen was readily removed from steel in a dryhydrogen atmosphere. This is possible because hydrogen atoms can diffuse against a high pressure of molecular hydrogen, if the partial pressure of dissociated hydrogen is low, as it is at nearambient temperatures.

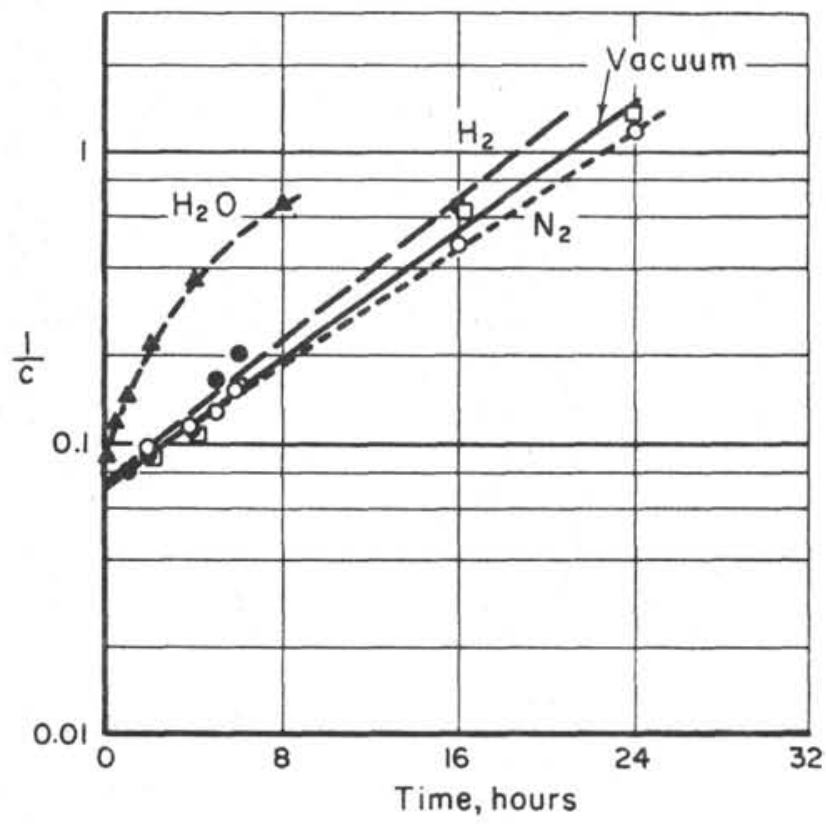

FIGURE 60. SEMILOGARITHMIC PLOTS SHOWING THAT A FIRST-ORDER RATE LAW (LINEAR RELATIONSHIP) APPLIES FOR HYDROGEN REMOVAL FROM STEEL AT $100 \mathrm{~F}$ (38 C) IN ENVIRONMENTS LOW IN MOISTURE ${ }^{(81)}$

(Removal of hydrogen from steel immersed in water, a second-order reaction, is shown for comparison.)
Although it has not been proved that the rate of hydrogen removal from steel in dry environments is diffusion controlled, for the low-carbon steel used in this investigation apparent diffusion coefficients calculated from measured first-order rate constants were in the range determined experimentally by other investigators for rather similar materials at this same temperature.

In another paper, which was part of the study of hydrogen absorption and desorption just referred to, Hudson et al $(52)$ confirmed the importance of steel surface reactions in the desorption of hydrogen from steel. The rate of hydrogen desorption as a function of cold work and environment is shown in Figures 61 and 62 (note the change in the rate scale), and in Table 21 . A maximum value of hydrogen desorption rate in water and in dry nitrogen at $100 \mathrm{~F}$ was observed at 20 to 30 percent cold reduction. Severely cold-worked steel exhibited a considerably lower desorption rate than less severely cold-worked or annealed materials (the effect of annealing is shown in Table 22), regardless of whether the environment was water or dried nitrogen. For reductions less than 67 percent, the desorption was much faster in water than in dried nitrogen. Similar effects of cold reduction and environment on rate of hydrogen desorption were obtained by these investigators for SAE 1020 killed and capped steels in still another investigation. (176) Although the killed steel had a higher saturation solubility for hydrogen on pickling, for most conditions it exhibited the lower rate of desorption.

Owe Berg(191) has suggested that migration of hydrogen atoms in steel is sufficiently rapid to maintain a nearly uniform hydrogen distribution in the metal during absorption and desorption, and that diffusion in the metal is very rapid compared with surface processes. The reader is referred to Barton's paper(117) on the mechanism of transport of hydrogen across a solution-metal interface (previously discussed in the present report under cathodic charging in the section on hydrogen entry) for a discussion of rate-controlling mechanisms.

Hudson and co-workers pointed out that if Owe Berg's hypothesis is valid, neither the firstorder rate law that they observed for dry environments nor the second-order rate law observed for moist environments could result from diffusion control, and in both cases, then, surface reactions presumably would be involved. In all estimates of diffusivity, the assumption is made that surface reactions may be neglected. Yet this work shows that in the presence of moisture this is not always the case. Therefore, the investigators suggested that some of the differences in reported diffusionrate measurements may result from surface effects.

Differences in steel composition, surface roughness, surface area, and geometry also influence the rate of removal of hydrogen from steel, and Hudson et al were planning to investigate these factors in a continuation of their work. 


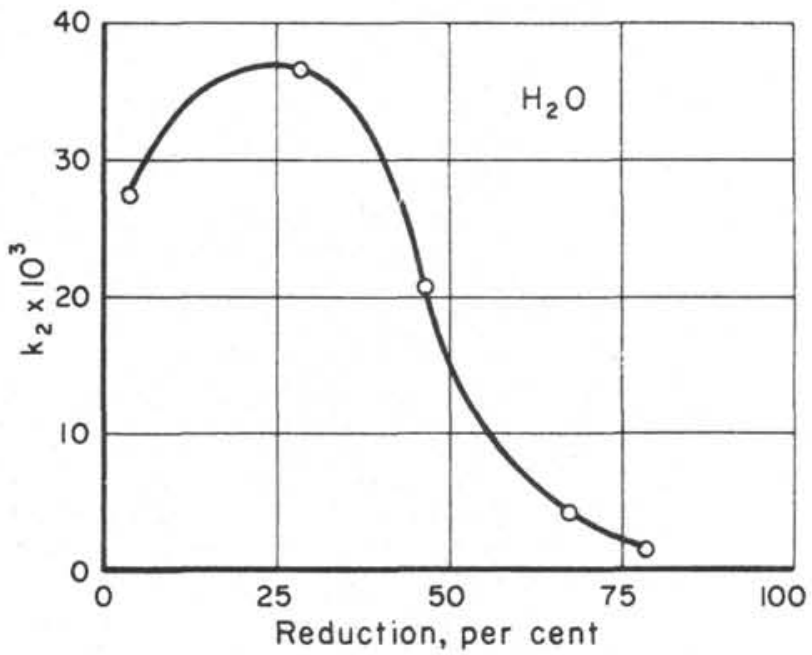

FIGURE 61. CHANGE IN REMOVAL RATE OF HYDROGEN FROM STEEL IMMERSED IN WATER AT $100 \mathrm{~F}(38 \mathrm{C})$ AS A FUNCTION OF COLD WORK ${ }^{(52)}$

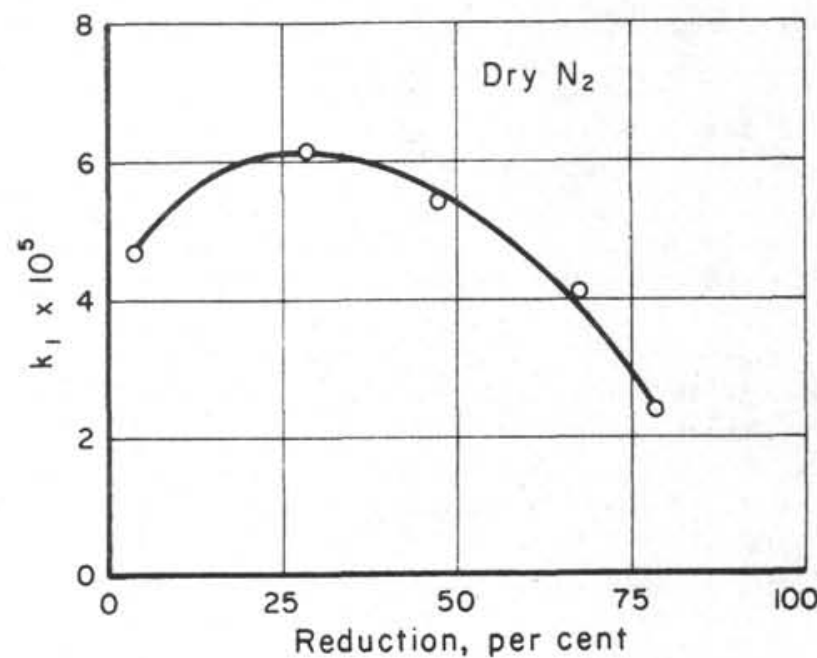

FIGURE 62. CHANGE IN HYDROGEN REMOVAL RATE FOR STEEL IN AN ENVIRONMENT OF DRY NITROGEN AT $100 \mathrm{~F}$ (38 C) AS A FUNCTION OF COLD WORK(52)

TABLE 21. RATE OF HYDROGEN DESORPTION FROM STEEL AS A FUNCTION OF COLD WORK(52)

\begin{tabular}{|c|c|c|c|c|}
\hline \multirow[b]{2}{*}{$\begin{array}{c}\text { Reduction, } \\
\%\end{array}$} & \multicolumn{2}{|c|}{$\begin{array}{l}\text { After } 30 \text {-Minute Pickle in } \\
2 \mathrm{~N} \mathrm{H}_{2} \mathrm{SO}_{4} \text { at } 100 \mathrm{~F}(38 \mathrm{C})\end{array}$} & \multicolumn{2}{|c|}{ Desorption Rate (a) } \\
\hline & $\begin{array}{c}\text { Hydrogen } \\
\text { Concentration, } \\
\text { cc/100 g }\end{array}$ & $\begin{array}{l}\text { Weight } \\
\text { Lass, } \\
\%\end{array}$ & $\begin{array}{l}\text { Water at } \\
100 \mathrm{~F}(38 \mathrm{C}), \\
\mathrm{k}_{2} \times 10^{3}\end{array}$ & $\begin{array}{c}\text { Dry } \mathrm{N}_{2} \text { at } \\
100 \mathrm{~F}(38 \mathrm{C}), \\
\mathrm{k}_{1} \times 10^{5}\end{array}$ \\
\hline 3.7 & 4.7 & 2.5 & 27.3 & 4.7 \\
\hline 28.3 & 7.1 & 2.4 & 36.8 & 6.1 \\
\hline 47.3 & 10.2 & 2.1 & 20.6 & 5.4 \\
\hline 67.6 & 20.0 & 2.3 & 4.1 & 4.1 \\
\hline 78.2 & 20.9 & 2.2 & 1.4 & 2.4 \\
\hline
\end{tabular}

(a) Unit for $\mathrm{k}_{2}$ is $\mathrm{g} / \mathrm{cc}(\mathrm{STP})$ sec $_{\text {; unit for }} \mathrm{k}_{1}$ is reciprocal seconds.

TABLE 22. RATE OF HYDROGEN DESORPTION FROM STEEL C AS A FUNCTION OF PROCESSING CONDITION(52)

\begin{tabular}{|c|c|c|c|c|c|}
\hline \multirow[b]{2}{*}{ Condition } & \multirow{2}{*}{$\begin{array}{l}\text { Time Pickled } \\
\text { in } 2 \mathrm{~N} \mathrm{H}_{2} \mathrm{SO}_{4} \text { at } \\
100 \mathrm{~F}(38 \mathrm{C}), \\
\text { min }\end{array}$} & \multirow{2}{*}{$\begin{array}{l}\text { Hydrogen } \\
\text { Concentration } \\
\text { After Pickling, } \\
\mathrm{cc} / 100 \mathrm{~g}\end{array}$} & \multirow[b]{2}{*}{$\begin{array}{c}\text { Weight } \\
\text { Loss, } \\
\%\end{array}$} & \multicolumn{2}{|c|}{ Desorption Rate (a) } \\
\hline & & & & $\begin{array}{c}\text { Water at } \\
100 \mathrm{~F}(38 \mathrm{C}) \text {, } \\
\mathrm{k}_{2} \times 10^{3}\end{array}$ & $\begin{array}{c}\text { Dry } \mathrm{N}_{2} \text { at } \\
100 \mathrm{~F}(38 \mathrm{C}), \\
\mathrm{k}_{1} \times 10^{5}\end{array}$ \\
\hline $\begin{array}{l}\text { Cold } \\
\text { reduced }\end{array}$ & 8 & 19 & 0.22 & 6.4 & 2.2 \\
\hline $\begin{array}{l}\text { Continuously } \\
\text { annealed }\end{array}$ & 15 & 12 & 0.23 & 18.2 & 5.2 \\
\hline $\begin{array}{l}\text { Box } \\
\text { annealed }\end{array}$ & 20 & 5 & 0.21 & 55.8 & 10.7 \\
\hline
\end{tabular}

(a) Unit for $k_{2}$ is $\mathrm{g} / \mathrm{cc}(\mathrm{STP})$ sec; unit for $\mathrm{k}_{1}$ is reciprocal seconds. 


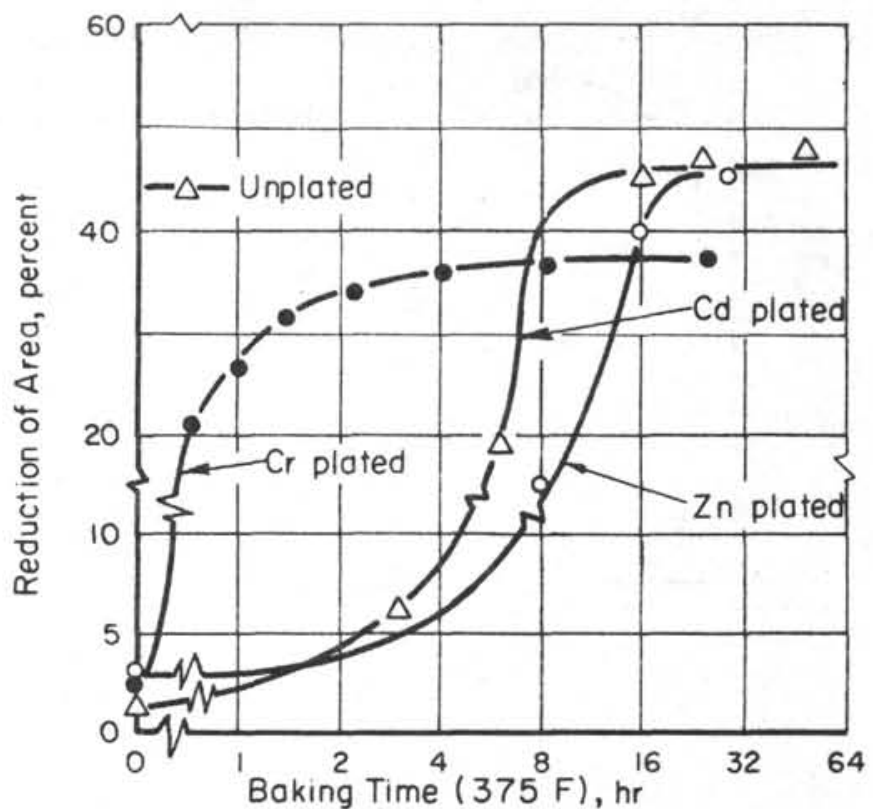

In addition to the effects that occur when hydrogen is concurrently plated with a desired metal electroplate (marked reduction in ductility and development of susceptibility to delayed hydrogen cracking), the plate has another effect. The presence of a more-or-less impermeable metal coating, such as cadmium, makes the evolution of hydrogen from the interior of the base metal more difficult; this may serve to aggravate the effects of embrittlement and delayed failure of electroplated steel. Although an appropriate baking treatment may restore most or all of the ductility to the plated steel, often such a treatment does not overcome the propensity toward delayed brittle failure,

R. D. Johnson et al $(140)$ showed that the delayed-failure behavior was almost identical for commercial cadmium-plated steel and the same steel cathodically charged with hydrogen, for the conditions used. However, the room-temperature aging characteristics of cadmium-plated specimens and hydrogen-charged nonplated specimens were markedly different; ductility was recovered more slowly in the case of the cadmium-plated specimens. Figure $55^{(187)}$ shows that chromium plate serves as a barrier to hinder evolution of hydrogen on aging, and, hence, to hinder recovery of ductility. Figure $63(187)$ which shows recovery by baking at $375 \mathrm{~F}$ demonstrates how the chromium plate also hinders recovery under these conditions, and further, that the cadmium plate commonly used for corrosion protection of high-strength steel parts acts as an even more effective barrier. The following data obtained by H. H. Johnson et al (192) also show the barrier effect of cadmium plate:

\section{Recovery Characteristics of Plated and Deplated Specimens}

(Normal, unplated ductility $=40-42.5$ percent reduction in area.)

\section{Baking Treatment}

$300 \mathrm{~F}, 0.5 \mathrm{hr}$

$300 \mathrm{~F}, 2 \mathrm{hr}$

Reduction in Area, percent
$\begin{gathered}\text { Deplated } \\ \text { Chemically } \quad \text { As Plated }\end{gathered}$

$\begin{array}{ll}41.5 & 10.5 \\ 42.5 & 13.5\end{array}$

Elsea and co-workers(118) performed experiments to determine the effect of a cadmium plate on the absorption and on the discharge of hydrogen by steel. A cadmium plate approximately 0.0003 inch thick was electrodeposited on one side of a permeability specimen. Both the cyanide and the fluoborate plating processes were used in plating the specimens. Several of the specimens were tested by using the cadmium-plated side of the specimen as the entrance surface or cell side. The remaining specimens were tested with the cadmium plate on the exit surface. Without exception, when
FIGURE 63. EFFECT OF BAKING TIME ON HYDROGEN EMBRITTLEMENT OF CHROMIUM-, CADMIUM-, AND ZINC-PLATED SPECIMENS (DATA BY NORTH AMERICAN AVIATION)

(4340 Steel, Hardness = Rockwell C 45.)

the cadmium plate was on the entrance surface, there was no absorption of hydrogen, even after several hours of charging with current densities of 10 to several hundred $\mathrm{ma} / \mathrm{in}^{2}$ for the poisoned 4 percent sulfuric acid electrolyte and $500 \mathrm{ma} / \mathrm{in} .^{2}$ for the sodium hydroxide electrolyte. However, when the specimens were placed so that the cadmium was on the exit surface, the flow of hydrogen through the specimen was restricted until the internal pressure of hydrogen blistered the cadmium plate. Hydrogen then permeated the specimen as though there were no plate present. The behavior was the same whether the cadmium plate was applied by the cyanide or the fluoborate process.

Morris, (128) in studying the permeation of hydrogen into steel by corrosion in 1 percent citric acid solution, discovered that a coating of tin on the side of the sheet not in contact with the acid (the exit side) retarded permeation of hydrogen through the steel. Effusion was not stopped completely, probably owing to discontinuities in the tin layer, he suggested. A film of oxide also retarded effusion, but a coating of lacquer had little effect.

In studying the rates of absorption and effusion of hydrogen obtained for $\alpha$-iron, Carmichael et al $(193)$ found that thin oxide films lowered the apparent diffusivity of annealed iron markedly.

Other investigators(194) determined the hydrogen permeability of Types 321 and 430 stainless steel and Hastelloy B, calorized Type 430 stainless steel, glass-coated Type 304 stainless 
steel, and three Hastelloy B samples coated with a proprietary material. The tests were performed at temperatures in the range of 1020 to $1510 \mathrm{~F}$ $(550$ to $820 \mathrm{C})$ and with hydrogen pressures of 1.1 , 1.5 , and $2.0 \mathrm{~atm}$. The permeabilities of the uncoated specimens were uniformly much greater than those of the surface-treated metals. A 3 to 7 -mil coating of a suitable, high-temperature glass enamel or 10 mils of surface calorizing was 10 to 100 times more effective as a hydrogen barrier than was 60 to 120 mils of untreated steel.

The recovery of the original properties of cadmium-plated high-strength steel parts is an important problem in the aircraft industry. At room temperature, the recovery of ductility that was lost as the result of hydrogen embrittlement incurred during cadmium plating has been found to be extremely slow and often is incomplete after very long aging times. For example, cadmiumplated rings cut from a tubular part made of SAE 4340 steel with a hardness of Rockwell C 50 showed no recovery of ductility after being aged for 2 weeks at room temperature (see Figure 64). However, the recovery of ductility in embrittled, cadmium-plated steel parts increases rapidly with increasing temperature, as Eakin and Lownie(129) showed for thin, cadmium-plated clock-spring steel. This is illustrated in Figure 65. They also found that, as the hardness level of the steel in- creased, the embrittlement became more severe and higher aging temperatures were required to produce complete recovery in a bend test. In a study of delayed failures in zinc-plated lockwashers, Valentine $\mathrm{e}^{(130)}$ found that a subsequent aging treatment at $400 \mathrm{~F}$ eliminated or reduced the delayed failures. However, in an investigation of many thousands of acid-descaled and cadmium-plated steel dome lockwashers, Stefanides(131) found no evidence that baking after plating was very helpful. Zapffe and Haslem(132-134) embrittled mild steel and hardenable stainless steel (17 percent chromium, 1 percent carbon) wires by electroplating with cadmium, chromium, zinc, tin, nickel, or lead.

They found that baking treatments were effective in recovering the original ductility. Figelman and Shreider(136) studied the effects of electroplating with chromium, copper, nickel, zinc, or cadmium on the ductility of heat-treated spring steel. The testing method consisted of measuring the bend angle necessary to produce failure of a flat specimen. They found that aging at 390 to $570 \mathrm{~F}(200$ to $300 \mathrm{C}$ ) was almost always effective in recovering the ductility lost as a result of the introduction of hydrogen into the base steel.

Although investigations such as the one on clock-spring steel by Eakin and Lownie indicate that temperatures up to at least $525 \mathrm{~F}$ greatly accelerate recovery of ductility lost as the result of

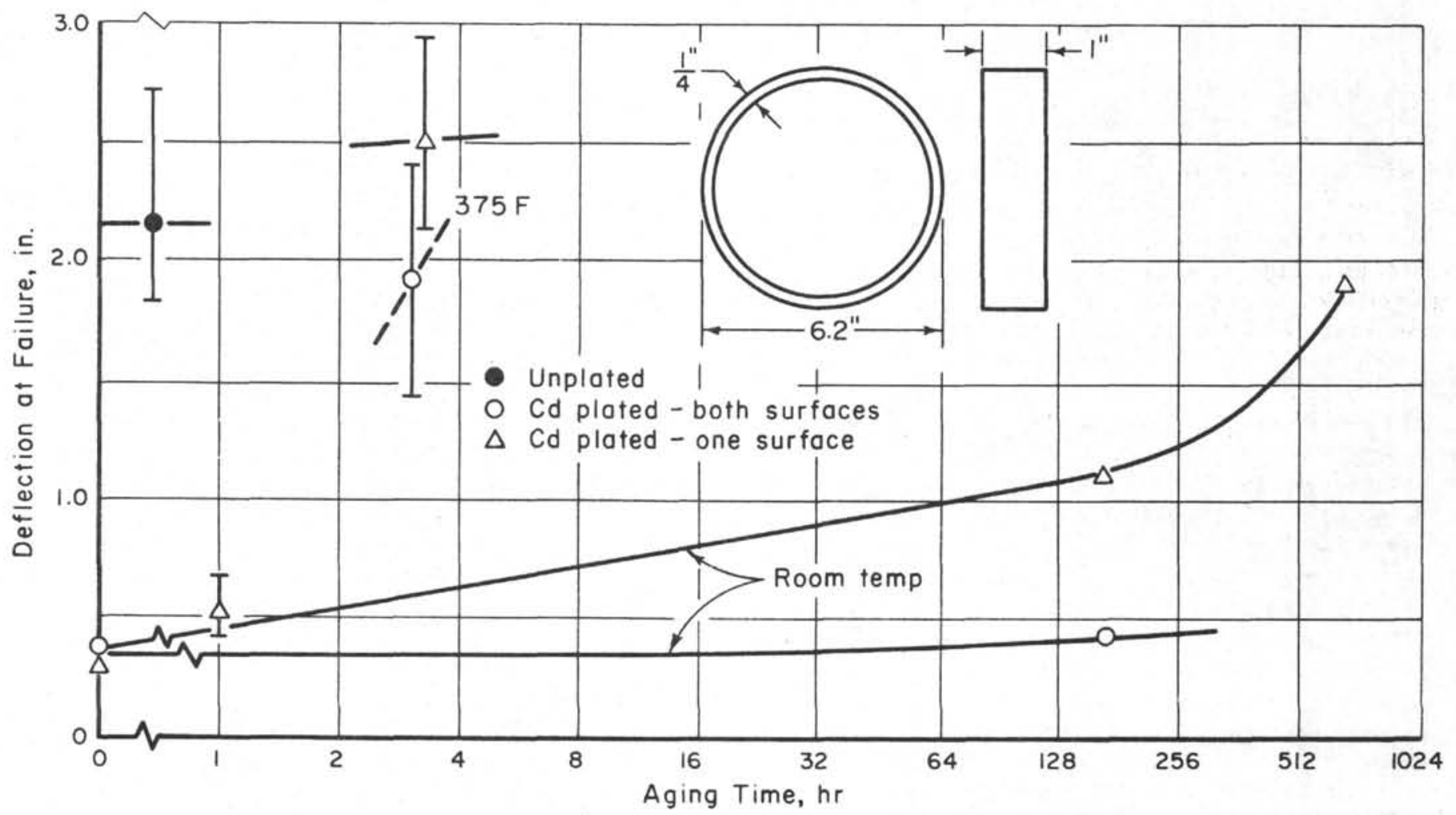

FIGURE 64. EFFECT OF ROOM-TEMPERATURE AGING AND BAKING AT 375 F ON HYDROGEN EMBRITTLEMENT OF CADMIUM-PLATED (0.001 IN.) STEEL TUBE (DATA BY MENASCO)(

(4340 Steel; Hardness = Rockwell C 50.) 


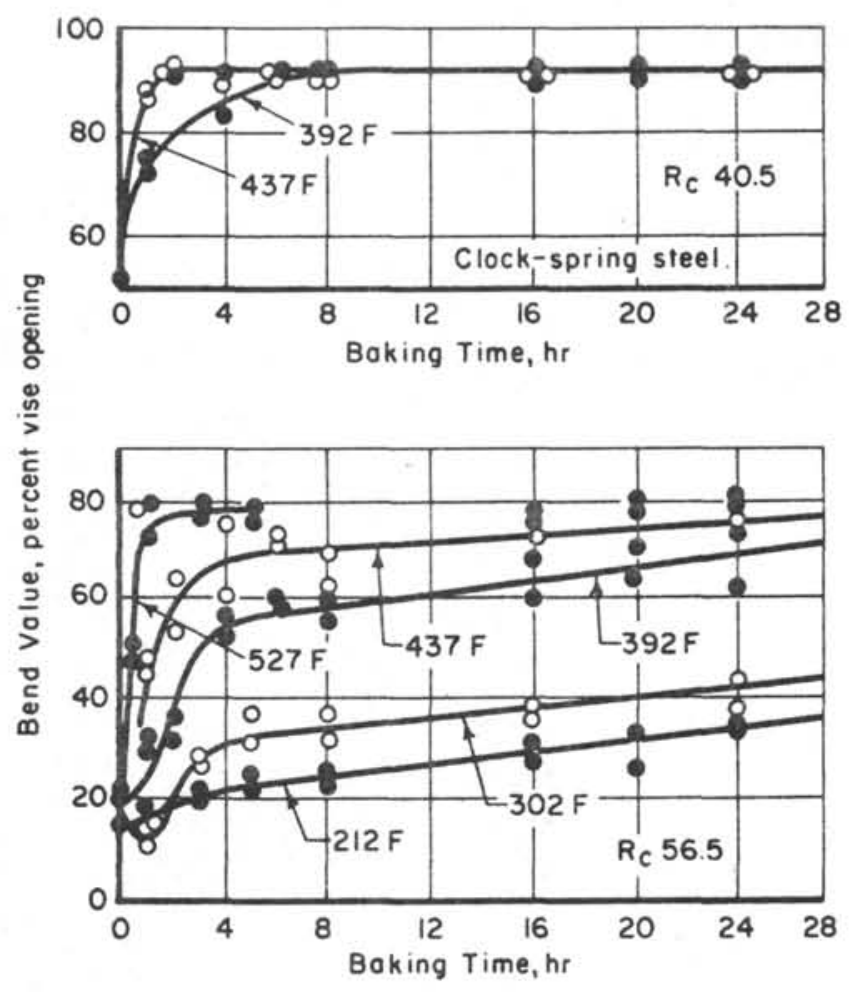

FIGURE 65. EFFECTS OF TEMPERATURE AND TIME ON RECOVERY FROM HYDROGEN EMBRITTLEMENT OF CADMIUMPLATED SPRING-STEEL STRIP (0.008 IN. $\times 1 \frac{1}{4}$ IN. )(AFTER EAKIN AND LOWNIE, REFERENCE 129) ${ }^{(187)}$

hydrogen embrittlement due to electroplating, some tests conducted on SAE 4340 steel indicated that the higher temperatures may be detrimental to the ductility of high-strength cadmium-plated parts. In any event, temperatures over $610 \mathrm{~F}$, the melting point of cadmium, must be avoided, because liquid cadmium can cause cracking of lowhydrogen steel. Also, baking temperatures higher than $400 \mathrm{~F}$ produce discoloration of cadmiumplated parts, and thus, are undesirable. It has been suggested that the presence of such an oxide film on the surface of the cadmium plate further interferes with the removal of hydrogen, and this may explain the adverse effects of baking at temperatures above $400 \mathrm{~F}$ that sometimes have been observed. Another explanation that might account for such an observed effect is the formation of a brittle laye $r$ at the steel-cadmium interface as the result of diffusion of some of the cadmium into the steel.

Before strength levels were boosted to the point where delayed brittle failures were encountered, the most common relief practice for hydrogen embrittlement resulting from cadmium plating consisted of baking at 375 to $400 \mathrm{~F}$ for 3 or 4 hours. When hydrogen-induced delayed brittle failures were encountered, baking times often were increased to 23 hours, but this practice was only partially effective in alleviating the susceptibility to hydrogen cracking.
Raring and Rinebolt $(137)$ studied the effect of baking at $350 \mathrm{~F}$ for $1 \frac{1}{2}$ hours on cadmiumplated, vacuum-melted 4340 steel at the 230,000psi strength level. Although the baking treatment restored the breaking strength of the plated specimens in the short-time tensile test nearly to that of the unplated specimens, the susceptibility to delayed brittle failure was not changed appreciably. After plating and baking, the lower critical stress was only about 47 percent of the notched tensile strength of specimens that were not plated. The hydrogen content before baking was 0.7 to 1.1 ppm; after baking it was 0.6 to $0.7 \mathrm{ppm}$. The effect of the treatment on the short-time tensile properties of unnotched tensile specimens was as follows:

\begin{tabular}{|c|c|c|}
\hline & $\begin{array}{l}\text { Before } \\
\text { Plating } \\
\end{array}$ & $\begin{array}{l}11 / 2 \text { Hours at } \\
350 \mathrm{~F} \\
\end{array}$ \\
\hline $\begin{array}{l}\text { Tensile Strength, } \\
\text { psi }\end{array}$ & 234,000 & 230,000 \\
\hline $\begin{array}{l}\text { Yield Strength, } \\
\text { psi }\end{array}$ & 208,000 & 208,000 \\
\hline $\begin{array}{l}\text { Elongation, percent } \\
\text { in } 1 \text { inch }\end{array}$ & 15.0 & 15.0 \\
\hline $\begin{array}{l}\text { Reduction in Area, } \\
\text { percent }\end{array}$ & 57.0 & 52.5 \\
\hline
\end{tabular}

Various other investigators also showed that, although suitable baking treatments resulted in full recovery of lost ductility, as indicated by a conventional tensile test, frequently such treatments did not eliminate susceptibility to delayed failures, especially for materials of the higher strength levels; for example, see Figure 66 . Delayed failures have occurred after baking for times at least as long as 100 hours. Sometimes the static loading tests of notched specimens may indicate essentially no recovery as a result of a baking treatment. Thus, it has been shown conclusively that data obtained in a short-time tensile test are not suitable criteria of the susceptibility to delayed brittle failure. Also, baking does not insure elimination of the susceptibility to such failures.

The recovery of parts cadmium plated on only one surface is considerably faster than that of parts plated on both surfaces. Figure 64 illustrates the difference for hollow parts plated in the one case only on the outer surface and in the other case on both surfaces. Now and then a specific lot 


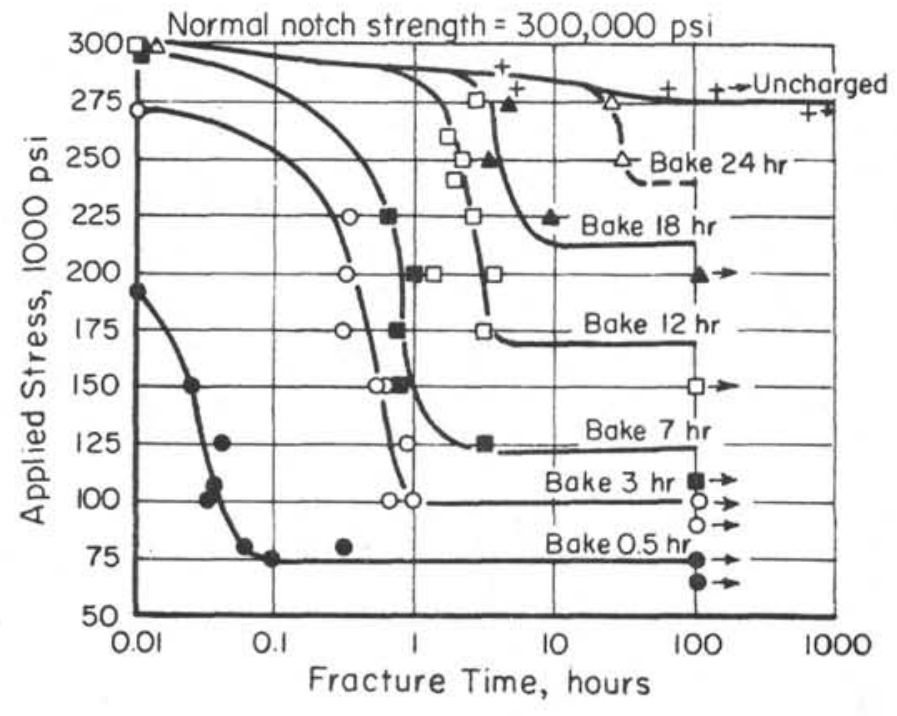

FIGURE 66. STATIC-FATIGUE CURVES FOR VARIOUS HYDROGEN CONCENTRATIONS CORRESPONDING TO DIFFERENT BAKING TIMES AT 300 F AFTER CATHODIC CHARGING(192)

(Sharp-notch specimens; 230,000-psi strength level.)

of cadmium-plated material is found which is especially resistant to the relief of hydrogen embrittlement. Often this is the result of variations in the structure of the cadmium plate. A somewhat porous plate offers less resistance to the effusion of hydrogen. Methods have been developed to intentionally produce a porous plate which permits hydrogen to diffuse out of the surface in a subsequent bake to remove hydrogen introduced in the plating operation [for example, see Reference (195)]. The factor that influences the type of plate produced is the use of a brightener in the cadmium-plating solution. One investigation showed that very small amounts of such an additive greatly reduced the recovery from hydrogen embrittlement of SAE 4340 steel heat treated to a hardness of Rockwell C 48 . Also, some plating baths are more efficient than others and plate out less hydrogen at the metal surface.

Residual, or Nondiffusible, Hydrogen

Studies of the removal of hydrogen from steel led to the concept of "residual", or "nondiffusible", hydrogen in iron and stecl. $(184,196,181,47,160)$ Residual hydrogen has been widely known for many years in the analysis of steels for hydrogen. It is chiefly responsible for the lack of general acceptance in the U. S. of the warm-extraction analytical method for hydrogen determination. The hydrogen is not all removed by this method, which involves measuring the hydrogen evolved by heating in the $\alpha$-range. Apparently, residual hydrogen can be extracted only at temperatures above about $1470 \mathrm{~F}$ $(800 \mathrm{C})$. Different investigators have reported that

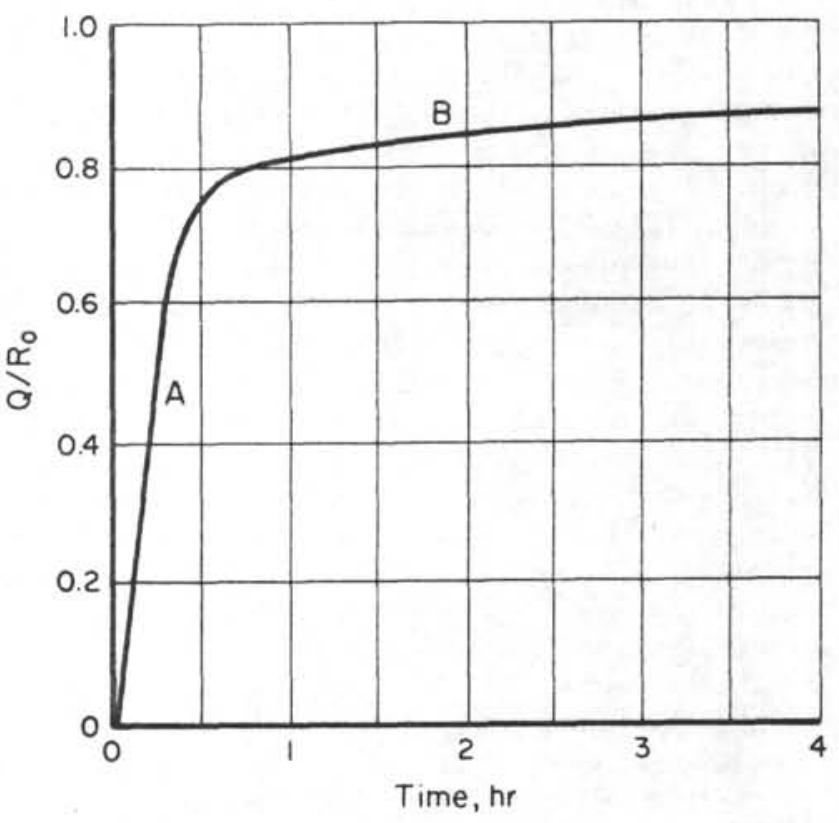

FIGURE 67. CURVE OF EXTRACTION OF HYDROGEN IN VACUUM AT 1110 F $(600 \mathrm{C})$, SHOWING TWO APPARENTLY DIFFERENT REGIMES: A, PERIOD OF RAPID EVOLUTION; B, PERIOD OF SLOW EVOLUTION; Q/R。 = RATIO OF HYDROGEN EXTRACTED AT ANY TIME TO THE TOTAL HYDROGEN COLLECTED AFTER 40 HOURS [AFTER BLETON, et al(197)] (198)

(Samples $1 / 2$ inch diameter and $1 / 2$ inch long.)

this residual form of hydrogen can be removed from steel only by drastic vacuum treatments at temperatures well up into the austenitic range, or even in the molten state (vacuum-fusion analysis). Thus, the terms "residual" and "nondiffusible" were used to describe a form of hydrogen in steel which is bound far more tenaciously than that described by the usual diffusion coefficient (given in Equation 38, page 40, and Figure 32, page 44, for example).

It was the results of experiments on the rate of removal of hydrogen from steel that led a number of investigators to suggest that this element exists in steel in two forms, each with different effects on the physical properties of steel. This conclusion was based in part on the type of extraction curve shown in Figure 67. However, this hypothesis is not confirmed by vacuumextraction experiments performed at $1200 \mathrm{~F}(650 \mathrm{C})$ and a theoretical treatment of diffusion performed by Demarez, Hock, and Meunier. (198) Their experiments purportedly showed that there is reasonable agreement between observed extraction rates and rates predicted from the laws of normal diffusion. They stated that it is thus possible to estimate the course of hydrogen evolution from the usual rolled products if the diffusion coefficient is known. 
Johnson and Hill(10) suggested recently that residual hydrogen is associated chemically with an impurity in iron that results in a compound that decomposes rapidly above $1470 \mathrm{~F}(800 \mathrm{C})$. They found large amounts of nondiffusible hydrogen in airmelted iron and only small, but detectable, amounts in several heats of vacuum-melted iron. 'They first considered that the compound is water resulting from the reduction of $\mathrm{FeO}$ by dissolved hydrogen. However, the oxygen contents of all vacuum-melted heats were sufficient to form large quantities of water, but very little residual hydrogen formed, even in a vacuum-melted heat to which an addition of $1200 \mathrm{ppm}$ of oxygen was made. Recent work by Podgurski(59) suggests that the compound may be methane. The identity of the compound is still uncertain. Hill and Johnson found that the rate of residual-hydrogen formation is very low at temperatures below $930 \mathrm{~F}(500 \mathrm{C})$, but increases rapidly at temperatures above $930 \mathrm{~F}$ and reaches a maximum at $1110 \mathrm{~F}(600 \mathrm{C})$. They suggested that the chemical fixing of hydrogen in steel occurs during cooling between 1470 and $930 \mathrm{~F}$ (800 and 500 C). If the steel is quenched through this range, very little should form and nearly all the hydrogen in the material should remain diffusible. If the steel is slowly cooled, extensive conversion of diffusible to residual hydrogen probably occurs. Previously reported contents of residual hydrogen in steel generally did not exceed $1 \mathrm{ppm}$. However, Hill and Johnson(13) demonstrated that up to $19 \mathrm{ppm}$ residual hydrogen may be formed in air-melted iron by prolonged holding at $1110 \mathrm{~F}(600 \mathrm{C})$ under hydrogen-pressure levels corresponding to diffusible hydrogen concentrations of approximately 7 ppm.

Johnson and $\mathrm{Hill}(47,13)$ found that certain grades of iron, when treated for several days at high pressures and at temperatures between 840 and $1200 \mathrm{~F}$ (450 and $650 \mathrm{C}$ ), will absorb considerably more hydrogen than is indicated by the solubility data shown in Figure 8, page 10. Furthermore, they found that the hydrogen thus introduced could be extracted in two separate fractions, one of which was evolved in accordance with the diffusion coefficient for annealed iron given in Figure 32, page 44. They found that the other fraction was removable only by more extreme extraction conditions, such as heating for several weeks at about $1110 \mathrm{~F}(600 \mathrm{C})$ or by heating for about 1 hour at 1560 to $1650 \mathrm{~F}$ (850 to $900 \mathrm{C})$.

In Figure 68, the evolution characteristics of hydrogen from two samples of iron, only one of which contained residual hydrogen, are shown. One sample was from a heat of iron that had been melted in air, and the other was vacuum melted; both were made from electrolytic-iron melting stock. Both samples were soaked in hydrogen gas at $62 \mathrm{~atm}$ pressure and $1085 \mathrm{~F}(585 \mathrm{C})$ for 5 days. This treatment introduced about 8.2 ppm of hydrogen into the vacuum-melted iron. Evolution of hydrogen from the hydrogen-charged vacuummelted iron was completely normal. All the hydrogen was evolved at $1065 \mathrm{~F}(575 \mathrm{C})$ at a rate which could be calculated from the known diffusion constant. After 6 hours at $1065 \mathrm{~F}$, the temperature was raised to $1470 \mathrm{~F}(800 \mathrm{C})$, but no additional hydrogen was evolved. For the air-melted iron, the rapid initial evolution of "diffusible" hydrogen at $1065 \mathrm{~F}$ was followed by a slow evolution which was still in progress at the end of 2 days. It appeared that complete extraction of the hydrogen at this temperature would take several weeks, so the temperature was raised to $1290 \mathrm{~F}(700 \mathrm{C})$. This resulted in a marked increase in the rate of evolution. Since it appeared that another day would be required for complete extraction, the temperature was raised again, this time to $1560 \mathrm{~F}(850 \mathrm{C})$. Again, the evolution increased, but extraction was complete in 1 hour at this temperature. Subsequent vacuum-fusion analyses of both samples showed that neither retained more than 0.2 ppm of hydrogen after the solid-state extractions just described. Thus, a total of $23.4 \mathrm{ppm}$ of hydrogen was evolved from the air-melted sample, as compared with $8.2 \mathrm{ppm}$ from the vacuum-melted sample, even though identical charging conditions had been used. The value of 8.2 ppm was exactly what was calculated using Sieverts' law and the data in Figure 8, page 10, and, therefore, represents the solubility at $62 \mathrm{~atm}$ and $1085 \mathrm{~F}(585 \mathrm{C})$. Thus, the hydrogencharged, air-melted sample contained $15.2 \mathrm{ppm}$ more hydrogen than given by the solubility data. Further experimental work showed that this extra hydrogen was evolved with an activation energy 16 times greater than the activation energy for normal diffusion at the se extraction temperatures.

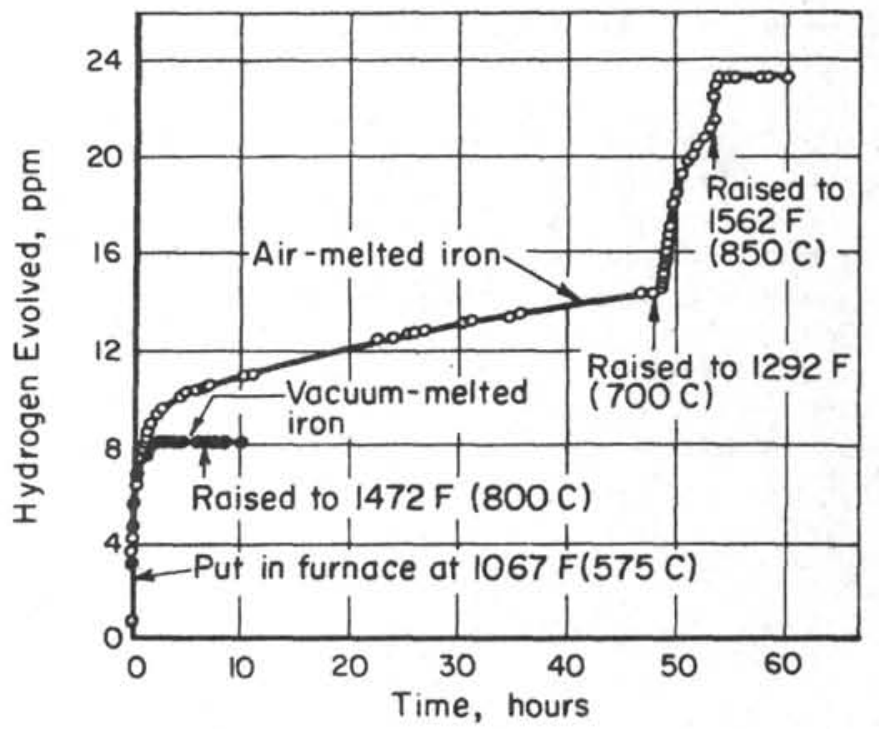

FIGURE 68. EVOLUTION OF HYDROGEN FROM CYLINDERS OF IRON 0.75 INCH IN DIAMETER BY 1.25 IN LONG(167)

Three different air -melted heats of iron showed similar tendencies to absorb extra amounts of hydrogen above the values indicated by the solubility curves (Figure 8 ). The amount of extra hydrogen increased with increasing duration of the charging treatment and with increasing pressure 
of gaseous hydrogen. No extra hydrogen was found in samples treated at temperatures below $750 \mathrm{~F}$ $(400 \mathrm{C})$, and only 2 to 5 ppm of extra hydrogen was found in samples treated at $1200 \mathrm{~F}(650 \mathrm{C})$. The largest amount of extra hydrogen found was $18 \mathrm{ppm}$, and this was in samples treated at $1085 \mathrm{~F}$ (585 C) for 150 hours. No detectable amounts of residual hydrogen were formed with 1 -hour treatments, only the amount of hydrogen indicated by the solubility curve in Figure 8 being introduced.

Three different heats of vacuum-melted iron all showed a similar ability to resist introduction of extra hydrogen, none being found in any heat after soaking in hydrogen at several temperatures and pressures covering the ranges in which residual hydrogen was introduced into air-melted samples.

By using samples of vacuum-melted iron or by using very short charging periods with air-melted iron, it was possible to prepare samples which contained no residual hydrogen. These precuations were observed in all experiments used by these investigators in determining the solubility and the diffusivity of hydrogen in steel (Figures 32 and 8 ). Thus, the deviations these investigators found in solubility and diffusivity at low temperatures (as discussed previously in the present report) were not related to residual hydrogen.

It has been shown that hydrogen embrittlement and delayed brittle failure of steel are related to the ability of hydrogen to diffuse, as has been discussed in earlier reports by the present authors (DMIC Memorandum 180 and DMIC Report 196). It is clear from the kinetics of evolution that in whatever form the "residual" hydrogen is contained in iron and steel, it is firmly bound and is essentially immobile and unable to diffuse in the temperature range (near room temperature) where these phenomena are observed. This indicates that residual hydrogen cannot contribute to these effects. Thus, conversion of hydrogen to this form would appear to have possible benefits. It would appear to be possible to convert some of the hydrogen in commercial steels (perhaps excluding vacuum-melted steel) into a chemically bound form during prolonged heat treatments at about $1110 \mathrm{~F}$. However, this is considerably above the tempering temperature used for most high-strength steels, with the exception of those that exhibit secondary hardening. Also, the kinetics of its formation prohibit the formation of this bound hydrogen at all temperatures normally used for electroplating from aqueous solutions and in the postplating baking treatments.

Although it would appear that residual hydrogen cannot contribute to hydrogen embrittlement or hydrogen cracking of steel, Hill and Johnson are of the opinion that residual hydrogen is responsible for serious grain-boundary weakening. Because of these apparently separate effects of the two forms of hydrogen, these investigators suggested that determinations of both diffusible and residual hydrogen should be made in the analysis of steel.

Podgurski(59) studied the anomalously high solubility reported for hydrogen in cold-worked steel at temperatures above $390 \mathrm{~F}(200 \mathrm{C})$. He attributed this to methane formed by a reaction between hydrogen and cementite; he quantitatively isolated this methane from steel.

\section{REFERENCES}

(1) Cotterill, P., "The Hydrogen Embrittlement of Metals", Progress in Metal Physics, Vol. 9 (Bruce Chalmers, Ed.), Pergamon Press, New York, New York, pp 201-301 (1961).

(2) Smith, D. P., Hydrogen in Metals, University of Chicago Press, Chicago, Illinois, 366 pp (1948).

(3) Tetelman, A. S., Wagner, C. N. J., and Robertson, W. D., "An X-Ray Inve stigation of the Effects of Hydrogen in Iron", Acta Met., 9, pp 205-215 (1961).

(4) Barrer, R. M., "Aspects of Gas-Metal Equilibrium, Interstitial Solution and Diffusion", Discussions Faraday Soc., Paper No. 4, pp 68-81 (1948).

(5) Ké, T. S., "Internal Friction in the Interstitial Solid Solutions of C and O in Tantalum", Phys. Rev., 74, pp 9-15 (1948).

(6) Bastien, P., "Phenomena of Fissuring and Cracking of Steel in the Presence of Hydrogen", Arch. Hutnictwa, 4, p 93 (1959).
(7) Plusquellec, J., Azou, P., and Bastien, P., "Localization of Hydrogen in the Lattice of Alpha Iron", Compt. Rend., 244, pp 11951197 (1957), in French.

(8) Bastien, P. G., "The Phenomena of Cracking and Fracture of Steel in the Presence of Hydrogen. Corrosion Under Stress in the Presence of Moist Hydrogen Sulfide", Physical Metallurgy of Stress-Corrosion Fracture (Thor N. Rhodin, Ed.), Amer. Inst. Mining, Met., and Petrol. Engrs., Met. Soc. Conferences, Vol. 4, Interscience, New York, New York, pp 311-340 (1959).

(9) Wert, C., and Zener, C., "Interstitial Atomic Diffusion Coefficients", Phys. Rev., 76 , pp 1169-1175 (1949).

(10) Johnson, E. W., and Hill, M. L., "The Diffusivity of Hydrogen in Alpha Iron", Trans. Met. Soc., AIME, 218, pp 1104-1112 (1960).

(11) Darmois, E., "Sur la pénétration de l'hydrogène dans le fer et quelques conséquences" (Penetration of Hydrogen into Iron and Some Consequences), Bull. Soc. Chim. France, p D170 (1949). 
(12) Heller, W. R., "Hydrogen in Iron and Its Alloys", Stress Corrosion Cracking and Embrittlement (W. D. Robertson, Ed.), The Electrochemical Society, John Wiley and Sons, New York, New York, pp 163-175 (1956).

(13) Hill, M. L., and Johnson, E. W., "The Solubility of Hydrogen in Alpha Iron", Trans. Met. Soc. AIME, 221, pp 622-629 (1961).

(14) Hill, M. L., and Johnson, E. W. , "Hydrogen in Cold Worked Iron-Carbon Alloys and the Mechanism of Hydrogen Embrittlement", Trans. Met. Soc. AIME, 215, pp 717-725 (1959).

(15) Zapffe, C. A., "Neumann Bands and the Planar-Pressure Theory of Hydrogen Embrittlement", J. Iron Steel Inst., 154, pp 123P-130P (1946).

(16) Zapffe, C. A., and Haslem, M. E., "A Test for Hydrogen Embrittlement and Its Application to $17 \%$ Chromium 1\% Carbon Stainless Steel Wire", Metals Technology, 13 (1), Tech. Paper 1954 (January, 1946); Trans. Am. Inst. Mining Met. Engrs., Iron and Steel Div., 167, p. 281 (1946).

(17) Zapffe, C. A., Discussion of "Metal Arc Welding of Steel" by S. A. Herres in Trans. Am. Soc. Metals, 39, pp 162-189 (1947); Trans. Am. Soc. Metals, 39, pp 190-191 (1947).

(18) Andrew, J. H., Bose, A. K., Lee, H., and Quarrell, A. G., "The Formation of HairLine Cracks - Part II", J. Iron Steel Inst., 146, pp 203P-243P (1942); Discussion pp 244P-282P.

(19) Andrew, J. H., and Lee, H., "Internal Stresses and the Formation of Hairline Cracks in Steel", Symposium on Internal Stresses in Metals and Alloys, Inst. of Metals, London, p. 265 (1947).

(20) Wever, F., and Pfarr, B., "Über die Ausbildung von Gitterstörungen bei der Kristallerholung und Rekristallisation" (Changes in the Lattice Constant as the Result of Cold Work and Their Removal by Crystal Recovery and Recrystallization), Mitt. Kaiser Wilhelm Inst. Eisenforschung, 15, pp 137-145 (1933).

(21) Baukloh, W. , and Stromburg, W., "Über die Wasserstoffkrankheit einiger Metalle" (On the Hydrogen Disease of Some Metals), Z. Metallk., 29, pp 427-433 (1937).
(22) Portevin, A., Chaudron, G., and Moreau, L., "Contribution à l'etude du rôle des gaz dans les métaux" (Contribution to the Study of the Role of Gases in Metals), Compt. Rend., 204, pp 1252-1254 (1937).

(23) Andrews, J. N., and Ubbelohde, A. R., "Overvoltage and Diffusion Through Iron and Palladium", Proc. Royal Soc., A253, pp 6-15 (1959).

(24) Smialowski, M. , Hydrogen in Steel, Pergamon Press, Oxford, and Addison-Wesley Publishing Company, Inc., Reading, Massachusetts, pp $154,175,25-63$ (1962).

(25) Lihl, F., "Änderung des Spannyngszustandes der Werkstoffoberfläche durch Atzen" (Changes of the Lattice Parameter and Stresses Produced in Steel by Pickling), Arch. Metallk., 1, pp 16-25 (1946).

(26) Glikman, L. A., and Snezhkova, T. N., "Origin of Residual Stresses in Steel Surfaces Saturated with Hydrogen Electrolytically", Zh. Tekhn. Fiz., 22, p. 1104 (1952).

(27) Szklarska-Smialowska, Z ., and Smialowski, M., "Creation of Stresses in Nickel Cathodes Due to Hydrogenation", Bull. Acad. Pol. Sci. Ser. Sci. Chim., 6, p. 427 (1958).

(28) Smialowski, M., and Szklarska-Smialowska, Z., "Linear Expansion of Iron Wires Due to Cathodic Hydrogenation", Bull. Acad. Pol. Sci., C1. III, 1, pp 159, 237 (1953).

(29) Foryst, J., and Smialowski, M. , Electrochemical Conference, Warsaw, 1955.

(30) Foryst, J., "Dependence of the Hydrogen Brittleness of Steel on the Content of Oxide Inclusions", Hutnicke Aktuality, 14, p. 47 (1958).

(31) Sieverts, A., "Occlusion and Diffusion of Gases in Metals", Z. Physik. Chem., 60, p. 169 (1907), in German.

(32) Sieverts, A., Krumbhaar, W. , and Jurisch, E., "The Solubility of Hydrogen in Copper, Iron, and Nickel", Z. Physik. Chem., 77, pp 591-613 (1911), in German.

(33) Sieverts, A., Zapf, G., and Moritz, H., "Die Lóslichkeit von Wasserstoff, Deuterium und Stickstoff in Eisen" (The Solubility of Hydrogen, Deuterium, and Nitrogen in Iron), Z. Physik. Chem., A 183, pp 19-37 (1938/ 1939). 
(34) Martin, E., "Ein Beitrag zur Frage der Aufnahmefähigkeit des reinen Eisens und einiger seiner Legierungselemente für Wasserstoff und Stickstoff" (A Contribution to the Question of the Solubility of Pure Iron and Some of Its Elementary Alloys for Hydrogen and Nitrogen), Arch. Eisenhüttenw., 3, pp 407-416 (1929).

(35) Luckmeyer-Hasse, L., and Schenck, H. , "Löslichkeit von Wasserstoff in einigen Metallen und Legierungen" (Solubility of Hydrogen in Some Metals and Alloys), Arch. Eisenhuttenw., 6, pp 209-214 (1932).

(36) Andrew, J. H. , Lee, H., and Quarrell, A. G., "The Determination of the Solubility of Hydrogen in Iron and Iron Alloys", J. Iron Steel Inst., 146, pp 181P-192P (1942).

(37) Armbruster, M. H., "The Solubility of Hydrogen at Low Pressure in Iron, Nickel, and Certain Steels at 400 to $600^{\circ}$ (C)", J. Am. Chem. Soc., 65, pp 1043-1054 (1943).

(38) Geller, W., and Sun, T., "Einfluss von Legie rungszusätzen auf die Wasserstoffdiffusion im Eisen und Beitrag zum System Eisen-Wasserstoff" (Influence of Alloy Additions on Hydrogen Diffusion in Iron and Contribution to the System Iron-Hydrogen), Arch. Eisenhüttenw., 21, pp 423-430 (1950).

(39) Zapffe, C. A., "Fe-H Iron-Hydrogen", Metals Handbook, 1948 Ed., Am. Soc. Metals, Metals Park, Novelty, Ohio, pp 1208-1209 (1948).

(40) Ham, W. R., and Rast, W. L., "A Study of the $A_{0}$ Point of Iron by Diffusion of Hydrogen", Trans. Am. Soc. Metals, 26, pp 885-902 (1938).

(41) Chang, P. L., and Bennett, W. D. G., "Diffusion of Hydrogen in Iron and Iron Alloys at Elevated Temperatures", J. Iron Steel Inst., 170, pp 205-213 (1952).

(42) Fowler, R. H., and Smithells, C. J., "A Theoretical Formula for the Solubility of Hydrogen in Metals", Proc. Royal Soc., A 160, pp 37-47 (1937).

(43) Dyakonov, A., and Samarin, A., "Analysis of the Absorption Process of Gases by Metals", Izvest. Akad. Nauk SSSR, No. 1, p. 121 (1946).

(44) Sieverts, A., and Hagen, H., "Das Absorptions-vermögen des festen Kobaltes für Wasserstoff und Stickstoff" (The Ability of Solid Cobalt to Absorb Hydrogen and Nitrogen), Z. Physik. Chem., A169, pp 237-240 (1934).
(45) Hawkins, N. J., "Solubility of Hydrogen Isotopes in Nickel and Type 347 Stainless Steel", Report No. KAPL-868, U. S. Atomic Energy Commission Publication (1953).

(46) Frank, R. C., Lee, R. W., and Williams, R. L., "Ratio of the Diffusion Coefficients for the Diffusion of Hydrogen and Deuterium in Steel", J. Appl. Phys., 29, pp 898-900 (1958).

(47) Johnson, E. W. , and Hill, M. L., "The Diffusion of Hydrogen in Iron and Ferritic Steels", Acta Met., 3, pp 99-101 (1955).

(48) Darken, L. S., and Smith, R. P., "Behavior of Hydrogen in Steel During and After Immersion in Acid", Corrosion, 5, pp 1-16 (1949).

(49) Bryan, W. L., and Dodge, B. F., "Diffusivity of Hydrogen in Pure Iron", A. I. Ch. E. J., $\underline{9}(2), 223-228$ (1963).

(50) Hudson, R. M. , Magor, J. K. , and Stragand, G. L., "Relationship Between Hydrogen Solubility and Reboiling Tendency in Enameling Steels", J. Am. Ceram. Soc., 41, pp 23-27 (1958).

(51) Keeler, J. H. , and Davis, H. M., "Density and Hydrogen Occlusion of Some Ferrous Metals", Trans. Am. Inst. Mining Met. Engrs., 197, pp 44-48 (1953).

(52) Hudson, R. M., Riedy, K. J., and Stragand, G. L., "Influence of Cold Work on Hydrogen Behavior in Steel", Corrosion, 16, pp 115t118 t (March, 1960).

(53) Emmett, P. H., and Harkness, R. W., "The Adsorption of Hydrogen by Iron Synthetic Ammonia Catalysts", J. Am. Chem. Soc., 57, pp 1631-1635 (1935).

(54) Duflot, J., "The Supersaturation of Iron by Cathodic Hydrogen", Publ. Sci. Tech. Min. Air, (265), pp 1-56 (1952), in French.

(55) Duflot, J., "Rôle des Traitements Thermiques, Mécaniques et Superficiels Dans le Chargement en Hydrogène Cathodique du Fer" (Role of Heat, Mechanical, and Surface Treatments in the Charging of Iron With Cathodic Hydrogen)', Rev. Mét. Mémoires, 49, pp 35-50 (1952).

(56) Naumann, K. F., and Carius, W., "Bruchbildung an Stählen bei Einwirkung von Schwefelwasserstoffwasser" (Formation of Fractures in Steels Under the Action of Hydrogen Sulfide Water), Arch. Eisenhüttenw., 30, pp 233-238 (1959). 
(57) Schuetz, A., and Robertson, W., "Hydrogen Absorption, Embrittlement and Fracture of Steel", Corrosion, 13, pp 437t-458t (1957).

(58) Raczynski, W. , and Smialowski, M. , "Penetration of Cathodically Evolved Hydrogen Into Mild Steel", Bull. Acad. Pol. Sci. Ser. Sci. Chim., 8, p 209 (1960).

(59) Podgurski, H. H., "Trapping of Hydrogen in Cold-Worked Steel", Trans. Met. Soc. AIME, 221, pp 389-394 (1961).

(60) Hudson, R. M. , Riedy, K. J. , and Stragand, G. L., "Influence of Cold-Reduction and Heat-Treatment Combinations on Hydrogen Solubility and Permeability in Steel", Corrosion, 17 (7), 334t-336t (1961).

(61) Carney, D. J., Chipman, J., and Grant, N. , "An Introduction to Gases in Steel", AIME Elec. Furn. Steel Proc., 6, pp 34-45 (1948).

(62) Bardenheuer, P., and Thanheiser, G. , "Untersuchungen über das Beizen von kohlenstoffarmen Flussstahlblechen" (Investigation on the Pickling of Low-Carbon Ingot-Steel Sheet), Mitt. Kaiser Wilhelm Inst. für Eisenforschung, 10, pp 323-342 (1928).

(63) Zapffe, C. A., and Sims, C. E., "Hydrogen, Flakes and Shatter Cracks", Metals and Alloys, 11 (5), 145-151 (1940); 11 (6), 177$184(194 \overline{0)} ; 12(1), 44-51$ (1940); and 12 (2), $145-148(19 \overline{40})$.

(64) Evans, U. R., The Corrosion and Oxidation of Metals: Scientific Principles and Practical Applications, Chapter XI, "Hydrogen Cracking and Blistering", St. Martin's Press, Inc., New York, New York, pp 393-426 (1960).

(65) Thompson, F. W., and Ubbelohde, A. R., "The Attack of Metals by Free Radicals and Atoms", J. Appl. Chem., 3, pp 27-36 (1953).

(66) Ewing, V. C. , and Ubbelohde, A. R., "Hydrogenation Through Metal Septa", Proc. Royal Soc., A230, pp 301-311 (1955).

(67) Bridgman, P. W., "The Compressibility of Five Gases to High Pressures", Proc. Am. Acad. Arts Sci., 59, pp 173-211 (1924).

(68) Bridgman, P. W., The Physics of High Pressure, G. Bell and Sons, Ltd., London, England, pp 96-97 (1949).

(69) Poulter, T. C., and Uffelman, L., "The Penetration of Hydrogen Through Steel at Four Thousand Atmospheres", Physics, 3, pp 147-148 (1932).
(70) Dodge, B. F., "High-Pressure Research in Chemical Engineering Department of Yale University", Trans. Am. Soc. Mech. Engrs., 75, pp 331-343 (1953).

(71) Smithells, C. J., and Ransley, C. E., "The Diffusion of Gases Through Metals", Proc. Royal Soc., A 150, pp $172-197$ (1935).

(72) Borelius, G. , and Lindblom, S. , "Durchgang von Wasserstoff durch Metalle" (Passage of Hydrogen Through Metals), Ann. Physik., 82, Series 4, pp 201-226 (1927).

(73) Sims, C. E., "The Behavior of Gases in Solid Iron and Steel", Gases in Metals, Am. Soc. Metals, Metals Park, Novelty, Ohio, p 149 (1953).

(74) Machu, W., and Ungersböch, O., "Kathodisches Beizen bei Gegenwart von Sparbeizstoffen" (Cathodic Pickling in the Presence of Inhibiting Pickling Agents), Arch. Eisenhüttenw., 15, pp 301-306 (1942).

(75) Zapffe, C. A., and Haslem, M. E., "Evaluation of Pickling Inhibitors from the Standpoint of Hydrogen Embrittlement", Wire and Wire Products, 23, pp 933-939, 1048-1053, 1080$1082,1126-1130,1172-1175$ (1948).

(76) Anderson, R. H., Allen, E. R., and Van der Meulen, P. A., "Uptake of Hydrogen by Certain Organic Inhibitors During Pickling of Steel in Hydrochloric Acid", Corrosion, 17, pp $437 \mathrm{t}-440 \mathrm{t}$ (1961).

(77) Uhlig, H. H. (Ed.), Corrosion Handbook, 1948 Ed., Wiley-Chapman and Hall, pp $910-912$ (1948).

(78) Baukloh, W., and Retzlaff, W., "Wasserstoffdurchlässigkeit von Stahl beim elektrolytischen Beizen" (Hydrogen Permeation of Steel by Electrolytic Pickling), Arch. Eisenhüttenw., 11, pp 97-99 (1937).

(79) Smialowski, M. , Hydrogen in Steel, Pergamon Press, Oxford, and Addison-Wesley Publishing Company, Inc., Reading, Massachusetts, pp 365-380 (1962).

(80) Homer, C. E., "Embrittlement of Spring Clips", Tin and Its Uses, No. 11, p 14 (October, 1941).

(81) Hudson, R. M., Norris, W. G., and Stragand, G. L., "Effect of Environment on the Rate of Hydrogen Removal from Steel", Ind. Eng. Chem., 51 (3), 319-324 (1959).

(82) Shank, M. E., Spaeth, C. E., Cooke, V. W., and Coyne, J. E., "Solid-Fuel Rocket Chambers for Operation at 240,000 Psi and Above", Parts I and II, Metal Progr., 76, pp 74-82 (November, 1959); pp 84-92 (December, 1959). 
(83) Spaeth, C. E., "Defects, Surface Finishes, and Hydrogen Embrittlement", Mechanical and Metallurgical Behavior of Sheet Materials, 7 th Proc. Sagamore Ordnance Materials Rescarch Conference. Racquette Lake, New York, pp III-11 to III-37 (August 16-19, 1960).

(84) Norton, F. J., "Diffusion of $\mathrm{D}_{2}$ from $\mathrm{D}_{2} \mathrm{O}$ Through Steel", J. Appl. Phys., 24, p 499 (1953),

(85) Norton, F. J., "Diffusion of Hydrogen From Water Through Steel", J. Appl. Phys., 11, pp 262-267 (1940).

(86) McCaldin, J. O., "Detector for Hydrogen Penetrating Steel", J. Appl. Phys., 27, p 307 (1956).

(87) Lawrence, S. C. , Jr., "Detection and Measurement of Sorbed Hydrogen", Hydrogen Embrittlement in Metal Finishing (Harold J. Read, Ed.), Reinhold Publishing Corporation, New York, New York, pp 97-108 (1961).

(88) Boeschoten, F., Van Egmond, W., and Kinderdijk, H. M. J., "Measurements on the Permeability of Hydrogen from $\mathrm{H}_{2}$ and $\mathrm{H}_{2} \mathrm{O}$ Through Steel, Stainless Steel, and Aluminum", Appl. Sci. Res., B8 (4), 378386 (1960).

(89) Swets, D. E., Frank, R. C., and Fry, D. L., "Environmental Effects on Hydrogen Permeation Through Steel During Abrasion", Trans. Met. Soc. AIME, 212 (2), 219-220 (1958).

(90) Frank, R. C., and Swets, D. E., "Hydrogen Permeation Through Steel During Abrasion", J. Appl. Phys., 28, p. 380 (1957).

(91) Frank, R. C., Swets, D. E., and Fry, D. L., "Mass Spectrometer Measurements of the Diffusion Coefficient of Hydrogen in Steel in the Temperature Range of $25^{\circ}-90^{\circ} \mathrm{C} "$, J. Appl. Phys., 29, pp 892-898 (1958).

(92) Swets, D. E., and Frank, R. C., "Hydrogen from a Hydrocarbon Lubricant Absorbed by Ball Bearings", Trans. Met. Soc. AIME, 221, pp 1082-1083 (1961).

(93) Warren, D., and Beckman, G. W., "Sulfide Corrosion Cracking of High Strength Bolting Material", Corrosion, 13, pp 631t-646t (1957).

(94) Bastien, P., Véron, H. , and Roques, C. , "Special Steels Resistant to Stress Corrosion by $\mathrm{H}_{2} \mathrm{~S}^{\prime \prime}$, Rev. Met. Mémoires, 55, pp 301 317 (1958), in French.
(95) Greco, E. C., and Wright, W. B., "Corrosion of Iron in an $\mathrm{H}_{2} \mathrm{~S}-\mathrm{CO}_{2}-\mathrm{H}_{2} \mathrm{O}$ System", Corrosion, 18, pp 119t-124t (1962).

(96) Skei, T., Wachter, A., Bonner, W. A., and Burnham, H. D., "Hydrogen Blistering of Steel in Hydrogen Sulfide Solutions", Corrosion, 9 (5), 163-172 (May, 1953).

(97) Fraser, J. P., and Treseder, R. S., "Cracking of High Strength Steels in Hydrogen Sulfide Solutions", Corrosion, $\underline{8}$ (10), 342360 (October, 1952).

(98) Karpenko, G. V., and Stepurenko, V. T., "The Effect of Hydrogen Sulfide Solution Upon the Mechanical Properties of Steel", Akad. Nauk Ukr. SSR. Institut Mashinovedeniya i Avtomatiki. The Effect of Working Media Upon the Properties of Steel. No. 1. Media Which Cause Hydrogen Absorption of Steel, Kiev, Izd-vo AN UkSSR (1961), in Russian.

(99) Herzog, E., and Malinowsky, E., "Embrittlement and Fractures of Steels Subjected to Stress in Saturated Solutions of $\mathrm{H}_{2} \mathrm{~S}^{\prime \prime}$, Mem. Sci. Rev. Met., 57, pp 535-549 (July, 1960), in French.

(100) Grundig, W., "Hydrogen Embrittlement as a Cause of Fracture of Steel Wires for Concrete Reinforcement", Bol. ABM, 14, pp 473-515 (October, 1958), in Portuguese; Abstract in J. Iron Steel Inst., 194, p 274 (1960).

(101) Bastien, P., and Amiot, P., "Mechanism of the Effect of Ionized Solutions of Hydrogen Sulfide on Iron and Steel", Compt. Rend. , 235, pp 1031-1033 (1952), in French.

(102) Herzog, E., "Stress Corrosion of Mild Steel and of Low-Alloy Steels", Corrosion et Anticorrosion, 2, pp 3-13, 57-68, 91-97 (1954), in French.

(103) Herzog, E., "Conditions for Stress Corrosion in Hydrogen Sulfide", Rev. Met. Mémoires, 55, pp 123-144 (1958), in French.

(104) Cauchois, L., Didier, J., and Herzog, E., "A Special N-80 Steel Tubing Developed in France to Resist Sulfide Stress Corrosion in Sour Gas Wells", Corrosion, 13, pp 263t269t (1957).

(105) Fraser, J. P., Eldredge, G. G. , and Treseder, R. S., "Laboratory and Field Methods for Quantitative Study of Sulfide Corrosion Cracking", Corrosion, 14 (11), $517 \mathrm{t}-523 \mathrm{t}$ (November, 1958). 
(106) Fraser, J. P., and Eldredge, G. G., "Influence of Metallurgical Variables on Resistance of Steels to Sulfide Corrosion Cracking", Corrosion, 14 (11), 524t-530t (November, 1958).

(107) Smialowski, M., Hydrogen in Steel, Pergamon Press, Oxford, and Addis onWesley Publishing Company, Inc. , Reading, Massachusetts, pp 389-410 (1962).

(108) Ewing, S. P., "Electrochemical Studies of the Hydrogen Sulfide Corrosion Mechanism", Corrosion, 11, pp 497t-501t (1955).

(109) Bonner, W. A., and Burnham, H. D., "Air Injection for Prevention of Hydrogen Penetration of Steel", Corrosion, 11, pp 447t-453t (1955).

(110) Bonner, W. A., "You Can Stop Hydrogen Attack", Petrol. Refiner, 37 (7), 111-114 (July, 1958).

(111) Morton, B. B., Discussion - Sulfide Stress Corrosion Cracking Symposium, Corrosion, 8, p 358 (1952).

(112) Bradley, B. W., and Dunne, N. R., "Corrosion Measurements in a Hydrogen Sulfide-Water Absorption Pilot Plant", Corrosion, 13, pp 238t-242t (1957).

(113) Bloom, F. K., "Stress Corrosion Cracking of Hardenable Stainless Steels", Corrosion, 11, pp 351t-361t (1955).

(114) Uhlig, H. H., "Action of Corrosion and Stress on $13 \% \mathrm{Cr}$ Stainless Steel", Metal Progr., 57, pp 486-487 (1950).

(115) Steigerwald, E. A., "Delayed Failure of High-Strength Steel in Liquid Environments", Proc. Am. Soc. Testing Materials", 60, pp 750-760 (1960).

(116) Smialowski, M., Hydrogen in Steel, Pergamon Press, Oxford, and AddisonWesley Publishing Company, Inc., Reading, Massachusetts, pp 131-153 (1962).

(117) Barton, R. J., "The Mechanism of Transport of Hydrogen Across a Solution-Metal Interface", Hydrogen Embrittlement in Metal Finishing (Harold J. Read, Ed.), Reinhold Publishing Corporation, New York, New York, pp 20-45 (1961).

(118) Simcoe, C. R., Elsea, A. R., and Manning, G. K., "An Investigation of Absorbed Hydrogen in Ultra-High-Strength Steel", Report No. WADC TR 56-598, Battelle Memorial Institute, Columbus, Ohio, under Air Force Contract AF 33(616)3202 (November 15, 1956).
(119) Smialowski, M., Hydrogen in Steel, Pergamon Press, Oxford, and AddisonWesley Publishing Company, Inc. , Reading, Massachusetts, pp 88-90, 110-111, 98-99, 70-71 (1962).

(120) Barrer, R. M., "Stationary and NonStationary States of Flow of Hydrogen in Palladium and Iron", Trans. Faraday Soc., 36, pp 1235-1248 (1940).

(121) Bolton, K., and Shreir, L. L., "Factors Affecting Hydrogen Absorption of HighStrength Steels During Cathodic Polarization", Corrosion Sci. , 3, pp 17-33 (1963).

(122) Barton, R. J., "On the Mechanism of Transport of Hydrogen Across a SolutionMetal Interface", Tech. Proc. Am. Electroplaters' Soc., 47, pp 116-123 (1960).

(123) Smialowski, M., and Szklarska-Smialowska, Z. , "New Method of Studying the Cathode Processes and Its Application", Izv. Akad. Nauk SSSR Otd. Khim Nauk, No. 2, p 225 (1954).

(124) Smialowski, M., and Szklarska-Smialowska, Z., "Expansion of Fe Coils as a Result of Cathodic Charging with Hydrogen", Bull. Acad. Pol. Sci., Cl III, 2, p 73 (1954).

(125) Smialowski, M., and Szklarska-Smialowska, Z., "Study of Hydrogen Depolarization. Influence of Electrolyte Composition on the Degree of Deformation of Iron Cathodes", Roczniki Chem., 29, p 85 (1955).

(126) Krupkowski, A., and Smialowski, M. , "Deformation of Iron Rods Under the Influence of Hydrogen Penetration", Arch. Hutnictwa, 1, p 101 (1956).

(127) Besnard, S., and Talbot, J., "Cathodic Hydrogen Diffusion in Pure and ZoneMelted Iron in the Presence of Sulphur", Rev. Mét. Mémoires Scientifiques, 56, pp 681-692 (1959), in French.

(128) Morris, T. N., "The Diffusion of Hydrogen Through Mild Steel Sheet During Acid Corrosion", J. Soc. Chem. Ind. (London), 54, pp 7T-13T (1935).

(129) Eakin, C. T., and Lownie, H. W. , Jr., "Reducing Embrittlement in Electroplating", The Iron Age, 158, pp 69-72 (November 21, 1946).

(130) Valentine, K. B., "Stress Cracking of Electroplated Lockwashers", Trans. Am. Soc. Metals, 38, pp 488-494 (1947).

(131) Stefanides, V., Discussion of Reference 130, Trans. Am. Soc. Metals, 38, pp 495-502 (1947). 
(132) Zapffe, C. A., and Haslem, M. E., "Measurement of Embrittlement During Chromium and Cadmium Electroplating and the Nature of Recovery of Plated Articles", Trans. Am. Soc. Metals, 39, pp 241-258 (1947).

(133) Zapffe, C. A., and Haslem, M. E., "Hydrogen Embrittlement in Cadmium and Zinc Electroplating", Plating, 37, pp 366371 (April, 1950).

(134) Zapffe, C. A., and Haslem, M. E., "Hydrogen Embrittlement in Nickel, Tin and Lead Electroplating", Plating, 37, pp 610-613 (1950).

(135) Potak, Ya. M., "Brittle Fracture of Steel and Steel Elements", Khrupkoe Razrushenie Stali i Stalnykh Detalei, Moscow (1955), in Russian. Data taken from Smialowski, M. Hydrogen in Steel, Pergamon Press, Oxford, and AddisonWesley Publishing Company, Inc., Reading, Massachusetts, pp 384-385 (1962).

(136) Figelman, M. A., and Shreider, A. V., "Hydrogen Embrittlement of Steel by Electroplating with $\mathrm{Cu}, \mathrm{Ni}, \mathrm{Zn}, \mathrm{Cd}, \mathrm{Cr}$ ", Zh. Prikladnoi Khim, 31, p 1184 (1958). This work is summarized in Smialowski, M. Hydrogen in Steel, Pergamon Press, Oxford, and Addison-Wesley Publishing Company, Inc., Reading, Massachusetts, p 385 (1962).

(137) Raring, R. H., and Rinebolt, J. A., "Static Fatigue of High-Strength Steel", Naval Research Laboratory Memorandum Report 452 (April, 1955).

(138) Rinebolt, J. A., "Progress Report on the Effect of Gases in Steel", Naval Research Laboratory Memorandum Report 345 (March, 1953, to July, 1954).

(139) Klier, E. P., Muvdi, B. B., and Sachs, G., "The Response of High-Strength Steels in the Range of 180,000 to 300,000 Psi to Hydrogen Embrittlement From Cadmium-Electroplating", Am. Soc. Testing Mater., Proc., 58, pp 597-619 (1958).

(140) Johnson, R. D., Johnson, H. H. , Barnett, W. J., and Troiano, A. R., "Hydrogen Embrittlement and Static Fatigue in High Strength Steel", Report No. WADC TN 55404, Case Institute of Technology, Cleveland, Ohio, under Air Force Contract AF 33(038)-22371 (August, 1955).
(141) Gurklis, J. A., McGraw, L. D., and Faust, C. L., "Hydrogen Embrittlement of Cadmium Plated Spring Stee1", Plating, 47 (10), 1146-1154 (October, 1960).

(142) McGraw, L. D., Snavely, C. A., Moore, H. L., Woodberry, P. T., and Faust, C. L., "A Fundamental Study of the Mechanism By Which Hydrogen Enters Metals During Chemical and Electrochemical Processing", National Advisory Committee for Aeronautics, Technical Note 2696 (April, 1952).

(143) Carlisle, M. E., "Methods of Testing for Hydrogen Embrittlement", Final Report No. NOR-59-47L, Northrop Corporation, Hawthorne, California, under Aerospace Research and Testing Committee Project w-95 (October 21, 1959).

(144) Wadsworth, G. B., and Johnson, B. G., "Standardization of Methods of Testing for Hydrogen Embrittlement", Final Report No. D3-3655, The Boeing Company, Wichita, Kansas, under Aerospace Research and Testing Committee Project 13-59 (May 29, 1961).

(145) Geyer, N. M., Lawless, G. W., and Cohen, B., "A New Look at the Hydrogen Embrittlement of Cadmium Coated High Strength Steels", Report No. WADC TR 58-481, Materials Laboratory, Wright-Patterson Air Force Base, Ohio (December, 1958).

(146) Geyer, N. M. , Lawless, G. W., and Cohen, B., "A New Look at the Hydrogen Embrittlement of Cadmium-Coated High-Strength Steel", Hydrogen Embrittlement in Metal Finishing (Harold J. Read, Ed.), Reinhold Publishing Corporation, New York, New York, pp 109-138 (1961).

(147) Beck, W., and Jankowsky, E. J., "The Effectiveness of Metallic Undercoats in Minimizing Plating Embrittlement of UltraHigh-Strength Steel", Hydrogen Embrittlement in Metal Finishing (Harold J. Read, Ed.), Reinhold Publishing Corporation, New York, New York, pp 139-165 (1961).

(148) Slaughter, E. R., Fletcher, E. E., Elsea, A. R., and Manning, G. K., "An Investigation of the Effects of Hydrogen on the Brittle Failure of High-Strength Steels", Report No. WADC TR 56-83, Battelle Memorial Institute, Columbus, Ohio, under Air Force Contract AF 33(616)-2103 (June, 1955).

(149) Hofmann, W., Rauls, W., and Vogt, J., "Verspródung von Stahl durch eine äussere Wasserstoffatmosphäre bei Raumtemperatur" (Embrittlement of Steel by an External Hydrogen Atmosphere at Room Temperature), Acta Met., 10, pp 688-690 (1962). 
(150) Baukloh, W., and Guthmann, H., "Wasserstoffdurchlässigkeit und Wasserstoffentkohlung von Stählen, Armco-Eisen, Kupfer, Nickel und Aluminium bei höheren Drücken" (Hydrogen Permeability and Hydrogen Decarburization of Steels, Armco Iron, Copper, Nickel, and Aluminum at High Pressures), Z. Metallk., 28, pp 34-40 (1936).

(151) Naumann, F. K., "Der Einfluss von Legierungszusätzen auf die Beständigkeit von Stahl gegen Wasserstoff unter lohem Druck" (The Influence of Alloy Additions on the Stability of Steel Toward Hydrogen at High Pressure), Tech. Mitt. Krupp, Forsch., 1, pp 223-243 (1938).

(152) Giauque, W. F., "The Entropy of Hydrogen and the Third Law of Thermodynamics: The Free Energy and Dissociation of Hydrogen", J. Am. Chem. Soc., 52, pp 4816-4831 (1930).

(153) Güntherschulze, A., Betz, H., and Kleinwächter, H., "Diffusion of Hydrogen and Deuterium Through Iron. I. Iron as Cathode for Spark Discharge", Z. Physik, 111, p 657 (1938/1939), in German.

(154) Güntherschulze, A., and Winter, A., "Diffusion of Hydrogen and Deuterium Through Iron. II. Spark Discharge in Mixtures of Hydrogen With Other Gases", Z. Physik, 112, p 648 (1939), in German.

(155) Maringer, R. E., Swetnam, E. B., Marsh, L. L., and Manning, G. K., "Study of Hydrogen Embrittlement of Iron by Internal-Friction Methods", Technical Note 4328 , Battelle Memorial Institute, Columbus, Ohio, for the National Advisory Committee for Aeronautics (September, 1958).

(156) Carney, D. J., "Gases in Liquid Iron and Steel", Gases in Metals, Amer. Soc. Metals, Metals Park, Novelty, Ohio, p 100 (1953).

(157) Barrer, R. M., Diffusion in and Through Solids, Cambridge University Press, Cambridge, England, p 224 (1951).

(158) Bennek, H., and Klotzbach, G., "Einfluss von Wasserstoffgehalt, Wasserstoffdurchlässigkeit und Wasserstofflöslichkeit auf die Flockenbildung im Stahl" (Influence of Hydrogen Content, Hydrogen Permeability, and Hydrogen Solubility on Flake Formation in Steel), Stahl u. Eisen, 61 (25), 597-606 (June 19, 1941); $61(2 \overline{6}), 624-630$ (June 26, 1941).
(159) Hobson, J. D., Discussion of Chang and Bennett's paper (Reference 41), J. Iron Steel Inst., 172, p 49 (1952).

(160) Hobson, J. D., "The Diffusion of Hydrogen in Steel at Temperatures of $-78^{\circ}$ to $200^{\circ} \mathrm{C}^{\prime \prime}, \mathrm{J}$. Iron Steel Inst., 189, pp 315-321 (1958).

(161) Sykes, C., Burton, H. H., and Gegg, C. C., "Hydrogen in Steel Manufacture", J. Iron Steel Inst., 156, pp 155-180 (1947).

(162) Stross, T. M., and Tompinins, F. C., "The Diffusion Coefficient of Hydrogen in Iron", J. Chem. Soc. (London), pp 230-234 (1956).

(163) Eichenauer, W., Künzig, H. , and Pebler, A., "Diffusion und Löslichkeit von Wasserstoff in $\alpha$-Eisen und Silber" (Diffusion and Solubility of Hydrogen in $\alpha$-Iron and Silver), Z. Metallk., 49, pp 220-225 (1958).

(164) Edwards, C. A., "Pickling; or, The Action of Acid Solutions on Mild Steel and the Diffusion of Hydrogen Through the Metal", J. Iron Steel Inst., 110, pp 9-44 (1924).

(165) Frank, R. C., "Some Observations Regarding the Present Status of Measurements of the Diffusion Coefficients of Hydrogen in Iron and Mild Steel", J. Appl. Physics, 29, pp 1262- 1263 (1958).

(166) Weiner, L. C. , and Gensamer, M., "The Effects of Aging and Straining on the Internal Friction of Hydrogen Charged 1020 Steel at Low Temperatures", Acta Met., 5, pp 692694 (1957).

(167) Hill, M. L., "The Behavior of Hydrogen in Iron and Steel", Hydrogen Embrittlement in Metal Finishing (Harold J. Read, Ed.), Reinhold Publishing Corporation, New York, New York, pp 46-80 (1961).

(168) Veysseyre, H., Azou, P., and Bastien, P., "Adsorption, Diffusion, and Desorption of Hydrogen in Iron", Compt. Rend., 254, pp 281-283 (1962), in French.

(169) McNabb, A., and Foster, P. K., "A New Analysis of the Diffusion of Hydrogen in Iron and Ferritic Steels", Trans. Met. Soc. AIME, 227, pp 618-627 (1963).

(170) Bhat, U. V., and Lloyd, H. K., "Effect of Cold-Work on Hydrogen in Steel" (Section VI of a series of papers by various authors describing investigations of the effect of cold work on steel), J. Iron Steel Inst., 165, pp 382-389 (1950). 
(171) Lewkonja, G., and Baukloh, W., "Wasserstoffdurchlässigkeit von Stahl bei 700 bis $1000^{\circ}$ (C)" (Hydrogen Permeability of Steel at 700 to $1000 \mathrm{C})$, Arch. Eisenhüttenw., 6, pp 453-457 (1933).

(172) Chaudron, G., and Moreau, L., "Beitrag zur Frage der Beizsprödigkeit von einkristallinem Eisen" (Contribution to the Problem of Pickling Embrittlement of Single Crystals of Iron), Arch. Metallk. , 2, pp 308-311 (1948).

(173) Bastien, P., "Influence of Cold Work on the Rate of Hydrogen Diffusion in Iron", Compt. Rend., 212, pp 788-790 (1941), in French.

(174) Bastien, P., "Absorption and Evolution of Hydrogen from Annealed and Cold-Worked Steels", Génie Civ., 118, p 9 (1941).

(175) Schumann, H., and Erdmann-Jesnitzer, F., "Einfluss des Werkstoffzustandes auf die Wasserstoffdiffusion in unlegiertem Stahl" (Influence of Material Condition on Hydrogen Diffusion in Unalloyed Steel), Arch. Eisenhüttenw., 24, pp 353-360 (1953).

(176) Hudson, R. M., and Stragand, G. L., "Effect of Cold Drawing on Hydrogen Behavior in Steel", Corrosion, 16, pp 253t-257t (May, 1960).

(177) De Kazinczy, F., "Effect of Stresses on Hydrogen Diffusion in Steel", Jernkontorets Ann., 139, pp 885-892 (1955), in English.

(178) Carter, S. F., "Effect of Melting Practice on Hydrogen", Proc. Elec. Furn. Steel Conf., 7, pp 267-301 (1949).

(179) Sims, C. E., "Some Observations on Gases in Steel", Amer. Inst. Mining and Met. Engrs., Proc. Elec. Furn. Steel Conf., 6, pp 46-52 (1948).

(180) Sims, C. E., Moore, G. A., and Williams, D. W., "The Effect of Hydrogen on the Ductility of Cast Steels", Trans. Am. Inst. Mining Met. Engrs., 176, p 283 (1948).

(181) Sims, C. E., "The Behavior of Gases in Solid Iron and Steel", Gases in Metals, Amer. Soc. for Metals, Metals Park, Novelty, Ohio, pp 157-161 (1953).

(182) Sims, C. E., "Hydrogen Elimination by Aging", Trans. Am. Inst. Mining Met. Engrs., 188, p 1321 (1950).
(183) Hobson, J. D., "The Removal of Hydrogen by Diffusion from Large Masses of Steel", J. Iron Steel Inst., 191, pp 342-352 (April, 1959).

(184) Moore, G. A., and Smith, D. P., "Occlusion and Evolution of Hydrogen by Pure Iron", Trans. Am. Inst. Mining Met Engrs., 135, pp 255-295 (1939).

(185) Zappfe, C. A., and Sims, C. E., "Hydrogen Embrittlement, Internal Stress and Defects in Steel", Metals Technology, 8 (5), Tech. Paper 1307 (August, 1941).

(186) Bardenheuer, P., and Ploum, H., "The Hydrogen Embrittlement of Steel in Dependence on the Amount of Absorbed Hydrogen", Mitt. Kaiser-Wilhelm Inst. Eisenforschung, 16, pp 137-140 (1934), in German.

(187) Sachs, G., and Beck, W., "Survey of LowAlloy Aircraft Steels Heat-Treated to High Strength Levels: Part 1. Hydrogen Embrittlement", Report No. WADC TR 53-254, Part 1, Syracuse University, Syracuse, New York, under Air Force Contract AF 33(616)-392 ( June, 1954).

(188) Bastien, P., "Recherches sur le Mécanisme de la fragilite de Décapage de l'acier" (Investigations Concerning the Mechanism Involved in the Brittleness Associated with the Cleaning of Steel. Evolution of the Process for Annealed Extra-Soft Steel), Rev. Mét. , Mémoires, 38, pp 225-238, 272-284 (1941).

(189) Slater, I. G., "The Effects of Pickling on the Properties of Carbon Steels", J. Iron Steel Inst., 128, pp 237-253 (1933).

(190) Lewis, F. A., and Ubbelohde, A. R., "Mechanisms of Removal of Hydrogen from Palladium-Hydrogen by Oxidation", J. Chem. Soc., Part 2, pp 1710-1716 (1954).

(191) Owe Berg, T. G., "Kinetics of Hydrogen Absorption, Desorption and Permeation of Metals", Corrosion, 14, pp 562t-566t (1958).

(192) Johnson, H. H., Morlet, J. G., and Troiano, A. R., "Hydrogen, Crack Initiation, and Delayed Failure in Steel", Trans. Met. Soc. AIME, 212, pp 528-536 (1958).

(193) Carmichael, D. C., Hornaday, J. R., Morris, A. E., and Parlee, N. A., "The Absorption and Effusion of Hydrogen in Alpha Iron", Trans. Met. Soc. AIME, 218, pp 826-832 (1960). 
(194) Rudd, D. W., and Vetrano, J. B., "Permeability of Metals and Enamelled Metals to Hydrogen", Report No. NAASR-6109, North American Aviation, Inc., Canoga Park, California, under AEC

Contract AT(11-1)-GEN-8 (October 30, 1961).

(195) Cash, D. J., and Scheuerman, W., "HighStrength Steel Can Be Cadmium Plated Without Embrittlement", Metal Progr., 75 (2), 90-93 (February, 1959).

(196) Derge, G., Peifer, W., and Richards, J. H., "The Sampling and Analysis of Steel for Hydrogen", Trans. Am. Inst. Mining Met. Engrs., 176, pp 219-247 (1948).
(197) Bleton, J., Mischonsniky, S. , Coin, G., and Bastien, P., "Le dosage de l'hydrogene dans l'acier liquide par la methode de $1^{\prime}$ extraction sous vide a $600^{\circ}$ (C)" (Quantitative Determination of Hydrogen in Molten Steel by the Method of Vacuum Extraction at 600 C), Rev. Met., 48, pp 471-485 (1951).

(198) Demarez, A., Hock, A. G., and Meunier, F. A., "Diffusion of Hydrogen in Mild Steel", Acta Met. , 2 (2), 214-223 (1954). 
(Securtty classification of title, hody of abstract and indexine annotation must be ontered when the overall report is classified) \begin{tabular}{|l|l|l|l}
\hline 1. ORIGINATING ACTIVITY (Corporate author) & 2a. REPORT SECURITY CLASSIFICATION
\end{tabular} Battelle Memorial Institute Defense Metals Information Center 505 King Avenue, Columbus, Ohio 43201 3. REPORT TITLE

Hydrogen Movement in Steel--Entry, Diffusion, and Elimination

\section{DESCRIPTIVE NOTES (Type of roport and Inclusive datoo)}

DMIC Report

5. AUTHOR(S) (Last name, first name, initial)

Fletcher, E. Ellis, and Elsea, Arthur R.

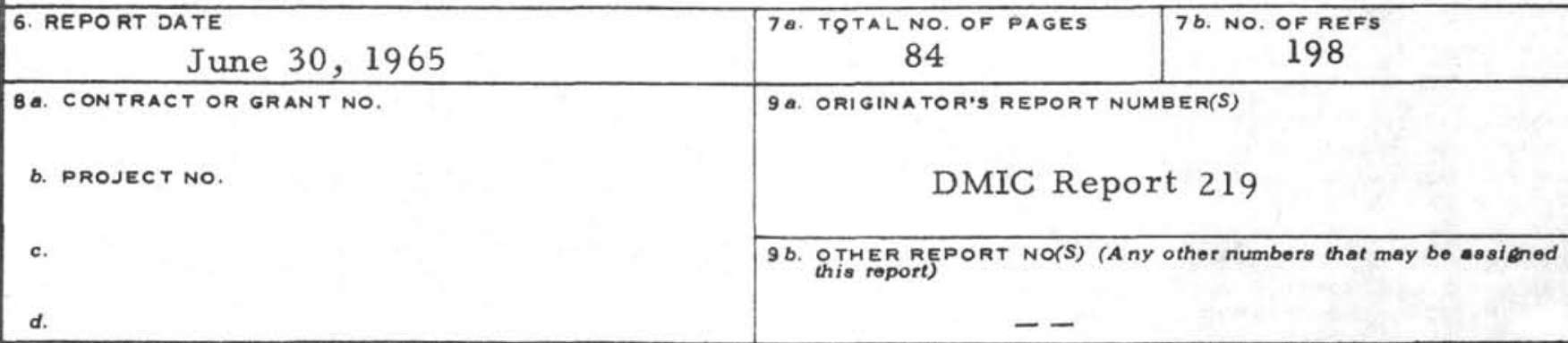

10. AVAILABILITY/LIMITATION NOTICES Copies of this report may be obtained, while the supply lasts, from DMIC at no cost by Government agencies, contractors, subcontractors, and their suppliers. Qualified requestors may also obtain copies of this report from the Defense Documentation Center (DDC), Alexandria, Virginia 22314.

\begin{tabular}{l|l} 
11. SUPPL EMENTARY NOTES & 12. SPONSORING MILITARY ACTIVITY
\end{tabular}

United States Air Force

Research and Technology Division 45433

Wright-Patterson Air Force Base, Ohio

13. ABSTRACT This report was prepared to aid in understanding the movement of hydrogen in steel. It considers the ways in which hydrogen enters steels, how it moves through steel, and methods whereby it may be removed from steel. The various factors that affect each of the se phenomena are considered. Since the solubility of hydrogen in steel affects the entry of hydrogen into the material and its movement through the metal and serves also as an indication of the magnitude of the concentration gradients to be expected, an understanding of the solubility of hydrogen is important in understanding othe $r$ aspects of the behavior of hydrogen in steel. The first section of this report, therefore, deals with the solubility of hydrogen, and the authors discuss such aspects of solubility as preferred lattice sites for hydrogen, lattice expansion, measurements of solubility, and estimates of equilibrium hydrogen pressure in steel. The second section concerns the permeation of hydrogen through steel; permeation consists of interactions at both the entry and exit surfaces of the metal as well as diffusion through the bulk metal. The various possibilities of hydrogen entry by corrosion processes, electrochemical processes. and other means are discussed, as well as the effects of temperature, pressure, crystal structure, cold work, and other variables on the diffusion of hydrogen through the bulk metal. Factors which influence the rate of hydrogen removal from iron and steel, such as temperature, section size, external environment, and coatings on the steel, are dealt with in the final section of the report. Related reports written for DMIC by the same authors are as follows: DMIC Memorandum 180, "The Problem of Hydrogen in Steel"; DMIC Report 196, "Hydrogen-Induced, Delayed, Brittle Failures of High-Strength Steels"; and DMIC Report 202, "The Effects of High-Pressure, High-Temperature Hydrogen on Steel". 


\begin{tabular}{|c|c|c|c|c|c|c|c|}
\hline \multirow[t]{2}{*}{14.} & \multirow{2}{*}{ KEY WORDS } & \multicolumn{2}{|c|}{ LINK A } & \multicolumn{2}{|c|}{ LINK B } & \multicolumn{2}{|c|}{ LINK C } \\
\hline & & ROLE & $W T$ & ROLE & WT & ROLE & $W T$ \\
\hline & & 8,7 & 3 & & & & \\
\hline & & 8,7 & 3 & & & & \\
\hline & & 8,7 & 3 & & & & \\
\hline & & 8,7 & 3 & & & & \\
\hline & & 8,7 & 3 & & & & \\
\hline & & 8,7 & 3 & & & & \\
\hline & & 1,2 & 3 & & & & \\
\hline & & 9 & 3 & & & & \\
\hline & & 6 & 3 & & & & \\
\hline & & 6 & 3 & & & & \\
\hline & & 6 & 3 & & & & \\
\hline & & 6 & 3 & & & & \\
\hline & & 6 & 3 & & & & \\
\hline & & 6 & $\frac{3}{3}$ & & & & \\
\hline
\end{tabular}

INSTRUCTIONS

1. ORIGINATING ACTIVITY: Enter the name and address of the contractor, subcontractor, grantee, Department of De fense activity or other organization (corporate author) issuing the report.

2a. REPORT SECURTY CLASSIFICATION: Enter the overall security classification of the report. Indicate whether "Restricted Data" is included. Marking is to be in accordance with appropriate security regulations.

2b. GROUP: Automatic downgrading is specified in DoD Directive 5200.10 and Armed Forces Industrial Manual. Enter the group number. Also, when applicable, show that optional markings have been used for Group 3 and Group 4 as authorized.

3. REPORT TITLE: Enter the complete report title in all capital letters. Titles in all cases should be unclassified. If a meaningful title cannot be selected without classification, show title classification in all capitals in parenthesis immediately following the title.

4. DESCRIPTIVE NOTES: If appropriate, enter the type of report, e.g., interim, progress, summary, annual, or final.

Give the inclusive dates when a specific reporting period is covered.

5. AUTHOR(S): Enter the name(s) of author(s) as shown on or in the report. Enter last name, first name, middle initial. If military, show rank and branch of service. The name of the principal aisthor is an absolute minimum requirement.

6. REPORT DATE: Enter the date of the report as day, month, year; or month, year. If more than one date appears on the report, use date of publication.

$7 \mathrm{a}$. TOTAL NUMBER OF PAGES: The total page count should follow normal pagination procedures, i. e., enter the number of pages containing information.

7b. NUMBER OF REFERENCES: Enter the total number of references cited in the report.

8a. CONTRACT OR GRANT NUMBER: If appropriate, enter the applicable number of the contract or grant under which the report was written

$8 b, 8 c, \& 8 d$. PROJECT NUMBER: Enter the appropriate military department identification, such as project number, subproject number, system numbers, task number, etc.

9a. ORIGINATOR'S REPORT NUMBER(S): Enter the official report number by which the document will be ident ified and controlled by the originating activity. This number must be unique to this report.

$9 b$. OTHER REPORT NUMBER(S): If the report has been assigned any other report numbers (either by the originator or by the sponsor), also enter this number(s).

10. AVAIL ABILITY/LIMITATION NOTICES: Enter any limitations on further dissemination of the report, other than those imposed by security classification, using standard statements such as:

(1) "Qualified requesters may obtain copies of this report from DDC."

(2) "Foreign announcement and dissemination of this report by DDC is not authorized."

(3) "U. S. Government agencies may obtain copies of this report directly from DDC. Other qual ified DDC users shall request through

(4) "U. S. military agencies may obtain copies of this report directly from DDC. Other qualified users shall request through

(5) "All distribution of this report is controlled. Qualified DDC users shall request through ,

If the report has been furnished to the Office of Technical Services, Department of Commerce, for sale to the public, indicate this fact and enter the price, if known.

11. SUPPLEMENTARY NOTES: Use for additional explanatory notes.

12. SPONSORING MILITARY ACTIVITY: Enter the name of the departmental project office or laboratory sponsoring (pay ing $(f o r)$ the research and development. Include address.

13. ABSTRACT: Enter an abstract giving a brief and factual summary of the document indicative of the report, even though it may also appear elsewhere in the body of the technical report. If additional space is required, a continuation sheet shall be attached.

It is highly desirable that the abstract of classified reports be unclassified. Each paragraph of the abstract shall end with an indication of the military security classification of the information in the paragraph, represented as (TS), (S), (C), or (U).

There is no limitation on the length of the abstract. However, the suggested length is from 150 to 225 words.

14. KEY WORDS: Key words are technically meaningful terms or short phrases that characterize a report and may be used as index entries for cataloging the report. Key words must be selected so that no security classification is required. Identifiers, such as equipment model designation, trade name, military project code name, geographic location, may be used as key words but will be followed by an indication of technical context. The assignment of links, rules, and weights is optional. 


\section{APPENDIXE}

\section{SAMPLE EXAMINATION}

Hillman-Kelley Global Marine, Inc.

5" O.D. $\times 19.50^{\#}$ Special BR-135 Drill Pipe 
FROM: Tube Investigation Division

SUBJECT: SAMPLE EXAMINATION

Hiliman-Kelley

Gloval Marine, Inc.

$5^{\prime \prime}$ O.D. $x$ 19.50\# Special

BR-135 Drill Pipe

Hillman-Kelley forwarded a 8-1/2" long pipe sample split in half of J\&I $5^{\prime \prime}$ O.D. $x$ 19.50\# Special BR-135 drill pipe submitted to them by Global Marine, Inc. Global Marine, Inc. requested the following opinions on the drill pipe that they are using aboard the Glomar Challenger:

(1) What is the scale?

(2) What is its cause?

(3) What is the best methods of removal both on shipboard at a remote location and at Houston?

(4) What is the best corrective action?

(5) What is the best method to prevent scale formation and pitting? Sample Examination: (Received 9/25/70):

Visual

Macroscopic examination revealed severe genter corrosion pitting on the inside pipe surface. There was no transverse fatigue cracking noted. Refer to attached photograph. The outside surface did not exhibit corrosive attack.

Longitudinal Mechanical Properties:

Specimen length and inside surface condition precluded determination of mechanical properties.

Hardness Determination:

33.3 Rockwell "C" Scale (average of three readings)

Chemical Check Analysis (Base Metal):

$$
\frac{\mathrm{C}}{.26} \frac{\mathrm{Nm}}{1.67} \frac{\mathrm{P}}{.018} \frac{\mathrm{S}}{.020} \frac{\mathrm{Si}}{.17} \frac{\mathrm{Mo}}{.44}
$$

Chemical Analysis - Corrosion Products:

$$
\frac{\mathrm{Cl}}{0.21 \%} \frac{\mathrm{SO}_{3}}{0.55 \%} \frac{\mathrm{CO}_{3}}{1.39 \%}
$$

Wall Thickness: $\frac{\text { Sample * }}{.358 / .375^{\prime \prime}} \quad \frac{\text { Nominal }}{.362^{\prime \prime}} \quad \frac{\text { Minimum }}{.317^{\prime \prime}}$

* Apperent original wall thickness

Microexamination: Structure wes normal for Special BR-135 drill pipe, tempered /249 
Page 2

November 5, 1970
SAMPLE_EXAMINATION

Hiliman-Kelley

\section{Discussion:}

Chemical check analysis of the base metal, wall thickness, hardness, and microstructure were normal for 5" O.D. $x$ 19.50\# Special BR-135 drill pipe.

The inside surface of the pipe sample exhibited severe general pitting typical of environmental corrosive attack. Chemical analysis of the scale (corrosion products) indicated .21\% chlorides, .55\% sulfites, and $1.39 \%$ carbonates. While percentage figures for chlorides, sulfites, and carbonates appear low, they are indicative of a corrosive media in the drilling string.

The small concentration of chloride indicates that salt water was not a major contributor but enhanced oxidation corrosion by serving as an electrolyte. The scale was magnetic which indicates the presence of a substantial amount of $\mathrm{Fe}_{3} \mathrm{O}_{4}$. This is typical for a string filled with drilling mud which limits the amount of available oxygen.

The presence of sulfites indicates the presence of hydrogen sulfide in the system which reacts with steel in the presence of water to form iron sulfide. This sets up a galvanic cell with the steel serving as a sacrificial anode resulting in pitting.

The concentration of carbonate in the scale indicates that excessive $\mathrm{CO}_{2}$ was in the system and this was the most severe causative mechanism of corrosive attack. The carbon dioxide converting to free carbonic acid caused severe pitting. Removal of the scale can be accomplished by abrasive blasting (shot or sand). Acid pickling after abrasive blasting of high strength-heat treated material is not recommended because of the potential of hydrogen embrittlement. 
Page 3

November 6, 1970
SAMPLE EXAMINATION

Hillman-Kelley

Cleaning the scale off the pipe will not significantly increase the life of the drill pipe because of the advanced stage of corrosion pitting. Continued use of drill pipe with the inside surface condition exhibited by the sample will ultimately result in failure by initiation and propagation of fatigue cracks at the base of corrosion pits.

The use of appropriate inhibitors is recommended. The services of a corrosion engineer should be obtained to determine the proper inhibitors and concentrations required $t$, prevent further deterioration of the drill pipe.

CC:

C. A. Iuese

C. A. Guess

Aliquippa Motallurgical Department

Tech.Ser.Div. -9

A.R.Aymardi

R.L.Guernsey

J.J.Lenker. $\hat{\alpha}$

C.J.Millner

E.J.Newton

CAG:Im

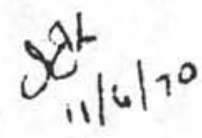




\title{
$\frac{\text { HILLMAN - KELIEY }}{\text { Globel Mer.IAs, Inc. }}$
}

\author{
$\underline{\mathrm{P}} \underline{\mathrm{H}} \underline{\mathrm{O}} \underline{\mathrm{T}} \underline{\mathrm{O}} \underline{\mathrm{R}} \underline{\mathrm{A}} \underline{\mathrm{P}} \underline{\mathrm{H}}$
}

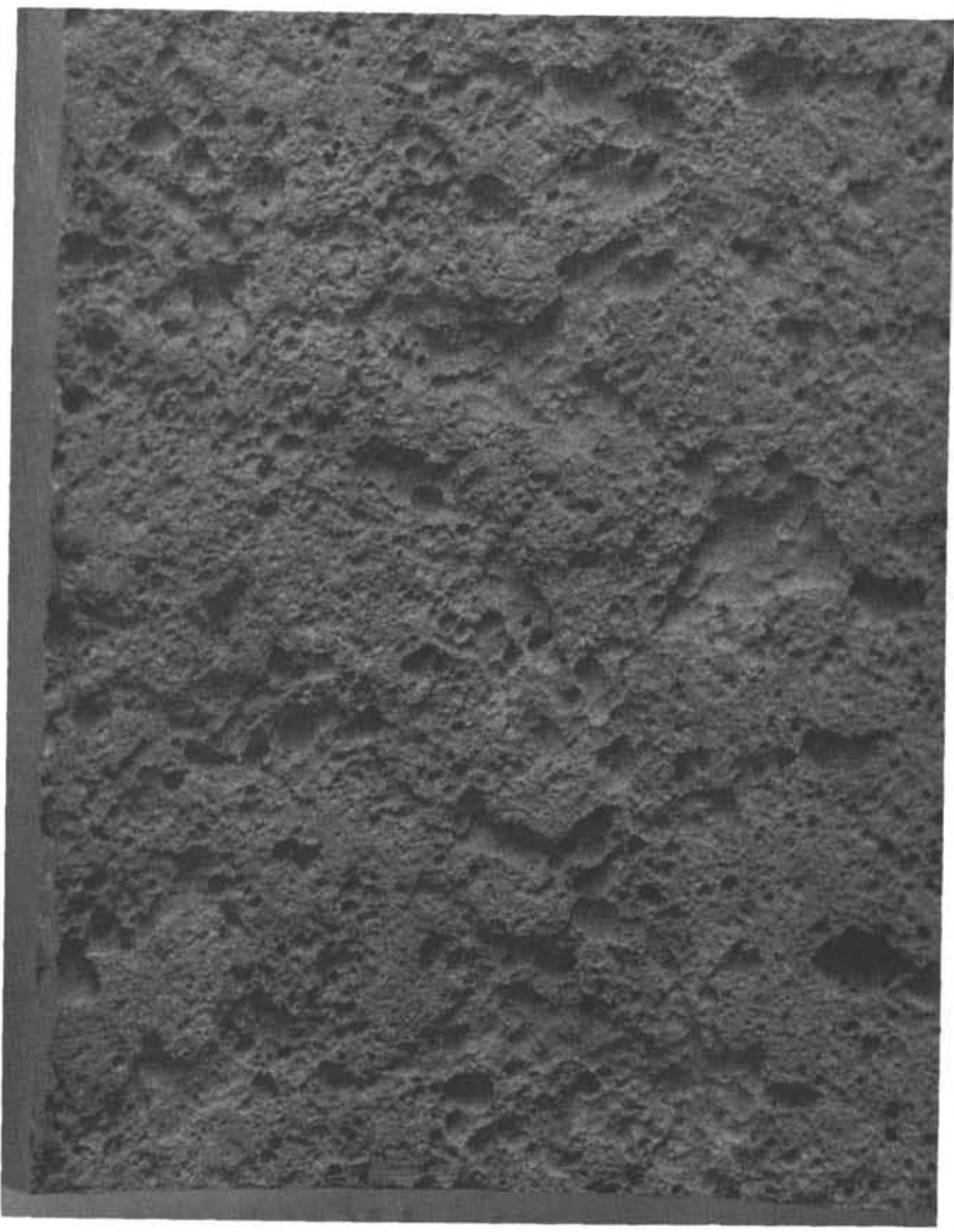

General corrosion pitting observed on the inside surface. No transverse fatigue cracking was noted. 


\section{APPENDIX F}

Study of Hydrogen-Stress Cracking of Deep Sea Drilling Project S-135 Drill Pipe if Exposed to Black Sea Water 


\section{ABSTRACT}

This study reviews the limitations of operating the Deep Sea Drilling Project's S-135 drill pipe in sea water containing hydrogen sulphide.

\section{INTRODUCTION}

The design and selection of the DSDP drill pipe did not preclude its use in sea water other than that in deep ocean basins. The extension of the DSDP program is producing requests to drill in waters that contain varying amounts of $\mathrm{H}_{2} \mathrm{~S}$. As many steels are susceptible to hydrogen stress cracking if exposed to $\mathrm{H}_{2} \mathrm{~S}$, DSDP has reviewed available literature and discussed the problem with experts in this field.

\section{CONCLUSIONS}

1. A review of papers on hydrogen-stress cracking of steels and discussions with people knowledgeable in this field indicate the S-135 drill pipe is susceptible to hydrogenstress cracking.

2. The DSDP S-135 drill pipe apparently is in the transition zone between high strength steels very susceptible to hydrogen stress cracking and low strength steels which are not affected by hydrogen entering the metal lattices.

3. The field studies on the effect of hydrogen sulphide on oil field tubular goods has been directed to casing and tubular goods, so information on its effect on drill pipe of grades above "E" is meager. 
4. So many factors influence hydrogen-stress cracking, e.g., steel hardness, chemical content, temperature, length of exposure to contamination, sress level, that physical tests of a given steel in various environment are necessary to determine its susceptibility to hydrogen stress cracking.

5. Preventing the entrance of hydrogen into the steel reduces hydrogen-stress cracking. The effect of the zinc rich coating on the DSDP drill pipe in preventing hydrogen entrance into the S-135 pipe is unknown.

6. Sonoscope inspections of drill pipe (tuboscope) have indicated there have been no drill string failures introduced by excessive stress levels in the drill pipe operating in a corrosive environment (sea water).

\section{RECOMMENDATIONS}

1. Contact testing laboratories such as Battelle Memorial Institute and Southwest Research for a recommended program to determine if DSDP's S-135 drill pipe is susceptible to hydrogen stress cracking and if it is, what is the maximum safe stress level at which we can operate the pipe in sea water with $\mathrm{H}_{2} \mathrm{~S}$ concentrations such as in the Black Sea.

2. From the above report, establish operating limits for the $\mathrm{S}-135$ drill pipe.

\section{DISCUSSION}

The failures in the oil industry of steel tubular goods attributed to hydrogen stress cracking from $\mathrm{H}_{2} \mathrm{~S}$ environment has established two rules of thumb to select steels:

1. An elongation of $23 \%$ to $25 \%$. This should be after a quench and temper, as as-rolled goods usually have local hard spots. The above valve has been established by the Mannersman Co. ${ }^{(1)}$ From experience gained in Canadian Oil Fields with high $\mathrm{H}_{2} \mathrm{~S}$ concentrations. 
2. Keep yield point of steel below 80,000 psi and hardness below $R_{c} 22$. These values $(2,3,4$, are generally accepted by the oil industry and have been established by experience of Pan American (and others) in West Texas gas fields with high $\mathrm{H}_{2} \mathrm{~S}$ concentrations. In addition, drilling or production fluids can be treated to reduce the effect of $\mathrm{H}_{2} \mathrm{~S}$ on steel. Normally, the drilling industry can minimize failures of hydrogen stress corrosion by using drill pipe that meets with one and two above. This sometimes requires drill strings tapered in weight and/or grade.

The ability of the Challenger to cut and recover a $21 / 2^{\prime \prime}$ dia core through $22,500^{\prime}$ of dril! string requires a drill string of high tensile strength. The pipe racker configuration requires a string of uniform weight and grade. Physical limitations of the ship make it difficult to carry two different strings, or would require off-loading the standby string. As drilling and coring is done without drilling fluid to the surface, treating the drilling fluid is very costly. Thus, if the DSDP drill pipe is to be used to drill in the Black Sea, it should be assumed it will be exposed to the $\mathrm{H}_{2} \mathrm{~S}$ at all times.

As the Glomar Challenger operates without a supply ship, logistically it would be easier to drill the holes in the Black Sea with the S-135 drill pipe. It should be noted the hydrogen in the steel is released if the pipe is exposed to the atmosphere, so is not permanently changed.

As the drill string length to drill in the Black Sea would be slightly over half the length of the longest drill string used, the pipe could loose an appreciable amount of its tensile strength and still operate satisfactorily. Thus, pending actual physical testing, use of the S-135 pipe in the Black Sea seems possible. 
Below are excerpts from Battels Defense Metals Report on "Stress-Corrosion Cracking and Hydrogen-Stress Cracking of High-Strength Steel."

Phosphorus, arsenic, antimony, sulfur, selenium, tellurium, and apparently the cyanide $\left(\mathrm{CN}^{-}\right)$ion are among the cathodic poisons which promote the entry of hydrogen into iron or steel during pickling or cathodic charging. (Hydrogen sulfide is a potent cathodic poison.

All types of steels with hardnesses above about Rockwell C 23 will crack in aqueous solutions that contain hydrogen sulfide. The results McGlasson and Greathouse obtained for a number of steels stressed below the yield point are listed in Table 1. These investigators also have summarized the work of other investigators on steels stressed above the yield stress (that is, cold worked) either before or during the tests (Table 2). They concluded that for a given strength level, low-chemistry quenched-and-tempered steels are less susceptible to sulfide cracking than are more highly alloyed steels. Additions of manganese, molybdenum, or nickel reportedly increase the susceptibility to sulfide cracking, while chromium tends to reduce susceptibility. Also, it is claimed that increasing the carbon content for the same strength level improves resistance to sulfide cracking. The French have developed a steel with a yield strength in the 80,000 to 90,000 -psi range that is superior to $\mathrm{N}-80$ steel in resistance to sulfide cracking. It has the following composition:

$\begin{array}{ll}\mathrm{C} & 0.12 \text { percent } \\ \mathrm{Cr}_{\mathrm{r}} & 2.0 \text { percent } \\ \mathrm{Mo} & 0.3 \text { percent } \\ \mathrm{Al} & 0.3 \text { percent }\end{array}$

For resistance to hydrogen sulfide cracking in oil-field applications such as casings and drill pipe, it is customary to specify that the steel be no harder than rockwell C 22 (ultimate tensile strength of about 110,000 to 115,000 psi and yield strength on the order of 95,000 psi, depending upon the structure). However, failures by sulfide cracking can occur even at that specified maximum strength level if the service stress is unusually high, or at even lower levels if the steel is plastically deformed. In the laboratory, McGlasson and Greathouse found no cracking on exposure to hydrogen sulfide solutions for steels with a hardness of Rockwell C 23 or less. However, in other work, sulfide cracking reportedly was obtained in material with yield strength of 67,000 psi at an applied stress of 55,000 psi, but steels with yield strengths in the range of 64,000 to 67,000 psi survived 300 days without cracking. Thus, there are hardness and applied-stress minimums below which a given steel will not crack when exposed to an aqueous system containing hydrogen sulfide; these are inversely related. The effect of hardness on the susceptibility to sulfide cracking of heat-treated AISI 4140 bolts in an investigation by Warren and Beckman 


\section{REFERENCES}

1. Telecon Mr. Hugh Planch, Plant Manager, Mannesman Calgary Rolling Mills.

2. Telecon W. Randall, Research Associate, Pan American Research, Tulsa, Oklahoma.

3. Dr. R. Knapp, Research Associate, ESSO Research Corporation, Houston, Texas.

4. W. F. Allinder, Texaco, Inc.

5. Report - Metals Protection in The Marine Environment, Louis J. Nowacki \& Walterk, BO-ID.

6. DMIC Report 232, July 29, 1966 - Stress Corrosion Cracking \& Hydrogen-Stress Cracking of High Strength Steels (with extensive reference list).

7. DMIC Report 219, June 30, 1965.

8. DMIC report 210 October 26-28, 1965, Problems in the Load-Carrying Applications of High-Strength Steel.

9. Final Report - Drill Pipe Phase II Mohole (Stress Corrosion \& Hydrogen Embrittlement Tests by Battelle.

cc K. E. Brunot

W. R. Jack

V. F. Larson

M.N.A. Peterson 


\section{Behavior of surface flaws}
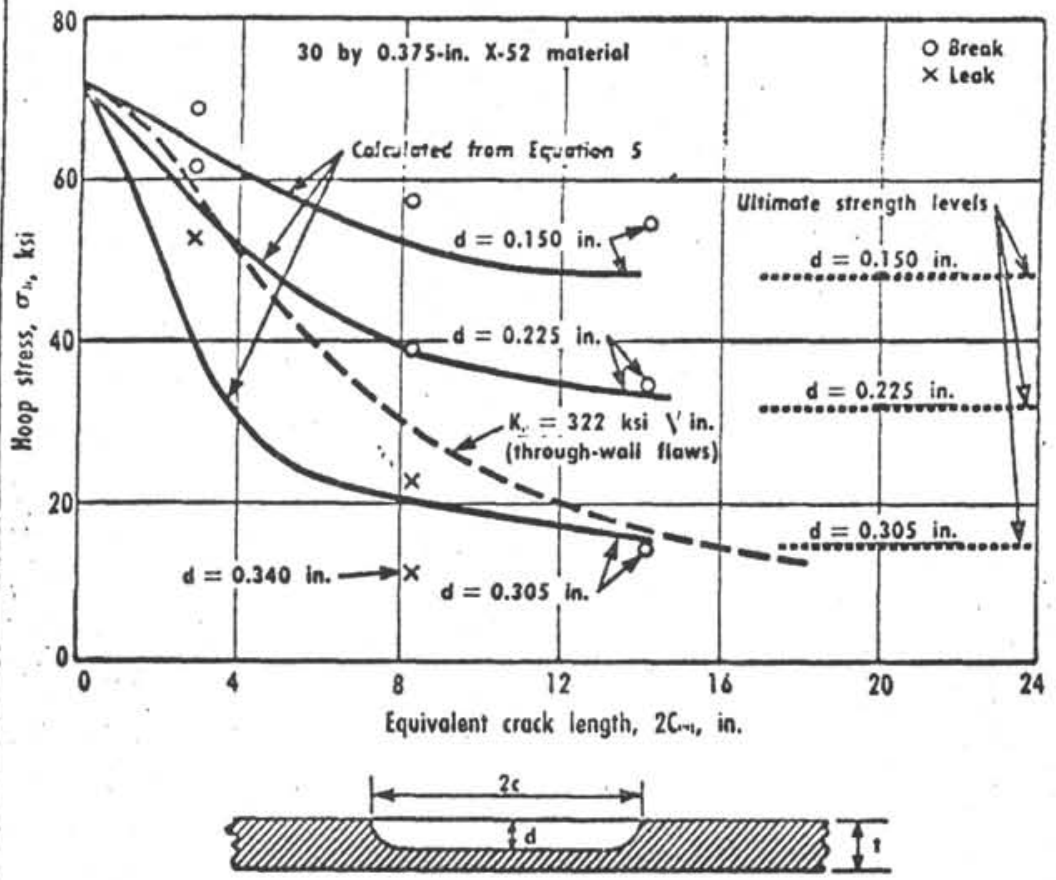

were compared with the pressure-vessel tests. The RE method showed the least standard deviation and the least scatter of data points thus giving it the best corrclation with full-scale pipe behavior, Fig. 18.

Four different expanders have been studied. two hydraulic and two mechanical. in pursuinz tie second ch jective. Data for all four show a good correlation between yield pressure determined from expander recordings and the yields determined by both

Failure causes

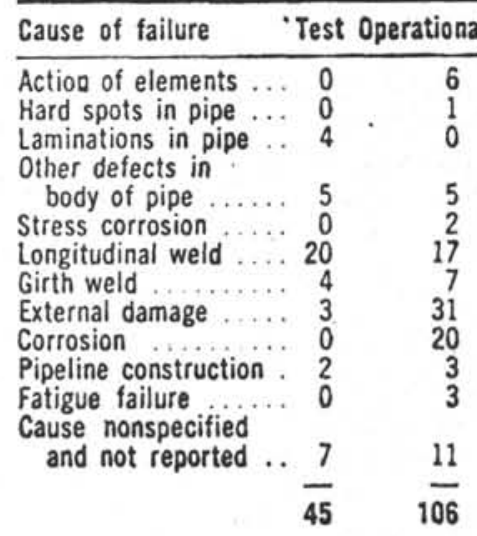

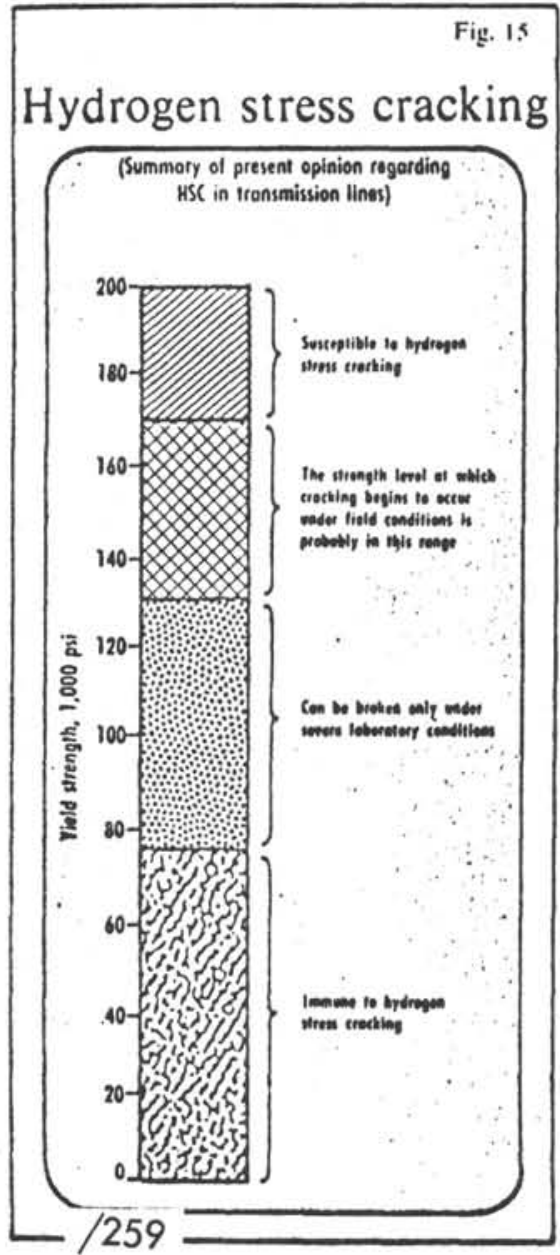

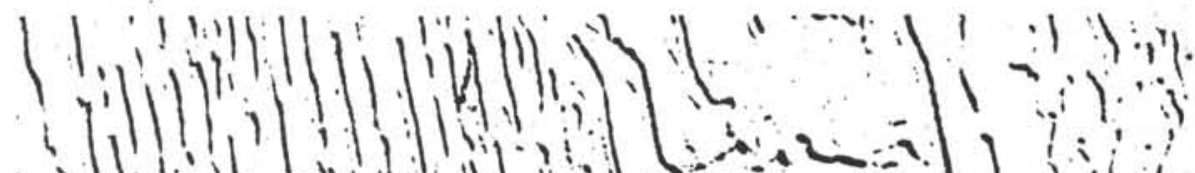

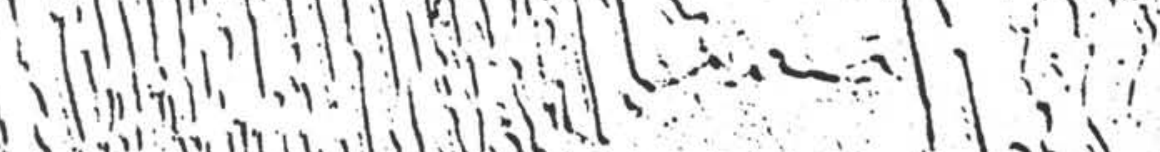
$\int_{1}$

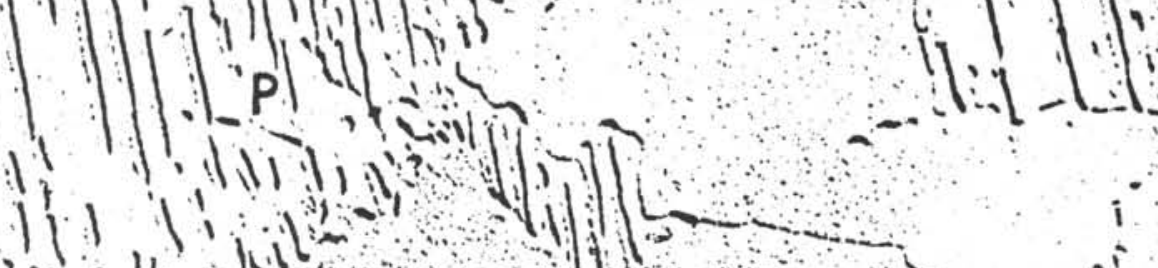

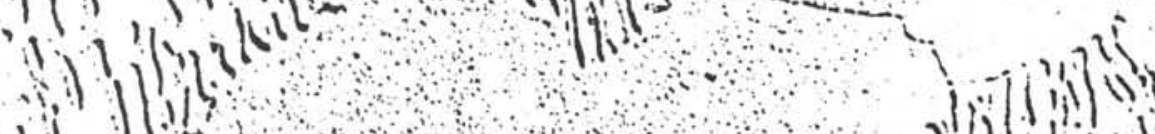

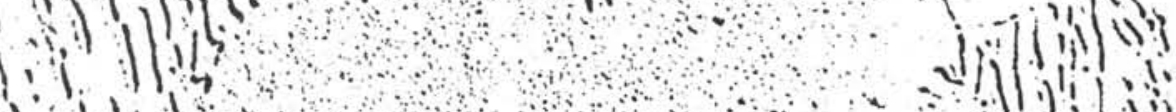

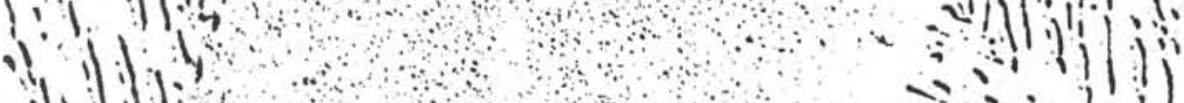
1) $113: 5$ $11 \therefore$ $40 \mu$ in<smiles>c1ccccc1</smiles><smiles>N#Cc1ccccc1</smiles>

1.

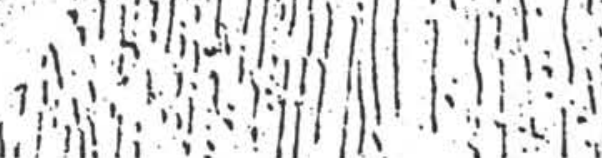
X-60 STEEL as received. Ferrite area is marked " $F$ " and pearlite area, "P." The appearance of $X-52$ is similar but the width of the carbide platelets in the pearlite and the ferrite grain size. are about twice as big in X-52 as in X-60. Fig. 16. 
BLACK SEA STATION NUMBER 1445
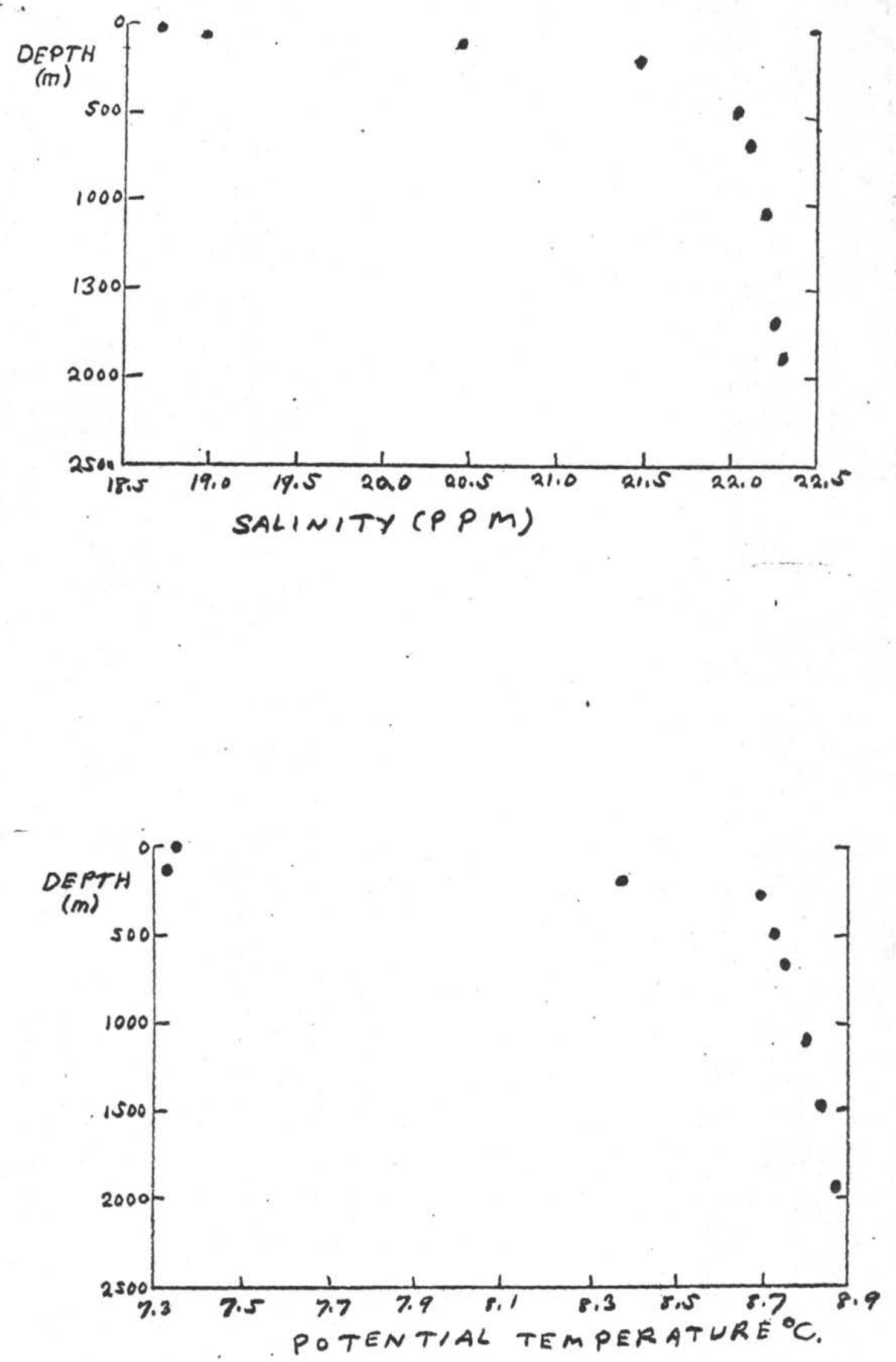

$/ 260$ 
BLACK SEA $H_{2} S$ (MILLIMOLES PER LITER)

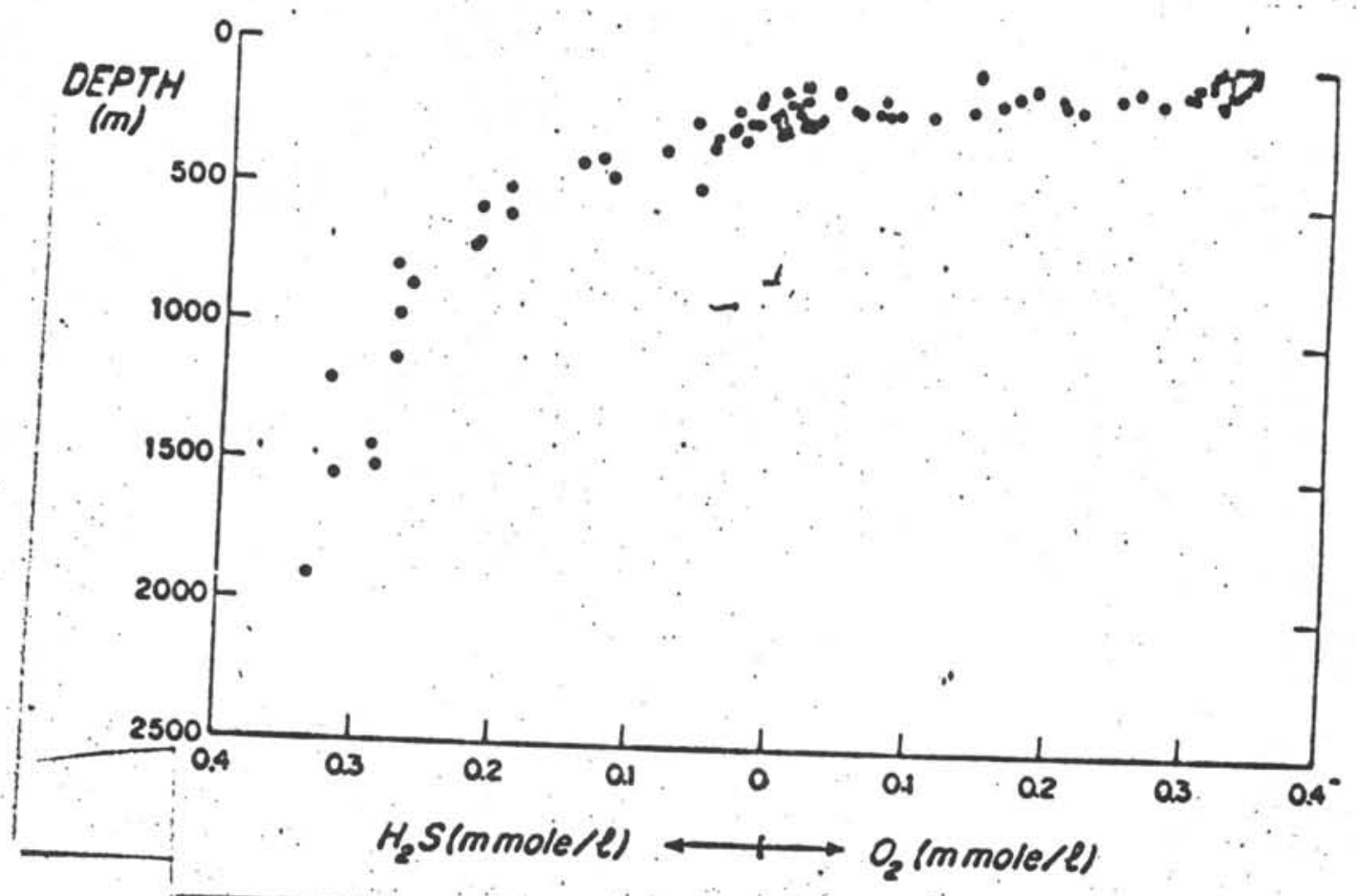


Chemical Composition and Mechanical propexties

GLOBAL MARXNG $-5^{\circ 1} \times 29.50 \%$, S-135

$53 " \times 24.70 \%, S-135$

Has

Nuabes $\begin{array}{llllllllll}619970 & 144.630 & 162,270 & 18.0 & .26 & 1.66 & .021 & .020 & .28 & .45\end{array}$

S.R. $\quad 149,080 \quad 162,600 \quad 20.0$

$\begin{array}{lllllllllll}610017 & 149,830 & 162,080 & 20.0 & .23 & 1.52 & .022 & .019 & .22 & .48\end{array}$

S.?. $\quad 144,060 \quad 157,360 \quad 19.0$

$\begin{array}{lllllllllllll}610111 & 142,370 & 156,500 & 21.0 & .26 & 1.71 & .022 & .020 & .19 & .45\end{array}$

S.R. . 142,970 156,150. 13.0

$\begin{array}{lllllllllll}625515 & 144,740 & 162,520 & 19.0 & .28 & 1.73 & .024 & .020 & .28 & .55\end{array}$

S.R. $153,550 \quad 100,400 \quad 24.0 \quad 02020$

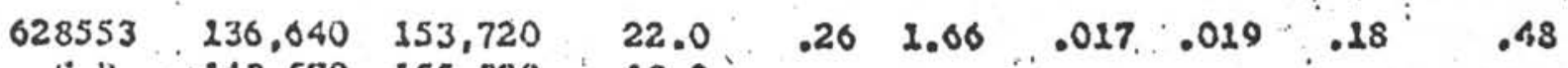

S.l.. $143,570155,320,13.0$. 130 1.06

$\begin{array}{llllllllllllll}637859 & 144,740 & 159,110 & 18.0 & .27 & 1.82 & .025 & .021 & .26 & .48\end{array}$

S.R. $151,570 \quad 164,540 \quad 20.0 \quad .021,0.028$

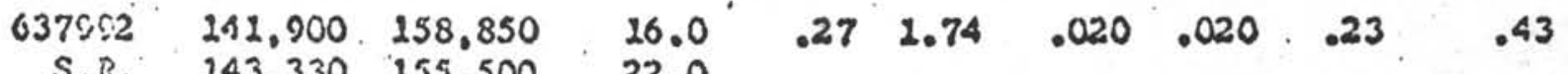

S.R. $\quad 243,330 \quad 155,500 \quad 22.0$

$\begin{array}{lllllllllllll}554702 & 149,470 & 160,280 & 18.0 & .26 & 1.66 & .022 & .020 & .28 & .45\end{array}$

S.R. $147,730 \quad 160,430 \quad 21.0 \cdots$

$\begin{array}{lllllllllllll}554703 & 145,300 & 260,950 & 20.0 & .28 & 2.82 & .022 & .029 & .22 & 028\end{array}$

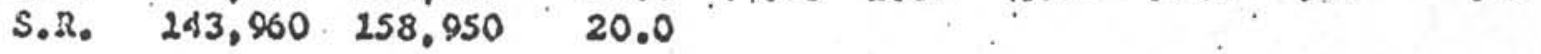

$\begin{array}{llllllllll}620065 & 136,020 & 153,670 & 22.0 & .28 & 1.70 & .022 & .029 & .28 & .48\end{array}$ 
APPENDIX G

Stress-Corrosion Cracking and Hydrogen-

Stress Cracking of High-Strength Steel 


\section{STRESS-CORROSION CRACKING AND HYDROGEN- STRESS CRACKING OF HIGH-STRENGTH STEEL}

\section{DEFENSE METALS INFORMATION CENTER}

Battelle Memorial Institute

Columbus, Ohio 43201 
The Defense Metals Information Center was established at Battelle Memorial Institute at the request of the Office of the Director of Defense Research and Engineering to provide Government contractors and their suppliers technical assistance and information on titanium, beryllium, magnesium, aluminum, high-strength steels, refractory metals, high-strength alloys for hightemperature service, and corrosion- and oxidation-resistant coatings. Its functions, under the direction of the Office of the Director of Defense Research and Engineering, are as follows:

1. To collect, store, and disseminate technical information on the current status of research and development of the above materials.

2. To supplement established Service activities in providing technical advisory services to producers, melters, and fabricators of the above materials, and to designers and fabricators of military equipment containing these materials.

3. To assist the Government agencies and their contractors in developing technical data required for preparation of specifications for the above materials.

4. On assignment, to conduct surveys, or laboratory research investigations, mainly of a short-range nature, as required, to ascertain causes of troubles encountered by fabricators, or to fill minor gaps in established research programs.

Contract No. AF $33(615)-3408$

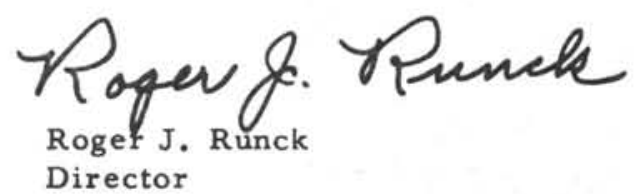

Notices

When Government drawings, specifications, or other data are used for any purpose other than in connection with a definitely related Government procurement operation, the United States Government thereby incurs no responsibility nor any obligation whatsoever; and the fact that the Government may have formulated, furnished, or in any way supplied the said drawings, specifications, or other data, is not to be regarded by implication or otherwise as in any manner licensing the holder or any other person or corporation, or conveying any rights or permission to manufacture, use, or sell any patented invention that may in any way be related thereto.

Qualified requesters may obtain copies of this report from the Defense Documentation Center (DDC), Cameron Station, Bldg. 5, 5010 Duke Street, Alexandria, Virginia, 22314. The distribution of this report is limited because the report contains technology identifiable with items on the strategic embargo lists excluded from export or re-export under U. S. Export Control Act of 1949 (63 STAT. 7), as amended (50 U.S.C. App. 2020.2031), as implemented by AFR 400-10.

Copies of this report should not be returned to the Research and Technology Division, WrightPatterson Air Force Base, Ohio, unless return is required by security considerations, contractual obligations, or notice on a specific document. 


\title{
STRESS-CORROSION CRACKING AND HYDROGEN-STRESS CRACKING OF HIGH-STRENGTH STEEL
}

\author{
E. E. Fletcher, W. E. Berry, and A. R. Elsea*
}

\section{SUMMARY}

Any of the high-strength steels is susceptible to delayed cracking under suitable conditions of applied or residual stress and environment. Frequently, such a brittle failure occurs at a stress that is only a fraction of the nominal yield strength of the material. Considerable controversy exists over whether such failures result from two separate and distinct phenomena or whether there is but one mechanism called by two different names (hydrogenstress cracking and stress-corrosion cracking). The appearance of the fracture surface is similar for both modes of failure, and this is one reason for difficulty in distinguishing between the two mechanisms and thereby contributes to the controversy.

This report has been prepared with the purpose of pointing out wherein the two fracture mechanisms under consideration are similar and wherein they differ. From the evidence available today, the present authors have concluded that there are two distinct mechanisms of delayed failure.

Stress-corrosion cracking is the process in which a crack propagates at least partially by the stress-induced corrosion of a susceptible metal at the advancing tip of the stress-corrosion crack. There is considerable evidence that this cracking results from the electrochemical corrosion of a metal subjected to tensile stresses, either residual (internal, such as may result from welding or heat treatment) or externally applied.

The phenomenon of hydrogen-stress cracking is cracking which occurs as the result of hydrogen in the metal lattice in combination with tensile stresses (or stresses that have tensile components). Hydrogen-stress cracking cannot occur if hydrogen is prevented from entering the steel, or if hydrogen that has entered during processing or service is removed before permanent damage has occurred. It generally is agreed that corrosion (the dissolution of metal with the formation of a corrosion product or products) plays no part in the actual fracture mechanism.

* Senior Metallurgical Engineer, Associate Chief, and Associate Chief, respectively, Ferrous and High Alloy Metallurgy and Corrosion Research Divisions, Battelle Memorial Institute, Columbus, Ohio
It is possible that under some circumstances both types of cracking occur simultaneously; this situation would be very confusing to those attempting to study the mechanism of one or the other of these types of cracking.

It is noteworthy that both fracture mechanisms seem to be promoted by higher strength levels, both require tensile stresses, both seem to involve an interval of time for the nucleation of a crack, and the fracture mode of both is generally intergranular, although some transgranular cracking is encountered. Another similarity is that, during or after exposure to certain environments, alloys fail under stresses it was assumed they could bear. Furthermore, both involve events occurring on the atomic scale.

However, certain differences also have been reported. For example, hydrogen-stress cracking is promoted by cathodic conditions, while stresscorrosion cracking is promoted by anodic conditions. Generally, increasing the temperature increases the likelihood of stress-corrosion cracking, but hydrogen-stress cracking is more prone to occur at temperatures not far from room temperature.

Insofar as is now known, the important factors in these two types of delayed cracking are strength level, steel composition, steel structure, applied and residual stresses, environment (whereby there is a tendency toward corrosion or the introduction of hydrogen into the steel), and time. These factors have been considered individually.

Strength level seems to play a different role in the two mechanisms. For example, nitrate and caustic cracking (stress-corrosion cracking) commonly occur in steels with yield strengths considerably below the lowest level in which hydrogenstress cracking can be readily achieved. However, a material is more prone to fail by either mechanis $m$ as the strength level is increased. Not enough data are available regarding cracking behavior for different steel compositions to shed much light on the issue. However, the cracking behavior of different steel structures provides limited evidence that these are separate phenomena. Applied stress apparently has the same role in both mechanisms. 
Some aspects about the environment provide perhaps the most convincing evidence for two mechanisms. Delayed fractures occurring under conditions of complete cathodic protection can hardly be attributed to stress corrosion. Conversely, fractures occurring under conditions where the cathode reaction does not involve reduction of hydrogen ions (as for example in nitrate solutions) can hardly be hydrogen-stress cracking. Under some circumstances, the mode of failure is not clearcut, as in hydrogen sulfide solutions or water. It appears likely that both types of cracking can be associated with some of these environments and, furthermore, that both may be acting simultaneously under some circumstances.

If impressing a low level of cathodic current (which tends to polarize the local cathode areas in the direction of the potential of the anodes) very greatly extends the breaking time, one concludes that the cracking process in the absence of impressed current is properly designated stresscorrosion cracking. However, if, for a given medium, imposing a small cathodic current decreases the breaking time whereas imposing anodic currents greatly extends life, the behavior indicates that in the case of no impressed current (the "natural" conditions), the failure occurs by hydrogen-stress cracking.

These responses to impressed currents appear to offer a promising means of distinguishing between the two mechanisms, at least in the labora- tory. However, they probably do not afford a practicable means of mitigating against cracking in highstrength steels. For example, if a system is made a little too cathodic in order to combat stress-

corrosion cracking, hydrogen cathodically charged into the steel may well cause delayed failures. Likewise, anodic currents impressed on a system to avoid hydrogen-stress cracking may accelerate ordinary corrosion beyond acceptable limits.

The nature of the potential-time curves obtained during stress-corrosion cracking and hydrogen-stress cracking, respectively, indicates a difference between the two fracture mechanisms.

A different response to variations in the temperature of the environment also suggests two modes of delayed brittle fracture.

It seems to be rather generally regarded that dissolution of metal (corrosion) at the advancing tip of the crack is essential for stresscorrosion cracking, whereas corrosion plays no part in the hydrogen-stress-cracking mechanism. However, corrosion can and frequently does involve liberation of atomic hydrogen as the cathode reaction, and a portion of this hydrogen may enter the steel and cause hydrogen-stress cracking. 
This report was prepared in response to a request from the Working Panel on Metals, SubGroup P on Materials, of The Technical Cooperation Program. The request was authorized by a letter from N. E. Promisel to the U. S. Department of Defense on June 17, 1965.

It is the purpose of this review to point out wherein the two fracture mechanisms under consideration (stress-corrosion cracking and hydrogenstress cracking) are similar and wherein they differ. To accomplish this end, the important factors that influence the tendency to promote cracking by the two mechanisms will be reviewed insofar as information is generally available in the current technical literature. The important factors as now known are strength level, steel composition, steel structure, applied and residual stresses, environment (whereby there is a tendency toward corrosion or the introduction of hydrogen into the steel), and time. These factors will be considered one at a time.

The report describes the current thinking and the state of the art with regard to these two modes of fracture. The present discussion will be limited to high-strength steels except where it is necessary to bring in other materials to point out differences between the two phenomena.

\section{FACTORS AFFECTING STRESS-CORROSION AND HYDROGEN-STRESS CRACKING}

\section{Introduction}

Hydrogen-stress cracking and stresscorrosion cracking are two fracture mechanisms that have been responsible for many serious and unexpected failures in high-strength steel pàrts (and in a number of other structural metals as well). During or after exposure to certain environments, alloys have failed under applied stresses which it was assumed they could safely withstand. Much effort has been expended in determining the relative sensitivity of various structural metals to failure by these mechanisms and in evaluating the effects of various environments on the tendency toward failure. In addition, many research investigations have been directed toward determining the mechanisms by which cracks are initiated and propagated in hydrogen-stress cracking and stress-corrosion cracking. In spite of this effort, neither mechanism is completely understood at present. The different investigators seem to have had varying ideas about each mechanism, and a number of theories have been proposed for each. For heither mechanism has any one theory been universally accepted as providing the explanation of how the environment to which the alloy is exposed can initiate a fracture and enable it to propagate, frequently under a very small stress. It has been reported that both stress-corrosion-cracking and hydrogen-stress-cracking failures have occurred in the laboratory at stresses as low as one-twentieth of the yield strength. much alike, some investigators believe that they are one and the same, the only difference being in the names used to describe the phenomenon. However, other investigators claim that, although there are some apparent similarities, the basic mechanisms are different, and many of the limiting conditions for the occurrence of the two types of cracking are different. A failure will sometimes occur under conditions such that it is called stress-corrosion cracking; at other times the conditions are such that the failure is called hydrogen-stress cracking. Thus, there may be two distinct fracture mechanisms. However, there is incomplete agreement as to which cracking phenomena should be termed stress-corrosion cracking and which are actually hydrogen-stress cracking.

In general, the two mechanisms may be characterized as follows:

Stress-corrosion cracking is the process in which a crack propagates at least partially by the stress-induced corrosion of a susceptible metal at the advancing tip of the stress-corrosion crack. There is considerable evidence that this cracking results from the electrochemical corrosion of a metal subjected to tensile stresses, either residual (internal, such as may result from welding or heat treatment or externally applied. That is, the propagation of a stress-corrosion crack depends on the flow of current between localized anodic and cathodic areas. Frequently, the corrosive environment alone will not cause corrosion, but only does so in the presence of stress. Very little evidence of corrosion may be apparent, perhaps none at all to the unaided eye. Indeed, if corrosion occurs uniformly at a high rate, stress-corrosion cracking is not encountered.

Cracking involves the creation of new surfaces, which requires energy; but of course, cracking is not the only way in which new surfaces are generated. Failure by dissolution of grain boundaries through selective electrochemical attack is not true fracture or cracking, for fracture involves the breaking of metal bonds. That is, fracture is a cohesive separation which occurs at a high speed (a maximum of about half the elasticshear-wave velocity and frequently about one-third the speed of sound), although the fracture may grow in small discrete increments, each propagating at high speed. Cracking occurs with little evidence of ductility, that is, with little plastic deformation and, hence, failures by cracking are termed brittle failures. Shear failures, on the other hand, occur by relatively slow propagation involving crystallographic slip and considerable plastic deformation; these are ductile failures.

A number of different phenomena have been called hydrogen embrittlement. The present report is concerned only with the one known as hydrogeninduced delayed brittle failure, hydrogenembrittlement cracking, or hydrogen-stress cracking. The phenomenon of hydrogen-stress cracking is cracking which occurs as the result of hydrogen 
in the metal lattice in combination with tensile stresses (or stresses that have tensile components). Hydrogen-stress cracking cannot occur if hydrogen is prevented from entering the steel, or if hydrogen that has entered during processing or service is removed before permanent damage has occurred. A critical combination of hydrogen and stress must be present in a susceptible material at a location suitable for crack nucleation, and under conditions that permit the hydrogen to diffuse through the lattice, before hydrogen-stress cracking will occur. It generally is agreed that corrosion (the dissolution of metal with the formation of a corrosion product or products) plays no part in the actual fracture mechanism. However, corrosion frequently is accompanied by the liberation of atomic hydrogen as the cathode reaction. If a portion of the atomic hydrogen thus liberated enters the steel, hydrogen-stress cracking then may ensue.

It appears likely that, under some circumstances, both types of cracking occur simultaneously; such occurrences probably are responsible for much of the confusion concerning these two types of cracking.

Insofar as is now known, the important factors that tend to promote cracking by the two mechanisms are strength level, steel composition, steel structure, applied and residual stresses, environment (whereby there is a tendency toward corrosion or the introduction of hydrogen into the steel), and time. These factors will now be considered individually.

\section{Strength Level}

Many experiments have shown conclusively that both the minimum stress and the time required to produce hydrogen-stress cracking decrease as the nominal tensile strength of the steel is increased. Thus, these delayed-type brittle failures become an increasingly severe problem as the strength level of steel is increased.

In the laboratory, Slaughter et al $(1) *$ studied the effect of strength level with a group of SAE 4340 steel specimens in which the ultimate tensile strength was varied from approximately 300,000 to $142,000 \mathrm{psi}$. All of these specimens were fully quenched to produce martensitic structures, and then tempered at temperatures in the range from 300 to $1200 \mathrm{~F}$ to produce the desired variations in strength. Smooth (unnotched) specimens were continuously charged with hydrogen cathodically while under sustained load. The results are shown in Figures 1 and 2. In addition, both figures show the effect of differences in structure, but this subject will be discussed later. As the strength level was decreased from 300,000 to 142,000 psi, the time to rupture in the higher range of stress increased by a factor of approximately 100; the stress required to cause rupture in 10,000 minutes increased from 15,000 to $45,000 \mathrm{psi}$ as the strength level was decreased in that range (see Figure 1).

*References are given on pages 19 and 20 .
The results obtained show that hydrogen entering the steel while it is under stress can cause it to lose up to 95 percent of its ability to withstand a sustained load, in the case of steel heat treated to a high strength level. Even at the lowest strength level tested for the tempered martensite $(142,000 \mathrm{psi})$, the steel lost approximately two-thirds of its load-carrying ability.

The same steel was isothermally transformed at $1200 \mathrm{~F}$ to produce a pearlitic structure which had a tensile strength of approximately $100,000 \mathrm{psi}$. Under the same charging and test conditions, delayed failures were obtained in unnotched specimens at this strength level, as indicated by the appropriate curve in Figure 1 and the data point for pearlite in Figure 2.

Other experiments in the authors' laboratory have resulted in hydrogen-stress cracking of two high-strength low-alloy steels with yield strengths in the range of 100,000 to $110,000 \mathrm{psi}$ (achieved by quenching and tempering). Delayed failures of another type of steel with a yield strength of 72,000 psi and tensile strength of 94,000 psi were obtained at three levels of applied stress between 60,000 and 68,000 psi.

Apparently, no well-authenticated instances of hydrogen-stress cracking have been reported for tensile strengths under about 100,000 psi or yield strengths under about 80,000 psi.

In general, field failures by hydrogenstress cracking have occurred only in steels with ultimate tensile strengths above about 160,000 psi. When tensile strengths were increased above about 180,000 psi, considerable trouble was experienced with hydrogen-stress cracking of cadmium-plated aircraft parts, hydrogen having been introduced into the steel during processing or service. There is some evidence that field failures have occurred by hydrogen-stress cracking in steels with tensile strengths as low as 130,000 psi. This conclusion is based on the examination of failures that initiated in hard spots in cathodically protected linepipe.

Unless specifically stated otherwise, when the concept of relative sensitivity to hydrogenstress cracking is considered in this report, reference is made to the effect of the variable under consideration on the minimum stress for failure or on the time to failure for a given material. Any one of the curves in Figure 1 represents the hydrogen-stress-cracking behavior of one specific material under one set of charging conditions. The curve tends to become horizontal for the lower applied stresses (longer failure times). Any combination of applied stress and time under stress that falls below this lower critical stress apparently does not result in failure, at least not in times near the arbitrarily selected runout time. Thus, under the conditions represented by the area below the horizontal portion of the curve (lower critical stress), the steel is considered not to be susceptible to failure. The portion of the figure above 


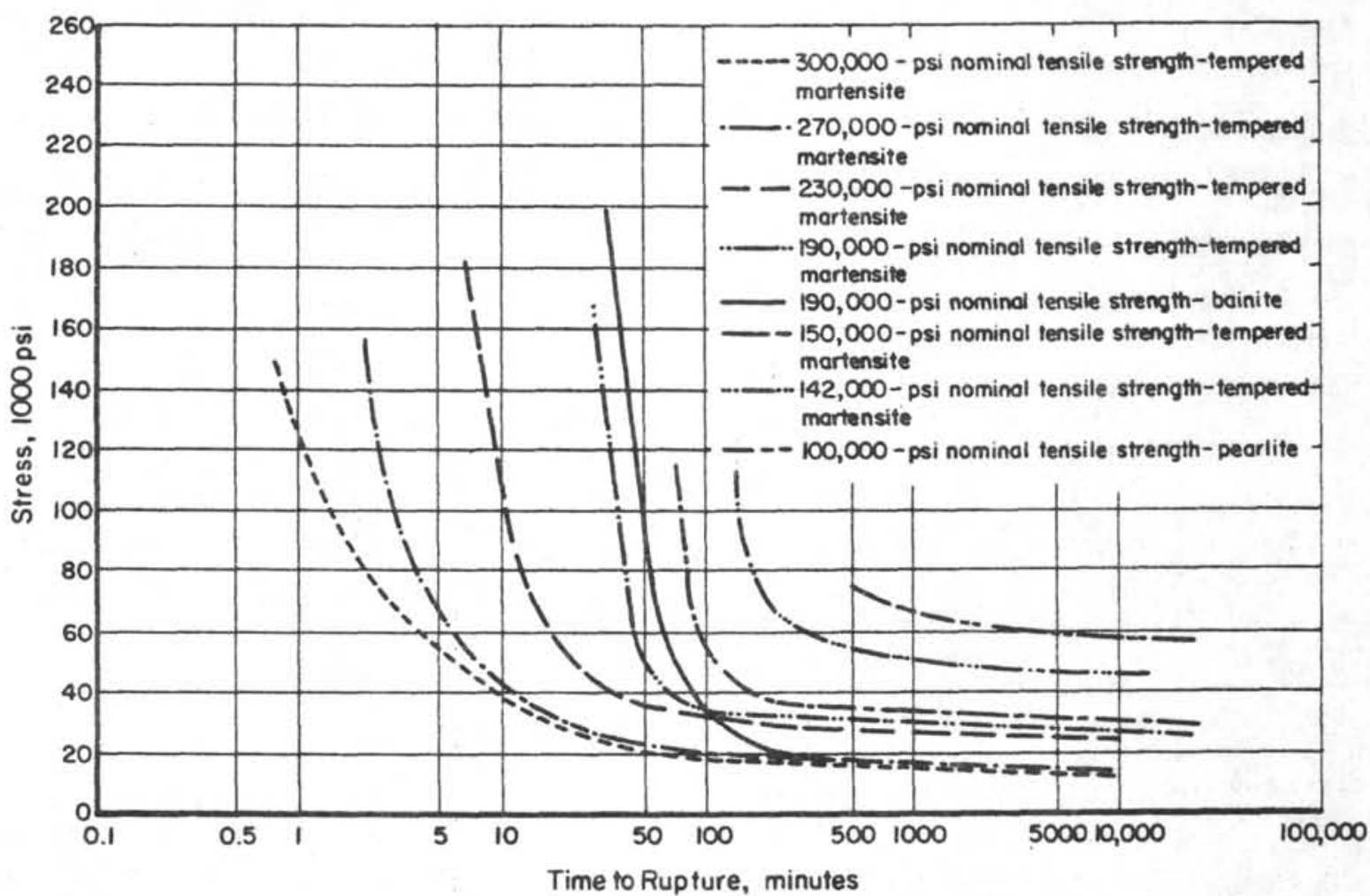

FIGURE 1. DELAYED-FAILURE CHARACTERISTICS OF UNNOTCHED SPECIMENS OF SAE 4340 STEEL DURING CATHODIC CHARGING WITH HYDROGEN UNDER STANDARDIZED CONDITIONS(1)**

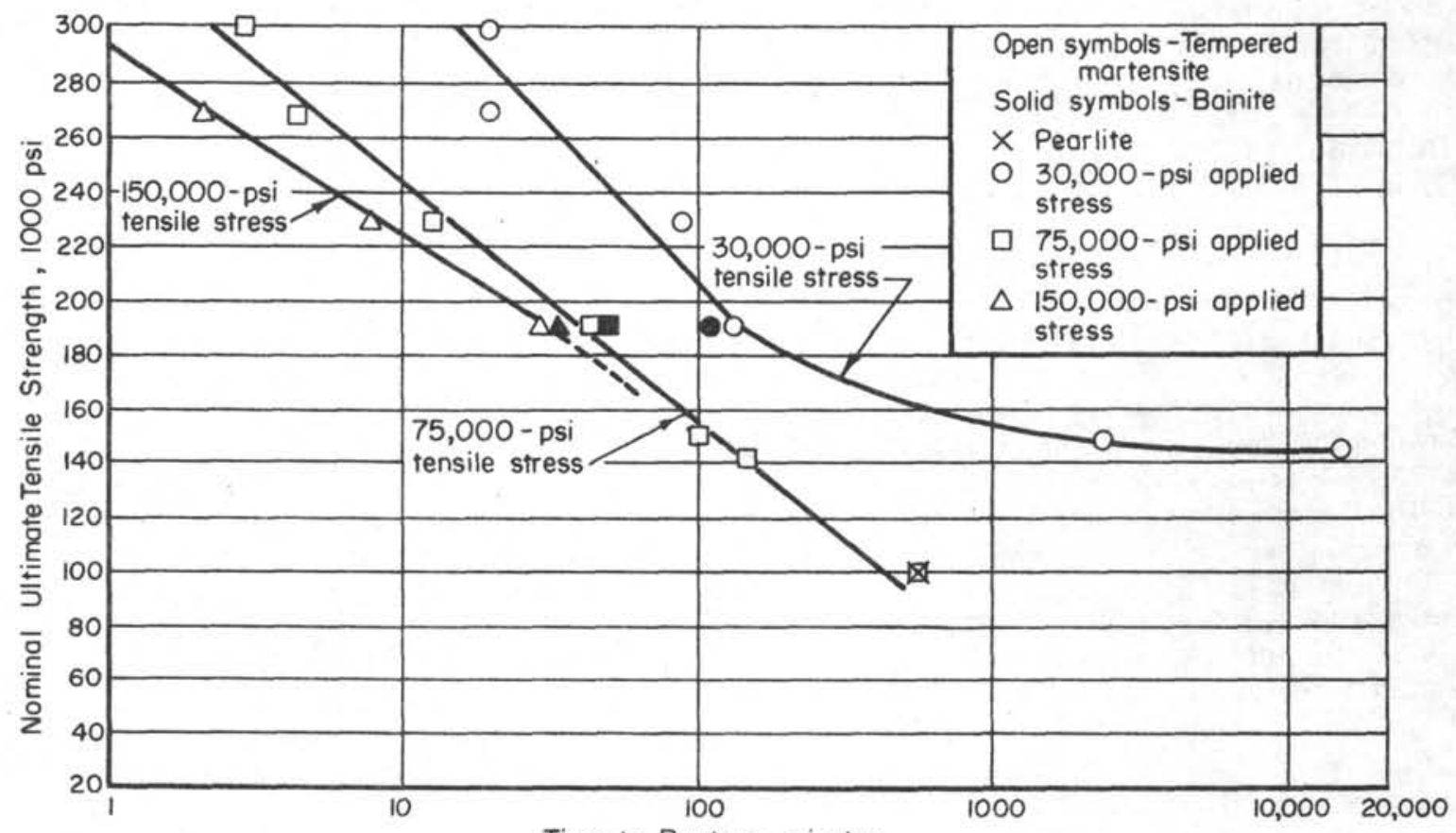

Time to Rupture, minutes

$\begin{array}{llllllllll} & 1 & 1 & 1 & 1 & 1 & 1 & \frac{1}{1} & & 16\end{array}$

Time to Rupture, days

FIGURE 2. EFFECT OF NOMINAL STRENGTH OF SAE 4340 STEEL ON THE TIME TO RUPTURE DURING CATHODIC CHARGING WITH HYDROGEN UNDER STANDARDIZED CONDITIONS WHILE UNDER STRESS $(1)^{*}$

* Battelle Charging Condition A:

Electrolyte:

Poison:

Current density:
4 percent by weight of $\mathrm{H}_{2} \mathrm{SO}_{4}$ in water

5 drops per liter of cathodic poison composed of $2 \mathrm{grams}$ phosphorus in 40 milliliters of $\mathrm{CS}_{2}$ $8 \mathrm{ma} /$ in. $^{2}$ 
the curveindicates the combinations of applied stress and time that will result in failure. Under these applied stresses, the steel is considered to be susceptible to fallure. The sensitivity to hydrogen depends on the value of the lower critical stress and on the times to failure at somewhat higher stresses. Thus, any variable which raises the lower critical stress or which moves the curve appreciably to the right (toward longer failure times) may be said to reduce the sensitivity to hydrogen-stress cracking. Conversely, any variable which moves the curve downward or to the left increases the sensitivity.

Stress-corrosion cracking has been encountered in steels of all strength levels. For example, caustic cracking has occurred at elevated temperatures in structural steels with minimum yield strengths of 30,000 to 33,000 psi. A welded storage tank of structural steel in the hot-rolled and annealed condition failed by stress-corrosion cracking after 3 years in service with 50 percent caustic at $120 \mathrm{~F}$. Another tank in service with 50 percent caustic at $100 \mathrm{~F}$ failed by caustic cracking in 10 years.

In the laboratory, steels with yield strengths as low as 43,000 psi have failed during exposure to nitrate solutions.

For resistance to hydrogen sulfide cracking in oil-field applications such as casings and drill pipe, it is customary to specify that the steel be no harder than Rockwell C 22 (ultimate tensile strength of about 110,000 to 115,000 psi and yield strength on the order of 95,000 psi, depending upon the structure). However, failures by sulfide cracking can occur even at that specified maximum strength level if the service stress is unusually high, or at even lower levels if the steel is plastically deformed. In the laboratory, McGlasson and Greathouse $\mathrm{e}^{(2)}$ found no cracking on exposure to hydrogen sulfide solutions for steels with a hardness of Rockwell C 23 or less (see Figure 3). However, in other work, (3) sulfide cracking reportedly was obtained in material with a yield strength of 67,000 psi at an applied stress of 55,000 psi, but steels with yield strengths in the range of 64,000 to 67,000 psi survived 300 days without cracking. Thus, there are hardness and applied-stress minimums below which a given steel will not crack when exposed to an aqueous system containing hydrogen sulfide; these are inversely related. The effect of hardness on the susceptibility to sulfide cracking of heat-treated AISI 4140 bolts in an investigation by Warren and Beckman (4) is shown in Figure 4.

Suss ${ }^{(5)}$ studied stress-corrosion cracking in $300 \mathrm{~F}$ water of Type 410 stainless steel heat treated to various strength levels. Failures were obtained for hardnesses above Rockwell C 25 to 30 .

As will be discussed more fully in the section on environment, considerable controversy exists as to whether sulfide cracking is a stress-corrosion- cracking phenomenon or whether it is a manifestation of hydrogen-stress cracking. In any event, higher strength levels are required for sulfide cracking than for stress-corrosion cracking in other environments. Also, in sulfide cracking, increasing the strength level of high-strength materials causes them to be more susceptible to cracking, as for example with 17-4PH and Type 410 stainless steels. This is the same behavior observed for authenticated hydrogen-stress cracking.

In summarizing the effects of strength level, the controversial area of sulfide cracking will be ignored. On this basis, there is a difference in behavior between hydrogen-stress cracking and accepted types of stress-corrosion cracking, such as nitrate or caustic cracking. This observation suggests that the two phenomena occur by different mechanisms.

\section{Composition}

Apparently, all the high-strength steels, including maraging steels and the precipitationhardening stainless steels as well as the martensitic steels, are susceptible to stress-corrosion cracking. (6) Austenitic stainless steels also are susceptible.

All types of steels with hardnesses above about Rockwell C 23 will crack in aqueous solutions that contain hydrogen sulfide. The results McGlasson and Greathouse $\mathrm{e}^{(2)}$ obtained for a number of steels stressed below the yield point are listed in Table 1. These investigators also have summarized the work of other investigators on steels stressed above the yield stress (that is, cold worked) either before or during the tests (Table 2). They concluded that for a given strength level, EF-chemistry quenched-and-tempered steels are less susceptible to sulfide cracking than are more highly alloyed steels. Additions of manganese, molybdenum, or nickel reportedly increase the susceptibility to sulfide cracking, while chromium tends to reduce susceptibility. $(2,7)$ Also, it is Craimed that increasing the carbon content for the same strength level improves resistance to sulfide cracking. (7) The French have developed a steel with a yield strength in the 80,000 to $90,000-p s i$ range that is superior to $\mathrm{N}-80$ steel in resistance to sulfide cracking. (8) It has the following composition:

$$
\begin{array}{lll}
C & 0.12 & \text { percent } \\
\mathrm{Cr} & 2.0 & \text { percent } \\
\text { Mo } & 0.3 & \text { percent } \\
\mathrm{Al} & 0.3 & \text { percent. }
\end{array}
$$

If the strength levels are the same, a steel of higher carbon content is more resistant to stress-corrosion cracking in nitrate solutions than is one of lower carbon content. In one investigation, nitrate cracking was obtained in a steel with 0.17 percent carbon, while no cracking 


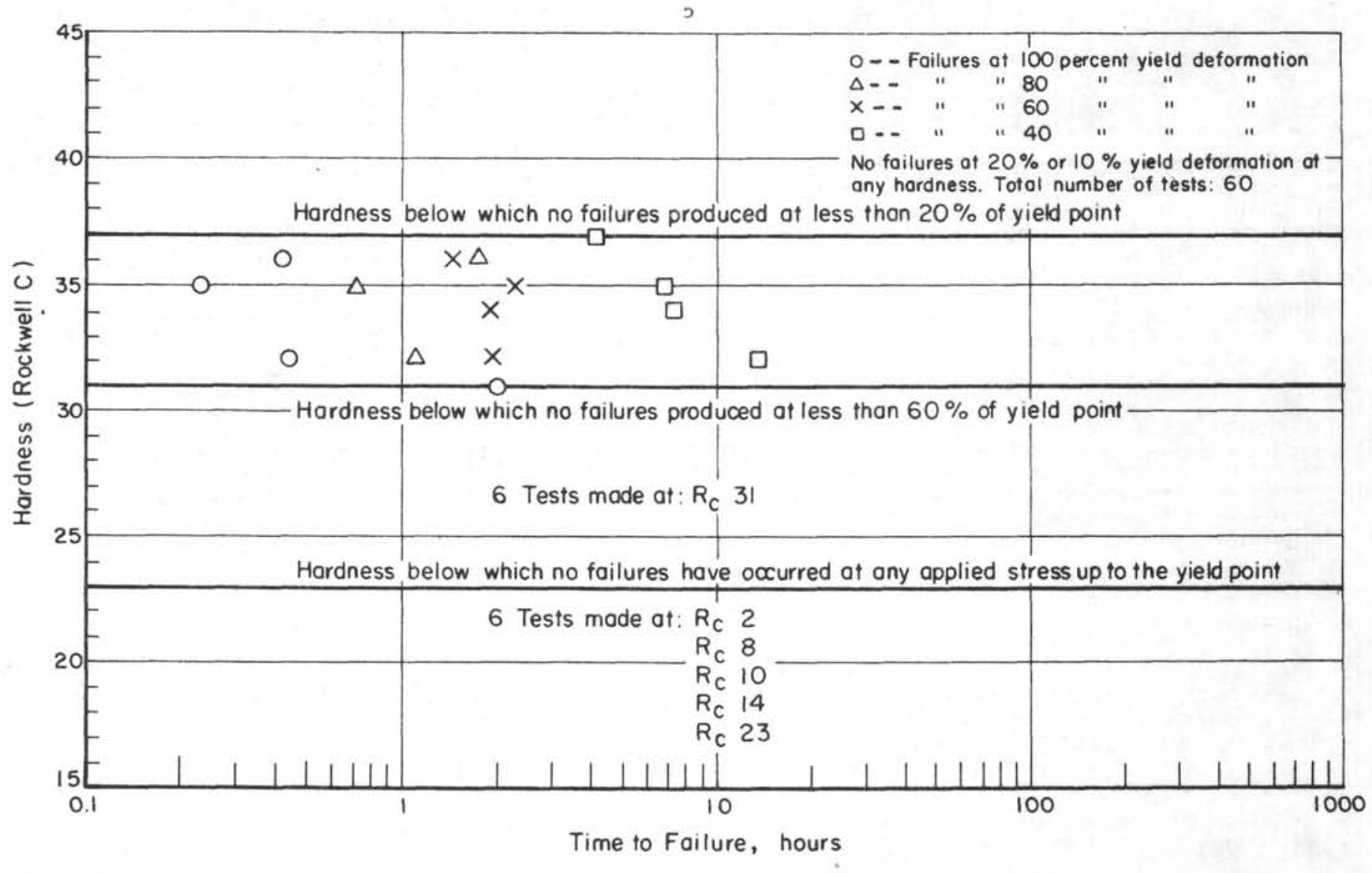

FIGURE 3. HARDNESS VERSUS TIME-TO-FAILURE DATA OBTAINED IN TESTS OF HEAT-TREATED J-55 AND N-80 STEEL IN 5 PERCENT NaC1 SATURATED (3000 ppm) WITH H $\mathrm{S}^{(2)}$

Insufficient data to cover entire hardness range. Data illustrate that limiting hardness level depends on applied stress.

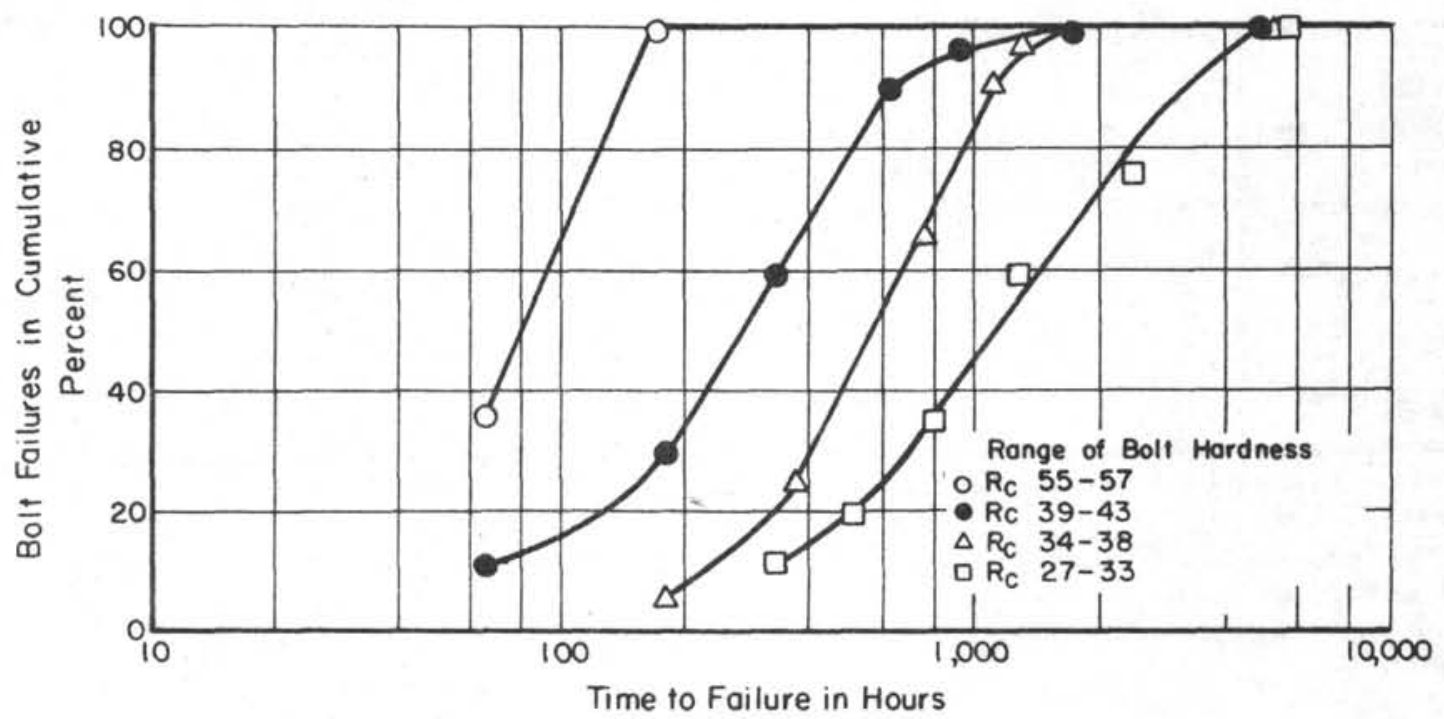

FIGURE 4. EFFECT OF HARDNESS ON TIME TO FAILURE OF AISI 4140 STEEL BOLTS EXPOSED IN AN H $\mathrm{H}_{2} \mathrm{~S}-\mathrm{H}_{2} \mathrm{O}$ SYSTEM AT $40 \mathrm{C}(104 \mathrm{~F})$ AND $250 \mathrm{PSI}(4)$ 
TABLE 1. SULFIDE CORROSION CRACKING PRODUCED IN NOTCHED SPECIMENS LOADED BELOW THE YIELD POINT (2)

\begin{tabular}{lcc}
\hline \multicolumn{1}{c}{ Material } & $\begin{array}{c}\text { Hardness, } \\
\text { Rockwell C }\end{array}$ & Times to Failure(a) \\
\hline 9 percent chrome & 33 & Within 6 months \\
AISI 4145 & 30 & Within 6 months \\
N-80(b) & 41 & 2 to 41 minutes \\
N-80 & 29 & 14 to 40 hours \\
N-80 & 26 & Less than 18 hours \\
N-80 & 35 & 2 to 20 hours \\
Martensitic stainless & 18 & Less than 24 hours \\
9 percent chrome & 37 & Less than 12 hours \\
\end{tabular}

(a) Times to fallure vary, depending on applied stress. The nature of the test was such as to not permit definition of exact time to failure.

(b) The series of $\mathrm{N}-80$ tests listed here was made on $\mathrm{N}-80$ material heat treated in ways to provide different hardness levels. This is a Mn-Mo steel containing about 0.46 percent carbon.

TABLE 2. STEEL ALLOYS, HEAT TREATMENTS, HARDNESS, AND STRESSES RESULTING IN SULFIDE CRACKING(a)(2)

\begin{tabular}{|c|c|c|c|}
\hline Steel & Heat Treatment & $\begin{array}{r}\text { Minimum } \\
\text { Hardness, } \\
\text { Rockwell C }\end{array}$ & $\begin{array}{l}\text { Minimum } \\
\text { Applied } \\
\text { Stress, psi }\end{array}$ \\
\hline API $J-55$ (b) & Quenched and Tempered & $30(\mathrm{e})$ & $80,000^{(\mathrm{c})}$ \\
\hline API $N-80$ & $\begin{array}{l}\text { Normalized } \\
\text { Normalized } \\
\text { Quenched and Tempered }\end{array}$ & $\begin{array}{l}24 \\
21 \\
28\end{array}$ & $\begin{array}{r}64,000^{(c)} \\
120,000^{(d)} \\
120,000^{(d)}\end{array}$ \\
\hline $\begin{array}{l}5 \text { percent nickel } \\
9 \text { percent nickel } \\
5 \text { percent chromium } \\
0 \text { percent chromium }\end{array}$ & $\begin{array}{l}\text { Normalized and Tempered } \\
\text { Normalized and Tempered } \\
\text { Normalized and Tempered } \\
\text { Normalized and Tempered }\end{array}$ & $\begin{array}{l}24 \\
24 \\
30(e) \\
25(e)\end{array}$ & $\begin{array}{r}80,000^{(c)} \\
60,000^{(c)} \\
120,000(d) \\
120,000^{(c)}\end{array}$ \\
\hline $\begin{array}{l}\text { Type } 322 \text { stainless } \\
\text { steel (Stainless W) }\end{array}$ & (f) & $44^{(e)}$ & $54,000^{(c)}$ \\
\hline
\end{tabular}

(a) Steels were stressed above the yield stress (cold worked) either before or during test.

(b) Not normal J-55 which is normalized to much lower hardnesses and does not normally exhibit cracking phenomenon.

(c) Specimens were prestressed above yield stress, then subsequently stressed to levels indicated.

(d) Specimens were stressed to a calculated stress which was in all cases above the yield stress of the material.

(e) Insufficient data available to determine these as minimum hardnesses, but they are the lowest hardnesses for which test data are reported.

(f) Yield-strength $(129,000 \mathrm{psi})$ and hardness values suggest that this was in the annealed condition (not age hardened). 
occurred in steels with 0.24 percent carbon or more. (9) For cracking in 500-hour tests in nitrate, Parkins ${ }^{(10)}$ listed the following values for threshold stress as a function of carbon content (no values of mechanical properties were given):

Carbon Content,
percent

0.07

0.08

0.09

0.11

0.16
Threshold Stress, psi

5,000
14,000
$12,000,18,000$
23,000
24,000

Uhlig and Sava(11) referred to work by Nehl and Werner ${ }^{(12)}$ which showed that an increase in carbon and aluminum improves resistance to stresscorrosion cracking in boiling 60 percent $\mathrm{Ca}\left(\mathrm{NO}_{3}\right)_{2}-$ 3 percent $\mathrm{NH}_{4} \mathrm{NO}_{3}$ solution. Preferably, the carbon and aluminum contents should be not less than 0.15 and 0.04 percent, respectively. They also mentioned work by Athavale and Eilender (13) which indicated that nitriding a steel produces increased resistance to stress-corrosion cracking. However, other investigators ${ }^{(14)}$ ascribed this improved resistance to compressive stresses introduced in the nitrided surface and not to the nitrogen itself. On the other hand, Uhlig and Sava stated that Parkins $(10,15)$ disagreed with the latter explanation, reporting instead that a nitrided steel that contained 0.095 percent nitrogen and 0.015 percent carbon still did not crack after heat treatment at $900 \mathrm{C}(1650 \mathrm{~F})$ followed by furnace cooling to effectively relieve internal stresses. Other investigators $(16,17)$ have reported that aluminumkilled steels are more resistant to cracking in caustic and nitrate solutions than are similar steels made by other melting practice. Weir (18) reported that a fine-grain steel is more resistant to caustic cracking than is a coarse-grain steel of the same carbon content, and that a fine-grain steel slightly enriched in carbon is quite resistant.

In experiments with $1: 1 \mathrm{HCl}$-water $+\mathrm{SeO}_{2}$, Fontana(19) observed that cracks started at pits associated with manganese sulfide inclusions.

Although austenitic stainless steels are susceptible to stress-corrosion cracking, it is reported that such a steel with 3 or 4 percent added silicon is not susceptible.

With regard to hydrogen-stress cracking, there are indications of minor effects of composition on the sensitivity to cracking. However, there is no evidence to indicate any martensitic steef exists which will not break under severe conditions. Variations in steel composition are known to affect the rate at which hydrogen is picked up from the environment and the rate at which it diffuses in the bulk steel. Thus, variations in the time to produce hydrogen-stress cracking do not necessarily reflect differences in the amount of hydrogen required to produce a crack. Unfortunate-
$1 y$, it is not yet feasible to separate out the entryrate and diffusion effects to determine whether differences in composition have an effect on the cracking mechanism itself.

In the authors! laboratory, a 5 percent chromium steel (Type $\mathrm{H}-11$ ) has taken longer to crack under given charging conditions than AISI 4340 steel of the same strength level $(260,000$ psi ultimate tensile strength) but of lower chromium content $(0.85$ percent), and longer to crack than AISI 4130 steel $(0.87$ percent chromium) at a considerably lower strength level $(180,000$ psi ultimate tensile strength). Cotton $(20)$ studied the hydrogen embrittlement of five aircraft-quality high-strength steels plated in three cyanide cadmium baths, as well as in other types of baths. The five steels were AMS 6427 (AISI 4330), AMS 6407, AMS 6418, AISI 4340 , and $4340-1.5 \mathrm{Si}$ heat treated to strength levels in the range of 220,000 to $300,000 \mathrm{psi}$, depending on the nature of the steel. The compositions were as follows:

Chemical Composition of Steels

\begin{tabular}{|c|c|c|c|c|c|}
\hline Constituent & $\begin{array}{c}\text { AMS } 6427 \\
\text { Steel } \\
\end{array}$ & $\begin{array}{c}\text { AMS } 6407 \\
\text { Steel } \\
\end{array}$ & $\begin{array}{c}\text { AMS } 6418 \\
\text { Steel } \\
\end{array}$ & $\begin{array}{c}\text { AISI } 4340 \\
\text { Steel } \\
\end{array}$ & $\begin{array}{l}4340-1.5 \mathrm{Si} \\
\text { Steel } \\
\end{array}$ \\
\hline Carbon & 0.30 & 0.28 & 0.28 & 0.42 & 0.38 \\
\hline Manganese & 0.88 & 0.74 & 1. 28 & 0.78 & 0.46 \\
\hline Silicon & 0.30 & 0.62 & 1. 40 & 0.21 & 1. 64 \\
\hline Nickel & 1.80 & 2. 08 & 1. 75 & 2.05 & 2.05 \\
\hline Chromium & 0.86 & 1.15 & - & 0.85 & 0.98 \\
\hline Molybdenum & 0.45 & 0.44 & 0.38 & 0.29 & 0.36 \\
\hline Phosphorus & 0.014 & 0.017 & 0.024 & 0.026 & 0.010 \\
\hline Sulfur & 0.014 & 0.013 & 0.010 & 0.011 & 0.017 \\
\hline Vanadium & 0.08 & - & - & - & 0.06 \\
\hline Aluminum & - & - & - & - & 0.095 \\
\hline
\end{tabular}

Static-loading tests were used, and the criterion for nonembrittlement was the ability of specimens given the same treatment to withstand a load of 75 percent of the notched ultimate tensile strength for 150 hours without failure. After being plated, all of the specimens were baked at 375 or $550 \mathrm{~F}$ for various periods ranging from 3 to 23 hours. Cotton listed the steels in order of increasing resistance to hydrogen embrittlement caused by cadmium electroplating, based solely on time to failure, as follows (strength level in parentheses): AISI $4340(260,000$ to $280,000 \mathrm{psi})$, AMS 6427 (AISI 4330) (220,000 to $240,000 \mathrm{psi}), 4340-1.5 \mathrm{Si}$ $(270,000$ to $300,000 \mathrm{psi})$, AMS $6407(220,000$ to 240,000 psi), AMS $6418(220,000$ to 240,000 psi). At these high strength levels, there was no consistent relationship between susceptibility to damage and strength level. These results showed that factors other than strength level and ductility of the steel are also important in determining the susceptibility of a steel to hydrogen damage. The silicon-modified 4340 steel ( 1.5 percent silicon) was more resistant to hydrogen-stress cracking than was the standard AISI 4340 steel, even though the strength level of the former was slightly higher. Of particular significance is the finding that the $4340-1.5 \mathrm{Si}$ steel at the 270,000 to $300,000-\mathrm{psi}$ strength level was more resistant to hydrogenstress cracking than was the AMS 6427 (4330) steel 
at the 220,000 to 240,000 -psi strength level. For the three steels with 0.28 to 0.30 percent carbon used at the 220,000 to 240,000-psi strength level, the high-silicon AMS 6418 steel (Hy-Tuf; 1. 40 percent silicon) was more resistant than were the steels of lower silicon content. Thus, it appears that silicon imparts a certain measure of resistance to hydrogen-stress cracking. Some investigators attribute this increased resistance to hydrogen-stress cracking of high-strength steels that results from silicon additions to the higher tempering temperatures used to achieve a given strength level in the silicon steels which produces a different fine structure of the tempered martensite as compared with that in the corresponding low-silicon steel. However, other investigators have shown that silicon and chromium additions reduce the diffusivity or the permeability of hydrogen in $\alpha$-iron. (21-24) Thus, one would expect the induction period before the onset of hydrogen-stress cracking under sustained load to be appreciably longer in high-silicon and highchromium steels.

Generally, various high-strength steels of a given strength level seem to exhibit about the same minimum stress for failure by hydrogenstress cracking (these lower stresses involve longer times where entry-rate effects are overridden). At high strength levels, differences in notch sensitivity complicate the situation; thus, a difference in breaking time between different materials at a high applied stress does not necessarily mean that there is a difference in sensitivity to hydrogen-stress cracking. For lower strength materials, variations in composition seemed to have little effect on the minimum hardness for cracking under severe cathodic charging conditions, as shown by Table 3 .

The available data do not provide sufficient information to determine whether, for a given hydrogen content in the steel, there is any difference in hydrogen-stress-cracking behavior as a result of differences in composition.

In summary, there is not enough information available to determine whether the behavior in regard to differences in composition would tend to suggest that hydrogen-stress crac.iing and stresscorrosion cracking are the same phenomenon or distinctly different phenomena. More work, performed under more carefully controlled conditions than have been used in the past, is needed to ascertain the effects of composition on these two fracture mechanisms, particularly for hydrogen-stress cracking.

\section{Structure}

Whereas steels of all types (including martensitic, bainitic, pearlitic-ferritic, and austenitic) are subject to stress-corrosion cracking, hydrogenstress cracking is common only in steels with martensitic or bainitic structures. For many years it

\section{TABLE 3. MINIMUM HARDNESS IN TUBING STEEL AT WHICH CRACKING OCCURRED $(\mathrm{a})(2)$}

\begin{tabular}{cc}
\hline Minimum Hardness \\
for Cracking, \\
Rockwell C
\end{tabular}

$\mathrm{N}-80$

3-1/2 percent nickel

5 percent nickel

9 percent nickel

9 percent chromium

12 percent chromium AISI 4140
17

20

20

17

21

19 (a) U-bend test specimens were exposed to artificial hydrogen-embrittlement tests. Cathodic charging in 5 percent $\mathrm{H}_{2} \mathrm{SO}_{4}$ containing $20 \mathrm{mg} /$ liter of arsenic as poisoner at $2 \mathrm{amp} / \mathrm{in} .{ }^{2}$ for 105 minutes.

was thought that austenitic steels were peculiarly immune to delayed failure induced by hydrogen and that only steels with body-centered cubic structures were susceptible. Cathodic charging of bulk specimens of austenitic steel, even under severe conditions for extended periods of time, resulted only in a partial loss of tensile ductility, but no delayed cracking. However, recently, hydrogen-stress cracking of a thin film of austenitic stainless steel was achieved in the laboratory. It appears as though it is extremely difficult to obtain hydrogen penetration beyond a thin surface layer of a bulk sample of austenite by cathodic charging at room temperature, even though austenite has a high solubility for hydrogen as compared with ferrite. It has been established that the diffusivity of hydrogen in austenite is low compared with that in ferrite of the same composition, and the presence of large amounts of chromium reduces it further (at least in ferrite).

A series of stress-corrosion experiments was performed on a stainless steel that can be treated to have either a martensitic or an austenitic structure. (25) First, the steel was refrigerated to form a martensitic structure. Evaluation showed that chemical attack was randomly nucleated and the structure was resistant to stress-corrosion cracking. When the austenitic version of the same alloy was deformed, coarse slip steps were formed, and these proved to be chemically active sites; this structure was susceptible to transgranular stress-corrosion cracking.

Apparently, the stress-corrosion cracking of austenitic stainless steel occurs only rarely at room temperature, but commonly at elevated temperatures. (6)

As is shown in Figures 1 and 2, hydrogenstress cracking has been obtained in steels with 
structures consisting of a mixture of pearlite and ferrite, but only rarely has this been observed. Most steels with this structure apparently are not strong enough to crack by this mechanism, since well-authenticated cracks of this type have been obtained only for tensile strengths of 100,000 psi and above (yield strength of approximately 80,000 psi and above). It would appear that the bulk of the pearlitic-ferritic steels can undergo their normal mode of ductile failure at stresses below that required for the hydrogen-stress-cracking mechanism to become operative.

Figures 1 and 2 also show that a steel treated to have either a bainite or a temperedmartensite structure at the same strength level (190,000-psi nominal ultimate tensile strength) exhibited essentially the same hydrogen-stresscracking behavior in the two conditions. Other data in these figures represent the behavior of structures ranging from pearlite with a little ferrite to martensite tempered at a low temperature; all structures were susceptible to hydrogenstress cracking. The times to failure and the minimum stresses for failure correlated very well with the ultimate-tensile-strength level.

The maraging steels, in which hardening is achieved by precipitation hardening of a lowcarbon iron-nickel martensite, are susceptible to hydrogen-stress cracking, but they exhibit reduced sensitivity as compared with conventional martensitic steels. $(26,27)$ There is evidence that the reduced sensitivity observed for these steels is the result of a lower hydrogen-entry rate than is found for conventional martensitic steels. (27)

Very recently, Uhlig and coworkers (28) cold worked an austenitic stainless steel, thereby introducing much ferrite into the structure, and succeeded in cracking the mixed structure completely through the section upon charging it with hydrogen. Apparently their test specimens were bent beyond the elastic limit. The strength level of the highly alloyed ferrite in this mixed structure was unknown.

Other investigations have shown that gross variations in structure (including spheroidite, coarse and fine lamellar pearlite, and tempered martensite) have considerable influence on the rate at which hydrogen enters steel and on its permeation and diffusion through steel. Apparently, there is no clear-cut evidence that variations in structure have any influence on the amount of hydrogen required to cause cracking at a given strength level, since a method for determining the amount of hydrogen at the advancing crack tip has not yet been developed. Of course, variations in the entry and diffusion of hydrogen would affect the time required to reach a critical concentration of hydrogen at a site suitable for initiation of cracking.
An investigation was performed to ascertain the minimum applied stress to cause cracking in Type 410 stainless steel heat treated so as to have different amounts of martensite and tested as bentbeam specimens in aqueous hydrogen sulfide solution. The hardness increased with increased percentage of martensite in the structure (see Figure 5). As shown in Figures 6 and 7 , above 75 percent martensite (Rockwell C 48 or 140,000-psi yield strength), the steel broke by sulfide cracking at all applied stresses. At the other extreme, no failures occurred in structures that contained less than 32 percent martensite (Rockwell C 30 or 62,000-psi yield strength), not even with applied stresses as high as 97 percent of the yield strength.

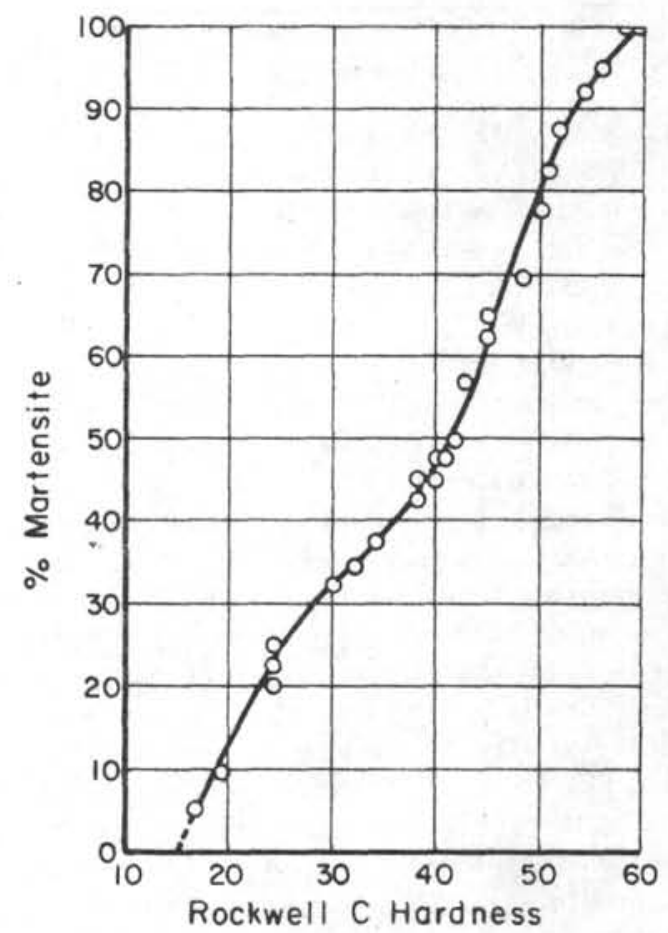

FIGURE 5. CURVE SHOWING \% MARTENSITE VER SUS HARDNESS IN SAMPLE OF TYPE 410 STAINLESS STEEL USED IN SULF IDE-CRACKING EXPERIMENTS ${ }^{(3)}$

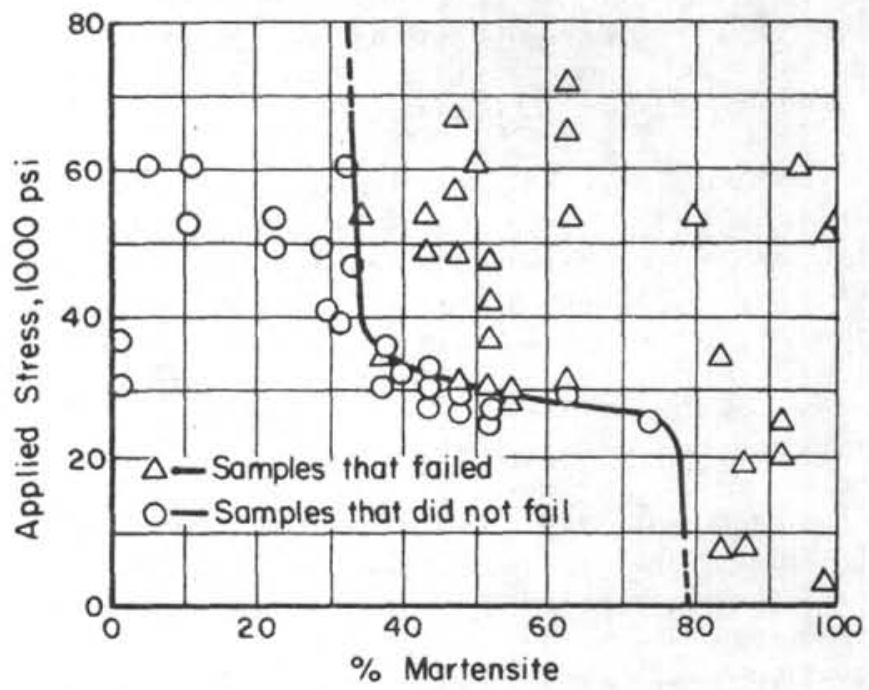

FIGURE 6. CURVE SHOW ING SULFIDE-CRACKING BEHAVIOR AS RELATED TO \% MARTENSITE AND APPLIED STRESS (AS POUNDS PER SQUARE INCH) (3) 


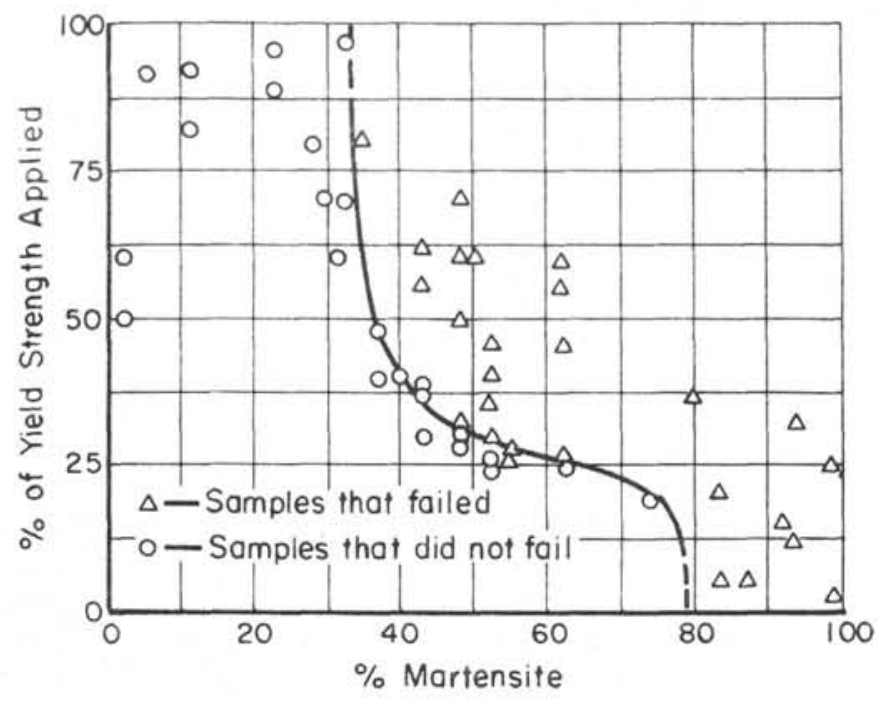

FIGURE 7. CURVE SHOWING SULFIDE-CRACKING BEHAVIOR AS RELATED TO PERCENT MARTENSITE AND APPLIED STRESS (AS A PERCENTAGE OF THE YIELD STRESS) (3)

It is reported that a specific structure is required to make the new French steel (referred to previously) resistant to sulfide cracking. It is claimed that the safe structure consists of ferrite without carbon in solid solution and which contains finely dispersed carbides (cementites partially substituted with chromium or molybdenum and carbides of molybdenum and vanadium). This structure is obtained by water quenching and tempering. Quenched-and-tempered steels can have either acicular or nonacicular structures, and Herzog $(29)$ found that the nonacicular structures performed better in bend tests conducted in sulfide solutions. At the same levels of yield strength or ultimate tensile strength, specimens with the acicular structure broke in 400 to 700 hours, but those with the nonacicular structure withstood more than 2000 hours' exposure under stress.

As was discussed previously, there is no general agreement as to whether sulfide cracking is stress-corrosion cracking, hydrogen-stress cracking, or sometimes both.

Other information pertaining to the effect of structure was obtained in studies of Type 410 stainless steel exposed to pressurized water at $300 \mathrm{~F}$ with no imposed potential. (5) All samples from two heats had failed in 2 weeks or less under stress. None of the samples from the third heat had failed after 8 weeks' exposure. The structure of the two heats consisted of tempered martensite, and the cracks that developed upon exposure were typical intergranular cracks. However, the structure of the heat that was resistant to cracking consisted of tempered martensite plus longitudinal stringers of delta ferrite; also, the prior austenite grain size of this material was smaller. After 8 weeks' exposure at an applied stress of 40,000 psi, small microcracks were present in the martensite, but propagation of these cracks had been stopped by the delta-ferrite stringers. For exposure at 80,000-psi applied stress, the presence of the delta ferrite appeared to have slowed the crack propagation. The slowing action apparently resulted whenever the crack had to deviate from a direction normal to the direction of the applied stress. Evidence was obtained which suggested that delta ferrite will not stop crack propagation whenever the crack moves in a direction parallel to the stringers.

There is a question, however, whether this phenomenon of cracking in water is stress-corrosion cracking or hydrogen-stress cracking. Had the sensitivity to cracking in the experiments just described also been observed with very small cathodic potentials impressed on the system to make it just a little more cathodic, the results would have been most revealing. As will be discussed in the section dealing with environment, a decreased sensitivity under these conditions would have indicated stresscorrosion cracking as the mechanism acting under the conditions originally used. If the mechanism were hydrogen-stress cracking, cracks would not have been expected to cross the ferrite in this material in which hardness measurements indicate that delta ferrite is considerably softer than the martensite. However, in some precipitationhardened stainless steels, the delta ferrite is age hardened markedly, and a ferrite of this nature might not retard either stress-corrosion or hydrogen-stress cracks.

Sufficient ferrite in a matrix of austenitic Type 304 stainless steel, which strengthens the austenite, reportedly stops stress-corrosion cracks initiated in the austenite.

A fine-grained steel has been reported to exhibit greater resistance to stress-corrosion cracking in caustic than does a steel of coarser grain size of the same carbon content. (18)

However, it is not clear whether this is a structural effect or is related to the aluminum probably used to obtain the fine grain size.

Schwier(30) performed stress-corrosioncracking experiments on portions of a given lot of steel which had been subjected to various heat treatments. Specimens were stressed in nitrate solution at up to 82 percent of their ultimate tensile strength. The best resistance to cracking (no cracking in 7000 minutes) was exhibited by drawn material (85,000-psi yield strength) and drawn-plus-stress-relieved material (108,000-psi yield strength); air-patented material (43,000-psi yield strength) was intermediate in resistance; while material in the oil-hardened condition (82,000-psi yield strength) exhibited the least resistance (failed in less than 160 minutes).

In summary, there is limited information on cracking in caustic or nitrate solutions which indicates that structure has an effect on the stresscorrosion phenomenon. Other data, which pertain to sulfide cracking and the cracking of Type 410 stainless steel in hot, pressurized water, belong to a gray area in which the mechanism of cracking is uncertain. On the basis of limited information, 
gross differences in structure (for example, tempered martensite versus tempered bainite) appear to have very little effect on the hydrogenstress cracking of high-strength steels at a given strength level, although variations in structure are known to affect hydrogen entry into, and movement in, steel. Of course, variations in the fine structure, such as those that result from tempering martensite at different temperatures, have an effect on sensitivity to hydrogen-stress cracking, the sensitivity being directly related to the strength level, as was discussed in the section dealing with strength level. It might be expected that changes in the fine structure also would affect the entry and movement of hydrogen through steel. Another possible difference in the two modes of failure is the behavior of austenitic stainless steel which, of course, is not a high-strength steel. These steels are susceptible to stresscorrosion cracking in suitable environments, but, in the bulk form, are highly resistant to hydrogenstress cracking. These effects of structure constitute additional evidence that the two types of failure are indeed separate and distinct phenomena.

\section{Applied and Residual Stresses}

Hydrogen-induced delayed brittle failures may occur over a wide range of applied tensile stress, and for a given specimen configuration, charging conditions, and test procedures, there is a minimum critical value of applied stress below which failure apparently does not occur in a given material. In general, the time for failure is not affected greatly by variations in the applied stress at high levels of stress. However, small variations in stress become significant as the lower critical stress level is approached.

The results of tests of hydrogen-charged material under static load usually are plotted as sustained load versus time to failure. Such a plot for notched steel specimens precharged with hydrogen is shown in Figure 8 . Figure 9 shows a series of such plots for samples of the same steel heat treated to three different strength levels. These data show clearly the significant decrease in ability to support a sustained load as a result of hydrogen in the steel. Applied stresses of as little as 40 percent of the yield strength (for a steel of 270,000-psi ultimate tensile strength) caused failure in only a few hours under sustained load. As is indicated in Figure 9, identical notched specimens in the uncharged condition were stressed at high loads and remained unbroken after times of over 250 hours. For a given strength level, there appeared to be only a slight dependence of failure time on the applied stress. Also, the time to failuite was of the same order of magnitude, regardless of strength level. Since the mobility of hydrogen may be expected to remain approximately independent of the strength level and applied stress, even in this early work it appeared that the time to failure may be associated with the diffusion of hydrogen; subsequent work established that this viewpoint was correct. These figures clearly show the
1

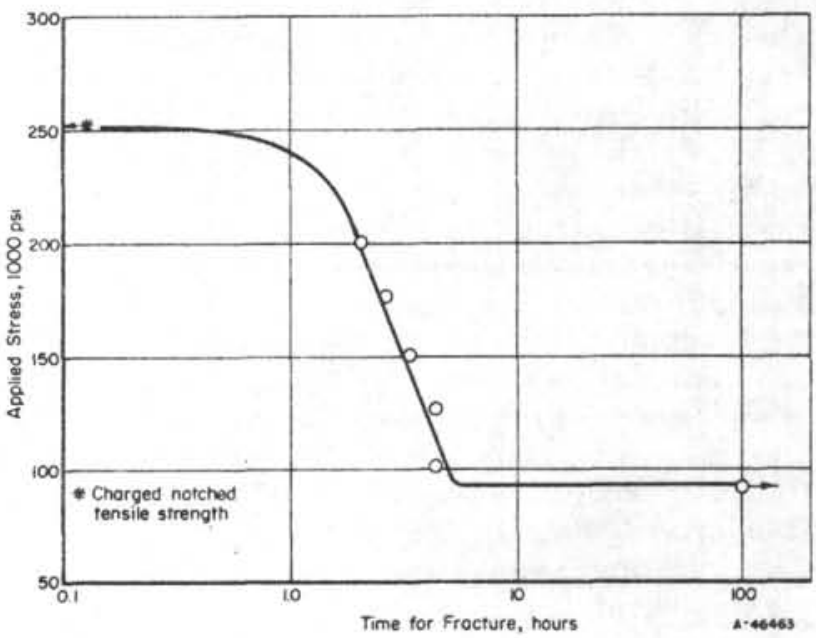

FIGURE 8. DELAYED-FAILURE BEHAVIOR OF SHARP-NOTCH SPECIMENS OF SAE 4340 STEEL AT THE 230,000-PSI STRENGTH LEVEL (31)

Aged 5 minutes. Case Institute of Technology Charging Condition A, as given in Figure 9.

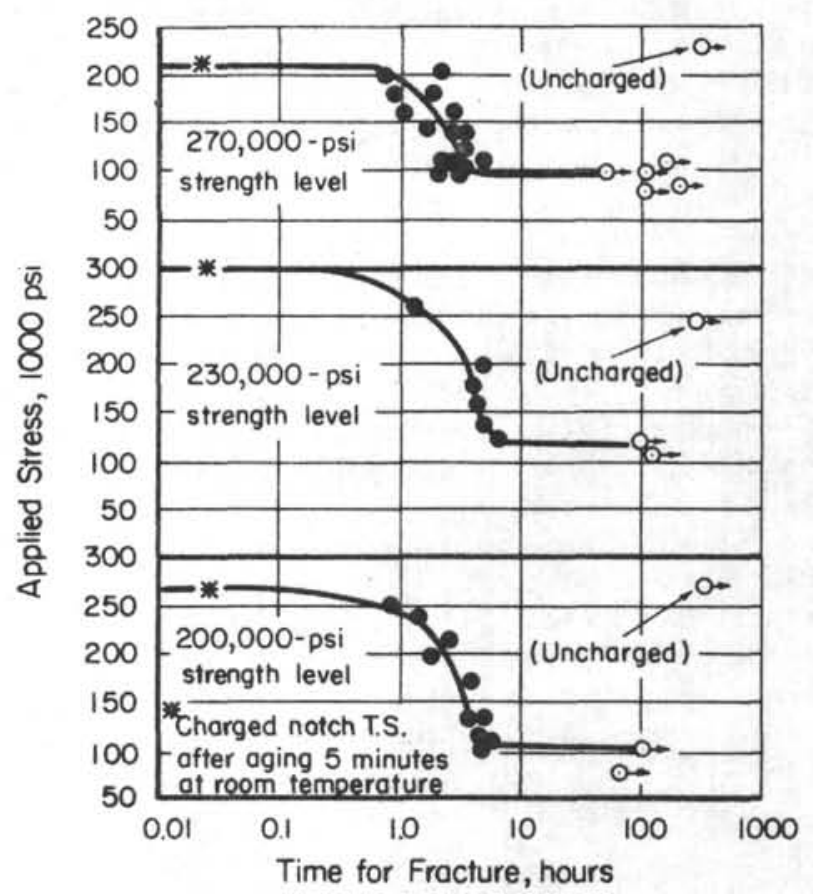

FIGURE 9. DELAYED-FAILURE TESTS ON SAEAISI 4340 STEEL HEAT TREATED TO SEVERAL STRENGTH LEVELS, SHOWING THE EFFECT OF HYDROGEN (32)

Fixed charging conditions, aged 5 minutes, sharp-notch specimens.

Case Institute of Technology Charging Condition A:

Electrolyte: $\quad 4$ percent $\mathrm{H}_{2} \mathrm{SO}_{4}$ in water

Poison: None

Current density: $20 \mathrm{ma} / \mathrm{in}^{2}$

Charging time: 5 minutes

Aging time: Measured from end of charging to start of test. 
occurrence of a minimum critical value of applied stress below which delayed failure did not occur in material of a given strength level. For the specimen geometry, notch acuity, charging conditions, and test conditions used in these experiments, the lower critical stress was nearly the same for the three strength levels. However, this is not always the case for other conditions. This behavior seems to be associated with precharged specimens in which hydrogen is continually being lost from the specimens during the period of static loading. Apparently, after only a few hours (less than 10 ), sufficient hydrogen is lost from the specimens so that delayed failures do not occur. For these precharged specimens, the lower critical stress was raised markedly as the notch acuity was decreased.

The effect of variation in applied stress when smooth (unnotched) specimens were cathodically charged with hydrogen continuously while under static load is illustrated by the data in Figures 1 and 2. Variations in applied stress affected the time to rupture in a similar manner under a wide range of strength levels, compositions, structures and, to a certain extent, hydrogen contents. When other conditions were held constant, there were two ranges of stress which produced different effects on the time to rupture, as is shown in Figure 1. In the higher range of applied stress, the time to rupture was relatively short and was only moderately affected by a change of stress. In the lower range of stress, a slight decrease of stress resulted in a large increase in the time to rupture, sometimes even a hundredfold. In these experiments where the specimens were continuously cathodically charged, delayed failures were obtained over a wide range of applied stresses; failures occurred at stresses as low as 5 percent of the ultimate tensile strength of the uncharged steel. In these and othe $r$ experiments, these same investigators showed that the minimum applied stress necessary to cause failure is related to the hydrogen content of the steel; it decreased as the hydrogen content increased. Both the minimum stress for failure and the time required to produce failure were relatively unaffected by differences in the composition or gross structure of the steel, but both decreased as the nominal tensile strength of the steel was increased.

The effect of applied stress in the sulfide cracking of high-strength steel is similar to that just described for hydrogen-stress cracking. This is shown by the work of Warren and Beckman, (4) for example, in which the sulfide cracking of highstrength AISI 4140 bolting material was studied. They found that, in the absence of plastic deformation, no bolt failures occurred at hardness levels below Rockwell C 27 , not even under stresses approaching the yield strength of the material. In the hardness range of Rockwell C 27 to 55, the cracking susceptibility increased with increases in the hardness (Figure 4) and applied stress (Figure 10). For each hardness, there appeared to be a minimum or threshold stress required to produce cracking. Increasing hardness lowered the minimum stresses for failure (Figure 11), the following data being typical of those obtained:

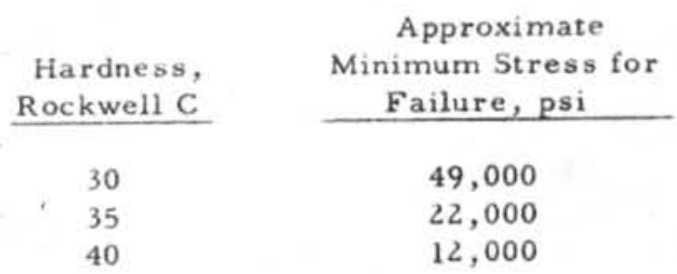

In addition, plastic deformation increased susceptibility to sulfide cracking by lowering the maximum hardness for absence of cracking to Rockwell C 22 . This effect is attributed partly to the residual stresses in cold-worked metal.

McGlasson and Greathouse $e^{(2)}$ also studied the sulfide cracking of heat-treated steels and likewise found that the limiting hardness level below which failures were not obtained depended upon the applied stress. The greater the applied stress, the lower was the critical hardness level. These results are shown in Figure 3.

Schwier ${ }^{(30)}$ studied the stress-corrosion cracking of high-strength steel in nitrate solutions. When he plotted his data as applied stress (as percent of ultisate tensile strength) versus time to failure, a curve resembling that in Figure 8 was obtained. That is, increasing the applied stress increased the sensitivity to cracking by reducing the time to failure. Although relatively few data are available which show the effect of applied stress on nitrate or caustic cracking (stresscorrosion cracking), as a general rule, as the applied stress is increased the sensitivity to stresscorrosion cracking is increased.

In welded or heat-treated parts, particularly those of complex shape, residual stresses can be very high, often approaching the yield strength of the material. In both hydrogen-stress cracking and stress-corrosion cracking, the effective applied stress is the sum of the residual internal stresses and the external applied stress of like sign. Highstrength steels can tolerate but small tensile stresses under conditions which favor stress corrosion or hydrogen entry, and the presence of notches merely makes matters worse. Thus, welding and heat-treating procedures and subsequent stress-relieving treatments that will provide a minimum of residual stresses are a necessary part of many fabricating procedures. Cold-worked metal may be susceptible to stress-corrosion cracking, so suitable annealing operations must follow many steps in fabrication.

Many data are available on the role of applied stress in hydrogen-stress cracking, but, except for a few isolated cases, only a few data related to this effect are available for known cases of stresscorrosion cracking (neglecting the controversial case of sulfide cracking). Those data available indicate that applied stress apparently has the same role in both mechanisms of fracture. 


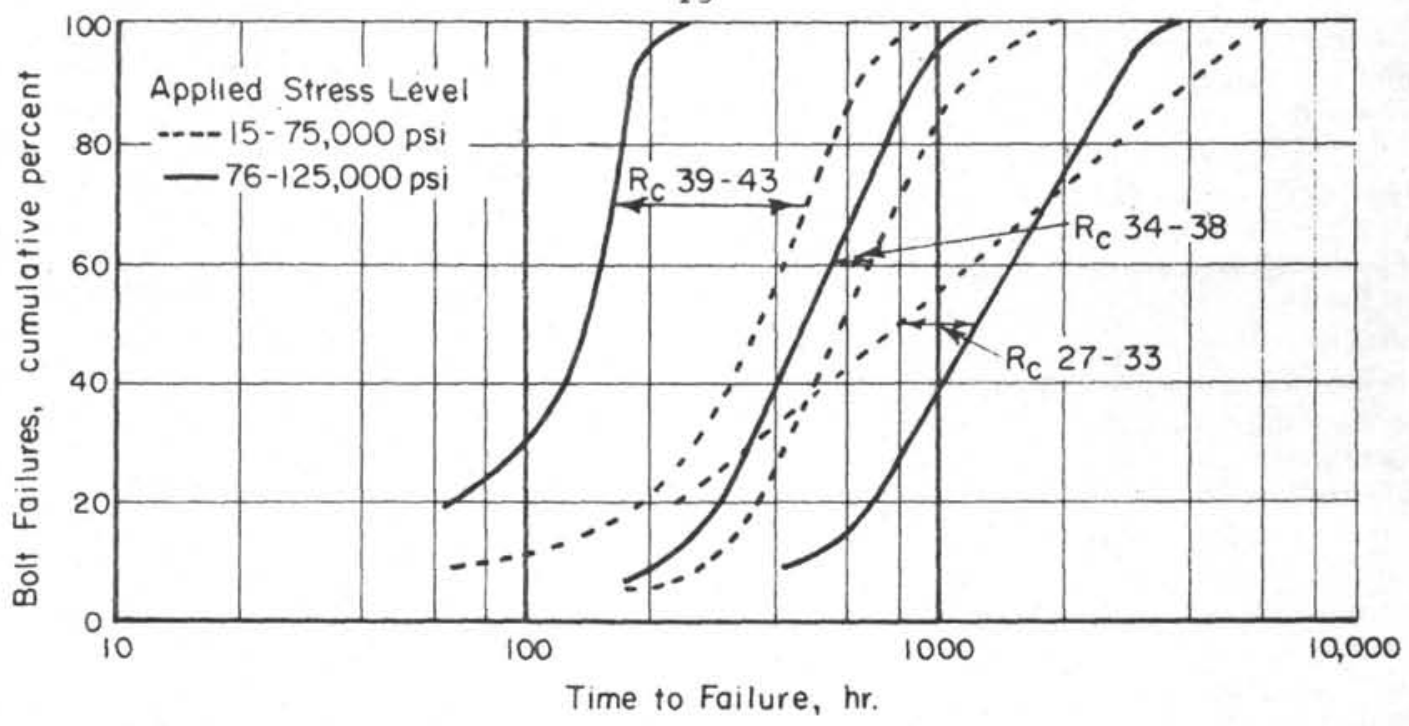

FIGURE 10. EFFECT OF APPLIED STRESS ON TIME TO FAILURE OF AISI 4140 STEEL BOLTS EXPOSED IN AN H 2 S- $\mathrm{H}_{2} \mathrm{O}$ SYSTEM AT $40 \mathrm{C}(104 \mathrm{~F})$ AND $250 \mathrm{PSI}(4)$

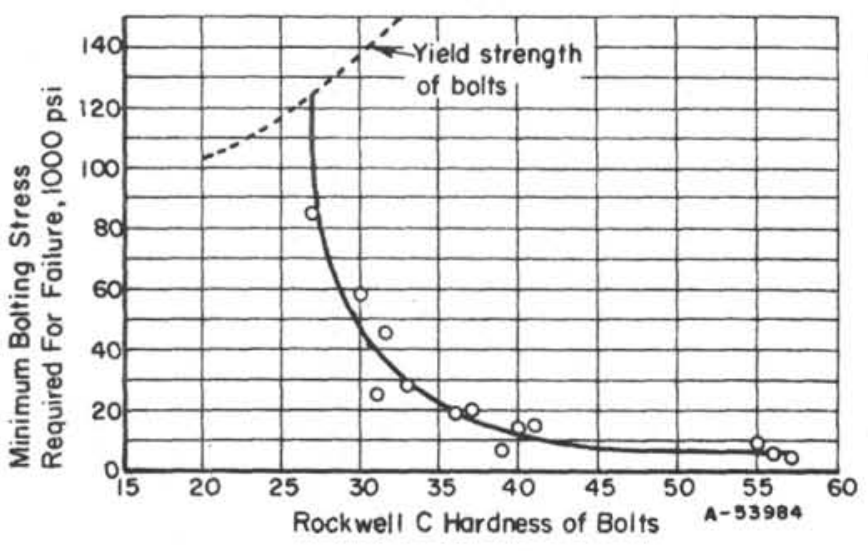

FIGURE 11. MINIMUM APPLIED STRESS REQUIRED TO PRODUCE CRACKING OF AISI 4140 STEEL BOLTS IN AN H2S$\mathrm{H}_{2} \mathrm{O}$ SYSTEM AT $40 \mathrm{C}(104 \mathrm{~F})$ AND $250 \operatorname{PSI}^{(4)}$

\section{Environment}

From the data presented thus far in this report, it should be evident that hydrogen-induced delayed brittle failures occur when a critical combination of stress, hydrogen content, and time is exceeded, provided conditions permit the hydrogen in the steel to move freely, either under a hydrogenconcentration gradient or under a stress gradient.

Many investigators have studied the effects of variations in hydrogen content. Because the problems'in hydrogen analysis are very great as a result of the small amount usually present and the great mobility of hydrogen even at room temperature, many of the investigations have relied upon such criteria as variations in cathodic charging 'time, in current density, in aging time after charging, or in the concentration of an acid pickling solution or time of exposure to acid chemical attack as the basis for evaluating the effects of variations in hydrogen content. Although hydrogen has been introduced into steel under a multitude of conditions, the results of the various investigations nearly all concur in showing that the delayed failures depend directly on the hydrogen content. If the hydrogen can be kept out or can be removed from the steel before the part is subjected to conditions which result in permanent damage, the problem is circumvented. However, this is not readily achieved because of the numerous processing operations that are potential sources of hydrogen and because of the very small amount of hydrogen (reportedly even less than $1 \mathrm{ppm}$ ) that can induce failure.

Hydrogen can be introduced into steel in many ways, including cathodic charging, the action of cathodic protection systems designed to minimize corrosion of metal structures, a wide variety of corrosion reactions, acid pickling, a number of cleaning procedures (including cathodic cleaning), electroplating with a wide variety of metals, exposure to high-pressure hydrogen at room temperature or exposure to atmospheres containing even much smaller partial pressures of hydrogen at elevated temperatures (including welding), exposure to water (corrosion) at room temperature or to moist atmospheres during heat treatment, vapor blasting, glow discharge, hydrocarbon lubricants, and hydrocarbon solvents. Insofar as hydrogenstress-cracking behavior is concerned, the nature of the environment seems to be relatively unimportant so long as a certain amount of hydrogen enters the steel. The minimum stress for failure is relatively unaffected by variations in environment, but the time to failure may vary greatly as it reflects variations in entry rate of the hydrogen.

Only nascent, or atomic, hydrogen can enter the steel lattice and diffuse through it; ordinary molecular hydrogen is not soluble in steel. When 
atomic hydrogen is generated at a steel surface, a portion of it may enter the steel while the remainder combines into the molecular form and passes harmlessly off insofar as the problem of hydrogenstress cracking is concerned. However, various substances affect the rate at which this recombination reaction takes place. Certain substances with high hydrogen overvoltages, known as cathodic poisons, slow down the recombination reaction, thereby giving the hydrogen atoms a greater lifetime and enhancing their chances of entering the steel. Phosphorus, arsenic, antimony, sulfur, selenium, tellurium, and apparently the cyanide $\left(\mathrm{CN}^{-}\right)$ion are among the cathodic poisons which promote the entry of hydrogen into iron or steel during pickling or cathodic charging. Hydrogen sulfide is a potent cathodic poison. Other compounds, viz., corrosion inhibitors of the type which become strongly chemisorbed on the surface of the polarized cathode at suitable potential values, act to greatly reduce penetration of hydrogen into an iron or steel cathode. The proper use of such inhibitors can reduce the pickup of hydrogen during acid pickling.

The condition of the steel surface, including such factors as surface roughness, the presence of a layer of cold-worked metal, and the presence of oxide films, also influences the entry of hydrogen into steel.

These environmental factors are important in that a greater or lesser amount of atomic hydrogen is presented to the steel. The condition of the surface, as well as the presence of cathodic poisons or inhibitors, affects entry rate. However, once a certain amount of hydrogen has been introduced into a susceptible steel which is at a sustained stress above the lower critical value, the hydrogenstress-cracking mechanism can become operative. It makes little difference just how the hydrogen was introduced into the steel.

If the entry surface and exit surface are in sufficiently close proximity, the hydrogen concentration may never build up to a level high enough to be troublesome. For example, such a condition might exist with sheet material or thin tubing on which atomic hydrogen is generated on one surface, depending on the strength level and sensitivity of the material and on the stress to which it is subjected.

Environmental conditions also have a great effect on the rate at which hydrogen leaves a steel part at surfaces which are not entry surfaces. An increase in temperature is very effective in accelerating the removal of hydrogen. Thus, baking at $400 \mathrm{~F}$ removes hydrogen some 250 to 500 times faster than aging at room temperature. However, aging in hot water is considerably more effective than aging in dry air at the same temperature, and other atmospheres also influence the rate of hydrogen removal. Oxide coatings or electroplated metal coatings on the steel surface tend to act as a barrier to the removal of hydrogen. A dense cadmium electroplate, frequently used for corrosion protection of high-strength steel parts, is virtually impervious to the passage of hydrogen. Thus, hydrogen introduced into steel by a prior heattreating, pickling, or cleaning operation tends to be trapped in the part by the cadmium electroplate. With a dense cadmium electroplate, baking apparently serves merely to redistribute the hydrogen within the part but not to remove it. With porous electroplates, baking may serve to remove much of the trapped hydrogen, but the protective value of the plate against corrosion may be inferior to that of a dense plate. Also, because cadmium is a sacrificial coating and, therefore, is anodic with respect to the steel, hydrogen can be generated cathodically at breaks in the coating where the steel is exposed.

The role played by corrosion appears to be essential to the stress-corrosion-cracking mechanism. When the proper conditions of stressinduced electrochemical corrosion are met in a susceptible material, it is generally agreed that metal goes into solution at the tip of the advancing crack, which is, therefore, an anode. Simultaneously, electrons are given off into the metal through which they flow to a localized region of the metal surface also in contact with the electrolyte. At this second area, the electrons participate in a reduction reaction; hence, the area is a cathode. The cathode reaction may be the reduction of positively charged hydrogen ions to atoms, which may in turn react with dissolved oxygen to form water, may recombine into molecular hydrogen and bubble off as hydrogen gas, or may dissolve in the metal. The last-mentioned possibility may give rise to simultaneous hydrogen-stress cracking in highstrength steels. However, some cathode reactions do not involve the reduction of hydrogen ions, and atomic hydrogen is not liberated at the se local cathodes. The thermodynamics of the reactions of iron indicate that hydrogen is liberated in acid solutions (below about $\mathrm{pH}=4$ ) and in highly alkaline solutions (above about $\mathrm{pH}=10$ ). In nitrate solutions, nitrites usually form at the cathode, and in weakly alkaline solutions, peroxides generally are formed. Although stress-corrosion cracking occurs at a local anode, the cathodic reaction must be maintained by removal of the corrosion products, for if the cathode reaction stops (cathode becomes polarized), the anode reaction likewise stops. The cathode area may be outside the crack or deep within it.

The propagation of the stress-corrosion crack depends at least partly upon the flow of current between the anodic and cathodic areas and, thus, is electrochemical in nature, as was mentioned above. If the electrochemical potential of the cathodic areas were adjusted to match the potential of the anodic areas, there no longer would be a driving force for the electrochemical reaction, no current would flow, and crack propagation would be expected to stop. Such an adjustment of the potential can be made by impressing small direct 
currents from an external source, and the procedure is called cathodic protection. This arrangement has been demonstrated to be effective in stopping or at least retarding cracking in several stress-corrosion systems. $(6,33)$

Brown $(34,6)$ and Bhatt and Phelps ${ }^{(35)}$ have proposed a procedure to be used in attempting to distinguish stress-corrosion cracking from hydrogen-stress cracking. It is based on the assumptions that (1) the term "stress-corrosion cracking" will be applied to the cracking that involves corrosion which occurs at anodic areas at the advancing tip of the crack, (2) electric currents flow between local anodes and local cathodes to effect this corrosion, and (3) impressing small cathodic currents from an auxiliary electrode should tend to polarize the local cathode areas in the direction of the potential of the anodes and thereby should tend to mitigate the corrosion and the attendant cracking. Figure 12 shows the effect of small currents (note that these are of the order of $\mathrm{microamperes}$ per square centimeter) on the

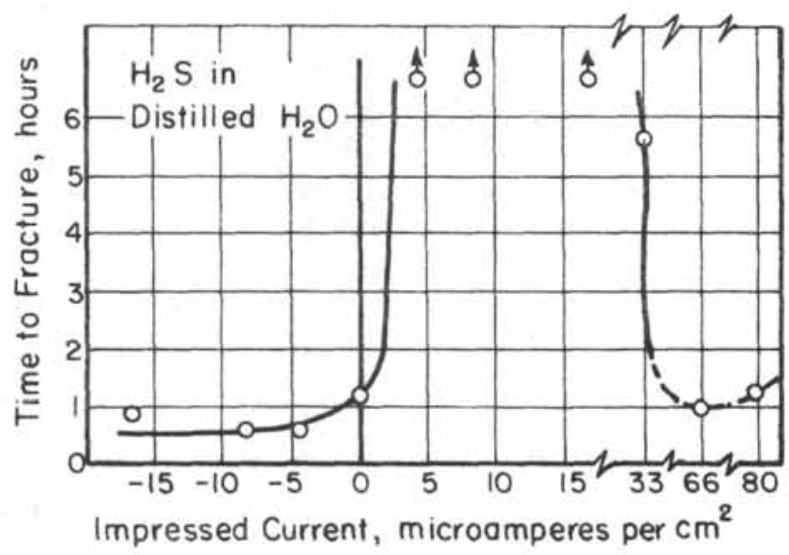

FIGURE 12. EFFECT OF IMPRESSED CURRENTS ON TIME TO FRACTURE OF A MARTENSITIC STEEL IN HYDROGEN SULFIDE SOLUTION(6)

A positive current in Figures 12, 13, and 14 indicates that the specimen is being made cathodic; a negative current indicates anodic.

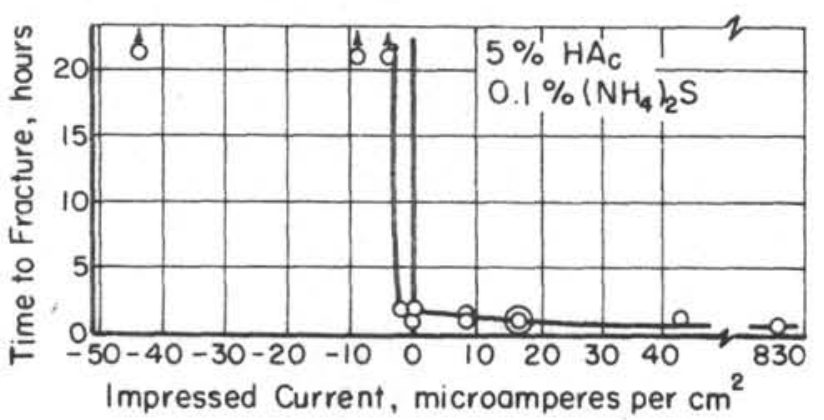

FIGURE 13. EFFECT OF IMPRESSED CURRENTS ON TIME TO FRACTURE OF A MARTENSITIC STEEL IN ACETIC ACID WITH SULFIDE POISON(6)
15

time to fracture of Type 410 stainless steel in a hydrogen sulfide solution. The fact that a low level of impressed cathodic current very greatly extended the breaking time was assumed to indicate that a corrosion reaction was stifled and the cracking process in this environment in the absence of impressed current is properly classified as stresscorrosion cracking. Note that at high current densities, the specimens also fractured after a short time; this was assumed to be hydrogenstress cracking from the hydrogen that was evolved cathodically.

Figure 13 shows the results of a similar study performed in a different medium. Here, imposing even a small cathodic current (evolution of hydrogen) decreased the breaking time, whereas the imposition of anodic currents (oxidizing conditions and reduction of hydrogen) greatly extended the life of the specimens. This behavior was believed to indicate that, in the case of no impressed current (that is, the "natural" cracking case), the failure occurs by the hydrogen-stress-cracking mechanism.

The results of a similar study performed with a solution of $\mathrm{NaCl}$ that contained acetic acid and hydrogen sulfide, a particularly agressive cracking medium, are shown in Figure 14. In this situation, impressing either anodic or cathodic currents on the specimen had no effect on the breaking time. Brown suggested that one possible explanation for this behavior is that both stress-corrosion cracking and hydrogen-stress cracking can occur in overlapping ranges of current density.

Brown (6) cautioned that these electrochemical analyses must be viewed as highly simplified and preliminary. However, he reported that they were consistent with two subsequent observations:

(1) conditions presumed by this analysis to induce stress-corrosion cracking caused the measured potential to behave during cracking as if the cracking were occurring along an active path, and (2) conditions presumed to induce hydrogen-stress cracking caused hydrogen to permeate a thin iron membrane.

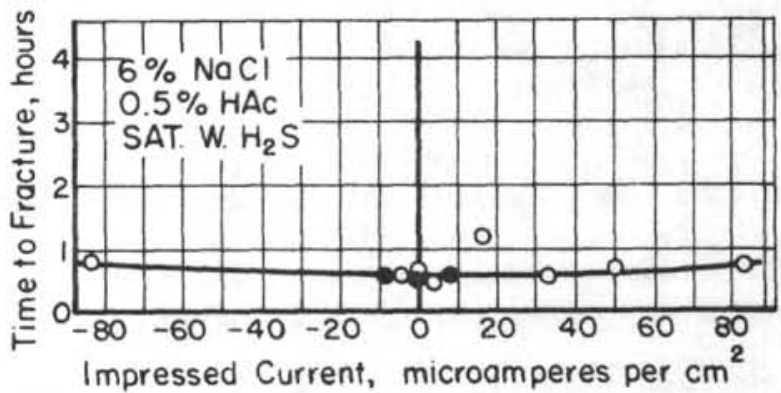

FIGURE 14. EFFECT OF IMPRESSED CURRENTS ON TIME TO FRACTURE OF A MARTENSITIC STEEL IN MIXTURE OF $\mathrm{NaCl}$, ACETIC ACID, AND SULFIDE ${ }^{(6)}$ 
Scharfstein and Eisenbrown have detected differences in the potential-time curves obtained during stress-corrosion cracking and hydrogenstress cracking. (36) Typical potential-time curves for stress-corrosion cracking were described as follows:

(1) There was a gradual rise in potential in the noble direction immediately after the specimen was exposed to the cracking medium.

(2) After a limiting potential was reached, there were rapid drops in potential to a more active value, followed by a rapid return to the normal value.

(3) When the specimen fractured, there was a very rapid drop to a more active potential.

Upon exposing a 12 percent chromium martensitic stainless steel to $1 \% \mathrm{HCl}-1 \% \mathrm{SeO}_{2}$ (a demonstrated promoter of hydrogen-stress cracking), the following potential values were obtained:

(1) There was a gradual drop to a more active potential during the first 30 minutes.

After the lowest potential was reached, there were rapid rises in potential followed by a rapid return to normal.

When the specimen failed, there was a sudden rise to a more noble potential.

When the 12 percent chromium steel was exposed to $5 \% \mathrm{H}_{2} \mathrm{SO}_{4}-0.1 \%\left(\mathrm{NH}_{4}\right)_{2} \mathrm{~S}$ (promotes hydrogen-stress cracking), the potential dropped to a more active value and remained there until cracking occurred. Thus, the potential-time curves were exactly opposite for stress-corrosion cracking and hydrogen-stress cracking. The difference in the shape of the potential curves for the two hydrogen-cracking media was attributed to reduction of selenious acid and deposition of selenium metal in the $\mathrm{HCl}$ solution. This produced a steady potential until fracture occurred. Fresh metal was then exposed, and the potential rose. In the sulfuric acid solution, only hydrogen was reduced and there was no competing process, thus accounting for the lowering of the potential to a steady value.

In general, stress-corrosion cracking requires a highly anodic area and localized low $\mathrm{pH}$ to get started. Examples of such sites are cracks in an oxide film, pits, crevices, and cold-worked material, the latter being highly anodic.

Some have raised the question of whether in stress-corrosion cracking there is an actual loss of metal or the material is merely being charged with hydrogen. In many environments very little corrosion takes place, and frequently it cannot be detected with the naked eye. However, in other instances, loss of metal and corrosion products have been observed. With the electron microscope, Swann, Nielsen, and others have detected corrosion tunnels, often nucleated in rows on the surface of an alloy. Oxide has been detected in the stresscorrosion cracks formed in austenitic stainless steel in certain environments. However, stresscorrosion cracking in $\mathrm{MgCl}_{2}$ does not appear to be associated with a solid corrosion product. $\mathrm{NaCl}$ is an aggressive corrodent; although it enters into the corrosion reaction, it is not found in the corrosion product. Its action is to hinder formation or repair of protective surface films.

Although a highly corrosive environment will not produce stress-corrosion cracking of highstrength steel, some such environments do result in hydrogen-stress cracking, for example in the acid pickling of steel.

Anhydrous agricultural ammonia will crack steel tanks at room temperature, but when a certain amount of water is added, the cracking is eliminated. Since the reaction might involve dissociated hydrogen, this may be hydrogen-stress cracking rather than stress-corrosion cracking. This type of cracking has been observed in steel plate with yield strengths of 37,000, 51,000, 48,000 , and 57,000 psi, for example, all values which would appear to be too low for hydrogenstress cracking. However, the cracking has occurred mostly near welds, and the strength of weld heat-affected zones frequently is considerably higher than that of the parent metal. The cracking has been reported to be intergranular in the heataffected zone but transgranular in the parent metal. In unwelded steel, such cracking resulting from exposure to agricultural ammonia has been observed in T-1 steel (116,000-psi yield strength). This steel is also susceptible to hydrogen-stress cracking when cathodically charged with hydrogen. The addition of 0.25 percent water eliminates the cracking in the ammonia environment. This may be related to a critical moisture content which forms a protective barrier film, since in other instances an excess of water aids in introducing hydrogen into high-strength steel. The presence of air increases the cracking rate resulting from exposure to ammonia; this is believed to be the result of $\mathrm{CO}_{2}$ present in the air.

Several instances of cyanide cracking have been reported; these failures are not well documented but structural steel was reported to be involved. Concentrations of only 2.6 to $3.5 \mathrm{~g}$ $\mathrm{HCN} /$ liter have caused cracking.

Stress-corrosion cracking has been observed in various nitrate solutions, including boiling mixtures of calcium and ammonium nitrates, 60 to 95 percent ammonium nitrate, concentrated nitric acid at $20 \mathrm{C}(68 \mathrm{~F})$, and dilute nitric acid that contained small amounts of $\mathrm{MnCl}_{2}$ used at 60 to $80 \mathrm{C}(140$ to $175 \mathrm{~F})$. 
The caustic cracking of steel is well known. Concentrations range from the small amounts used in boiler feedwater to at least 50 percent $\mathrm{NaOH}$ used in chemical-processing operations. Numerous failures have occurred in boilers at elevated temperatures and in storage tanks, usually at elevated temperatures but also at ambient temperatures. Agents added to boilers to inhibit cracking include tobacco juice, tannin, nitrates, sulfates, phosphates, waste sulfite liquor, lignin, bark extract, and quebracho extract. Cracking can be accelerated by the addition of silicates, $\mathrm{PbO}$, $\mathrm{MnO}_{4}$, or $\mathrm{Na}_{2} \mathrm{CrO}_{4}$.

It is believed that the stress-corrosion cracking of austenitic stainless steels generally is related to chlorides or caustic. However, stress-corrosion cracking of high-strength martensitic steels can result from exposure to any of a large number of different types of environments, even including humid argon. Some very mild media have resulted in stress-corrosion cracking of specimens with coatings generally considered to be good barriers against corrosive attack. Water free from chloride ions will crack Type 410 martensitic stainless steel or 17-4PH stainless steel, but not low-strength steels. However, this may be a case of hydrogen-stress cracking. It is not necessary for the corrodent to be a bulk aqueous solution; it may be a thin adsorbed layer of an aqueous solution.

Cracking is produced in aqueous solutions containing $15.2 \mathrm{ppm}$ of hydrogen sulfide and even less. (2) The term sulfide-corrosion cracking has been used by many to describe the cracking of steel in sulfide environments. There has been no complete agreement among investigators whether it is a stress-induced electrochemical phenomenon with loss of metal occurring at the tip of the advancing crack and, hence, stress-corrosion cracking, or whether it is a hydrogen-stress-cracking mechanism that is operative. Many are inclined to the latter viewpoint. However, some of the data of Brown discussed above suggest that both mechandsms may be operative simultaneously in at least some instances of sulfide cracking.

The temperature of the environment is important in both hydrogen-stress cracking and stress-corrosion cracking. The maximum susceptibility to hydrogen-stress cracking occurs at about room temperature. The decreased susceptibility at lower temperatures results from the decrease in the hydrogen-diffusion rate with decreasing temperature. Since hydrogen does not diffuse so rapidly to the region of triaxial stress just in advance of the tip of the crack, the required hydrogen concentration cannot be built up so rapidly and crack propagation is slowed or stops altogether at sufficiently low temperatures (such as the temperature of liquid nitrogen). Troiano and coworkers at Case Institute of Technology (37) have suggested that the disappearance of hydrogen embrittlement and hydrogen-stress cracking at somewhat elevated temperatures ( 300 or $400 \mathrm{~F}$ ) also may be related to stress-induced hydrogen diffusion. Because the driving force tending to concentrate hydrogen in the region of maximum triaxiality is stress induced, the driving force presumably is independent of temperature. However, the force tending to homogenize the solid solution presumably increases with temperature. Thus, at elevated temperatures, the required hydrogen gradient cannot be created and embrittlement and cracking tendencies should decrease, just as has been observed.

Susceptibility to stress-corrosion cracking increases as the temperature increases, and particularly as the temperature is raised above the normal boiling point of aqueous solutions. However, this behavior is not observed with hydrogen sulfide solutions; for these, the susceptibility is greatest near room temperature, just as for hydrogen-stress cracking.

If notched specimens of high-strength steels are broken over a range of temperatures, they exhibit a transition from brittleness at lower temperatures to toughness at higher temperatures. Because of this transition-temperature effect, the length of crack required to set off catastrophic brittle fracture is increased as the test temperature is increased in the transition range (which for many high-strength steels and a number of specimen geometries is in the general region of room temperature). Thus, if one attempts to measure a temperature coefficient of either hydrogen-stress cracking or stress-corrosion cracking by observing merely the effect of temperature on time to failure, he may be observing the combined effects of change in temperature on true stress-corrosioncracking and hydrogen-stress-cracking rates and on purely mechanical fracture.

In gaseous atmospheres, the entry rate of hydrogen into steel increases as the partial pressure of dissociated hydrogen atoms in the atmosphere increases. Few data are available regarding a pressure effect in stress-corrosion cracking, but this phenomenon generally involves an aqueous environment or molten salts.

To summarize the effects of environment, it has been shown that both stress-corrosion cracking and hydrogen-stress cracking can occur under a great variety of environmental conditions. However, it appears that certain environments favor only one type of cracking or the other. This observation, the observed difference in behavior of the two types of cracking under impressed electrical currents, and the different behavior observed for variations in temperature suggest that hydrogen-stress cracking and stress-corrosion cracking actually are different fracture mechanisms. However, there is an area that includes sulfide cracking and cracking in water where the distinction is not clearcut. It may be that both types of cracking are operative in these systems, possibly sometimes simultaneously. 


\section{Time}

It is obvious from previous discussions that time is a factor in both mechanisms of cracking. Many factors related to the environment, such as composition, concentration, and temperature, can affect the rate at which atomic hydrogen is liberated at the steel surface or the aggressiveness of the corrosion reaction, and other factors (such as steel composition, the presence of cathodic poisons, and the nature of the steel surface) affect the rate at which hydrogen enters the bulk'steel. These various factors, of course, influence the time required to nucleate a crack. Apart from the matter of getting hydrogen into the steel, the hydrogenstress-cracking mechanism itself is diffusion controlled. Hydrogen must diffuse to the region of maximum triaxial stress a short distance in advance of the crack tip before the crack can propagate another incremental distance. As the crack propagates, the region of triaxial stress also moves, so, in most instances, hydrogen must move if crack propagation is to continue. The hydrogen and the crack thus move in stepwise fashion until the crack has grown to the point where the remaining section can no longer support the load, and terminal catastrophic failure ensues. Stress-corrosion cracking proceeds by the timedependent corrosion at the tip of the crack which makes possible a cohesive separation at low stress, and this proceeds until the section suddenly fails mechanically from overstress.

If, under the same charging conditions, two steels differ in hydrogen entry rate, the steel with the lower entry rate requires a longer time to build up the necessary amount of hydrogen in a critical area where a crack can nucleate. If the same amount of hydrogen is required to crack the two steels, then that one with the low entry rate would take longer to crack and would be considered to be less susceptible to hydrogen-stress cracking. There is considerable evidence to support differences of this type among various steels. Among high-strength steels, the re is little evidence to date to indicate great differences in the ability of steels to tolerate different amounts of hydrogen.

If, under given test conditions, one steel is less notch sensitive than another, it may require a longer time to fracture by either stress-corrosion cracking or hydrogen-stress cracking. This results not because of a lower rate of stress corrosion or of hydrogen entry but because a longer crack must be produced before it is of a critical size to result in the terminal catastrophic fracture which is purely mechanical in nature. High-strength steels usually are more notch sensitive than are those of lower strength, so it is not necessary for a crack to grow to as great a length in the former before catastrophic terminal failure. This automatically gives shorter failure times as the strength level is increased. Also, for purely geometric reasons, a thick steel specimen is more susceptible to brittle fracture than is a thin one. This applies not only to fractures of mechanical origin but to hydrogen-stress cracking and stress- corrosion cracking as well. Thus, a stresscorrosion crack or a hydrogen-stress crack may not have to be nearly so extensive in a thick specimen as in a thin one to set off catastrophic brittle failure.

In the laboratory where it was known that cracking conditions prevailed continuously, the longest delay known to the authors of this report was 355 days. This was the time to visible stresscorrosion cracking of an $18 \mathrm{Ni}$ maraging steel (303,000-psi yield strength) exposed to natural seawater. (38) Under these same conditions, AISI 4340 steel (240,000-psi yield strength) cracked in 6 days. In the authors' laboratory, a sample of carbon-manganese steel heat treated to a yield strength of 156,000 psi (169,000-psi ultimate tensile strength) failed after 1147 hours under mild cathodic charging conditions; this is the longest delay before failure by hydrogen-stress cracking of which the present authors are aware.

Both fracture mechanisms are time dependent, and the time variable does not appear to provide a means of distinguishing between them.

\section{Fracture Characteristics}

Fractures produced by either stresscorrosion or hydrogen-stress cracking in highstrength steels are characterized by almost complete lack of visual evidence of plastic deformation. There is considerable evidence to indicate that both types of cracks tend to grow in a direction normal to the maximum tensile stress. Furthermore, both types of cracks are predominantly intergranular in character in high-strength steels, although some transgranular cracks also are observed.

In general, hydrogen-stress cracking produces a few nonbranching cracks. Stresscorrosion cracking usually produces several secondary cracks, in addition to the major crack; both the major crack and the secondary cracks often are branching.

In general, the fracture surfaces appear quite similar in the two mechanisms of fracture. However, certain subtle differences have been observed which some investigators have attributed to the different cracking processes. For example, Tiner et al (39) working with AISI 4340 steel in aerated 3 percent $\mathrm{NaCl}$ solution have separated the fracture into three stages: incubation, stable crack-growth period, and final rupture. During the incubation stage, cracks were fan shaped and intergranular, and they extended to a depth of several mils. In the stable-crack region (greater than 5 to 6 mils below the surface), the crack path in relationship to the prior austenite grains was found to be both intergranular and transgranular. The intergranular portion was related to a stress-corrosion-cracking mechanism, while the transgranular path was attributed to hydrogenstress cracking. These fracture areas were identified in electron-microscope fractographs. The final stage was tensile rupture of the material. 
(1) Slaughter, E. R., Fletcher, E. E., Elsea, A. R., and Manning, G. K., "An Investigation of the Effects of Hydrogen on the Brittle Failure of High-Strength Steels", Report No. WADC TR 56-83, Battelle Memorial Institute, Columbus, Ohio, for Materials Laboratory, Wright-Patterson Air Force Base, Ohio (June, 1955).

(2) McGlasson, R. L. , and Greathouse, W. D. , "Stress Corrosion Cracking of Oil Country Tubular Goods", Corrosion, 15 (8), 437t442t (August, 1959).

(3) Baldy, M. F., and Bowden, R. C. , Jr., "The Effect of Martensite on Sulfide Stress Corrosion Cracking", Corrosion, 11 (10), $417 \mathrm{t}-422 \mathrm{t}$ (October, 1955).

(4) Warren, D., and Beckman, G. W., "Sulfide Corrosion Cracking of High Strength Bolting Material", Corrosion, 13 (10), 631t-646t (October, 1957).

(5) Suss, H., "Practicality of Establishing Threshold Values to Eliminate Stress Corrosion Failures in Metals and Alloys", Corrosion, 17 (2), 61t-66t (February, 1961).

(6) Brown, B. F., "Stress-Corrosion Cracking and Related Phenomena in High Strength Steels, A Review of the Problem, With an Annotated Bibliography", Report NRL 6041, U. S. Naval Research Laboratory, Washington, D. C. (November 6, 1963).

(7) Fraser, J. P., and Eldredge, G. G., "Influence of Metallurgical Variables on Resistance of Steels to Sulfide Corrosion Cracking", Corrosion, 14 (11), 524t-530t (November, 1958).

(8) Cauchois, L., Didier, J., and Herzog, E., "A Special N-80 Steel Tubing Developed in France to Resist Sulfide Stress Corrosion in Sour Gas Wells", Corrosion, 13 (4), 263t269t (April, 1957).

(9) Degarmo, E. P., and Cornet, I., "Effect of Preheating on Stress Corrosion Cracking of Steel Weldments", Welding Journal Supplement, 34, pp 472s-475s (1955).

(10) Parkins, R. N., "The Stress-Corrosion Cracking of Mild Steel in Nitrate Solutions", J. Iron Steel Inst., 172, pp 149-161 (1952).

(11) Uhlig, H. H. , and Sava, J., "Effect of Heat Treatment on Stress-Corrosion Cracking of Iron and Mild Steel", ASM Trans. Quarterly, 56, pp 361-376 (1963).
(12) Nehl, F., and Werner, W., "LaugenbestHndigkeit von Flussstahl in Abhüngigkeit von Alterungsneigung, WHrmebehandlung und Aluminiumgehalt" (Dependence of Resistance to Liquors [Nitrates] of Ingot Steel on Aging Tendency, Heat Treatment, and Aluminum Content), Stahl u. Eisen, 59, pp 1155-1157 (1939).

(13) Athavale, G., and Eilender, W. , Korr. u. Metallschutz, 16, p 127 (1940).

(14) Waber, J. T., McDonald, H. J. , and Longtin, B. , "Theory of Stress Corrosion Cracking of Mild Steel in Nitrate Solutions", Trans. Electrochem. Soc., 87, pp 209-230 (1945).

(15) Parkins, R. N., "Stress Corrosion Cracking of Mild Steel", Stress Corrosion Cracking and Embrittlement (W. D. Robertson, Editor), John Wiley \& Sons, Inc., New York, pp 140-157 (1956).

(16) Uhlig, H. H., "The Stress-Corrosion Cracking of Iron and Some Ferrous Alloys", Metals Handbook, 1948 Ed., Amer. Soc. for Metals, Metals Park, Ohio, pp 233234 (1948).

(17) Jones, D. D. , "Caustic Cracking - Its Occurrence in Steam Boilers", Corrosion Tech., 4, pp 56-59 (February, 1957).

(18) Weir, C. D., "Caustic Cracking: StressCorrosion Tests in Sodium Hydroxide at Elevated Temperatures", Institution Mech. Engrs. (London), Proc. War Emergency Issues, 163, pp 18-26 (1950).

(19) Fontana, M. G., "Stress Corrosion Cracking in Type 403 Stainless Steel", Report No. WADC TR 56-242, The Ohio State University, Columbus, Ohio, for Wright-Patterson Air Force Base, Ohio (August, 1956).

(20) Cotton, W. L., "Hydrogen Embrittlement of High-Strength Steels During Cadmium, Chromium, and Electroless Nickel Plating", Plating, 47, pp 169-175 (February, 1960).

(21) Chang, P. L., and Bennett, W. D. G., "Diffusion of Hydrogen in Iron and Iron Alloys at Elevated Temperatures", J. Iron Steel Inst., 170, pp 205-213 (1952).

(22) Hobson, J. D., "The Diffusion of Hydrogen in Steel at Temperatures of $-78^{\circ}$ to $200^{\circ} \mathrm{C} "$, J. Iron Steel Inst., 189, pp 315-321 (1958). 
(23) Geller, W., and Sun, T., "Einfluss von Legierungszusłtzen auf die Wasserstoffdiffusion im Eisen und Beitrag zum System Eisen-Wasserstoff" (Influence of Alloy Additions on Hydrogen Diffusion in Iron and Contribution to the System Iron-Hydrogen), Arch. Eisenhuttenw., 21, pp 423-430 (1950).

(24) Bhat, U. V., and Lloyd, H. K., "Effect of Cold-Work on Hydrogen in Steel", (Section VI of a series of papers by various authors describing investigations of the effect of cold work on steel), J. Iron Steel Inst., 165, pp 382-389 (1950).

(25) Swann, P. R., "Stress Corrosion Failure", Scientific American, 214 (2), 72-81 (February, 1966).

(26) Gray, H. R. , and Troiano, A. R. , "How Hydrogen Affects Maraging Steel", Metal Progress, 85 (4), 75-78 (April, 1964).

(27) Groeneveld, T. P. , Fletcher, E. E., and Elsea, A. R., "A Study of Hydrogen Embrittlement of Various Alloys", Summary Report, Battelle Memorial Institute, Columbus Laboratories, Columbus, Ohio, for NASA/ George C. Marshall Space Flight Center under NASA contract NAS 8-20029 (June 23, 1966).

(28) Matsushima, I. , Deegan, D. , and Uhlig, H. H., "Stress Corrosion and Hydrogen Cracking of 17-7 Stainless Steel", Corrosion, 22 (1), 23-27 (January, 1966).

(29) Herzog, E., "Developing Steels to Resist Hydrogen Sulfide", Ind. Engr. Chem., 53 (9), 64A-67A (September, 1961).

(30) Schwier, F., "Stress Corrosion and Relaxation of High Carbon Steel for Prestressed Concrete", Wire and Wire Prod., 30 (12), 1473-1474, 1514-1521 (1955).

(31) Barnett, W. J., and Troiano, A. R., "Crack Propagation in the Hydrogen-Induced Brittle Fracture of Steel", Report No. WADC TN 55-405, Case Institute of Technology, Cleveland, Ohio, for Wright-Patterson Air Force Base, Ohio (August, 1955).
(32) Frohmberg, R. P., Barnett, W. J., and Troiano, A. R., "Delayed Failure and Hydrogen Embrittlement in Steel", Trans. ASM, 47, pp 892-923 (1955).

Brennert, S., "Stress Corrosion in Stainless Steels. Effect of Potential Difference Between Liquid and Metal", Jernkontorets Annaler, 144, pp 560-566 (1960).

Bhatt, H. J., and Phelps, E. H., "Effect of Solution $\mathrm{pH}$ on the Mechanism of Stress Corrosion Cracking of a Martensitic Stainless Steel", Corrosion, 17 (9), 430t-434t (September, 1961).

(36) Scharfstein, L. R., and Eisenbrown, C. M., "Potential-Time Curves Obtained During the Stress Cracking of Metals", Nature, 188 , pp 572-573 (November 12, 1960).

(37) Morlet, J. G., Johnson, H. H., and Troiano, A. R., "A New Concept of Hydrogen Embrittlement in Steel", Report No. WADC TR 57-190, Case Institute of Technology, Cleveland, Ohio, for Wright-Patterson Air Force Base, Ohio (March, 1957).

Dean, S. W., and Copson, H. R., "Stress Corrosion Behavior of Maraging Nickel Steels in Natural Environments", Corrosion, 21 (3), 95-103 (March, 1965).

Tiner, N. A., Gilpin, C. B. , and Toy, S. M. , "A Microstructural Study of Stress Corrosion Cracking in Martensitic 4340 Steel", Astropower Laboratory, Advance Systems and Technology, Missile and Space Systems Division, Douglas Aircraft Company, Inc. , Douglas Paper 3381 , presented at the conference of the RIAS on the EnvironmentalSensitive Mechanical Behavior of Metals, Baltimore, Maryland, June 7-8, 1965. 


\section{DEFENSE METALS INFORMA TION CENTER \\ Battelle Memorial Institute \\ Columbus, Ohio 43201}

Copies of the technical reports listed below may be obtained, while the supply lasts, from DMIC at no cost by Government agencies, and by Government contractors, subcontractors, and their suppliers. Qualified requestors may also order copies of these reports from the Defense Documentation Center (DDC), Cameron Station, Building 5, 5010 Duke Street, Alexandria, Virginia 22314 . A complete listing of previously issued DMIC reports may be obtained by writing DMIC.

DMIC

Number
Title

Thin-Sheet Rolling, Report of an Informal Symposium of the Metalworking Processes and Equipment Program (MPEP), May 17, 1965 (AD 465246)

Corrosion of Materials by Ethylene Glycol-Water, May 10, 1965 (AD 466284)

Physical Metallurgy of Alloy 718, June 1, 1965 (AD 466476)

Third Status Report of the U. S. Government Metalworking Processes and Equipment Program, June 16, 1965 (AD 468246)

Hydrogen Movement in Steel - Entry, Diffusion, and Elimination, June 30, 1965 (AD 474578)

Comparison of Chemical Analyses of Refractory Alloys - A Survey Conducted by the Materials Advisory Board as Part of the Refractory Metals Sheet Rolling Program (RMSRP), September 10, 1965 (AD 473980)

Fourth Status Report of the U. S. Government Metalworking Processes and Equipment Program, December 7, 1965 (AD 476783)

High-Purity Metals, January 3, 1966

New Developments in High-Strength Stainless Steels, January 3, 1966

Ignition of Metals in Oxygen, February 1, 1966

Fifth Status Report of the U. S. Government Metalworking Processes and Equipment Program, June 10, 1966

Metal Deformation Processing, Volume II (A Survey Conducted as Part of the Metalworking Processes and Equipment Program (MPEP)), July 7, 1966

Compatibility of Liquid and Vapor Alkali Metals With Construction Materials, April 15 , 1966 Stress-Corrosion Cracking of Aluminum Alloys, July 1, 1966

Welding High-Strength Steels, July 15, 1966

Physical Metallurgy of Beryllium, June 24, 1966

Final Report of Refractory Metals Sheet Rolling Program (to be issued at a later date) 